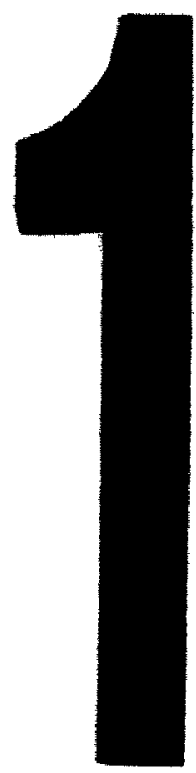

PM-1 3\%, $x$ 4" PHOTOGRAPHIC MICROCOPY TARGET NBS 1010a ANSA/ISO \#2 EOUIVALENT

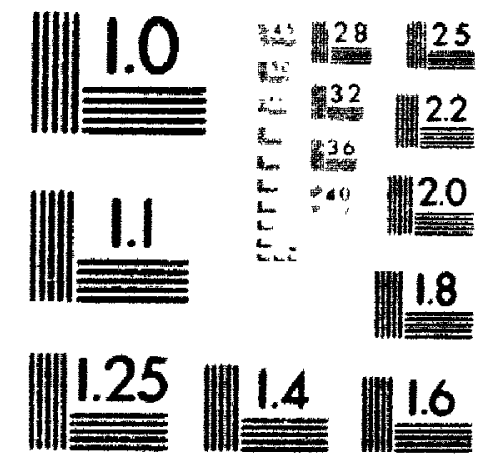


The quality of this microform is heavily jependent upon the quality of the original thesis submitted for microfilming. Every effort has been made to ensure the highest quality of reproduction possible.

If pages are missing, contact the university which granted the degree.

Some pages may have indistinct print especially if the original pages were typed with a poor typewriter ribbon or if the university sent us an inferior photocopy.

Reproduction in full or in part of this microform is governed by the Canadian Copyright Act, R.S.C. 1970, c. C-30, and subsequent amendments.
La qualité de cette microforme dépend grandement de la qualité de la thèse soumise au microfilmage. Nous avons tout fait pour assurer une qualité supérieure de reproduction.

S'il manque des pages, veuillez communiquer avec l'université qui a conféré le grade.

La qualité d'impression de certaines pages peut laisser à désirer, surtout si les pages originales ont été dactylographiées à l'aide d'un ruban usé ou si l'université nous a fait parvenir une photocopie de qualité inférieure.

La reproduction, même partielle, de cette microforme est soumise à la Loi canadienne sur le droit d'auteur, SRC 1970, c. C-30, et ses amendements subséquents. 


\title{
Believable Specifications: Organizing and Describing Object Interfaces Using Protocol Conformance
}

\author{
by \\ David G. Thomson. B.C.S.
}

\begin{abstract}
A thesis submitted to
the Farulty of Graduate Studies and Research

in partial fulfillnont of

the recpuirements for the degree of

Master of Computer Science
\end{abstract}

Sihool of Computer Science

Carleton Cniversity

Ottawa. Ontario

March 1993

(1)1993. David G. Thomson 
Acquisitions and Bibliographic Services Branch

395 Welthngton Street Ottawa. Ontano KIA ON4
Bibiiothèque nationale

du Canada

Direction des acquistions et des services bibliographiques

395. rue Wellington

Otlawa (Ontaro)
The author has granted an irrevocable non-exclusive licence allowing the National Library of Canada to reproduce, loan, distribute or sell copies of his/her thesis by any means and in any form or format, making this thesis available to interested persons.

The author retains ownership of the copyright in his/her thesis. Neither the thesis nor substantial extracts from it may be printed or otherwise reproduced without his/her permission.
L'auteur a accordé une licence irrévocable et non exclusive permettant à la Bibliothèque nationale du Canada de reproduire, prêter, distribuer ou vendre des copies de sa thèse de quelque manière et sous quelque forme que ce soit pour mettre des exemplaires de cette thèse à la disposition des personnes intéressées.

L'auteur conserve la propriété du droit d'auteur qui protège sa thèse. Ni la thèse ni des extraits substantiels de celle-ci ne doivent être imprimés ou autrement reproduits sans son autorisation. 
Nome

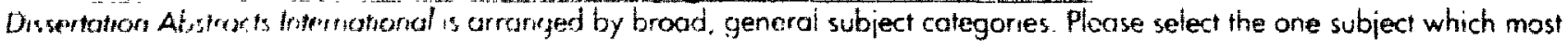
nurarly deswibes the content of your dissertation Enter the corresponding four-digit code in the spoces provided

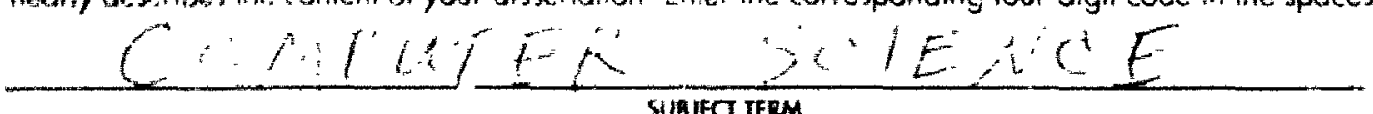
SUEHECT IERM

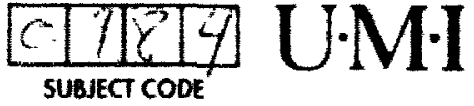

\section{Subject Cakegories}

\section{TME HUMANITUES AND SOCIAL SCIENCES}

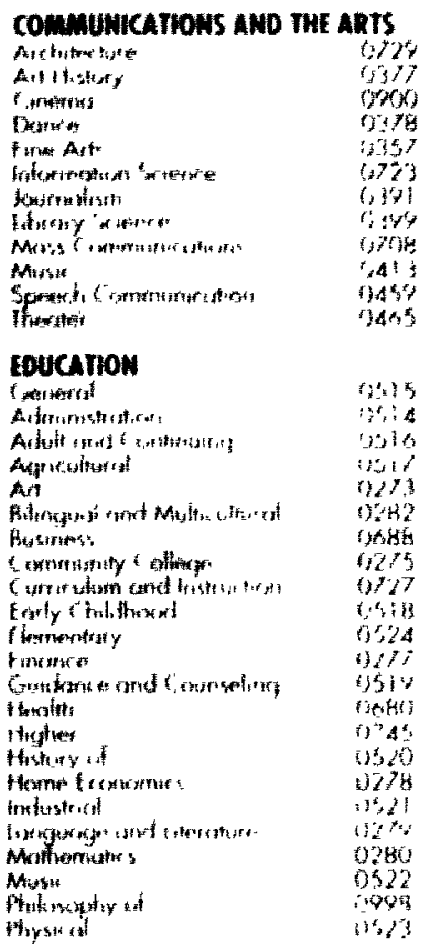

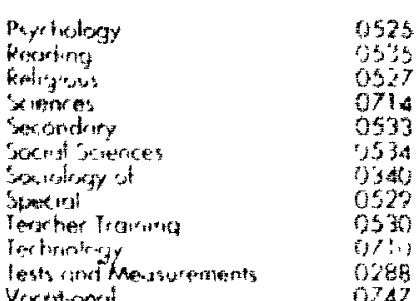

\section{LAHGUAGE, UTERATURE AND} LIMGUISIICS

toryutrap

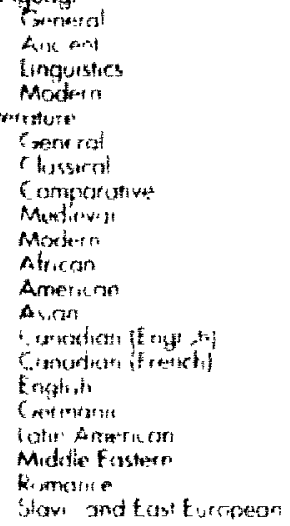

$\ln , 74$

0290

Git

OAOI

0294

0795

ozog

U3'

059

0315

452

0355

Q1!:

$03 i 2$

0,15

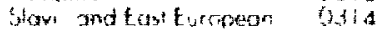

\section{PHIOSOPHY, RELIGION ANO}

THEOLOGY

Findosoptry

Fehror:

Buticat stith:

Ciergy
Histony of

Fistory of

theoliogy

\section{SOCAA sciences}

Amertion Sivdies

Arthropology

Archoes

Cultural

Business Adrimistration

Genergi

Accounting

Bonking

Manjgement

Morketing

Conedien Studes

Econorite's

Agriesiturol

Gomimerte Bsstross

Firares

Aislesty

labor

Folktor

Gougrupty

Gerontology

History

Gemerdi
0422

03:

?.21

13.9

प? 20

0,372

0323

0,324

$032 \%$

0310

0272

0770

0,454

0338
0385

0385

0503

0505

3508

0509

$05: 0$

0511

0306

0351

6578

THE SCIENCES AND ENGINEERING

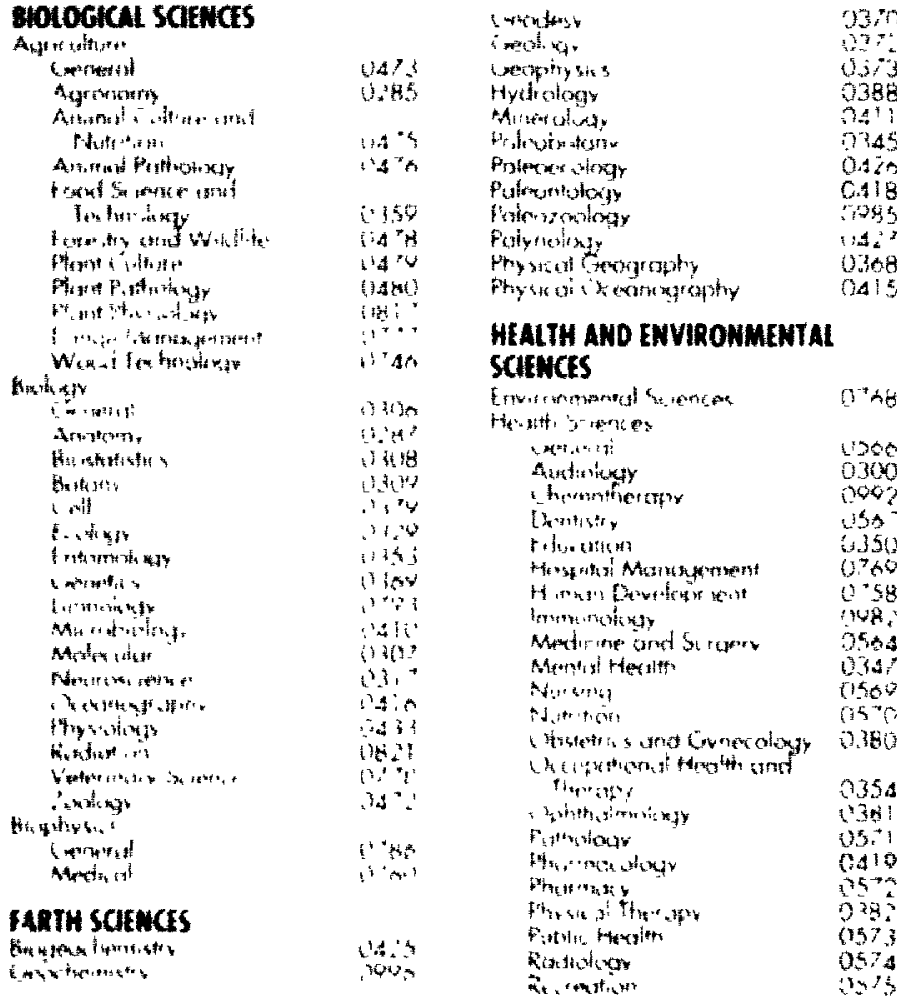

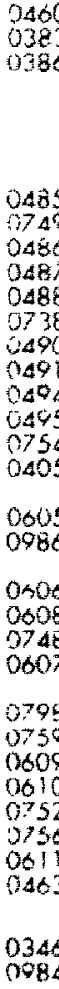

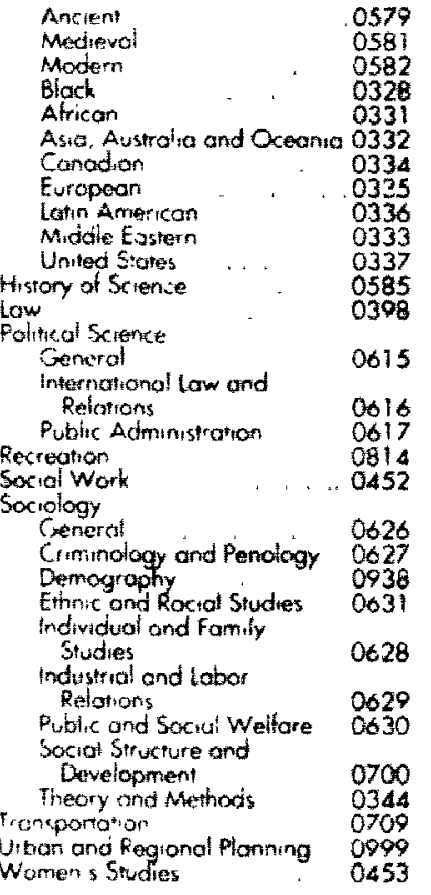

Fngineen

Aerospace

Agriculturni

Automolive

Bionedico

Crvit

Electronics and Elertucat

Heot and Thermodynamics

Hydroulic

Industrigl

Marine

Matericis Sxence

Mechor:ted

Metriluigy

Mining

Nucleor

Pockoging

Perroleum

Sonitary and Municipal

System Scrence

Geotectinology

Operations Research

Plostirs Tachrology

Textile Texhology

\section{Bronolosy}

Eenerd

Eenario

Developmentol

Levelopmentol

ixperenes

Personolity

Physiologicol

Pyychobrorgy

Psychometres

Soxid 
T'o undersigned hereby recommend to

the Fareulty of Ciratuate Studies and lirenotroh arecrutaner of this thesis

Believable Specitications:

Organizing and Describing Object Interfaces

Using Protocol Conformance

smbmitted by David (i. Thomsen. B.C.S.

in partial fulfillmunt of

the recuirements for the degrese of

Master of Compunter Sciener.
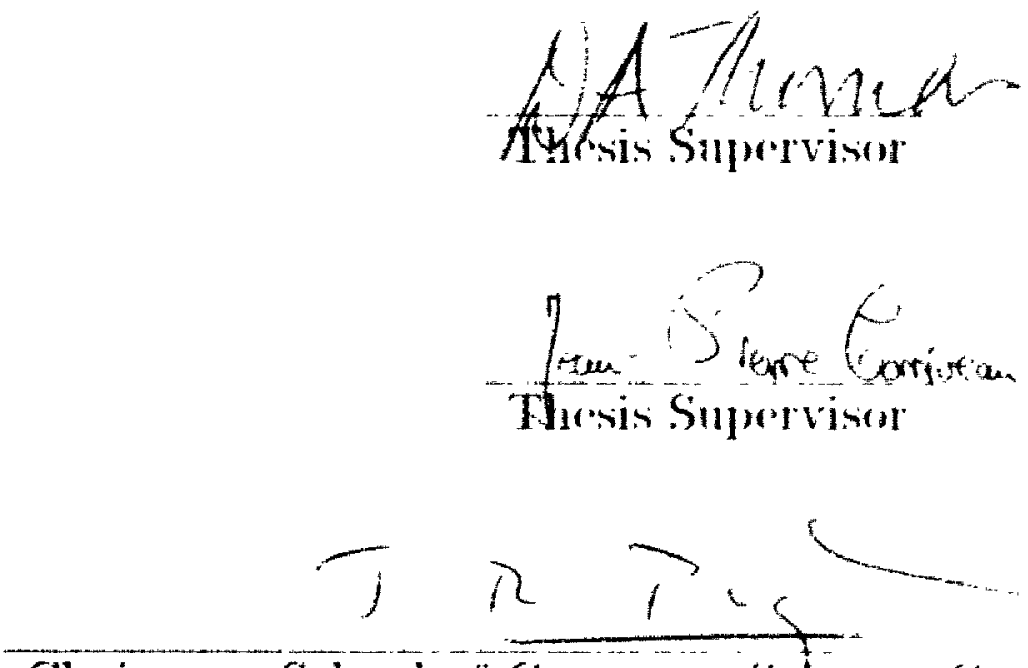

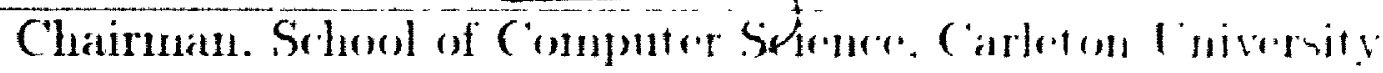

SnAy $\frac{13.1913}{D \text { Ditr. }}$ 


\section{Acknowledgements}

Find I wond like to thank my nhisors Dave Thomas and Jan-Piorre Corfivean. Dave Thoman provided much guidance and eneomagement. and is one of

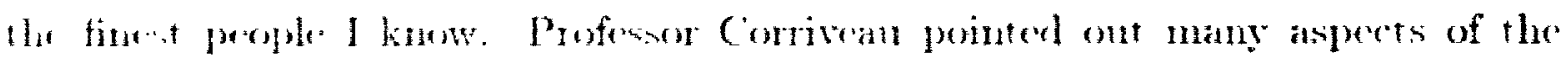

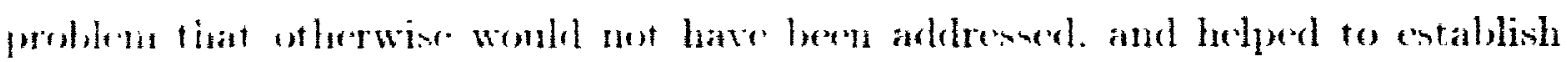
the sone of the thesis. Brian Barry has beren an invaluable somuding board. and stegented many ideas which have contributed signifiontly to the thesis.

I was very fortunate to hare two additional readers, Greg Adams and John Dumovich, who take thesis realing very serionsly. John pointerl out many areas

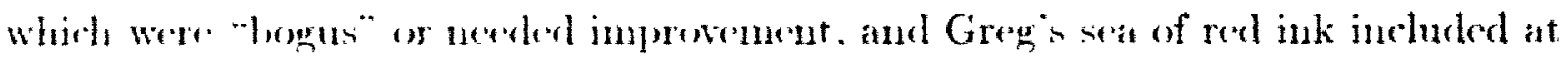
lavet two shegestions for other thenis topies!

I would like to thank OTI for allowing me the time and resoures to ro this work. I would especially like to thank all ny friends and co-workers for corering for me and putting up with a "now gou see him now you dont" Dave Thomson.

Finally I wonll like we thank my hotlue for being a cool guy (it takes the

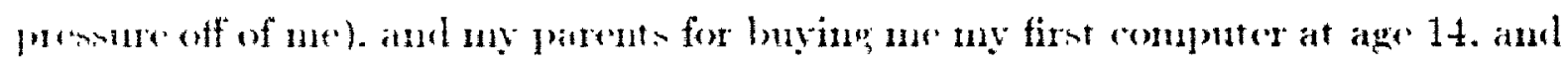

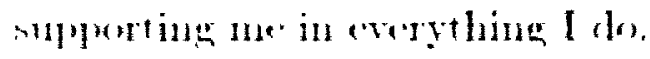

Dave Thommon. March 1993 


\begin{abstract}

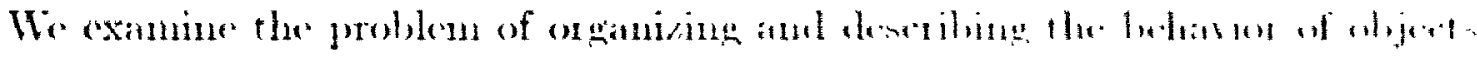

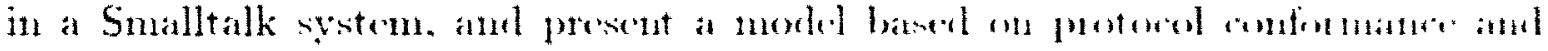

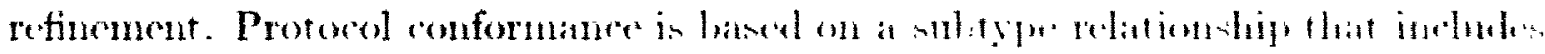

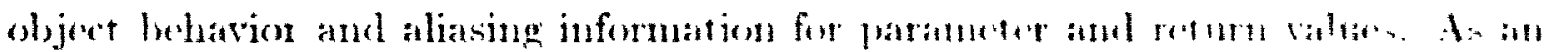

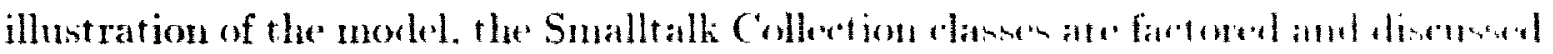
using the approwh.
\end{abstract}

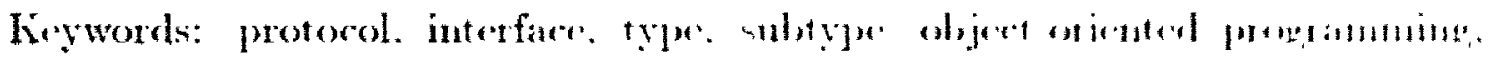
Smatltalk. specitiontion 


\section{Contents}

1 Int roduction 1

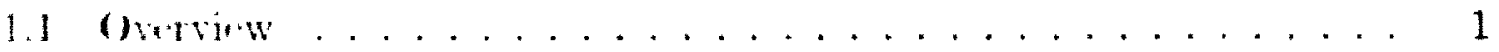

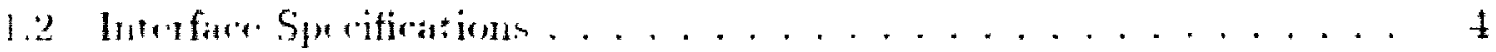

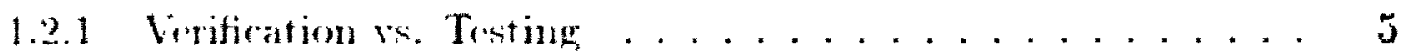

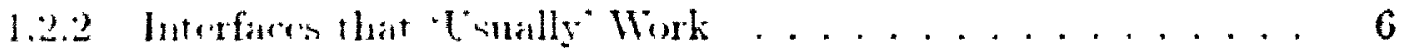

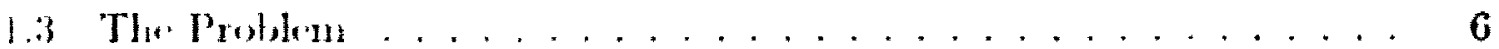

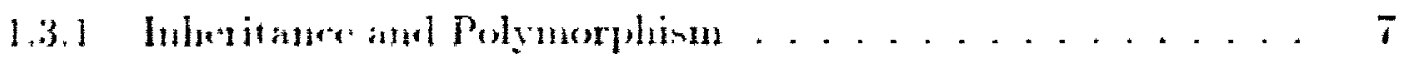

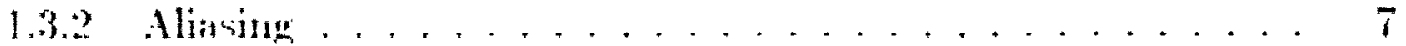

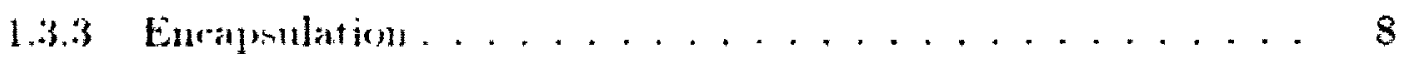

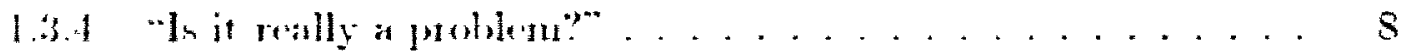

1.3 .5$, What can I roly on?" ................. 9

1.3 .6 "The Spere is the conlo" ................ 10

1.1 Notivation ........................... 11

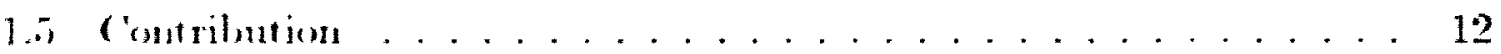

1.6 Organization of the Thesis . . . . . . . . . . . . . 13

2 Backgromind and Related Work 14

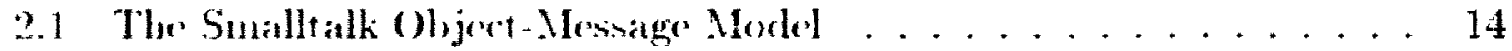

2.2 A Framework for Charactorizing Approaches . . . . . . . . 15

2.2 .1 Gromp Membership . . . . . . . . . . . 16

2.2 Relationships Between Gromps . . . . . . . . . . . 19

2.2 .3 Deseription of Bollavior ................ 24

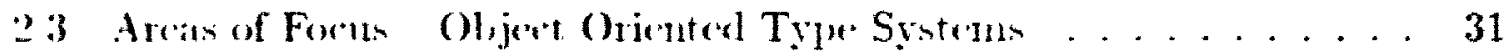

2.4 Orerview of Rolated Work . . . . . . . . . . . . . . . 33

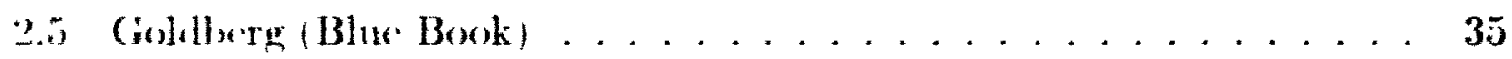

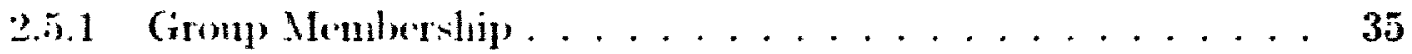

2.5 Rolationshipe Botwen Gromps ........... 36

2.5.3 Dencription of Behavior . . . . . . . . . . . 36

2.5 .4 Summary ...................... 43

2.6 IIBII Red Book . . . . . . . . . . . . . . . . . . . . . . 44

2.6.1 Cirouj, Nomberslij . . . . . . . . . . . . 44

26.2 Relationship Betwen Grome ............ 45

2.6 .3 Description of Bellaviot ................. 47

26.4 Summary . . . . . . . . . . . . . . . . . 49

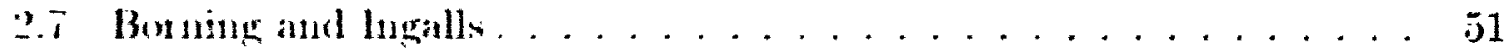

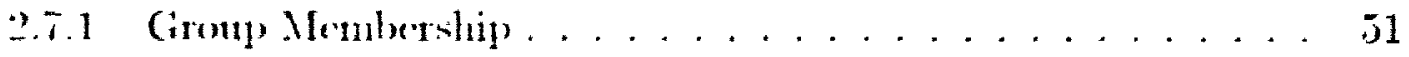

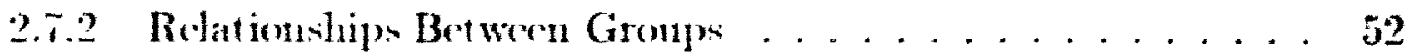

27.3 Deweription of Bellavior . . . . . . . . . . . . 54

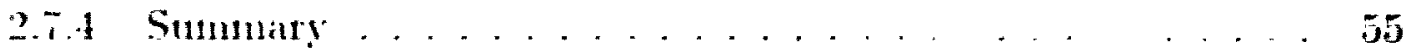

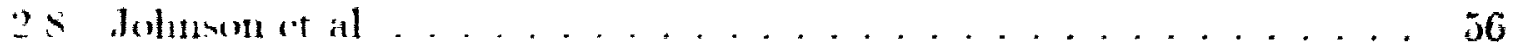




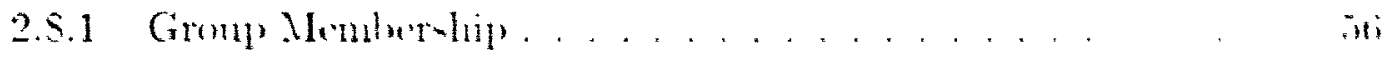

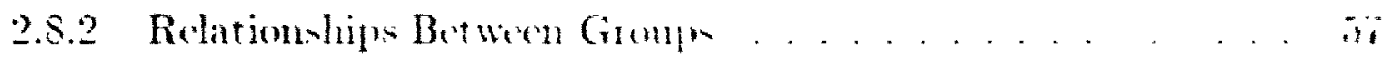

2.S.3 Dencription of Buharen . . . . . . . . . . . . . . . in

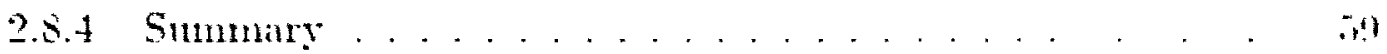

2.9 Vill . . . . . . . . . . . . . . . . . . . . . . .

2.9 .1 Group Mrombership . . . . . . . . . . . . . . (il

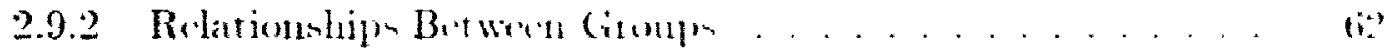

2.9.3 Description of Brharior . . . . . . . . . . . tis

2.9 .4 Summaty .....................

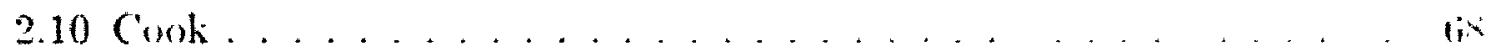

2.10.1 Grom Mlombership. . . . . . . . . . . . . . 16.

2.10.2 Relationships Betwern Ciromp . . . . . . . . . . . (is)

2.10.3 Description of Beharior . . . . . . . . . . . . . . .

2.10 .4 Summary ......................

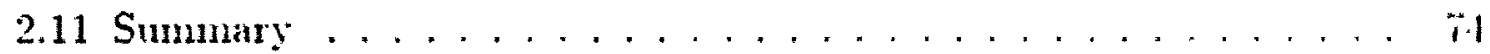

3 The Protocol Model $\quad 77$

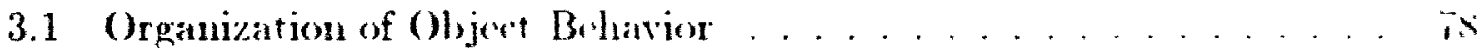

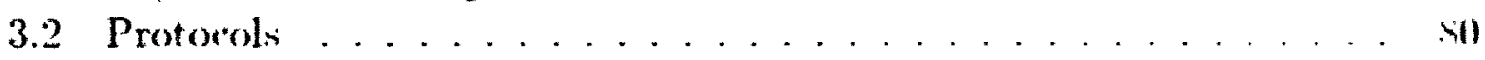

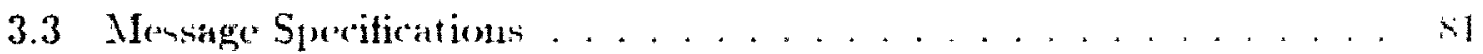

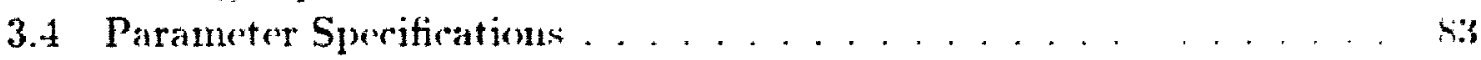

3.4.1 Paraneter Interface Dofinitions . . . . . . . . . . . . . .

3.4.2 Parameter Aliasing Attributom . . . . . . . . . .

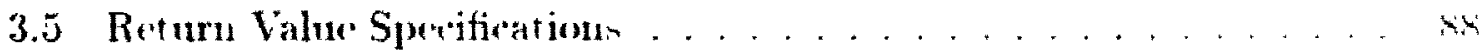

3.5.1 Return Value Interface Dofinitions . . . . . . . . . . 91

3.5.2 Return Value Aliasing Attrilntes . . . . . . . . . . . 4

3.5.3 Behavioral Deneriptions . . . . . . . . . . . . . .

3.6 Sumnary .......................... . . . . . . .

4 Conformance and Refinement $\quad$ 100

4.1 Conformanre ........................... InII

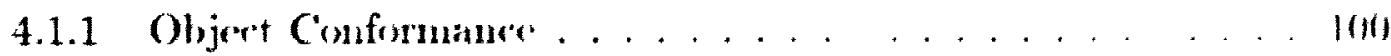

4.1.2 Protocol Conformaner. . . . . . . . . . . . . . 101

4.1 .3 Message Sperifieation Confomatur. . . . . . . . . I0\%

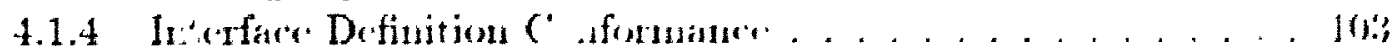

4.1.5 Parametes Alinsing C'onformand . . . . . . . . . . . . In.

4.1.6 Return Value Aliasing Atribute comfommone , . . . . 101

4.1.7 Behaviomal Description Confonmane. . . . . . . . . I0

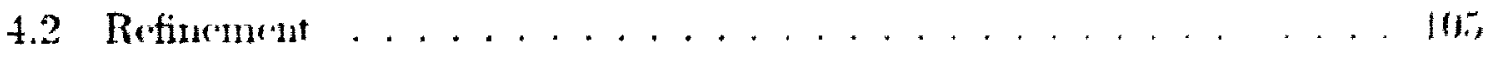

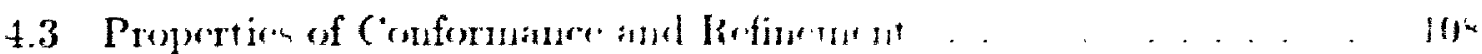

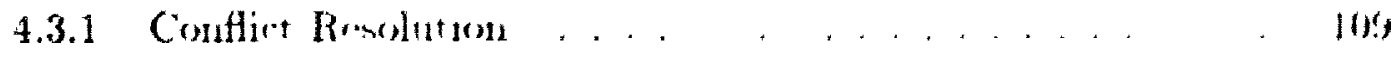

$\$ .3 .2$ Substitutability . . . . . . . . . . . . 111 


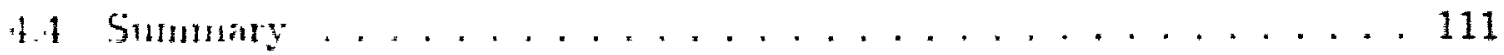

5 Applying the Model 112

5.1 Alutrat and Comerete Protomols . . . . . . . . . . . . 112

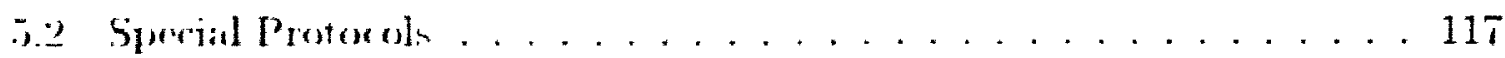

氵.3 A Fuctoring of Thr Collection Classes . . . . . . . . . . . . 119

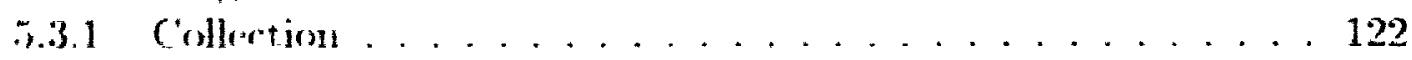

5.3 .2 DirtionaryAcosscollertion ............... 124

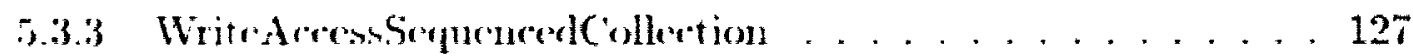

5.3.1 RearlAcressSequenedCollection . . . . . . . . . . 132

5.3.5 ElementRoumablicollertion ............. 134

5.3.6 Elrment AdrableCollection .............. 135

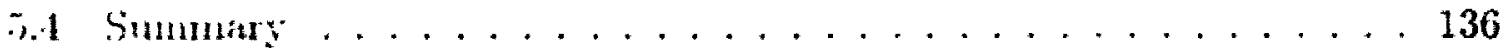

(f Conclusions and Future Work 137

6.1 Evaluation. . . . . . . . . . . . . . . 137

(j.1.1 Disrnssion. . . . . . . . .......... 141

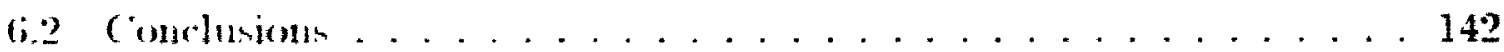

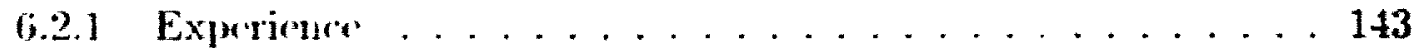

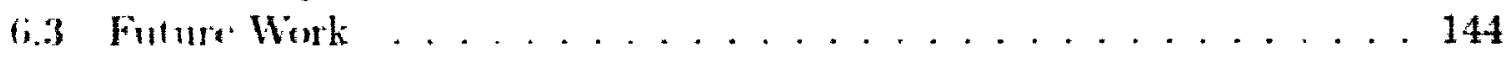

6.4 The Final Word . . . . . . . . . . . . . . . . . . 146

$\begin{array}{lr}\text { Koferences } & 147\end{array}$

A Appemdix A: Sample Protocol Specification 152 


\section{List of Figures}

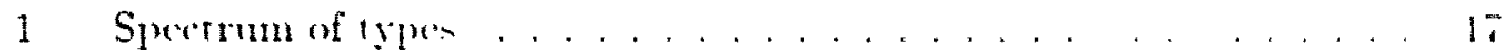

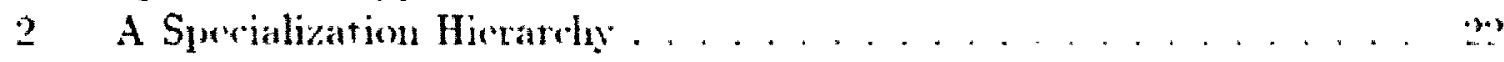

3 Composition and Retintment . . . . . . . . . . . . . . . .

4 The inportan of sulstintutility . . . . . . . . . . . . . 30

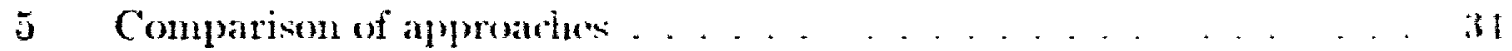

6 Method cannollation in Smallatk . . . . . . . . . . . . . . . 3i

7 The inheritane hicrardy for collections . . . . . . . . . . . 3i

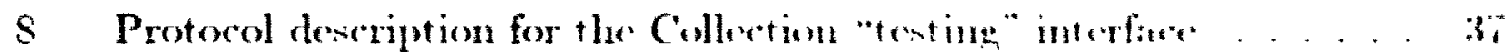

9 The \#add: protered description . . . . . . . . . . . . . . . 3

10) The \#assoriationdtifAbsent: protorol deneriptions. . . . . . . 3

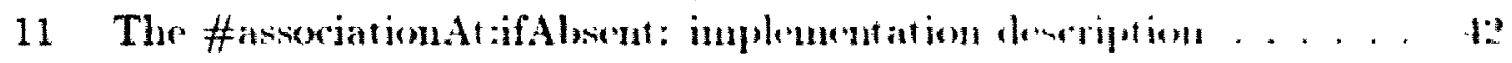

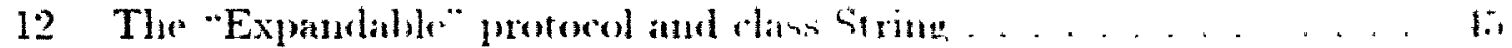

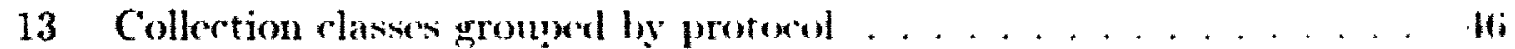

14 Rolating Classes To Protocols . . . . . . . . . . . . . 16

15 Examplo signaturo dofinitions for typo (Hojot . . . . . . . . . . . 5.?

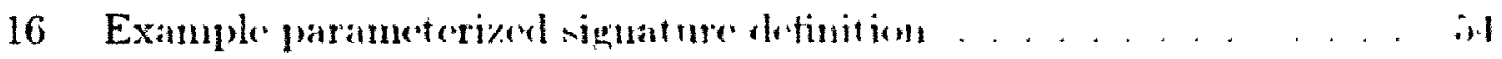

17 Subtype Relationships in Typed Sualltalk . . . . . . . . . . . . . . .

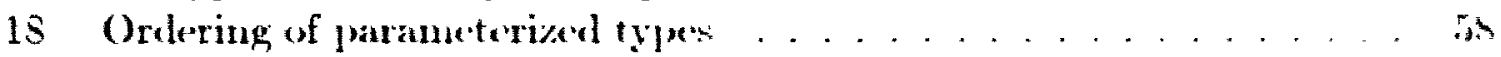

19 Valid Conformaner and inleritane ovmbinations . . . . . . . . 63

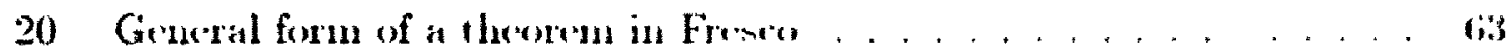

21 A SymbolTabl. TCD rxampl. . . . . . . . . . . . . . तil

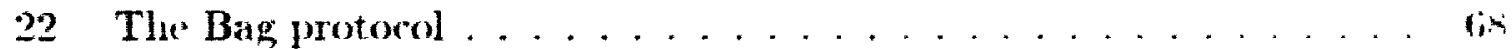

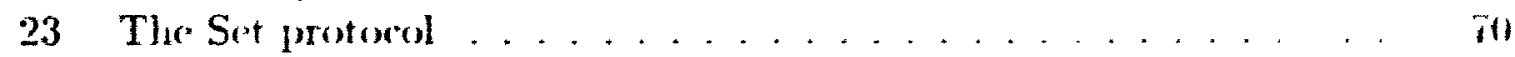

24 Interfaces ve. Inheritance . . . . . . . . . . . . . . il

25 The \#arlitall we hod for elas Bay . . . . . . . . . . . . . j9

26 An example glossary entry . . . . . . . . . . . . . . . . . . . . . .

27 An example meksage sperificition . . . . . . . . . . . . . . . . .

28 A parameter specification . . . . . . . . . . . . . . . . . .3

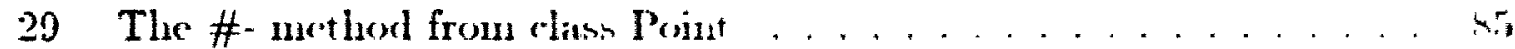

30 The \#adrlall: mothod for Collention . . . . . . . . . . . . . . \$

31 The \#add: wothod for Diotionany . . . . . . . . . . . . si

32 A roturn value specifiontion . . . . . . . . . . . . . . . . .

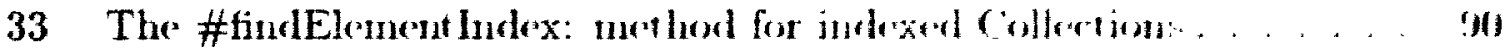

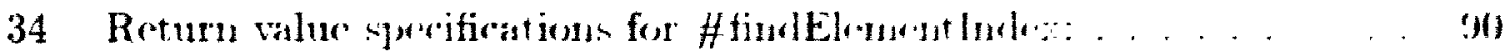

35 The \#renove: methor for Sot . . . . . . . . . . . . . . . . \$1

36 The \#arldAll: nussage sperifieation . . . . . . . . . . . . . s,

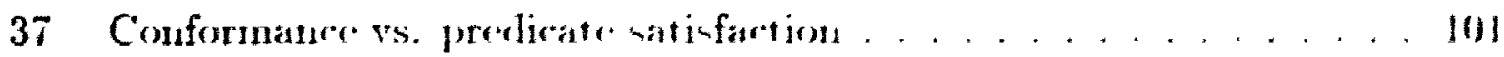

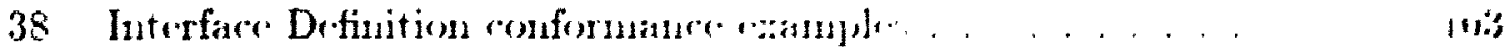

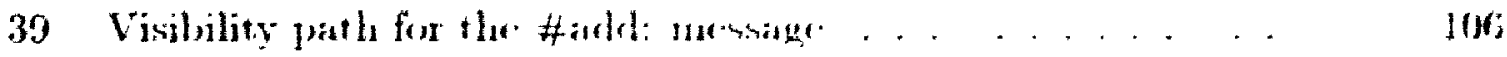

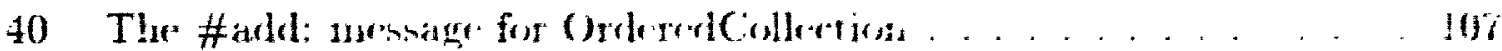


41 The potential for specifiotion contlicts. . . . . . . . . . 109

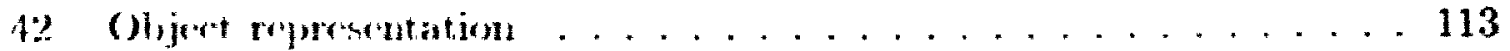

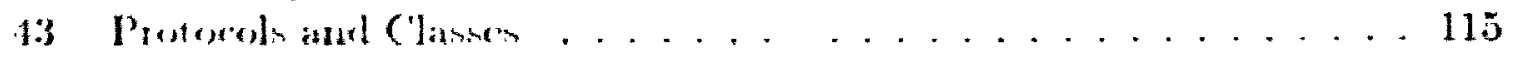

14 Iofining All and Xothiug . . . . . . . . . . . . 118

45 Conformano Graph for the Collention class . . . . . . . . . . 121

46) Message sedecten in the collection protorol . . . . . . . . . . 122

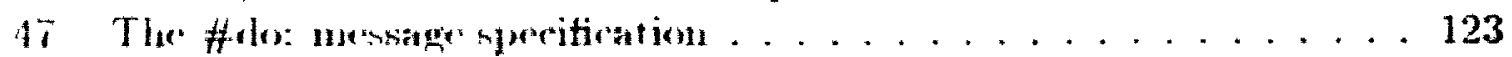

Is Messige solestors common to all Dictionarion . . . . . . . . . . . 124

19 Mrsages defining write aceess to seduened Collections . . . . . . 127

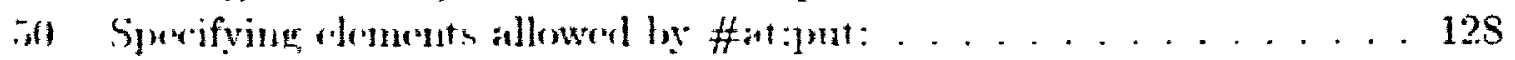

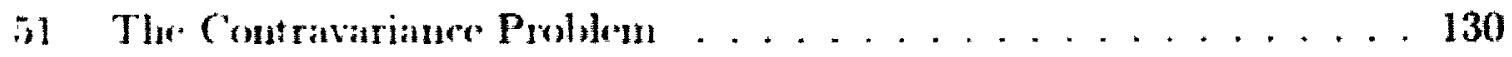

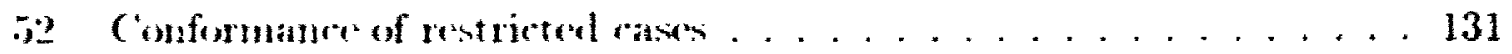

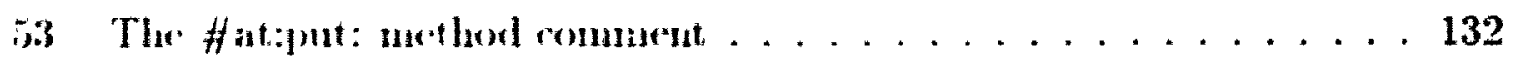

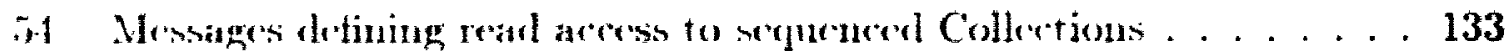

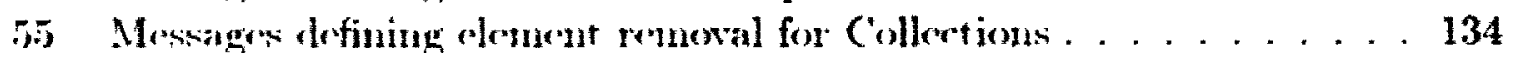

y6 Mrsagers dotining oloment adling for Colloctions . . . . . . . 135

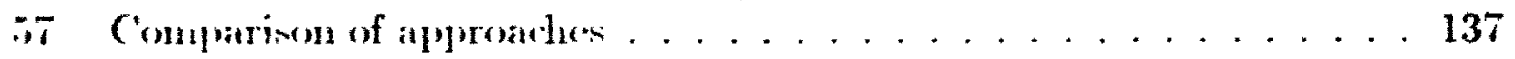




\section{Chapter 1}

\section{Introduction}

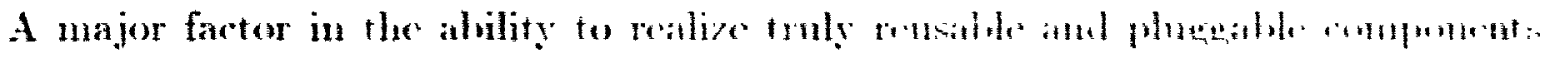

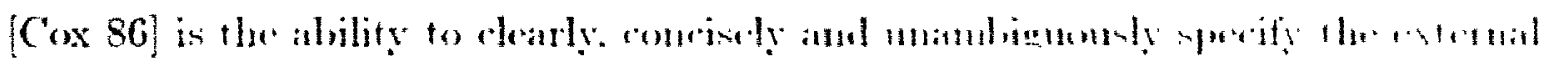

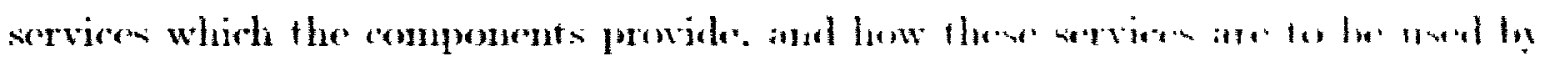

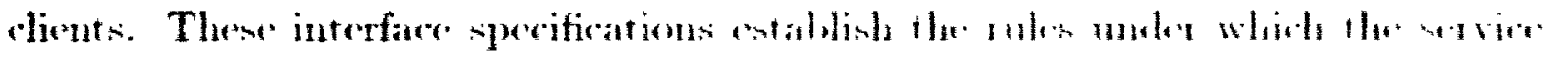

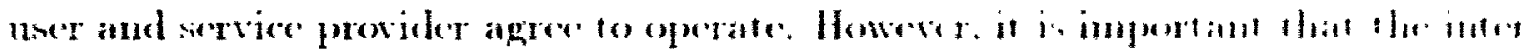

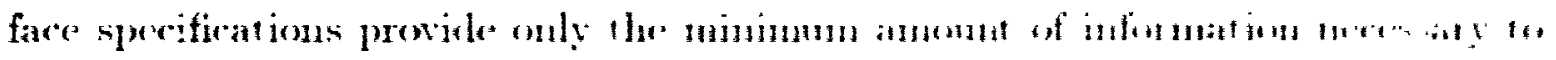

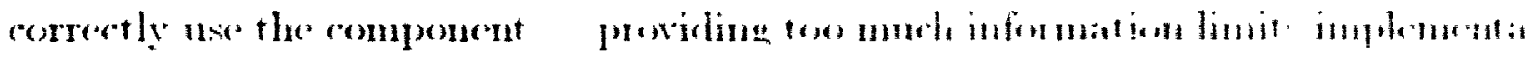

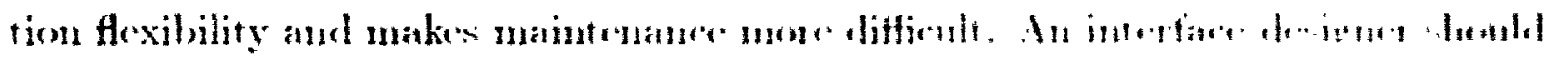

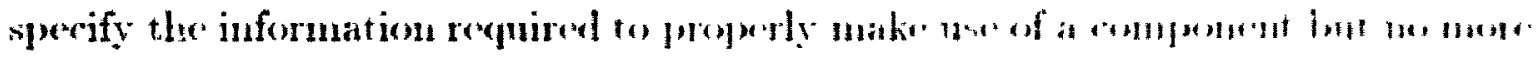

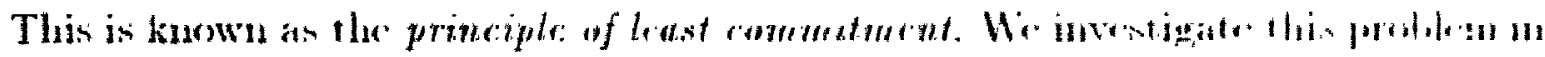
the comext of the object-oriented langnage Smallatk.

\subsection{Overview}

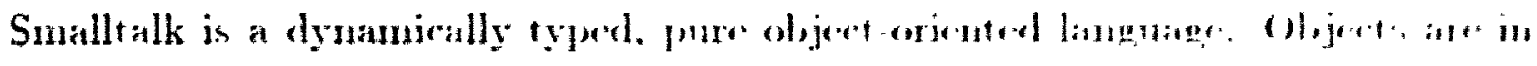

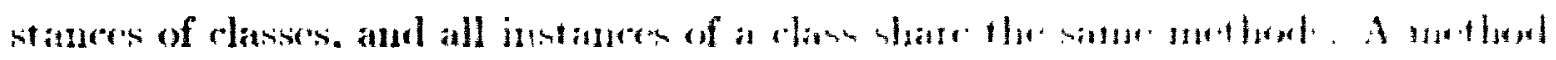

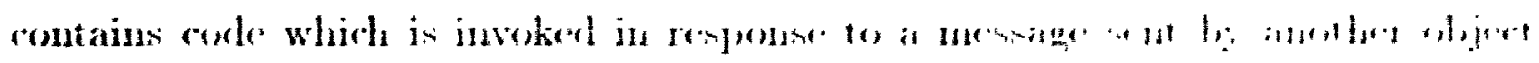

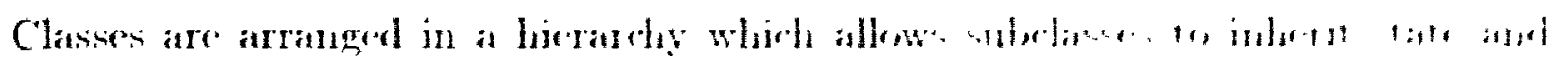

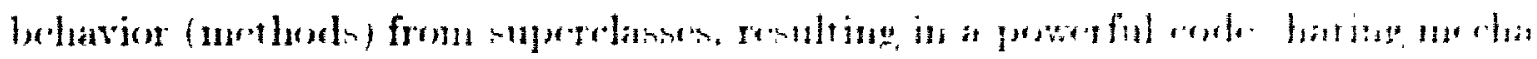
niisul.

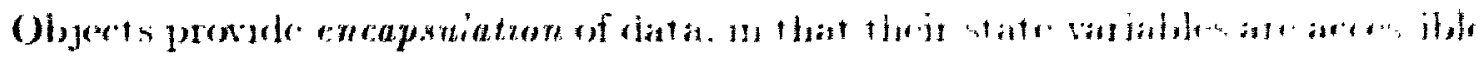

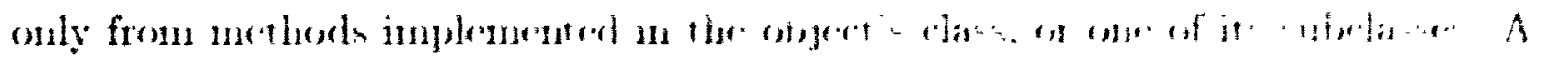




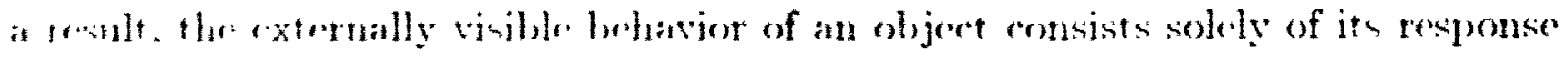

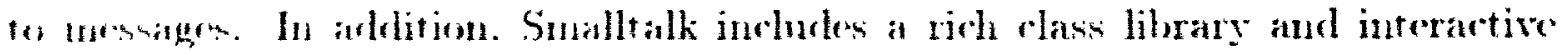

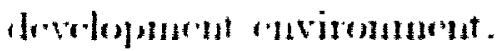

Hintoriolly, most sperifications for Smallalk systems have been incomplete

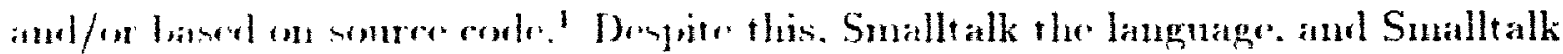

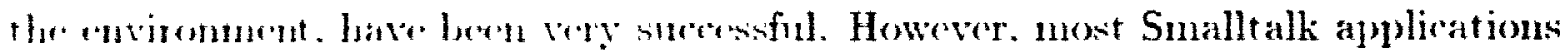
hane leen developed la individuals or small teams where the details of how inter-

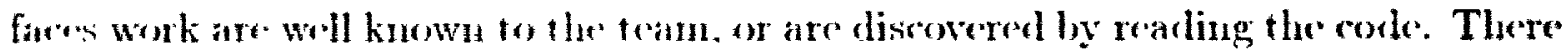

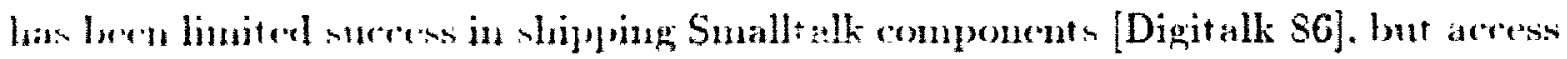
to the source codf has here chsential to understanding how the component interfares are to be wed. Areses on the somere code is an advantage ju that romponents

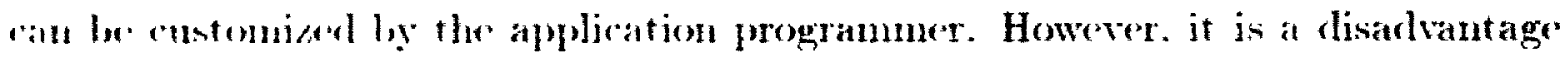
to the extent that it results in a weaker form of reuse than black box component rone. which is, at present, virtually imposible due to the lack of workable Smallatk iuterface speritiontions.

The langunge detinition for Smallatk is minimal. and basic data types that are momally included in the definition of traditional languages are provided by a hawe elass libnary. Howerer. the composition of this class library raries between Suallalk systems. With the avalability of commercial Smalltalk systems from moval voulors' [Digitalk 90] [Dịitalk 89] [PPS 92] [OTI 92] there is a growing moximon to atalish standards [ONG: 92] [IBM 92] [ANSI 93] for the base library in wrole to alkow at leat at a certain level, the derelopment of portable application colle. A recurring problem in these etforts is that of adeguately sperifying what the interfaes are, and what they do, without oversperification and umeressary liate sowards a partionlat inplementation. The flexibility provided by dymanic

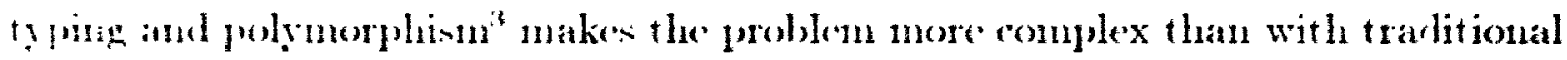

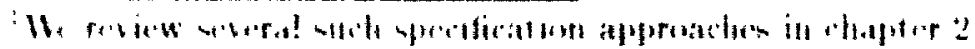

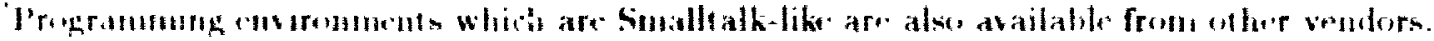

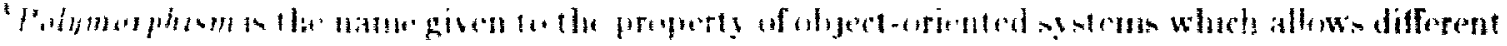


languatges.

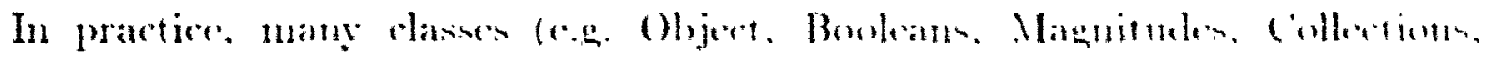

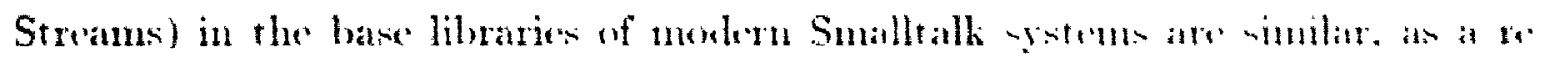

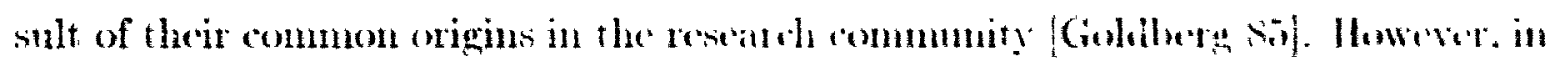
many cases the details are sutticiently different that it is dittionlt to wries portable cole. Methods often operate identionly for a wirle tange of anes, hut differ in

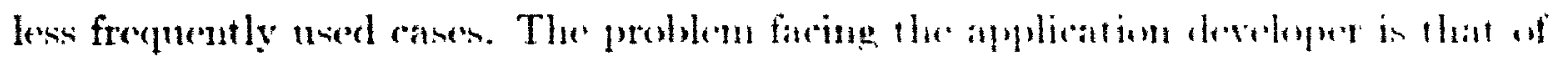

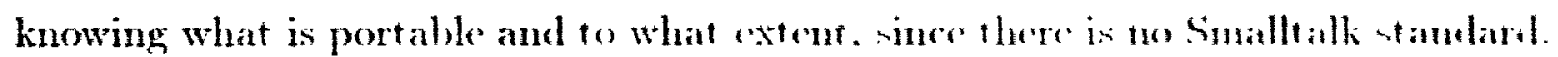

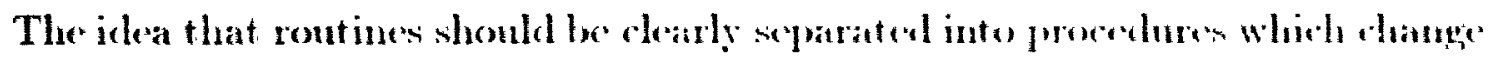

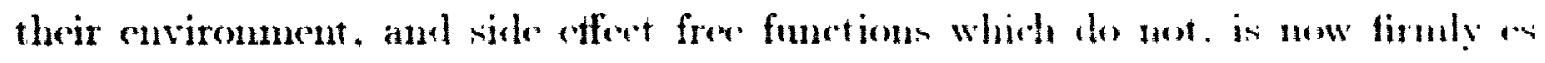
tablished in the programming community [Hoge 9)] [Wikstmm sit. In Sinalltalk

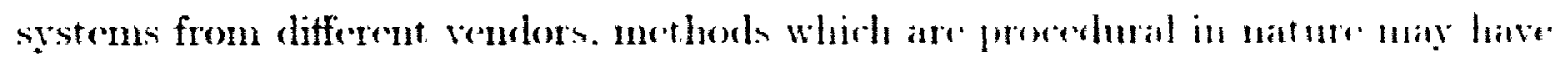
equivalent side efferts. hut return a different value. Since all methods in Simallatk

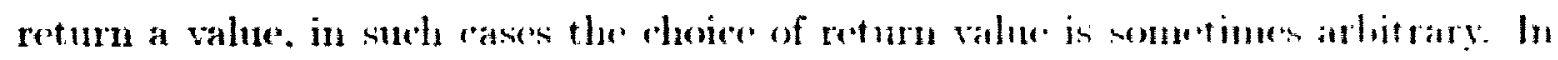
fact, due to such differenes's Smallatk programmers often adopt informal rule: to

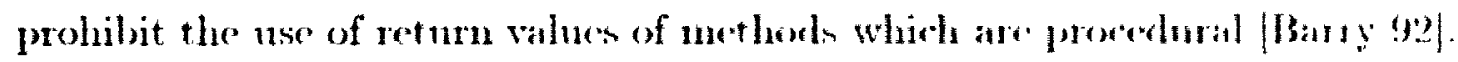

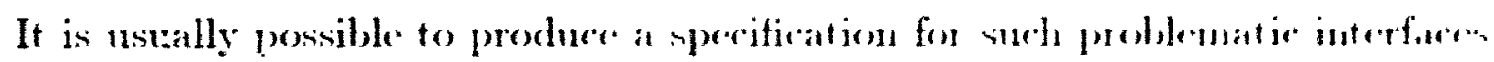
which is both useful to the appliation pregranumer. and allows exinting implenum

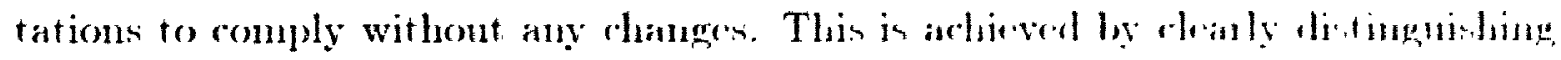

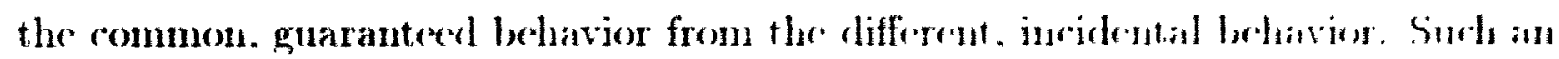

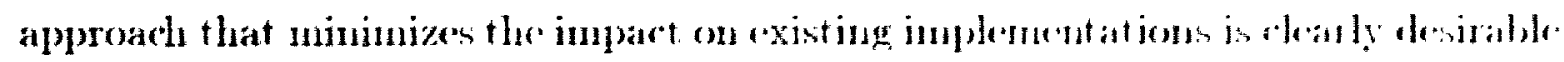

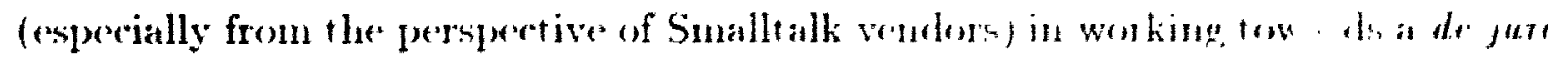

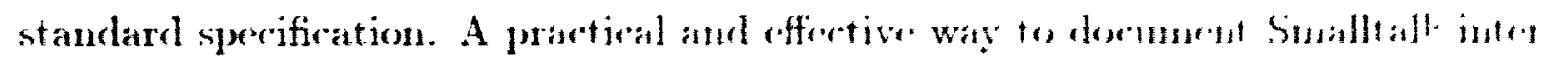

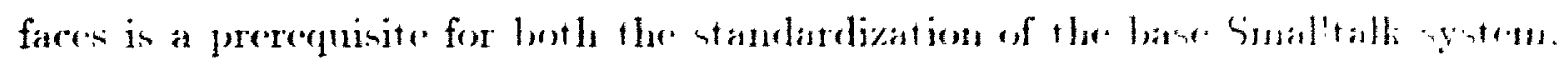
and the surecess of third party value-irlded :omupenenth.

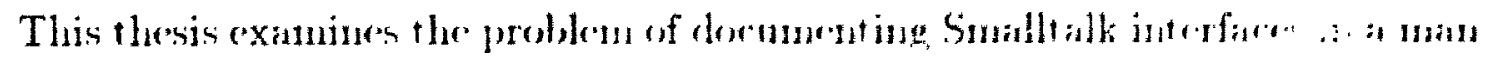

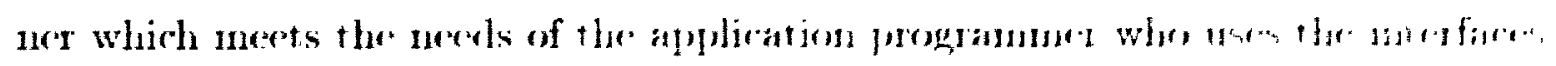

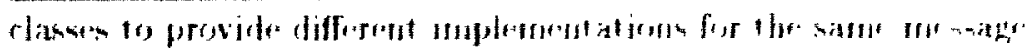


and the Subllath romponent dereloper who must implement such interfaces. We

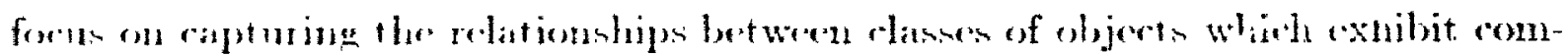
mon be havior. in order to facilitate interface eperifientions that are independent of inlinitinu...

\subsection{Interface Specifications}

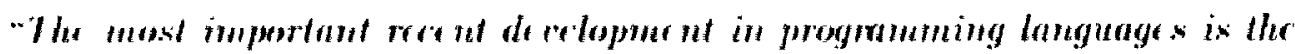

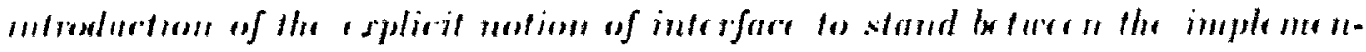
tationn of ane rabstrartion and its clients."

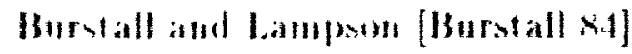

The inlea of sparating sperifiontion from implementation is well acrepted in the softwan anginering conmmuty [Liskov 86$]$. This approarh allows the contin" 11a] refinement and mhancement of syotems while maintaining hackward interfare compatibility with prevous in plenentations. and farilitates portability by allowing different implenentations of the same interfaces.

Services provided by a software component are typically documented in terms of the following charactedistirs:

- Sirvire name.

- Type and moaning of the paraneters.

- Doweription of the lechavior of the service ice. its function aild externally visible side afferts.

- Type and maninge of the return value (if any").

An interface sperifieation acts as a "contract" [Mcyer 90] between a service provider and a servie user. It outlines the services provided, the conditions of wriece and the gualanteres the service provider is willing to make. At the same

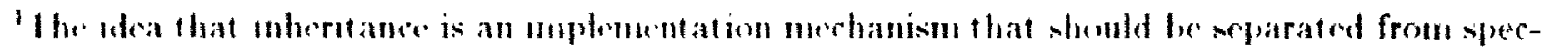

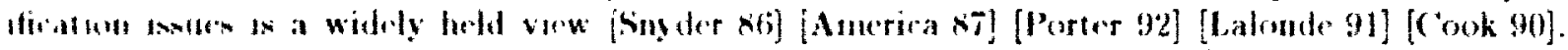

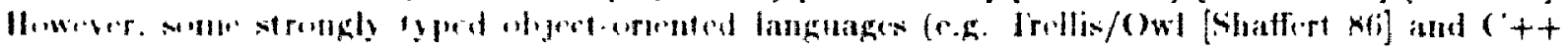
Strountrup seip) comblume them 


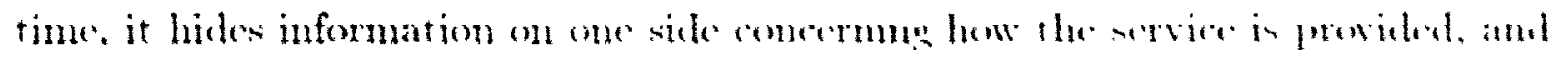

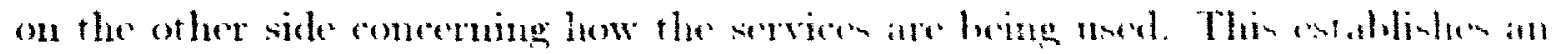
agreement under which service providers and servide asers and be independently developed and maintained.

\subsubsection{Verification vs. Testing}

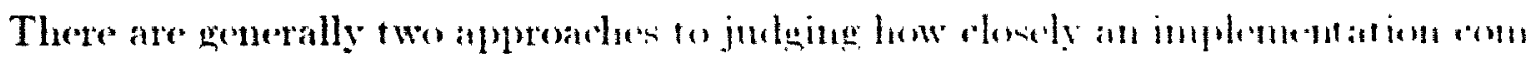
plies with a specification. The first is by formal coritiontion whidh prome corrent

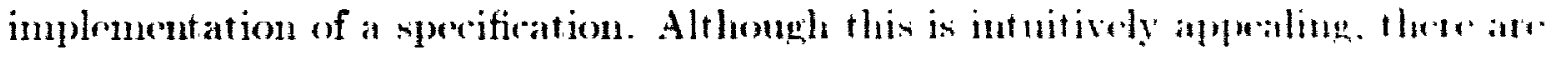

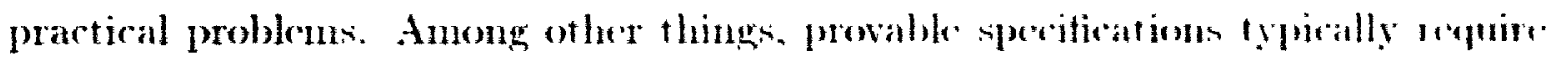
people to have specialized training in formal metheds in enter ter rabl and write them. This results in a communication problem, and in particulan make it diflicult

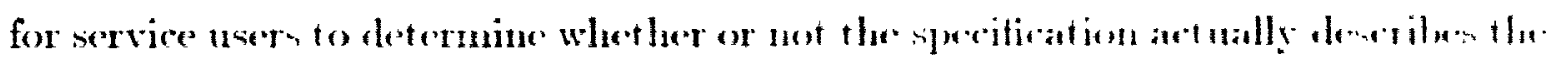
desired behation of the system. [Holt 92] notes that "Althengh fermal metheoh-hold great promise for inproving the process of woftware development, If to turw theme methods have had limited impart on the artmal derelognent of sof ware.". and given

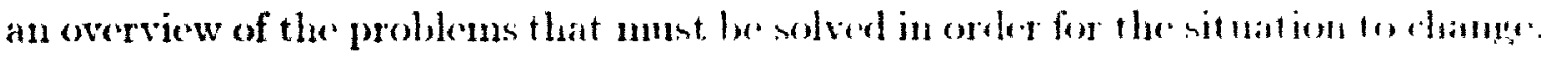
Many researchers believe that informal metheds which ane loowely based on formal

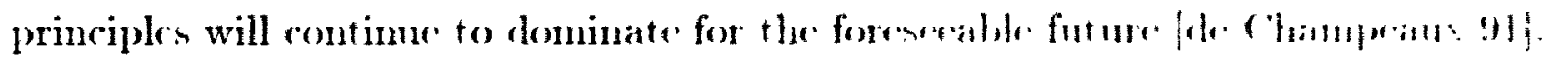

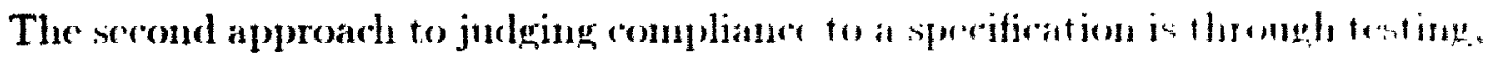

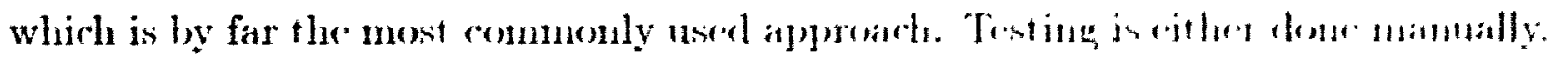

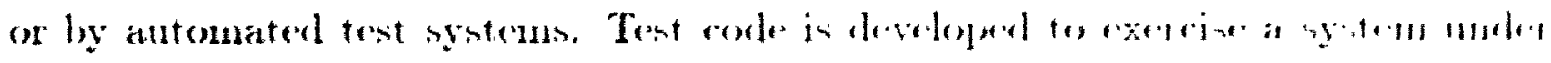

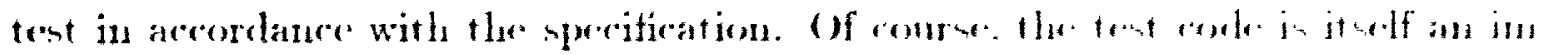

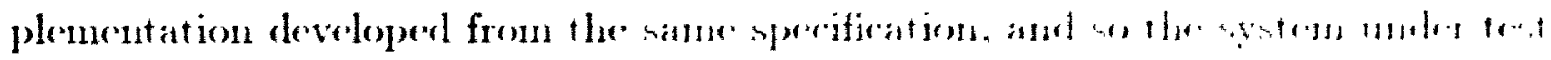

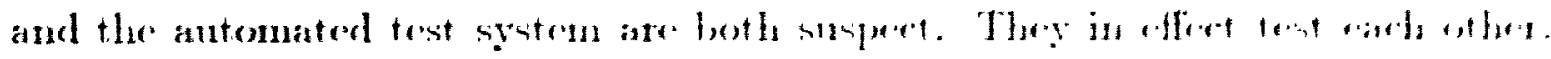

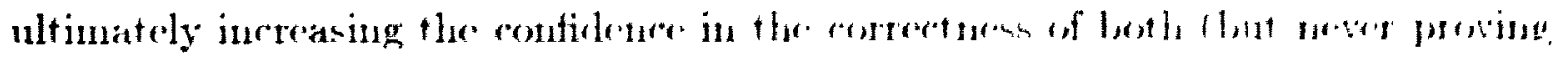

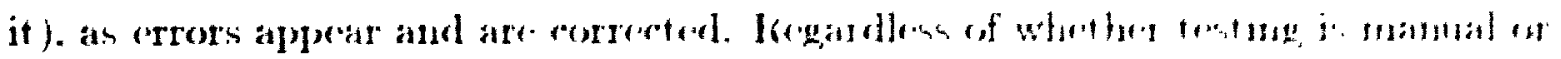

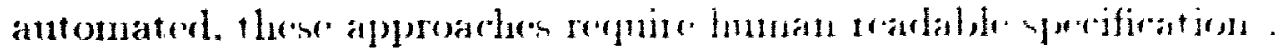




\subsubsection{Interfaces that 'Usually' Work}

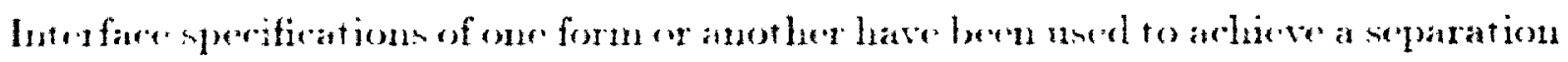
latwen clint and implemention in many systems, both hardware and software. A motalle hardware anuple is the Intel 8086 family of mieroprocessor [Inte] 90].

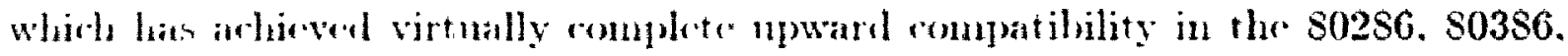
and s0186 poremsors. A prominent sof ware 'xamplo is the Luix operating system ('programming interface [Lnix 83]. Most Linix $\mathrm{C}$ interfares are now standardized in thr IFEE POSIX speritiation [IEEE 90]. allowing implenent at ions as varying as

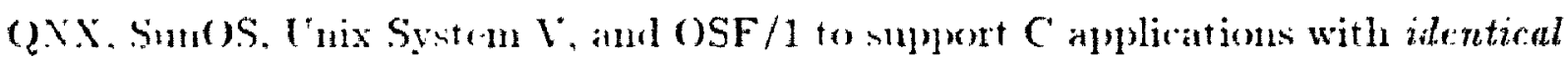
entroverale on all platforms.

As simpleas they are. the Luix mantal pages are an example of a very sucessful interface opereitiontion. One of the main reanoms for this sucess is the fact that they ane simple. concise, and readily arailable to programmers. They are sufticienty presise to allow progranumers to develop applications that une the interfaces without the ned to examine the somere cole to understand what a call really does. Of rourse they do lawe limitations. and trial and error experimentation with an int orface is still owasomally requited to fill in missing dotails.

\subsection{The Problem}

Intorfare speritioations lave not been used as suceessully with Smallatk systems. Ironically. this is partly due to the fact that Snalltalk code tends to be much sinpler and mone conteid than ( conle. The de facto form of Smallalk interface dormuenfation is the methed comment, which is a short. informal deseription of what the

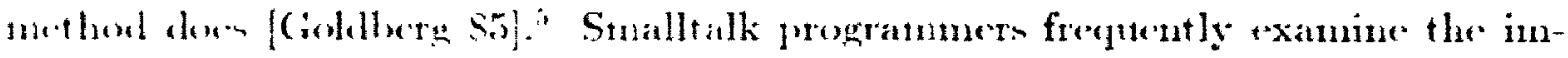
flanentation of a method in order to resolve anbigntios or missing information it the metlod comment [Skublies 91] [Meger 90) [Gold 91]. The implementation is the

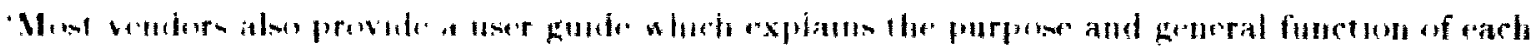

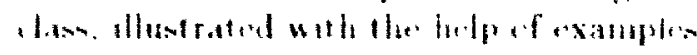




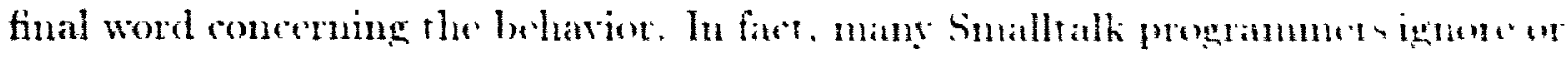

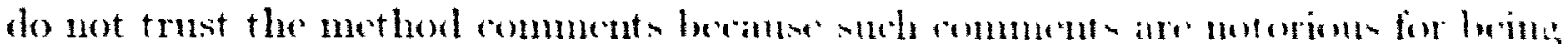
incomplete or incorren [Barry 92].

\subsubsection{Inheritance and Polymorphism}

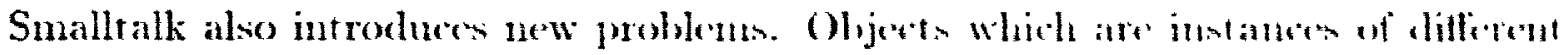

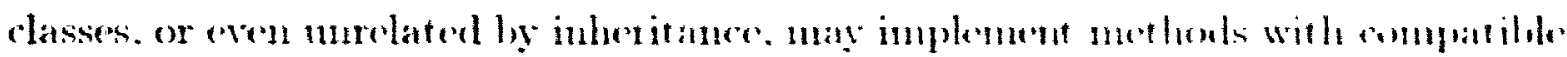

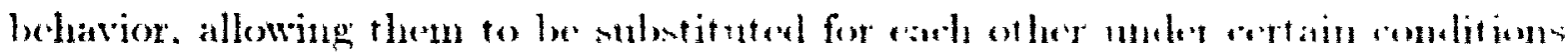
(polymorphism). On the other hand. Classes that ate related ly inleritaner naty

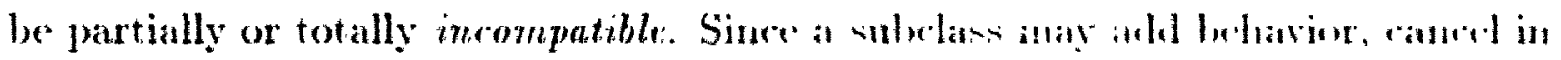

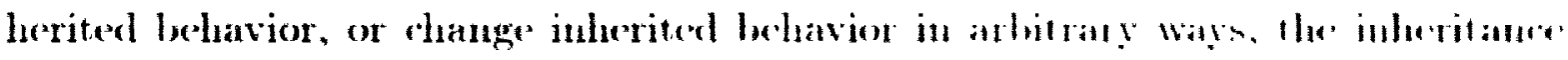
relationship alone guaranteres mirtually mothemg about an object sextennally visible.

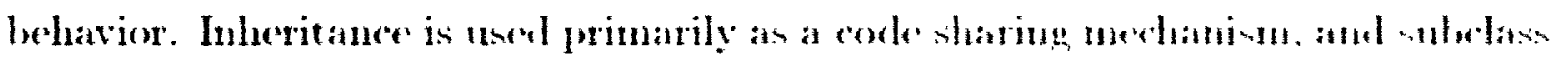
ing may or may not reflect behaviomal similaritien.

In the interest of reuse, the dymanic nature of Smallatk allowe complentuts to be built that will work with elasses that are not get implemented for ane pathally implemented), provided they eventually implenent the ropuired lentarion. These

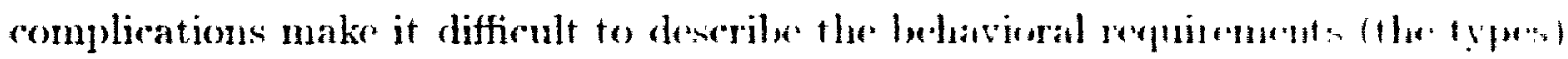
of parameters and returiz values.

\subsubsection{Aliasing}

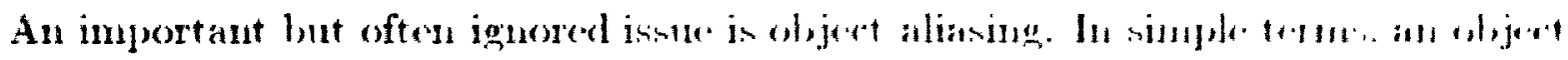

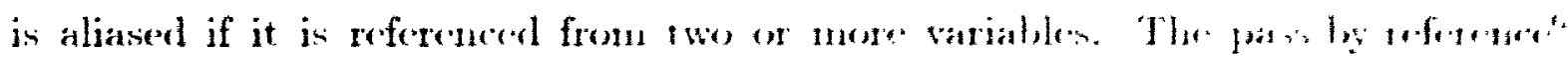

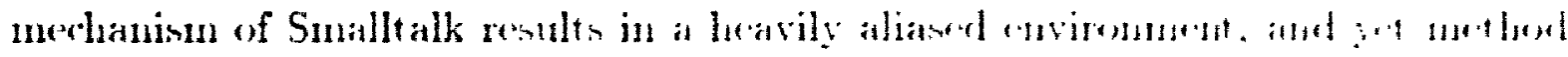

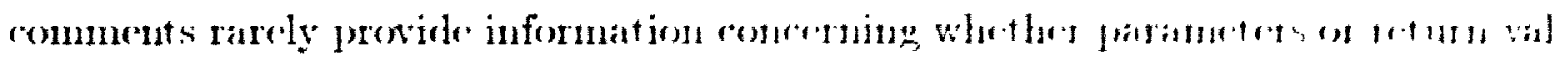

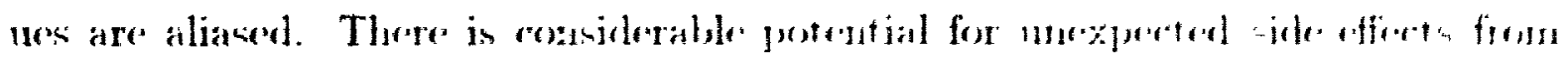

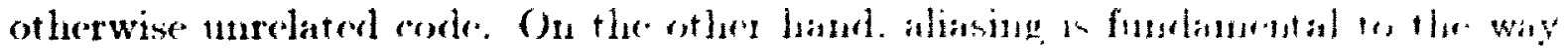

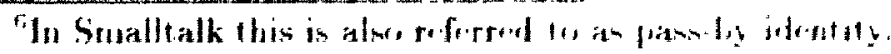




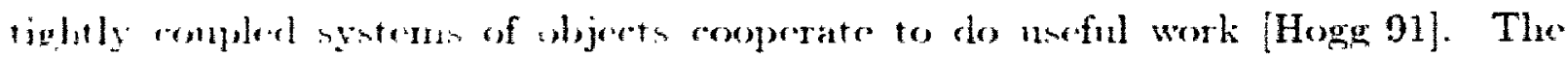

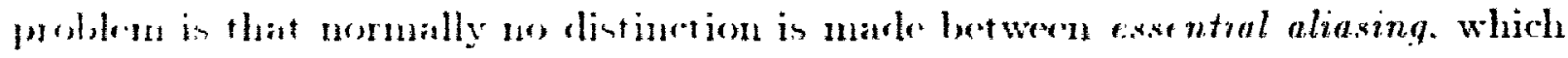
in fumbumental to the behavior of the interface, and incedsental aliasing. which is a sirle reffert of the implementation that should not be relied upon.

\subsubsection{Enrapsulation}

It is incuir that whil. Sublltalk is touted for its support of ancapsulation tirough

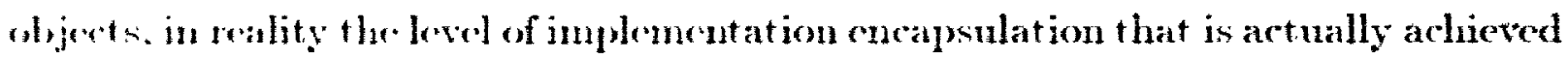
at both the object and component ${ }^{7}$ level is quite low. This is in part due to the languatge itsolf [Suyder 86]. but also due to the way Suallalk systems are (not) sweified, distributed. and usel, nince Suallalk componout rouse typically requires areses to the implementation. From this perspective. a $C$ library often does a nmeh leetwe jol, of encapsulating behavior. [Hogg 91] states "...the big lie of objectoriated programming is that ol,ject provide enoxpsulation". In a pass by reference moled sweh as Smalltalk where pointers are passed as parameters and return values. it is a complex problem to localize the potential for affecting the state (and subsequest luhavion of an objent. Encapsulation can be somewhat improved through disciplined software angime ring approaches [Lieberherr 88] which himit the ability of elient rode to send nexsages to olijerets which comprise the state of otlere objects whide are service provides. Howerer, the problem of describing the concapsulated lidavior remains.

\subsection{4 "Is it really a problem?"}

The powly donmented nature of Smalltalk interfaces is often dowmplayed by the Smallath commmity since the somere corle is mormally atailable for inspection as repuired. Howerer. this aspert of Smallalk systems has created a barrier to entry

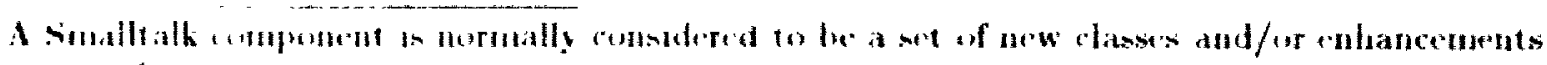

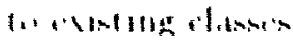




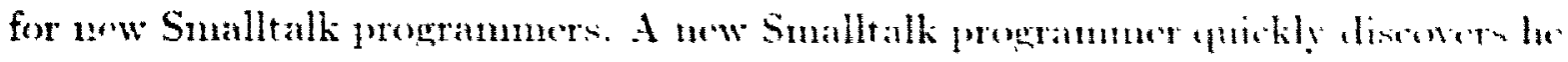

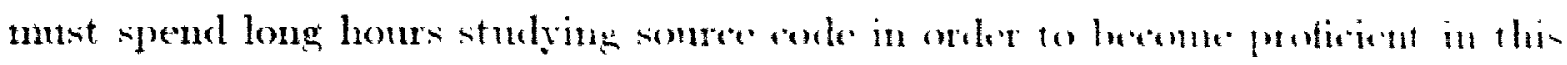
powerful new enviroment. Recognizing this problems. some organi, at ions imstitute formal or informal mentoring protranus which give urw programmers ateres to a

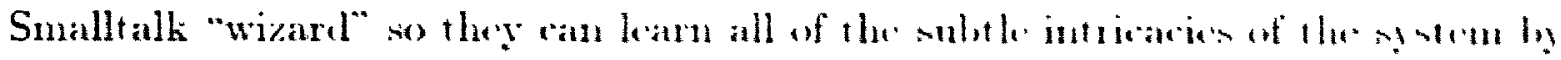
"osmowis". This is currently the most effertion way we learn smalltalls.

\subsection{5 "What can I rely on?"}

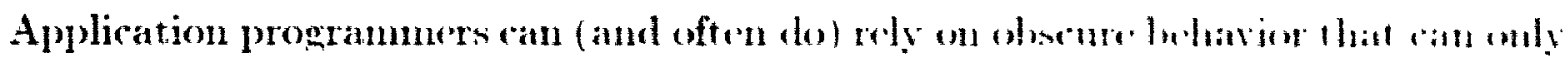

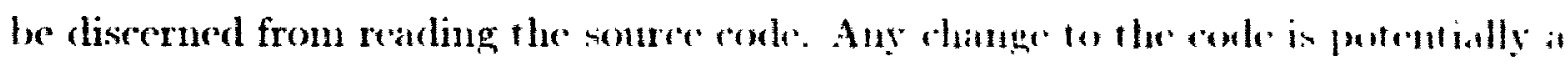

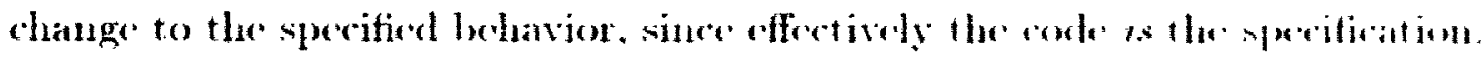

Major problems soon berome apparent when a Smallalk womtor or connewent

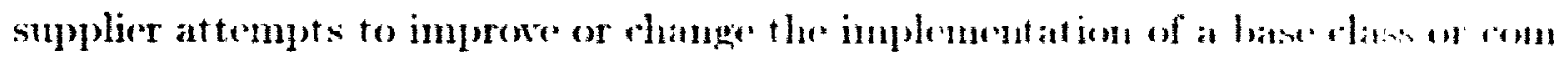

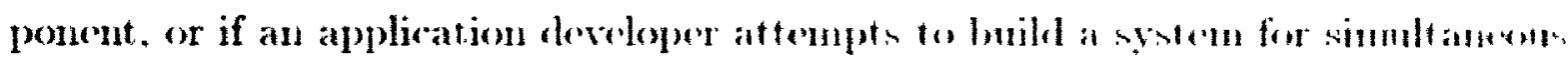
deployment on Smallatk systems from different venters. A problem with many

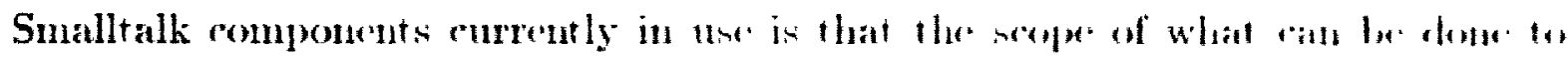

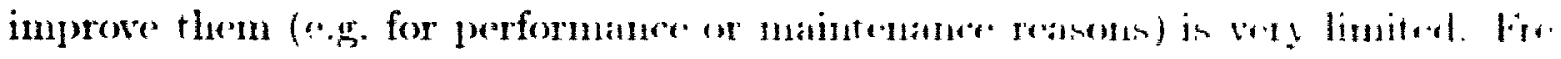

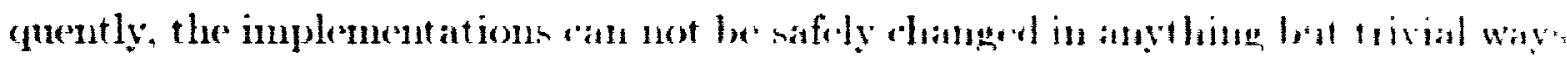
because of the potential for breaking client application come.

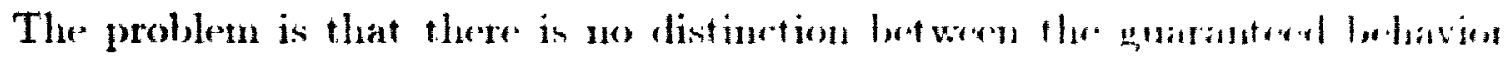

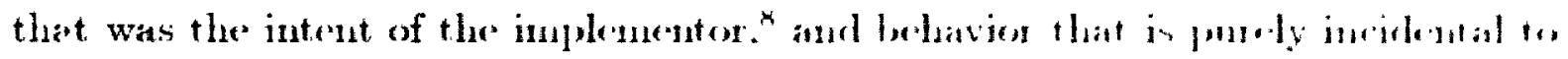

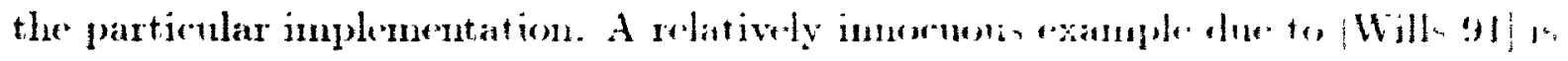

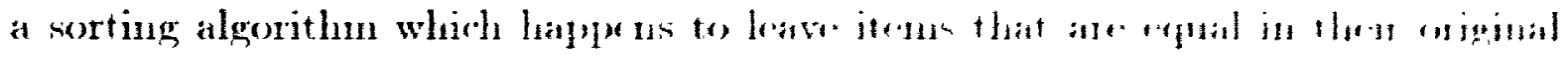

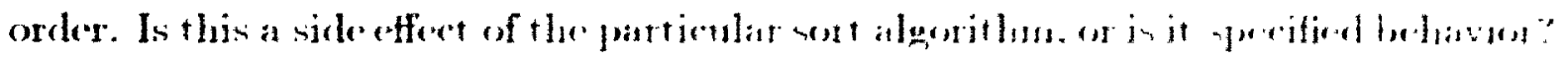

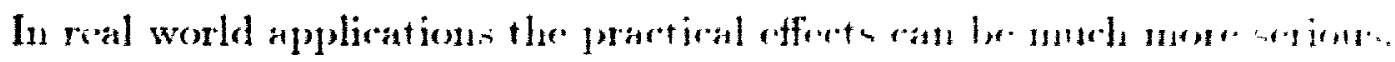

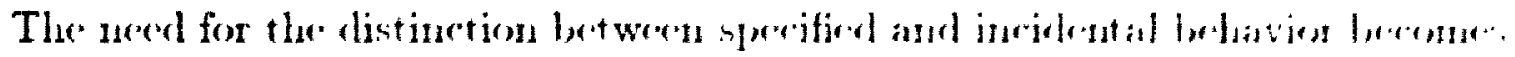

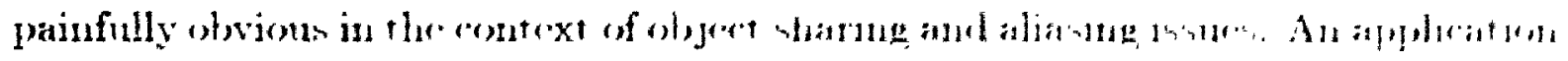

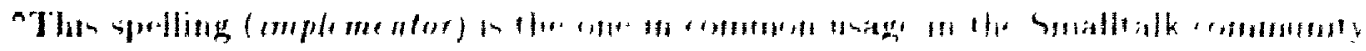




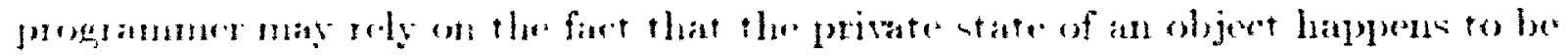
whomed an the result of a method, and that state moditiontions to the return ralue will affectively rhange the state of the original olject. Conversely the programmer might rely on the faret that state is not returned. Tle rules regarding who can modify the state of an whjert must someluow be retlected in the "contracts" between the service providess and server users, without unduly exposing the implenentation.

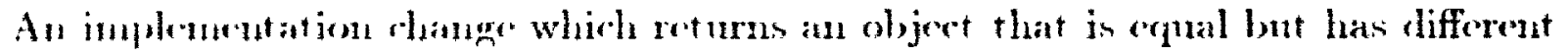

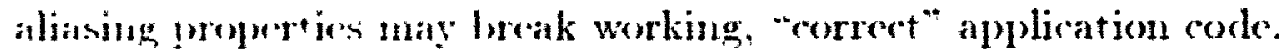

\section{1..3.6 "The Sper is the Code"}

While Sundtalk conle sorves as a concive specitication for simple operations. as complexify increases it beromes more ditfientt to deduce what a method doest from its cole. The afferts of inheritane nake matters even worse [Snyder 86], both for the appliation proganmer and for the implementor. Many methods in the baso library are ditficult to mulerstand due to deep hiorarchies, differing implementations anong, elasses, and mothod overriding and cancellation" [Lalonde 91] [Lalonde 86] [Wigner se]. It is not umusmal for a new Smallalk proglanmer to have to trace exention with a debngere in ordes to nuderstand the actual behavior. The combination of polymorphism and methor overriding makes it very diffient to understand He Inhaver of rasses deep in a hierarchy, and how they are implemented. In particulat, a nessage send to self ${ }^{10}$ may actually invoke a method in the same class. a soluthass. of a superelasis. This is describod as the Yoyo Problem by [Tarenzer 89]

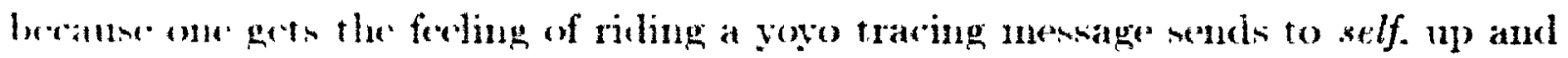
lown a hieraroly.

In suld "anes methods are "aceidentally" inherited" and either do not work "r violate representation invariants of the superelass [Cook 92]. Methods whid

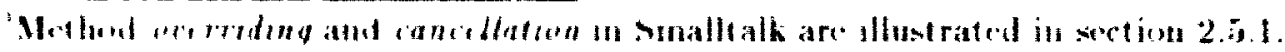

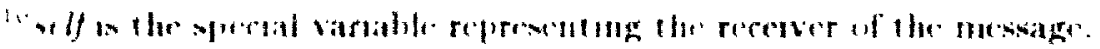

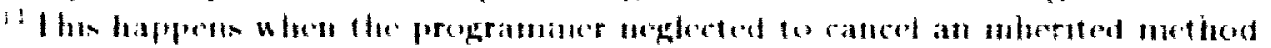




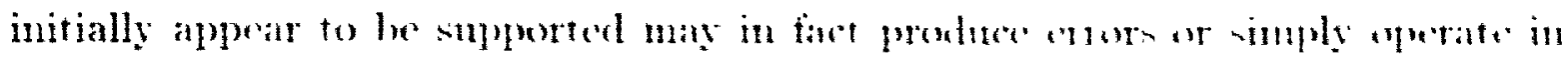

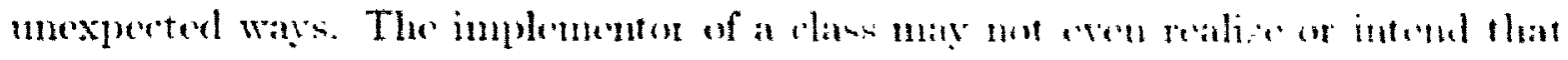

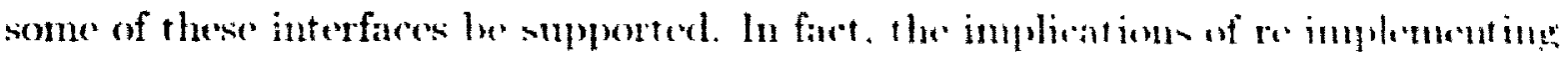

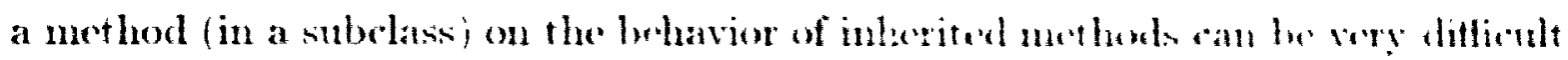

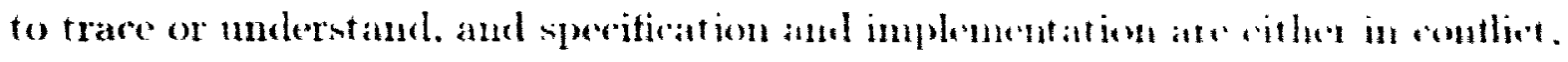
or hopelowsly intertwined.

\subsection{Motivation}

Approximately six variants of the Smallalk base libary are tow anmmentally

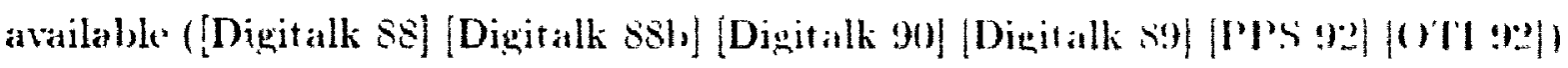
on a total of over fifteren different latelware and operating syatem combinations.

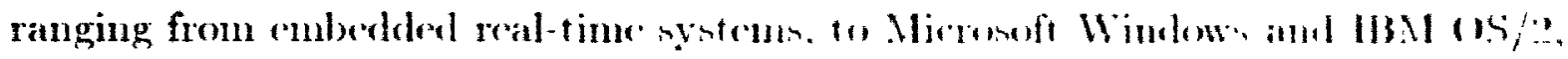
to Unix systems sllpporting X/Windows hased uner interfater.

The recont explosion of platforms supjorting graphical user interfares hat caured woftware suppliers to seramble to provide their applications on as many plit fou me:

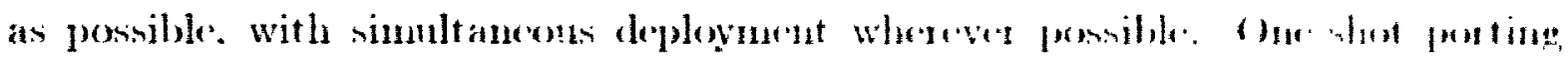

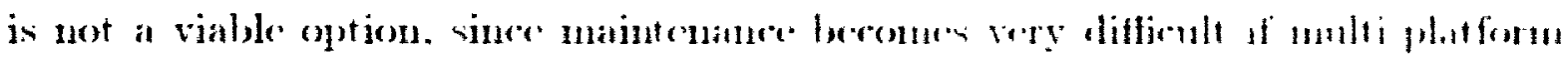
applications can not be at least partially if not tolally single andured.

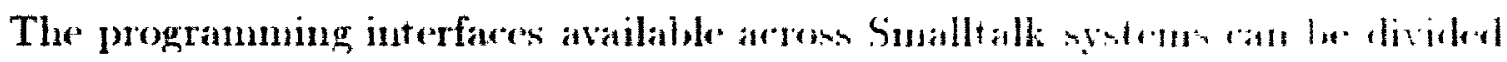

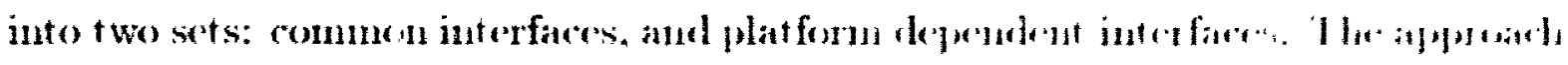

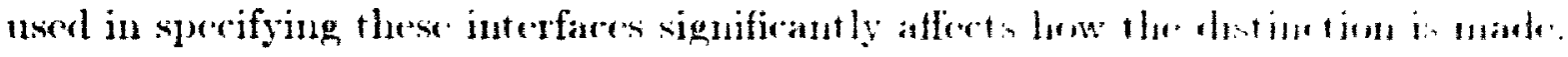

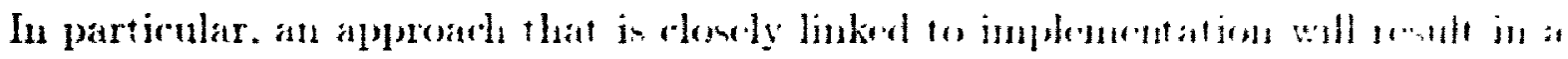

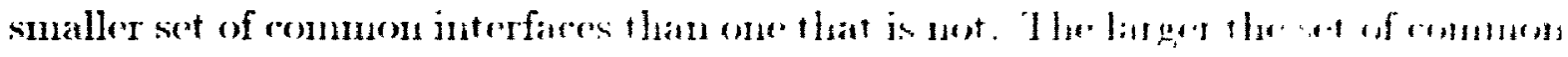

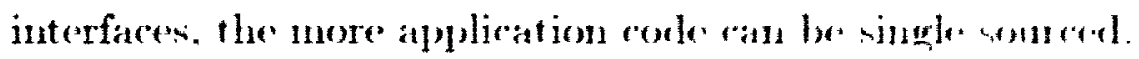

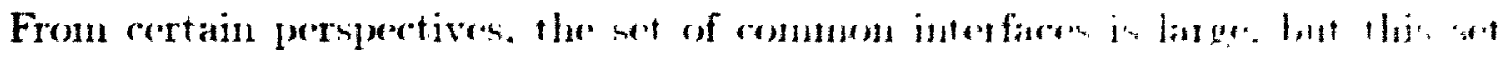

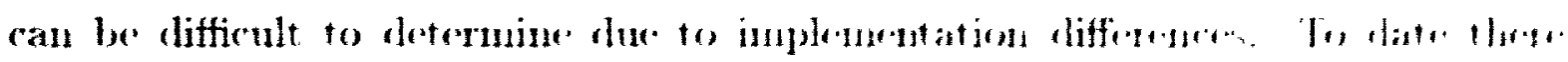

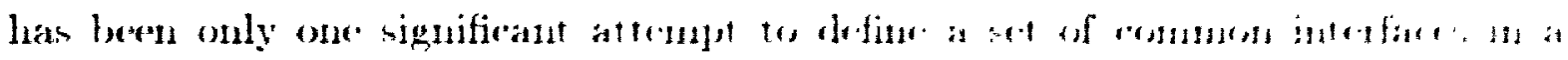

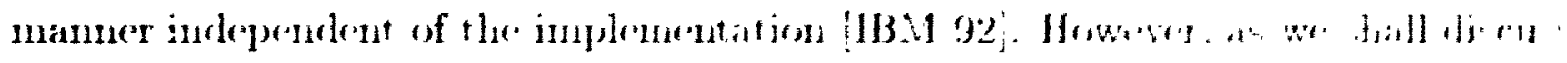


in rhapher 2 . it has soreral inportant weaknesses. In partionlar. the approach does

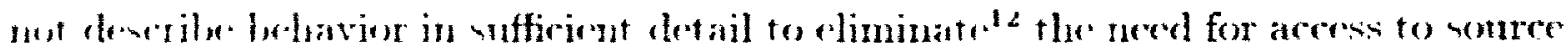
reule.

Somere colve inspertion may be an areptable requirenent for a developer working with a single. Suballalk implementation. However, its suitability diminishes quickly when a progranmen untst inspert multiple implementations and generalize their common propertien in order to write portahle code.

\subsection{Contribution}

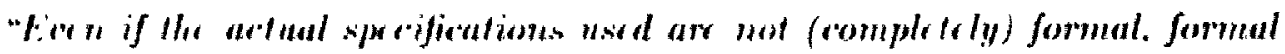
terhinque sould help us to de rolop a frame uork for sperifying compone nts in-

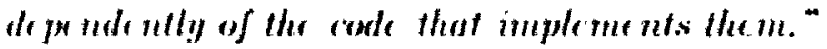

OOPlsis 91 Formal Mathods Panel [de Champenux 91]

Wr present a deseripitive morlel for specifying and grouping the belavior of Smallalk objects into mits called protocols. Protocols are independent of implemontation inle ritance relarionships, and deseribe essential aspects of behavior while

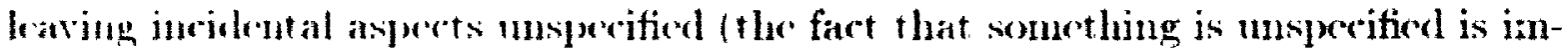
luitant information to a diligent application programmer).

Protocols are in turu used to deseribe the properties of message parameters and weturn values. Wi then establish conformance and refinement substitutability mationships which arrange protocols in a lattice. providing a complete picture of the behavioral relationalips of a set of classes. Conformanere provides the flexibility to deserilw parameters and teturn values without naming particular classes.

Wi draw from renent work on object-oriented type systems, and aliasing prewotion. Although sulh appoaches are primarily focuser on implementation issues. many of the problems are the wame, In particular. we show that while the paranetor cont ravariance ${ }^{13}$ rule (required for substitutability) limits flexibility in strongly yped object arented implenentation systems. the same problem does not orcur

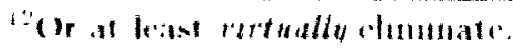

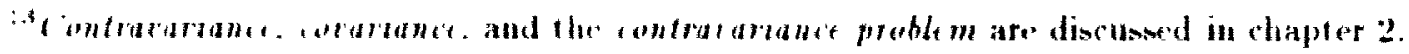


with a sperifiontion syitem.

The proterol model is intemded to provide a client's view" of smalltalk com ponent interfaces. independently of inplementation. This provides improwerl on capsulation, and facilitates the decelogment of applications which will work with different inplementations of the same interfates.

Wo illestrate onr ideas by presenting a factoring of the suallath collection

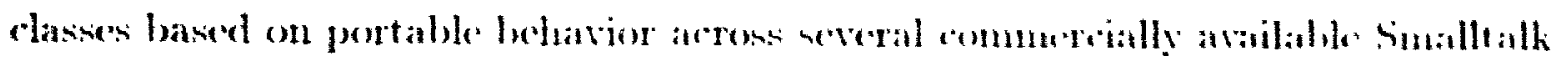

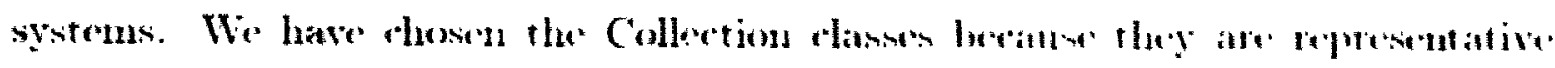
of the issues involved in sperifying Snallatk systems, and levanse many oflect

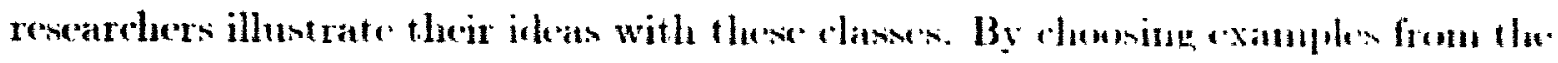
Collections, we can compare onr approath with other work.

\subsection{Organization of the Thesis}

In chapter 2 we establish a framework in which to review approanda fon anganizing

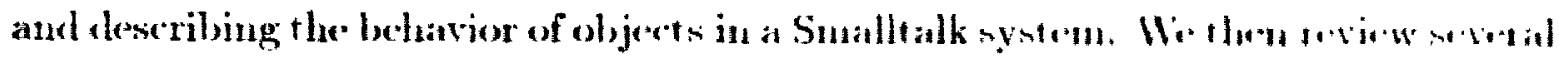

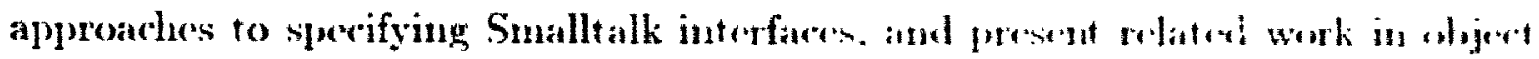
oriented type systems. In chapter 3 we present on descriptive model whide ongat

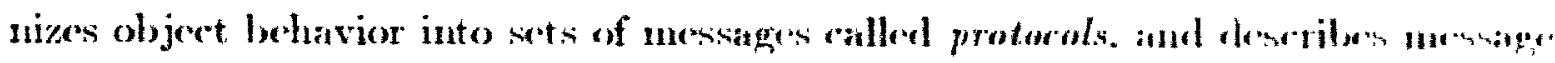

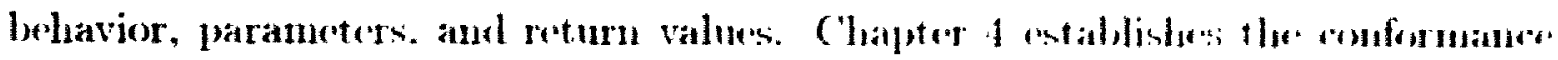
and refinement relations and their implieations for describing bedavion. In chapher 5 we show how the model is applied and present a factorimg, of the Sualltalk ral

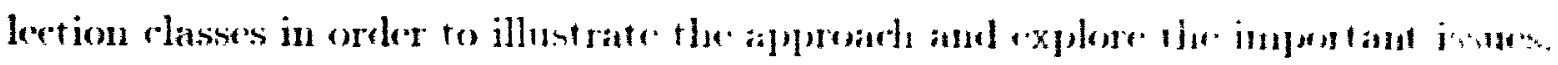

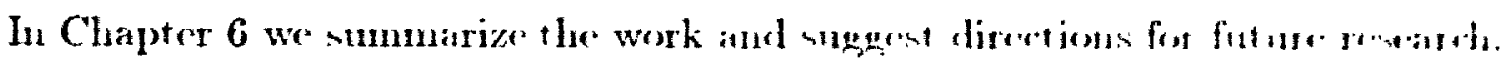

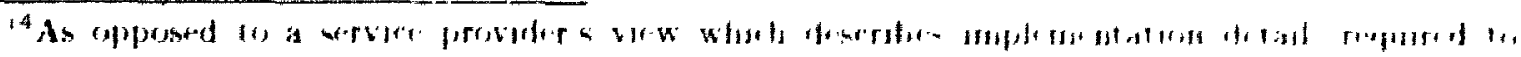
subclass wowlug flases.
} 


\section{Chapter 2}

\section{Background and Related Work}

In thiv chatuer we establish a framework in which to characterize approaches to the problem of describing the behavion of objects in Suallalk. We then examine a mumber of representative approades in the context of this framework. We define mu ue of erminoleng where there is the porential for confusion over different

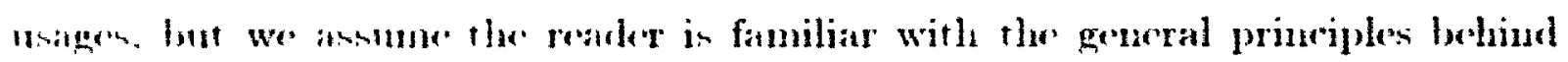
object oriented languages. and Smallalk in particulat.

\subsection{The Smalltalk Object-Message Model}

An aloget is an instance of a particular class. A method contains code which is invoked when a messagr is sent to an ohjert. A method is irlentified uniquely by the diss of the object receivine the message and a message selfetor. A message renkist of a mexiage selector and mesage paraneters.

Simalltalk is a pass-by referener system. Objects have a unique identity - that is it is possible to ask if two variables reference the same object. independent of any sotion of cruality of values.

Polymorphism is the nane given to the property of olject-oriented systems which allow different abjects to respend to the same message in different (or sinilar) ways, since different classes mat have methods which can be inoked by a given inesinge.

All whinets an the same class shate the sane methods. and the sume represent a- 


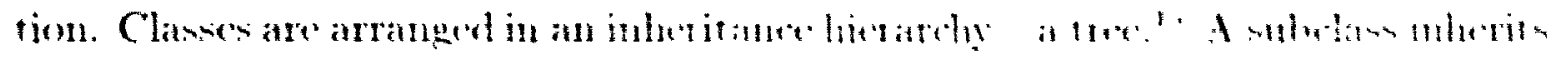

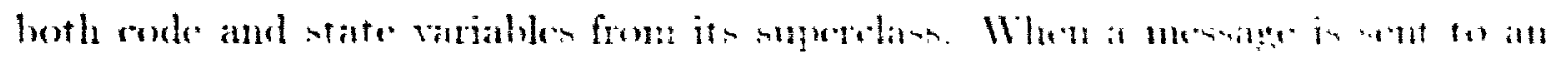

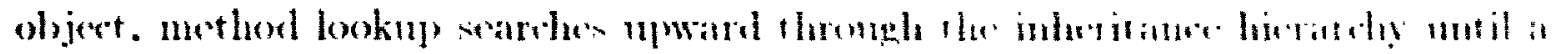

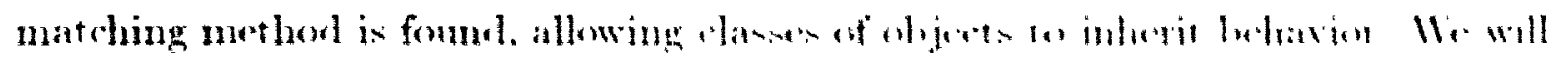

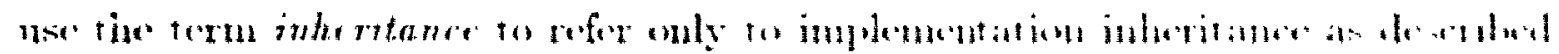
allowe.".

Inleritance is a powerful implementation me hamism. -mpun

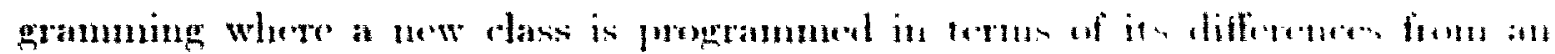

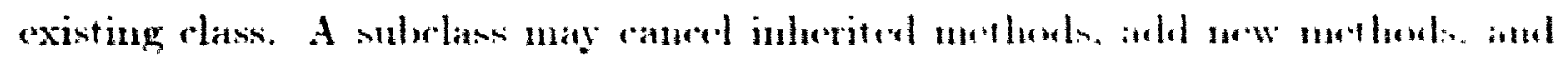

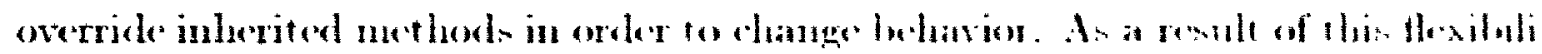

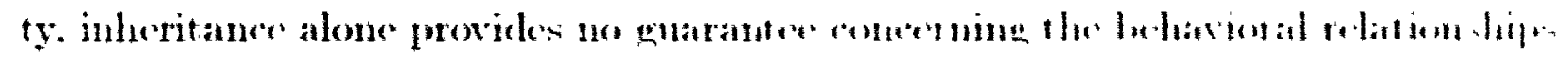

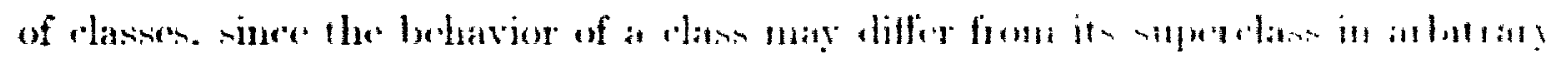
wayss.

\subsection{A Framework for Characterizing Approaches}

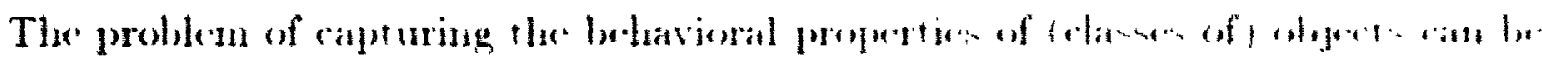

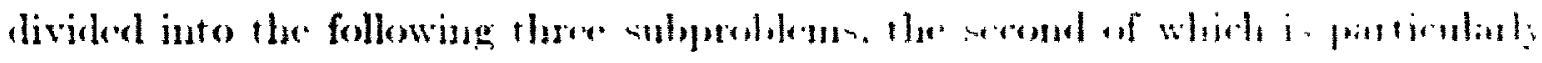
ingertant for abject orjented syotrins.

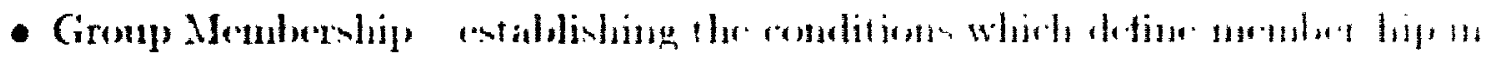

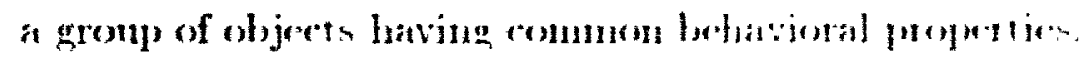

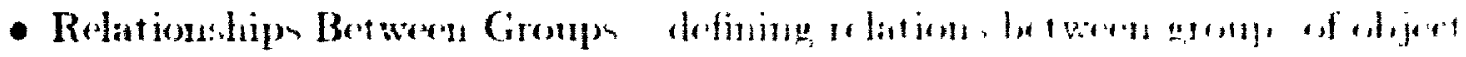

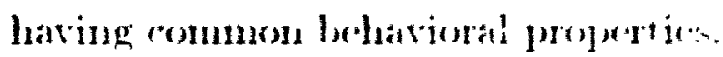

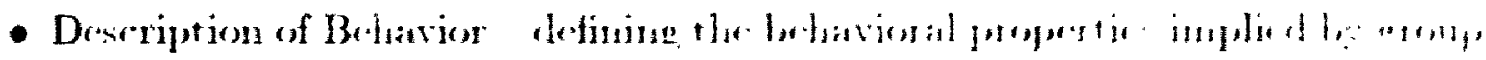
membership.

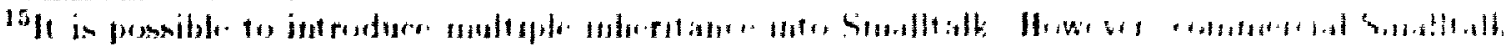

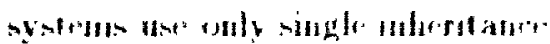

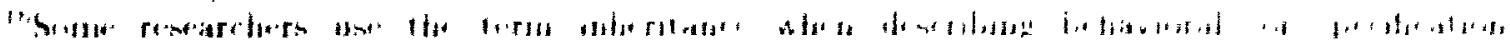

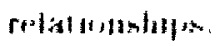


Dropite the fart that wo have irlentified these an weparate problems in fart they

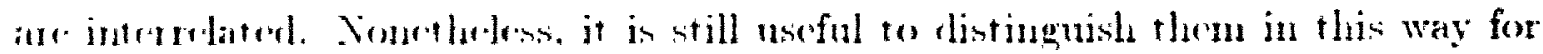

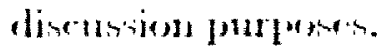

Netre that we are enucerned with establishing greups of oljects which have com

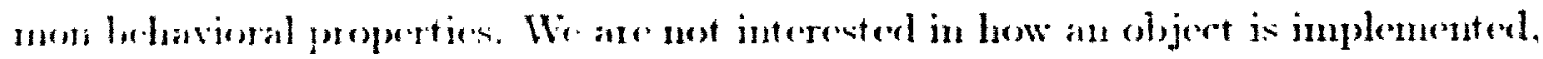

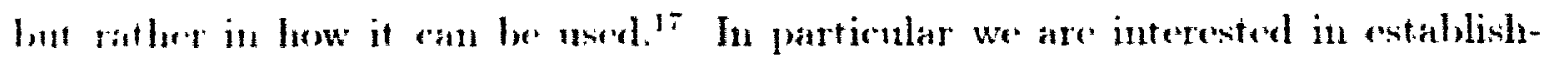
ing grompluge of olojerts which have some intrinsic property in common which is extenually vivithe. The result is that ong grompings establish a statir view of the

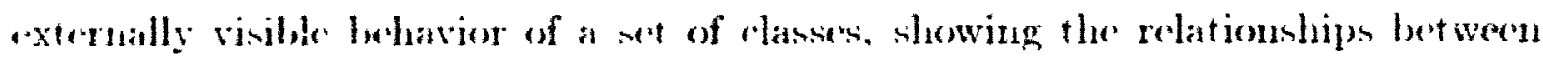

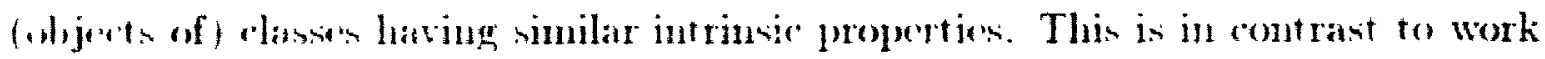

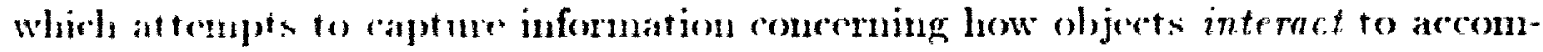
plish work [Holm 90] [Adams 92] [Wirfs-Brock 90].

\subsubsection{Group Membership}

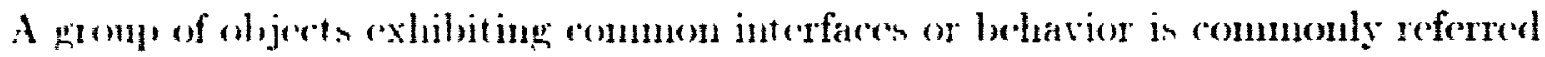

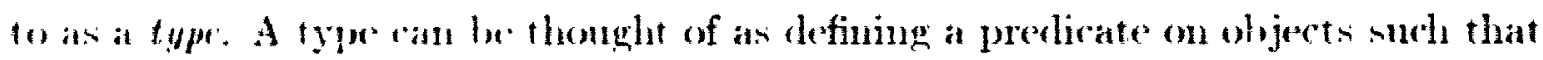

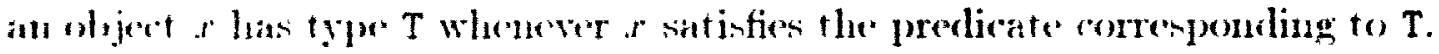

There is a wide range of riews in the object-oriented community concerning how sull a predieate dotines membership in a type. some emphasizing the inplenen-

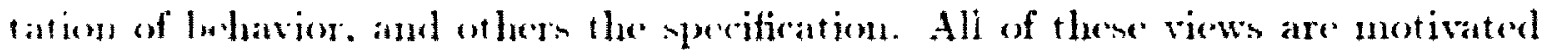

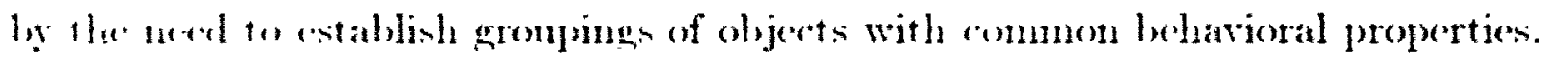

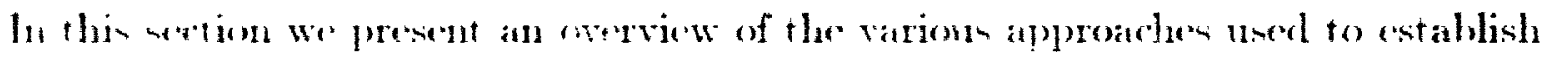

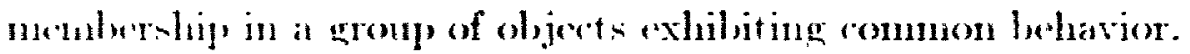

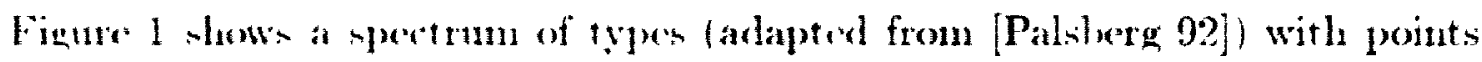

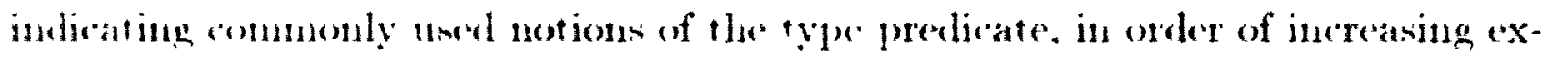

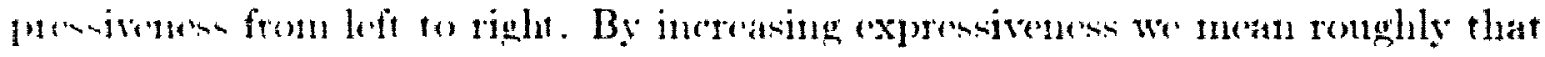

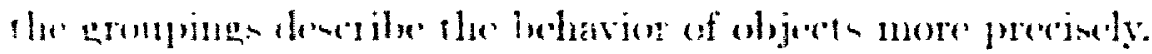

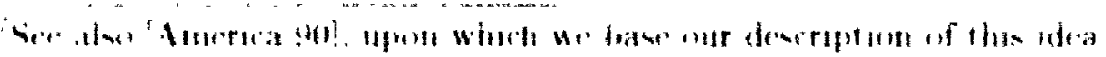




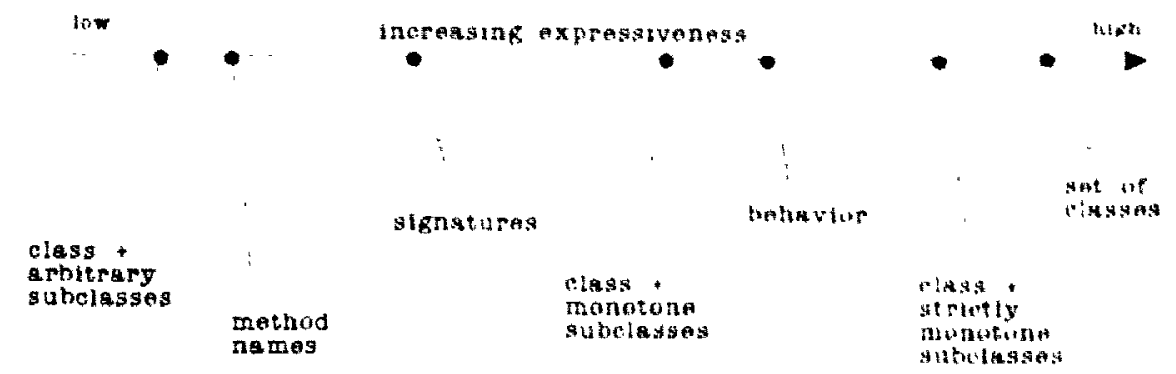

Figure 1: Sperirum of types

Moving from left to right across the spectrom, membership of an objoct in at tye is characterized an follows:

- Class and Arbitrary Subelanses The objert in an instance of a particulat dass

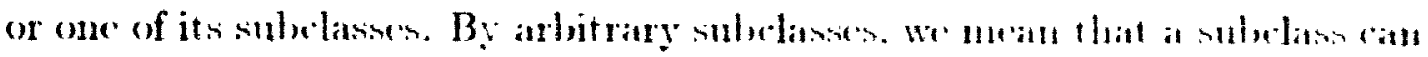
add methorim. change the behavion of inherited methols, on ranere inherited nucthorls.

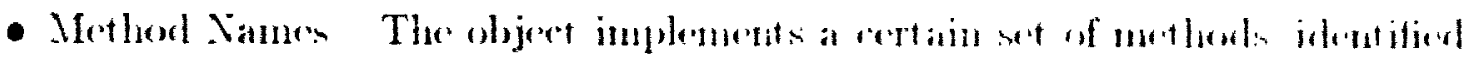
only by their mesuge selectors.

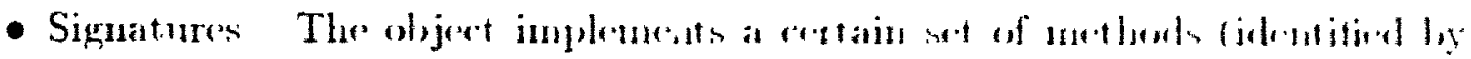

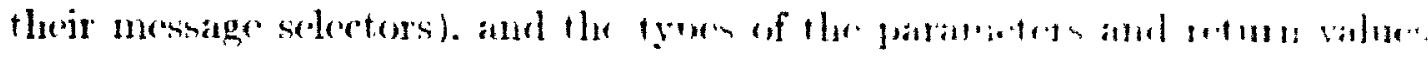

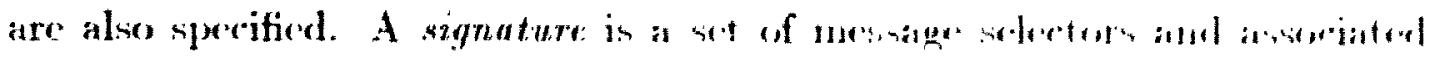
paraneter and returu type information.

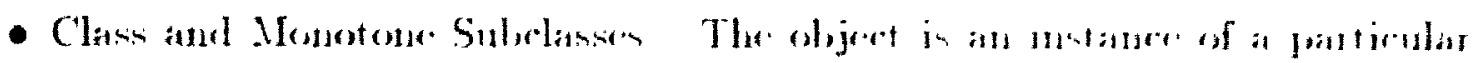

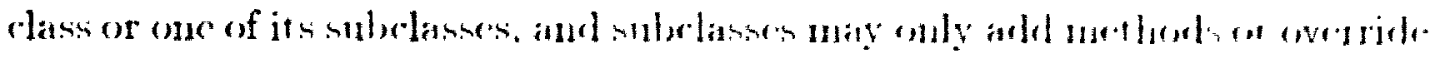
methods (no method rancellations).

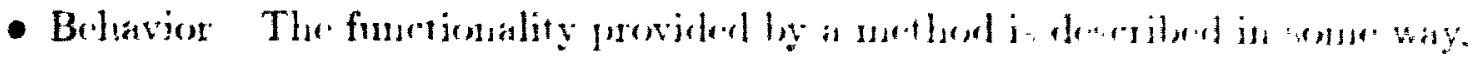

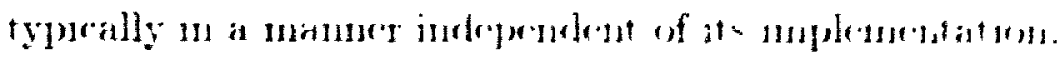


- Clans and Strictly Memotone Subclasses The otject is an instance of a particular clans or one of its subelassess. and subclasse's may only add methods.

- Sot of Classess - The oljoert is an instance of one of a set of classes.

Allowing anbitary subelasses is not a very uscful definition of behavior. since sublass behavior may differ from superclass behatior in arbitrary ways. The method names appronch is some what of an improvement siner it guarantees that an objert will at least respend to a set of messages. However the action taken in response to a message is left wusperified. and there is no guatante that the param-

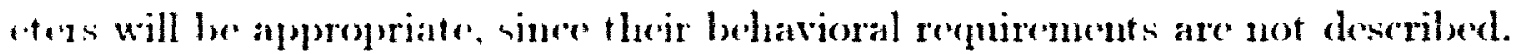

Since signatures impose restrietions on parameters and return values. they rin be used to garanter type sufety. in the seuse that all nessages sent will be muderstool. ${ }^{1 \times}$ However, signatures have limitations as shown by the following eximple [Palsberg 92]. Consider two disues. Cowboy with methods \#draw, \#move, ind \#shoot, and Rertangle whirh implements \#draw and \#move. but in completely different ways. Signature fait to capture this difference. A Cowboy substituted for "Rertangle may be type safe. but will certainly result in nun-time errors.

Momotone sublanses provide signature compatibility, but still may change the fellavion of iuherited methods in incompatible ways. Behavioral deseriptions usually induck signatures and belancionlly relate paraneters and return values indepen-

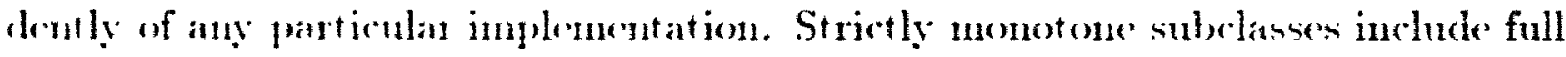
belavior. and even require that the behavior have a part ionlar implementation.

Sots of classes are the mose limiting. in the sense that they can only deserribe whers in existence at the time the type is defined. since cach aceeptable class must lie lintud.

It should be noted that type menbership critcria need not be related to inplenentation clases or inheritance at all. Some systems define types as sots of

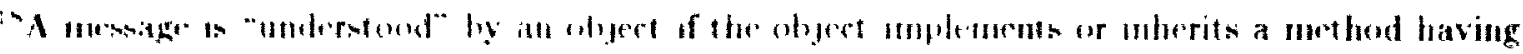

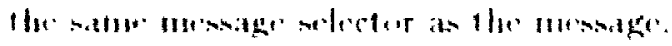




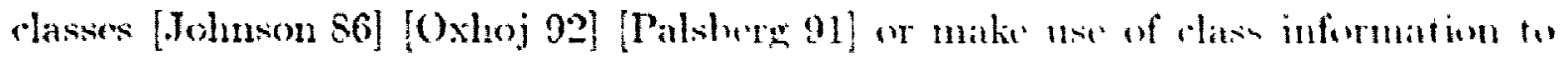
define types [Borning S2]. However, method names, signalures, and helhaver hased models can be detined ondependently of rlasses. and rlasises can be thought of as implementing types. In fant, a type may deseribe only atain anpere of the be havior of a class, and thus a chass may implement several you simmltamenty

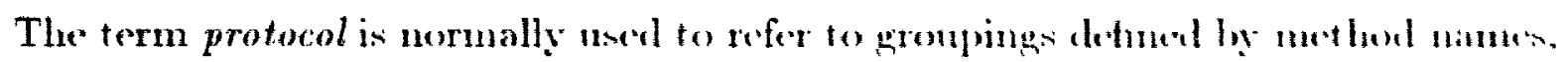
signatures, or behavior. In this context the terms type and protosol ath be und somewhat interchangeably:

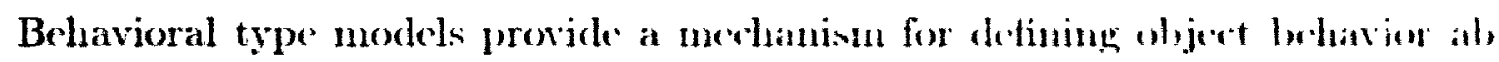

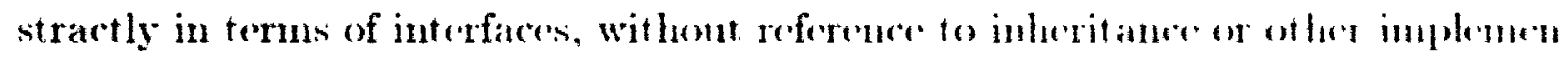

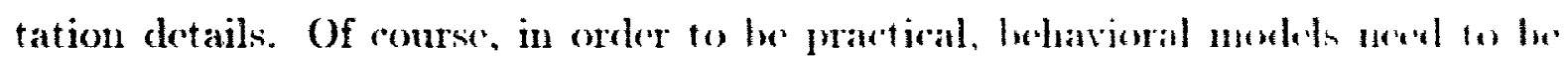
associated with the clatsses that inplement the behavion themph enme sont af relit tionship.

\subsubsection{Relationships Between Groups}

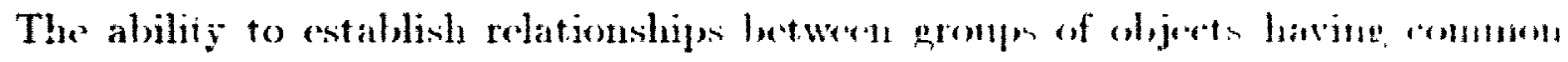

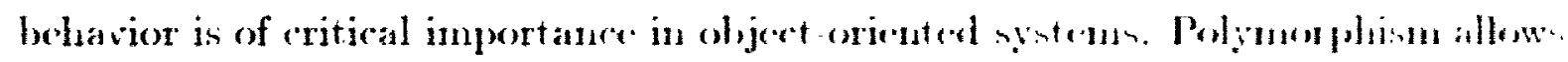

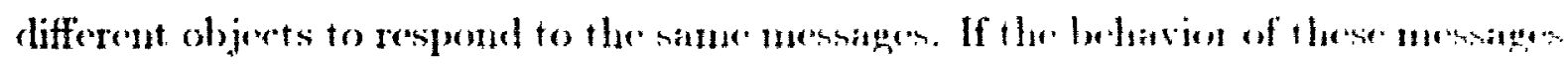
is compatible then objects of one type nay be substitutable for objects of amother type moler cortain conditions.

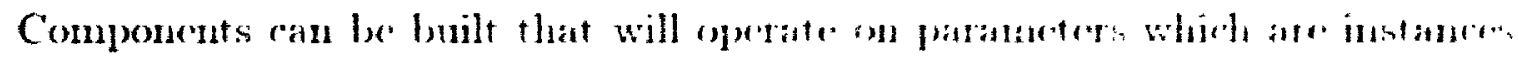

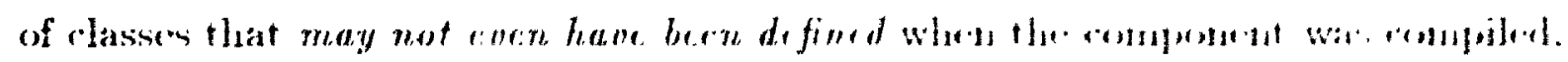

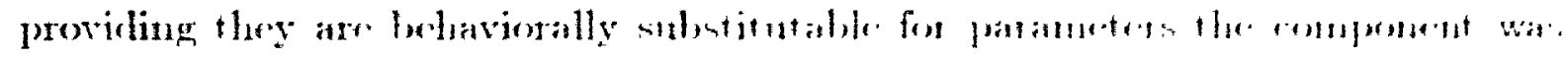

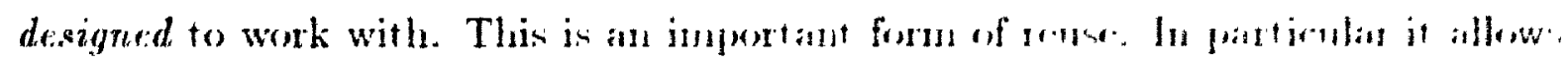

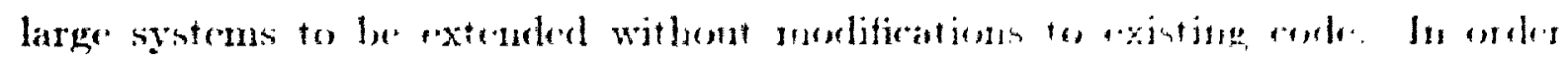

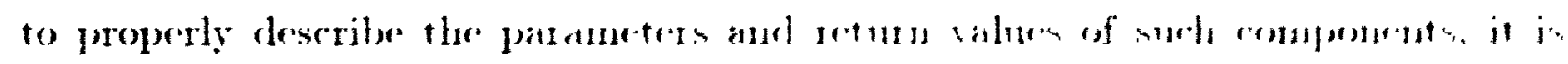

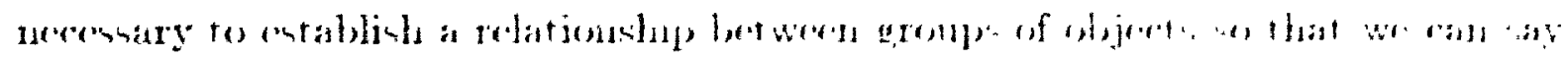

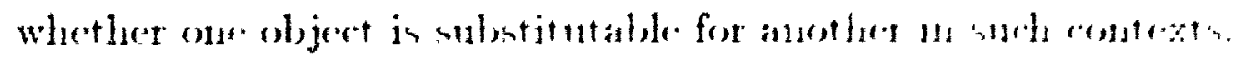




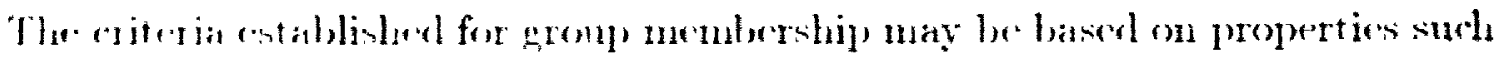

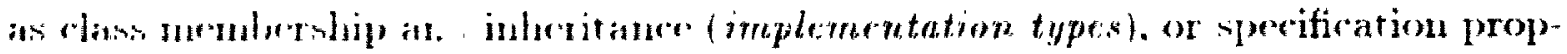
reties such as externally visible behavion (speraficateon types). Depending on the" fathinata eriteria ased, the ontesponding relationship between groups may be

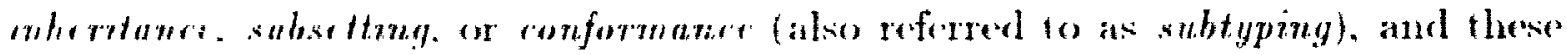

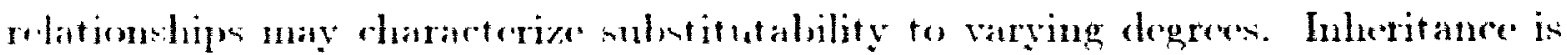
an inplementation mationship which relates elasses through subelassang. Suts of Choses are related thromgh subsetting which establishes both an implenentation (class menhership) and a sperifoation (externally visible belnavor) relationship). Confomano and sulyping are not an comsistently defined in the literature.

('onformance is rypieally a sperifiation relationship used with specification type, (or protorols), when describing belaviomal interfaces. Subtyping normally refers to a subetitutability relationship between eitler sperification or implementation types. A type $S$ is a subtype of a type $T$ if all (possible) objects of tyoe $S$ are sulm itutalla for parameters of methods written to aceept objects of type T. The requialent edationship wien using protocol terminology is conformance." Whether discuscing subtyping or anformance. it is important to irlentify whether or not a substitutablity rolationship is inplied.

In order to guaranter substitutability [Weguer S8], subtype operations must acrept at least all parameters acrepted by the stupertypes return a subset of the

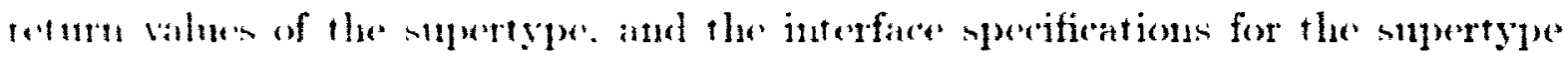
mont hold in the shlogye. In other words. a type $S$ is a subtype of a type $T$ if:

- S providen at loant the operations of $T$.

- For carh operation in T. the correponding operation in $\mathrm{S}$ has the same number of paraneters. and cither hoth returu a value or mejther return a value.

- The types of the parameders of $S:$ operations are the sane or supertypes of

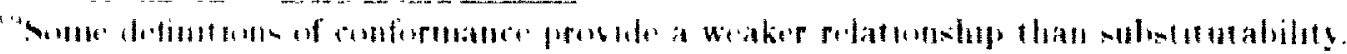

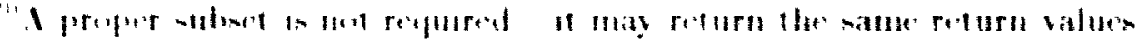


the correspoming paraneters of the oproutum in $T$. The is known an the contratariance rule for parametess [Cardelli $s !$.

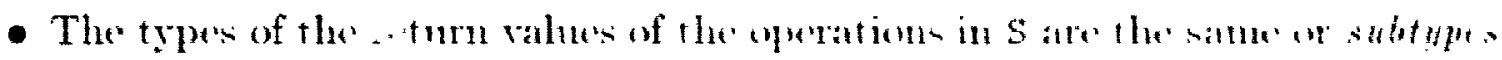
of the results of the corresponding operations in $\mathrm{T}$. This in hewwit at the conariance rule for returu values [Cardelli st]).

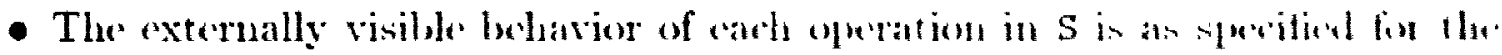
corresponding operation in $T$.

If only the first four hold. then $\mathrm{S}$ is signature substhtulable for $\mathrm{T}$. Thin as the has is for type safoty.

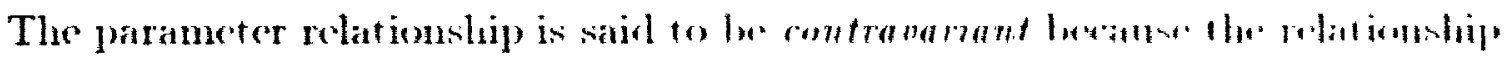

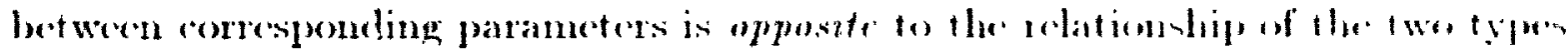

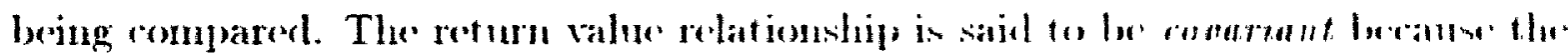
relationship between corresponding return values parallels the gelationship for the

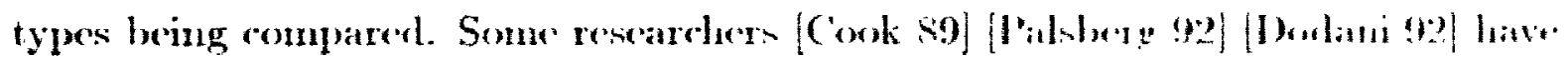

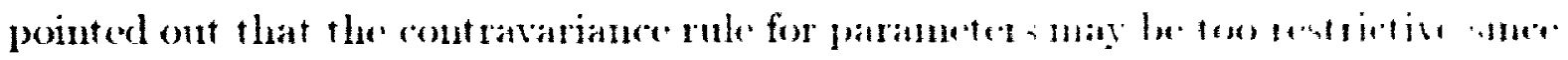

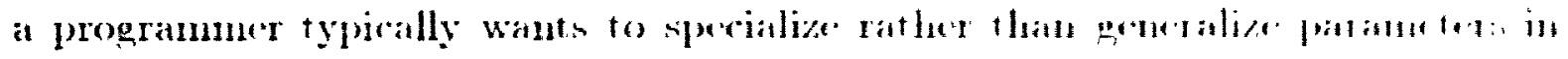
subtypes. This is referred to as the contranarane problem.

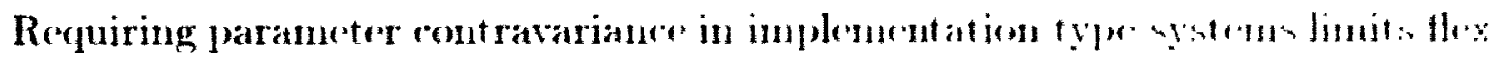

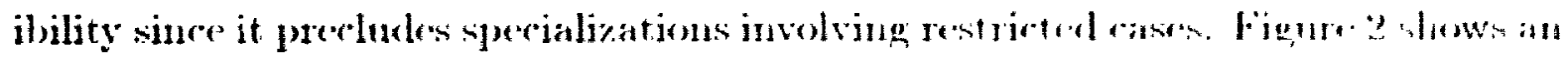

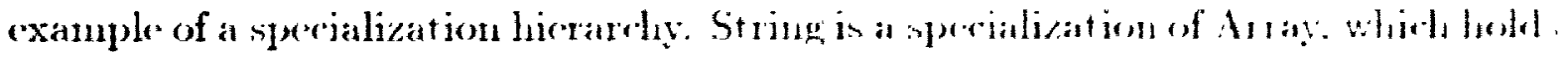

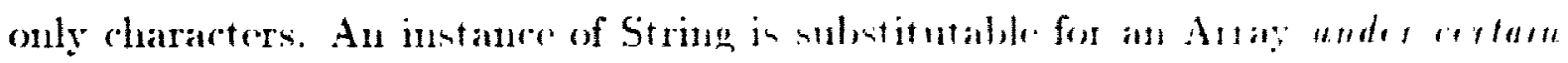

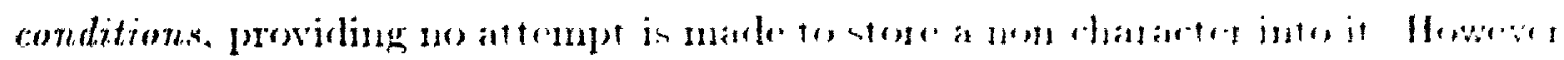

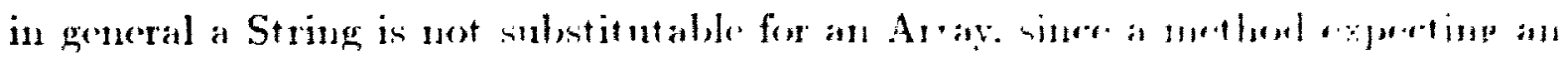
Array may try to store an anbitray ol,ject into the Stoine.

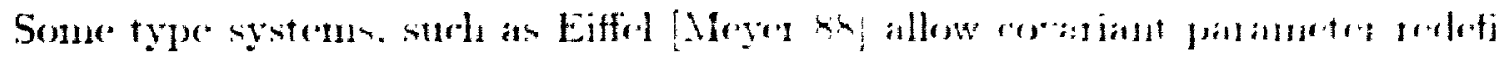

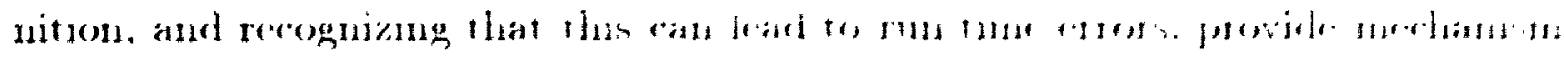

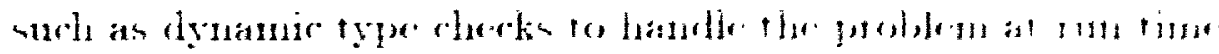




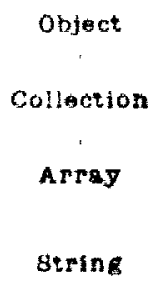

Figure 2: A Sperialization Hierardy

For completeness, most type systems [Palsberg 92] define two special types: NONE and $A N Y$. NONE is the sulbtype of all other types. and is defined such that there are no classes which implement the type. $A N Y$ is the exact opposite, in that it is the supertype of all types. Any object of type NONE has all possible behamor, and is substitutable for all other objects. Since there may be incompatibe operation name collisions between different types. stoh an object is. in general. inponsilbe to implement. Thus it is convenient to define NONE such that there are un objects of that type. In other words. NONE has maximal behavior. and no whjers implement the type. ANY han minimal behavior. and all objects implement the type.

Sert of elassess are a form of type union. A type nuion is a logieal OR of types whel that an object is a monber of the type if it is a menber of one or more types in Here dinjunction. For exannle, consider a mion of three types, T1, T2, and T3, writIn an T1 $\mid$ T2 $\mid$ T3. An objert $r$ is a member of the type union if is a member of ather T1. T2. or T3. or any combination. This can be a somewhat confusing con"ept. beraten the anion really describes distinet kinds of objerts, which may have

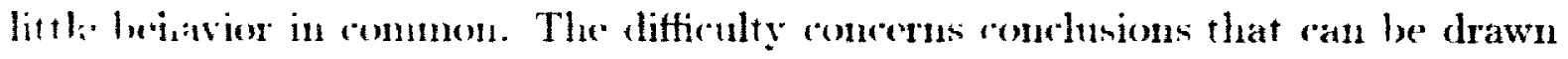
conernine the behavion of an oljoct which satisfies a union type. The only assured ferhavior in that of the nearest common supertype. ${ }^{21}$ and this property is ned in

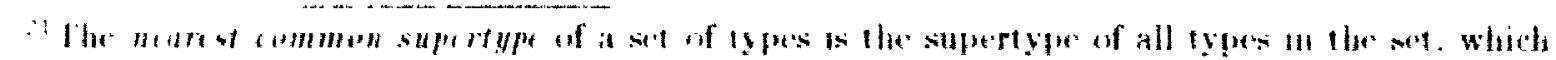

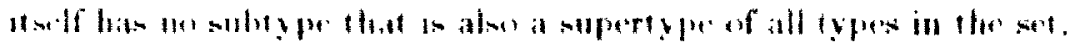




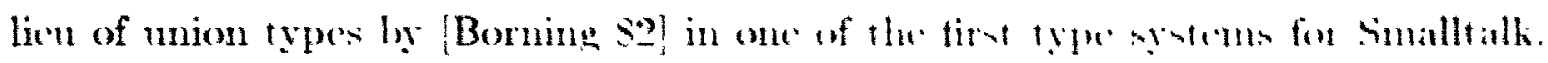
Howerer, moion types can provide more sperific information than the narest com mons supertype) throngh the use of tupe casme rum time testing of an alject:

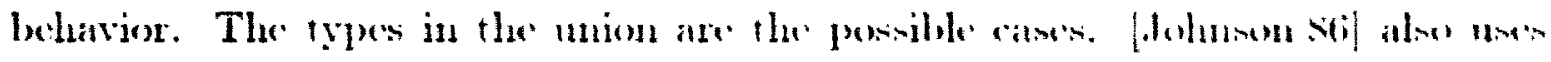

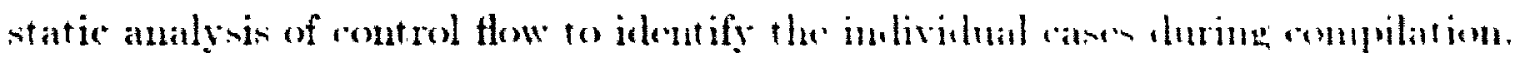

Establishing a relationship betwen groups of objects having common hetarias serves two different roles in a specitication. First, it is fundumental o lecing alle to describe the properties of parancters and return values in a polymorphic system.

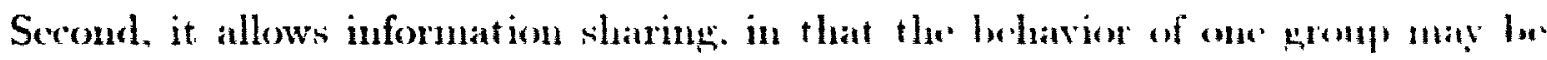

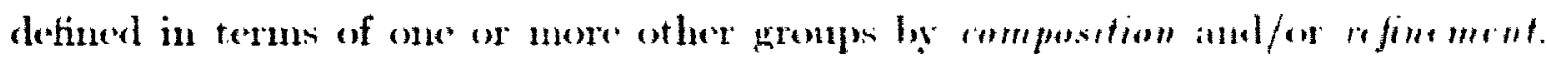

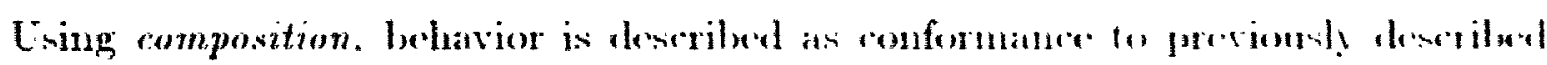
behaviors. and refinement describs new lohavior in terms of increaningly prevere statcments concerning previonsly deseriled linhavion.

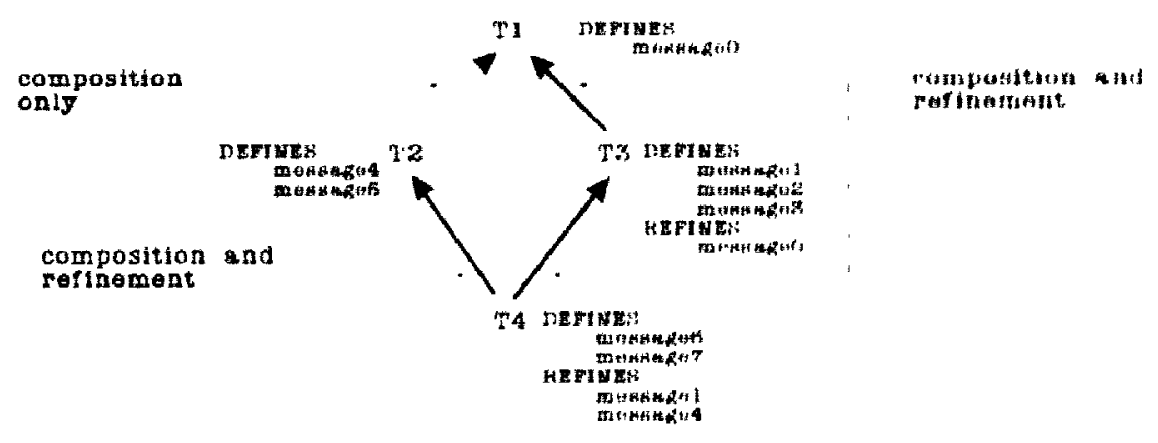

Figure 3: Comprition and Refintment

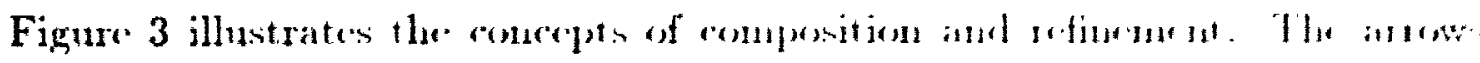

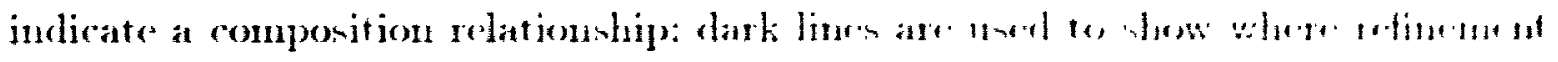

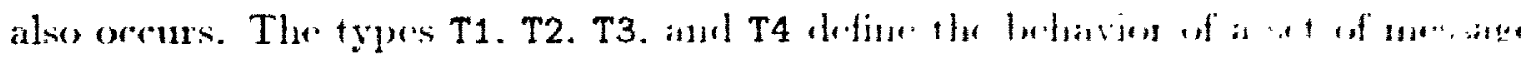

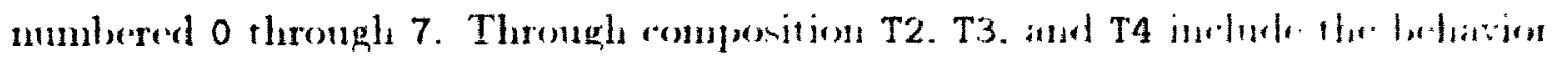

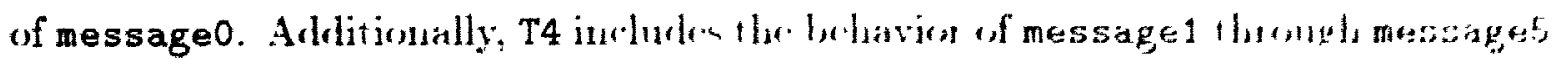

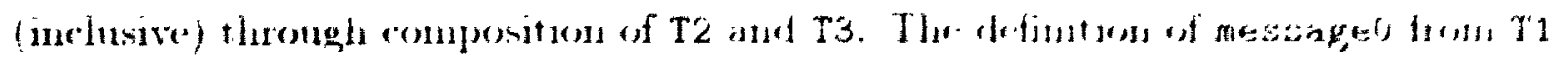

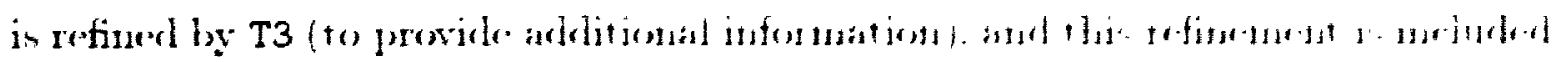


in T4 throngh connusition. Finally. T4 refines message 1 and message 4 from T3 and T2 respertively.

Approaden that support refinement of behavior. as opposed to just composition (thromgh conformance) are more powerful since subtypes or conformant protocols povide additional information concerning asperts of inchavior that have been left unsureified by the supertype (or conformed-to pretorol). In addition to allowing behation to be describerl in more detail, refinement also allows generalization and sperialization of parancter and return values according to the substitutalility rule. The use of romposition alone would result in the paraneter and return value definitions being exactly the same.

\subsubsection{Description of Behavior}

One of the most important arlanes in software enginering is the use of abstracfions. An abstraction encapsulates the details of how a particular service is implemented, reducing the amount of detail that must be understood at one time, and allowing the programmer to concentrate on higher lewel problems. [Liskov 86] provides an excellent discussion of the principles of alsstraction in software dewel"punent. and the role of speritiontions in describing the externally visble behavior of itistractions.

Abstraction by specification focuses on the behavior that a client can depend on frem a servie provider withont exposing the details concerning how the behavior is implemented. Two important advant ages of this approach are [Liskov 86]:

- Locality The implementation of onc alstraction can be read or written withont the requirement to examine the inplementation of any ofher abstracton. To write a program that uses an abstrartion. a progranmer need only mulerstand the abstraction's behavior not the details of its implementation. 


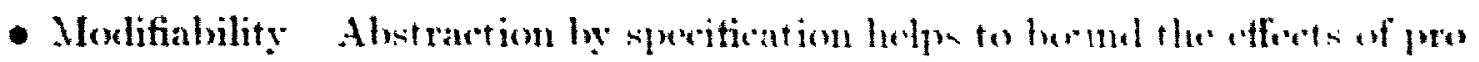
gram modification and mantenance. If the implenentition of an alsotration changes but its specitiontion does not, the reat of the program will mot le affected by the change.

An interface is the point where the servior prosiler and rient ment. It is that part of a component implementation which is matre visible to the client ly the service provider. An interface sperification detines the anditions under whids the serviec provider agress to provide the servier. and the promises the serviere provider is willing to make. An interface speritication defines the bumblary of an abstraction - only the information required to use the servien shombl he providud by the interfaer speritiontion, and no more. In this way. the interfine onedpulates the implementation.

\section{Attributes of Specifications}

Three attributes wheh are important for sperifieations ane as follows [hinken sid:

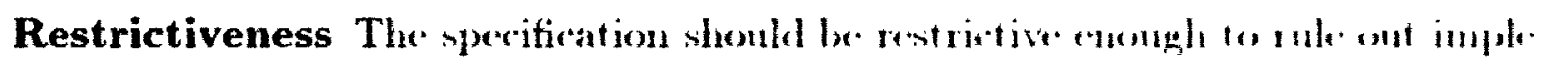
mentations that are nuaceptable to it abstractionis unes.

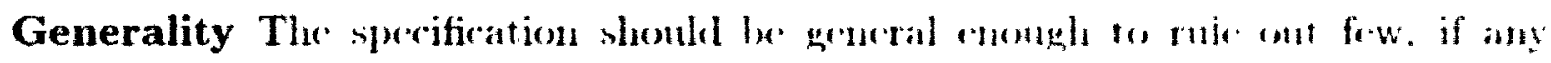
acceptable implomentations.

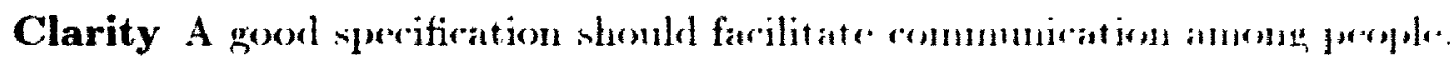

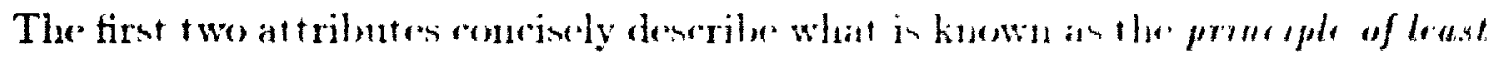

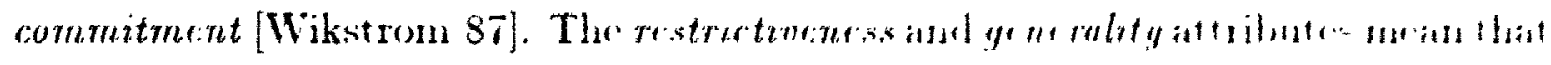

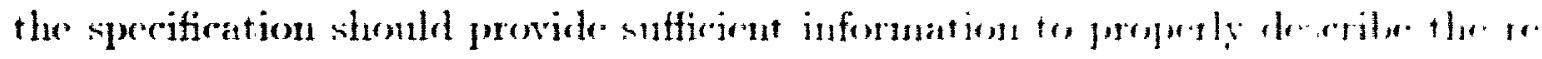

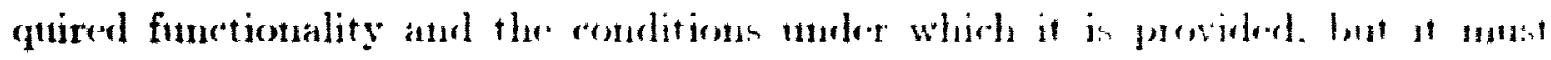

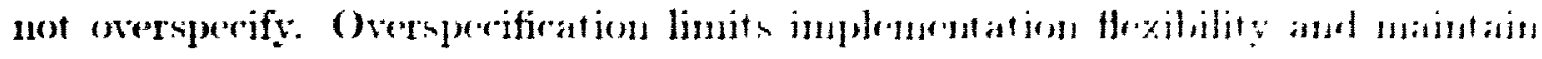

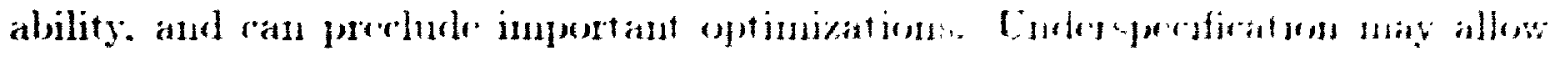
implementations with molemirable propertion. 
A goed dheck for generality is to examine every property of a specificarion and ask whether it is really neerled. If not. it shombl bo diminated or neakened. An intportant fartor in arhieving generality is making a distinction between essential and ancadrutal bedavior, and conuring that only essential behavior forms a part of the uncifiation. Essential helanior is that which is fundamental to the service being provided and presimably the utility of the interface would be severely limitad if it were omitted. Incidental behavior is a side effect of implementation clanien or the speritiontion approach. Essential behnvior is intended as part of the servine commintment, while incidental behavior is not. The distinction is up to the interfare desizur.

Thr clarity attribute requires that a specification be easy to read and understind. A sperification may be sufficiently restrictive and sufficiently general and may have exactly the right meaning. but this is not enough. If the meaning is dithoult for realers to discower. the specitiontion's utility is severely linited. Clarity is difficult to dharaterize. According to [Liskow 86], conciseness, redundancy, and structure are the nest important factors in achieving datity. The most conrise par sutation may zot be the best specitication. but is often a good starting point. Redundaney plays an innortant role because it reduces the likelihood that an injortant point will lac missed. Presenting the same information in different ways gives readers a lenchmark against which they can double cherk their understanding. Adrtitionally, while redundaney does not redues the mumber of crors in it yerification. it makes them more evident and provides the reader with an oplentunity to notice them.

Structure serves two roles. First. it acts as a categorization mechanism to make thing a casier to find. Sreond. structure can provide information itself as a result of properties associated with the structuring mechanism. A strong structuring re-

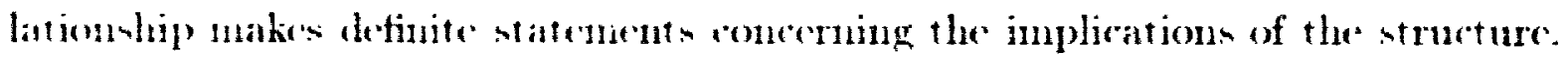
For cxample, in our society the parent/child relationship provides information con- 
cerning both geneties and legal obligations for support. A weaker strmeturing roba tionship, such as "friend" prorides information with lese certainty. The stonger the properties associated with a structuring rodationship, the mone signitiont the infor mation provided by structure alome. In particular we are interested in the wrueture provided by defining relationslips betwen gromps of oljowts having similat lediav :or.

\section{Definitional vs. Operational}

Specifientions can be characterized as being either defintional of operatomal [Liskov 86]. A definitional speritication indicates a set of propertien that at are rect implementation will exhibit, whereas an operational specifiontion gives a meripe for how the results should be compured. In some canes. a definitional sperifination can be much more concise than an operational our. for "xample in specificition for square root which can simply state that the relationship lew ween the inswer and the parameter is surh that the answer squared is equal to the parameter. An oper

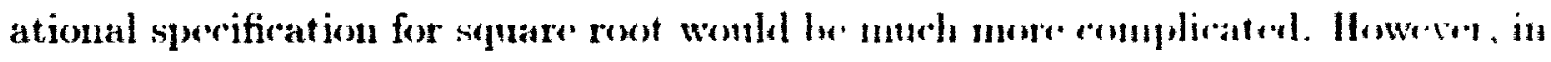
other cases it is mucli simpler to use an operational spreification. sumb as for a por gram which calculates an income tax return, becanse the prothem it se If is momally st ated operationally.

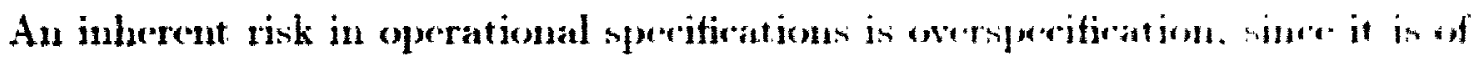

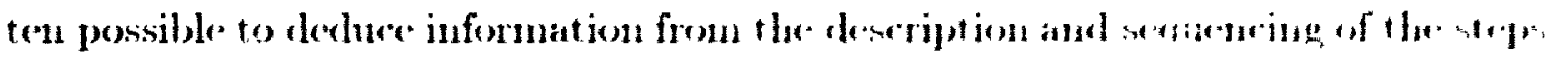

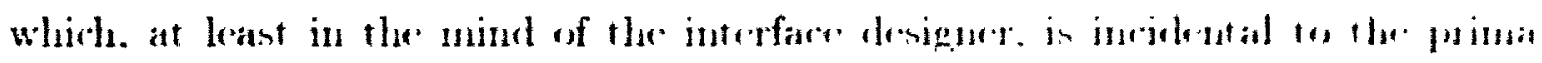

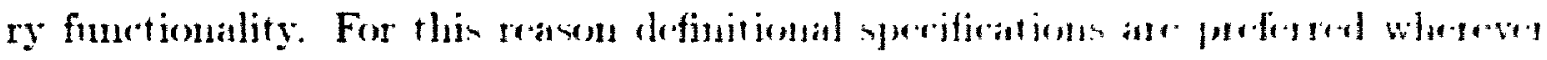
possible.

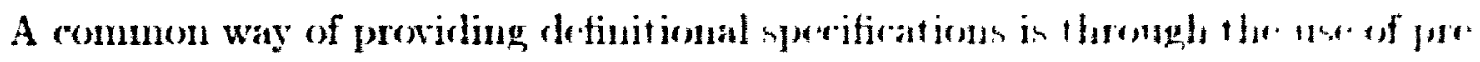

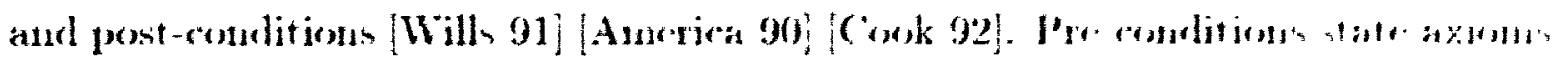

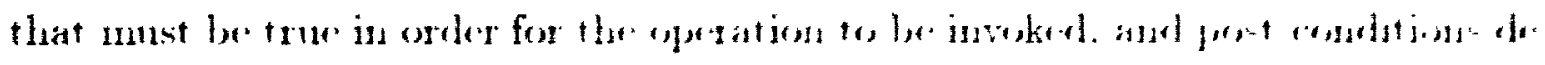

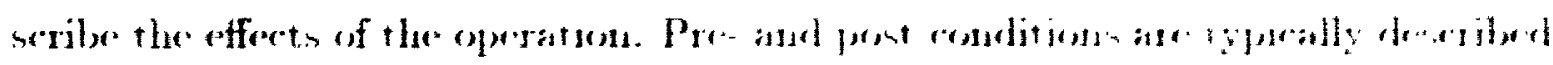


"wing some sont of notation based on a model of the object ss state.

\section{Aliasing Information}

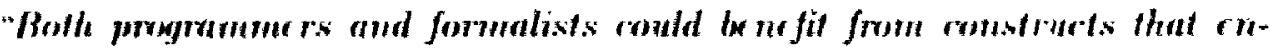
limere the lowatity of analysis by annotating me thods in torms of the ir resulting aliasinely propm rlits."

Goneva Convention On The Treatment of Objert Aliasing [Hogg 92]

An important as]wet of lollavior is aliasing. [Hogg 92] provides an excellent werview of the problen of aliasing in object-oriented systems.

An olijert is aliased if there are referenes to it from two or more variables.22 Enles mantged carrefully, aliases can result in mysterions bugs as variables "secm to dhange their values on their own". An example from procedural languages in at follows [Hogg 92]. Consid $\mathrm{r}$ a call-by-reference matrix multiply procedure mult (left,right, result) which multiplies the first two matrices and puts the resnlt in the third. This may work fine until a programmer calls it as mult $(a, b, a)$. If the implement or of the multiply procedure did not consider the possibility that a paraneters mat be alianed with the result, the result is likely to be a meaningless jumble of mumbers. Even worse. wo error is reported.

Aliasing is also a problem for formal approathes sines it an make event the simplest expressions diffionlt to prowe. Cousider the simple Hoare expression:

$$
\{x=\text { true }\}:=\text { false }\{x=\text { true }\}
$$

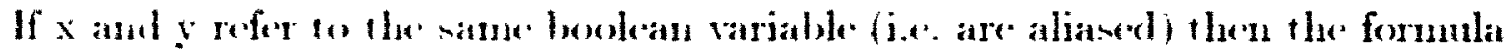
will not be valid. and proving that alianing can not oreur ran be difficult.

While the allawing problem is considered to be "under control" in traditional language [Hoge 9:]. the anproadhes to the problem have for the most part proven

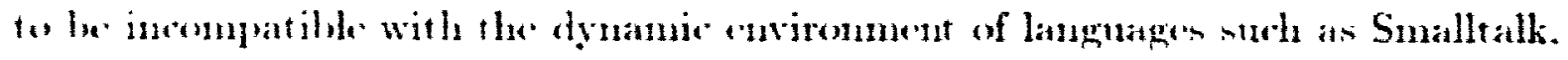
which at also hearily aliamed.

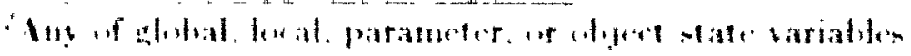




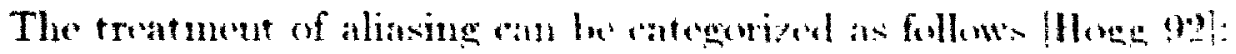

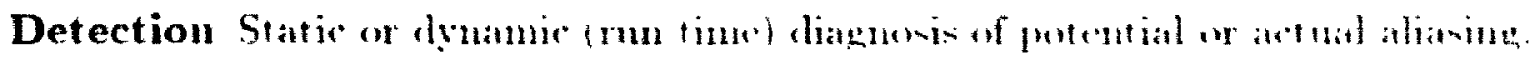

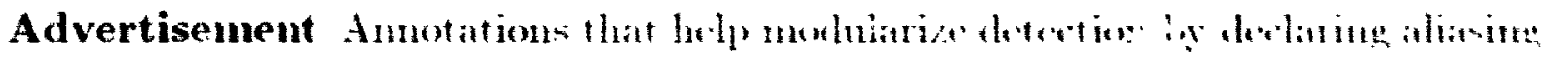
propertises of micthods.

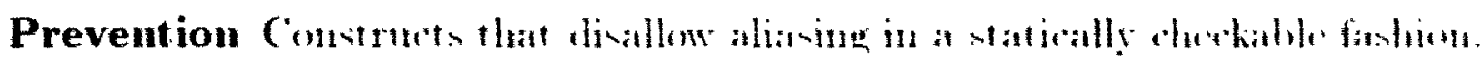

Control Approades that indate the effect of alianing.

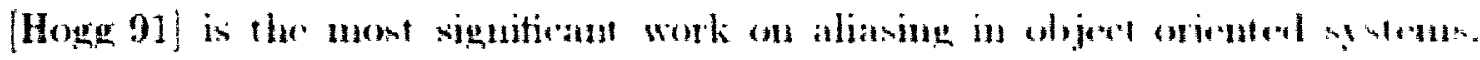

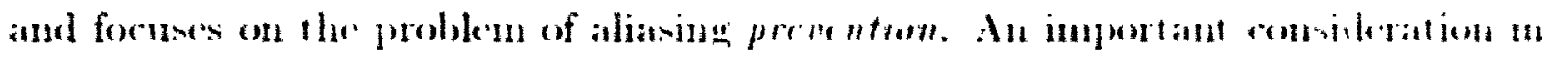

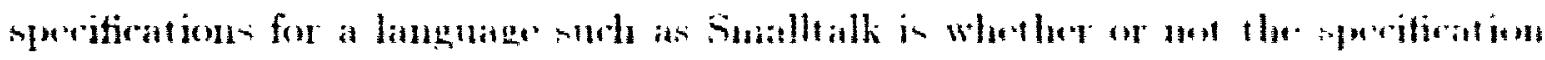

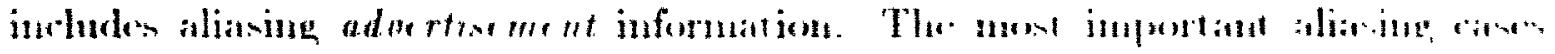

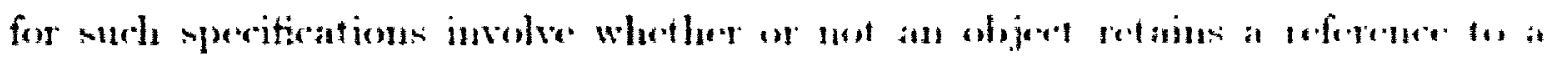

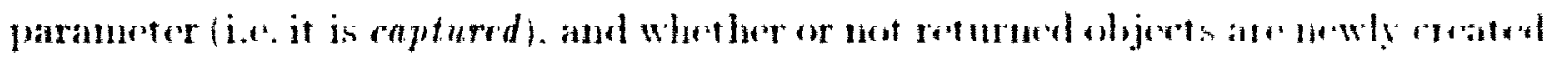
(matiased).

\section{Parameters and Return Value's}

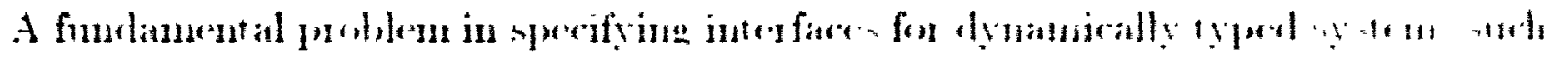

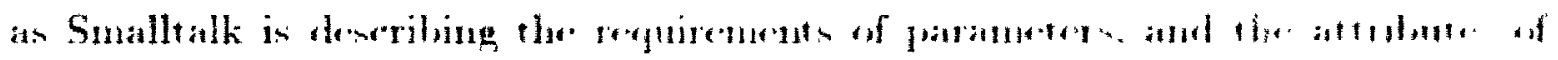

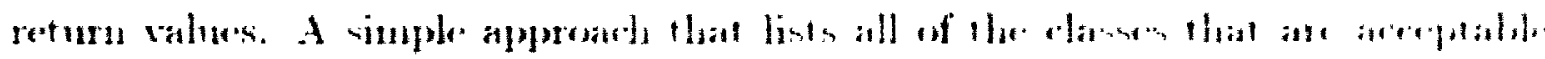

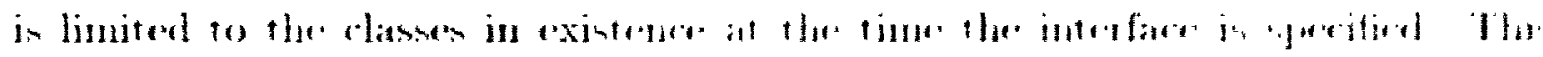

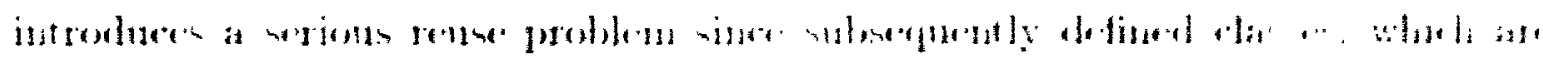

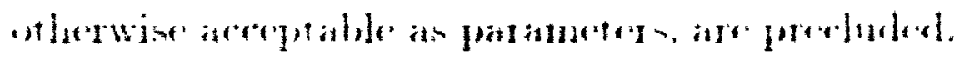

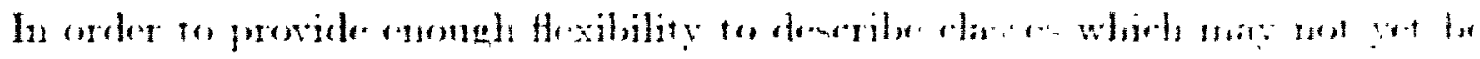

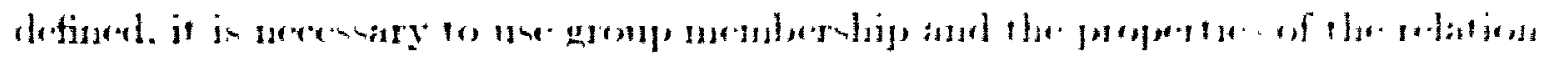

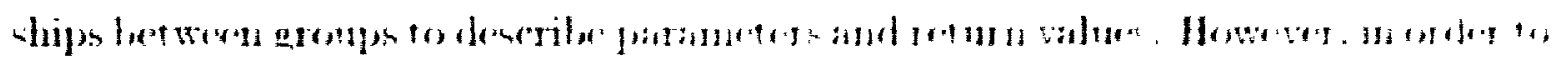

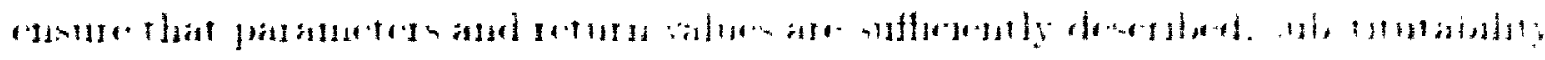

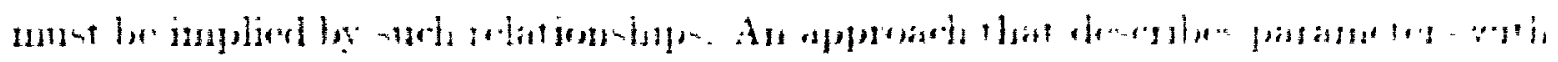




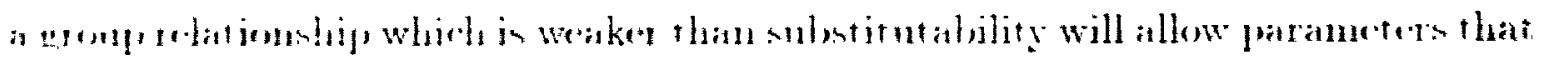

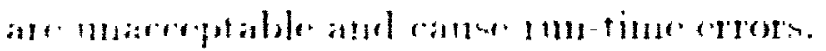

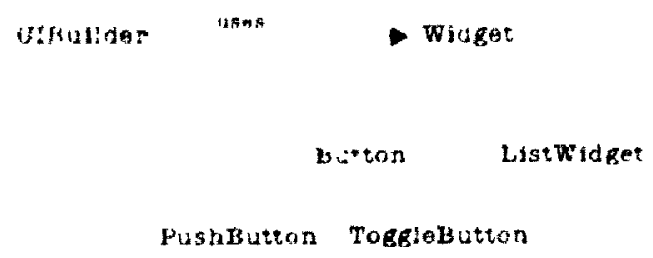

Figner 4: The importance of substitutability

The pener of a sulstitutalility relationship is illustrated by figure 4 . In this eximple. the Widget hierarchy implements a set of user interfaer classes, and the CIBuilder ans in denignel to work with the external interface defined by Widget in when t.e suppert the interative design of user interfaces. The LiBnilder makes ne

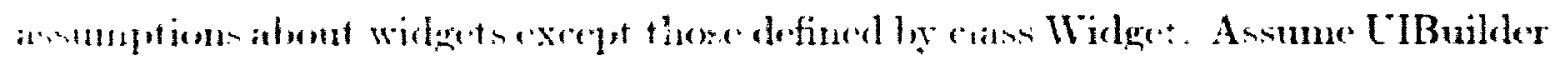

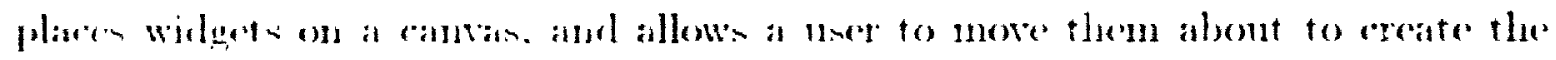
denired layout. Sinere IBBulder redien only on the extermally visible behavior of Wirget. Butroms and List Widgets an also be layed ont if they exhibit the same extemal bedavior. It in income puential whether they add additional behavior or not the epreration of the CHBuilder will not be atferted. In other word. other

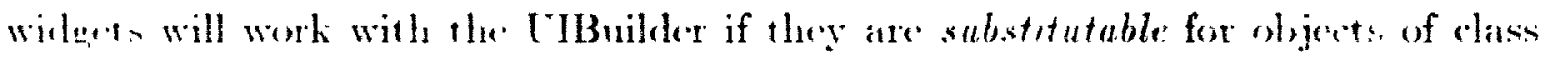

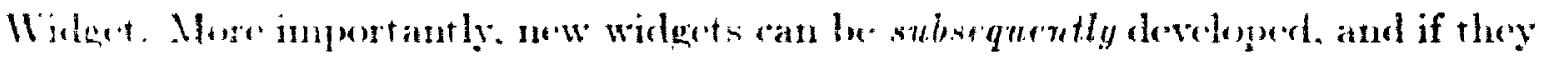

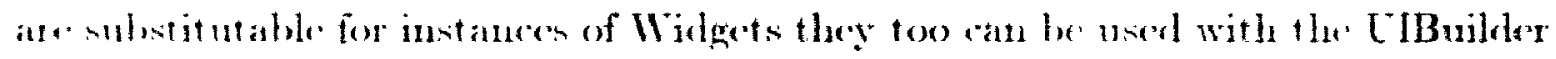

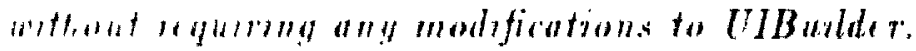

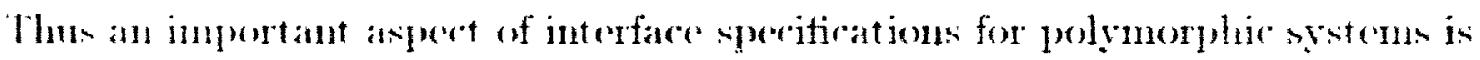

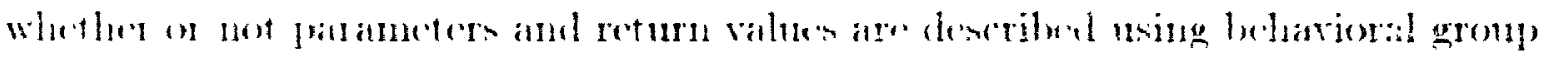

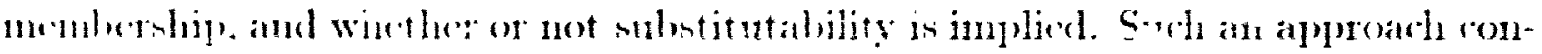

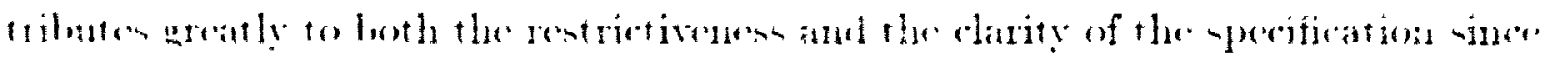

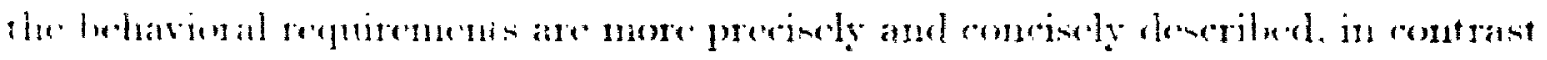


to approaches where parameter and return value att ributes mast be discened from context or methorl comments. Most resenteders agme hat such type information

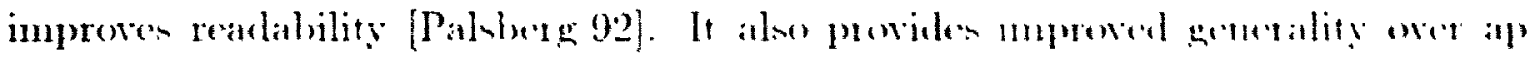
proaches that inplicitly indicate paraneter and retum value attributes ly expering

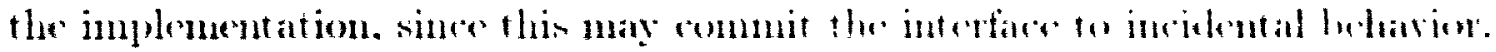

Signatures describe parameter and return value information in this way. lant wet

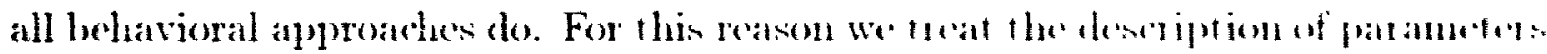
and return values as a separate isome.

\subsection{Areas of Focus - Object-Oriented Typo Systems}

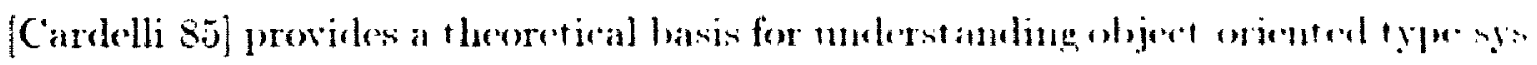

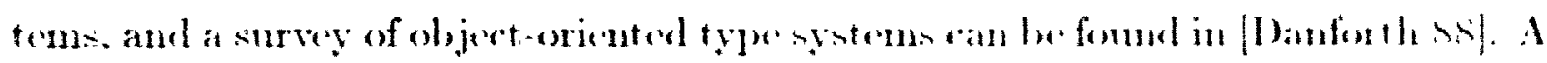

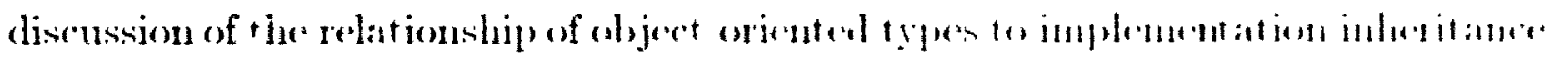
man be fould in [Lalonde 91], and [Whene SN].

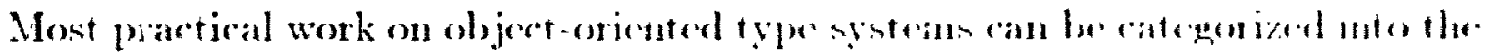
following areas of focms:

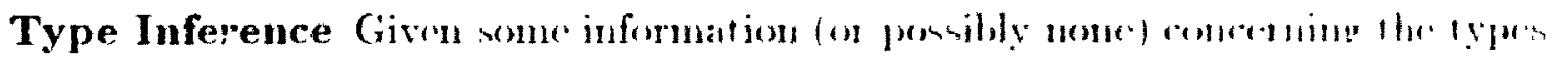

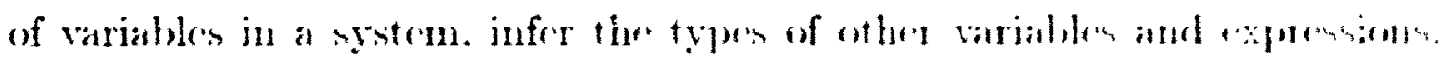

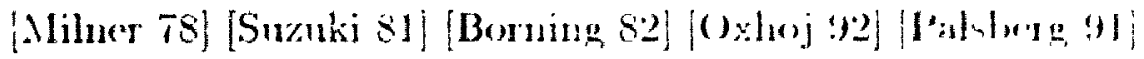

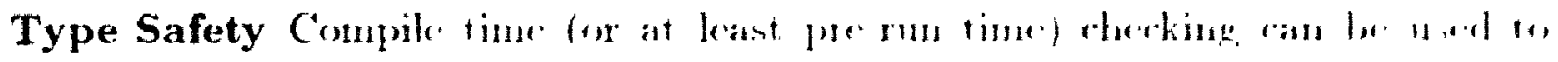

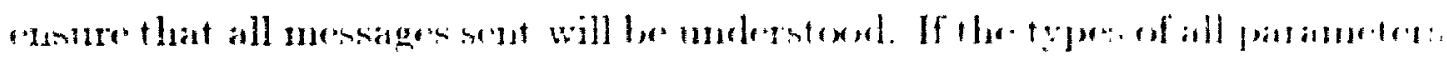

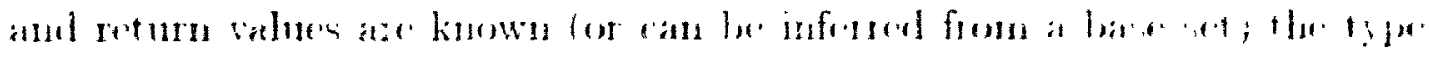

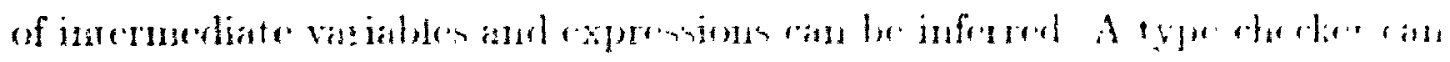

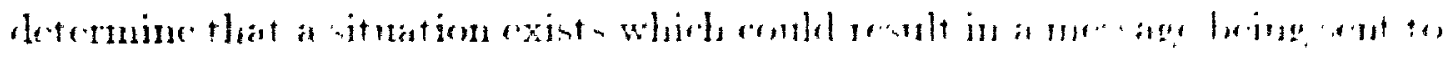

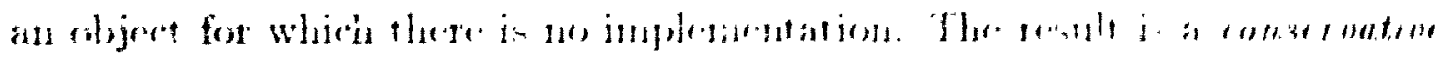

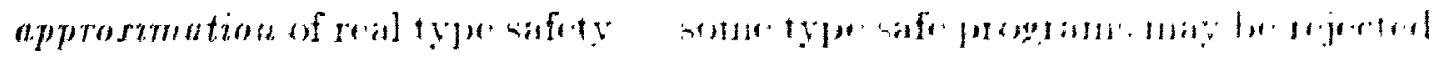

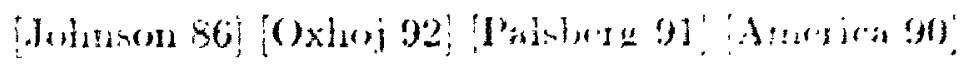


Compiler Optimizations of a variablo can be irlentified at ompale time an repre-

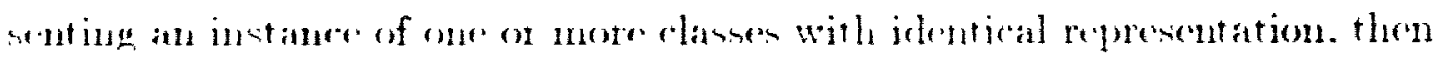
wertain comples optimizat ions such as inlining and pre-loop range cherking rim be ued. Thin is particulinly useful for array operations, which are notoromsly show in Smallatk since range dherhing (and a message send) is done on crery acress. In arddition. if a variahle can be identitied at compile time as repersonting an instance of a particular class. the'n run time method lookup ran le avoided and the implenentation of the method an be identified at ronupile time. [Johnson 80 ]

Vorification The subetitutalidity relationship an be uned to deal with polymorphism in formal verifiation systems [Leavens 90]. [Wills 91] also heses at type system with a combination of formal and informal technigues to show that two lifferent implenentations have equavalent behavior and thus that substituting one for the other can not break working, corvectly written code.

Interface Documentation Since types make a statement concening beharior. they are ideal for both organizing olject behatior through subtyping. and for describing the requirements of parametere and return values. This approach ham been uned renently by [Cook 92] to describe the Smallalk Collertion rasues, and in a weaker form. by [IBM 92] to specify Suallalk base

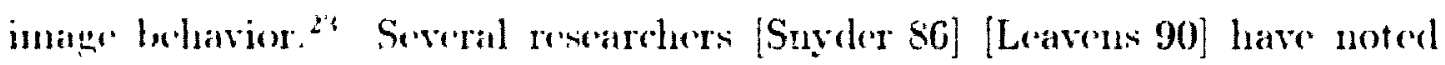
that smallatk progatumers work with an informal type model, even though Smallalk doe not -upport any type syotem. This suggests that a type (or protocoll bandel approach may be a natural way to present specifications of whiject oriented systems.

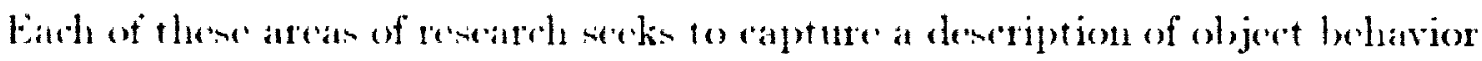

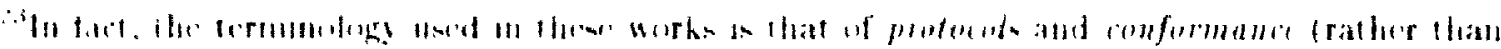

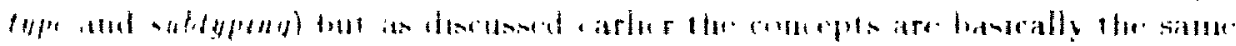




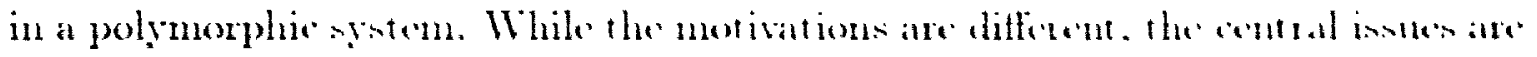
the sames.

\subsection{Overview Of Related Work}

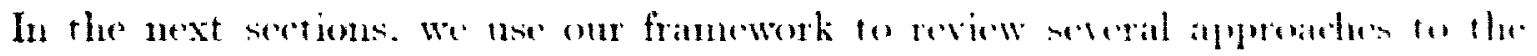

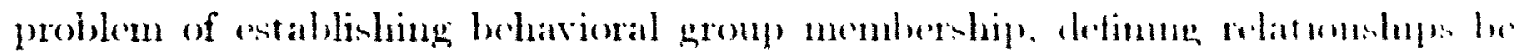

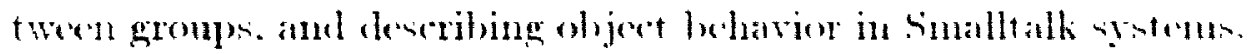

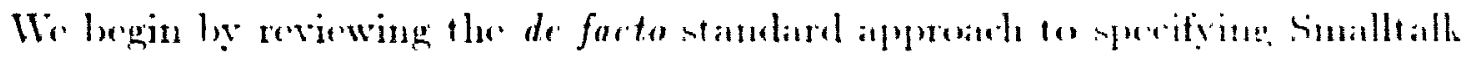

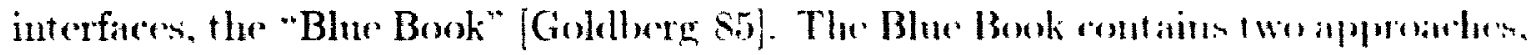
one based on method comments (protocol destrpteons), and otw bised an senume cole (implementation descriptions). Wo disems theme separately.

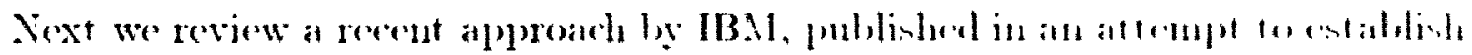

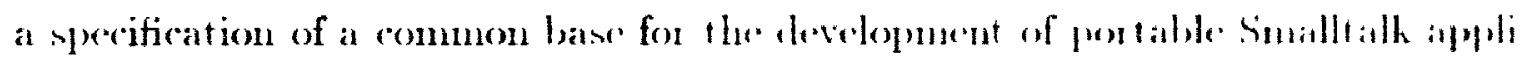

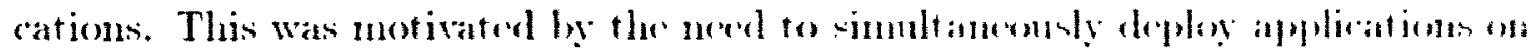

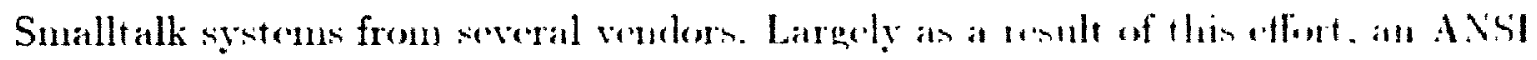

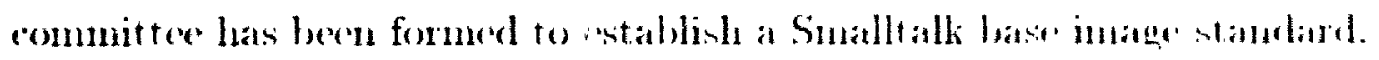

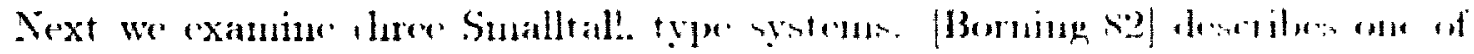

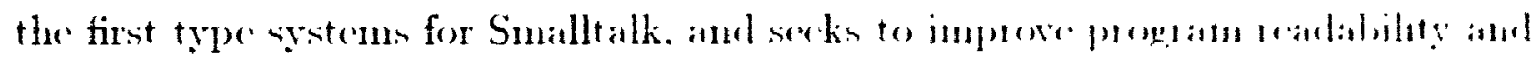

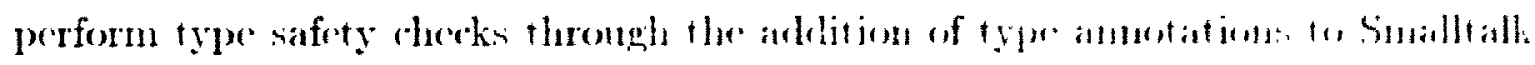

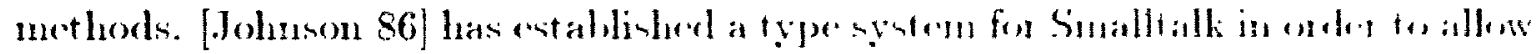

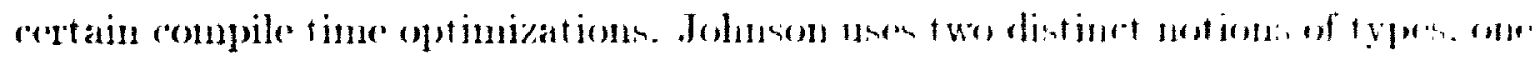

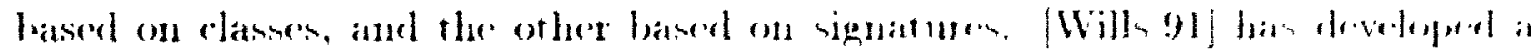

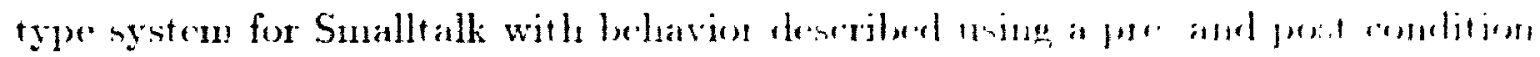

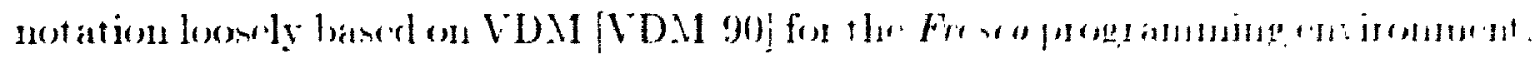

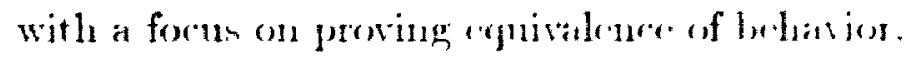

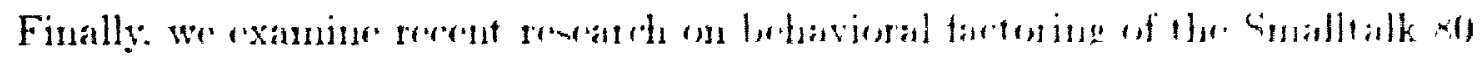

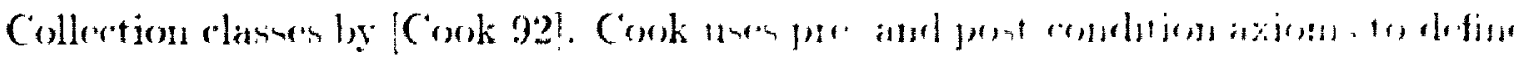

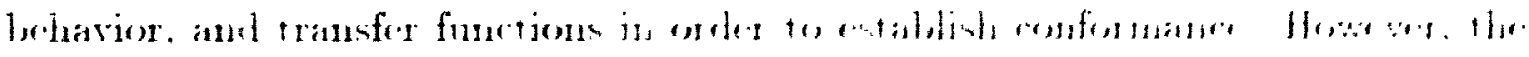




\begin{tabular}{|c|c|c|c|c|c|c|c|c|}
\hline & 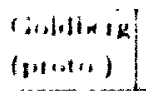 & $\begin{array}{l}\text { findlim+lk } \\
\text { (mimple) }\end{array}$ & 11511 & Hentatis & 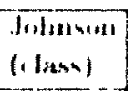 & 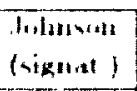 & Wills & c "wah \\
\hline fworill & link & Irin. & in. & 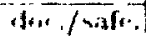 & मpinima. & "p? & lerif & lin: \\
\hline 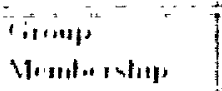 & 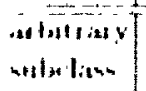 & $\begin{array}{l}\text { aflitian } \\
\text { wheliase }\end{array}$ & Imllav & ignal int? & 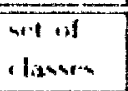 & slghat lite & Iwhavior & forhavior \\
\hline 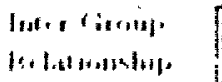 & inherit. & witierit. & confinsul. & confotiti. & $4 t 1, a+1$ & fonftersu. & romfonin. & conform \\
\hline 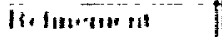 & in: & in:" & $\operatorname{lna}$ & lintiteel & no & yes & 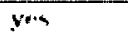 & II" \\
\hline Sul intatatalutity & In' & ai! & $1+1$ & 110 & $y$ & ins & $y+4$ & nits \\
\hline 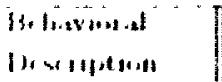 & nimingeint & $\cdots m$ & 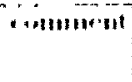 & w1w" & riste & minte & $\begin{array}{l}1 \mathrm{ne} / \mathrm{p} \times \mathrm{m} \\
\text { andr. }\end{array}$ & $\begin{array}{l}\text { profinme } \\
\text { inmi. }\end{array}$ \\
\hline$(3, / 1) \cdot 1$ & Intexd & ip. & $1+1 x+1$ & $1 / A$ & $\therefore / A$ & $2 / 4$ & A.t. & atef \\
\hline 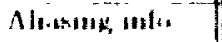 & wits" & ionl. & ini, & $\therefore / A$ & ravle & $N / A$ & 110) & I11 \\
\hline$|\therefore 21.210| /\left|r_{r}\right|$ & stimen & MH: & athete & $v+m$ & yom & ves & sen & IIs \\
\hline Mralin liwenes & lisw & bighli & Jiw & low & high & lisw & high & ateriags \\
\hline riavelity & avelas" & low & Inkh & high & low & hinh & high & lingl: \\
\hline ' l.21 its & If+n & int'Ingr & 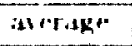 & avereag' & $" / A$ & $\therefore / A$ & alv'alat: & avel asge \\
\hline
\end{tabular}

Figure 5: Comparison of approaticen

appoand does not suppent substitutability simer parameer and ceturn types are

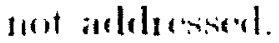

Figure 5 smmmatress the approaldes. eraluated using the frame work. While the

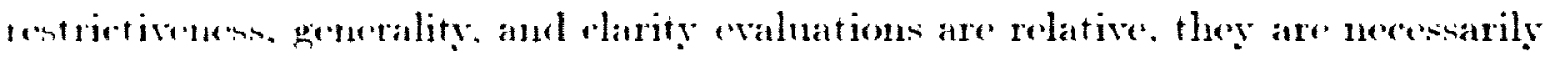
somewhat subjective: however we explain the rationale in our review. 


\subsection{Goldberg (Blue Book)}

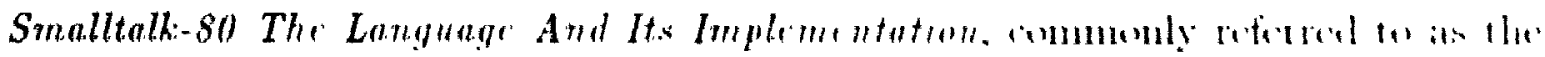

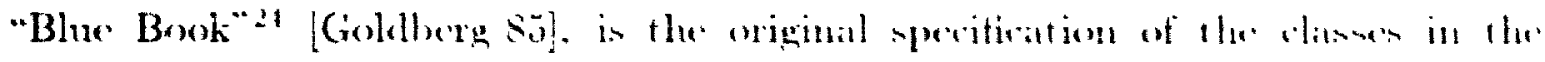
Smalltalk-80 sỵstem.

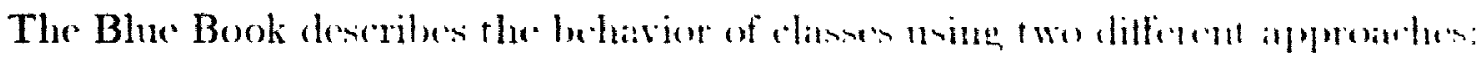

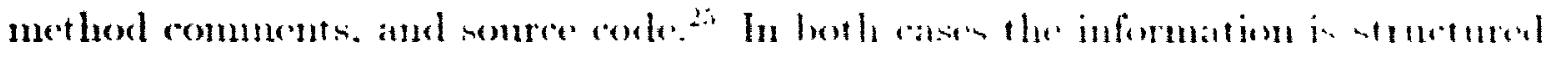

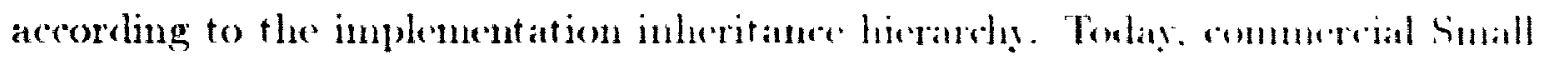

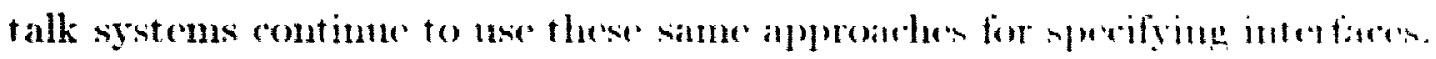

\subsubsection{Group Membership}

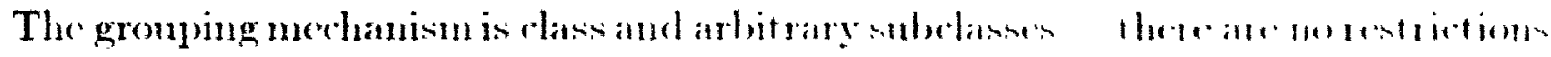

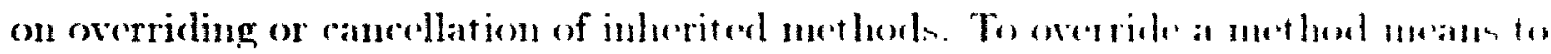

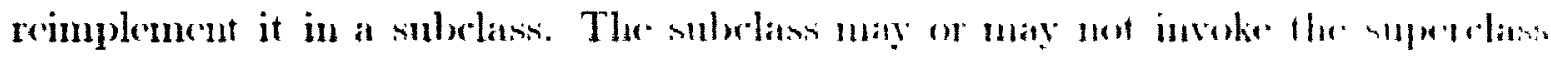

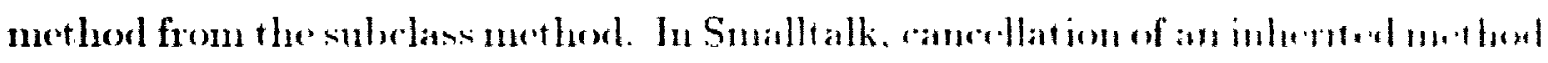

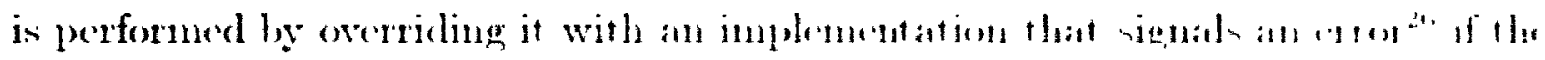

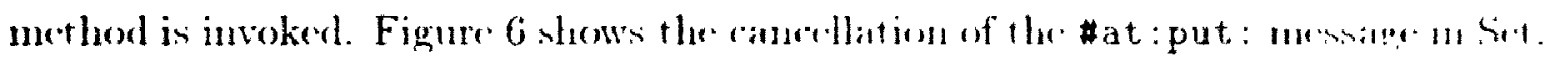
which is otherwise inlerited from ()hijert.

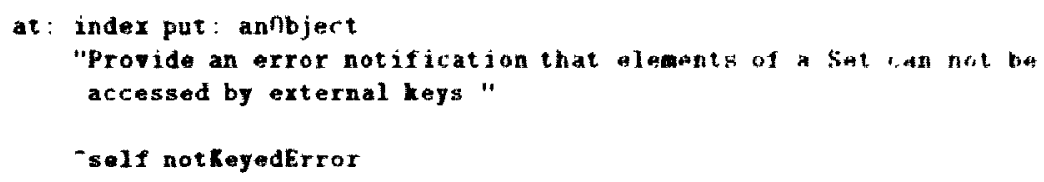

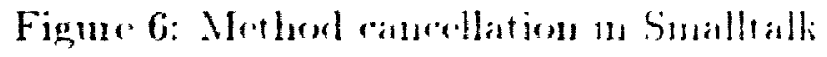

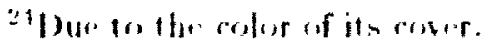

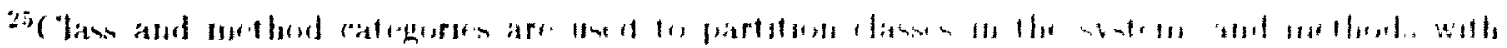

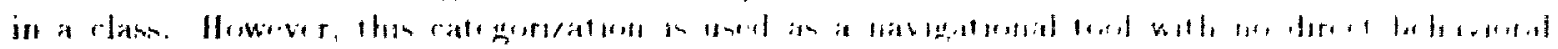
implications.

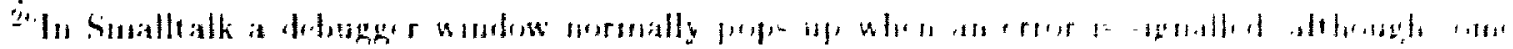

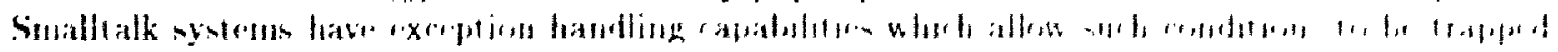
ly the applation
} 
Nemberthe in a particular class maken a defintive statement about behavior.

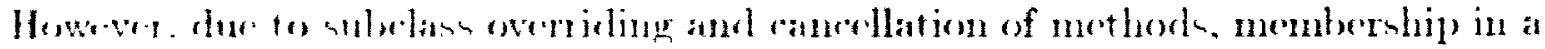

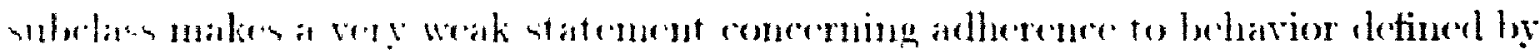
the ruperithans.

\subsubsection{Relationships Between Groups}

Inheritane is the merhanion used to relate clasmes to tach other. The reader is ne.ented with in inheritane hierarchy. such as that hown in figure $t$.

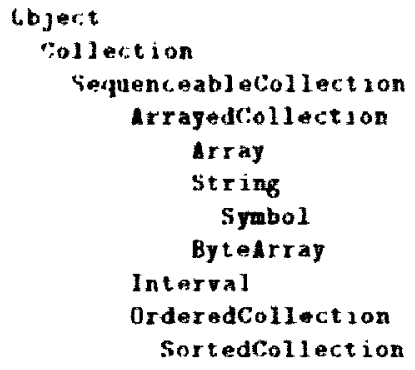

Figue 7: The inheritane hicrarchy for Collection

The structuring mechanism is inheritance, and is therefore not at substitutalility rolationship. Thin has two implientions for the sperification. The first relates to low well paraneters and return values can be describel. The second relates to how

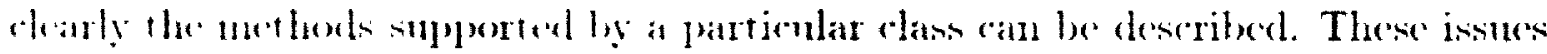

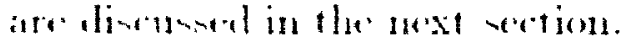

\subsubsection{Description of Behavior}

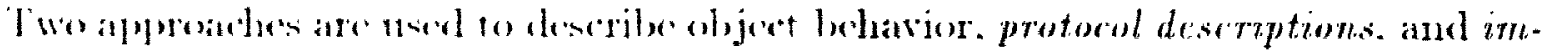

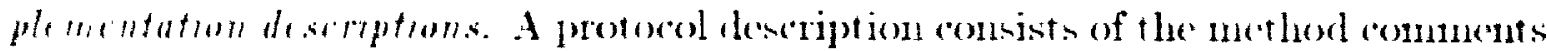
for a dise and an inplementation dereription in the sonder code.

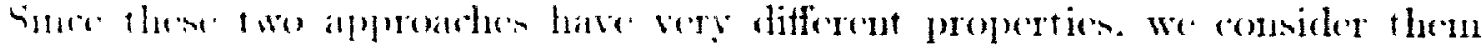

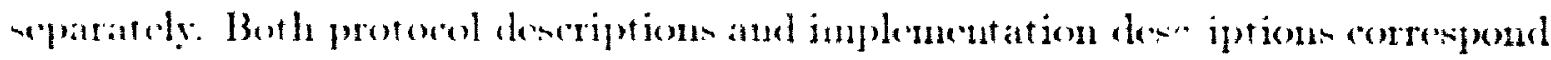




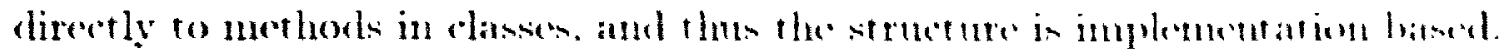

\section{Protocol Descriptions}

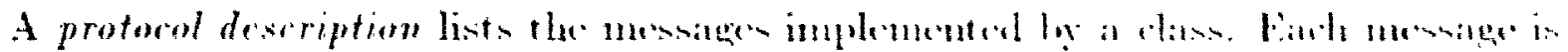
accompanied by a comment deseribine the operation an inntance of the dans will perform when it receives that message. Within a class. methods are pattitioned into necthod categories, which are also called interfaren.

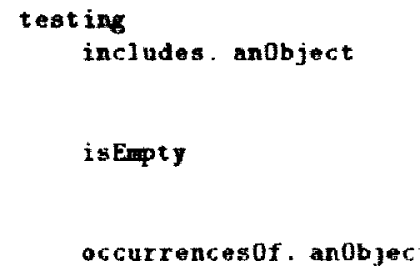

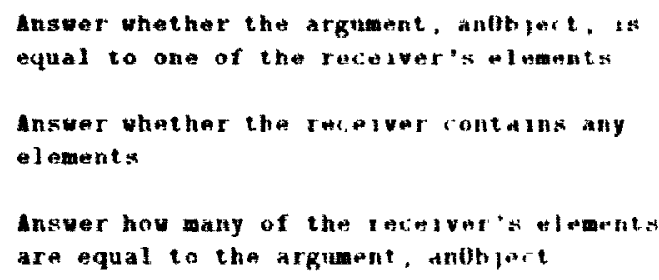

Figure 8: Protocol dencription for the collection "tonting" matfere

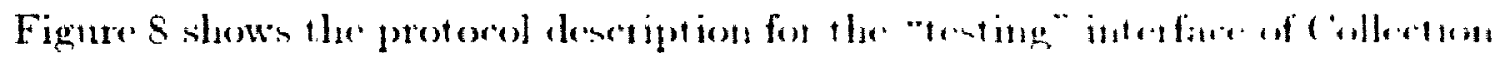

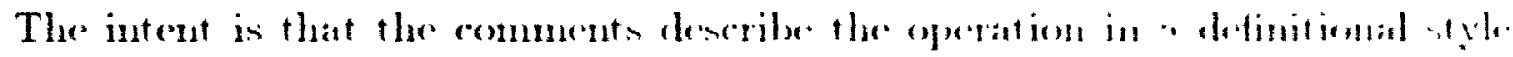
that is, what not how. In practioes a mixture of eprerational and definitional tylen are userl.

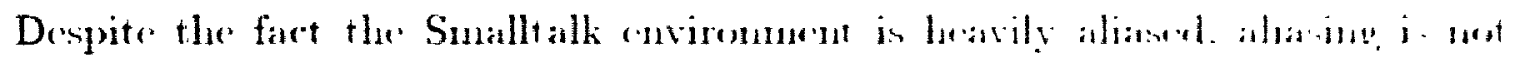

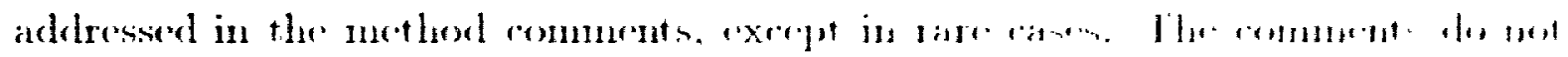

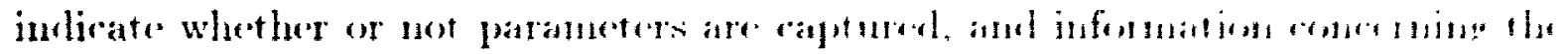

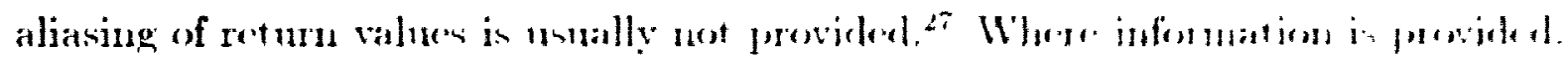

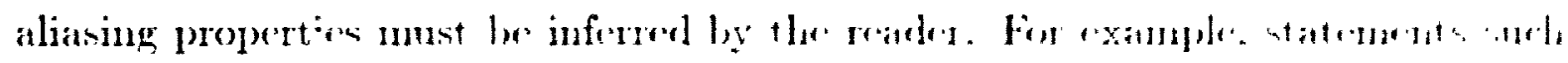

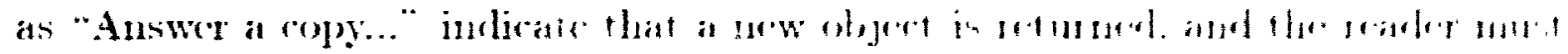

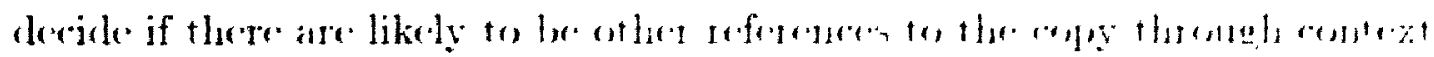

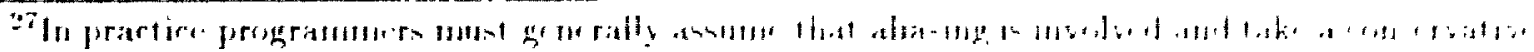

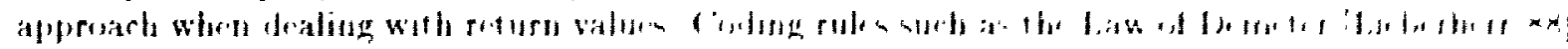

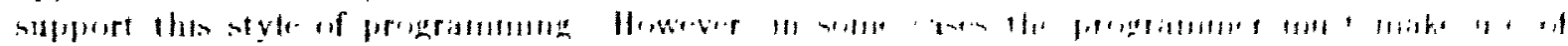

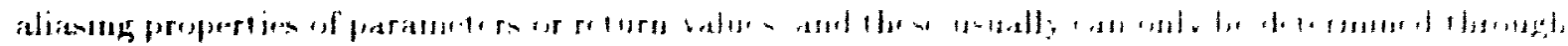
interetien of the implementations
} 
adring

add naubjart
Include the axruent, nev0bject, as one of the recelper's alements. Answer newobject.

Figner 9: The \#arld: protorol description

Figne.9 whow the denctiption of the add: mothod for Collention. Finowledge of the pat ardiems of the Smalltalk ystrmallow the reacler to discern that "Inchude" mean that the argument is raptured. and not just that subseguent traversals of the

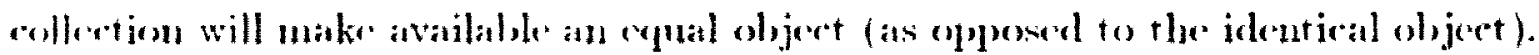

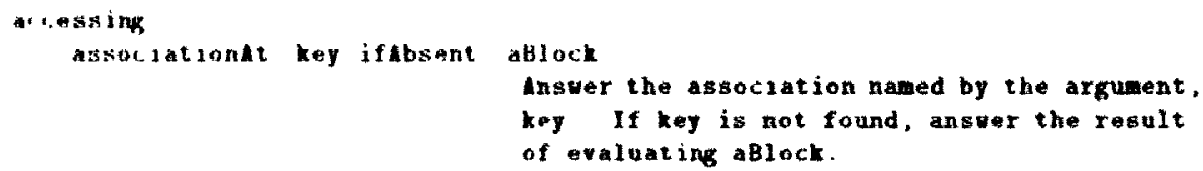

Figure 10: The \#asomiationAt:iftbent: protool deseriptions

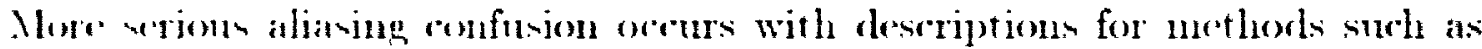
associationat: if absent: in Dictionary. Shown in figure 10. There are two kinds of dietionaries in the Smalltalk system. Dictionary and IdentityDictionary. Both kinds of dictionaries maintain $\{k$ k. ralue $\}$ mappings. Dictionary uses cquality for hey lonkuy and is inplemented as a collection of Assoriations. which are objects

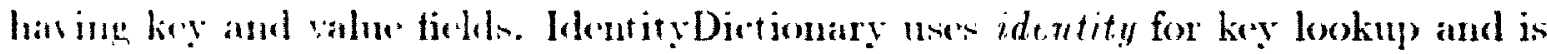
implenented lyg soring leys and values at odd and even offects in a collection. reyeretively. The wording of the muthod romment seme to indioate that stored state

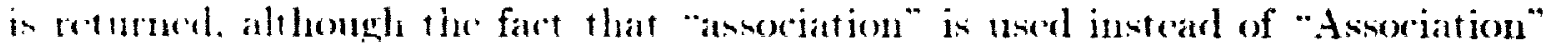
may loave dombly in the minds of somme rearlers.tn

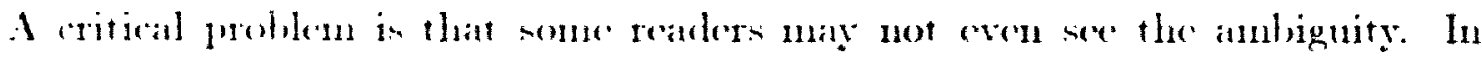

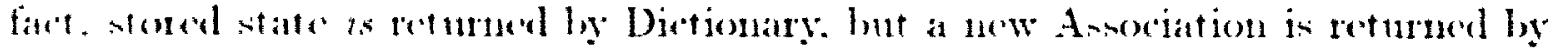

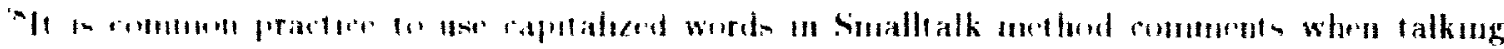

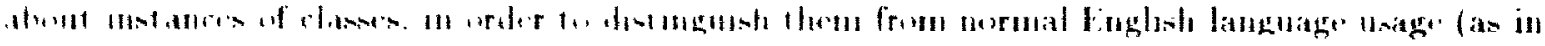
.1 13illinary" 


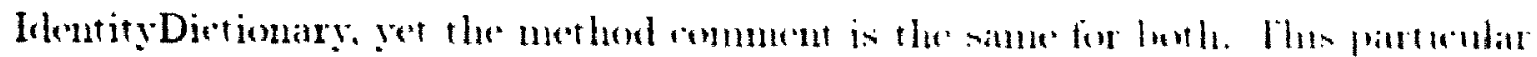

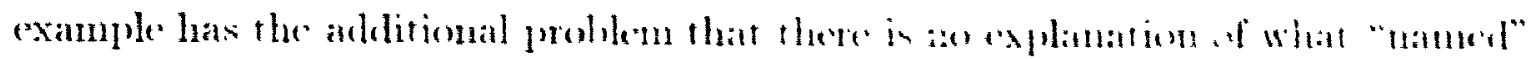
means. The roader is expected to infer that for Dertionary it manu. "hey hesup

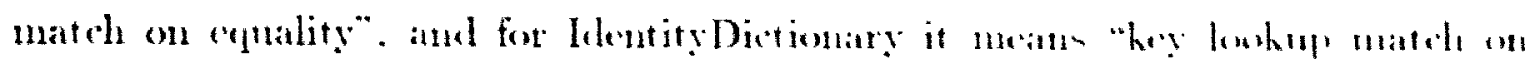
identity".

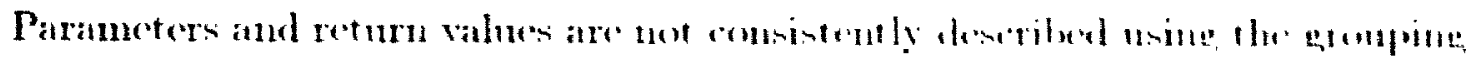

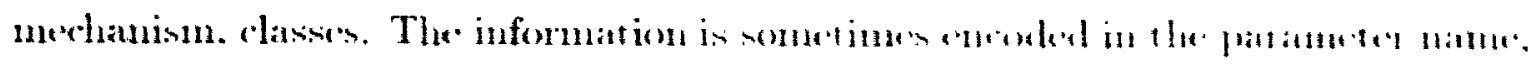

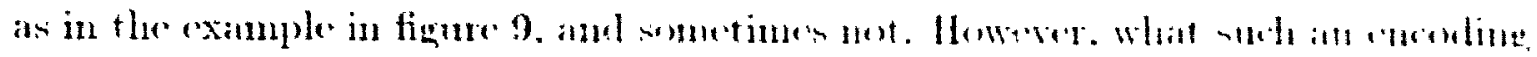

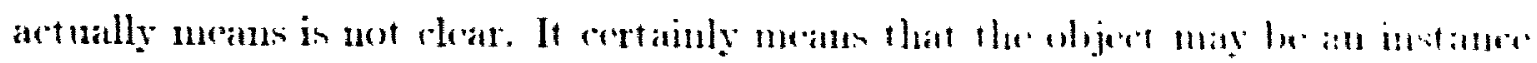

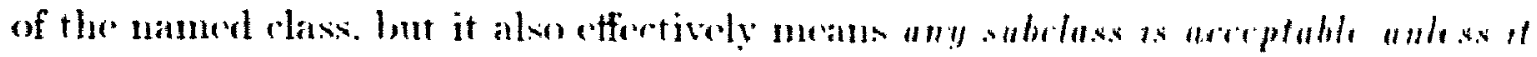
won it work:

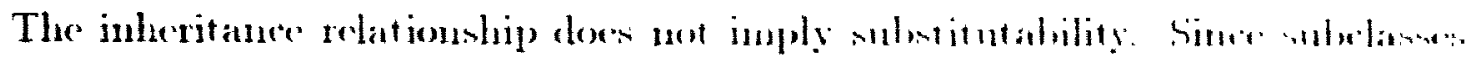

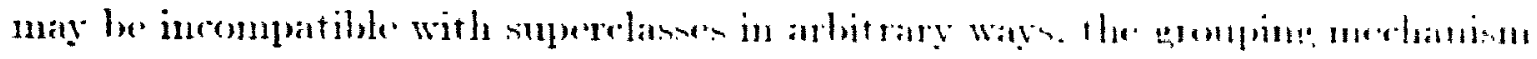

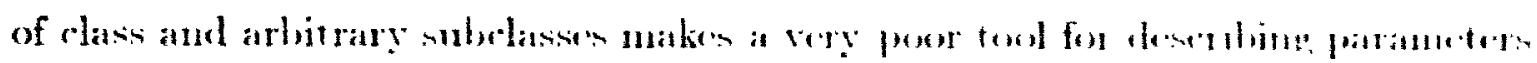

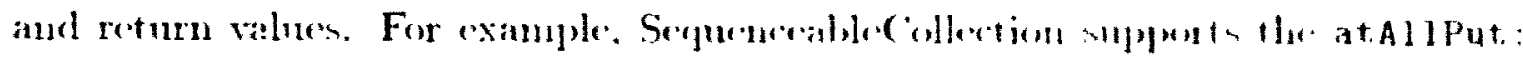

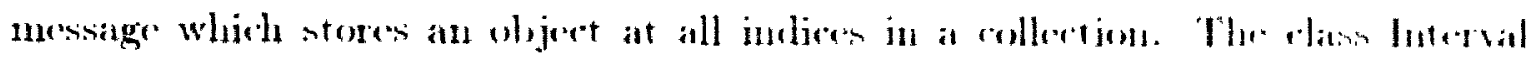

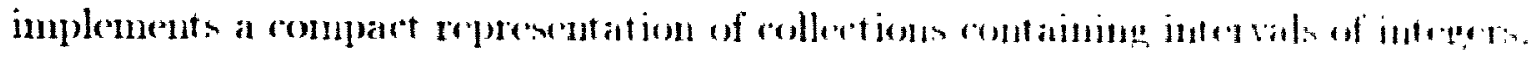

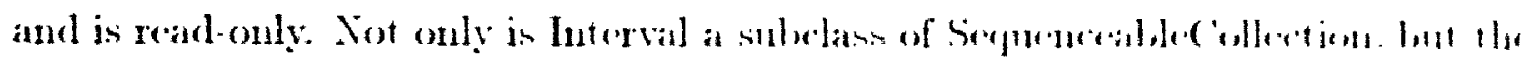

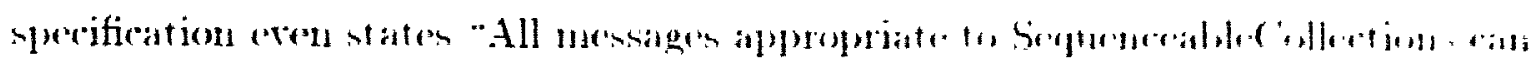

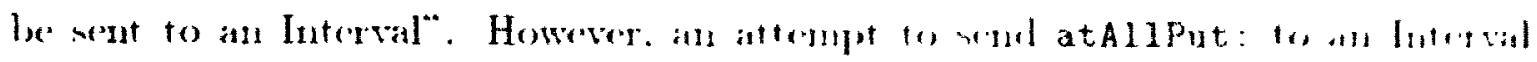

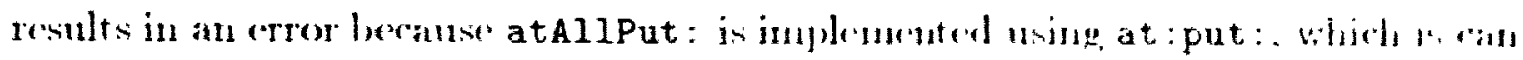

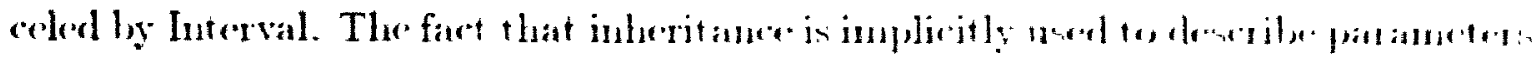

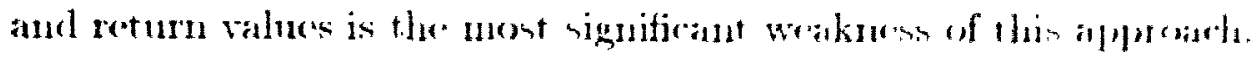

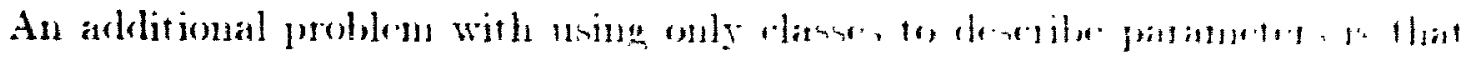

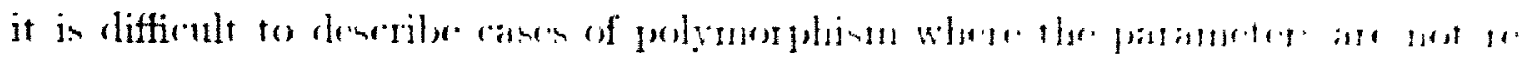

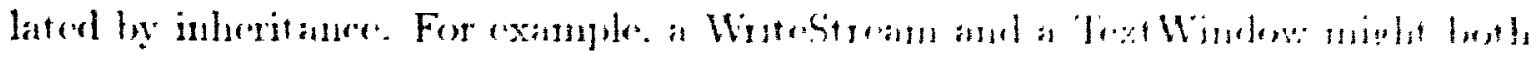

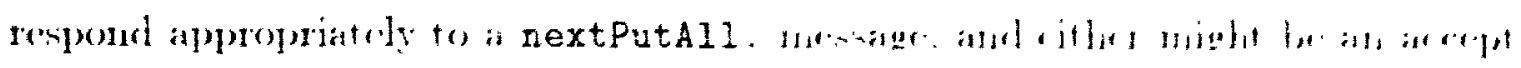

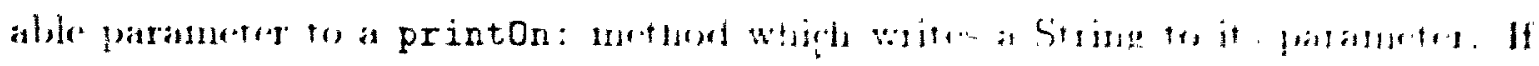


Wite. Suman and T.xo Window do not have a common superdess which supports

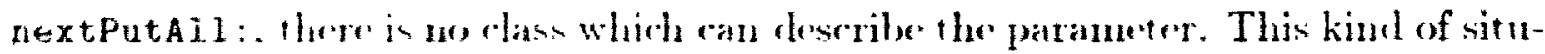

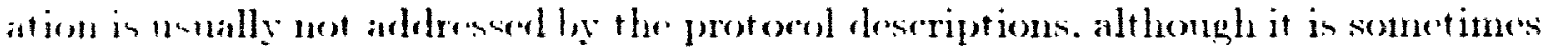
findled with pat anuerer nimes like aWritestreamorTextWindow if the opportmity

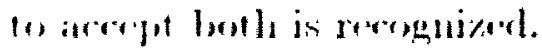

When a class enoding is not used to deseribe parameters. a semantic name

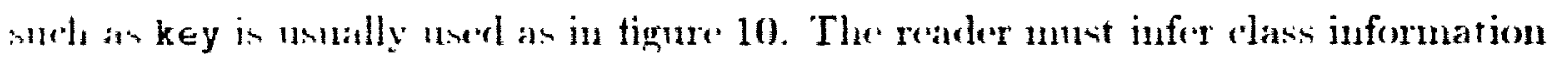
from contest. Similarly the reater is expected to infer the behaviomal attributes of at meturn value, in in the isempty message in figure 8 . The phrase "Answer whether..." tells the reader that the result must be a Boceon. Similarly phrases such an "Anwer how many..." or "Answer the position..." tyipally indieate an integer value, alt lumgh the latter may also indieate a point in cartesian coordinates.

Finally, beatus the protocol descriptions parallel the implementation. it can be diflicult to determine cxactly what mesinges are supported by a particular class. and how the lechavior differs from the superclass.

As an example of the former, it is not initially obvious that \#at: and \#at : put: are supported by Dietionary, sine these are defined in object. and the description

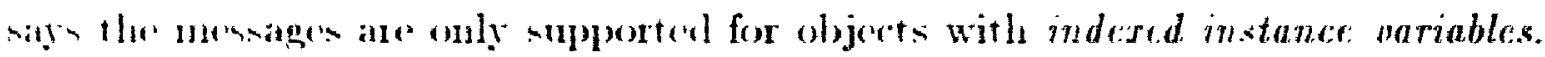
The seader must understand the representation of Dietionary in order to deduece

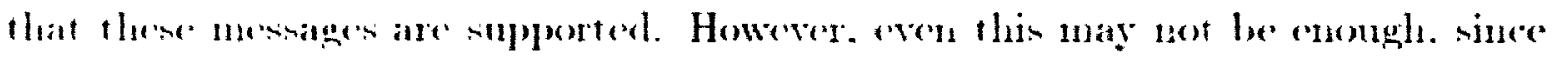
buth Set and Dietionary have indexed instanes variables. lut \#at: and \#at :put:

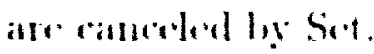

As an example of the latter, the Blue Booh doe not make it clear whether or not the select: mentage is -nperted for Dictionaries, and there is no indication that

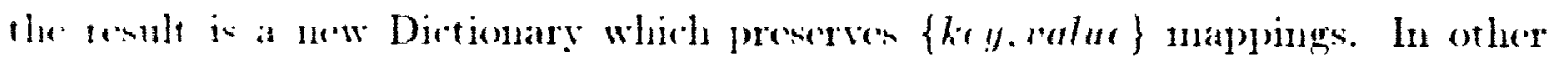

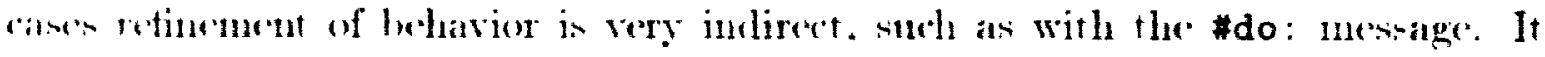

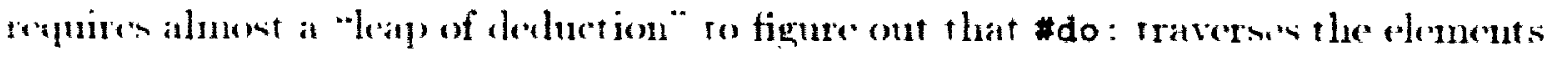

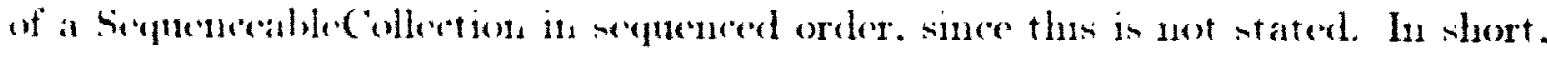




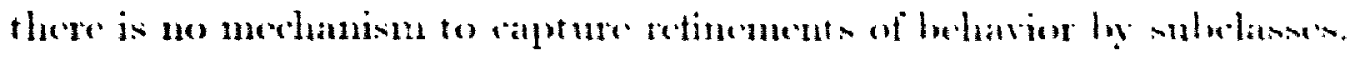

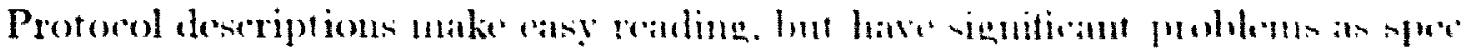

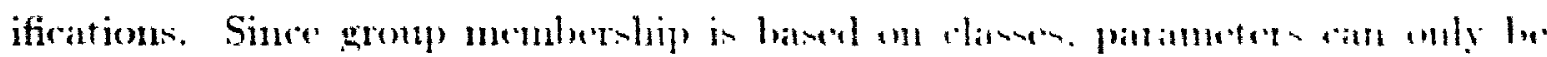
loosely described. Intimate knowledge of the paradigme and implentention of the

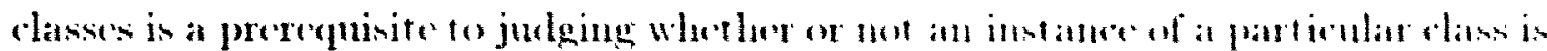

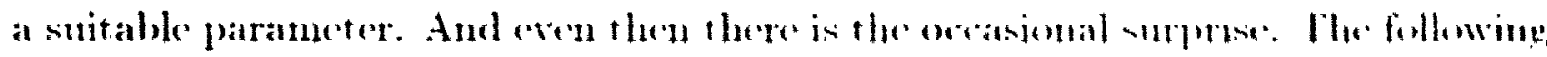
quote sums up this problem quite stereine ty:

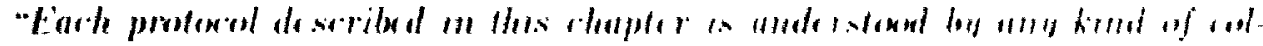
lertion, anless that rollectionn sperifieally disallows it"

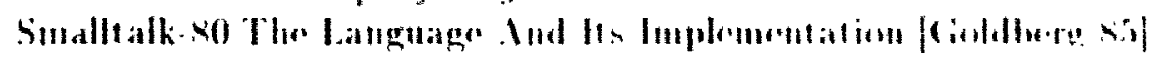

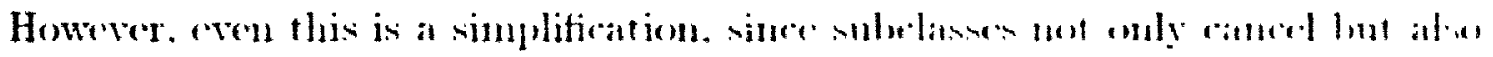
change behavior in incompatible ways.

\section{Implementation Descriptions}

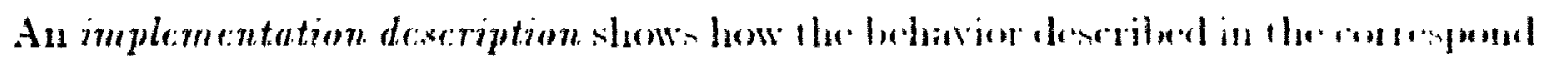

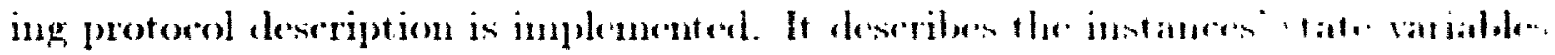

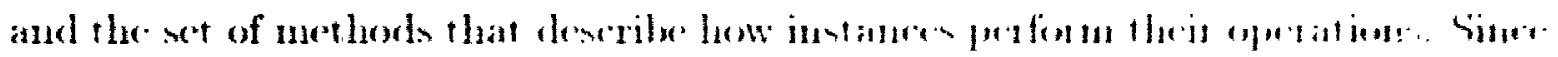

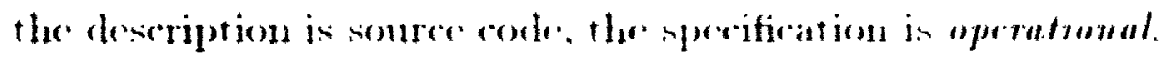

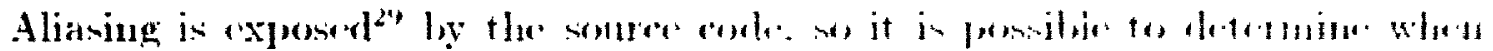

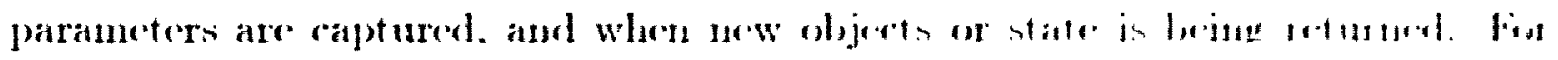

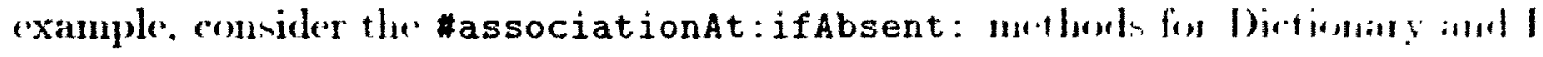
dentityDirtionary Mown in fignr. $11 .: "$

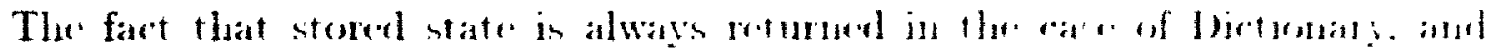

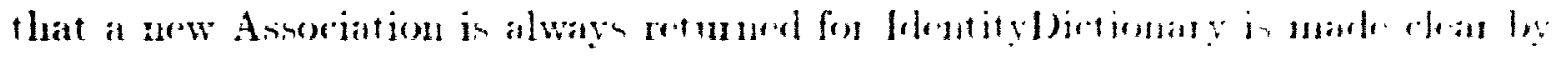

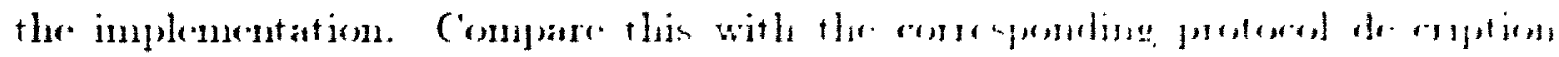

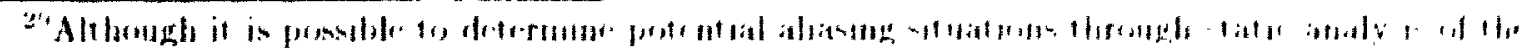

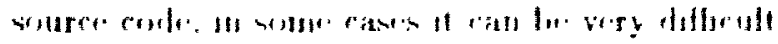

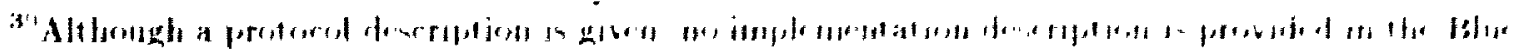

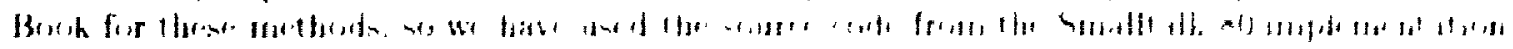




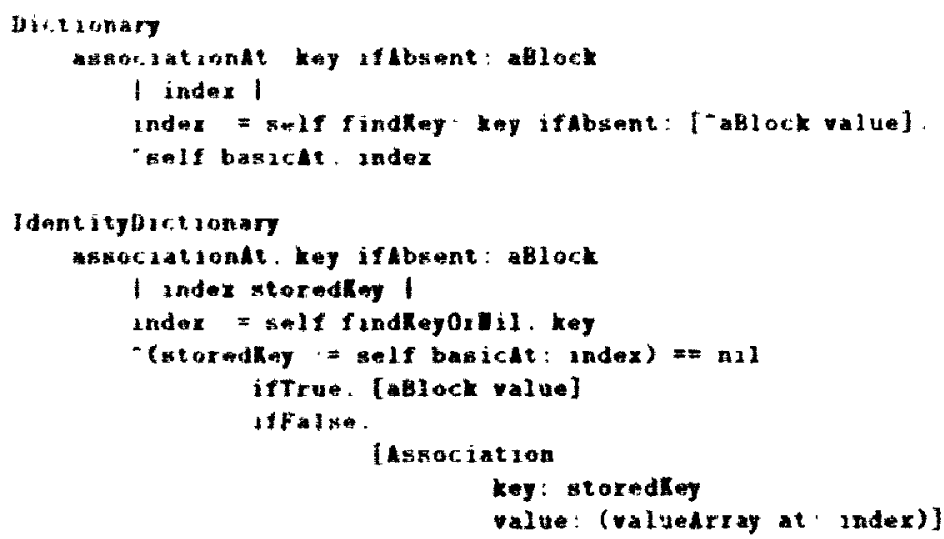

Figure 11: The HascoliationAt ifAlesent: implenentation description

in ligure 10. An cxamination of the implementations of findkey : ifAbsent: and findkey0rlil: would wereal the differences in key lookup.

fuplementation dencriptions suffer from the same problems with parameter deseriptions that protonol descriptions do. although the situation is somewhat improved by ancess to the somere code. An examination of the implementation reverds which mesiagen are sent to parameters and implicitly, the expected behavior. Howcor, if parameters are captured for later use, or are passed through several levels of messige semds. it can lo difficult to understand exactly what behavior is expected.

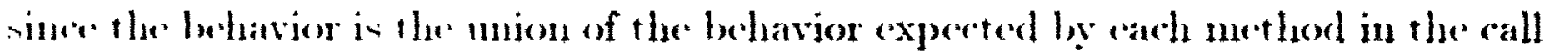
rhain. Similarly, if the return value is a result of a chain of mentage semds it cam be diflecult to divern what exactly is being aeturned. enperially if objects with distinet behavion are renturned for different cases.

Finally the Yoyo problem [Tacen\%er S9] makes execution difticult to trace with-

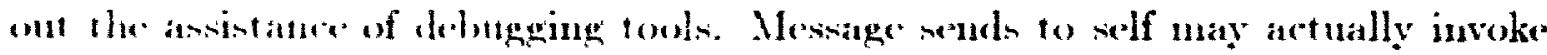
methods in the same class, a superelans, or a subclas. This combined with method oretriding and cancellation makes it difficult to molerstand which methods are actwally run. 


\subsubsection{Summary}

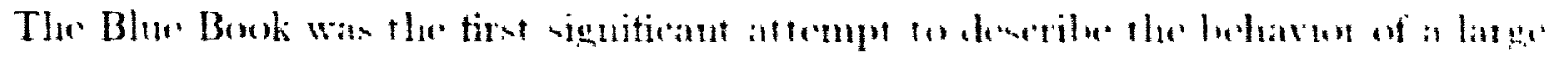

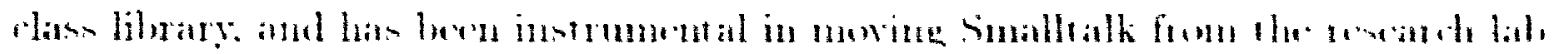

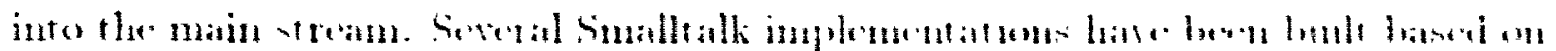

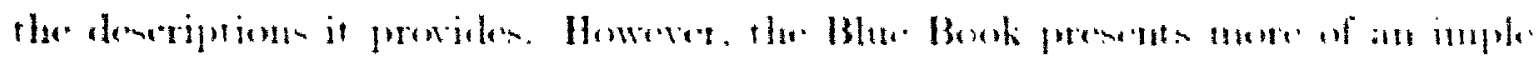

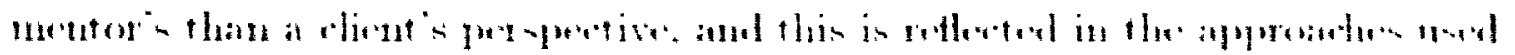

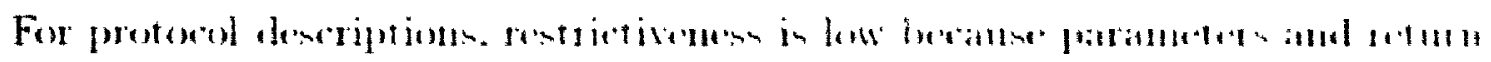

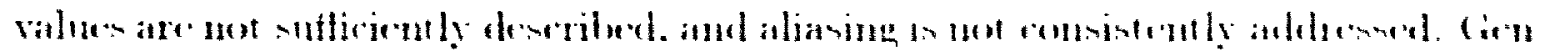

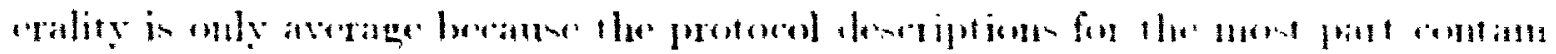

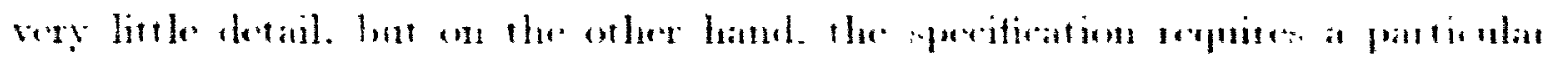

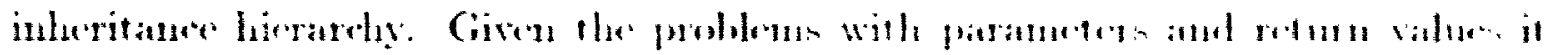

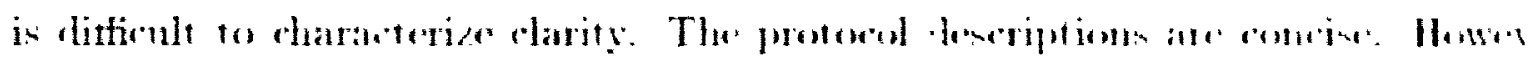

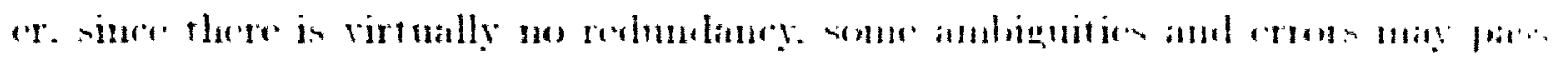

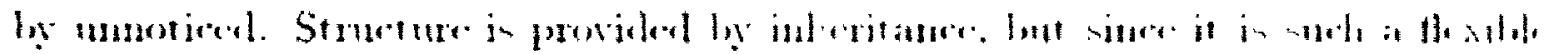

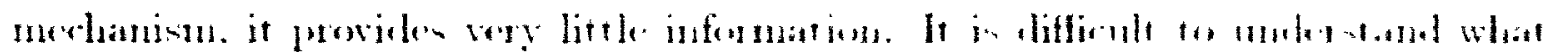

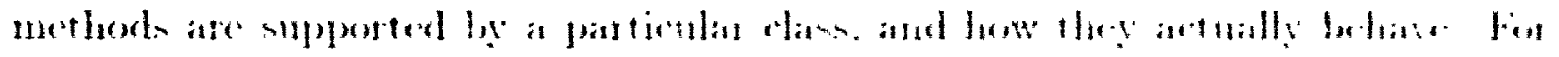

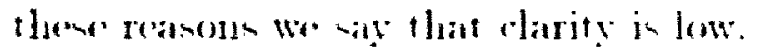

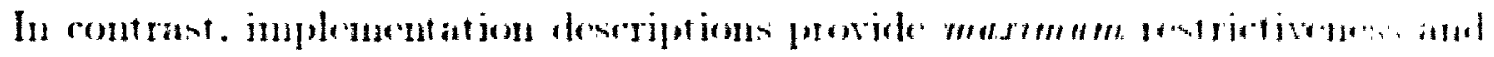

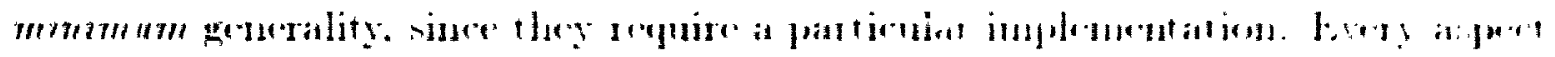

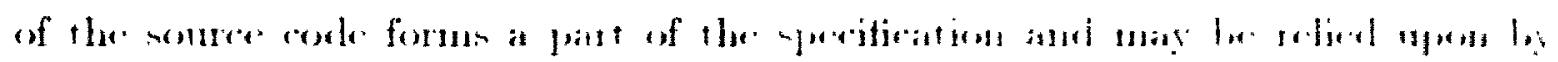

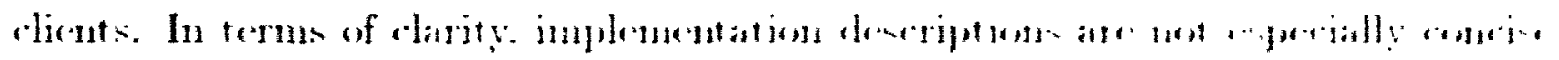

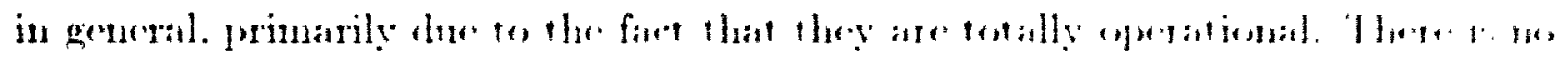

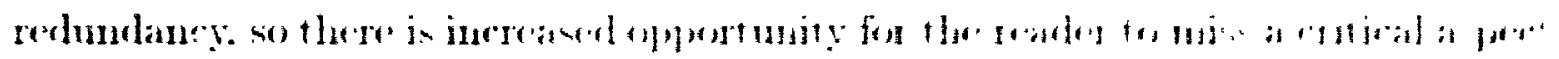

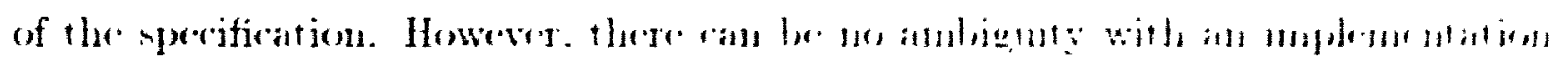

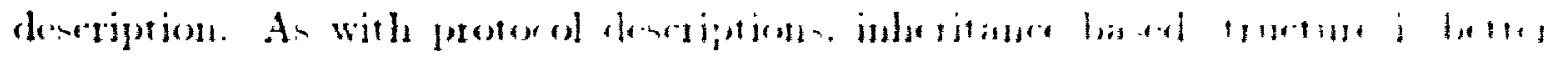

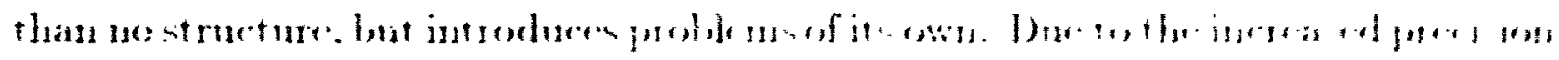

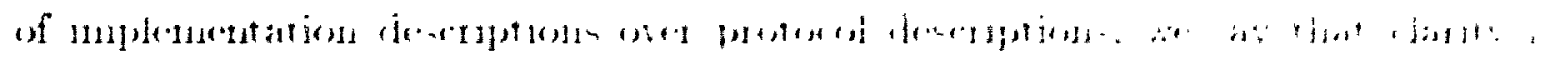
avriage. 


\subsection{IBM Red Book}

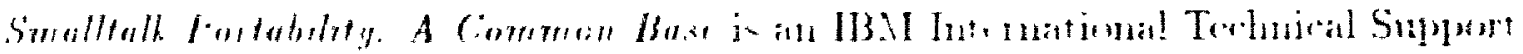

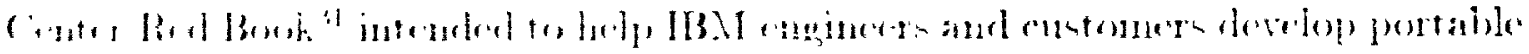

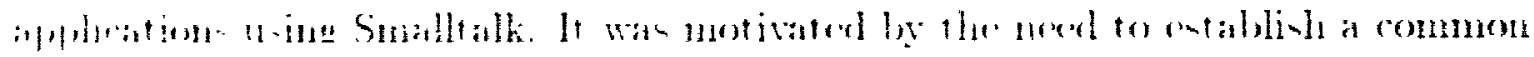

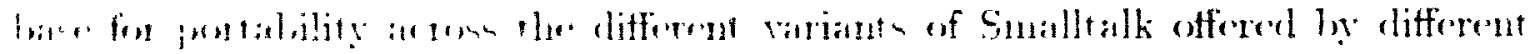

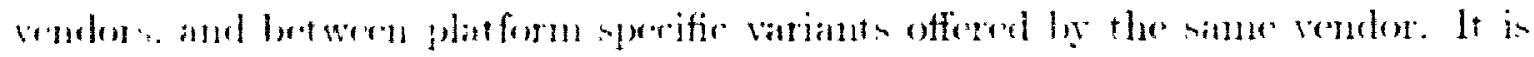

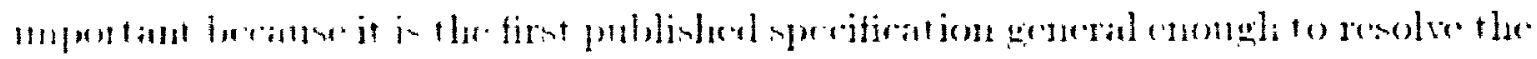

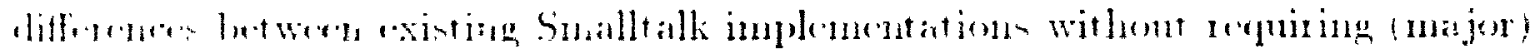
Hatue?, the the implementitions.

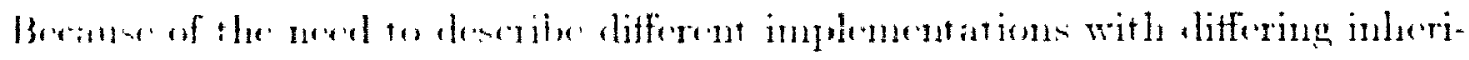

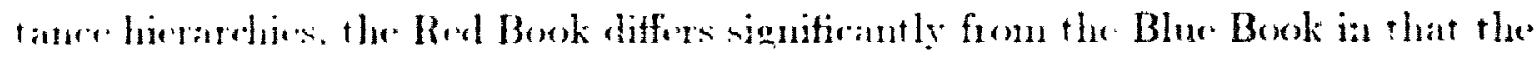

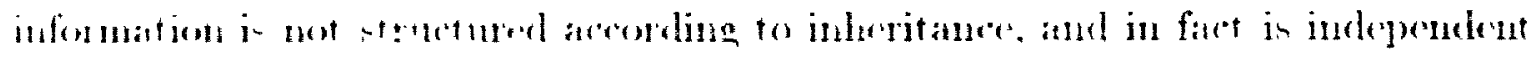

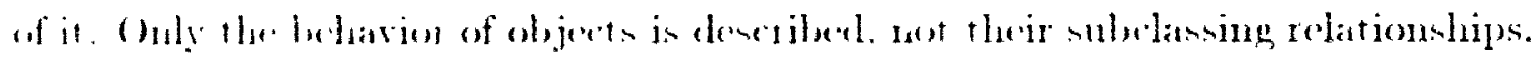

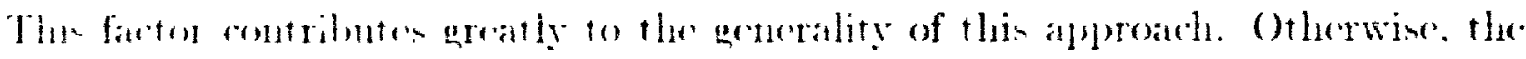

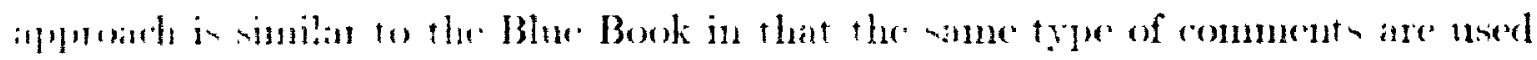

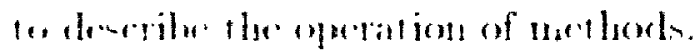

\subsection{1 (iroup Mrubership}

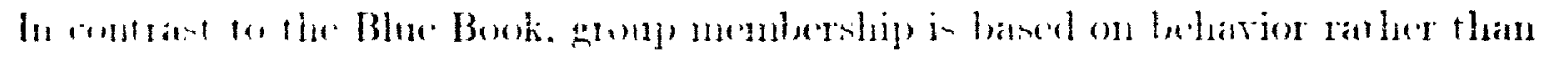

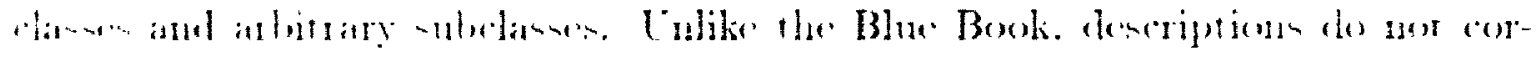

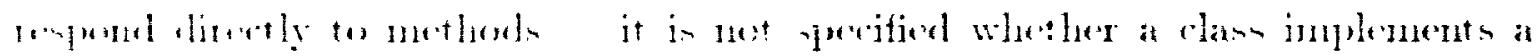

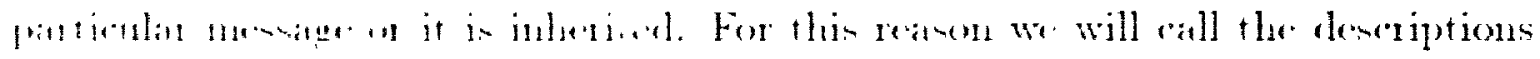

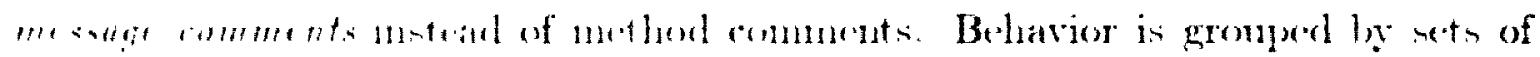

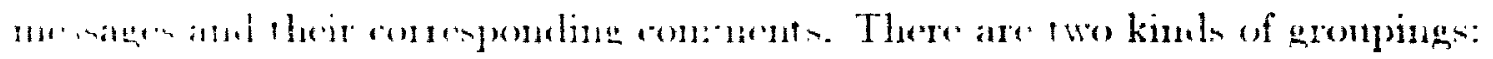

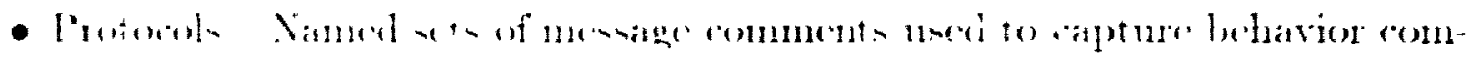
mon en multiplin. clann

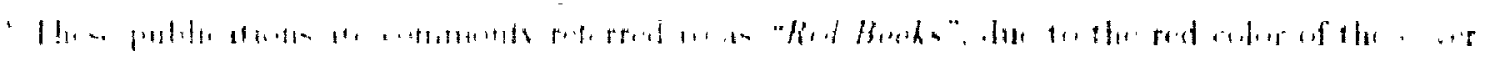




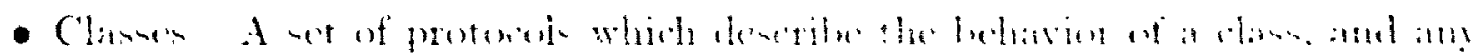

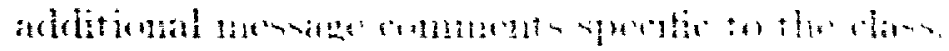

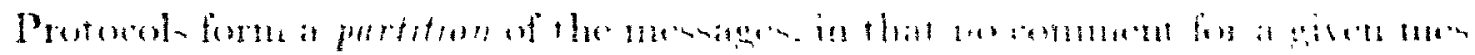

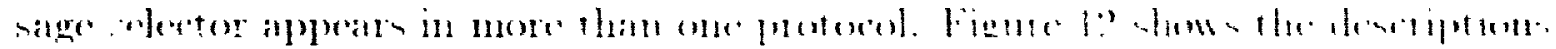

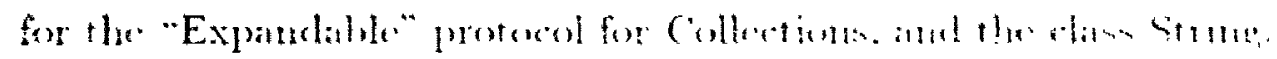

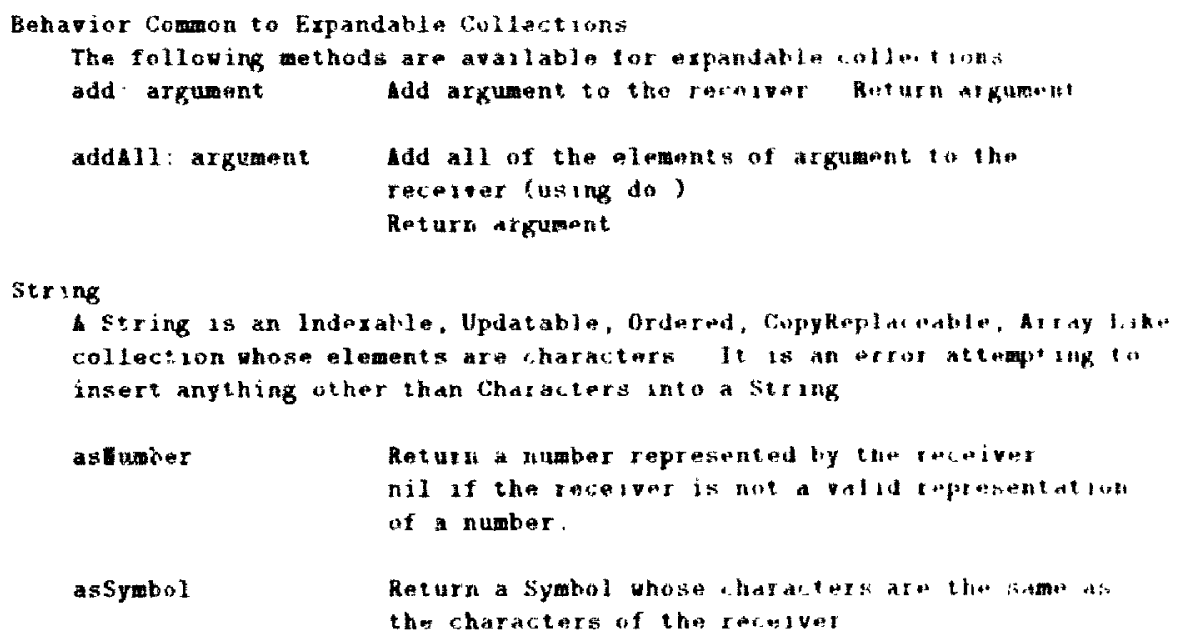

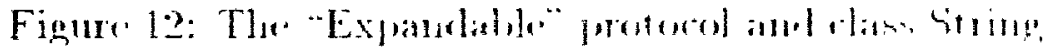

\subsubsection{Relationships Between Groups}

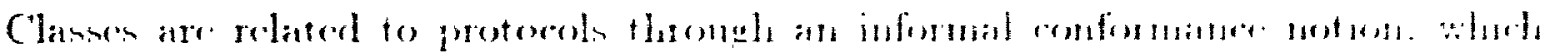

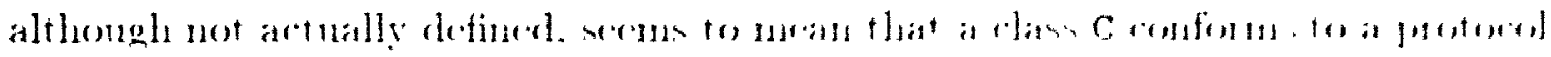

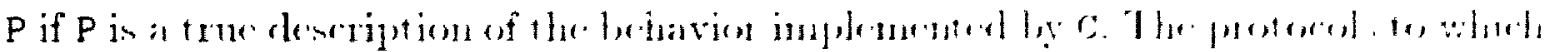

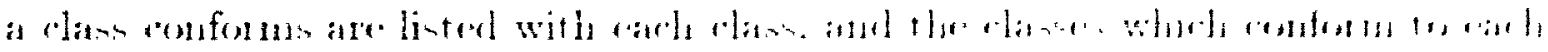

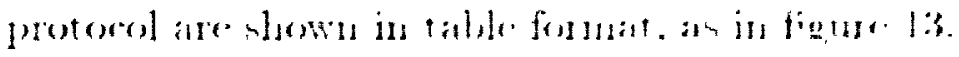

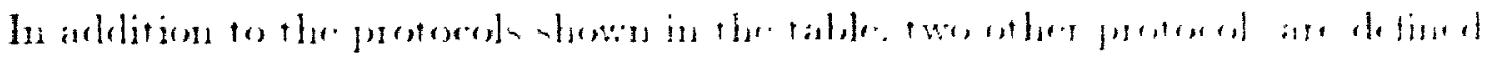

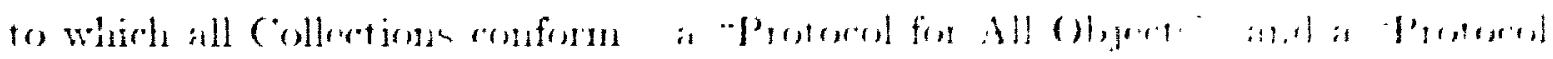
for All rollention".

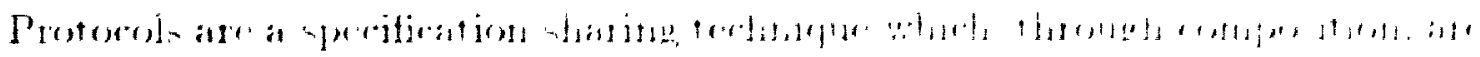



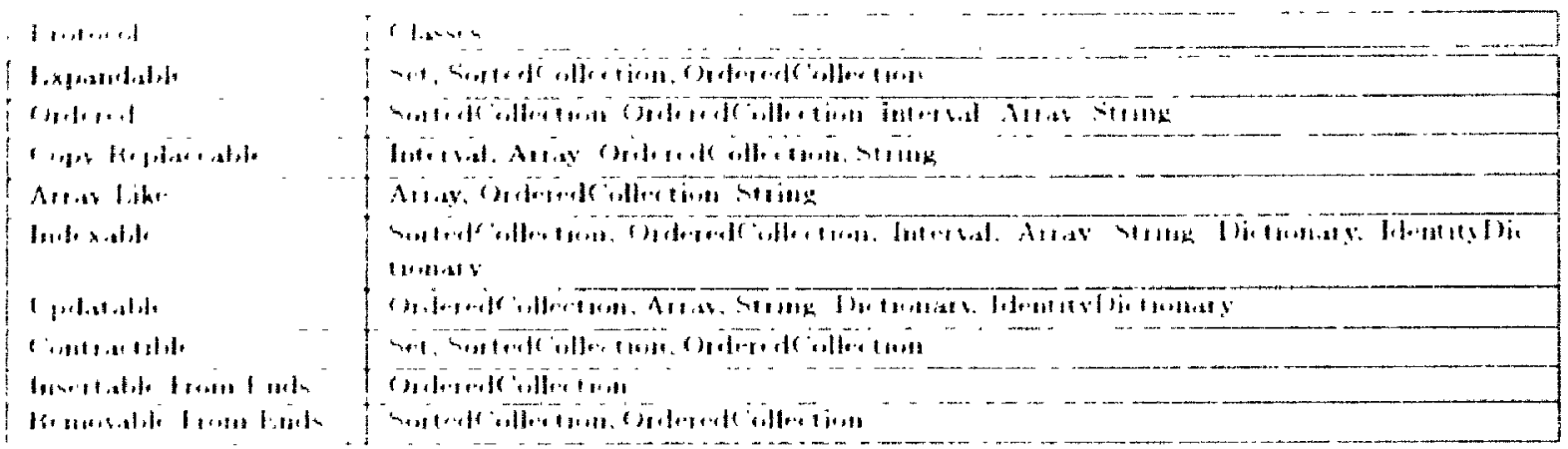

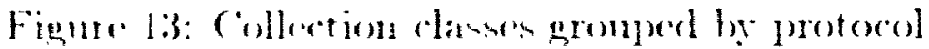

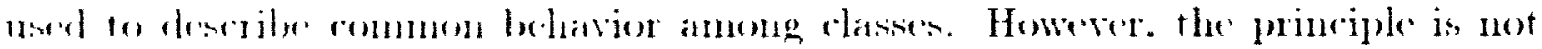

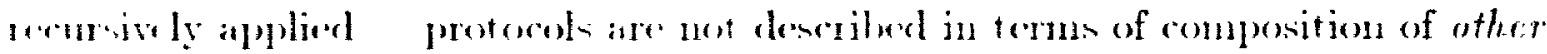

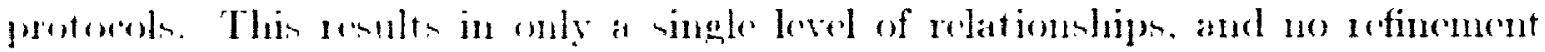
apratility.

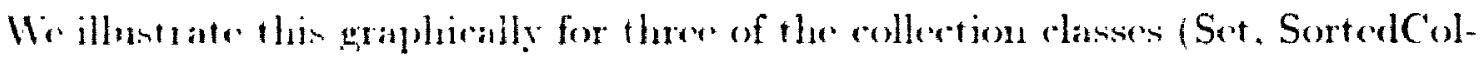
lecient and hoterval) in tigure 14. Clases are shown in bold type. The arrows show

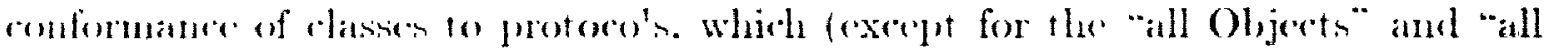

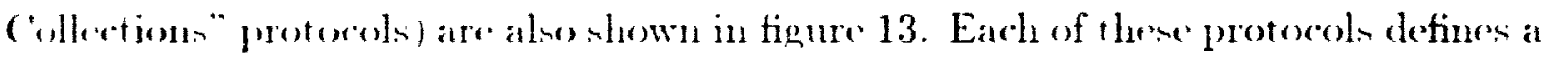

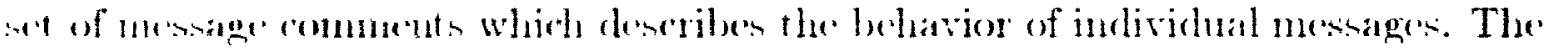

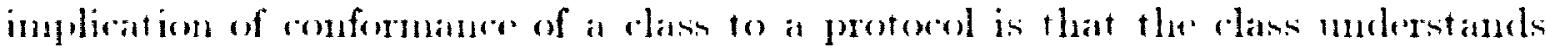
all of the mesages in the protowol and they operate as rescribed in the protocols menstge remmonthts.

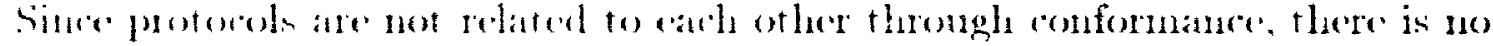

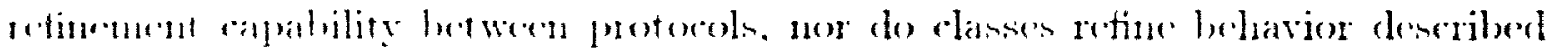

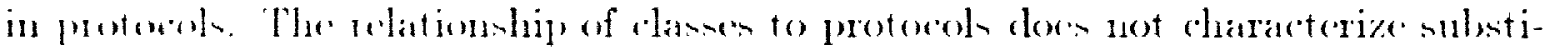

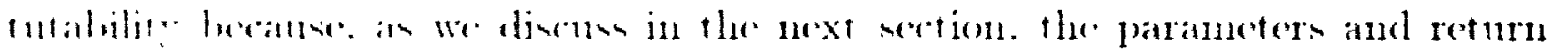

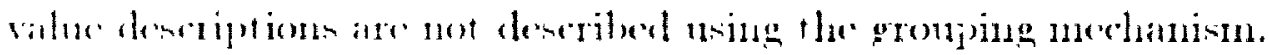




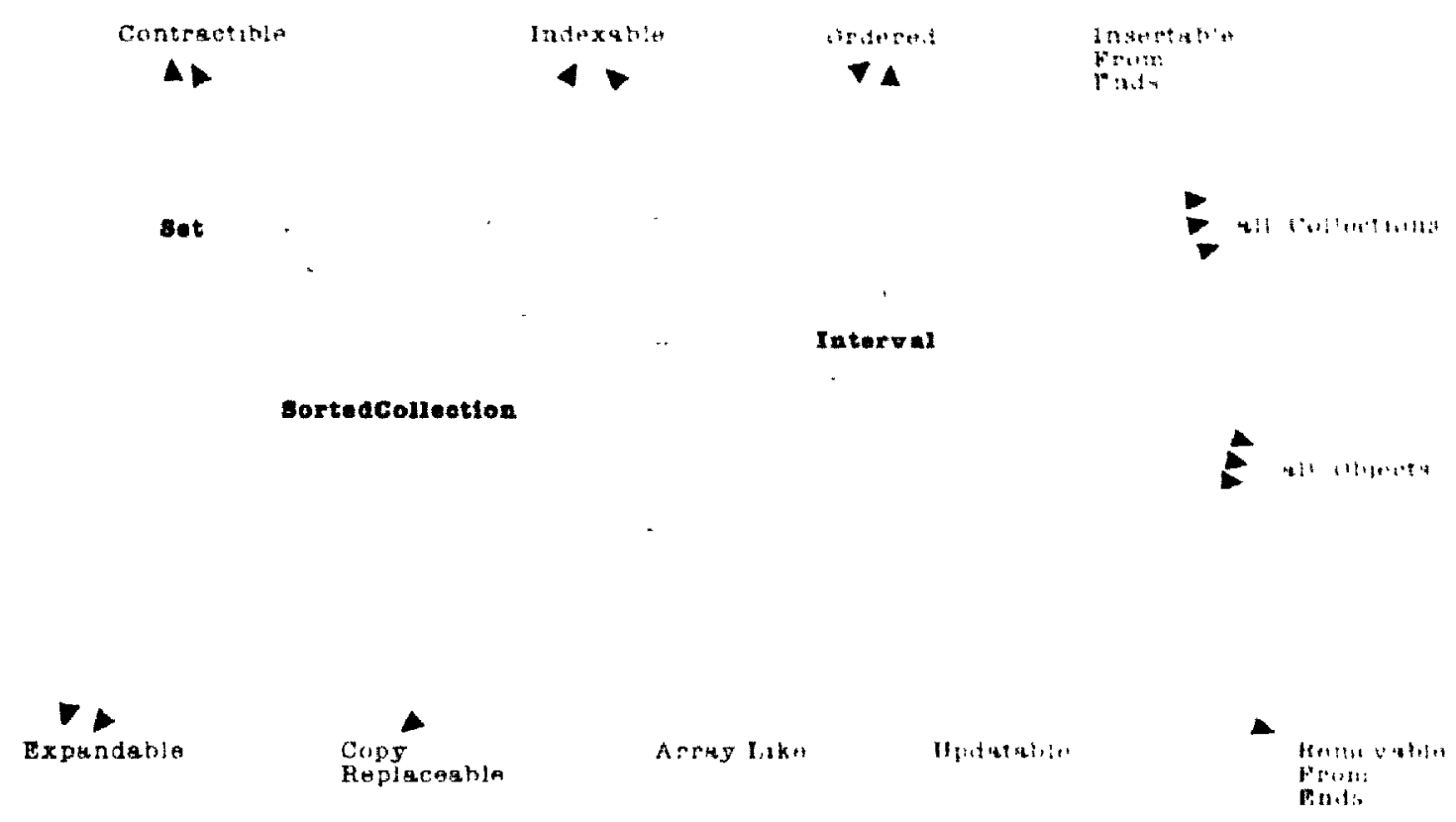

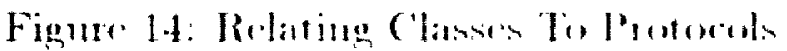

\subsubsection{Description of Behavior}

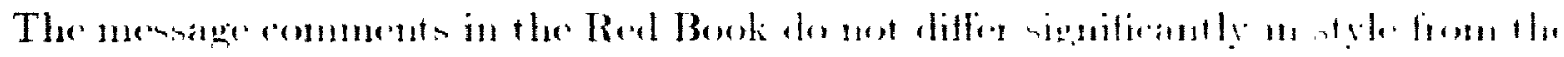

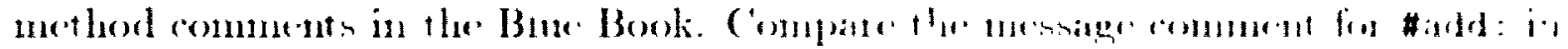

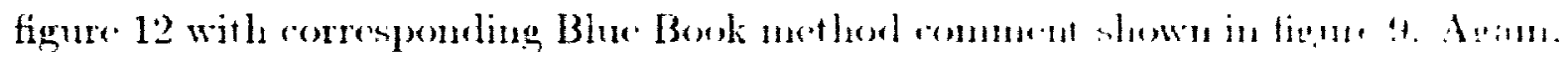
a mixture of definitional and operational tylen an weal.

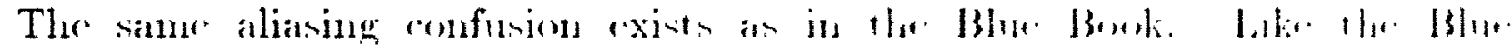

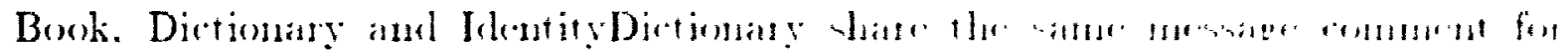

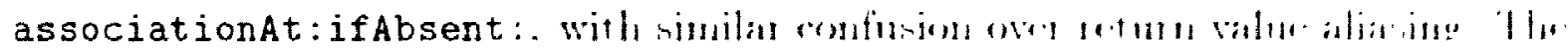

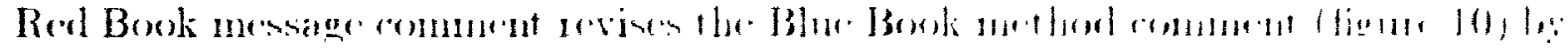

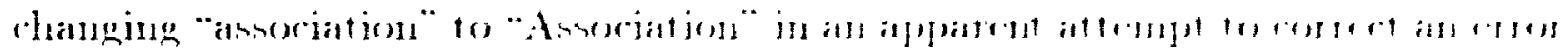

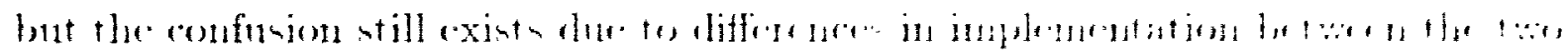
kind of Dirtionariten.

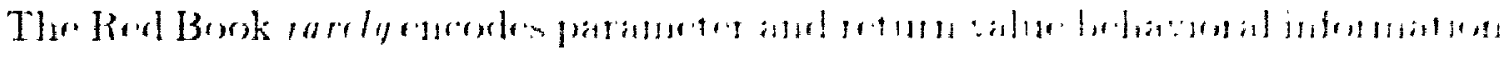

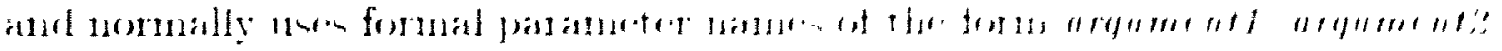

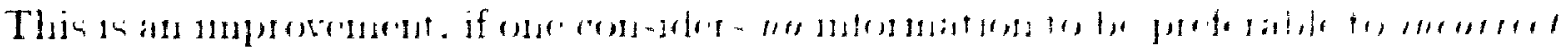




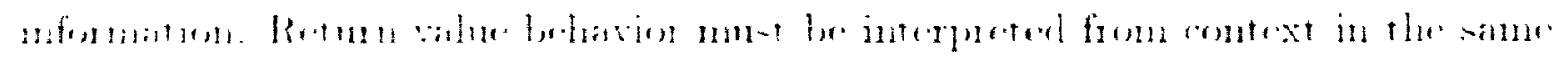

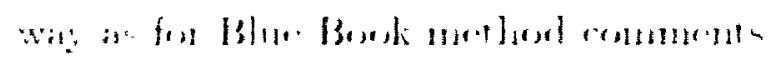

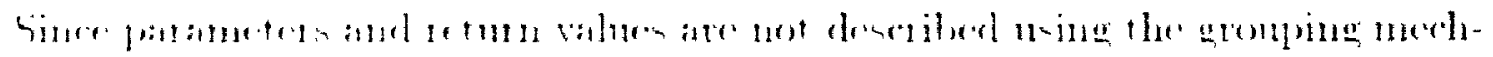

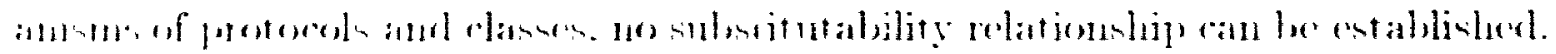

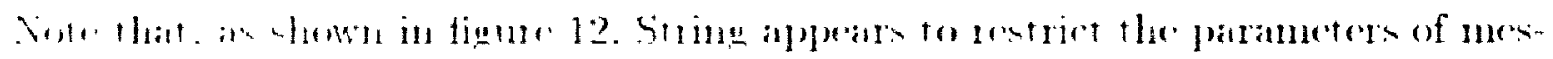

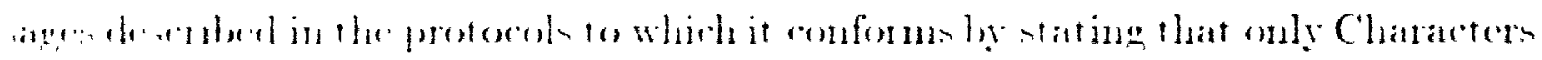

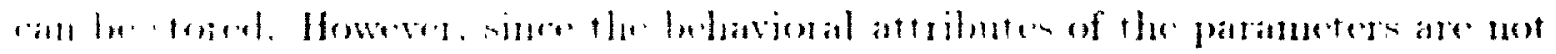

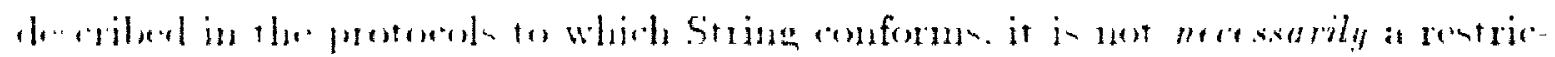

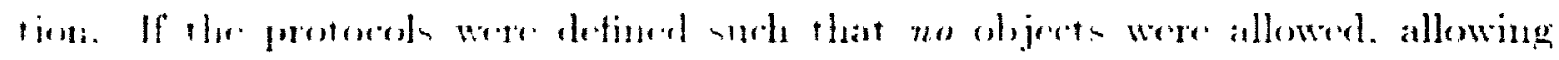

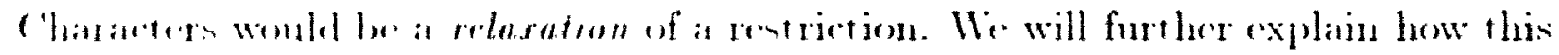

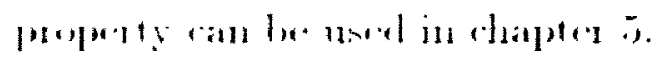

Ohe impostant ditferener from the Blue Book in that the is no rancellation

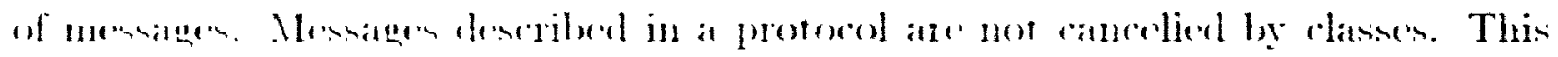

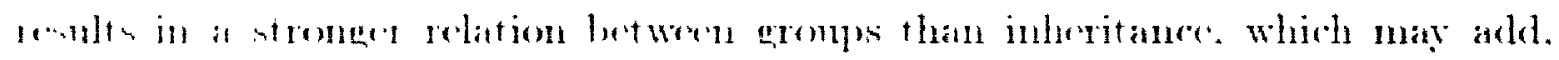

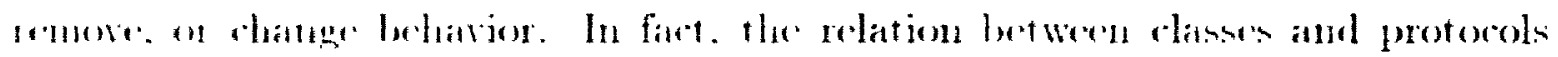

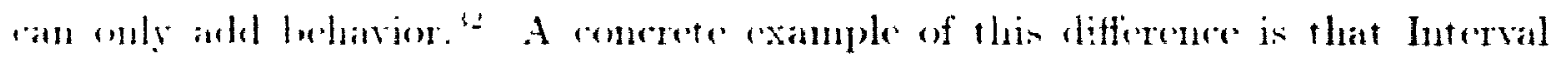

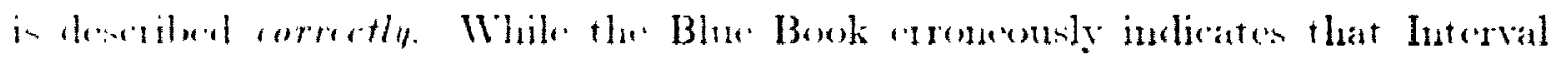

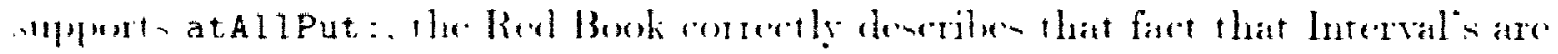
mon molitialile.

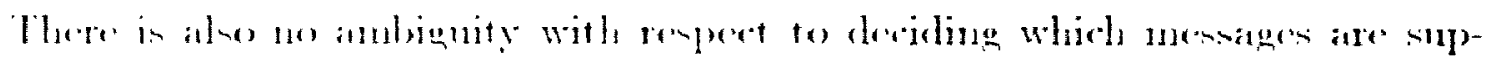

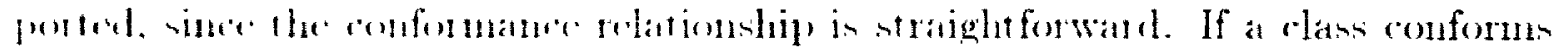

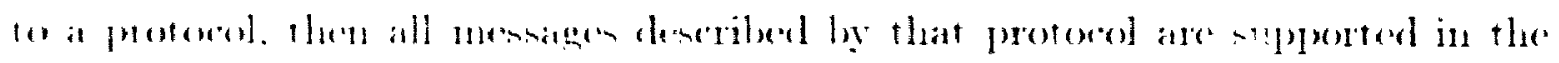

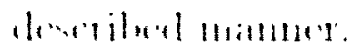

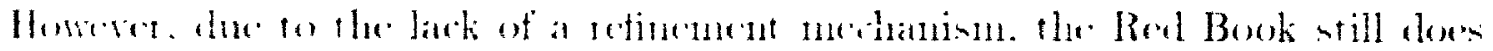

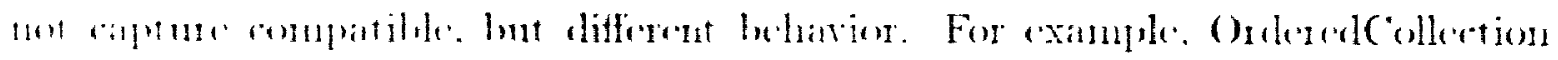

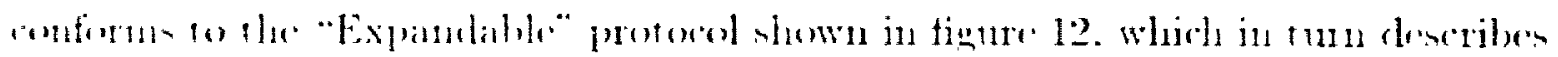

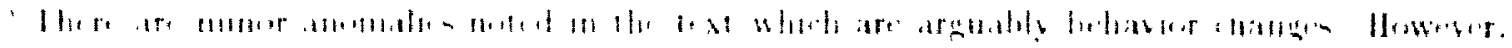
Hling int int 


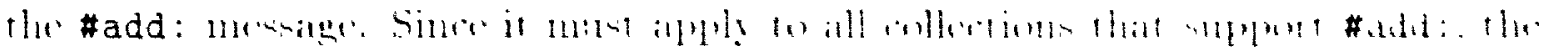

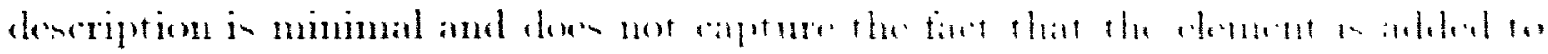
the end of an CrderedCollwetion.

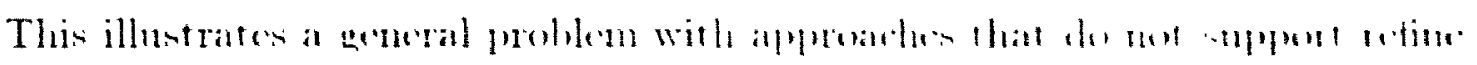

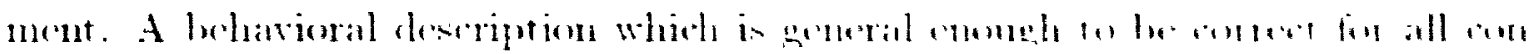

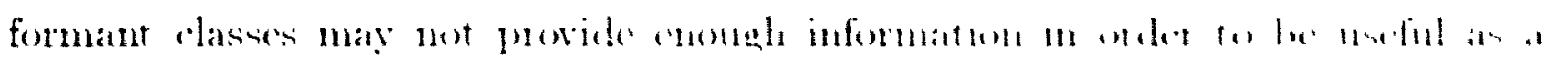

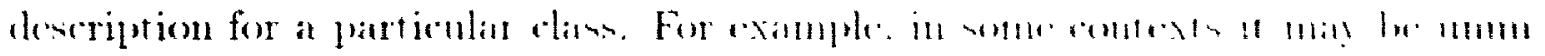

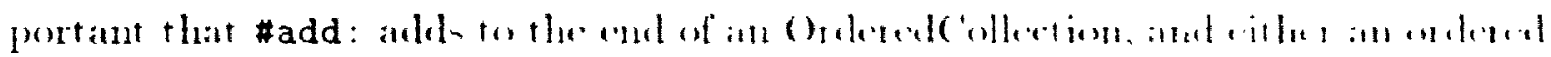

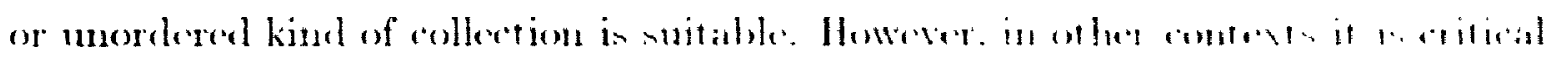

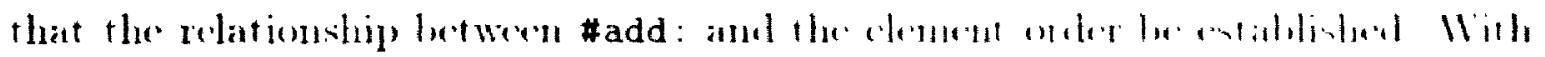

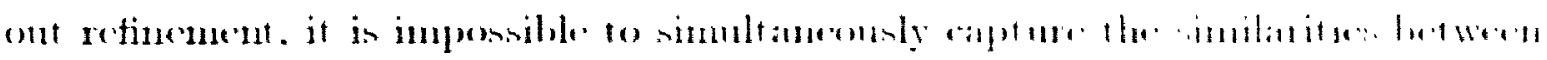

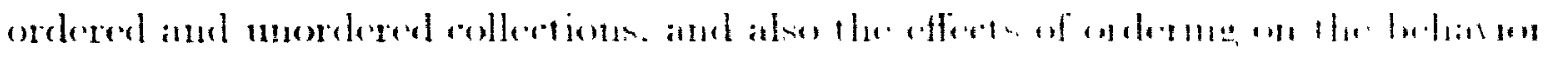

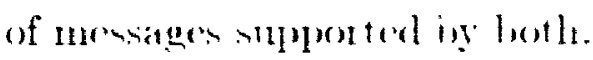

\subsubsection{Summary}

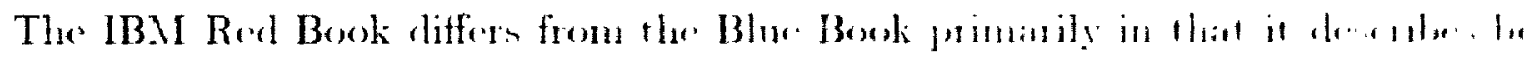

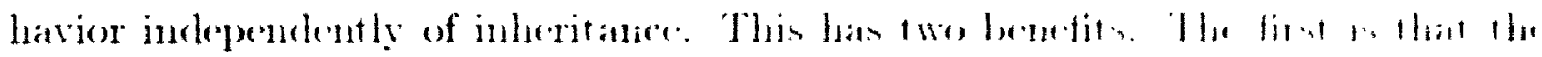

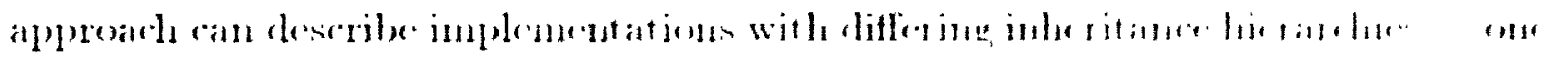

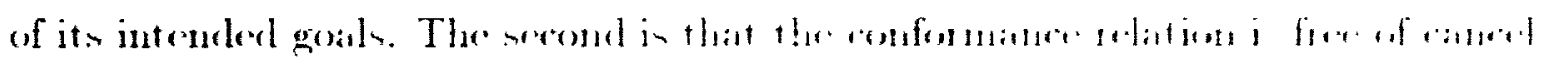

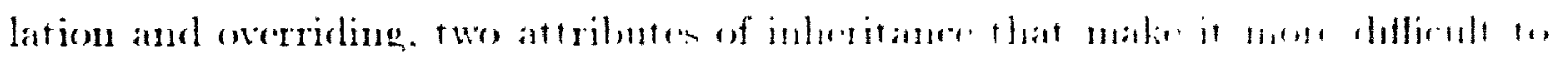

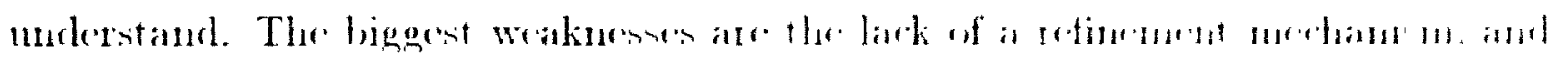

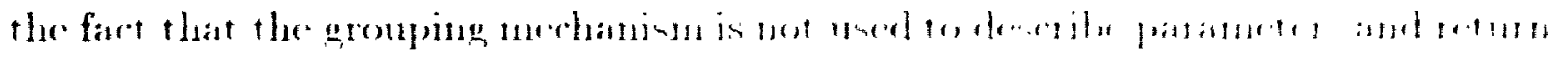
values.

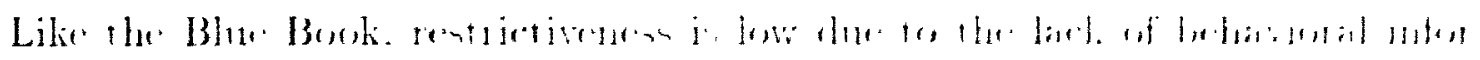

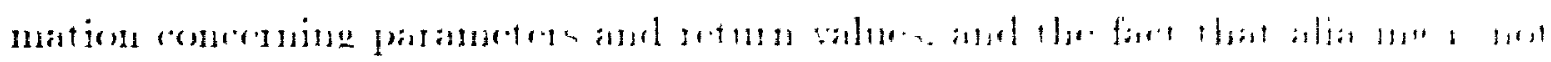

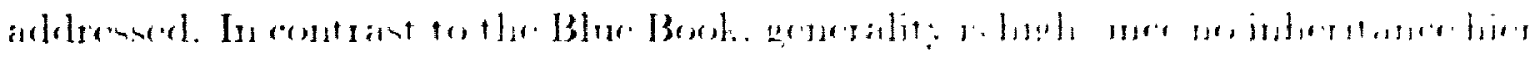

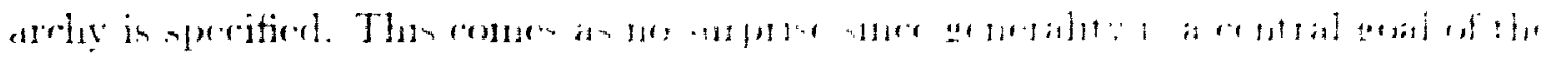

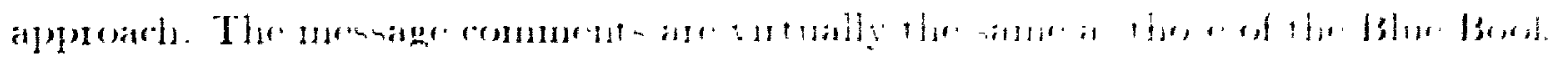




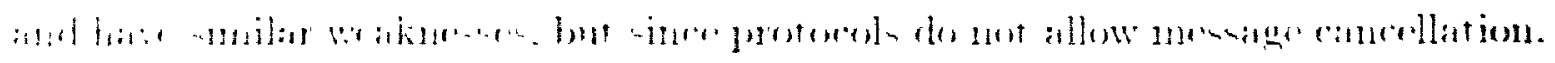

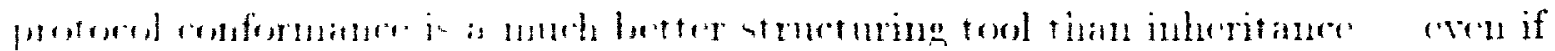

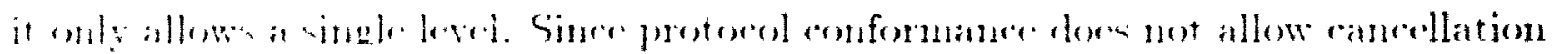

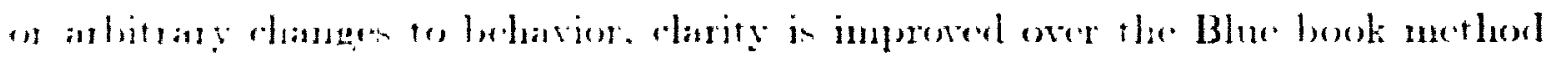

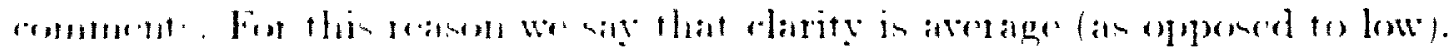




\subsection{Borning and Ingalls}

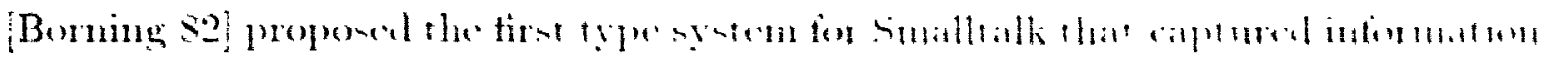

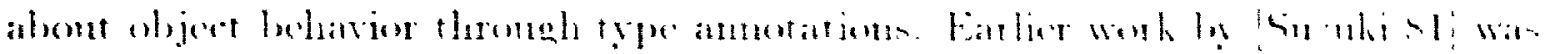

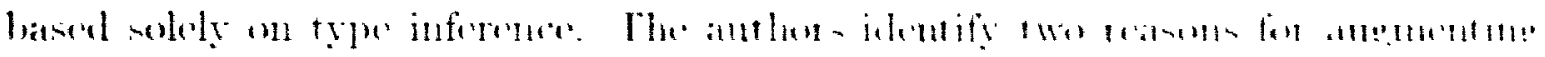
Smallalk with a type system.

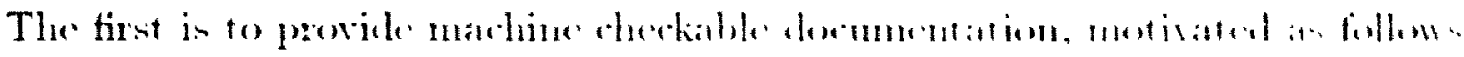

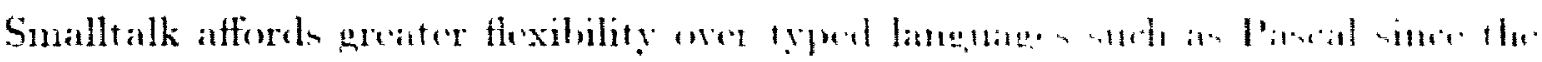

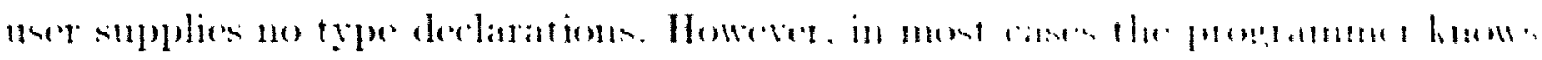

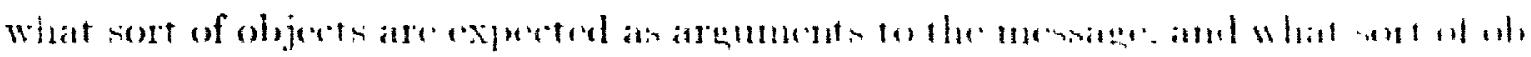

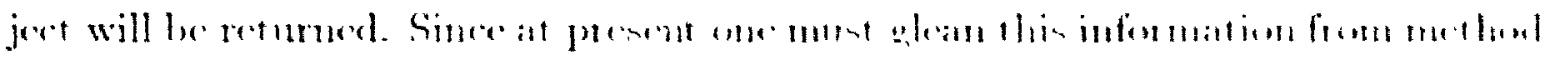

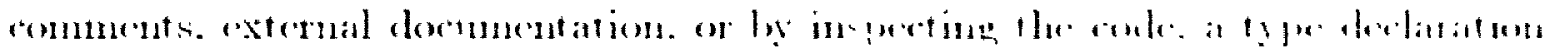
system womld provide a valuable form of dowmentation.

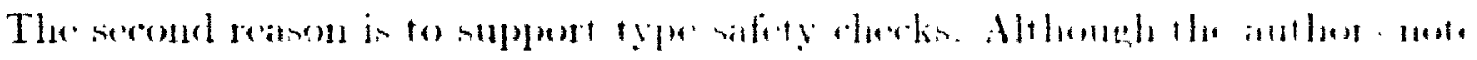

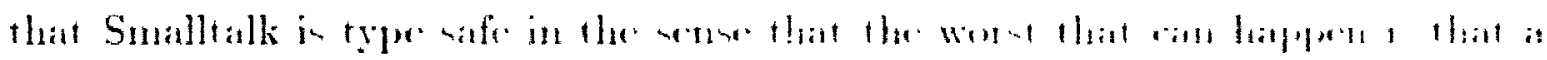

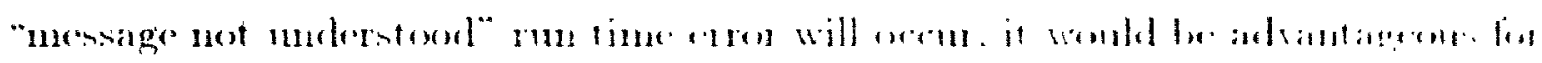

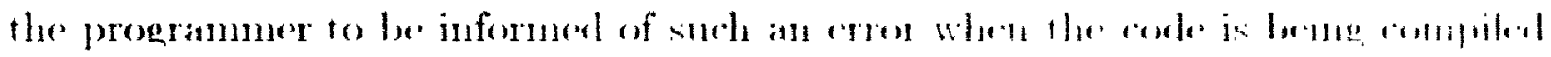
mather than when it is hedeg ward.

\subsubsection{Ciroup Membership}

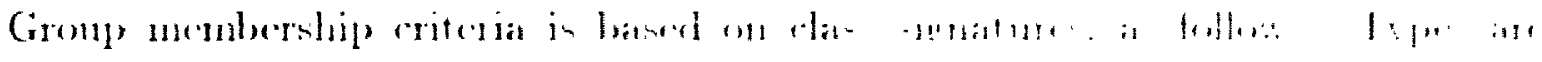

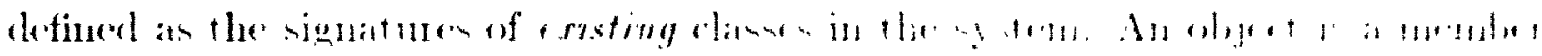

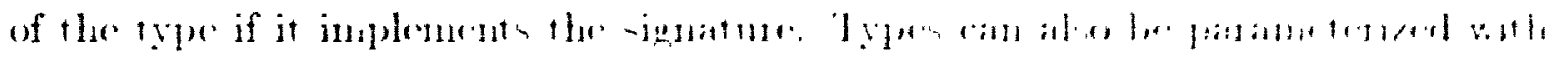

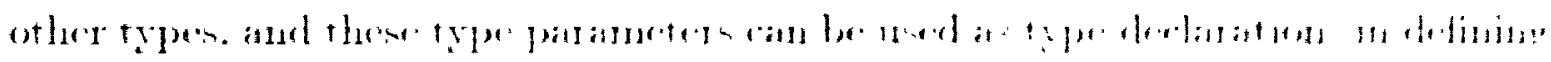

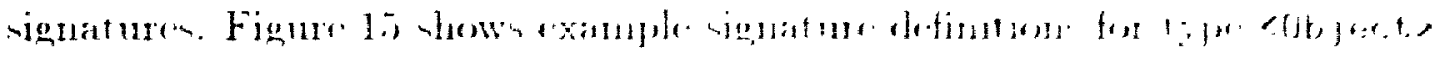




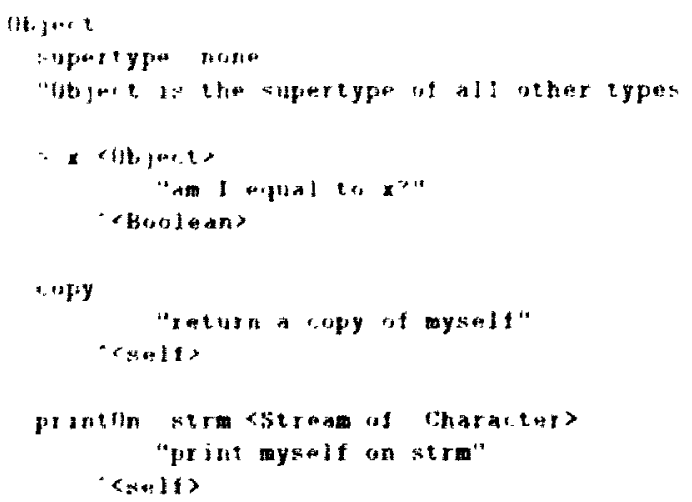

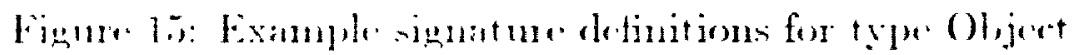

\subsubsection{Relationships Between Groups}

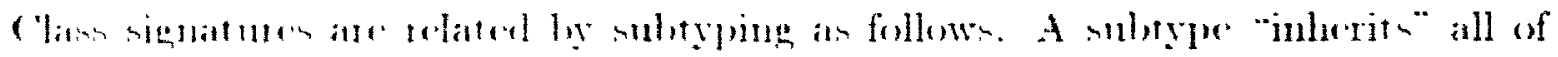

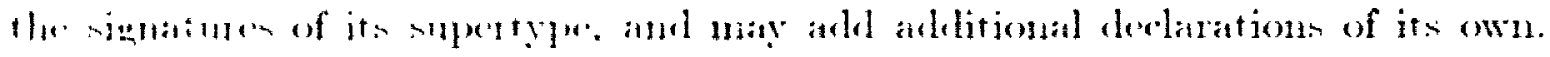

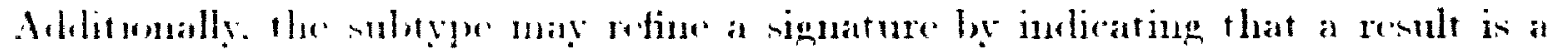

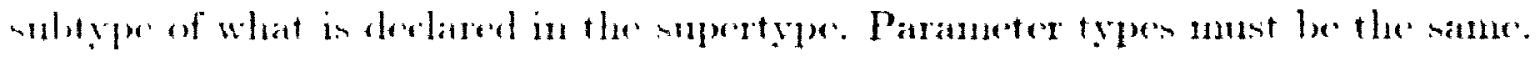

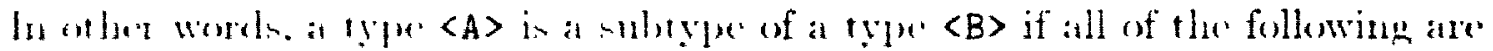
11111:

- $\langle A\rangle$ contand a viphatme definition for all signatures in $\langle B\rangle$.

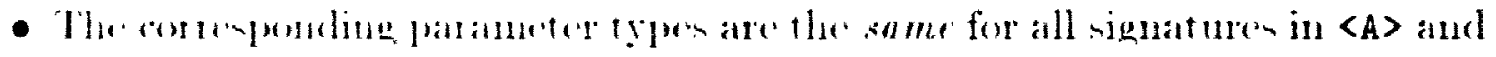
<B>.

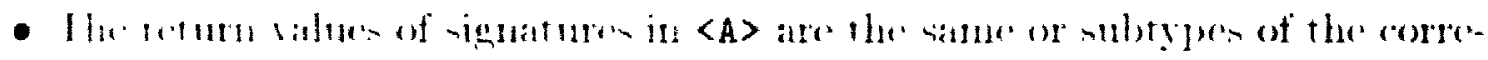

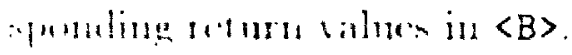

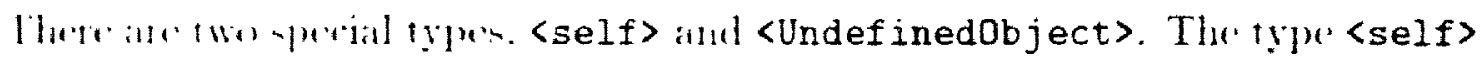

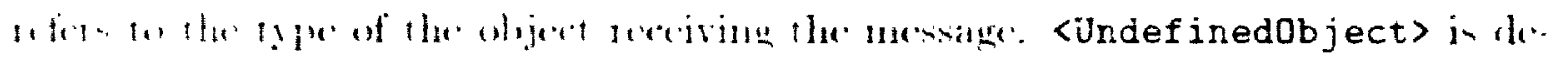

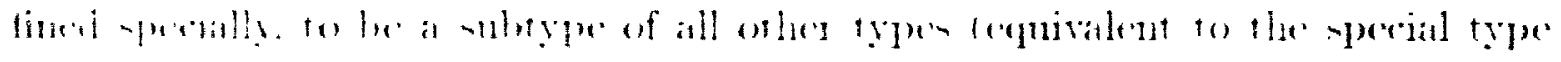

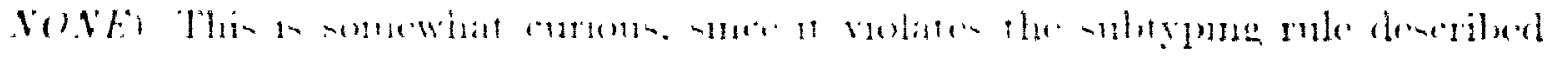




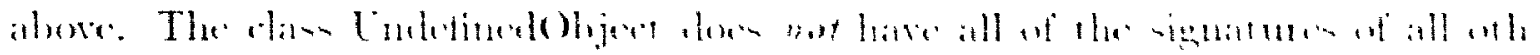

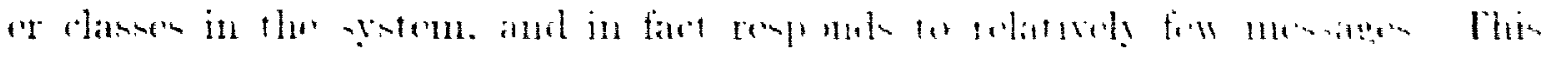

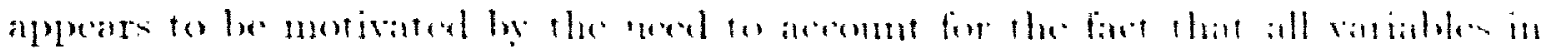

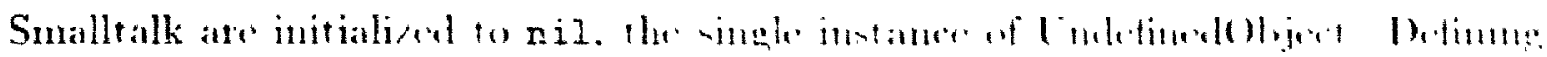

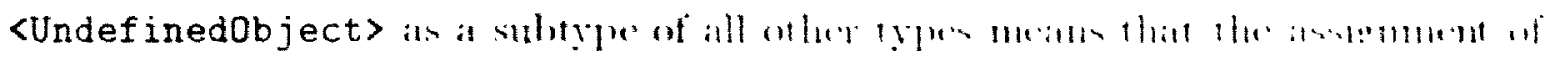
nil to any varable is type corrert.

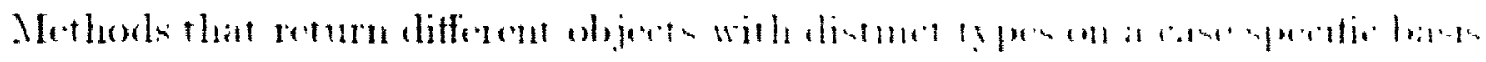

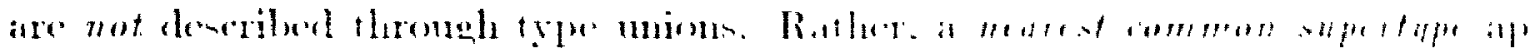

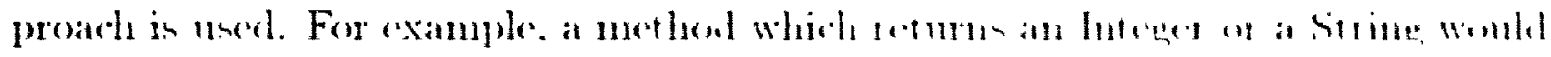

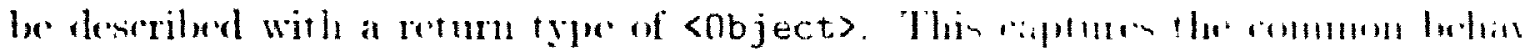

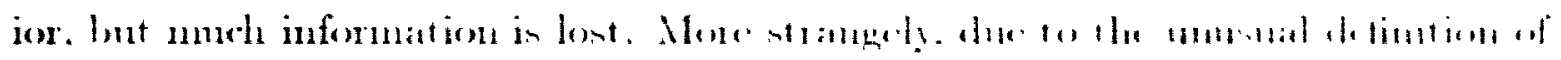

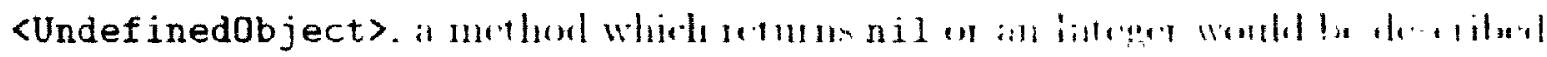

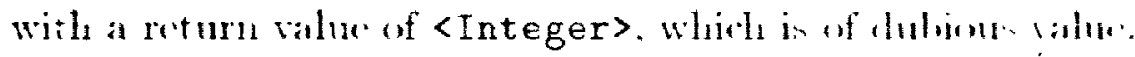

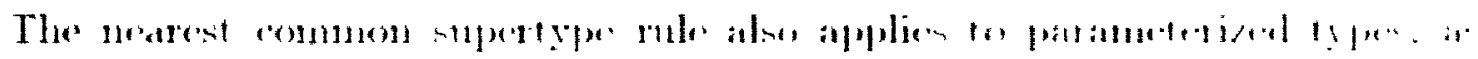

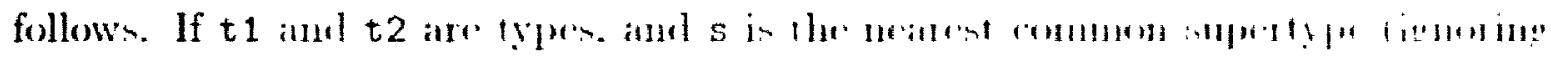

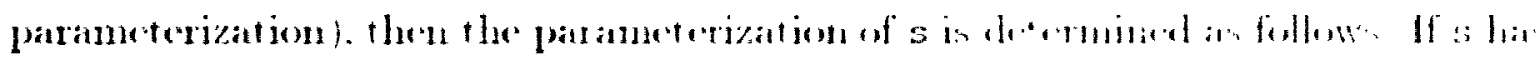

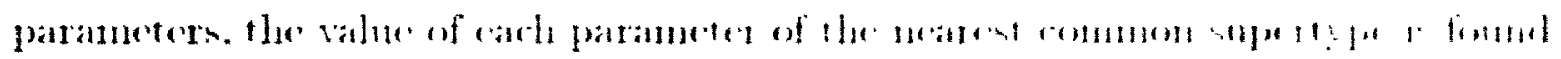

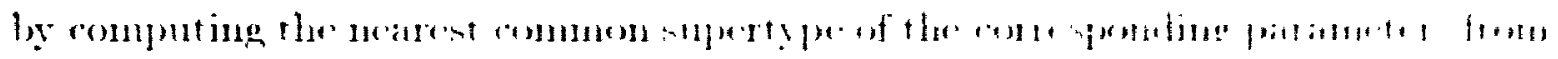
t1 and t2.

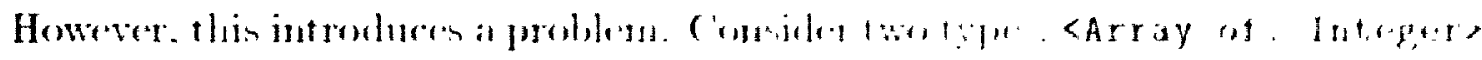

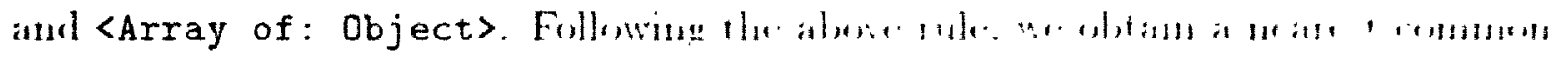

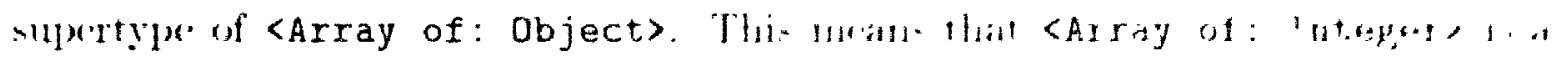

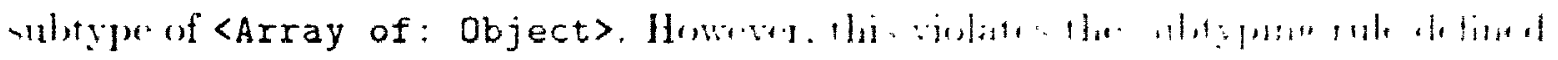

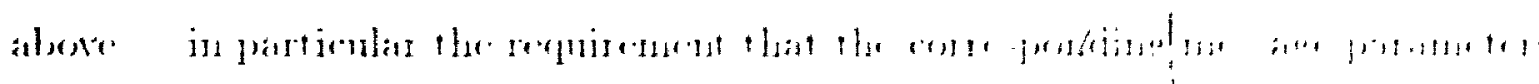

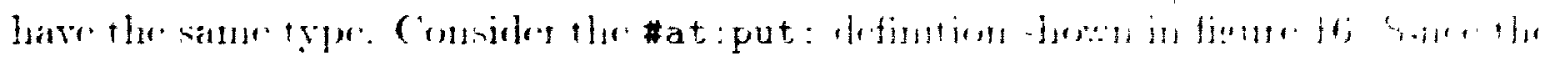

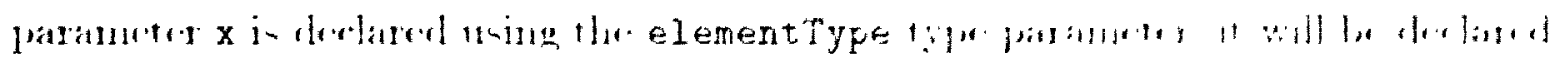

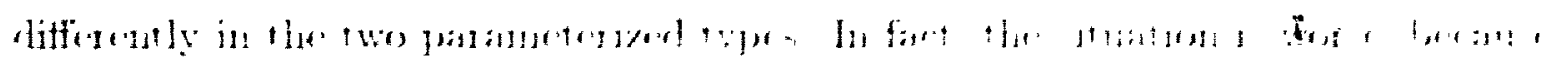

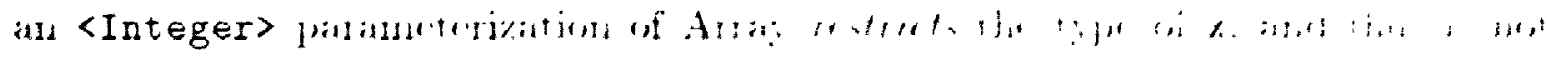




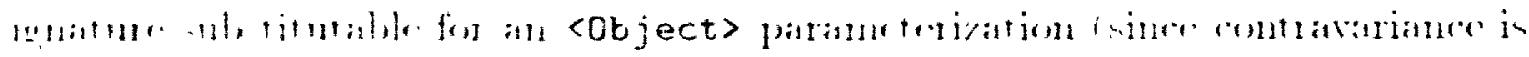
indintall.

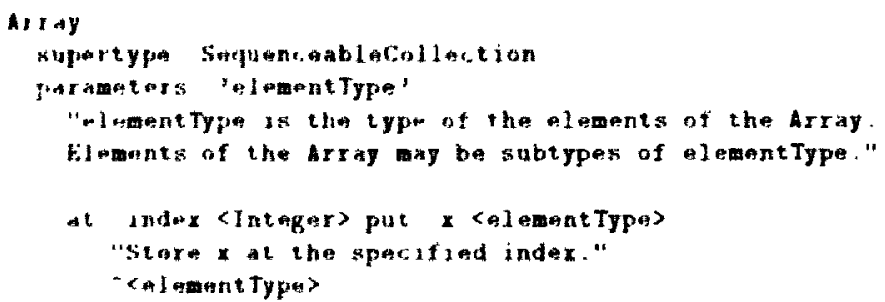

Figur 16: Exanjule paraneterized signature definition

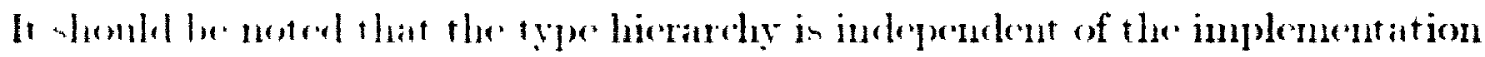

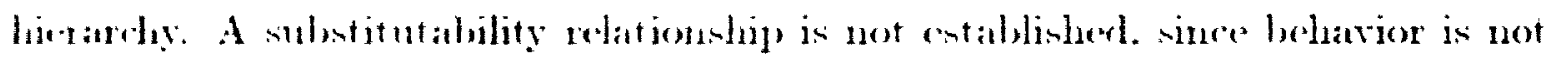

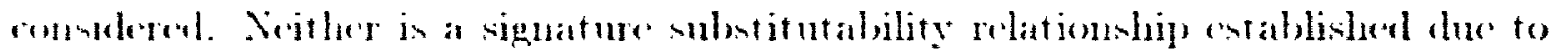
the polbens with parameterized tyen.

\subsubsection{Description of Behavior}

The typen ane jus signat ures and do not inchule any description of behatior. Param-

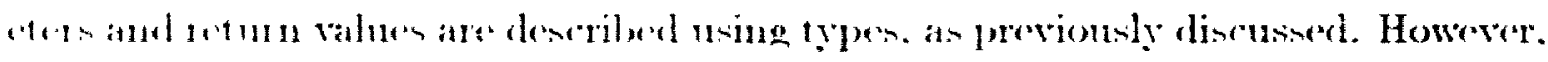

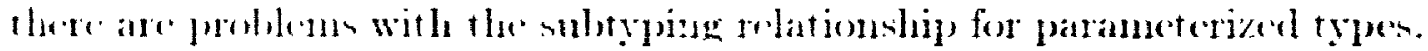

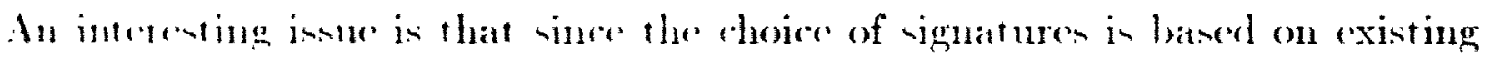

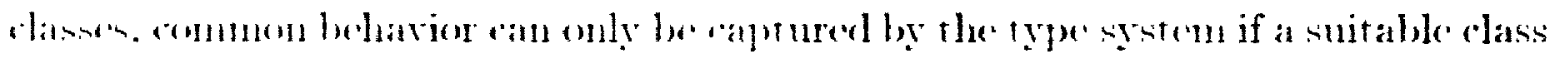
"xims which derrilne this behavior. This is quite limiting berane the arrangement

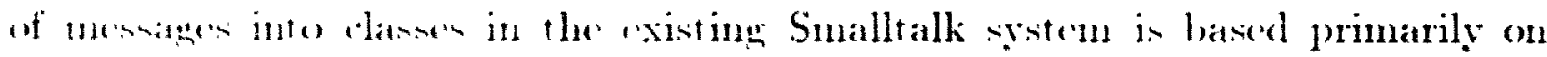
implemeatation aepuntements. Thin is the same poblem the Blue Book hats, in that

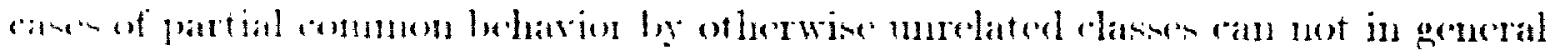

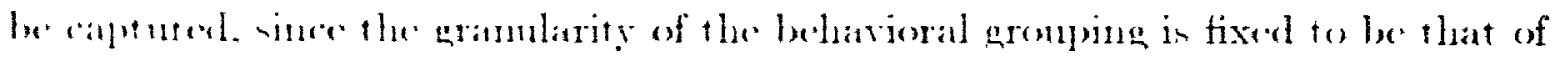

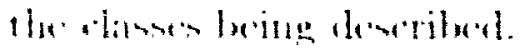

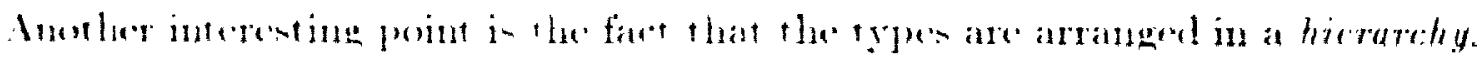

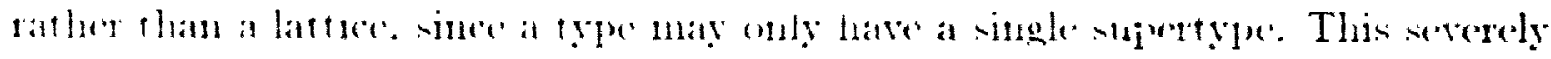




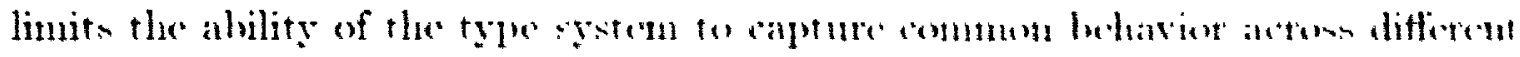

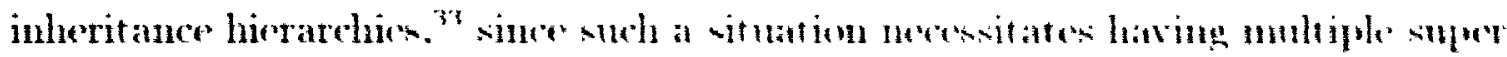

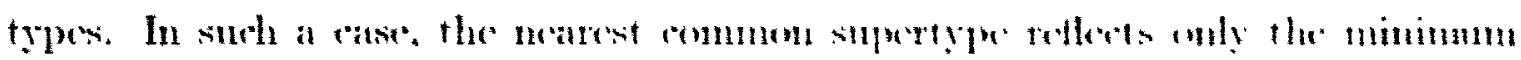
common beluavior.

\subsubsection{Summary}

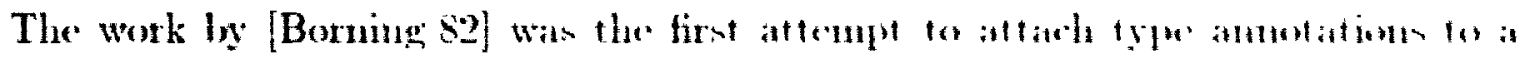

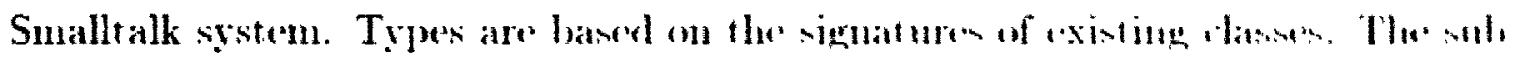

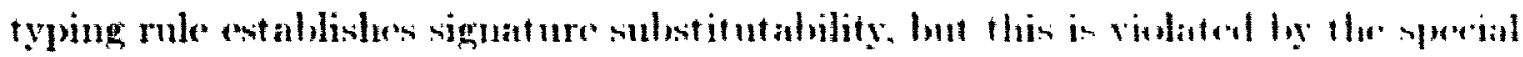
detinition of <Undefinedobject>. and the common sulpertype rule for parameter

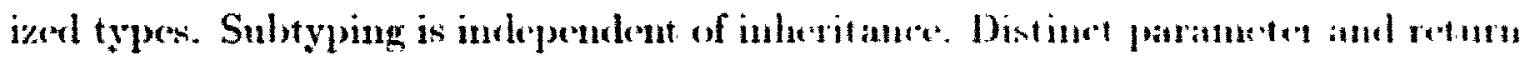
values are deseribed by the mearest common sulpertyly.

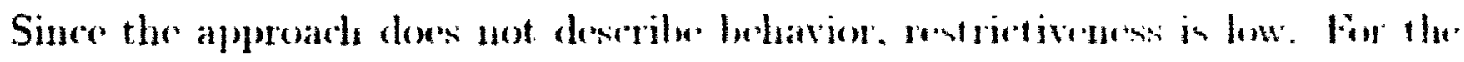

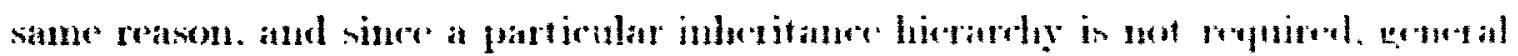
ity is high. Althongh Whavior is uot included in the shlegping melationship and there is a problem relating paraneterized types. when uned in conjunction with

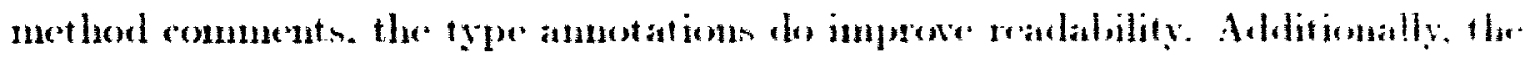

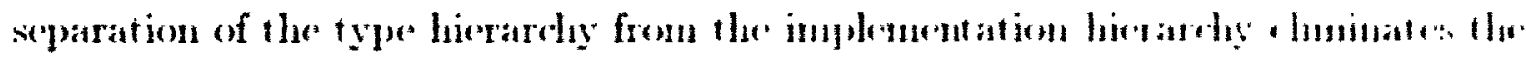

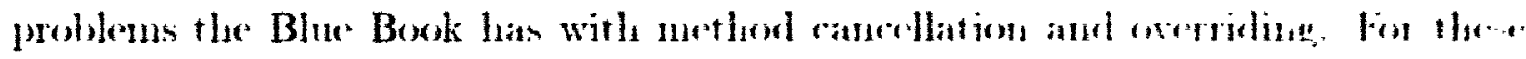
roasons we say tlat darity is avelage.

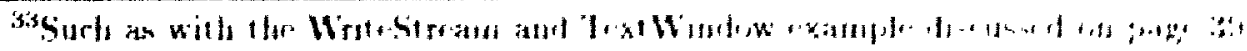




\subsection{Johnson et al}

The Tyyod Smalltalk projert [Johnson 86] [Graver 90] is conrerned with investigat-

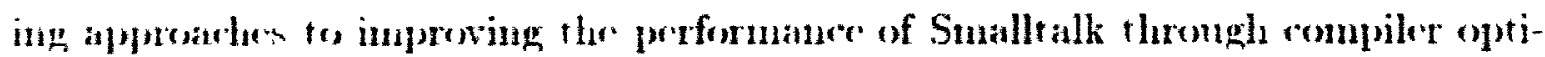
mizations. Johmeon suggests that major performaner improwenents in Smalltalk mquare at type systrm that will allow tratitionat kinds of empiler optimizations to be applion. Because Smalltalk is dynamically typed. a compiler has no way to dectrmine the method that will rum when a message is sent. and cannot tell whether an operation has side offects or will affect conirol flow. Thus common subexpression climination, dead corle romoval, and other strategies used in traditional languages "an not le nedel. If the methed cau be detcrmined at compile time. inlining is also pemsible reduring relatively expensive context creation to simple operations like lownhing.

\section{2.x.1 Group Membership}

Jehunom defines three gromping medhanisms, two hased on classes. and one based ons signatuses:

Object Types A type is a (pomibly) parameterized class.

Union Types A type jo a set of (possibly) parameterized classes.

Signatures A type is a sut of message types. where a message type describes the parancter and return types for a mestage.

Objert tyes are clames which are paraneterized with union types to dearibe the persible oljocts that the state variables of instances of a class may inold. For

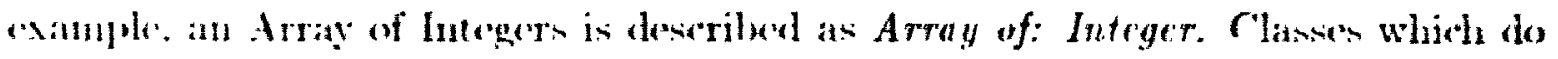
not have (externally vishle) state cariables suet as linteger. are not paraneterized. An As sily of Arrays of luteder is deseribed Array of: (Array of: Integer). 


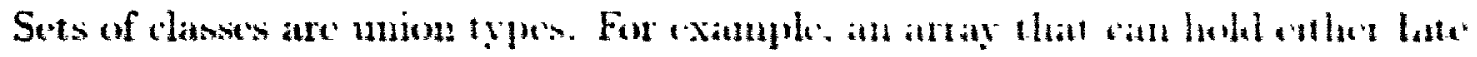

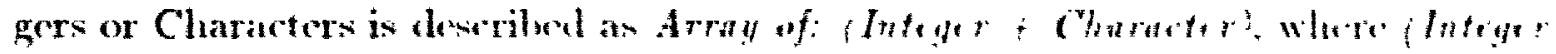

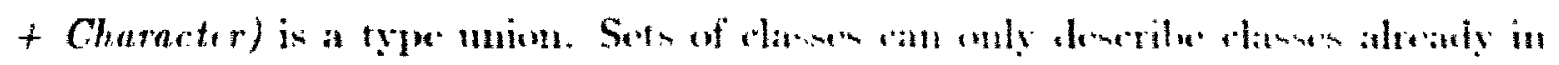

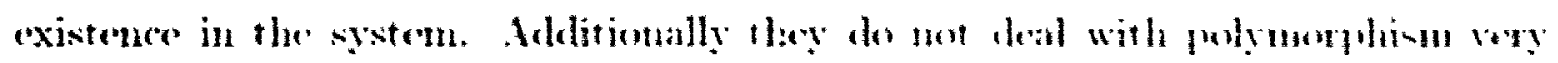

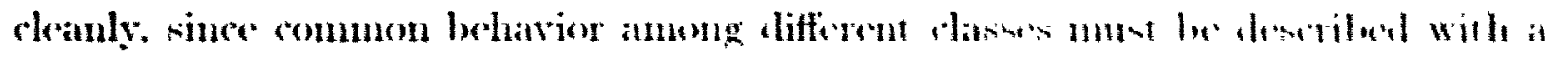

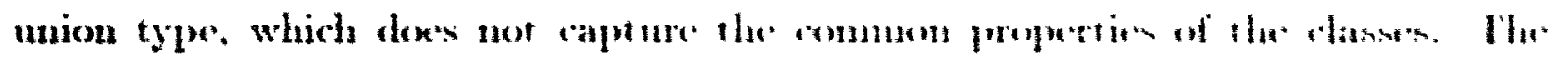

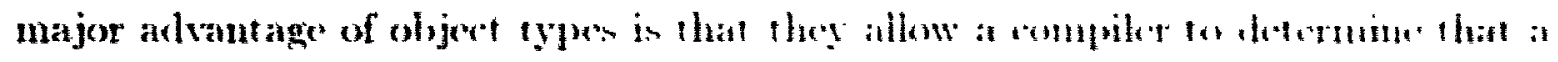

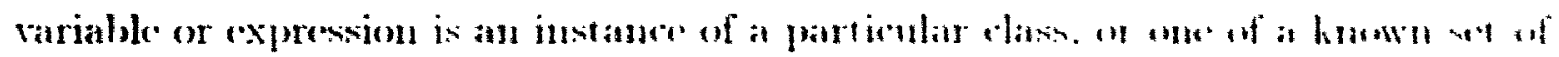

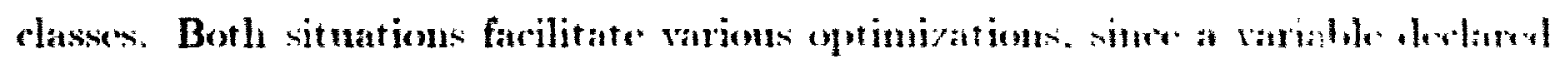

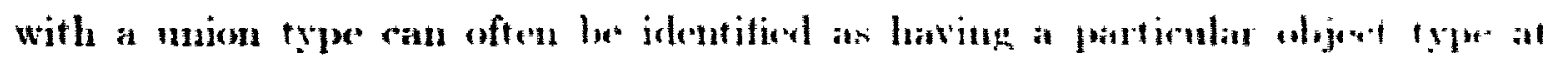
varions points in a method. throngh static analywis of program tyje rasing.

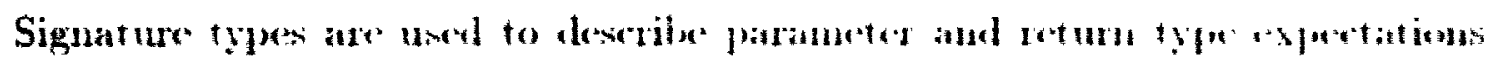

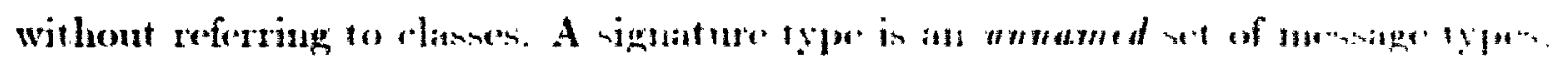
which are nessage manes with parameter and returu value type infomation. Fot

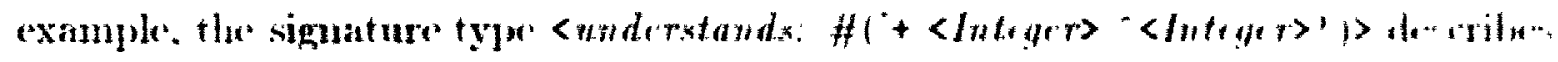

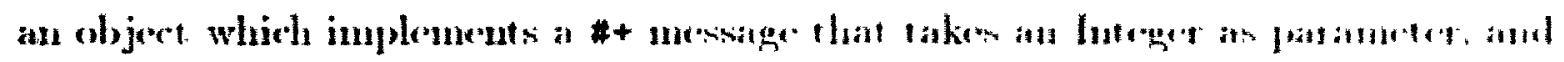

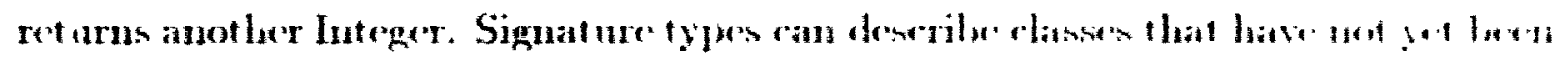

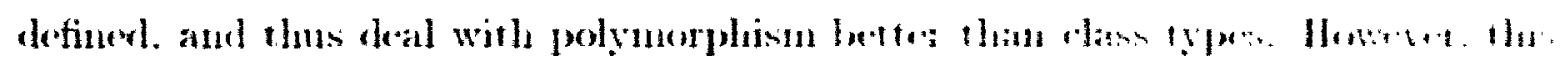

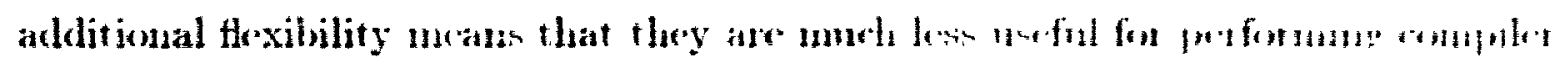
optimizations, since they do not identify a partionlay clines.

\subsubsection{Relationships Between Giroups}

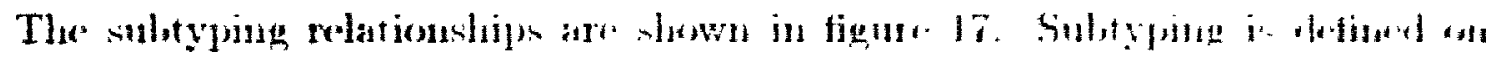

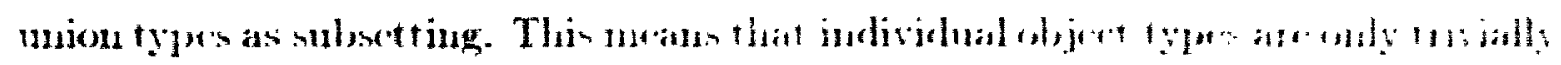

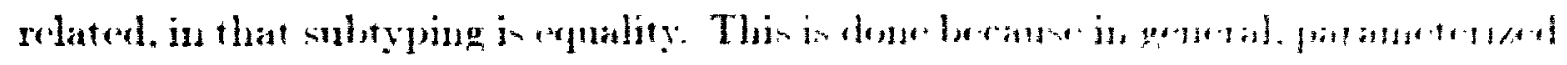
types are not comparable in terme of a -1 bly

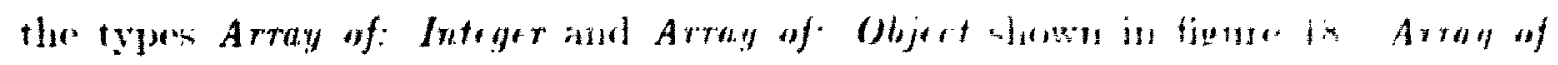

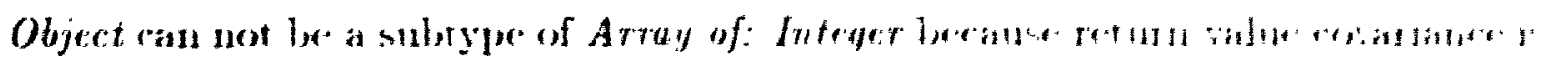




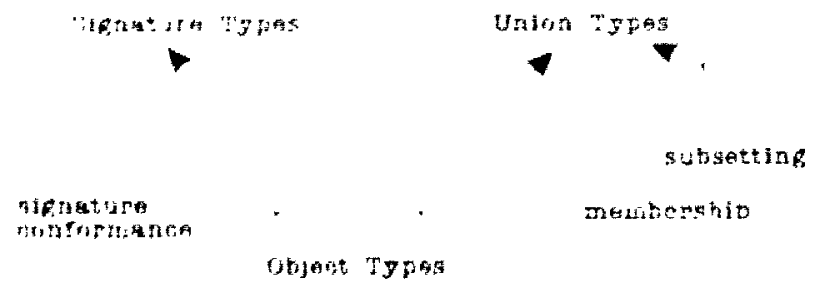

Figure 17: Sultype Pelationships in Typed Smallalk

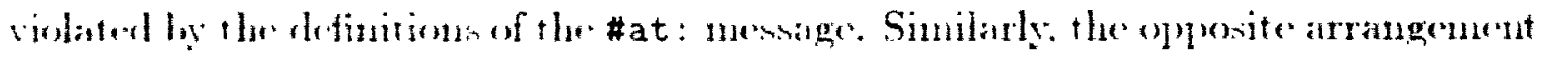

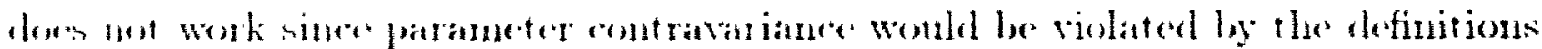

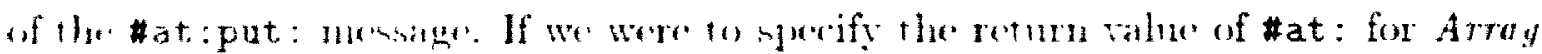

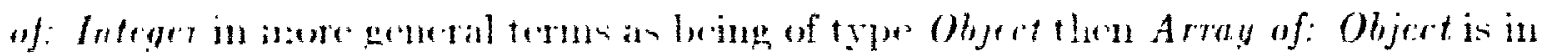

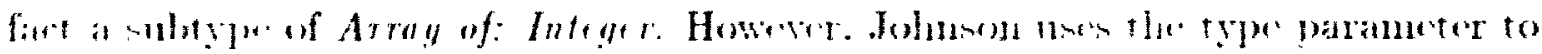

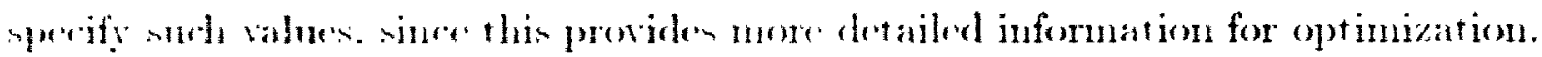

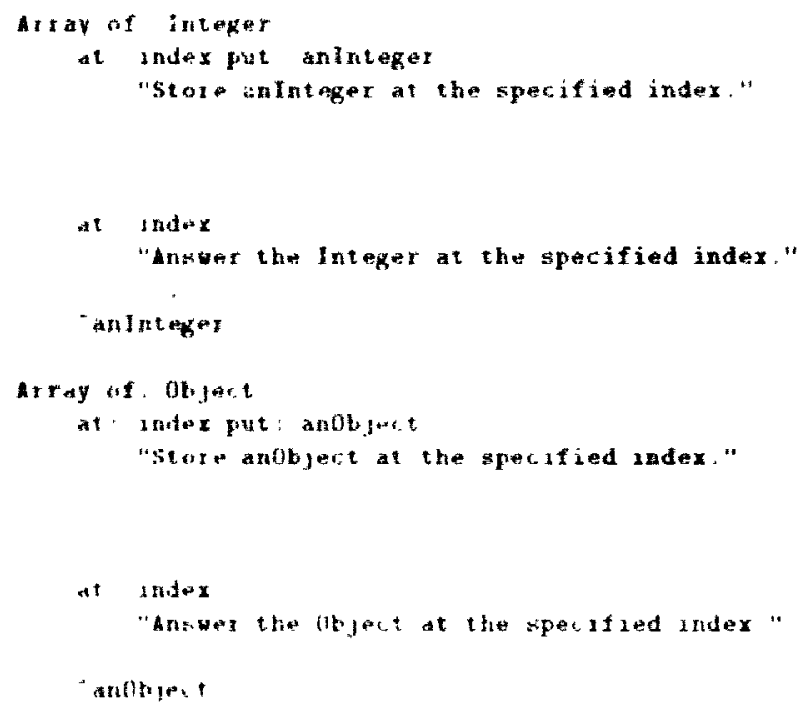

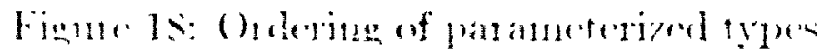

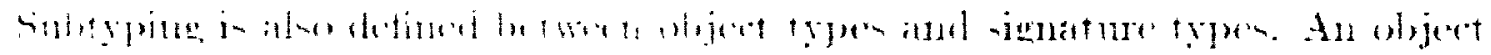

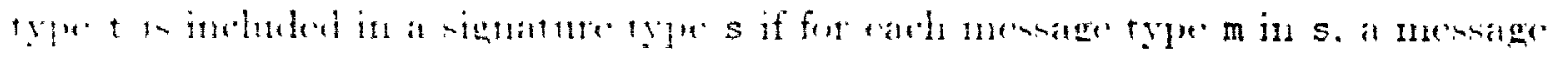




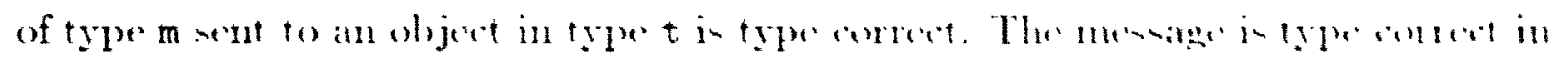

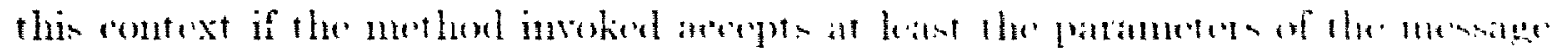

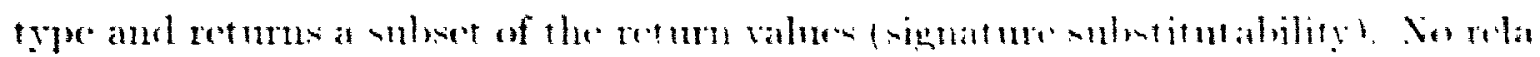

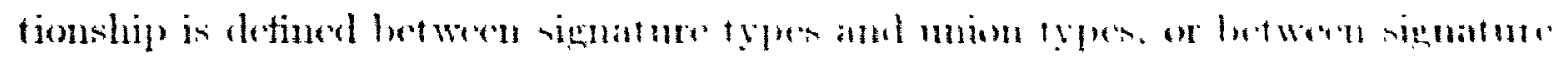

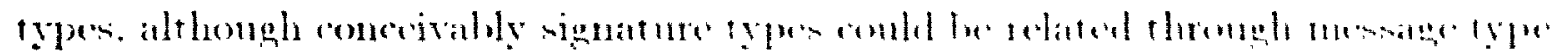
subsetting.

\subsubsection{Description of Behavior}

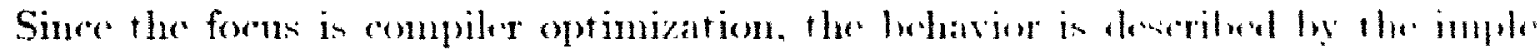
mentation. Howerer. there are some interenting points.

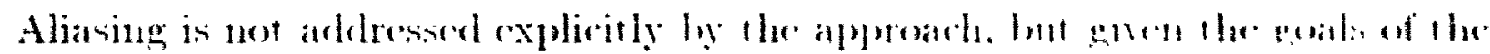

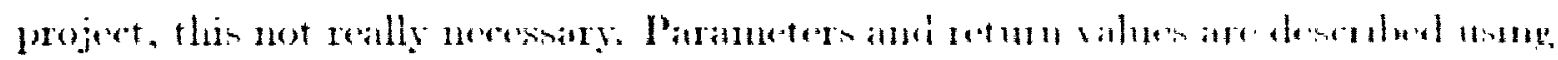

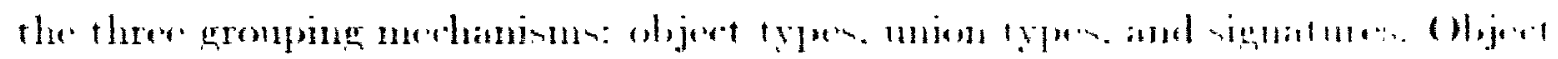

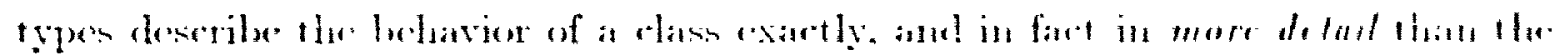

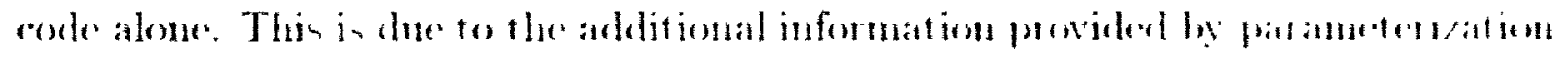

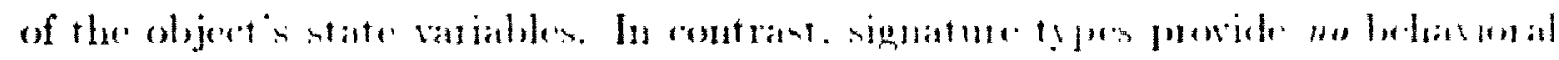
information they are just mensige type templatem.

\subsubsection{Summary}

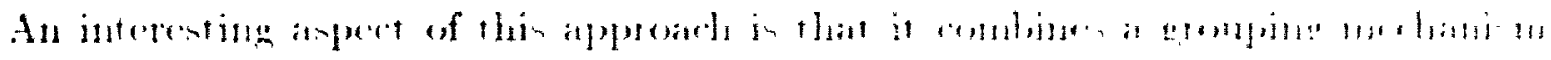

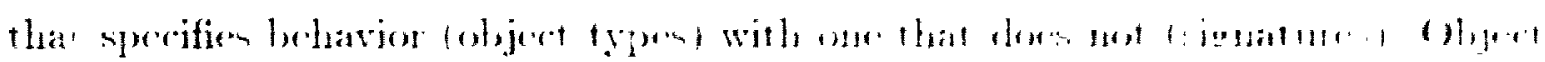

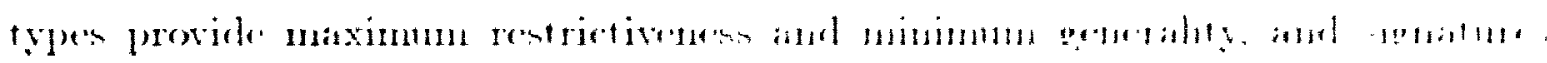

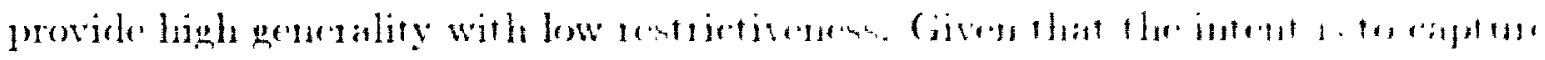

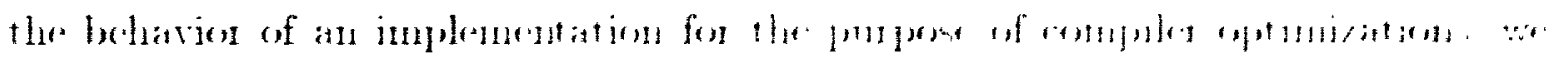
do not rabluate clanim!

Signatures atr a

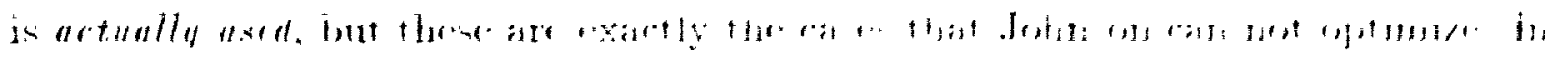

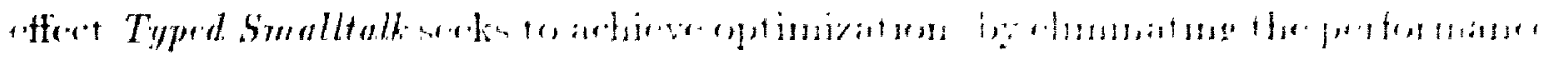




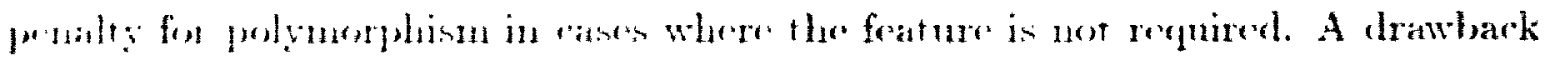

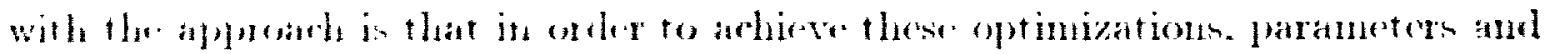

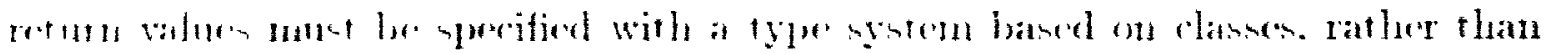

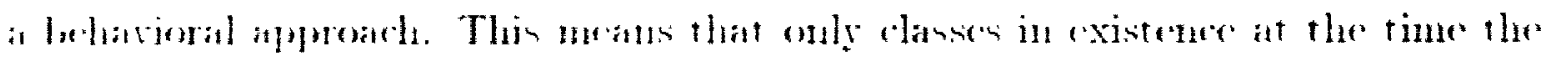

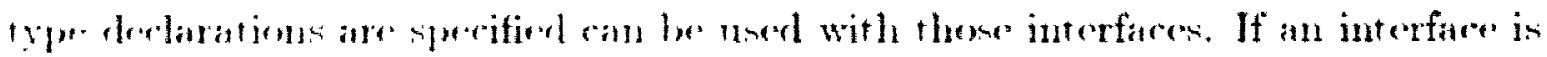
perified using objont types, then reme is encerdy limited. If signatures are used. the corle comos be optimized. 


\subsection{Wills}

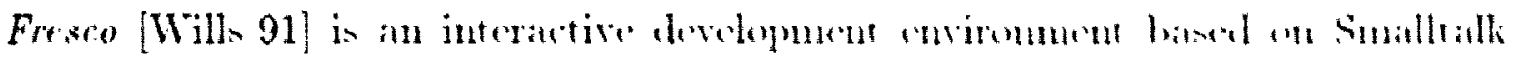
Small alk is extended lyy Fresco in the following rwo ways:

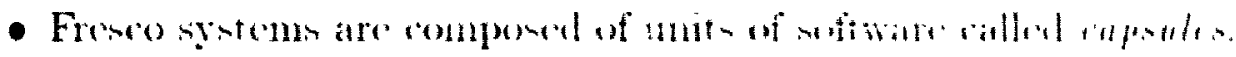

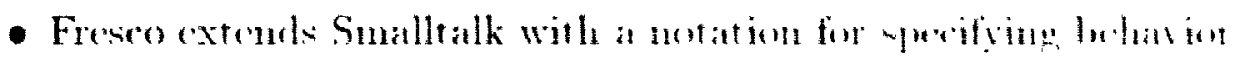

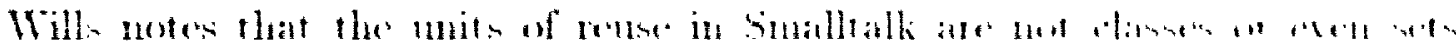

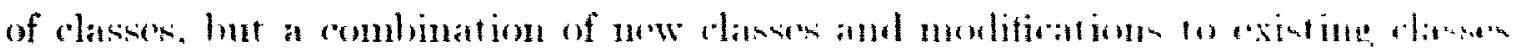
Freareralls these units of renere capsulex.

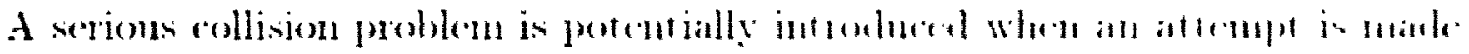

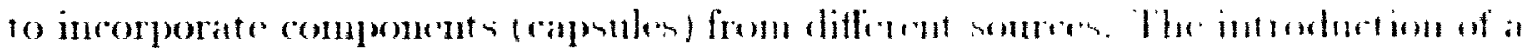

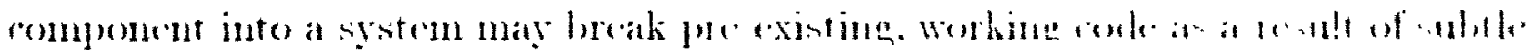

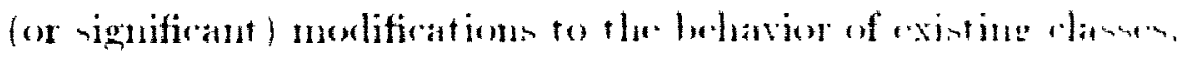

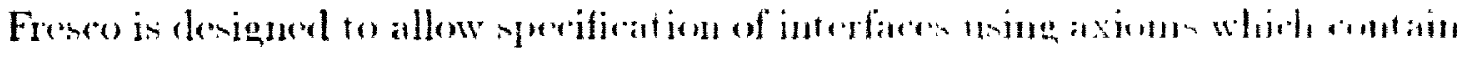

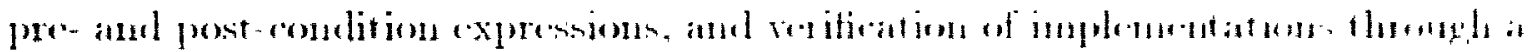

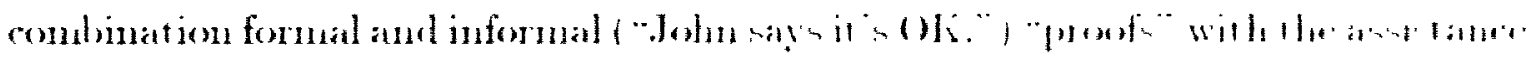

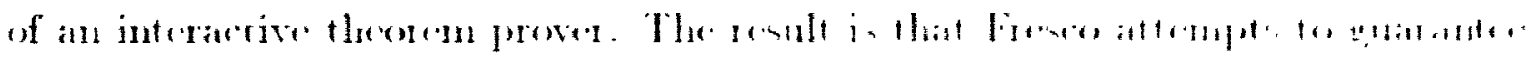

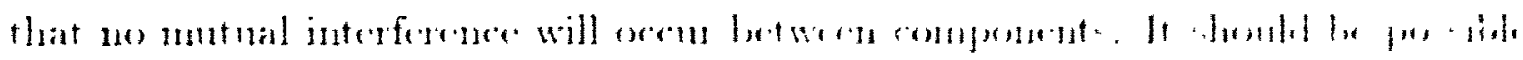

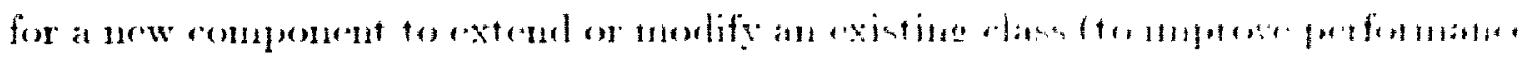

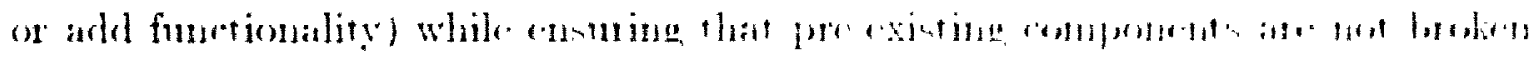
by the rhange.

\subsubsection{Group Membership}

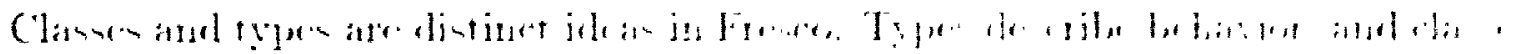

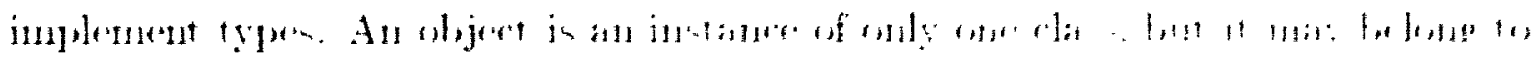

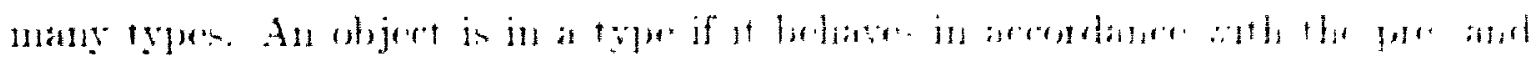

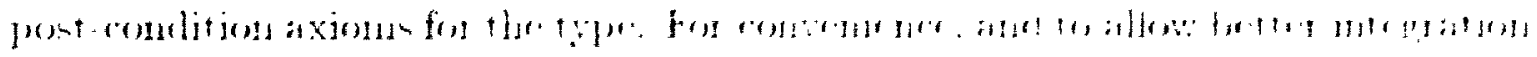




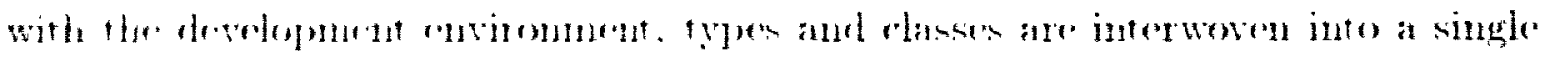

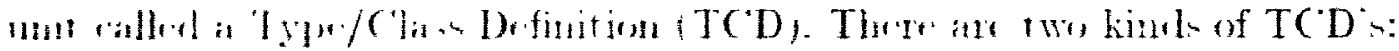

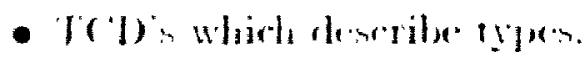

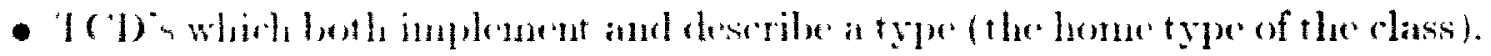

\subsubsection{Relationships Between Giroups}

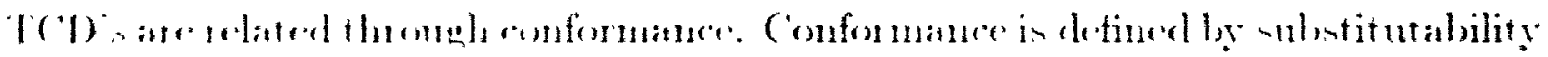
at. follows. A typ C conforms to type $A$ if and only if all objects of type $C$ are

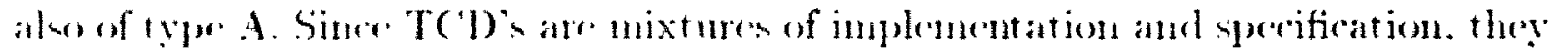

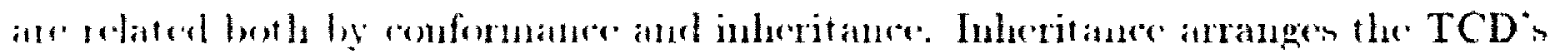

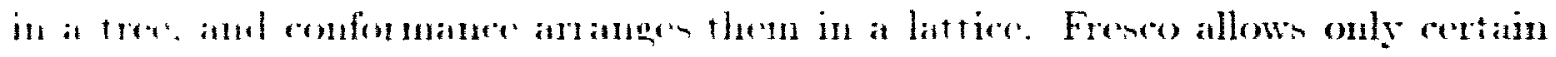
nombination of inheritance and onformance:

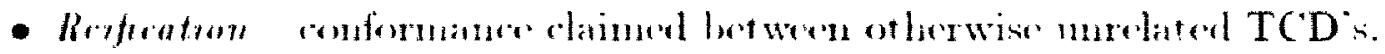

- Nomconforment mberetaner in which the state variables and methods of a

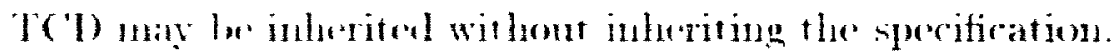

- Confarmunt mhe ritane in which a TCD is clained to eonform to its parent. whith has a deritiontom, and may or may uot have an indelementation.

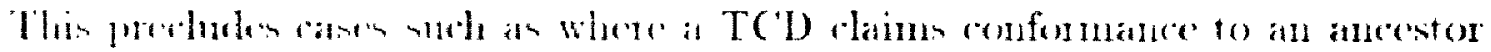

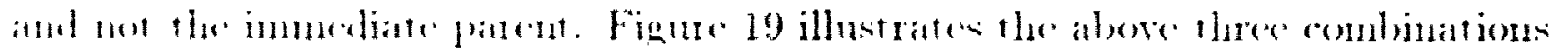

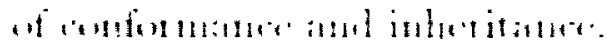

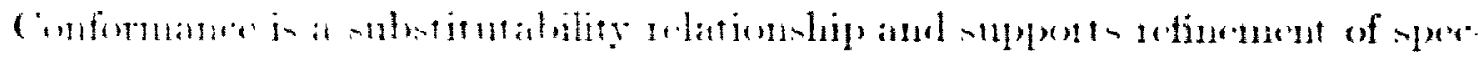

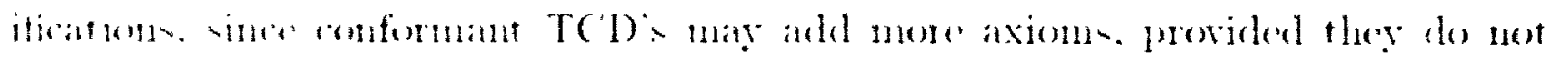

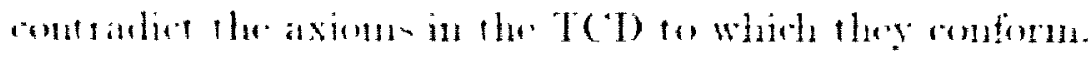




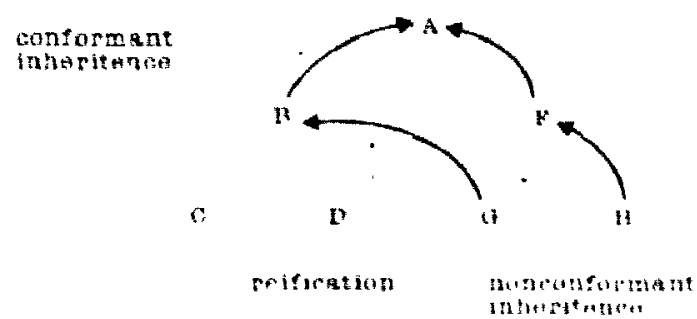

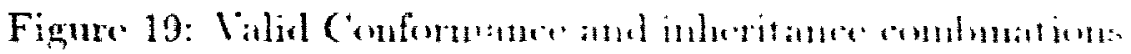

\subsubsection{Description of Behavior}

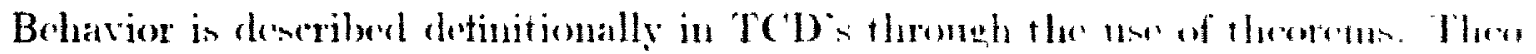

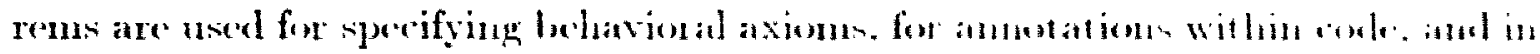

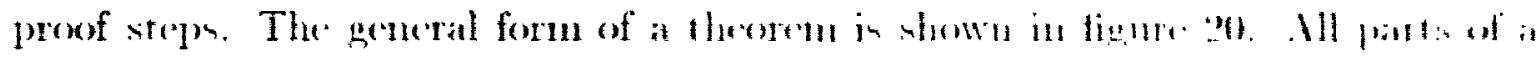
theorem may le omitted exent the pouteomition.

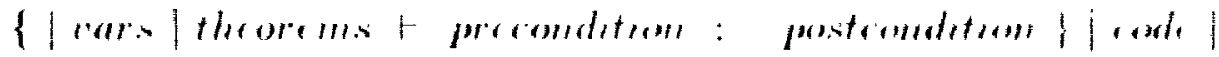

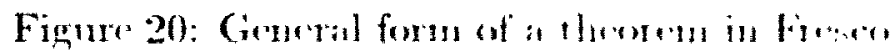

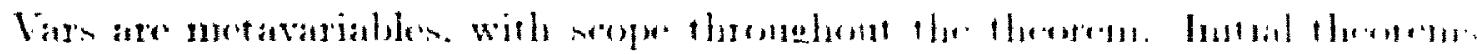

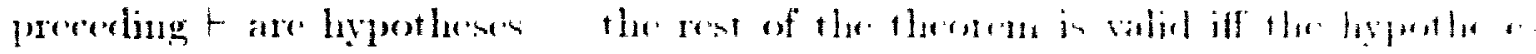

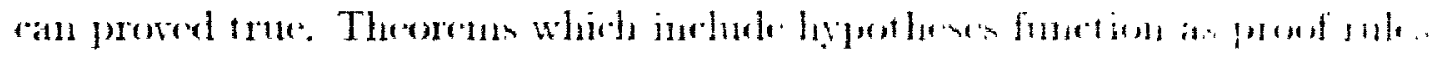

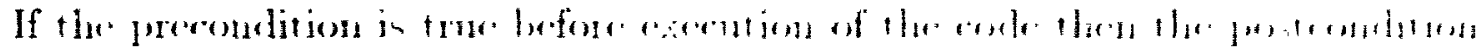

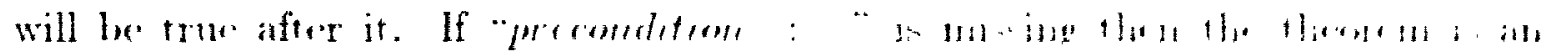

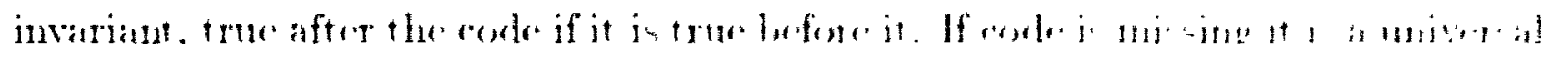

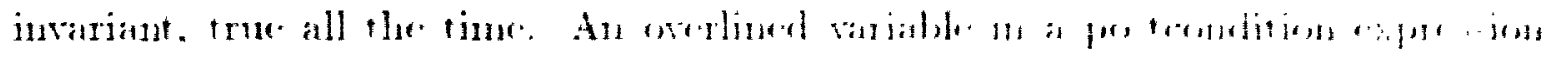

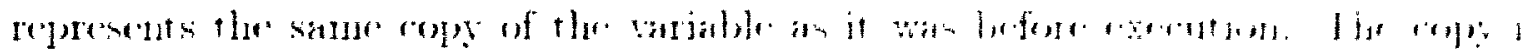

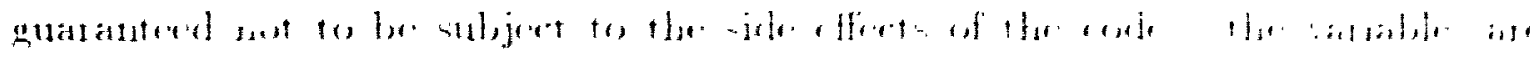

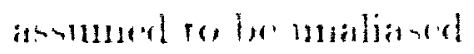

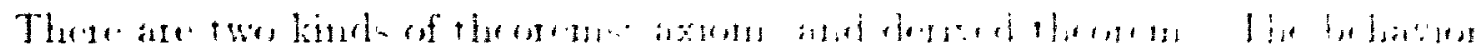




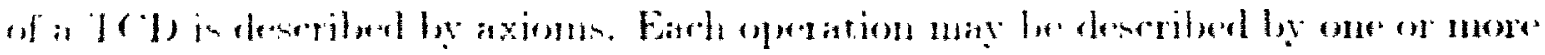

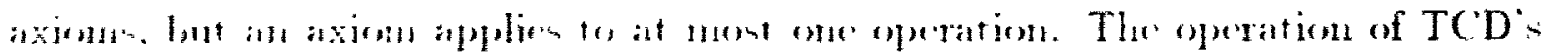

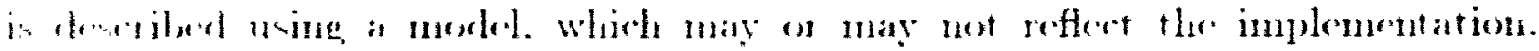

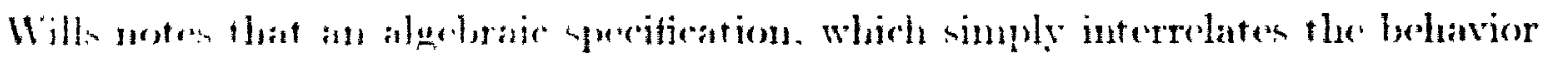

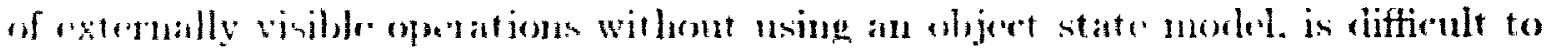
ux: fol anything but simplo typex.

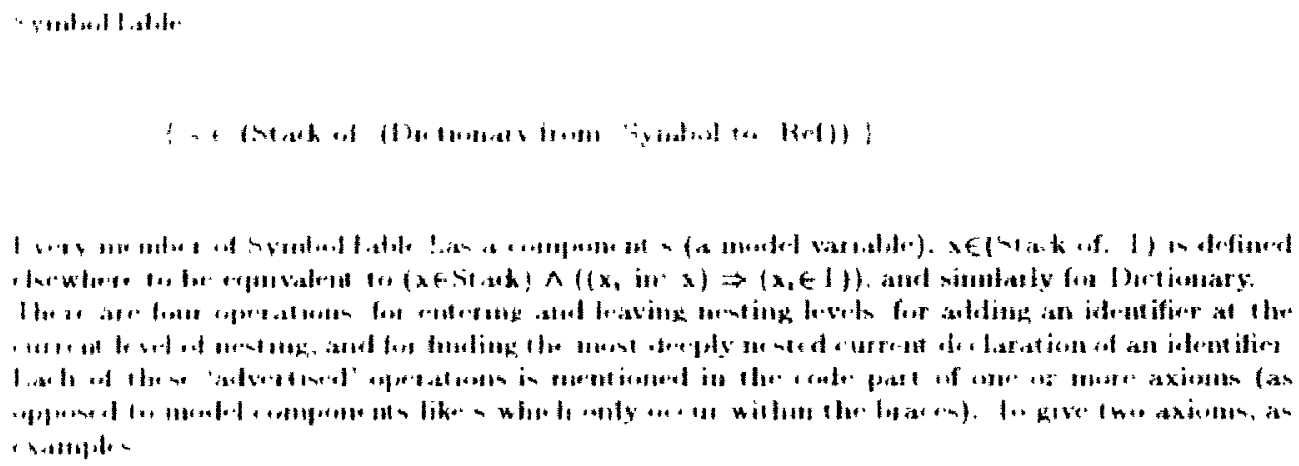

Figure 21: A SymbolTable TCD example

Figne : 1 show an example of how a TCD is specified. The operation \#declare:with: is not guananeed to work nulens its tirst argument is a Symbol

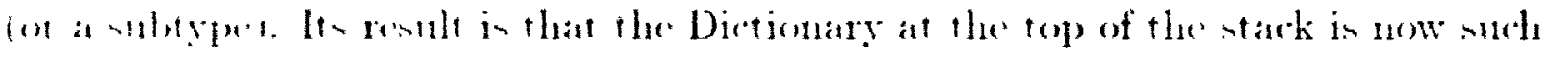
that it map id to ref. The operition \#leave works only if the sark in not ompty.

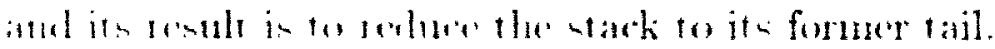

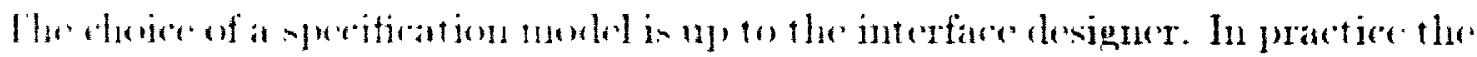

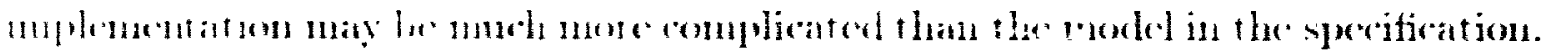

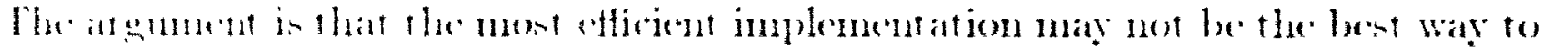

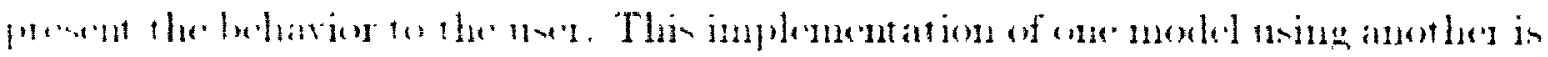

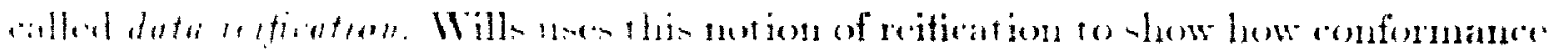

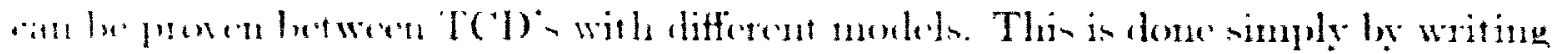




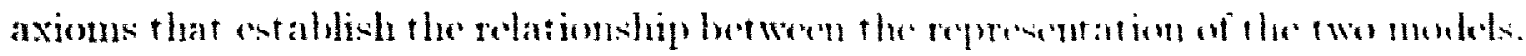

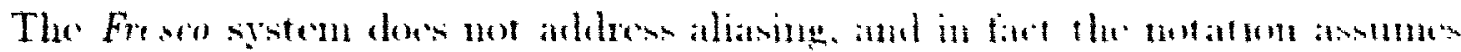

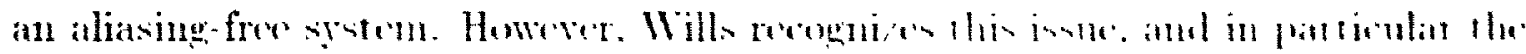

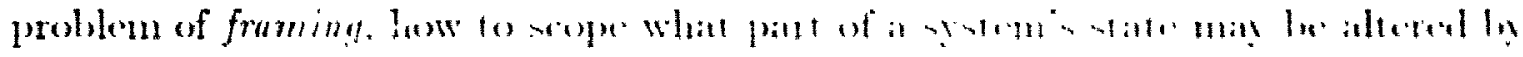

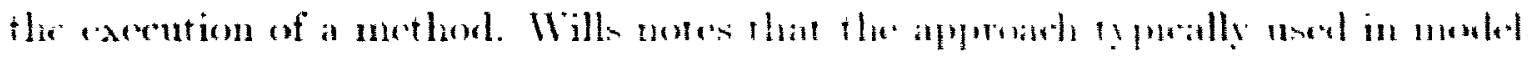
hased speritiontons. Where the frame is a set of rariables. will not work fon llwe followin: reasons:

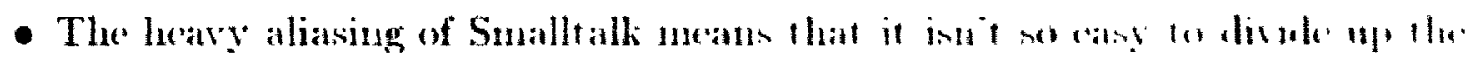

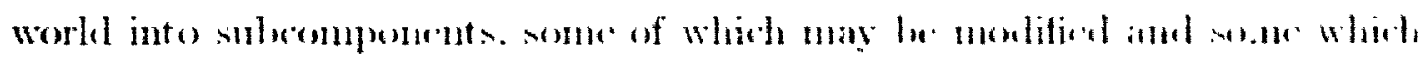

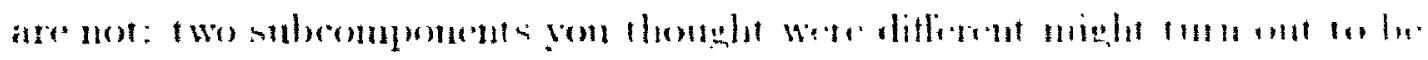

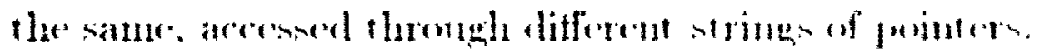

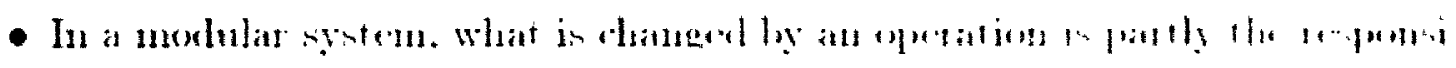

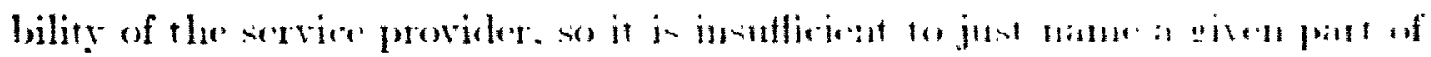
the whole state.

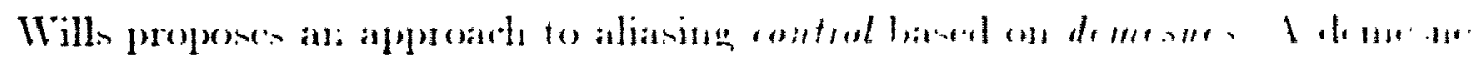

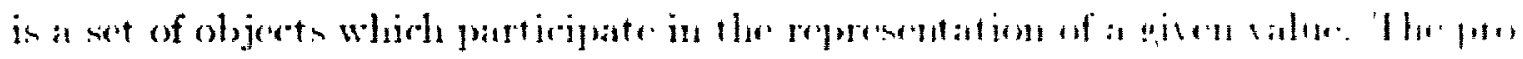

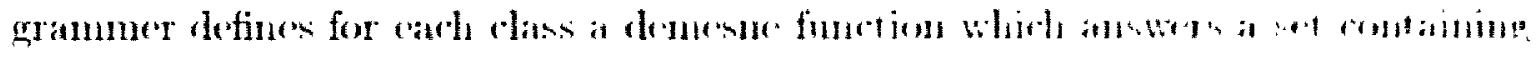

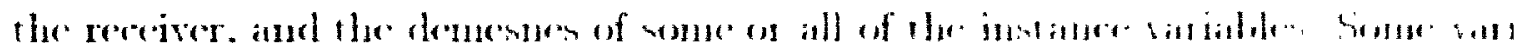

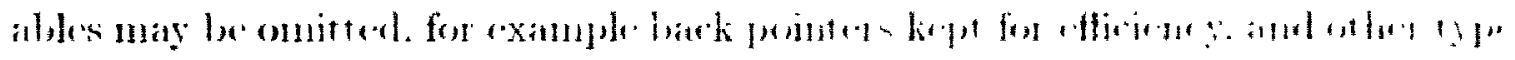

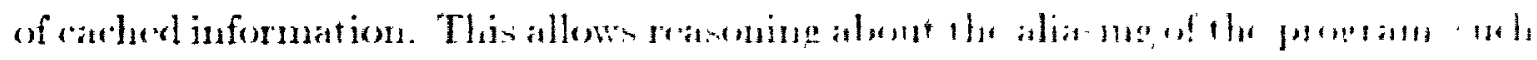

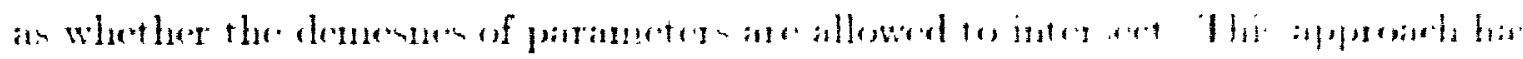

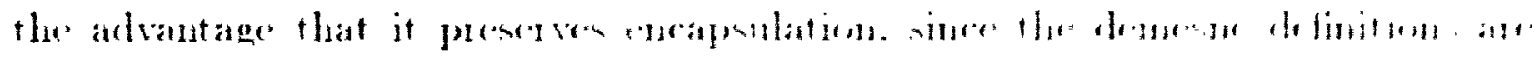
localized with their own clatses.

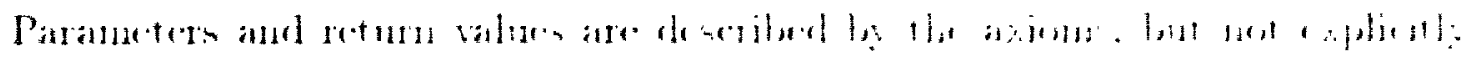

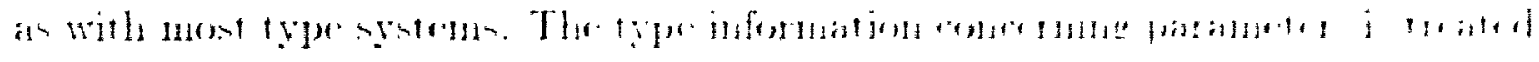

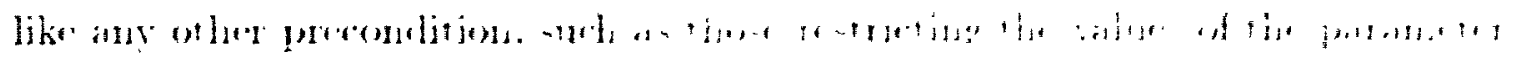

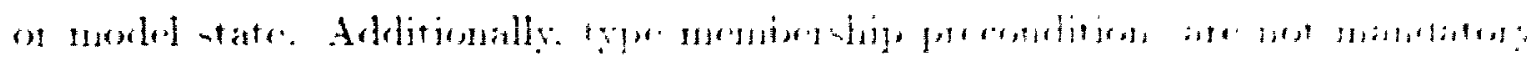




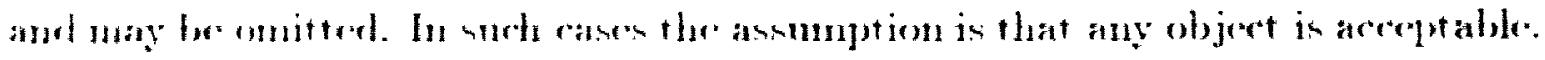

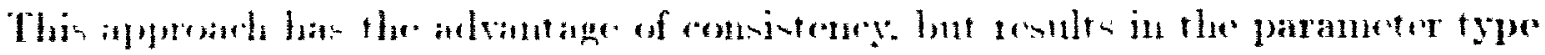

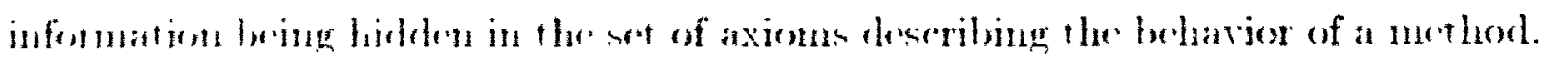

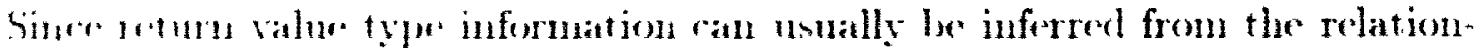
Ship of the retmin value to partuneters or the moded used to describe the TCD. it womld generally be redundant to provide it. However, this can make return type

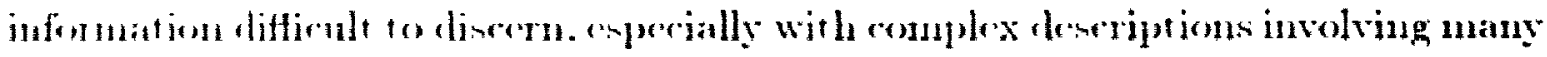
ixism.

\subsubsection{Summary}

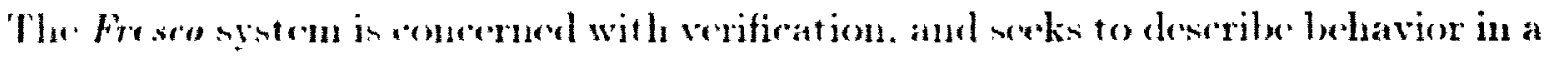
way that is compatilise with antomated theorem provers. The programmer supplices fonminl on informat proof that the code implements llye axions, and it is checked

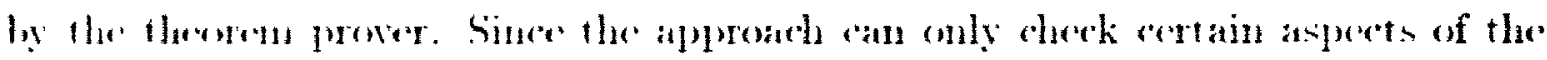
conle anation the aximen, the implementation can not be fully verified. Howerer. ats ustef by Will. the framewotk of axions and the obligat ion to provide cren informal profe brings aluent a meanureable increase in reliability.

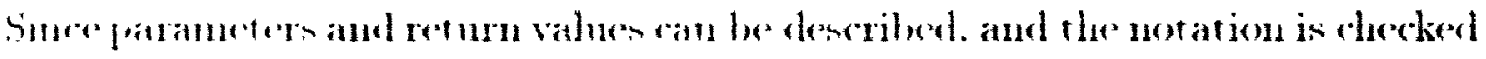

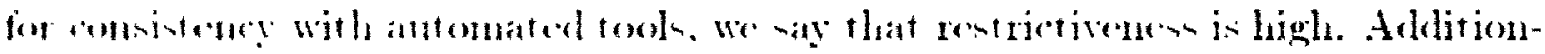

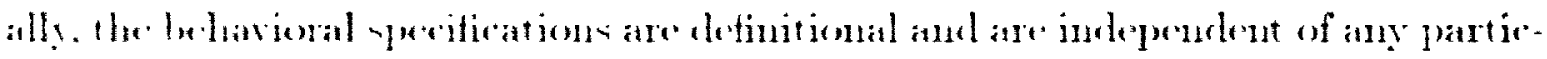

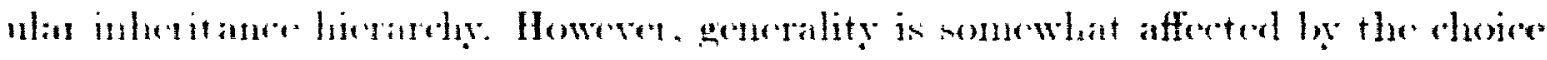

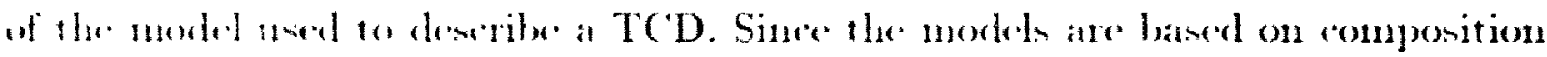
of enter le (C) s. incidenal behation may implicitly fom a part of the sperification

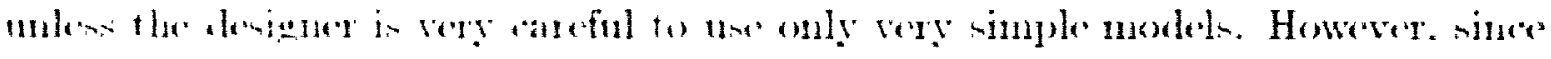

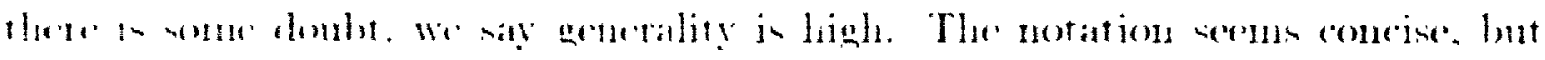

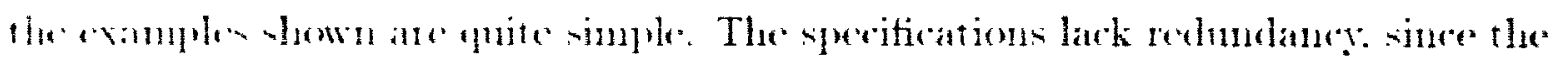

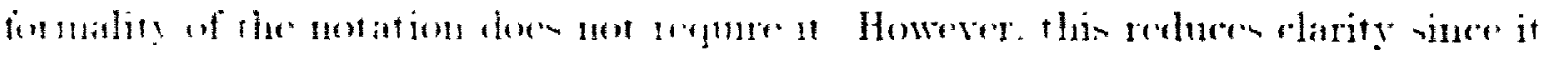

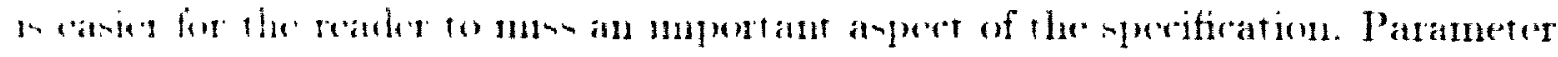




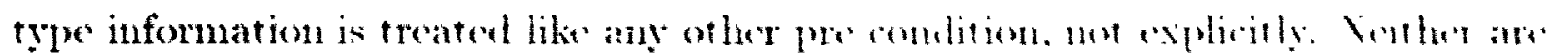

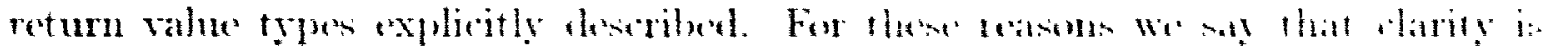
arerage. 


\subsection{Cook}

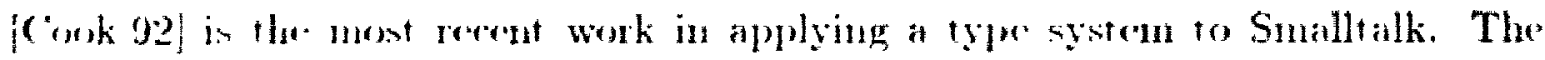

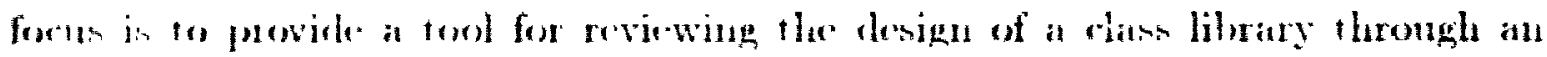

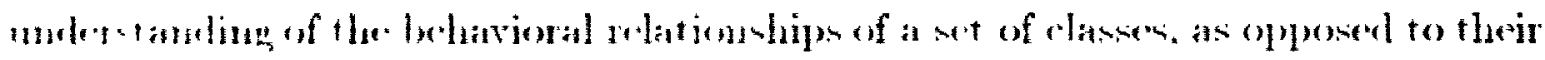
implomentition whtionships.

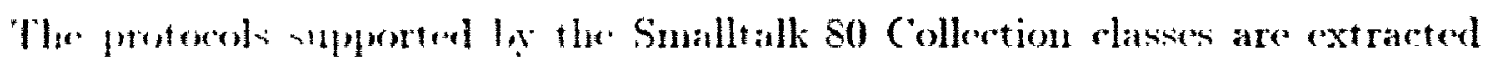

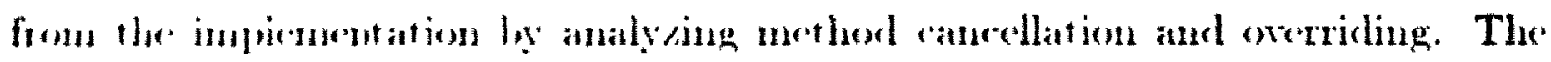

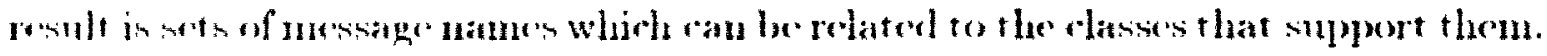

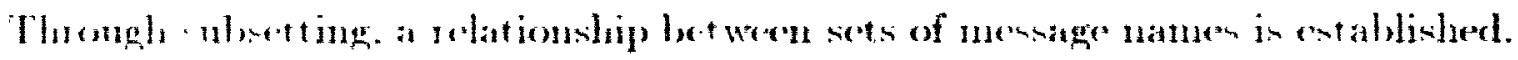

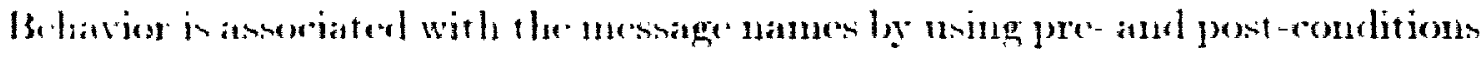

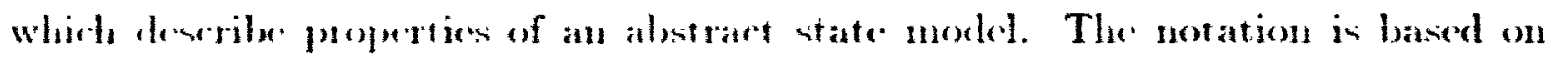
[Amolina 90]. and gesults in alternative view of the Smalltalk-80 Colletion classes

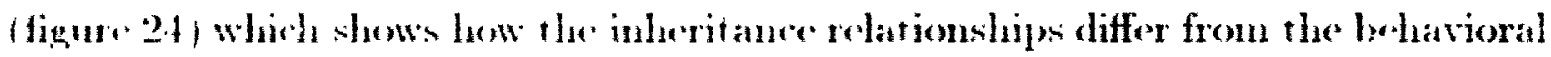

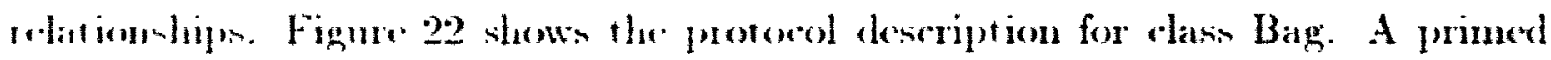
fimetion (r.g. $F^{\prime}$ ) indieaten the value of the tepresentation before the operation.

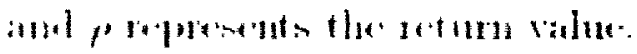

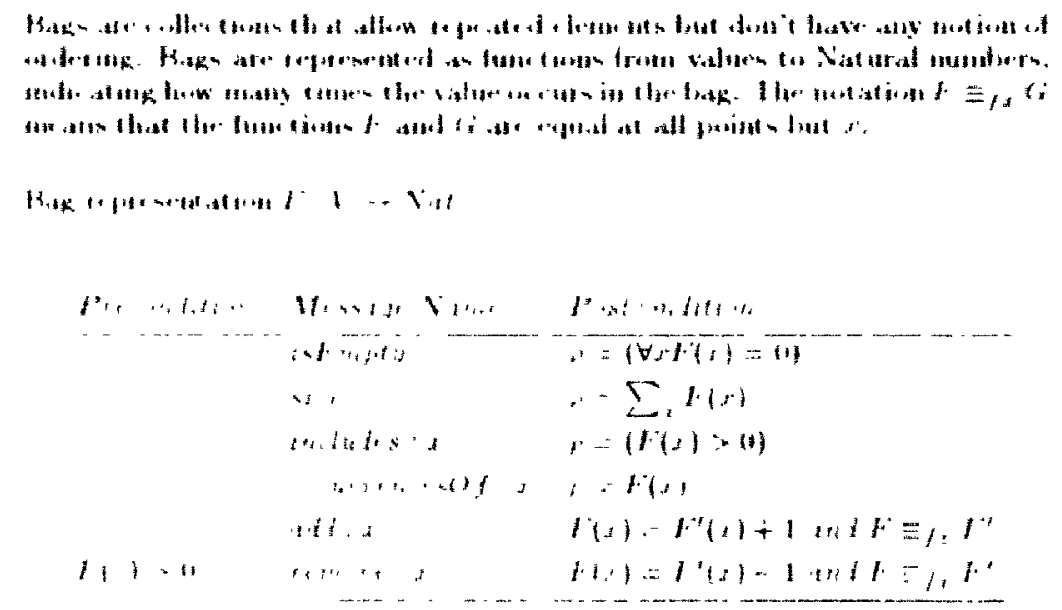

Figure 22: The Bag proworol 


\subsubsection{Group Membership}

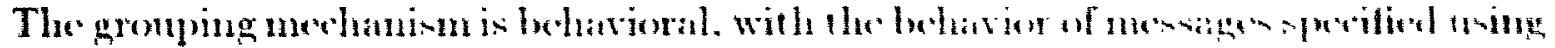

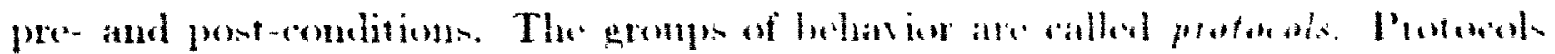

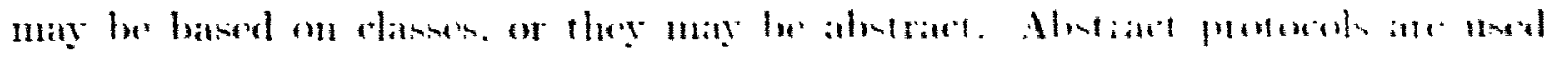

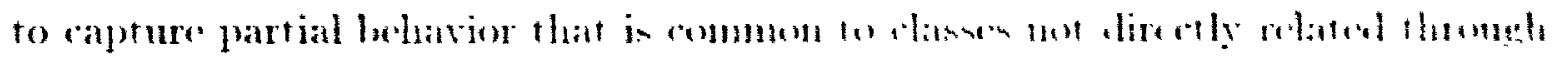
inheritance.

\subsubsection{Relationships Between Ciroups}

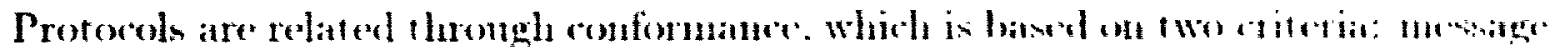

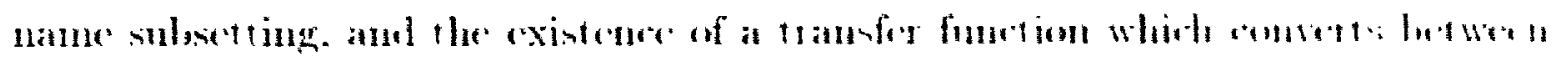

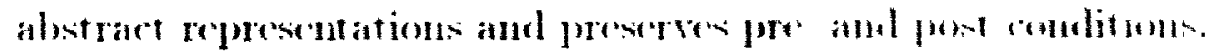

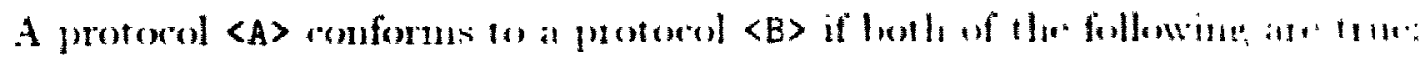

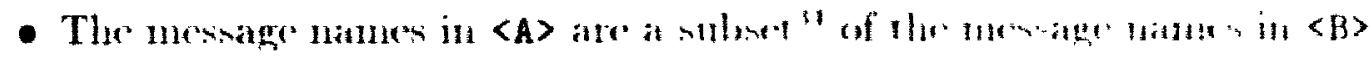

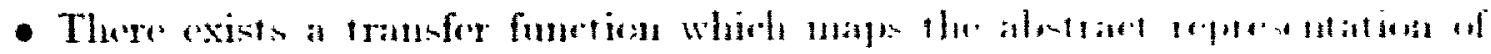

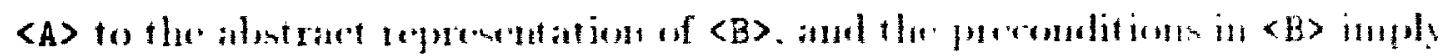

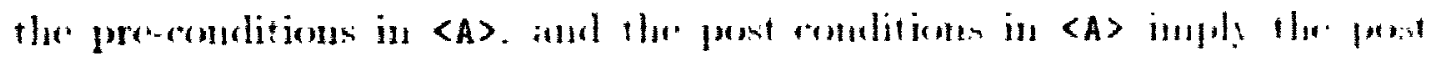
conditions in 〈B〉.

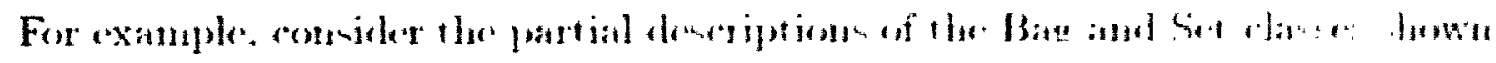

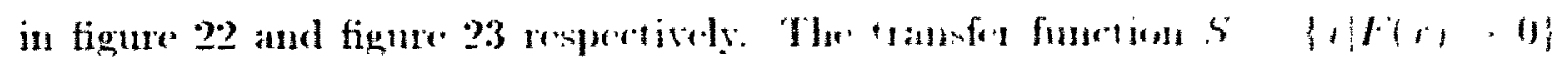

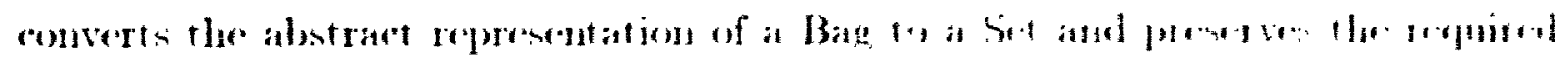
pro-and pont-condinions.

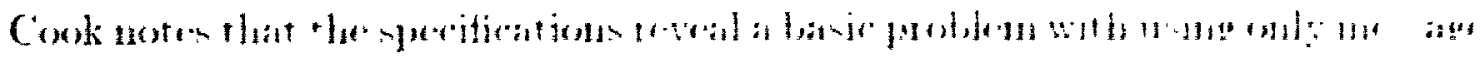

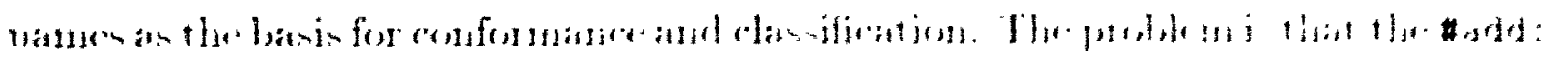

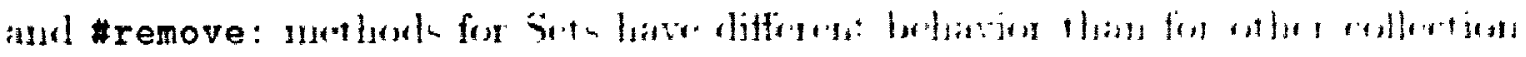

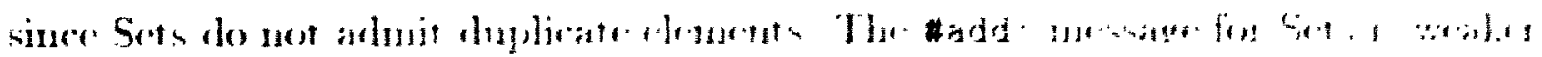

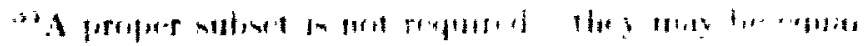




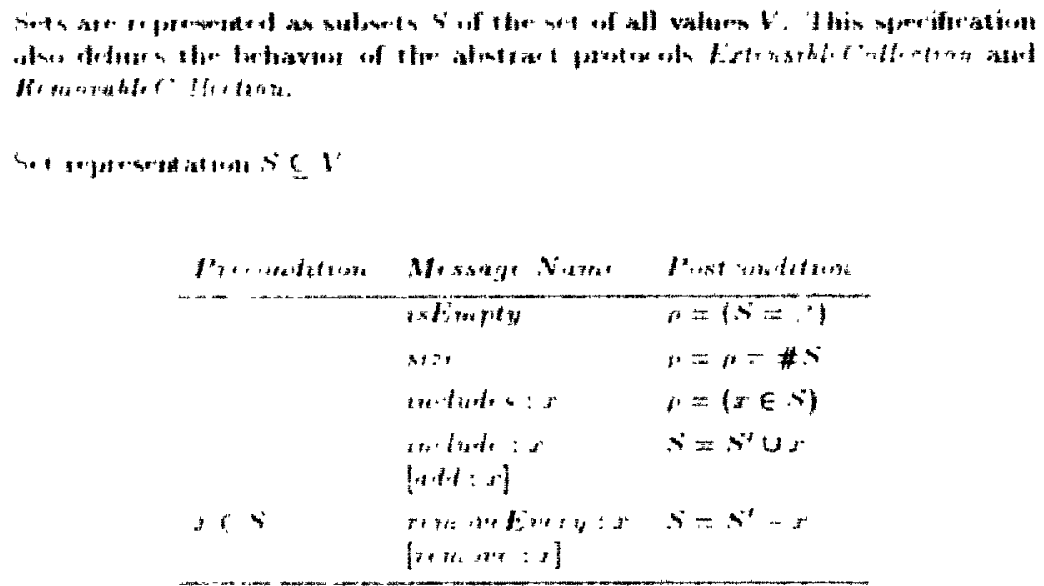

Figure 23: The Sit protocol

sine it only amsurn that the elenent is present. Cook also argues that \#remove: for Sith is aronger, since it eliminates the element eompletely. Howerer. the latter naty" be a side effect of the not ation. sine regatdless of the type of collection if there is only on' elenu'nt. *renove : diminates it complotely.

In croler to advesos the problem where messages with the same name have incompatihle behwior. Cook proposes nessige renaming where appropriate. In the ease of Sit. \#add: has lwen monmel to \#include:, and \#remove: has hern ronamod to * removeEvery : as reflected in figure 23.

The pre and post-eondition implication requirements for conformance mean conformant potorols may woaken the preconditions and strengthen post-

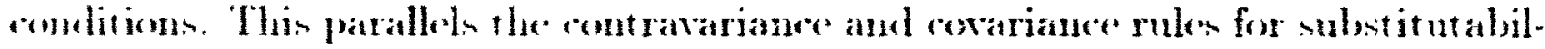

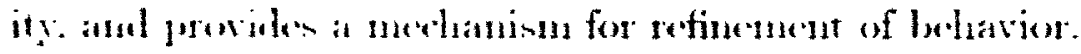

Howerer, an ingortant onnderation is that parameter and return types are dewerbed only implicitly in the abstract representations. and are not considered in stablishing the conformance rolationship. For this reason. a stubstitutability

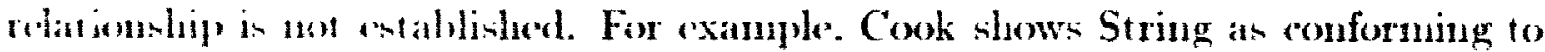
Aray and Array and Dietionary looth conforming to an IndexedCollection protocol 
which allows arbitrary key. In the former case. Strings are net mbitimtalde for

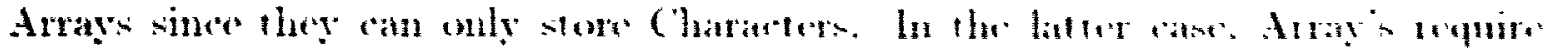

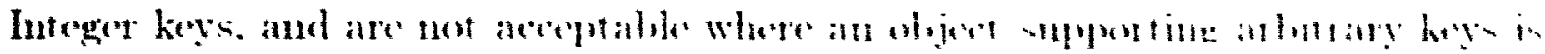
required.

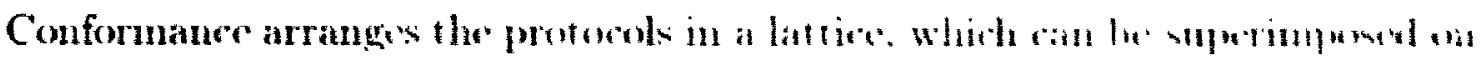

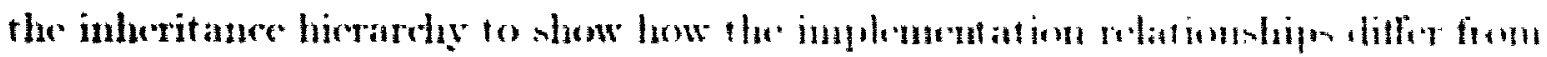

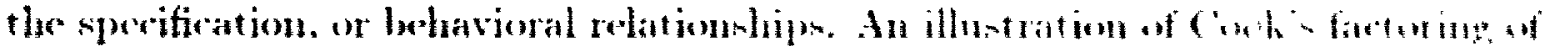

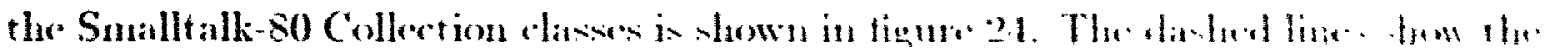

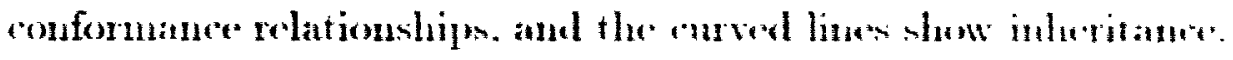

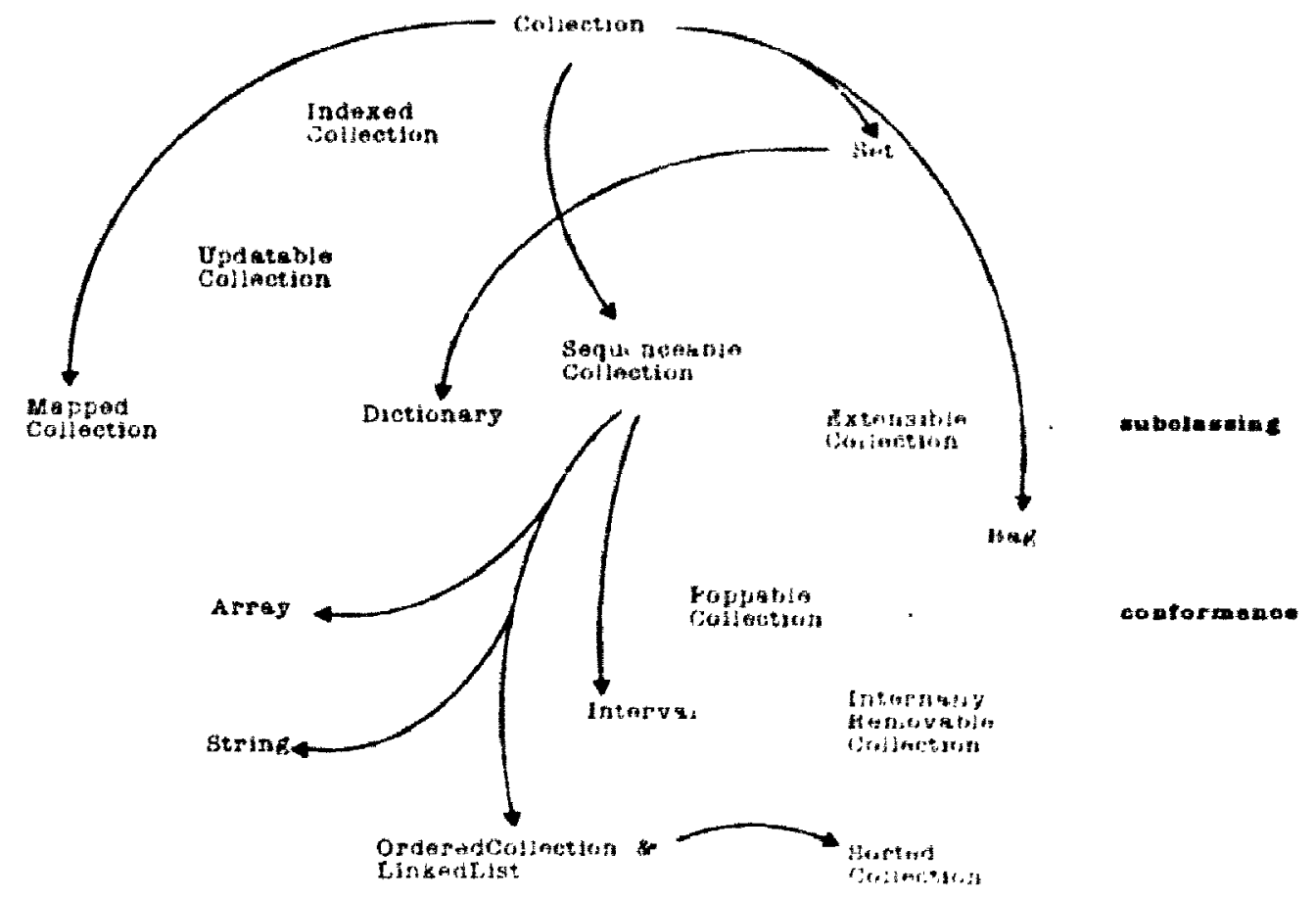

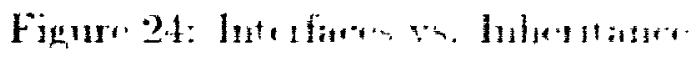

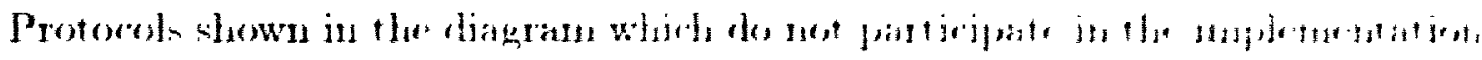

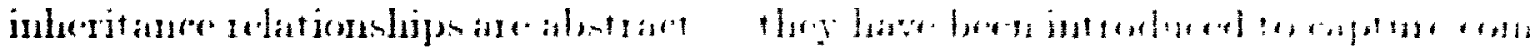

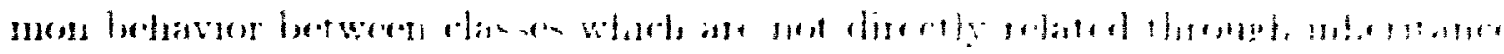




\subsubsection{Descripiton of Bohavior}

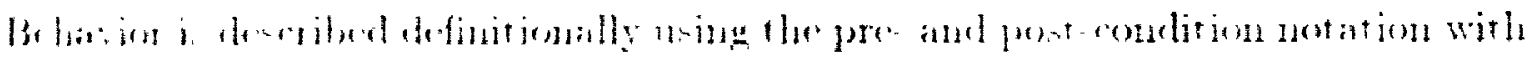

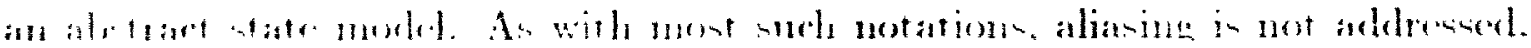

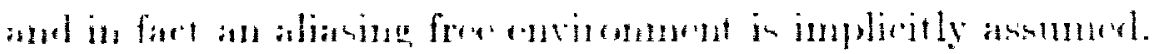

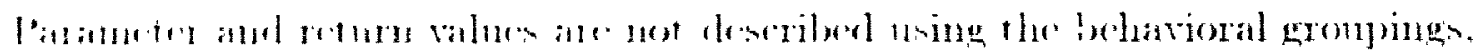

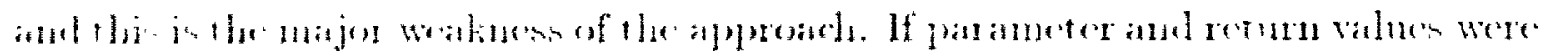

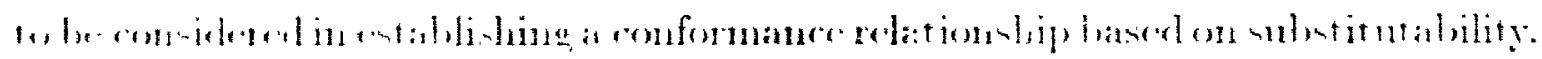

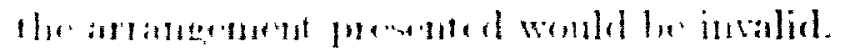

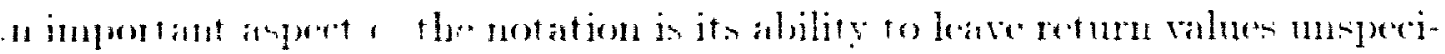

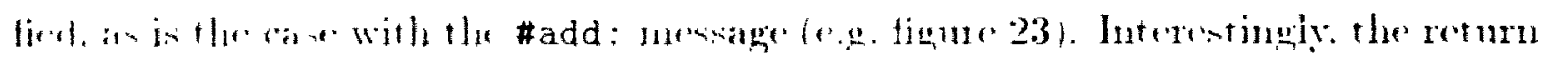

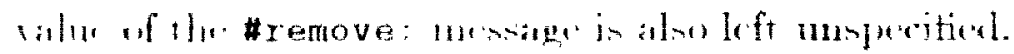

\subsubsection{Summary}

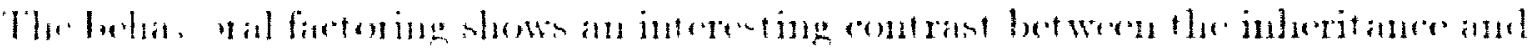

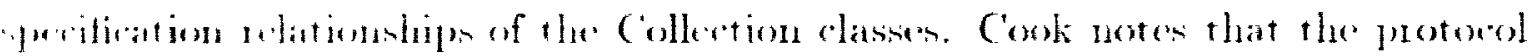

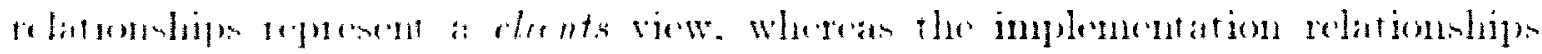

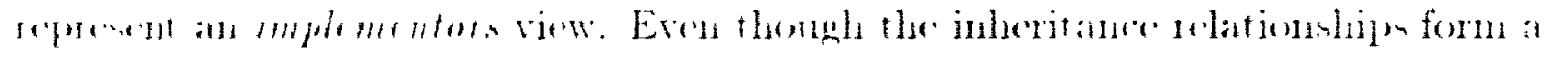

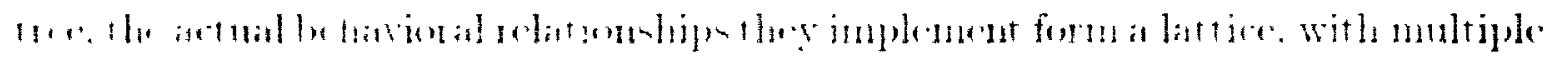

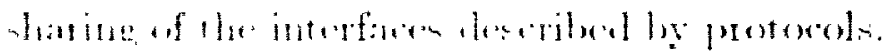

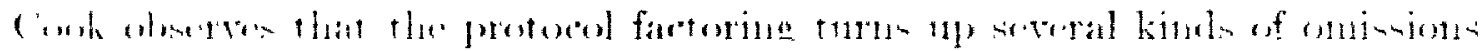

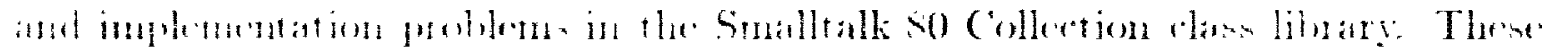
i11: :

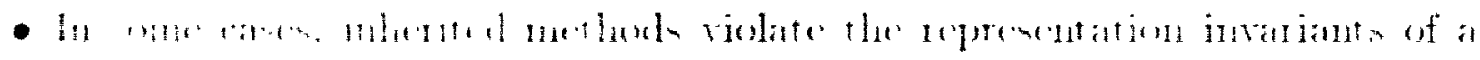

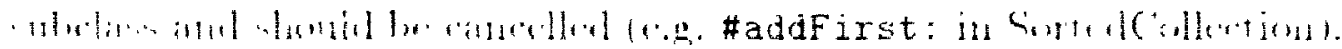

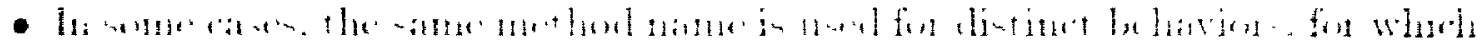

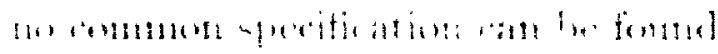

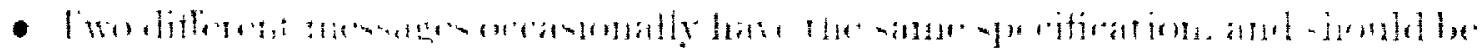




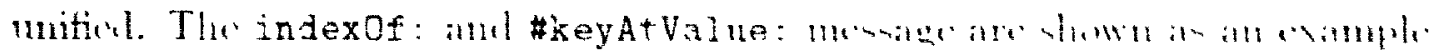

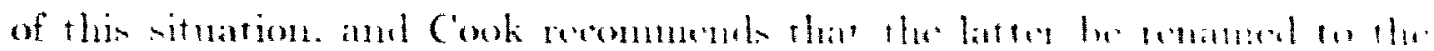
former.

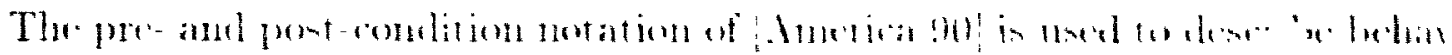

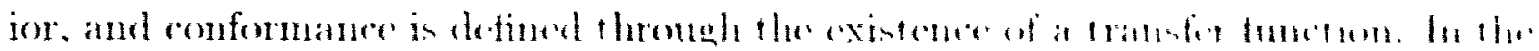

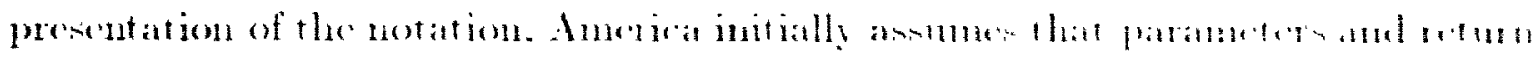

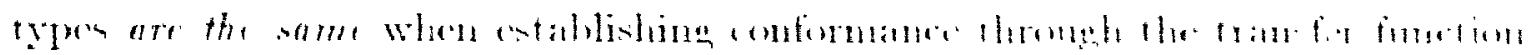

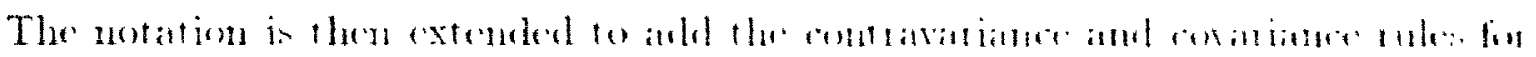

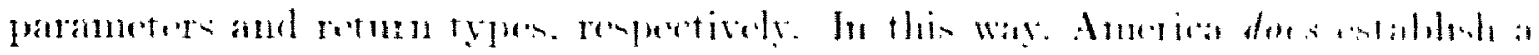

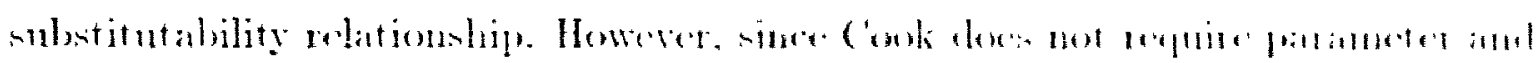

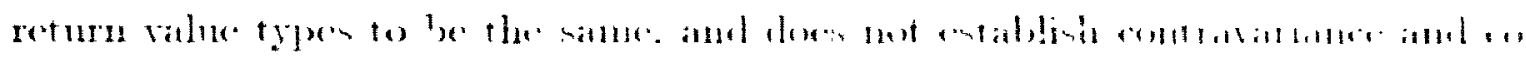

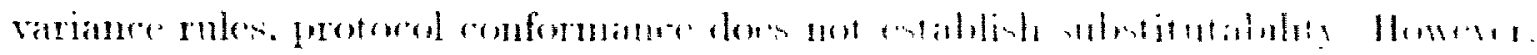

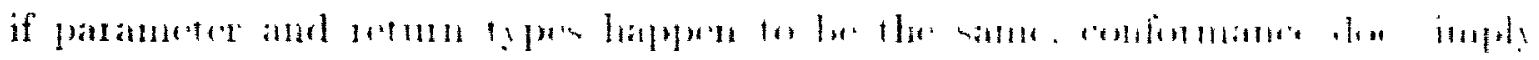
sulutitutability.

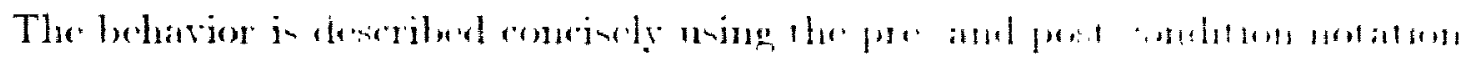

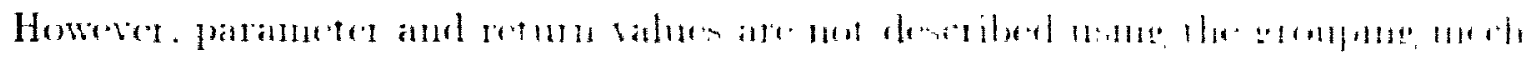

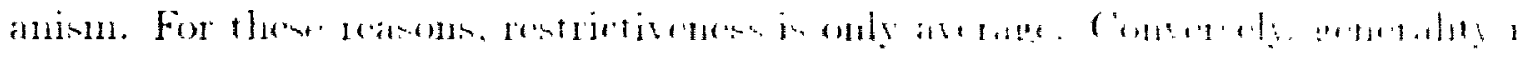

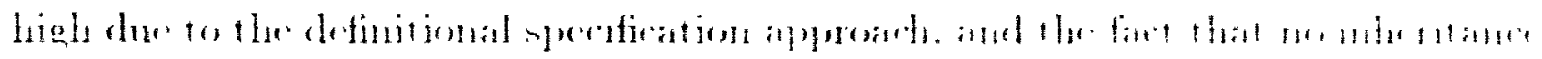

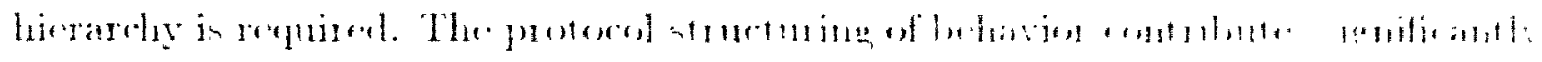
to dat ity Howerere an

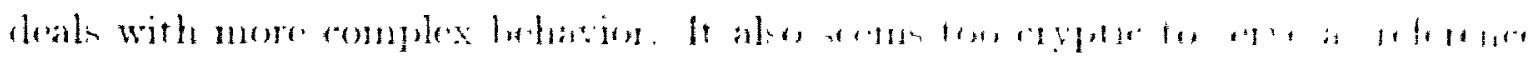

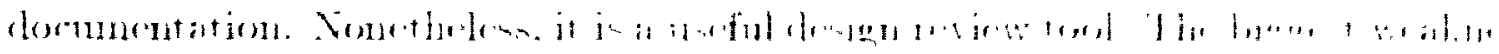

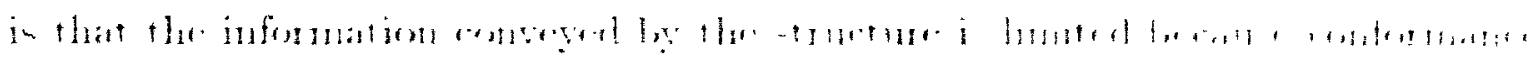

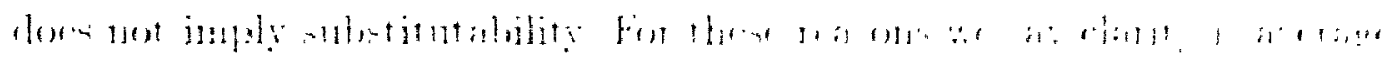




\subsection{Summary}

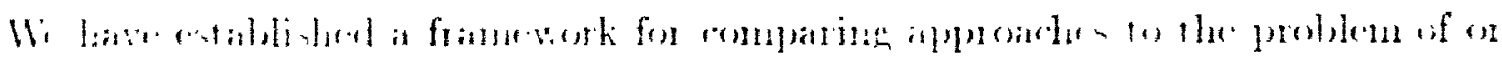

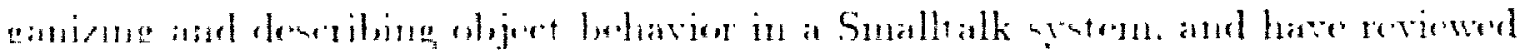

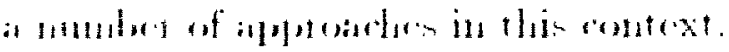

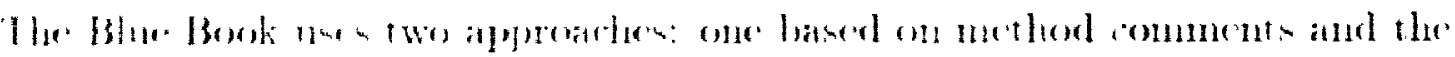

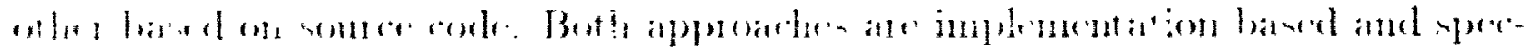

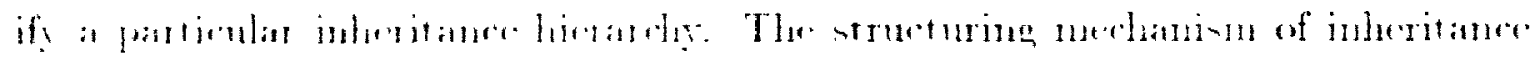

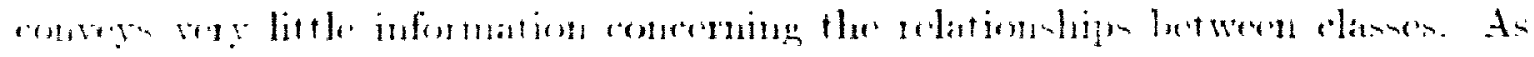

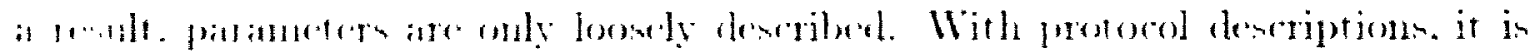

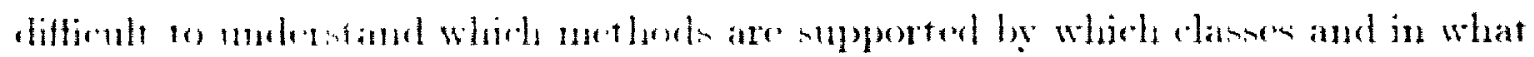

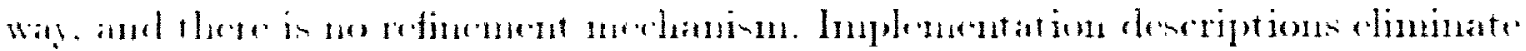

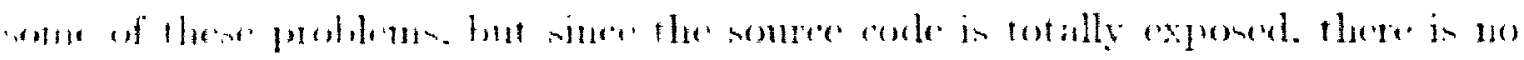

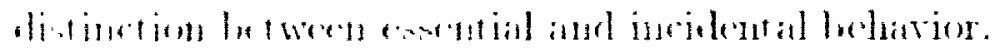

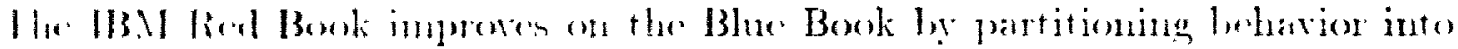

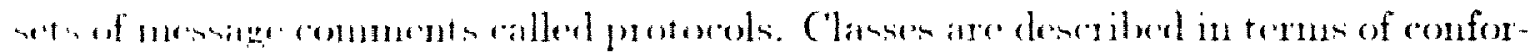

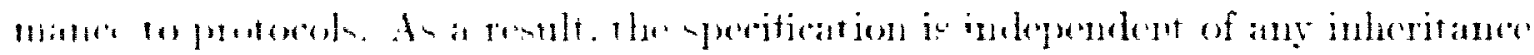

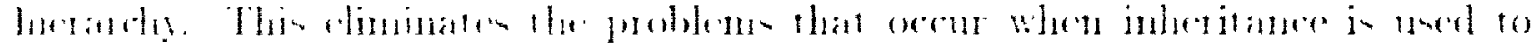

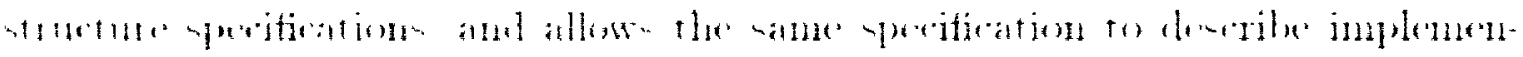

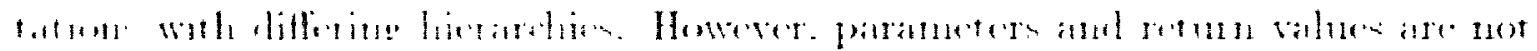

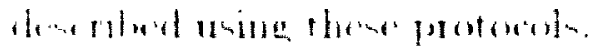

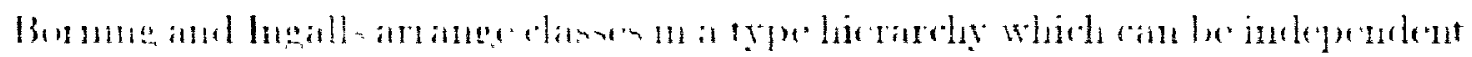

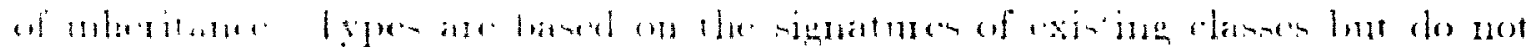

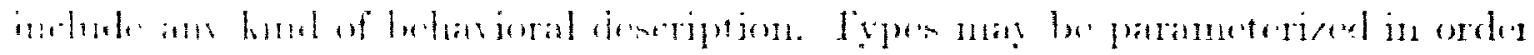

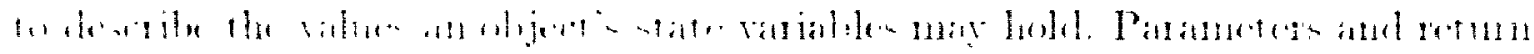

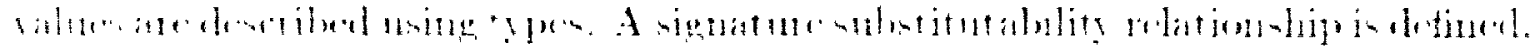

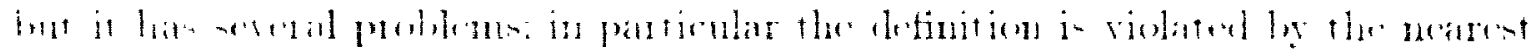

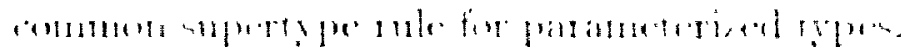

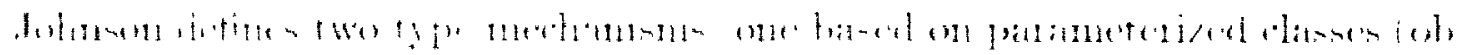




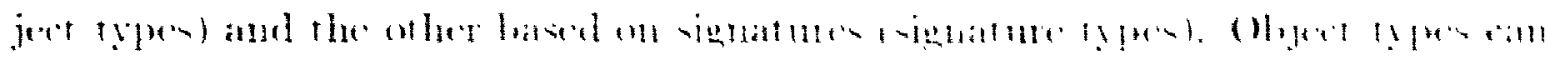

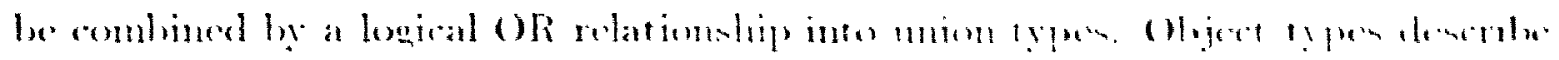

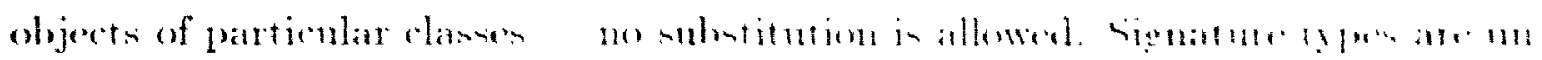

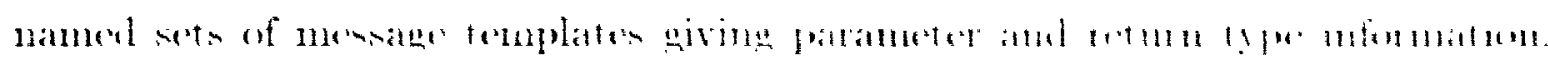

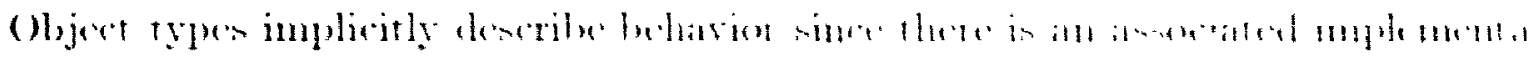

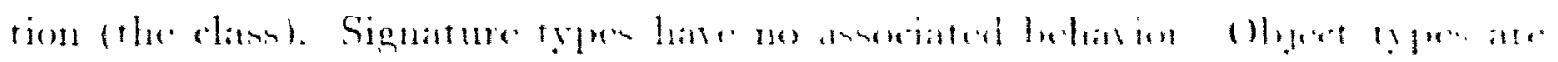

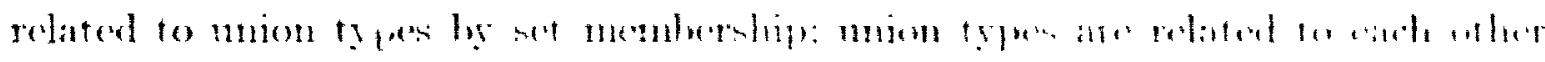

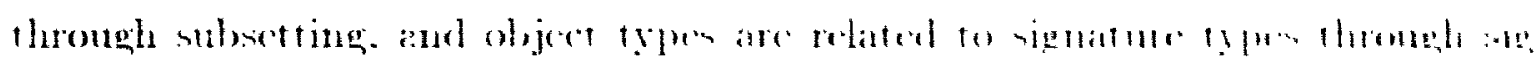

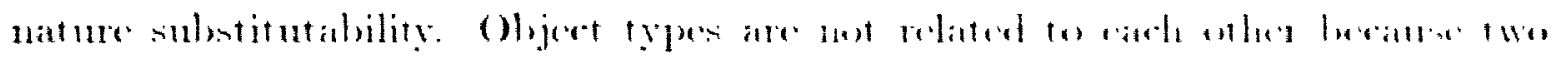

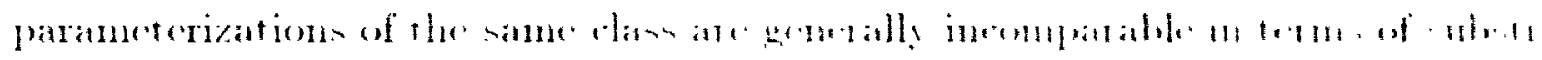
tutalility.

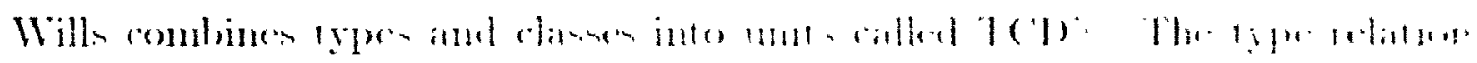

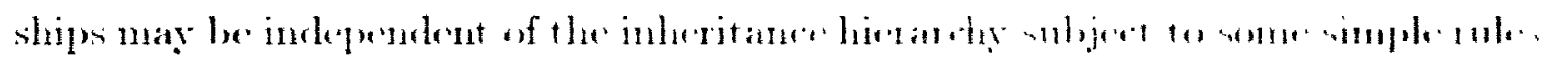

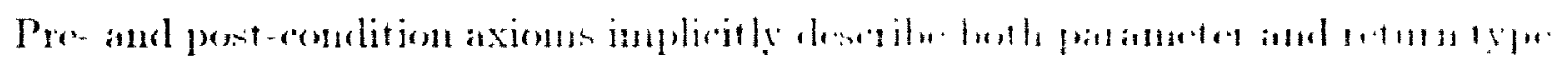

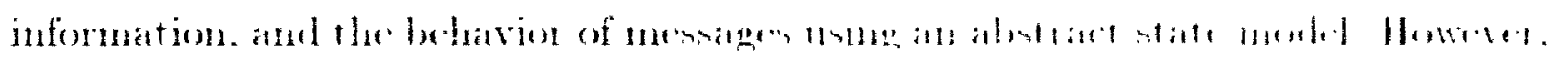

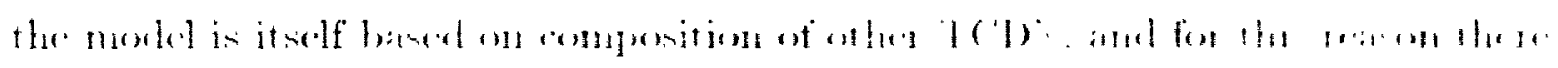

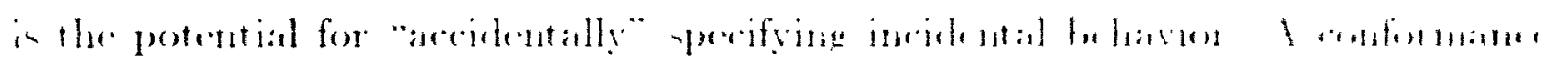

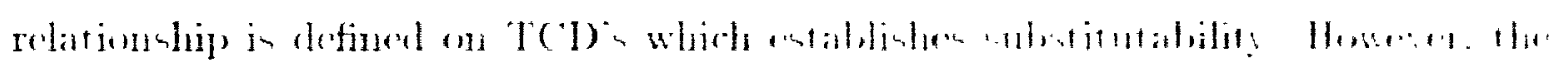

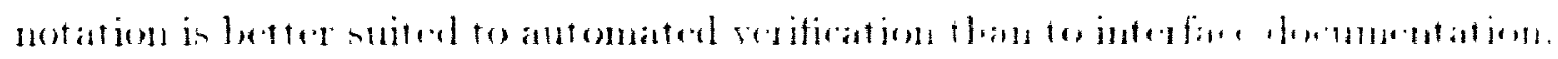

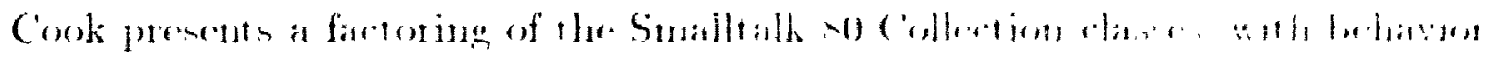

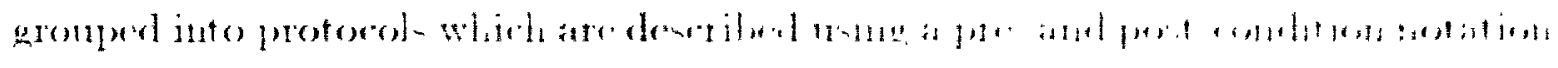

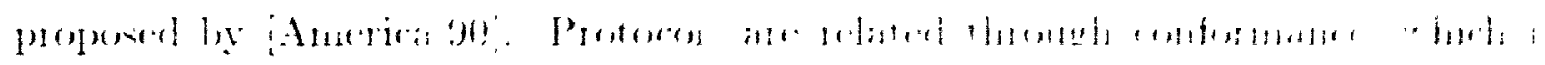

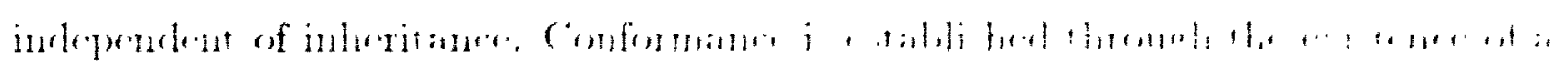

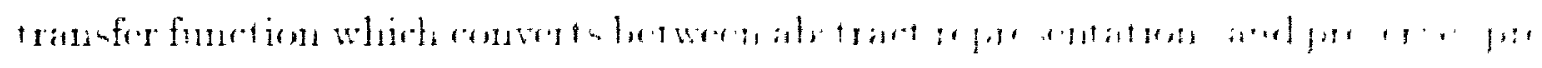

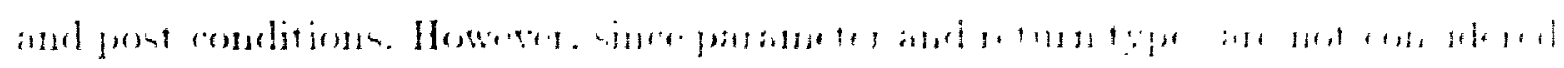

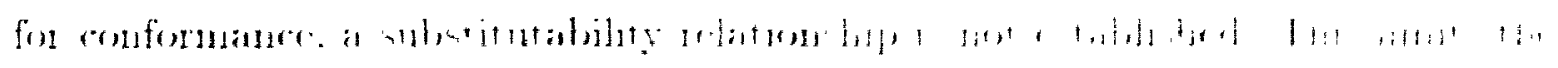

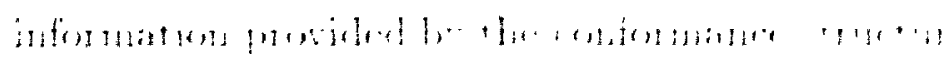

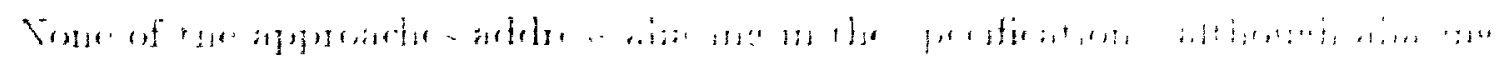




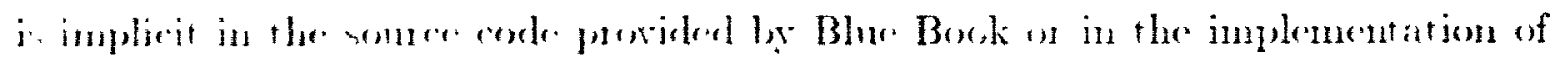

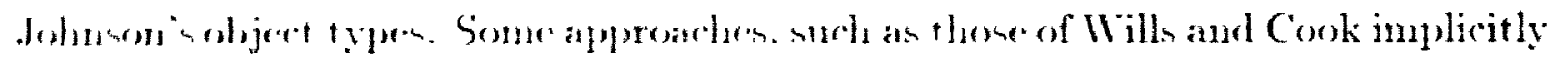

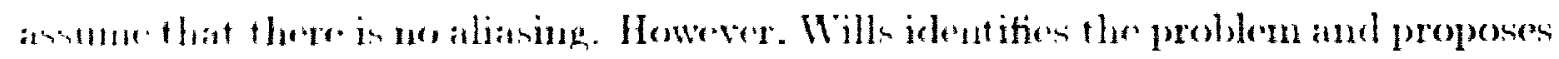

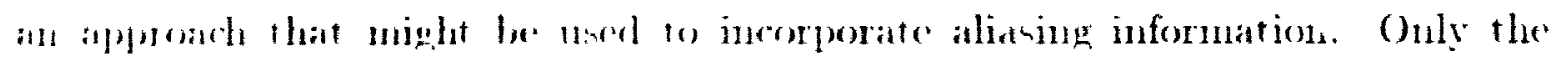

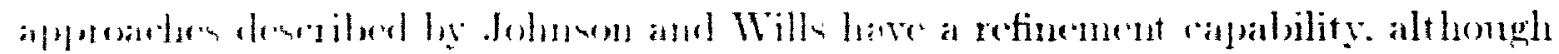

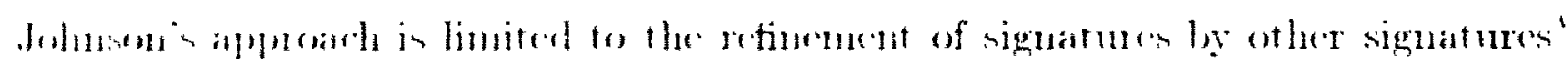

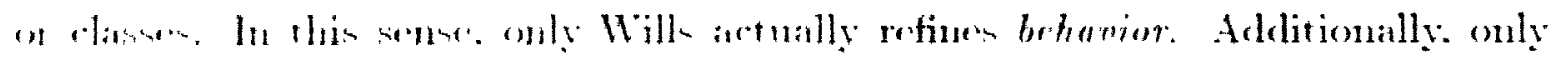
Johum and Wills entablish substitutability. Finally. only Juhuson has the ability

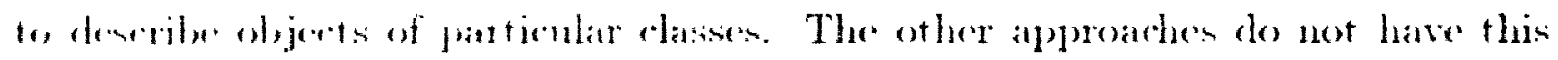

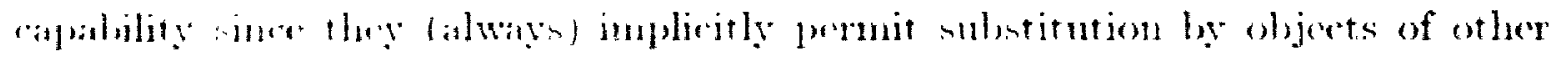
nlasm. 


\section{Chapter 3}

\section{The Protocol Model}

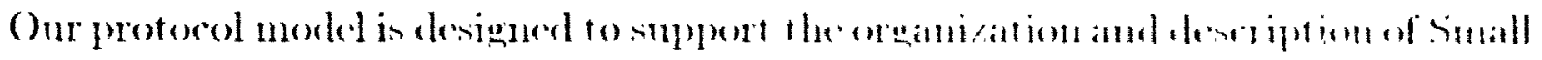

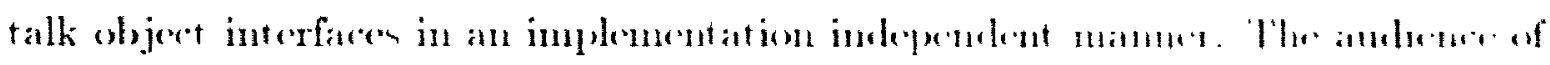

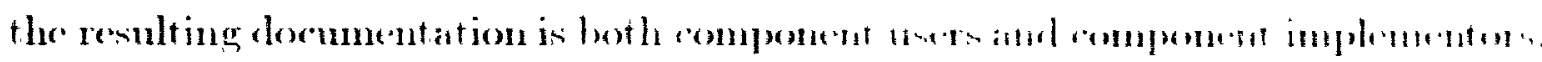
The protorol moskel is intended to foe ned in the followines ways:

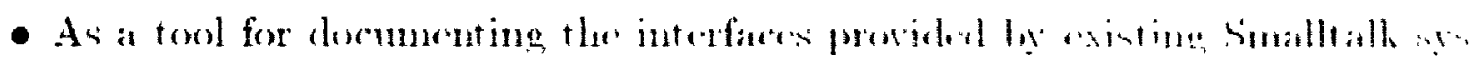

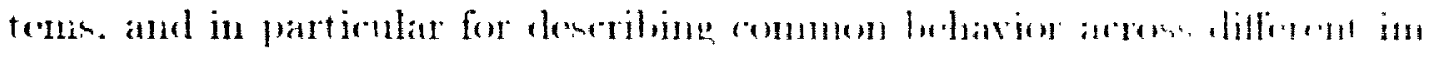
plenentations.

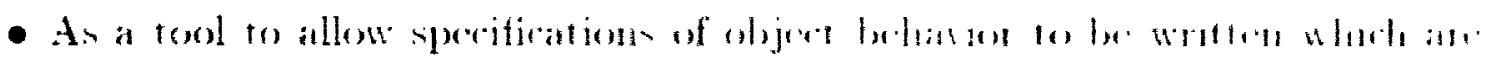

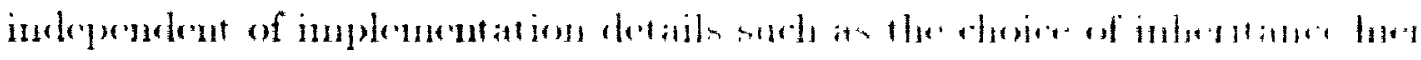
archies or other incidestal diffirences.

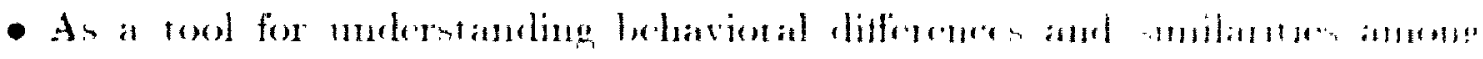

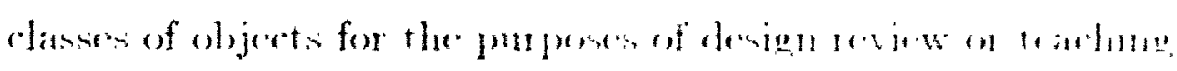

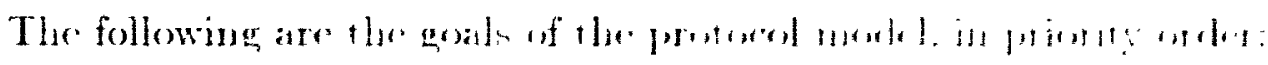

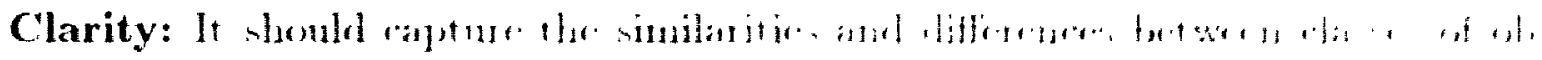

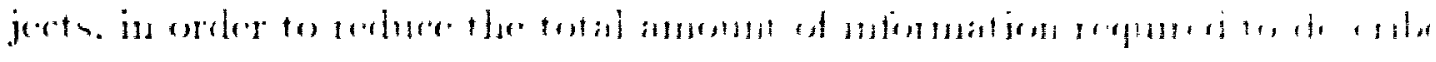

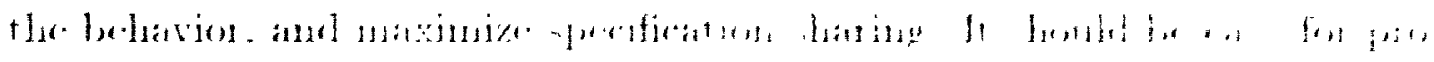

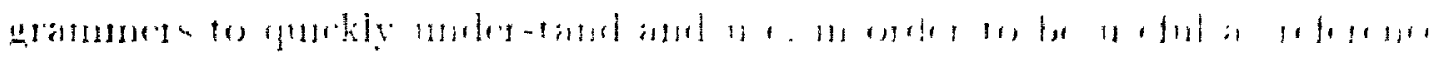
formututiting 


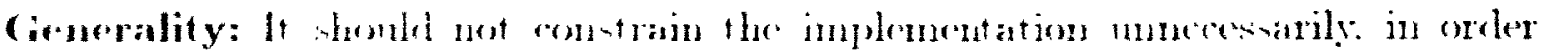

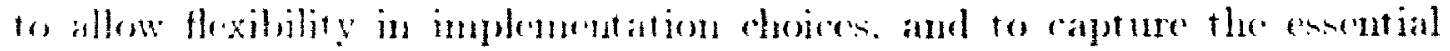
sindarities antong different risting inplemontations while allowing incident al

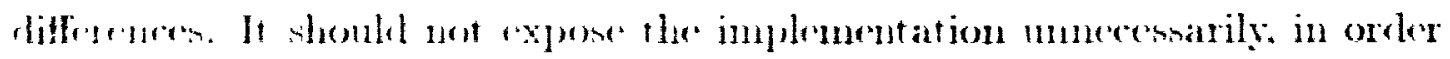
w prenent rient applications from making use of incislental behavior which naty lo whloget to duanger.

Restrictiveness: It shond dempile the behavor in suflecient detail to allow both

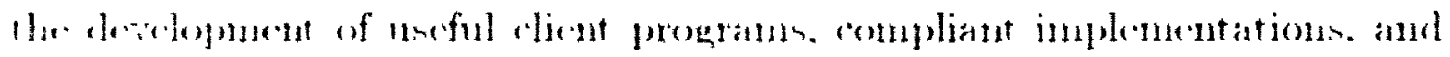
indepentent test ande.

\subsection{Organization of Object Behavior}

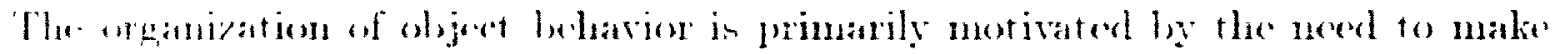

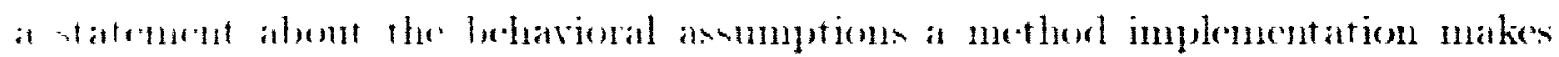

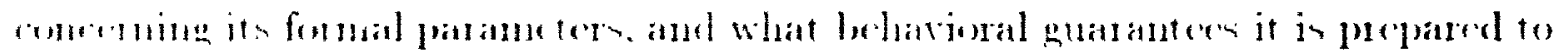

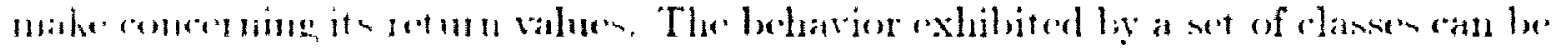

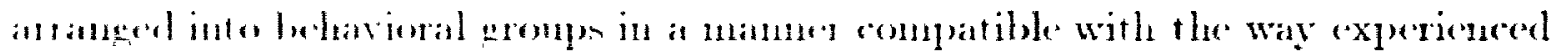

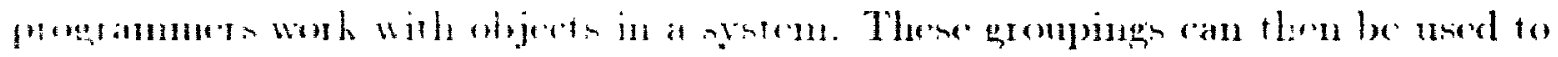

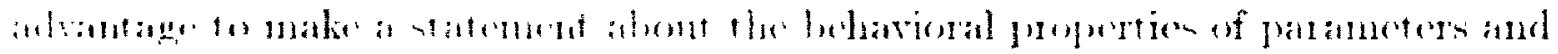
netmin sillin.

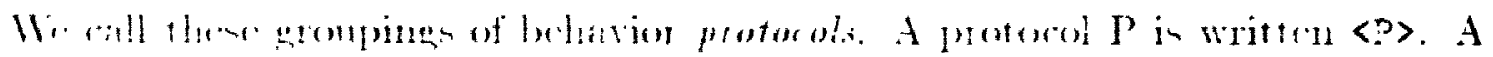

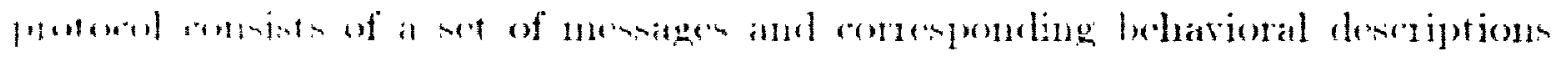

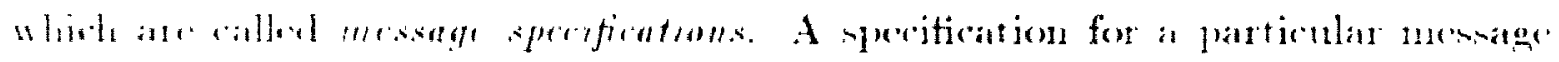

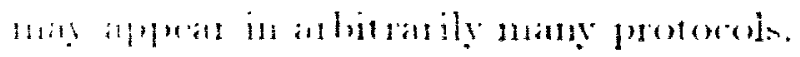

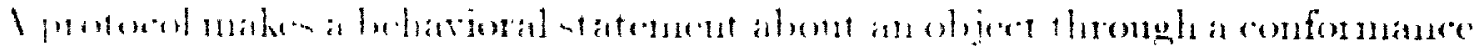

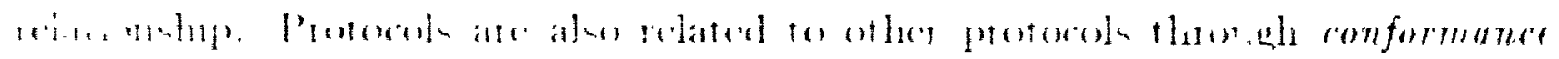

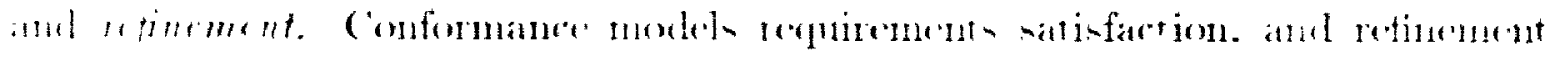

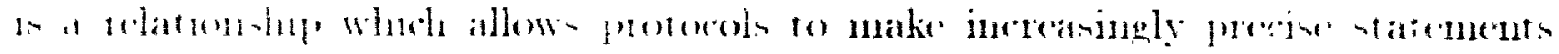

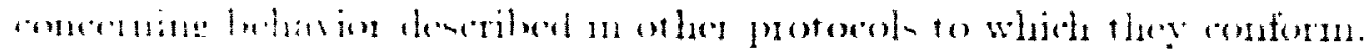




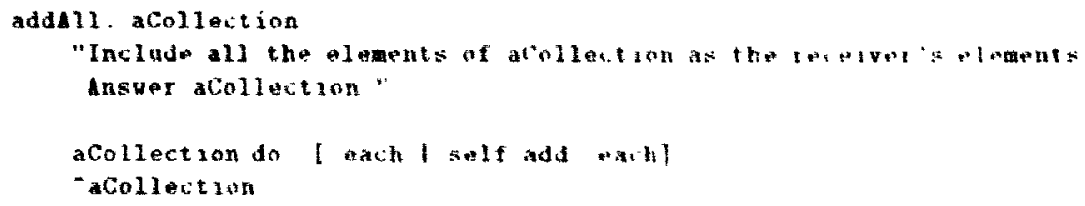

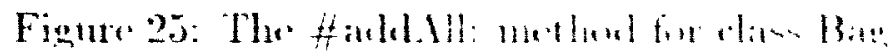

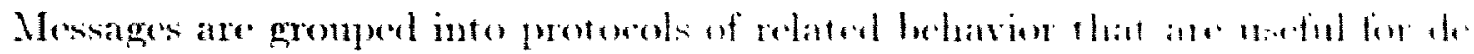

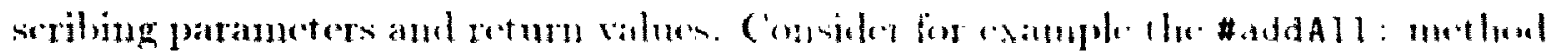

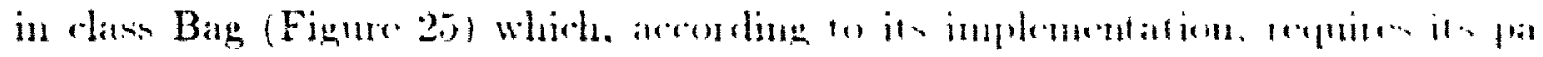

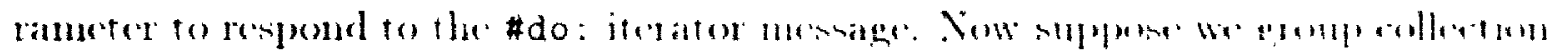

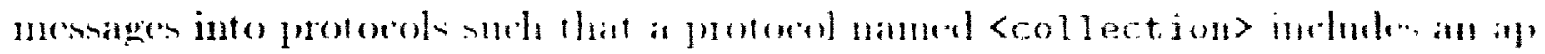

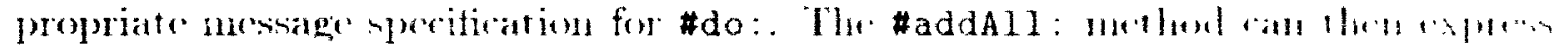

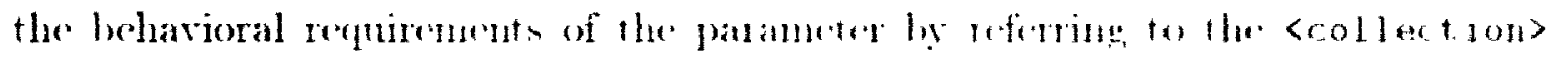
protorol.

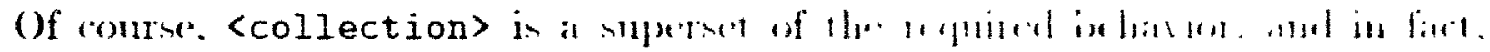

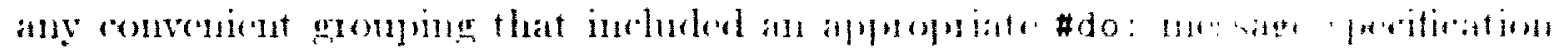

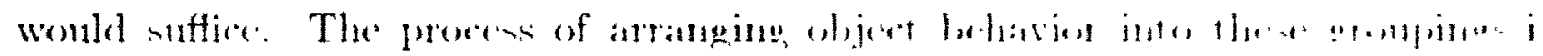

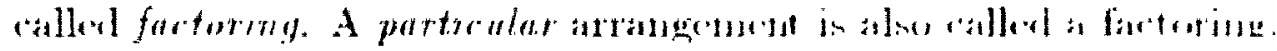

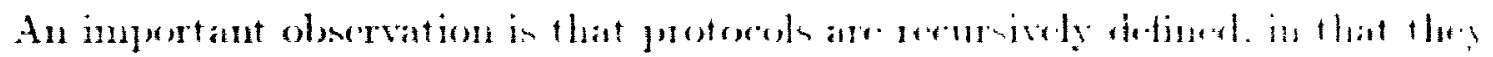

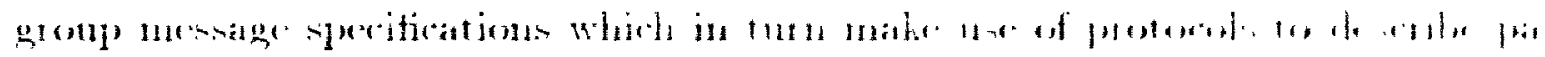

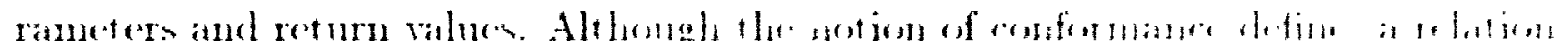

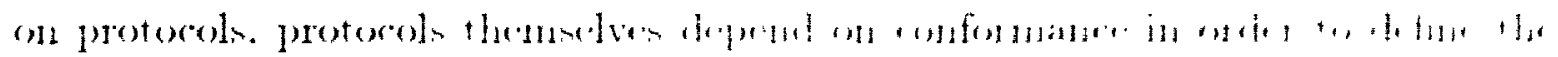

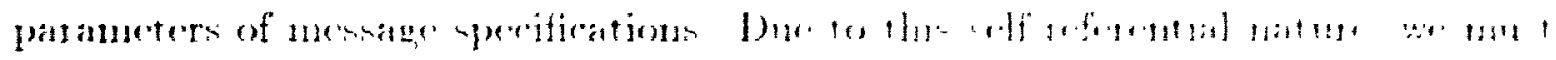

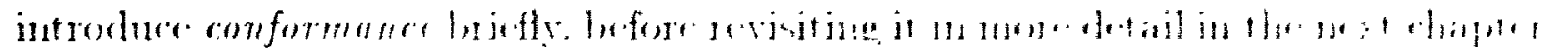

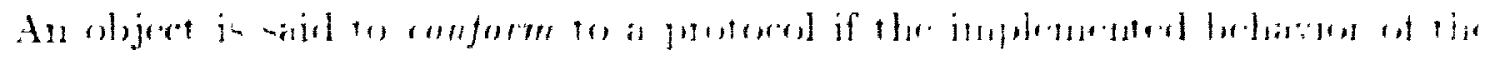

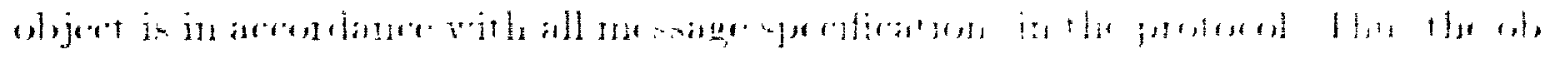

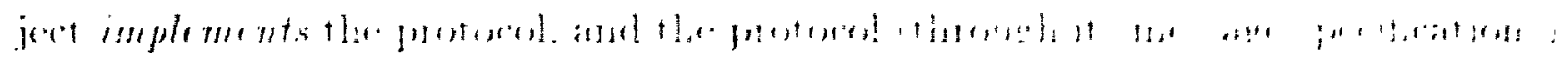

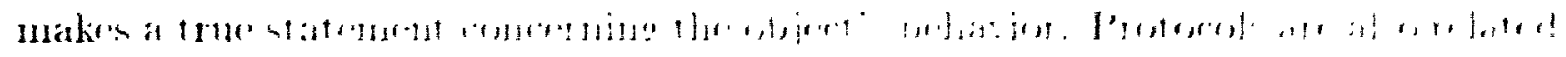




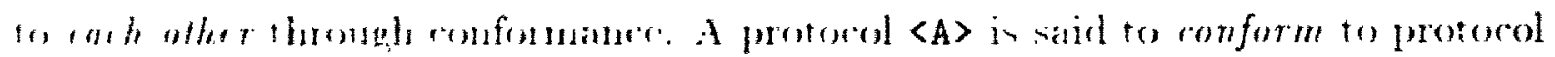
$\langle B\rangle$ if all whjort whinh anform $u\langle A\rangle$ aluo conform in $\langle B\rangle$. The next sections

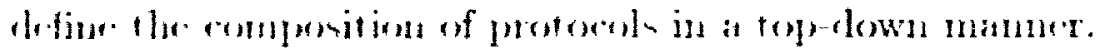

\subsection{Protocols}

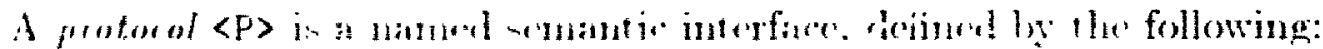

- A glomsing of tormus.

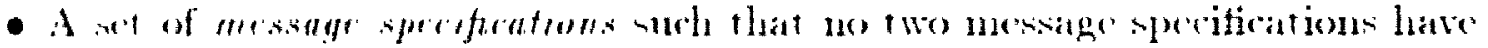
the surne mestege stretor,

The glossory of terms defines terminology that is used by the message speri-

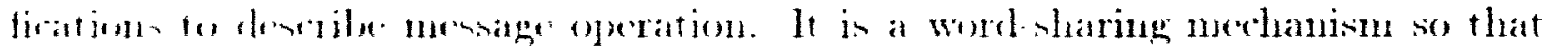

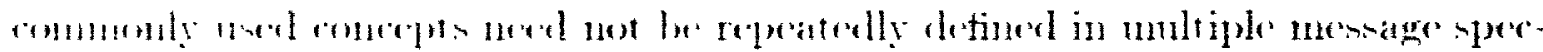

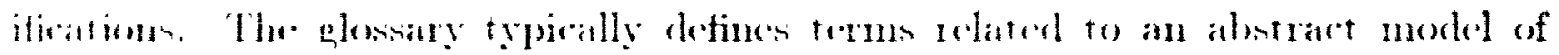

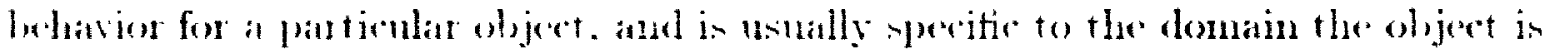
alphlinel to.

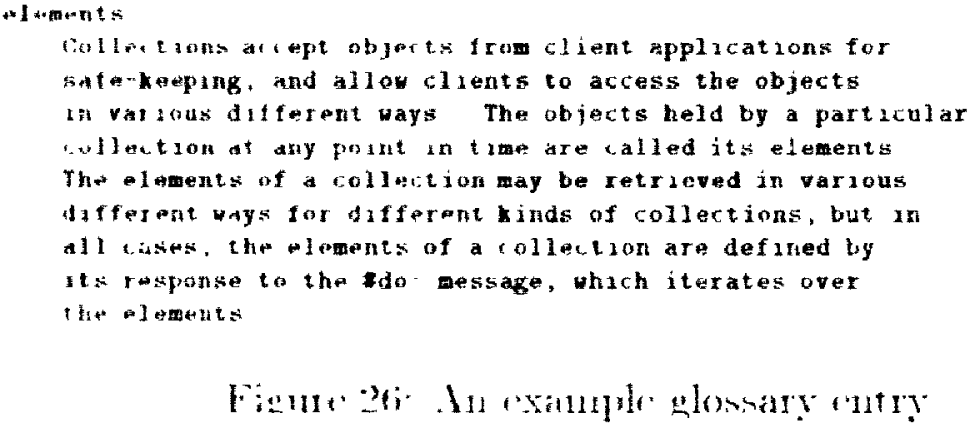

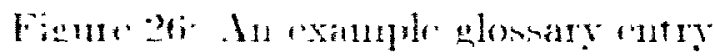

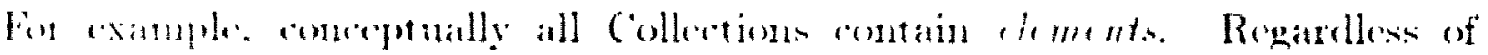

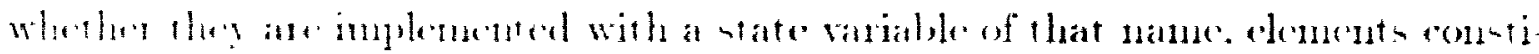

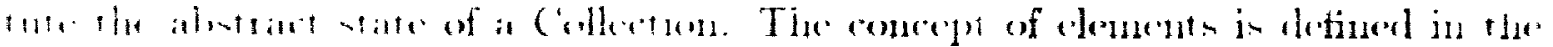

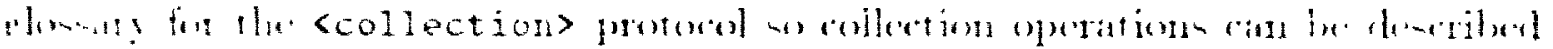




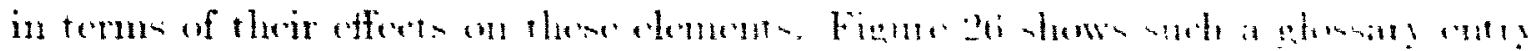

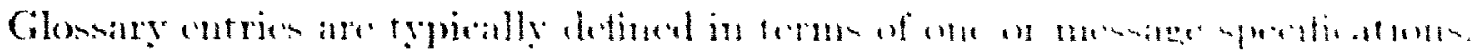

\subsection{Message Specifications}

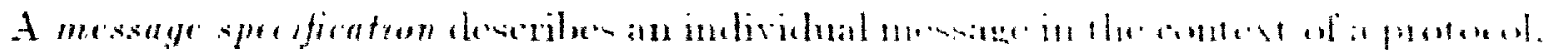
and is tetined ly the followint:

- Anematgereloctor.

- A set of paraneter yeritiontions.

- A set of return value speritiontions.

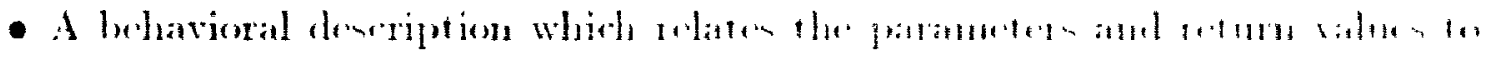

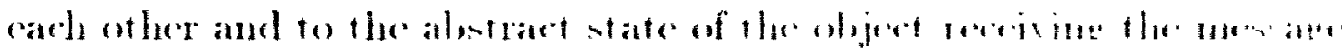

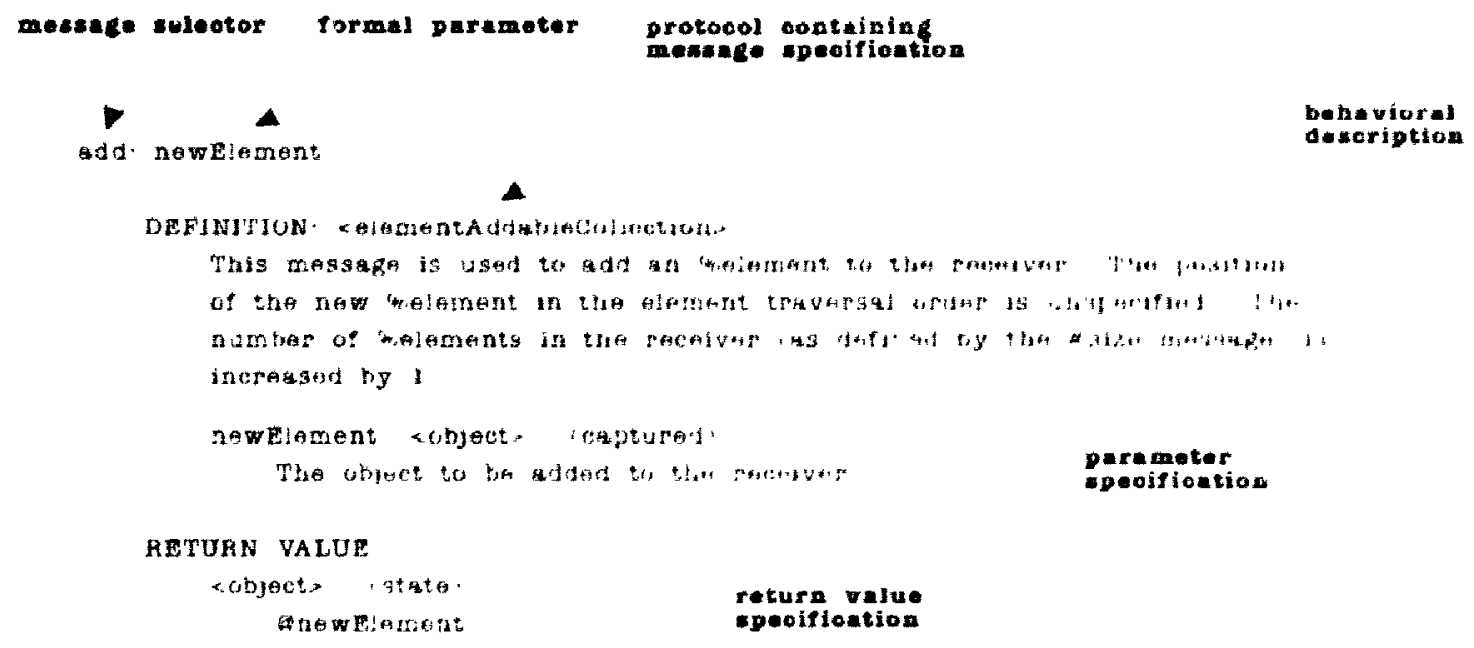

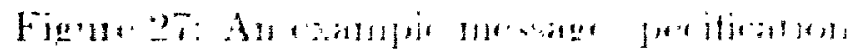

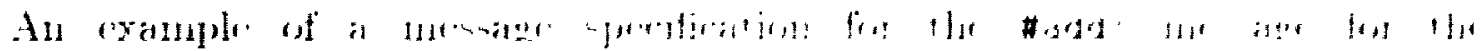

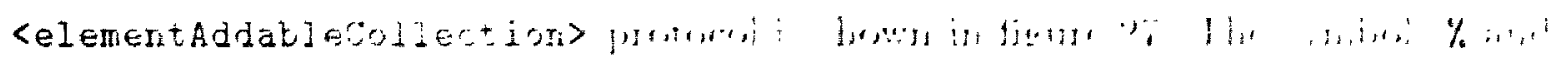
O 


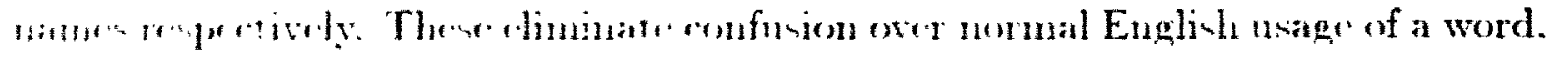

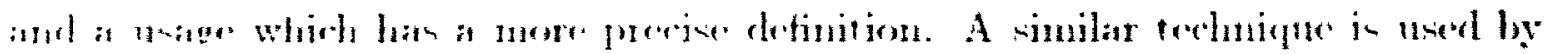

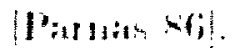

A mentage siperitiontion has no semantic meaning outside of the rontext of a

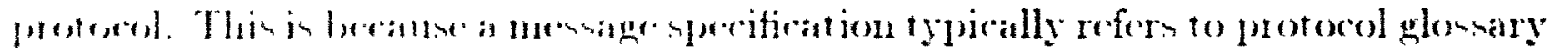

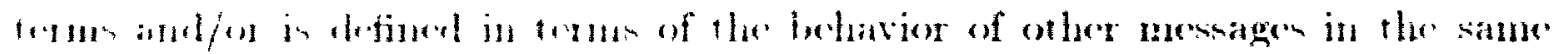
[intrined.

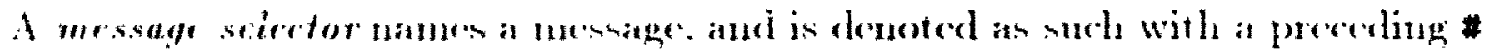

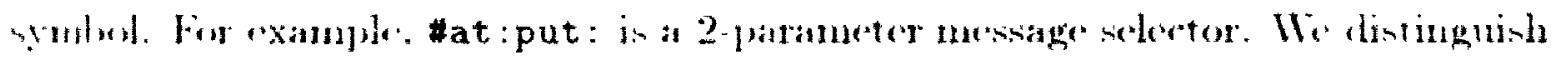

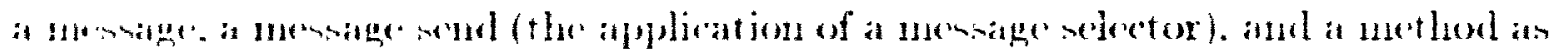
followe:

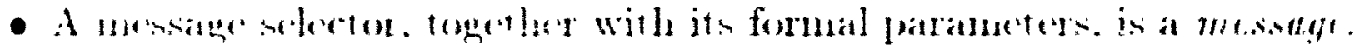

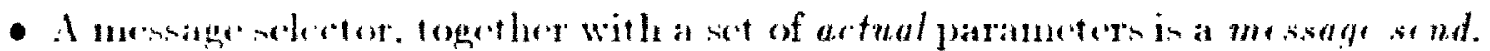

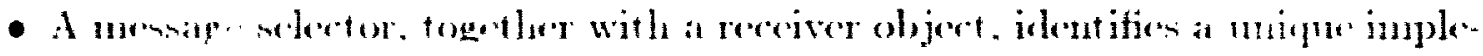
meditation of the meshage tat method).

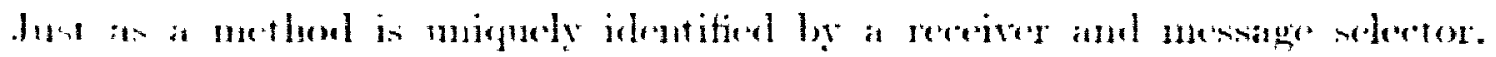

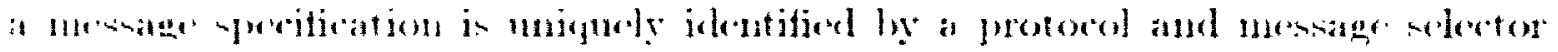

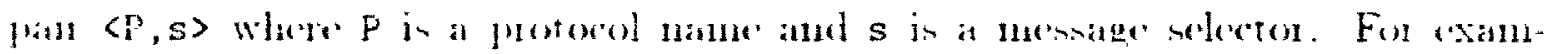

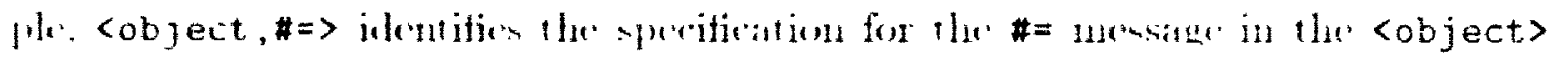
111110.1. 


\subsection{Parameter Specifications}

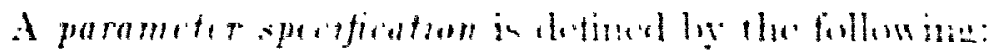

- A paramerer namir.

- A trextual rencription.

- A paramerer interfire definirisu.

- A parameter aliasing, attributr.

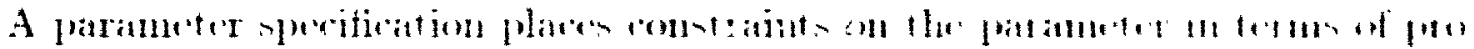

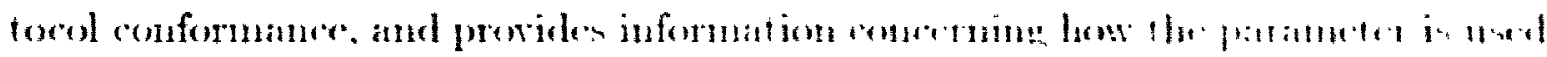

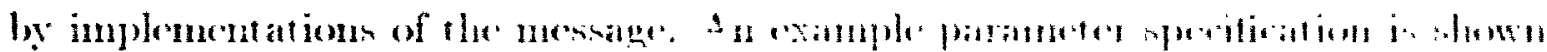
in figure.2S.

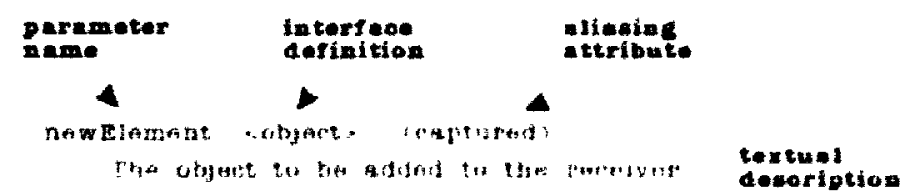

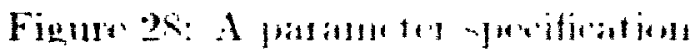

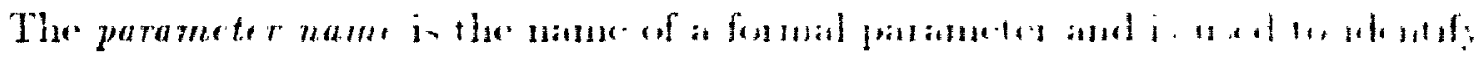

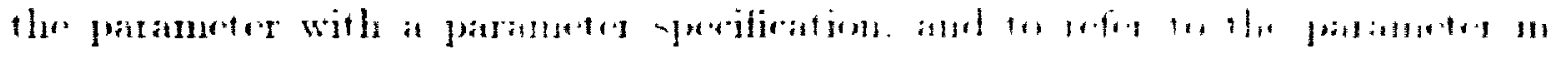
textmal dencriptinens.

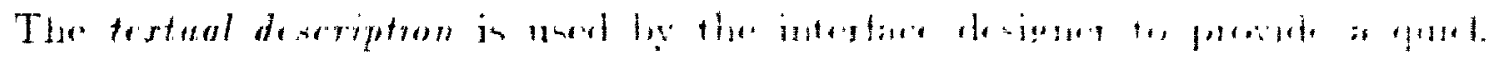

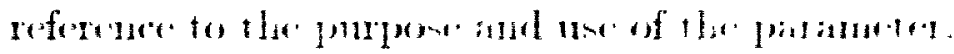




\section{4.i Parameter Interface Definitions}

A parameter unterfoce defintion is defined as ather of the following:

- A single protured name $\langle P\rangle$.

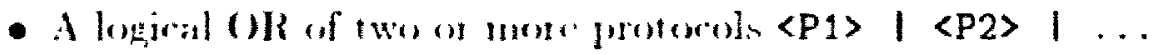

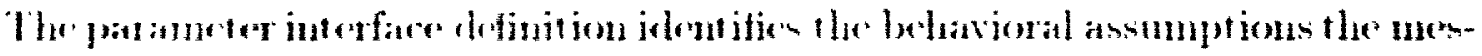

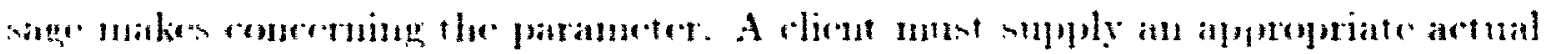

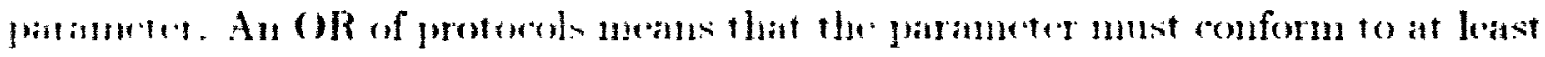

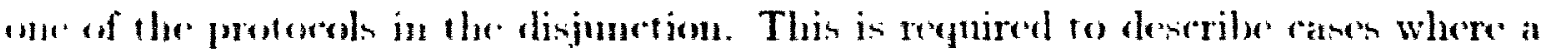

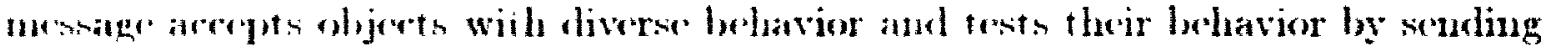
mensues in ofder to delemine the action to be taken." Sote that this is differ-

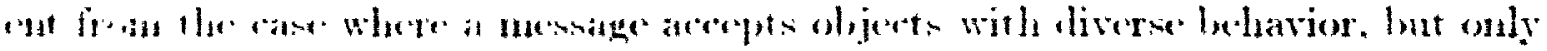

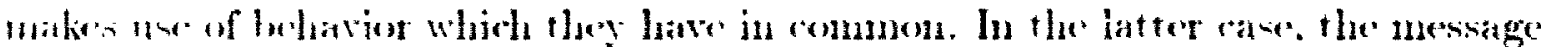
in wot really draling with diverse rases of belation.

It is important to notice that when a message spereitien that a given formal

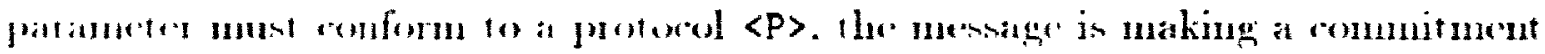

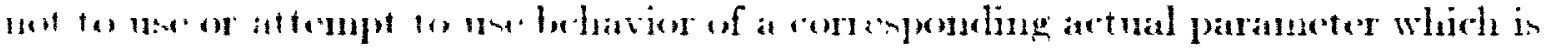

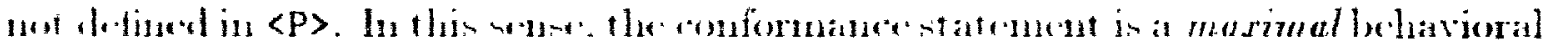

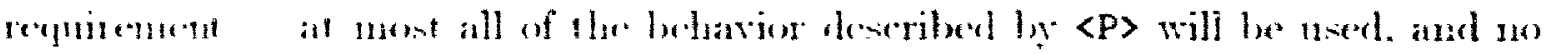
nitire.

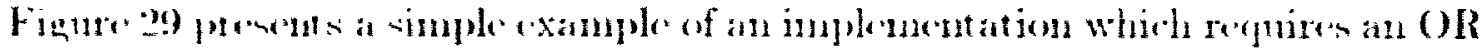

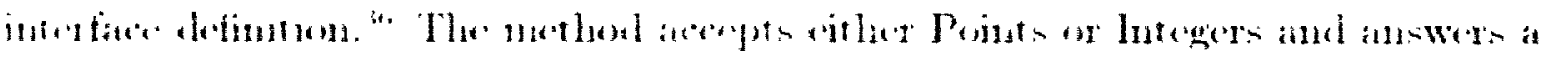

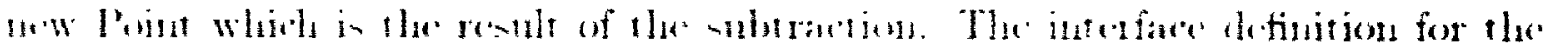

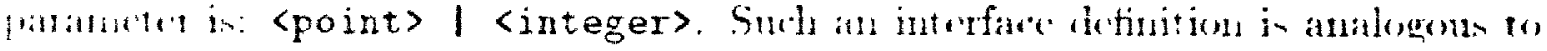

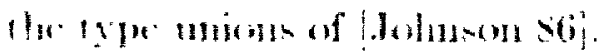

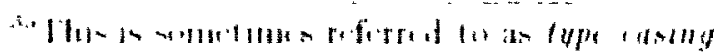

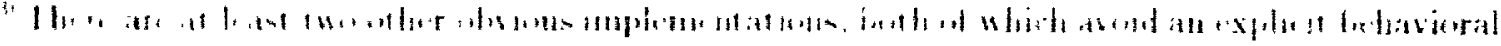

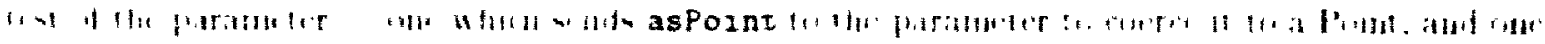

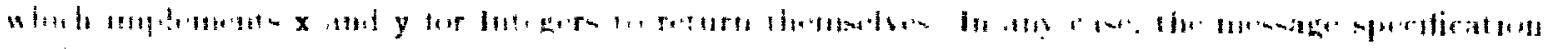

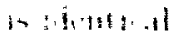




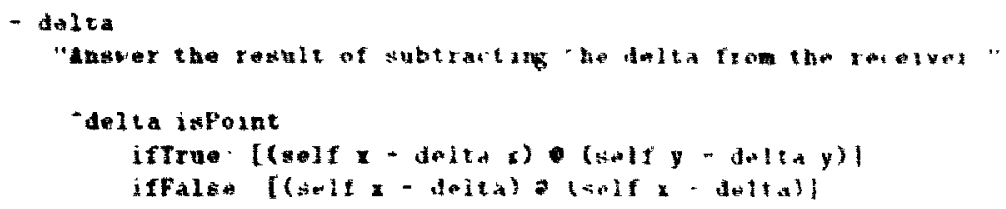

Figure 29: The it uxthen foun cim lione

\subsubsection{Parameter Aliasing Attributess}

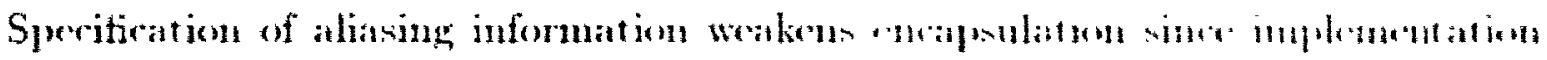

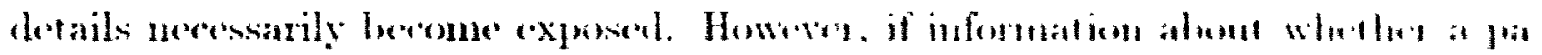

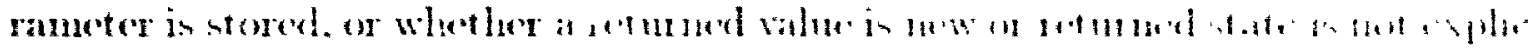

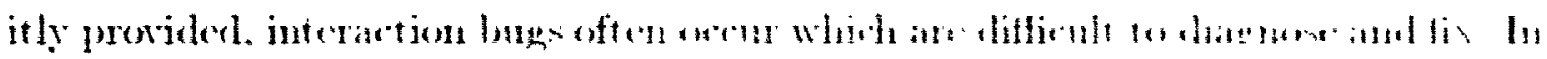

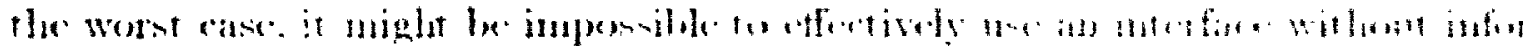

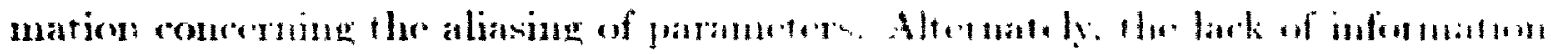

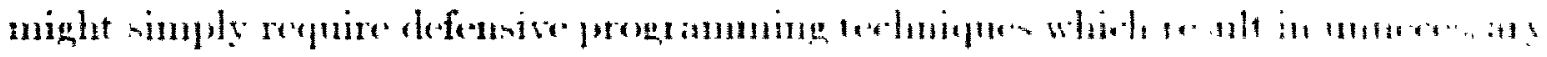

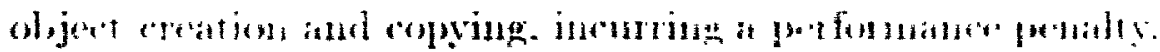

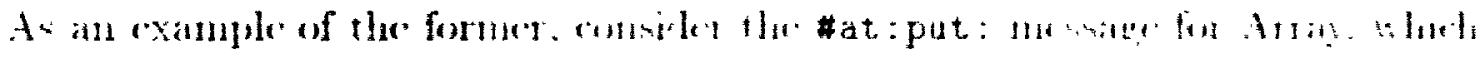

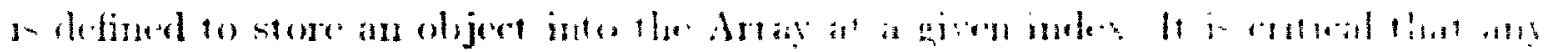

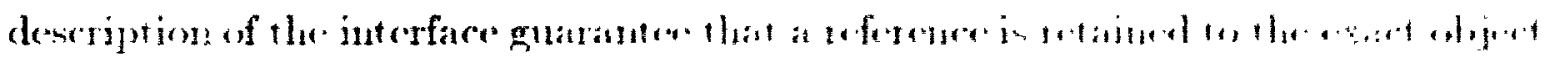

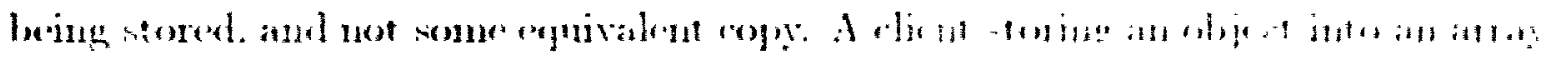

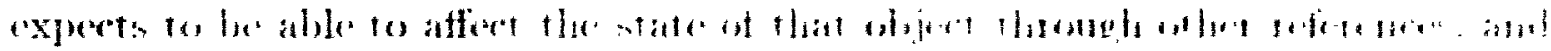

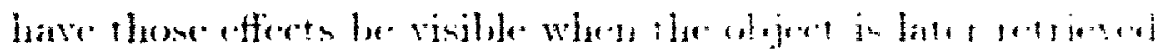

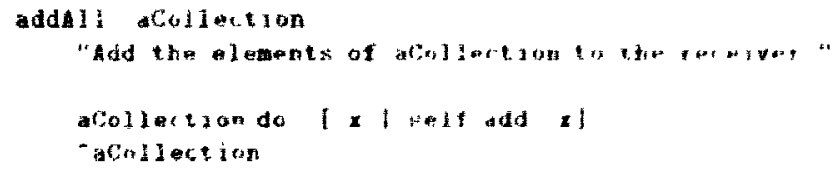

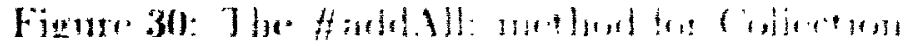

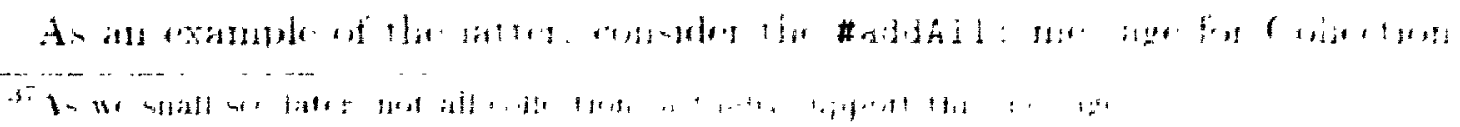





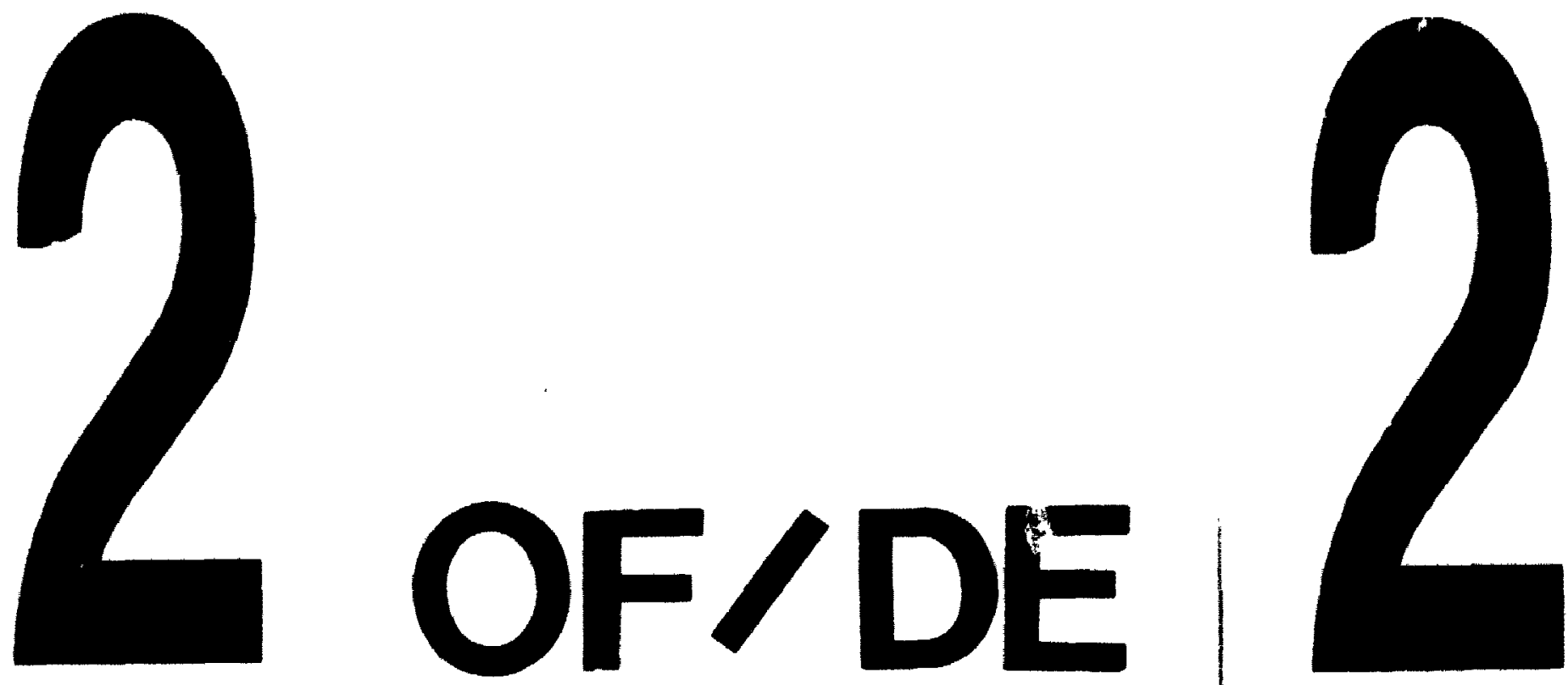

FM-1 3" 2 "X4" PHOTOGRAPHIC MICROCOPY TARGET NBS 1010a ANSI//SO \#2 EOUIVALENT

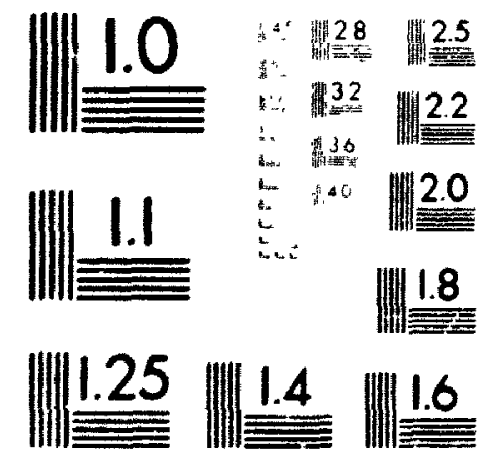




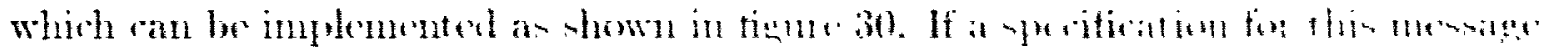

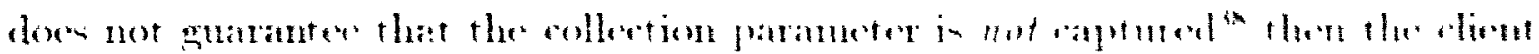

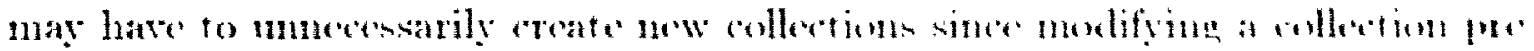

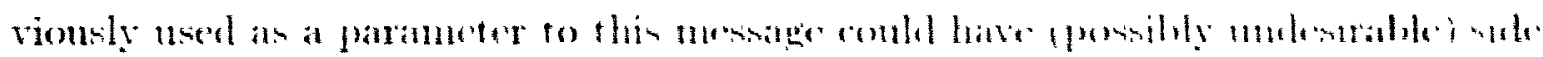
ifferts.

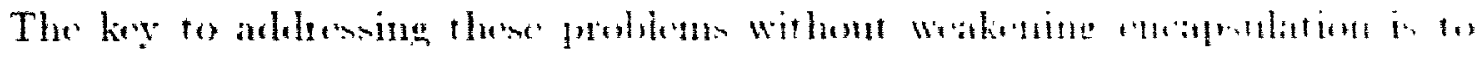

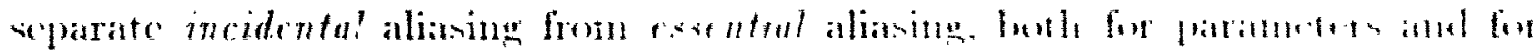

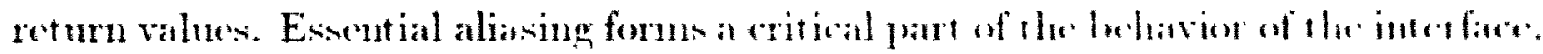

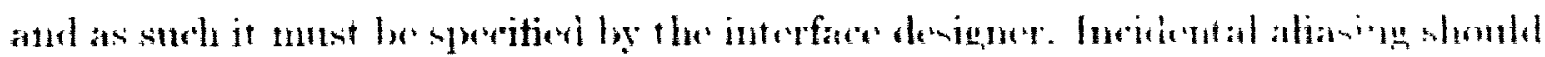

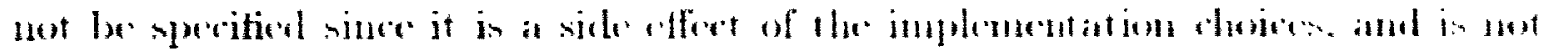

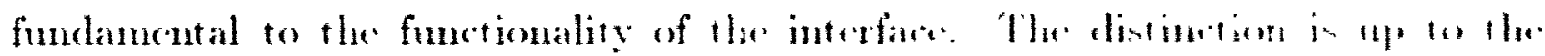
interface denigner.

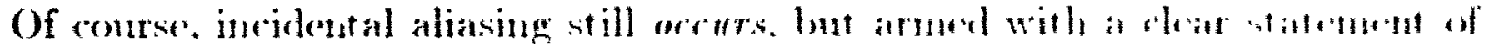

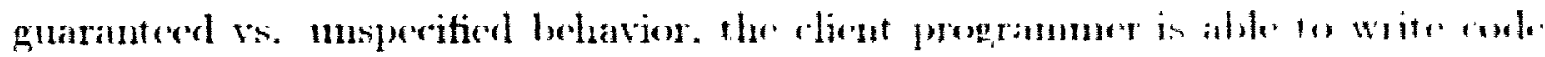

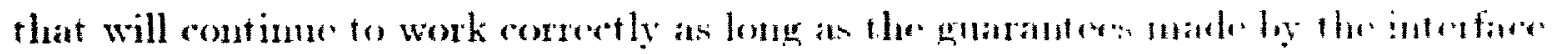
liolil.

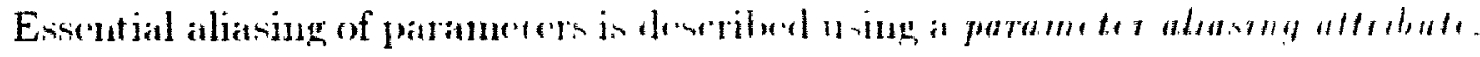
which is one of the following inlentifiers:"

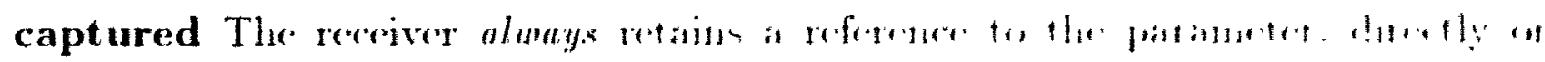
indirectly as a result of thin menage".

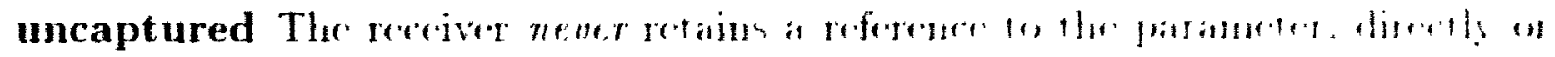
inclireetly, as a result of this menate.

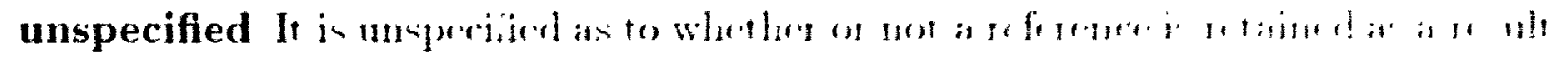

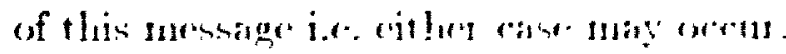

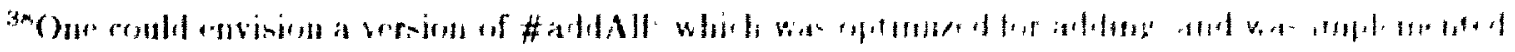

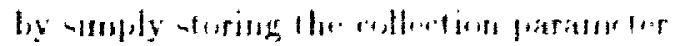

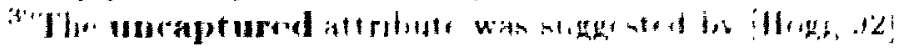


The captured and uncaptured amothtions ane selfexplantory. Howerer. the

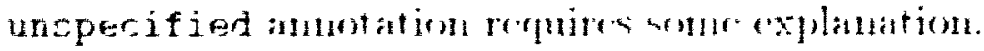

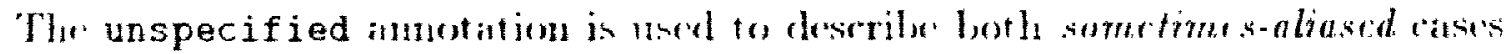
nud also her mos where the interfare designer has dereded not to expose the information. A sometines aliased an is when. as a result of conditional expressions, different exerution path of a mothon result in different aliasing. Tler impliontion

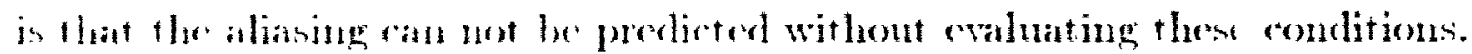

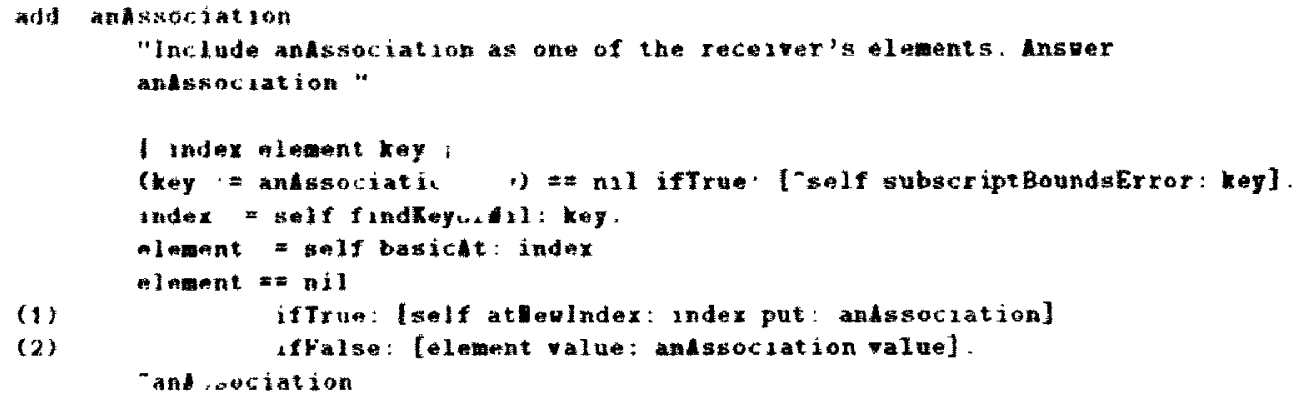

Figure 31: The \#idd: method for Dictionary

An example whith illustrates both ranes is the \#add: nethod in Dietionary

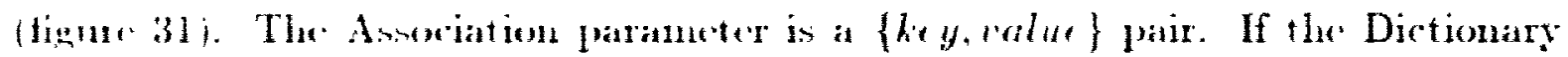

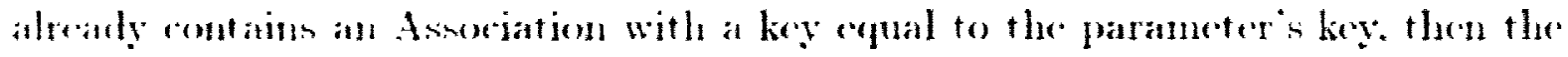

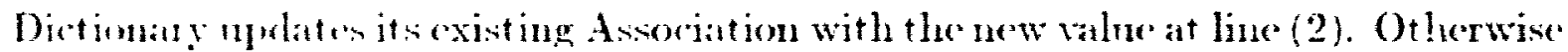
it is a new key, and the parmeter is stored at line (1). Thes the paranerer is aptured only in the rase where it routanes a new key i.e. it is sometimes-aliased.

From tha perspertive of an application progennmet, one conld argue that it is

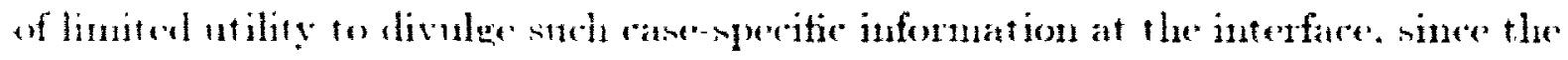

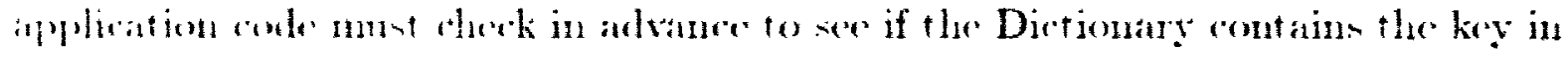

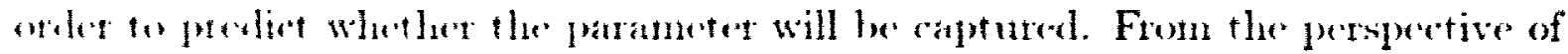

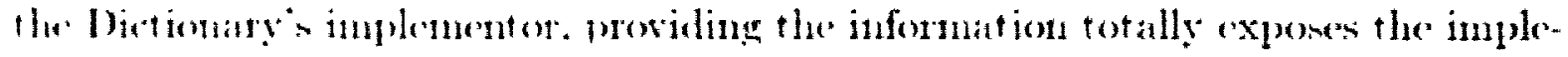
mentation leoth that the representation is compoomed of Asomations, and that

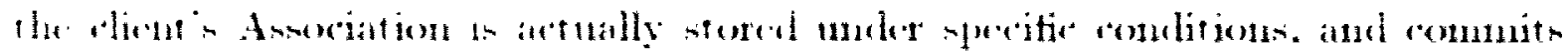


the Dietionary to thi- hetherior.

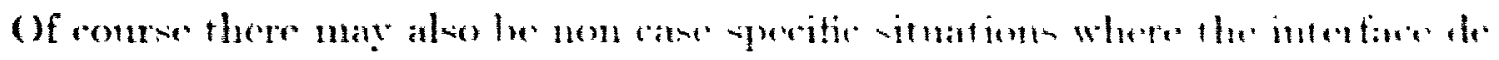
signer decides not to expose the aliasing of the parame tere simply for implementation

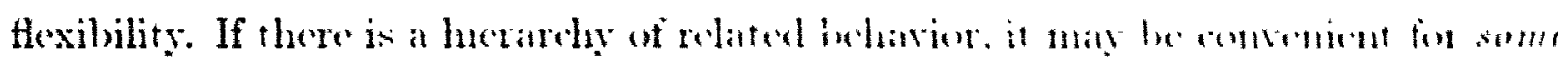

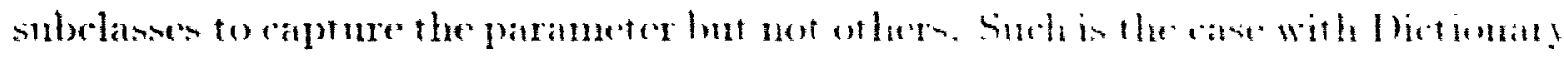

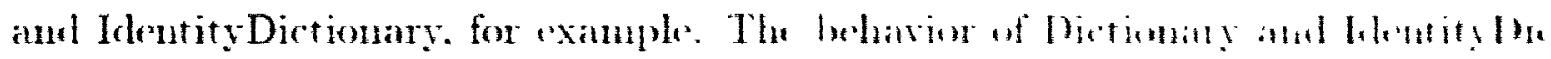

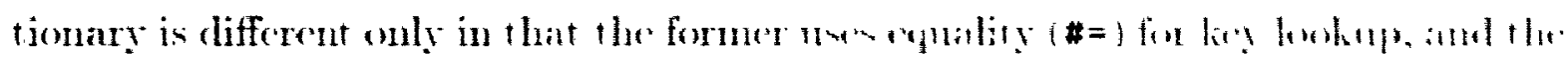

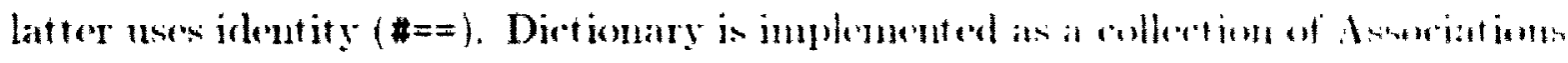

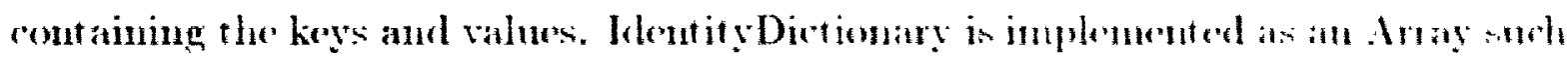

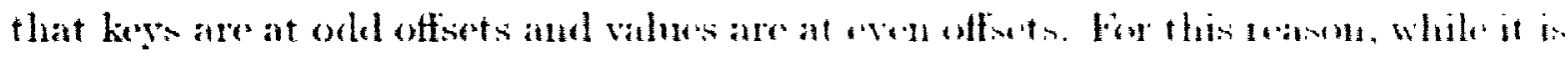

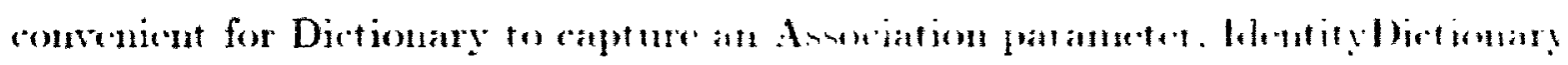

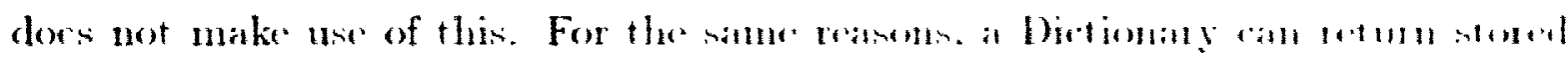

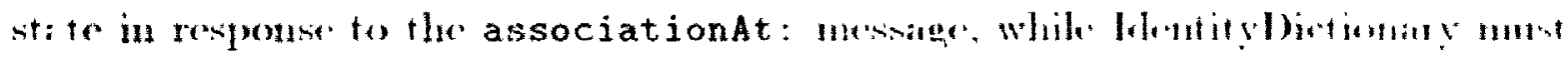
create a 11 ' $w^{\circ}$ Association and tine.

The unspecified amotation gives the interfare lesigure the Hexilility to avent

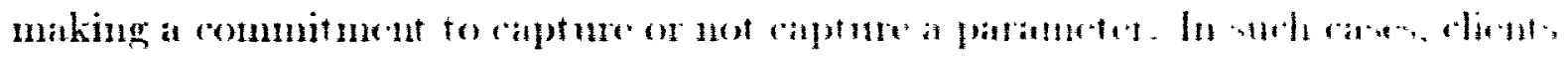

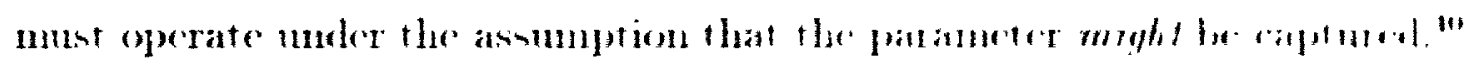

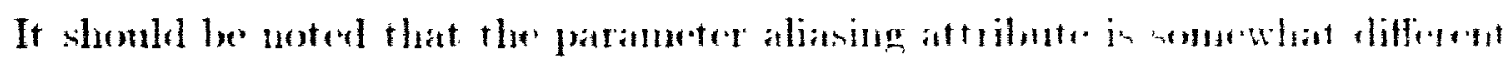
from the interface definition in that the formet is a commitment an the part w whe

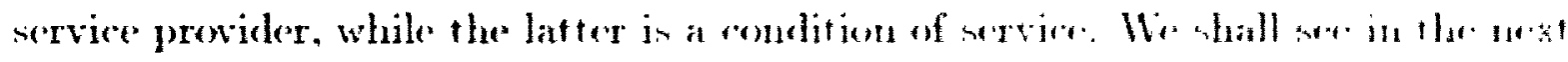

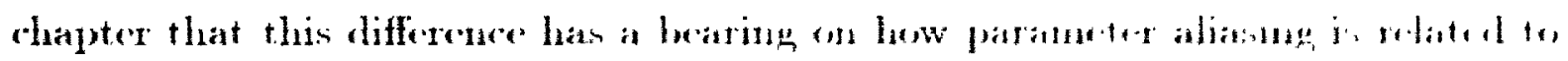
conformaner between mestage speritirations.

\subsection{Return Value Specifications}

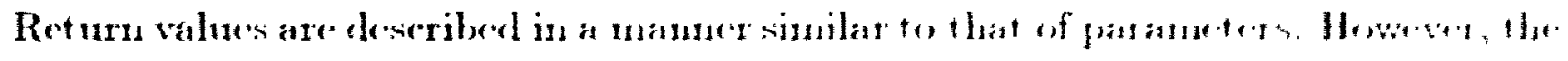

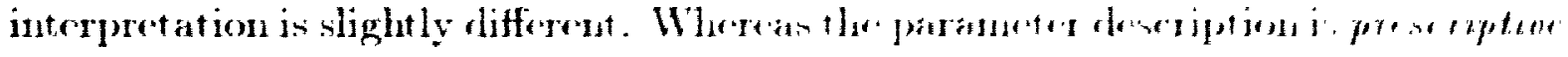

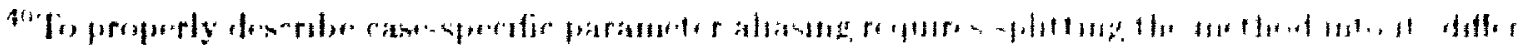

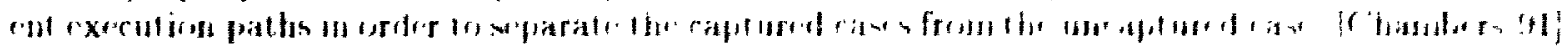

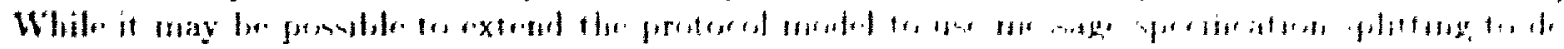

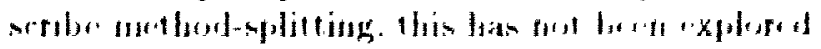




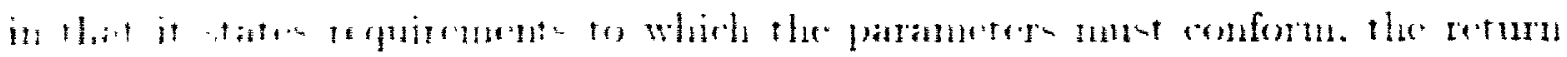

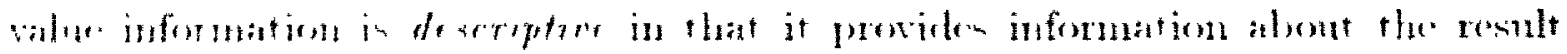

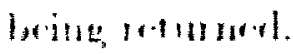

A retarn malue sperification is detined by the following:

- A texthal rescription.

- A retrun valuo jurotofol.

- A retman value aliasing attribute.

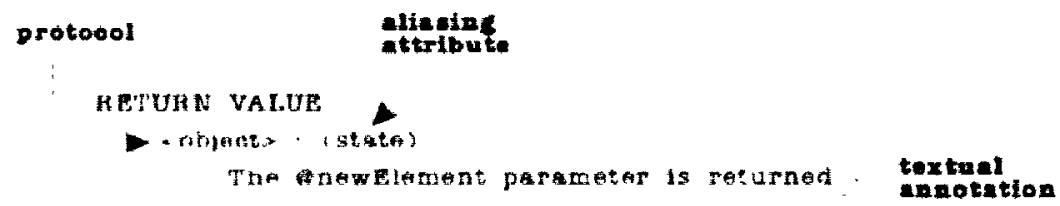

Figur. 32: A retum molue specitiotion

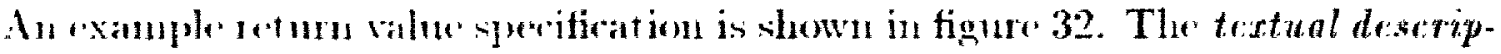

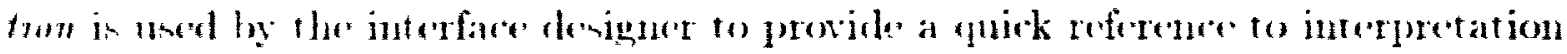
of thentuall wathe.

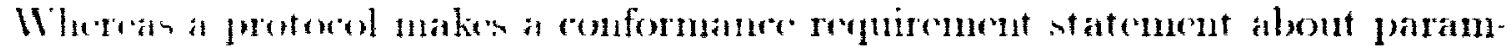

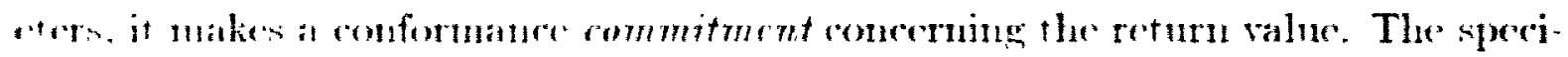
fintion ghanantes that the return walue will conform to the sperified protocol.

A message meritiontion may haw multiple distinet return value specifications.

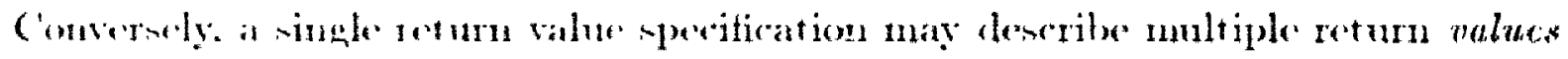

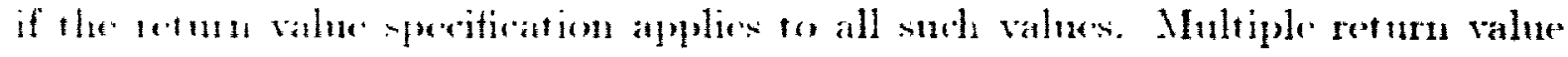

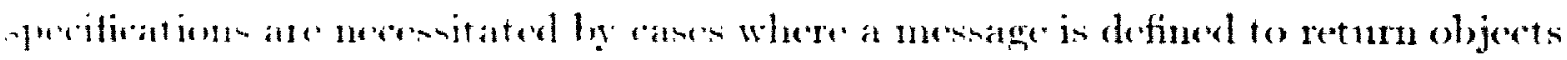

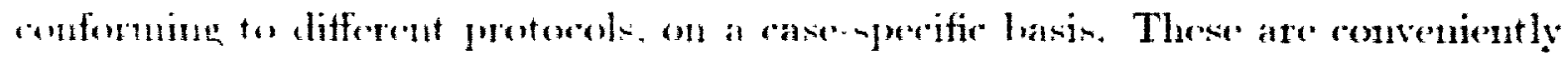

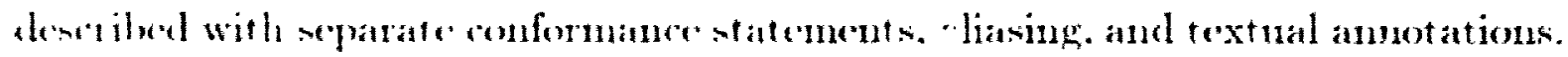

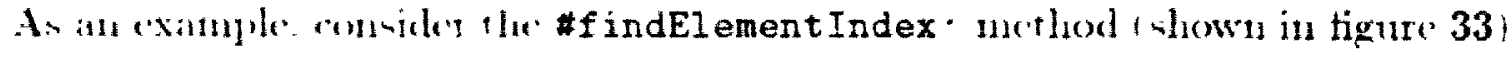

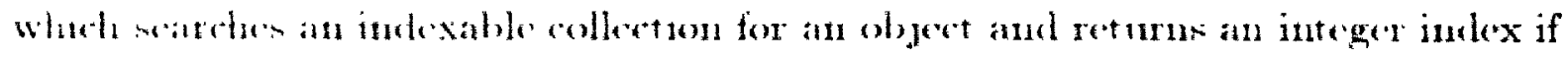




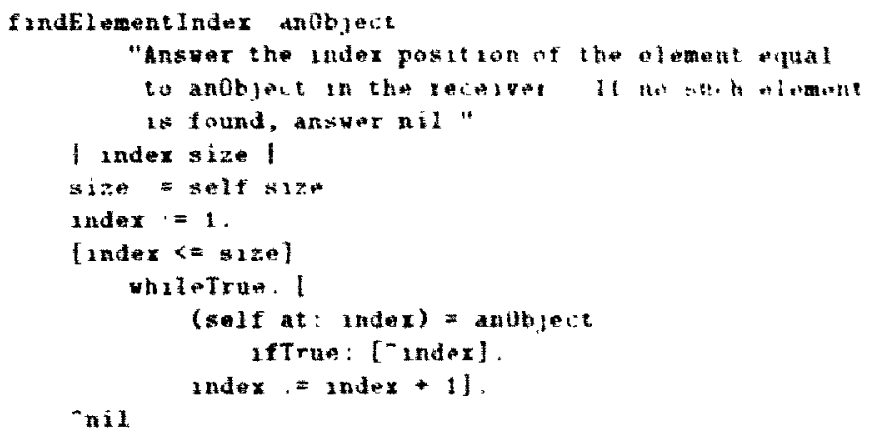

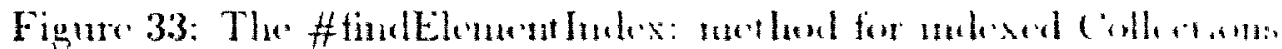

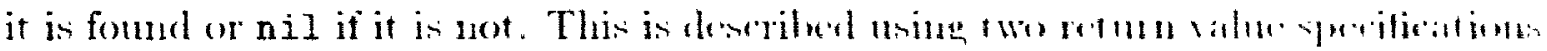

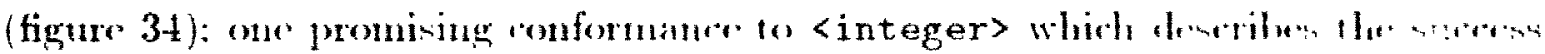

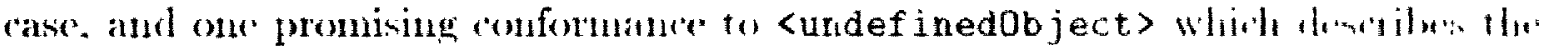

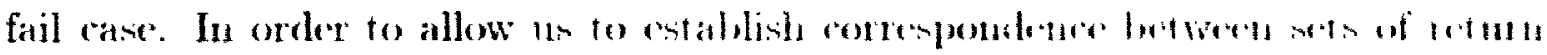

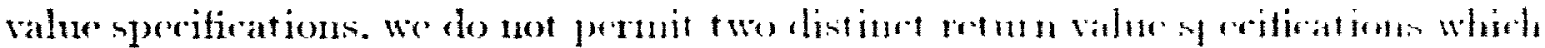
promise conformane io the same protosed.

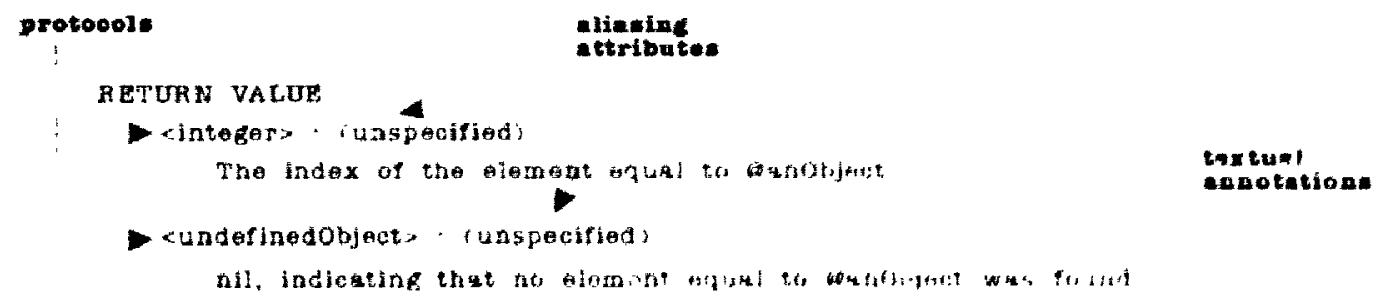

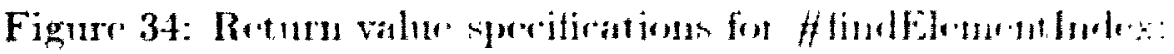

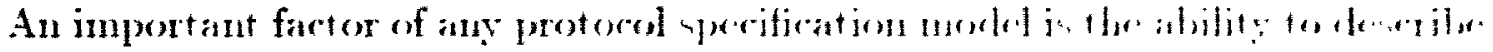

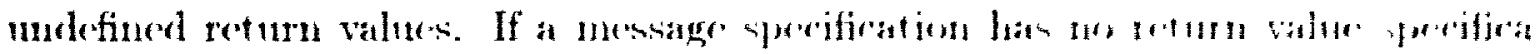

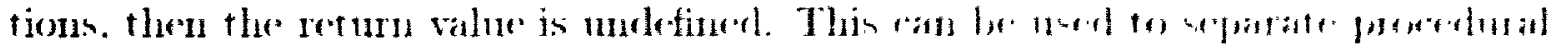

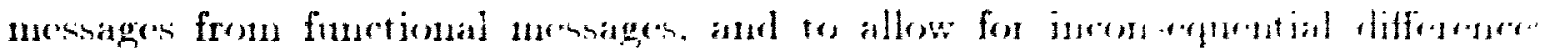

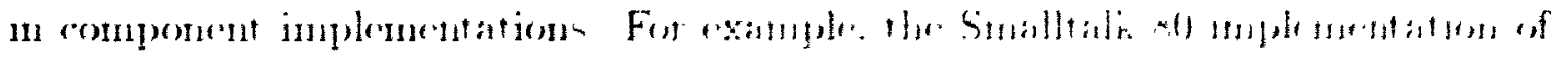

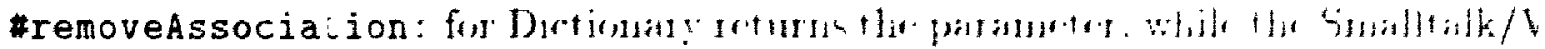




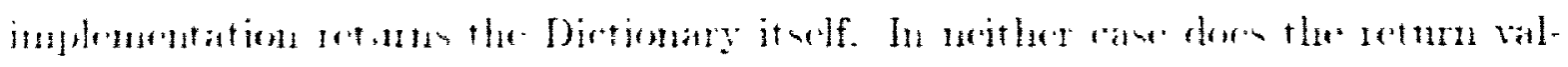

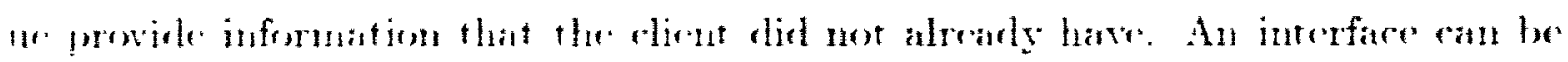
speritied to allow such inplenentations that refum different results but are of herwise ofuratienally cquivalent. In such cases. the fart that an object is returned is

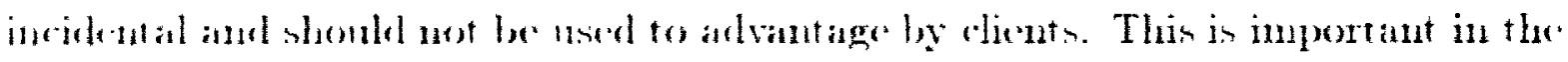

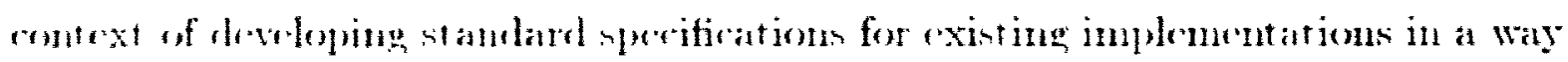
that mininizen eolle changes.

\subsubsection{Return Value Interface Definitions}

lin onder to relate return values through confomance. we define the return value unferface de fintion for a mestage yerification to be the single return value protocol. or Her legionl on of the protores in each distinet return value sperification. The return value interfare detinition for the example in figure 33 is:

\section{〈integer> | <undefinedobject>}

These interface definitions ate inplieit in the deseriptions. wine such cases are artually dencribod threugh the use of multiple retum value specifieations. If a

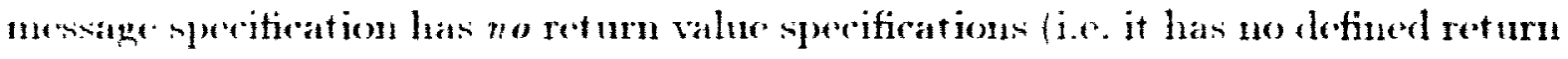
valuel. then it is not prepared to guarantec anything about the behavior of the afturued object. Howerer. we rexpire that all objects conform to <object> protocol: therefore the defanlt interfare definition. which applesto to anessage sperifieation with un meturn value specitiontions, is <objects.

\subsubsection{Return Value Aliasing Attributes}

The return value aliasing at ribute is used to provide (or hide) information about the islentity of the whum value. Many return values are used for are intended to b. und in a read only manuer 11,4 , the tate of such a return value as intended

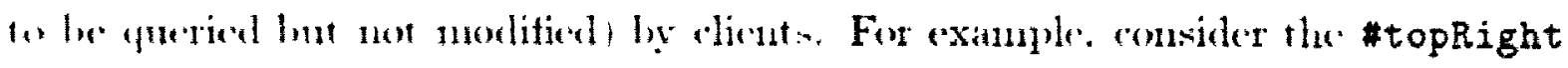




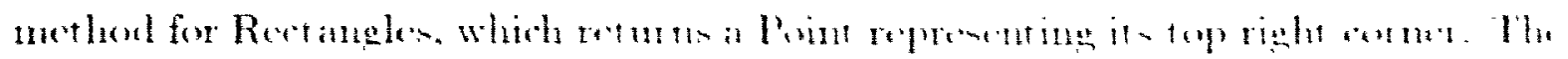

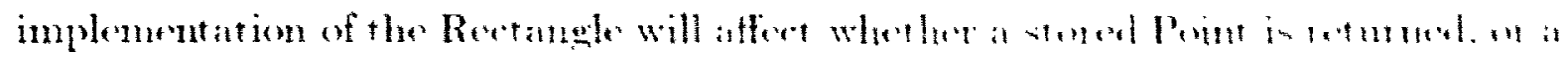

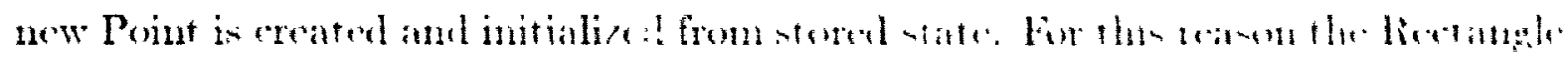

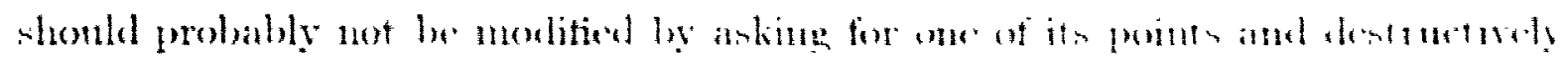

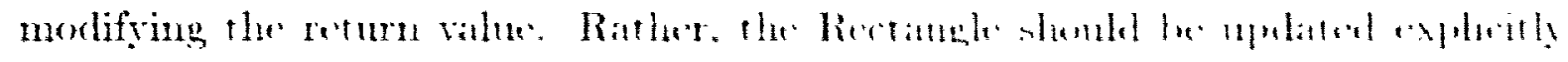

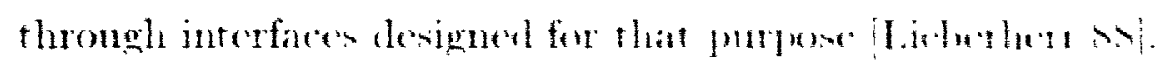

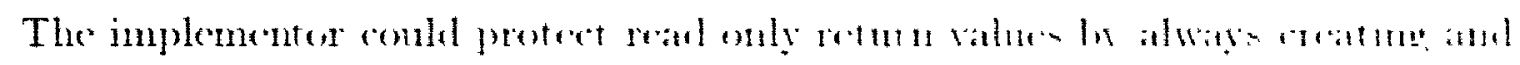

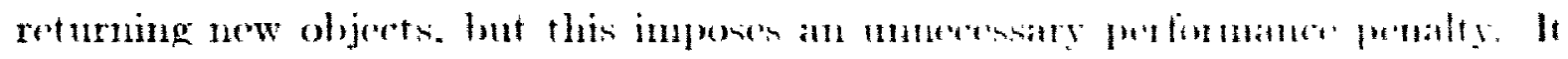
should be inconseguential to the application corts whether a rotumed alject in

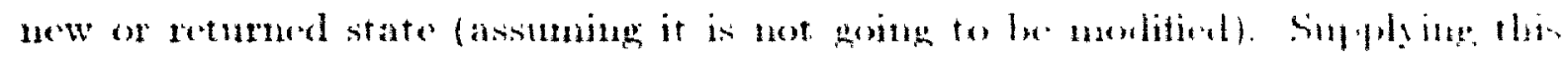

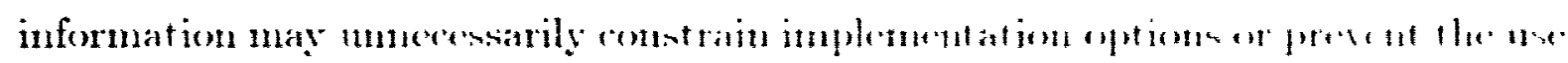

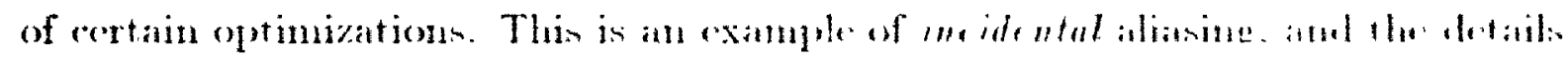

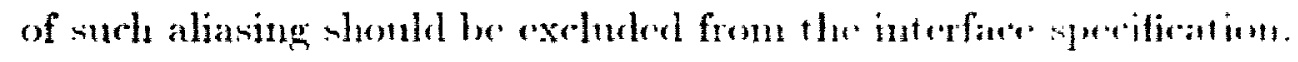

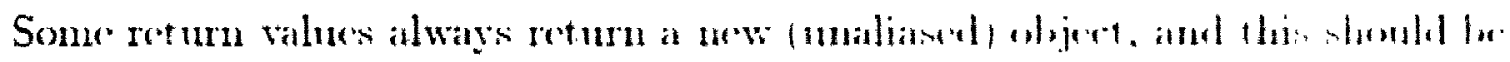

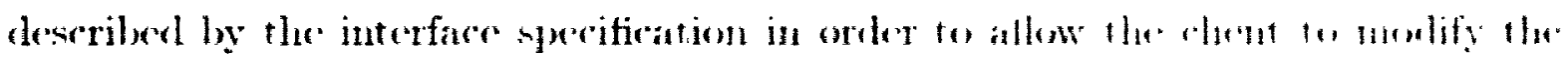

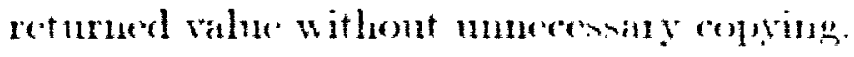

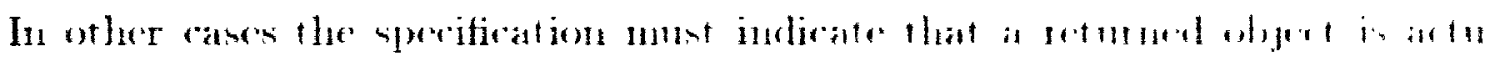

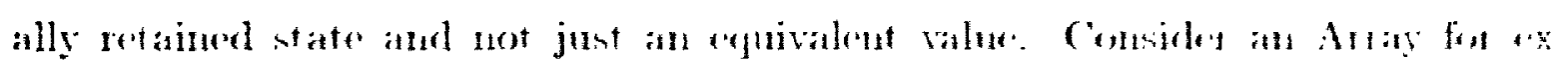

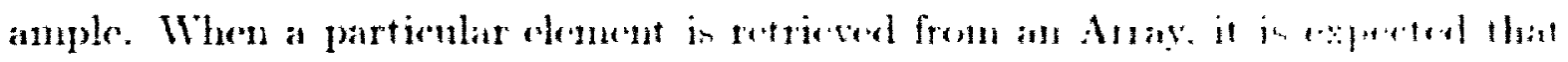

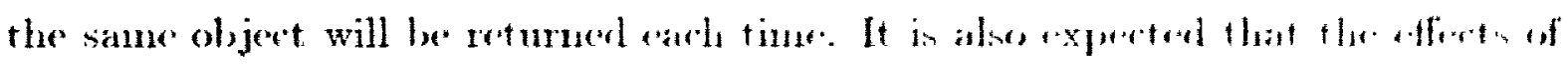

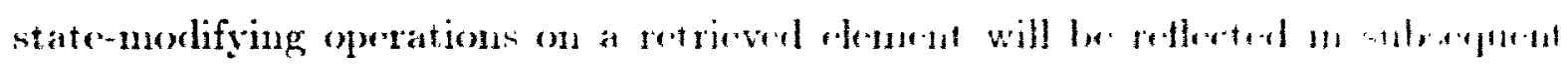

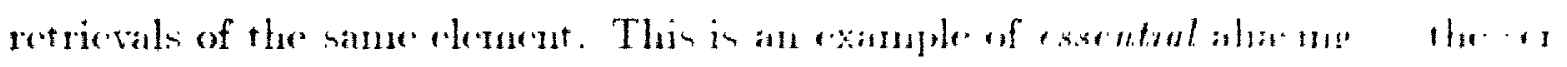

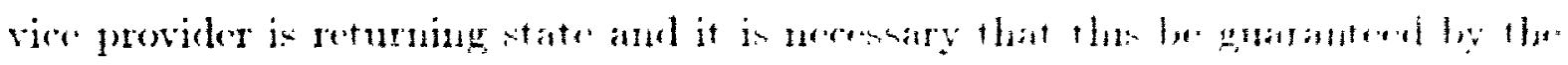
interfares sperification.

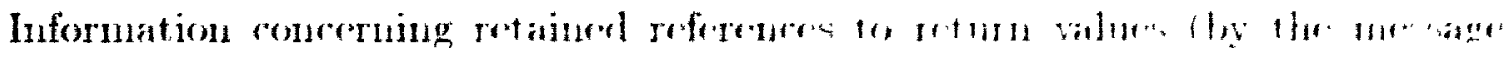

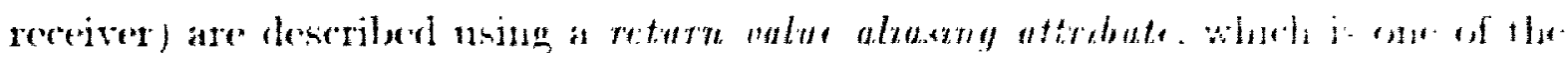
following irlontitiors: 


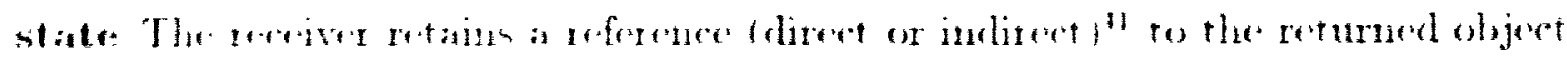

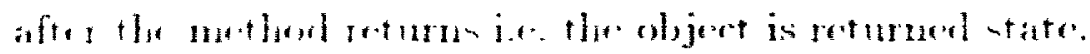

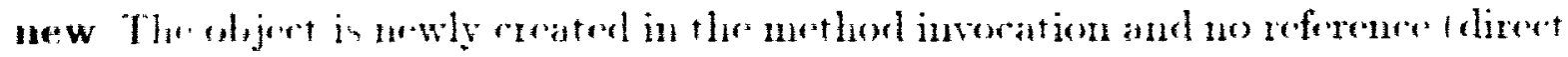

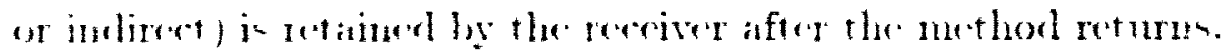

mospecifod So information is providol as to the origin or retained references to thes alsent.

The state attribute indirates lhat the returuel object is guamated to be

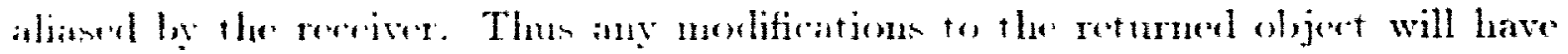

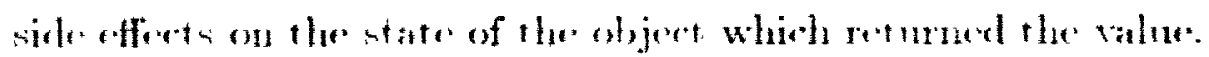

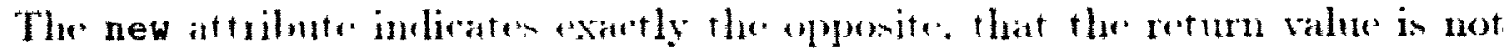
only mureforenced hy the object returning it. But it in not referemed by any object whatsenerer. The ralley of the mothorl holds the sole reference.

The unspecified attrimte is ned to avoid providing information comerning alising of the return value. This may be because the interfat de designer wants to avoid committing to a particular implementation (i.e. it is incidental aliasing). or beatue the alianing is not known. The client must treat the returned object aceordingly, and not perform dest ructive operations on it for in the course of doing so. molertand that mouported and/or nomportablo belavior is being nsed).

Thim unspecified attribute is also used for cases which are not described by

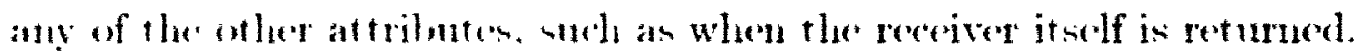

There are other interenting situations. but they are more complicated than they initially appear. For cxample, it may be useful to distinguish the case where a return ralue was sate but is no longer referened (directly or indirectly) by the werive after the mothod retums. Such a cane is demonstrated by the remove:

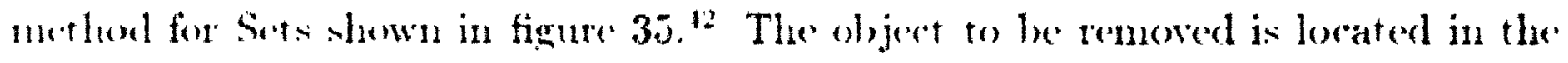

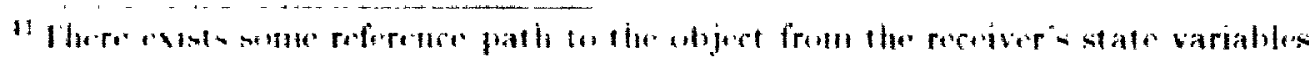

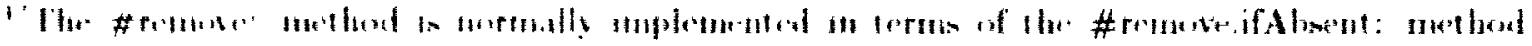




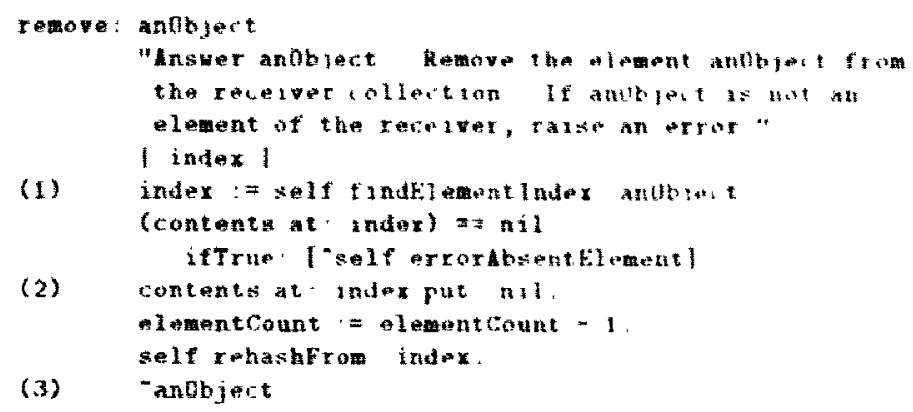

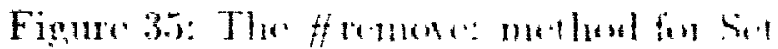

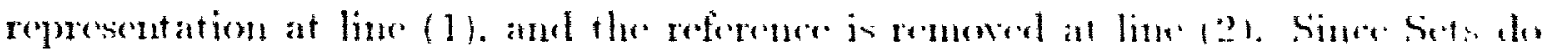

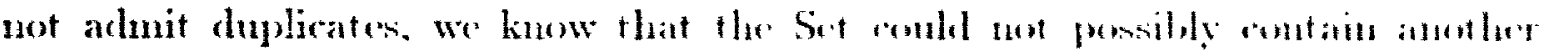

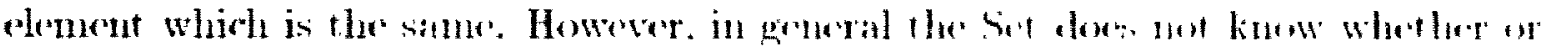

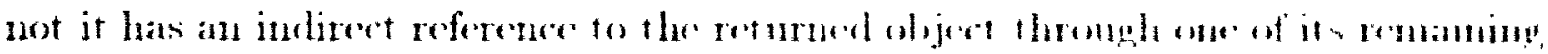

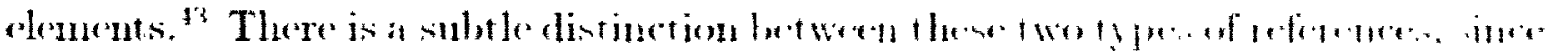

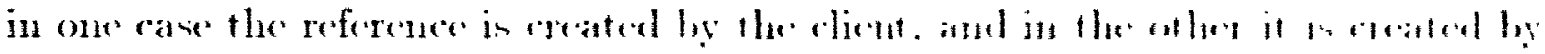

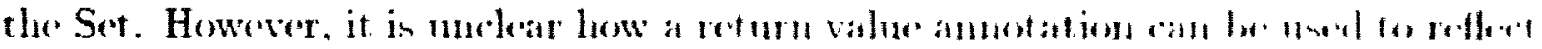

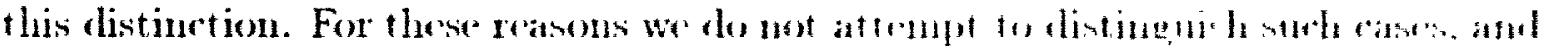
they are deseribed using the unspecified anmotion.

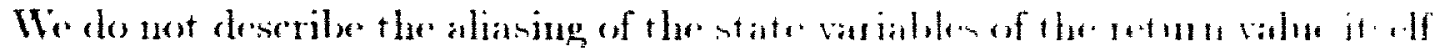

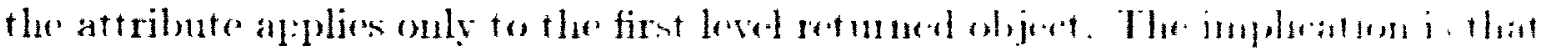

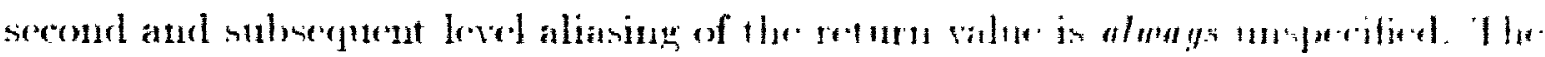

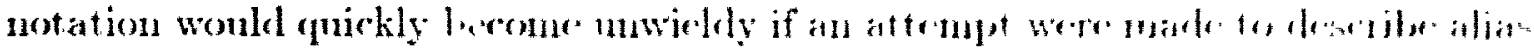

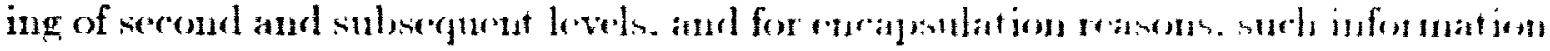

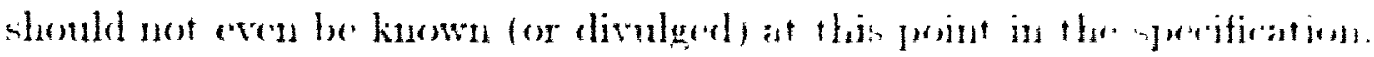

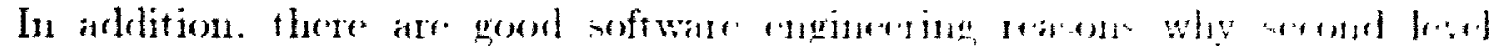

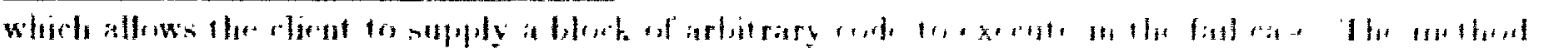

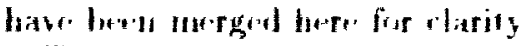

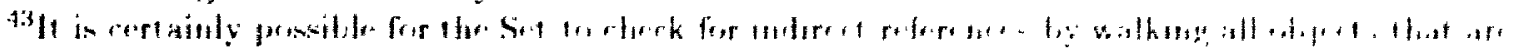

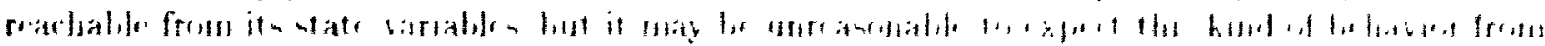

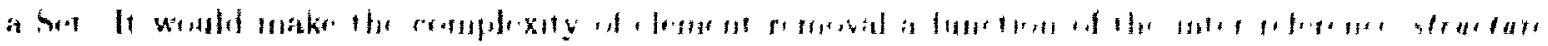

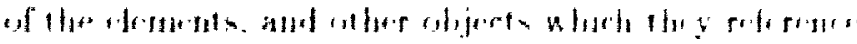




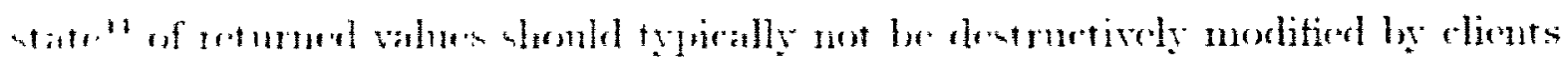

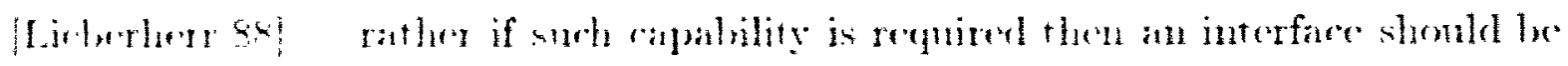

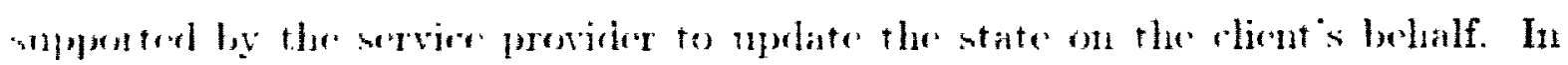

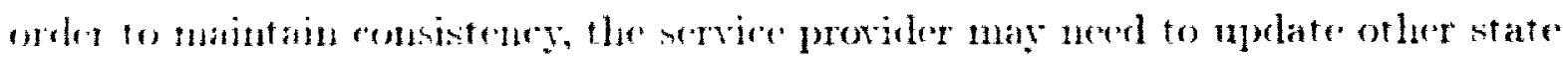

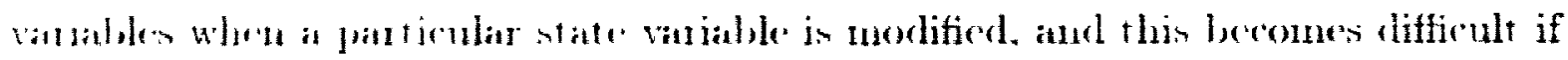

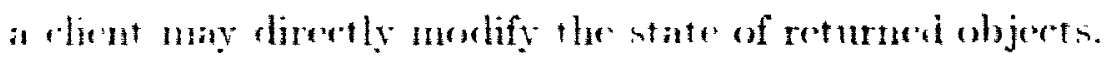

An exerption orme in the rase where the returned state is an object whels

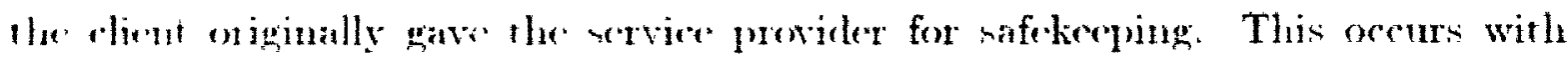

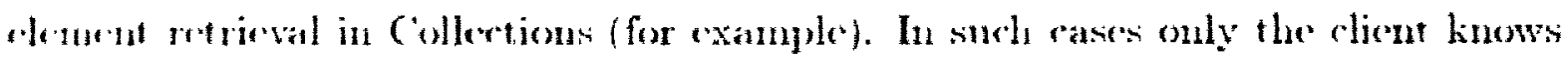

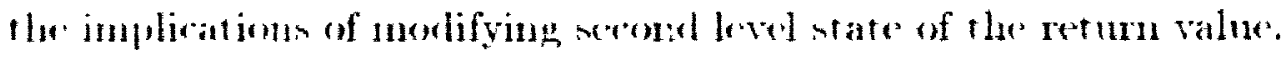

Tine fart that aliasing of seomel (aud subsequent) level state is unspecified

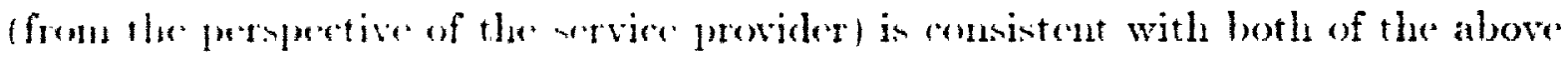
ranen, fo the fint rase. the servere previder is unwilling to divulge the aliasing of

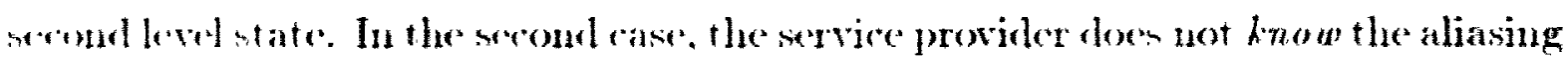
of serond lovel state. since the object was croated and initialized by the client. In the former case. the client must not destructively nodify serond level state under any ronclitions. and in the latter atse. the dient knows the exact identity of the

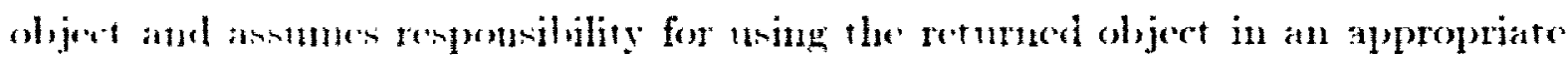
ntammer.

(omsintent with the two cases described abowe we use an unspecified annom fat ion as oplowed to read as [Hogg 91] does. Our approach puts the ouns on the - linet to draw the appenpriate conclusion based on the promises nade by the service poritis.

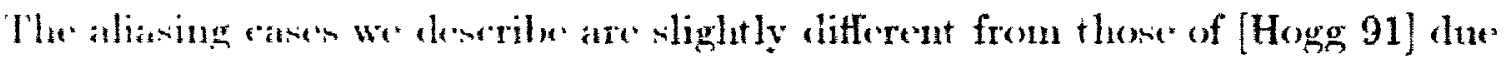
w the fuet that we are interested in aliasing advertiscment rather than aliasing prenetron. One aliasing distinctions are notivated by the need to disclose fand

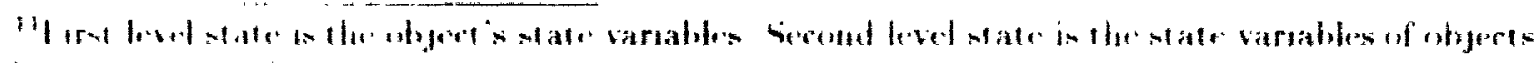
aeferement ly ters lened state. 


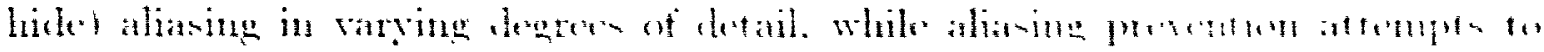

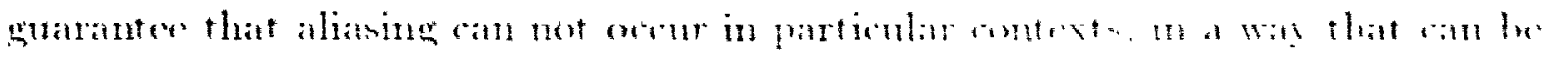
-tationally dremkerl.

\subsubsection{Behavioral Descriptions}

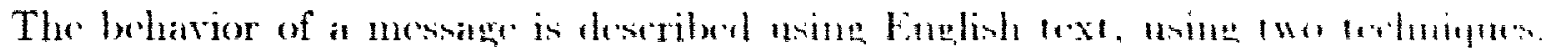

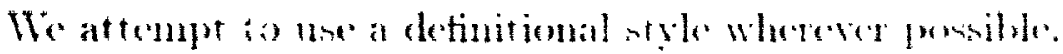

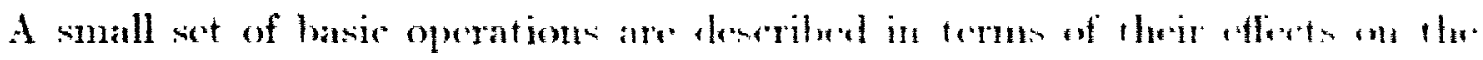

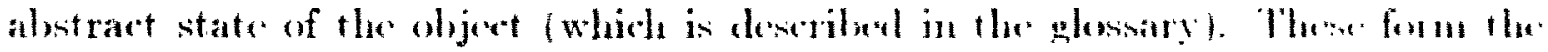

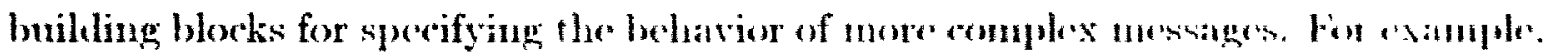

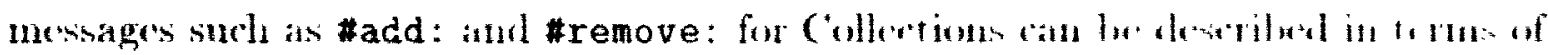

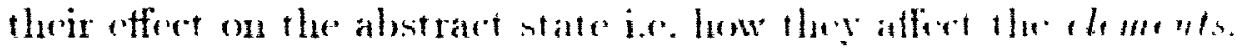

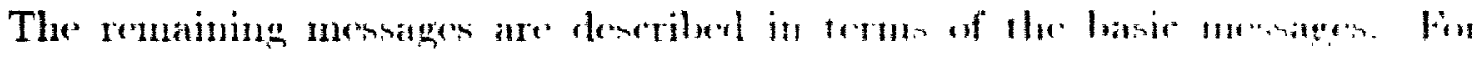

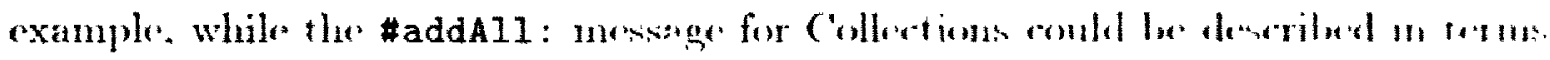

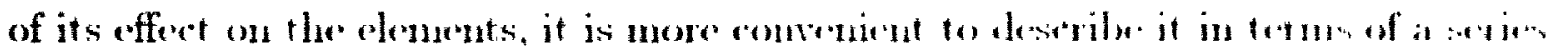

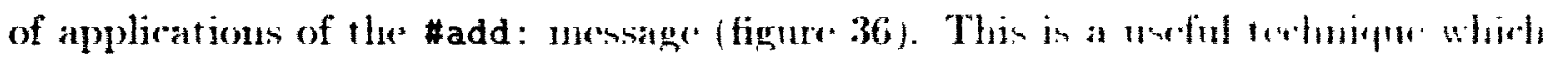

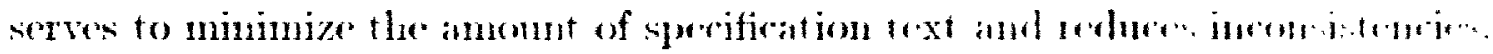

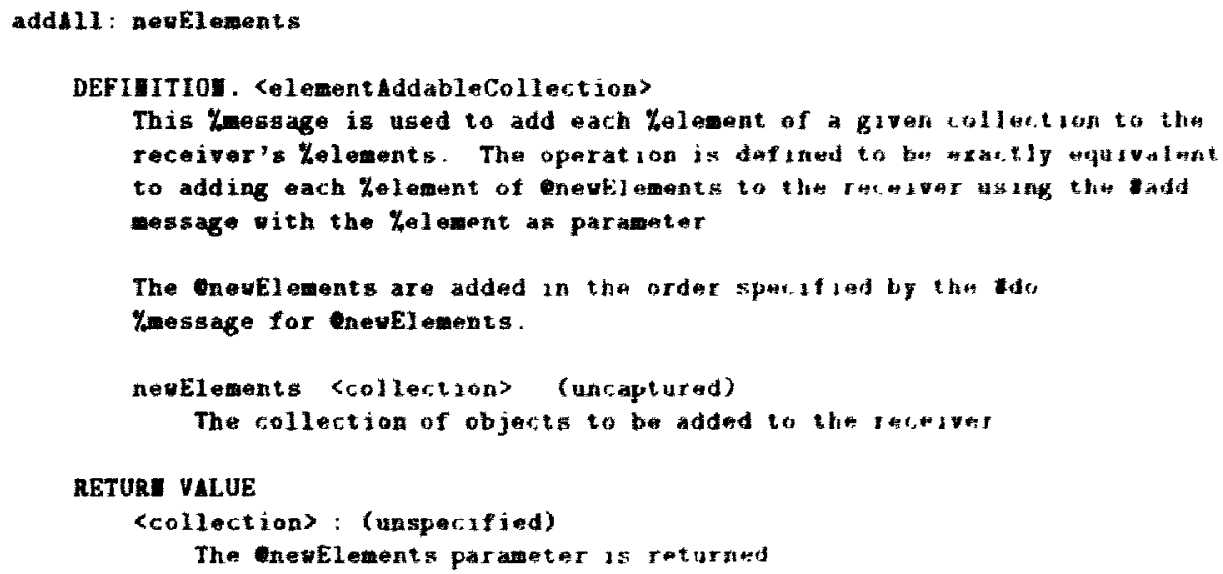

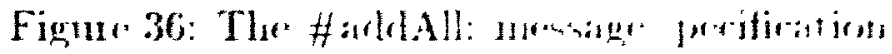




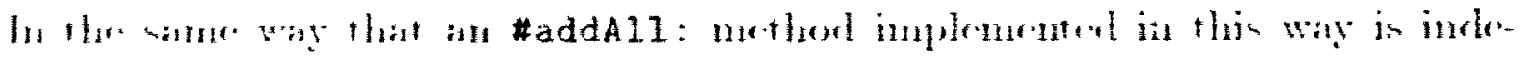
perrlont of the implementation of the Collection. a message speritied in this way is

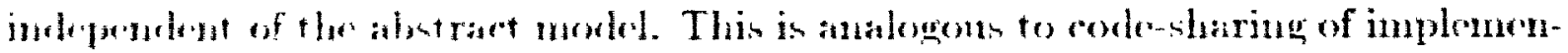

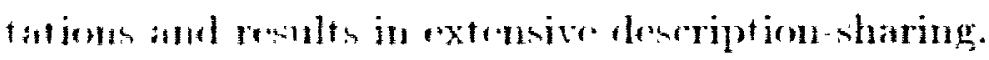

In many cases there no sereral different sets of messages which can be ned to

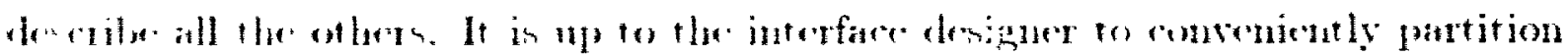

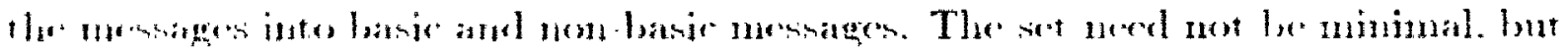

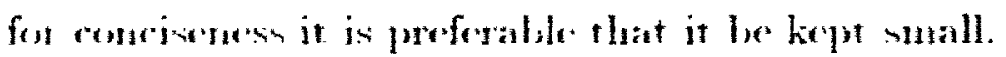

lather than attempting to dotine general coneepts stoh as equality of objects

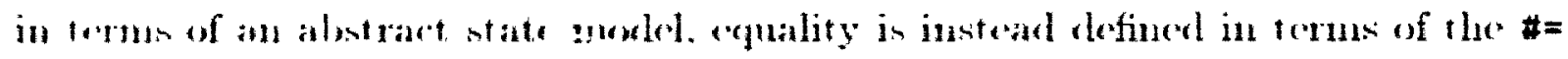
mustage. The \# = messige can then be defined in terms of the abstrat state model

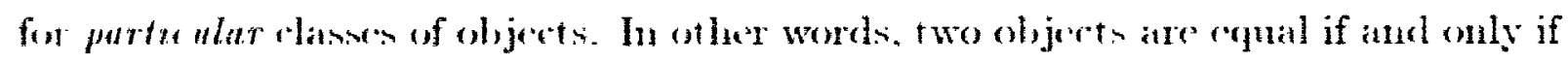
\#= nemagx returns true when the two bojets are compared. This is actually more correct than attempting to do it the other way around since it is the response of

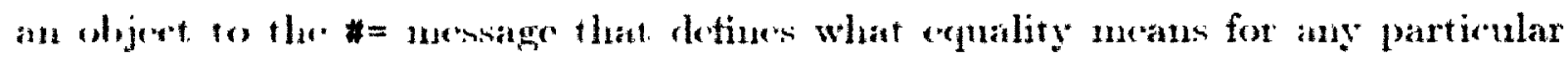
olijeret.

Enelish text is, of comrse. prone to anbiguties. In order to completely. and

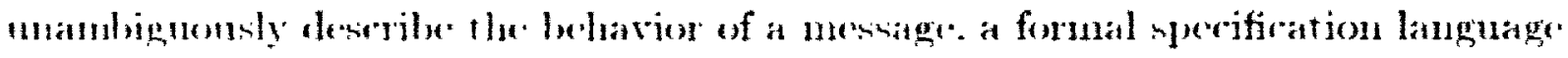

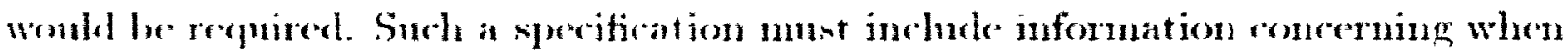
the nessige can be sent. condition son the values of the partuneterte the value of

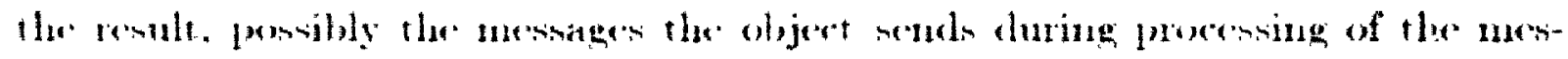

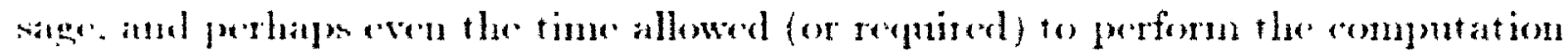
Ameriea si]. Howeres. there are some obstacles to the practionl application of formal torkininum.

[Amerioa si] notes that "Lufortumately. formal specification technology is not ye in a pention that formal speritiations of this kind can be included in a practical

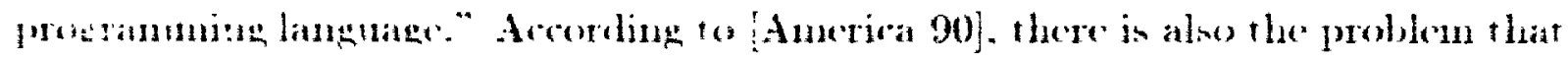

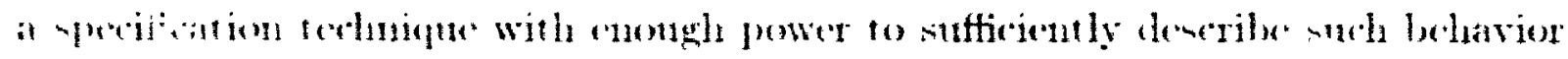




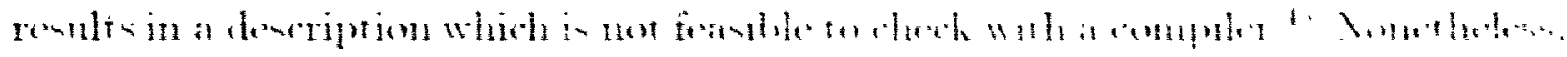

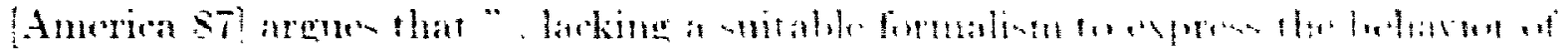

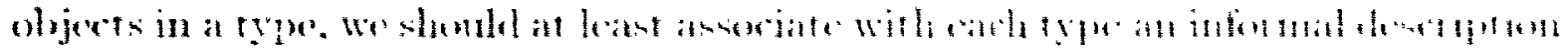

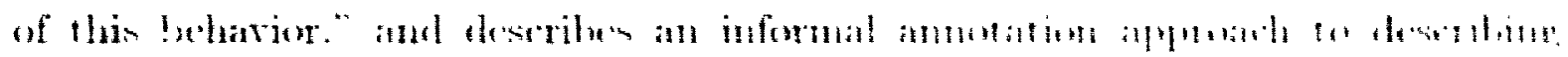

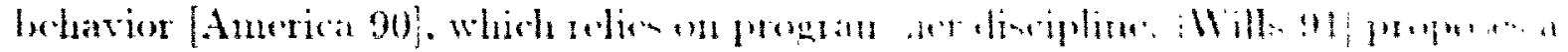

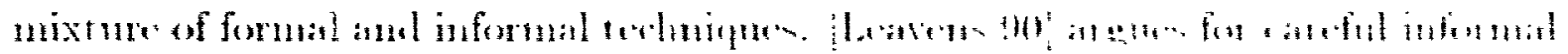

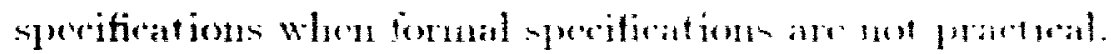

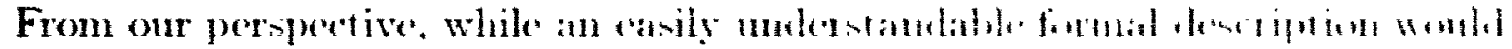

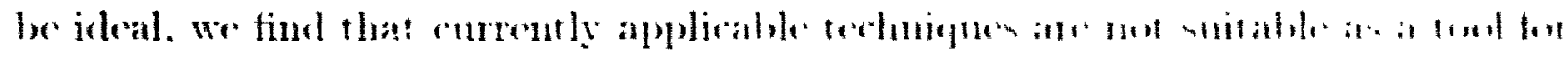

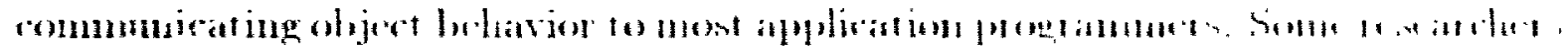

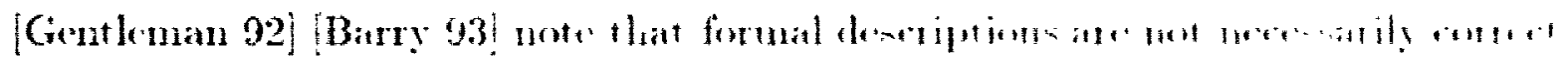

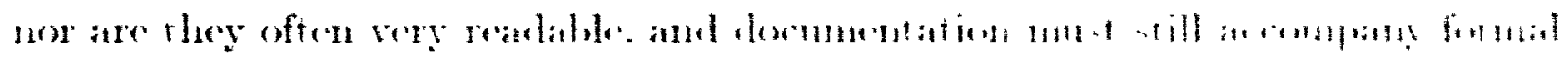

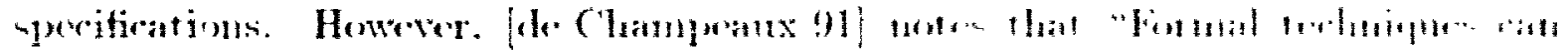

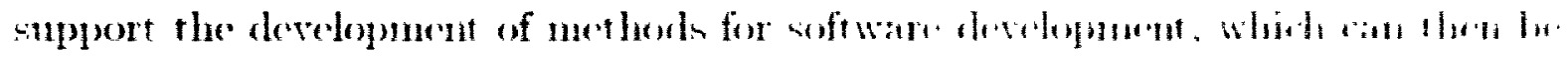

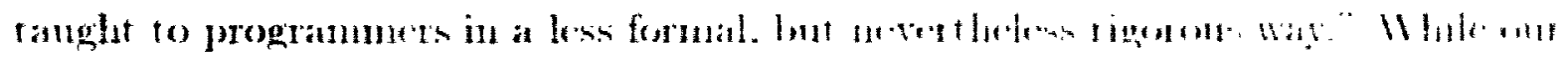

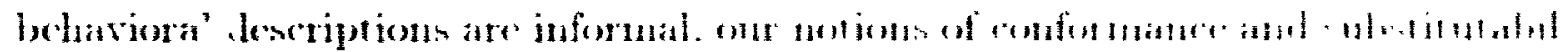

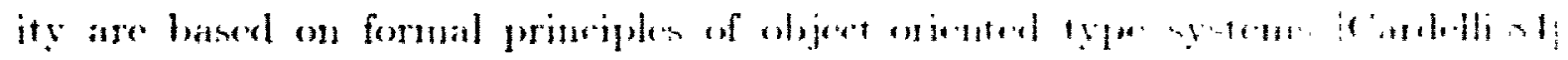
[Ameriva 90$]$.

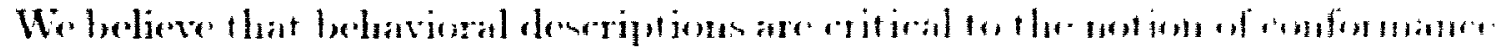

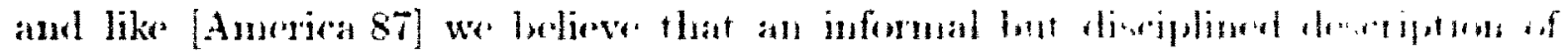

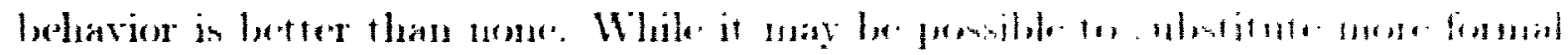

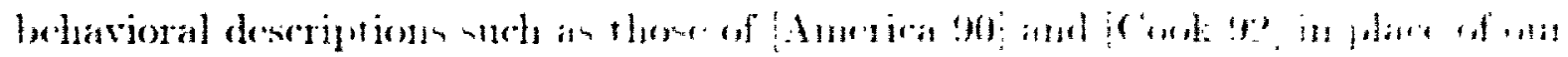

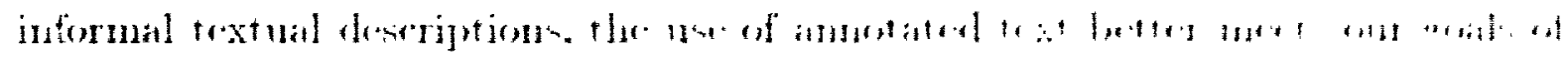

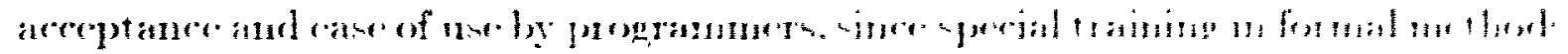

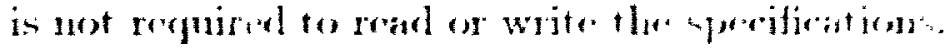

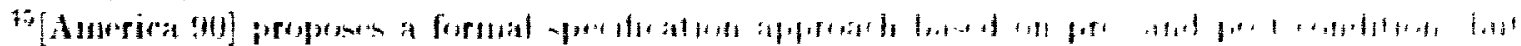

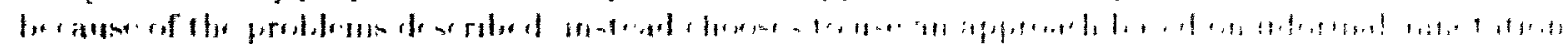

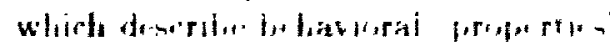




\subsection{Summary}

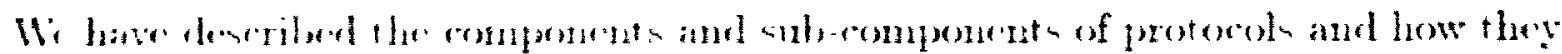

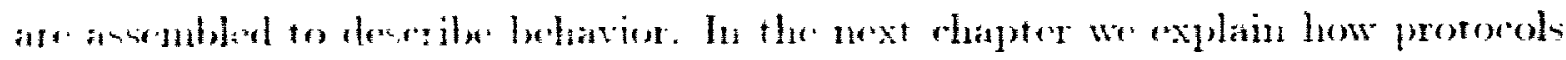

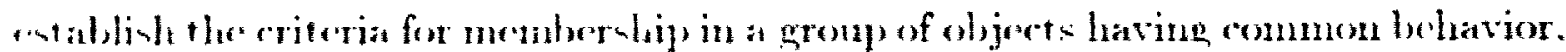

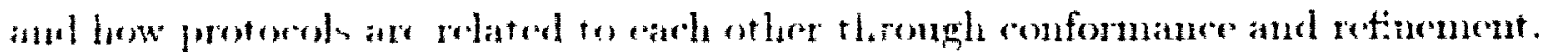




\section{Chapter 4}

\section{Conformance and Refinement}

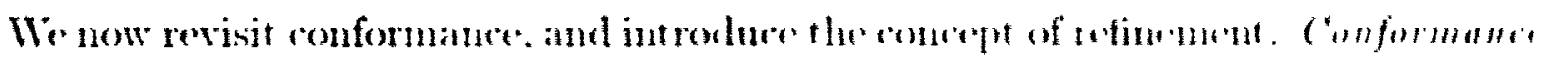
allowe a proterol to be defined through compesition of orfer protencels. Rifinement

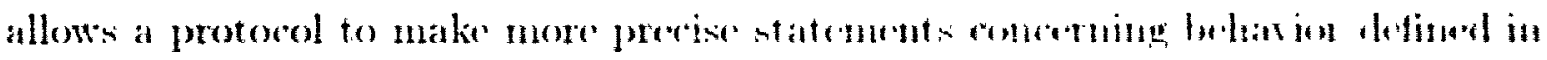

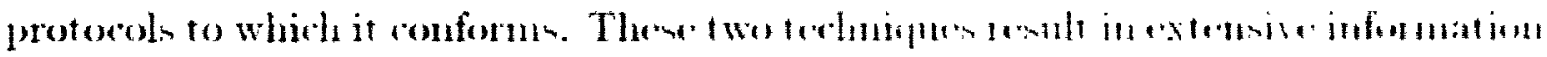
sharing. and extablish a strong structuring merhanimu.

\subsection{Conformance}

Conformance is defined on oljects and protomolis. Adelitionally in the contest of

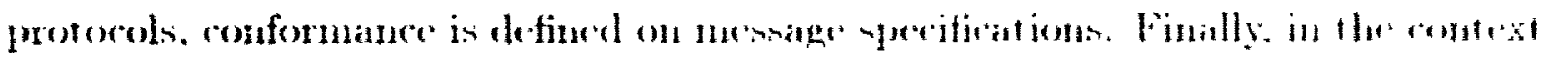

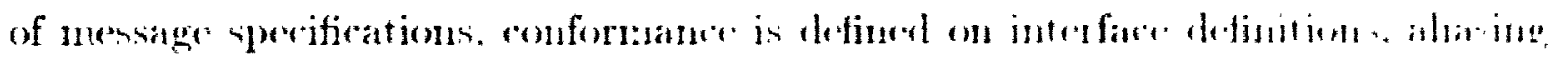

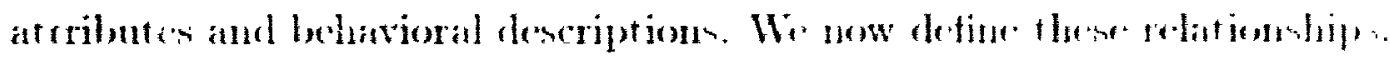

\subsubsection{Object Conformance}

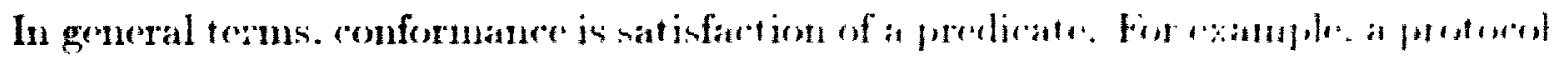

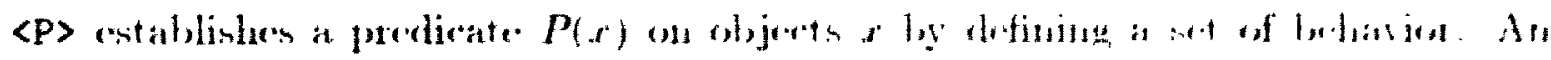

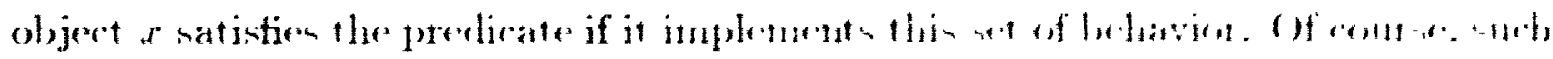

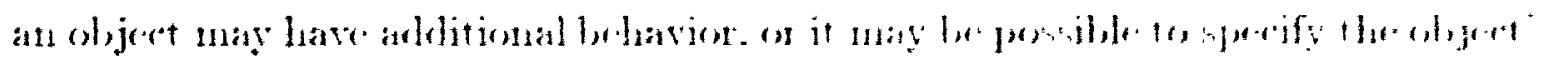

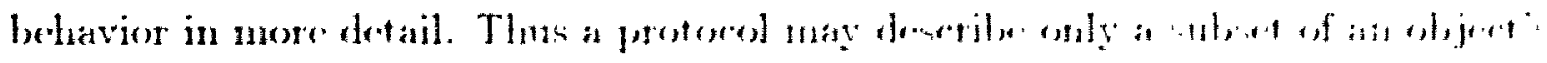

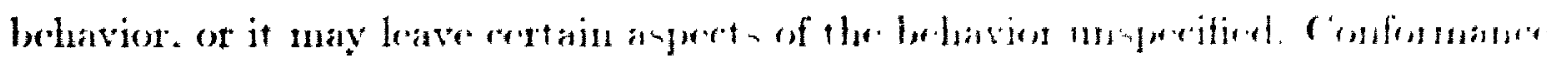
of and object $x$ to a protorol $\langle P\rangle$ is writhin $r\langle=\langle P\rangle$. 


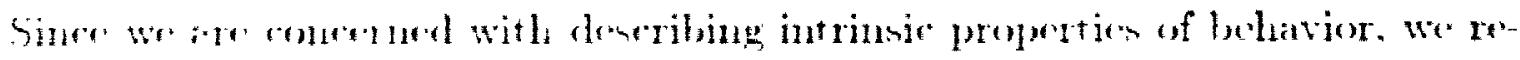
guire that all objeres of the sime chans nerensarily conform to the same protocols.

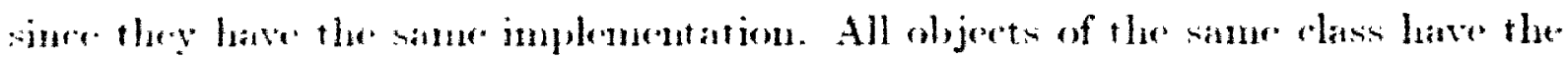
sane intringe poppertien when they are created. and thene properties can not change

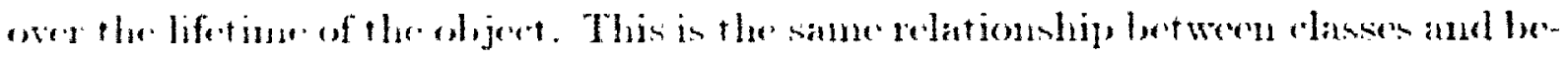

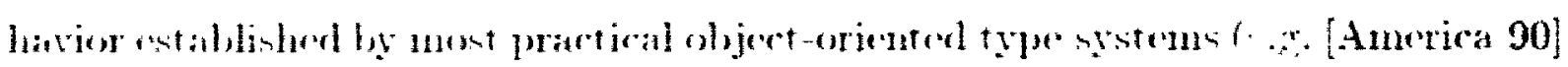

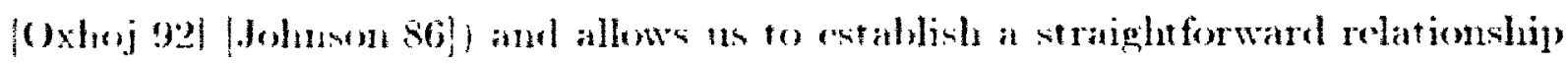
leetween ratures and potorols.

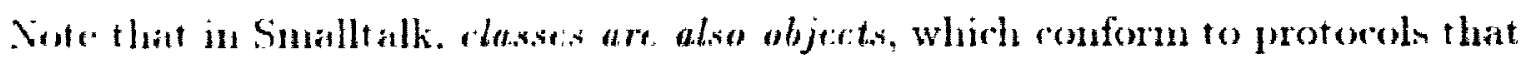
describe behavien common to objecte which happen to be classes. For this reason we talk aluen the ledhation of objects. and classes are the mechanism by whech the lechavion in implenented.

\subsubsection{Protocol Conformance}

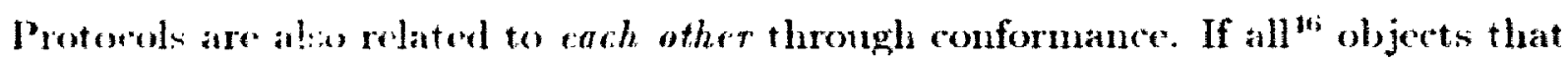
conform to a protocol $\langle P\rangle$ also fonform to a protocol $\langle Q\rangle$. then $\langle P\rangle$ in defined to inniom $\mid 0\langle Q\rangle$, writton $\langle P\rangle\langle=\langle Q\rangle$. It follows from this that if $\langle P\rangle\langle=\langle Q\rangle$ then for any objuct $x$, if $x\langle=\langle\mathrm{P}\rangle$ then $x\langle=\langle\mathrm{Q}\rangle$. If both $\langle\mathrm{P}\rangle\langle=\langle\mathrm{Q}\rangle$ and $\langle\mathrm{Q}\rangle\langle=\langle\mathrm{P}\rangle$ then nerensarily $\langle P\rangle$ and $\langle Q\rangle$ define the same behavior i.e. $\langle Q\rangle=\langle P\rangle$. We define these relationships in trrms of predieate satisfaction in figure 37 .

$\begin{array}{ll}\langle\mathrm{P}\rangle\langle=\langle Q\rangle & \text { iff } \forall x \cdot P(x) \Longrightarrow Q(x) \\ \langle\mathrm{P}\rangle=\langle Q\rangle & \text { iff } \forall \cdot r . P(\cdot r) \Longleftrightarrow Q(x)\end{array}$

Fisure 37: Conformane vs. predicate satiffaction

Wi now entablinh neessary and sufficient conditions for protocol conformance. A protiseol $\langle P\rangle$ conforms to a protucol $\langle Q\rangle$ if and only if both of the following are

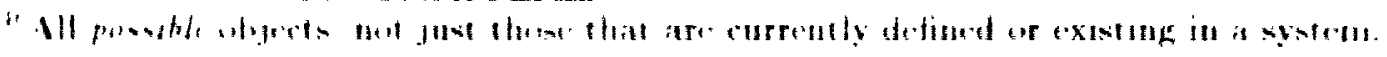


true:

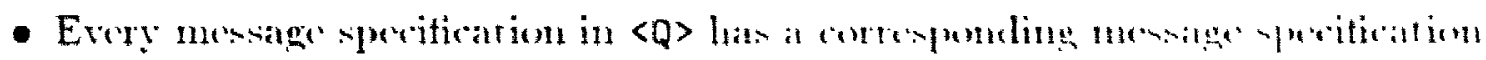

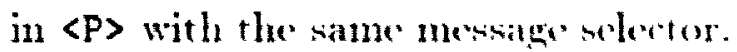

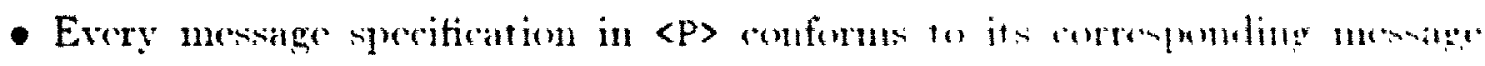
specification in $\langle Q\rangle$.

This means that in order for $\langle P\rangle$ to conform $t 0\langle Q\rangle$, $\langle P\rangle$ nunt aldine me

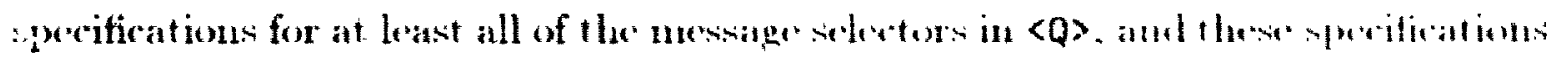
must sperify compatible behavior.

Conformance is transitive. If $\langle A\rangle\langle=\langle B\rangle$ and $\langle B\rangle\langle=\langle C\rangle \|$ he $\langle A\rangle\langle=\langle C\rangle$. Sim

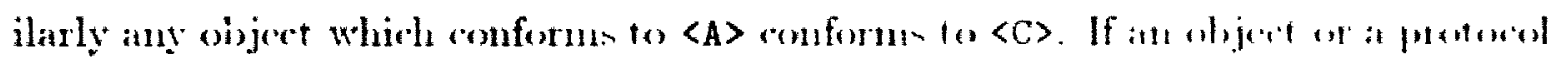

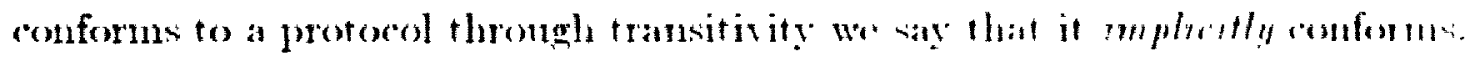

\subsubsection{Message Specification Conformance}

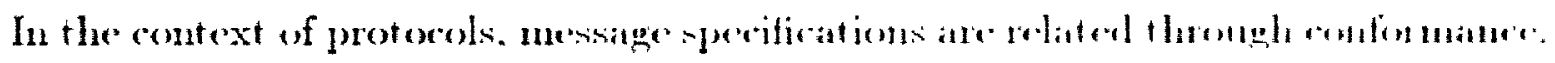

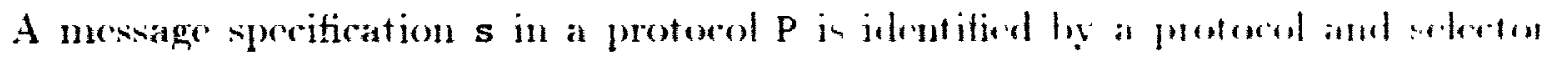

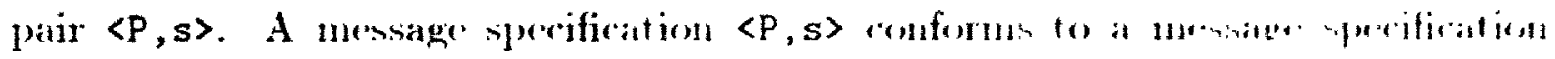
$\langle Q, t\rangle$ where $P, Q$ are protorols and $s, t$ are mestage whelors if and anly if all of the following are true:

- s and t are the shinto message selectort.

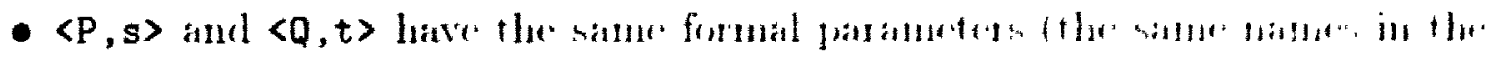
same positions).

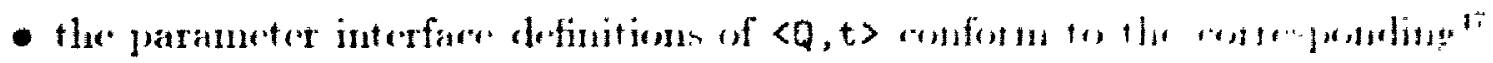

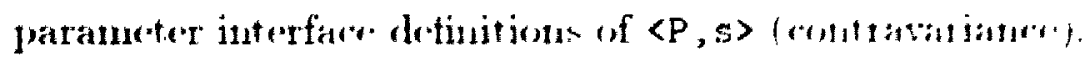

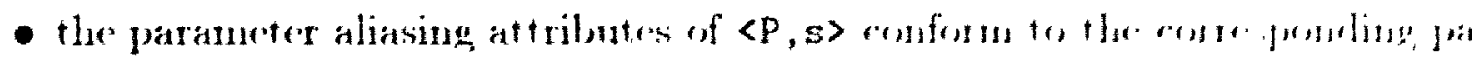
rameter aliasing attributer of $\langle Q, t\rangle$ (anminume)

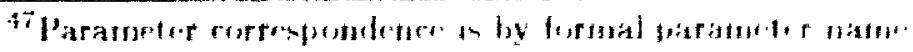




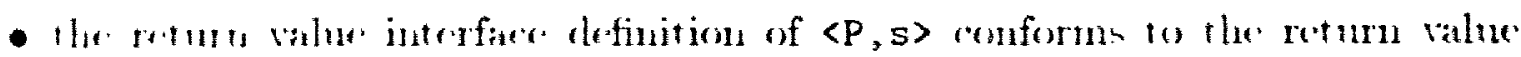
intref far definition of $\langle Q, t\rangle$ (romariane $)$.

- Hhe return value alinsing attributes of $\langle\mathrm{P}, \mathrm{s}\rangle$ conforms to the corresponding ${ }^{4}$ setmo value aliasing attributes of $\langle Q, t\rangle$ (cosariatere).

- Her lehavioral deseription of $\langle P, s\rangle$ conforms to the behavioral description of $\langle Q, t\rangle$ (a)varianer $)$.

\subsubsection{Interface Definition Conformance}

Revall that an interface definition is either a single protocol. or a logical OR of two or more proterols. We define interface definition conformance as follows. The protored set for an interfare defintion is the set of protocols in the disjunction (or the set romisting of the single protorol). An interface definition I conforms to an interface definition 1 if and only if the protocol set for I is a subset of the protocol net for I." Figne 38 shows some examule conformance gelationships for interfare delinitions.

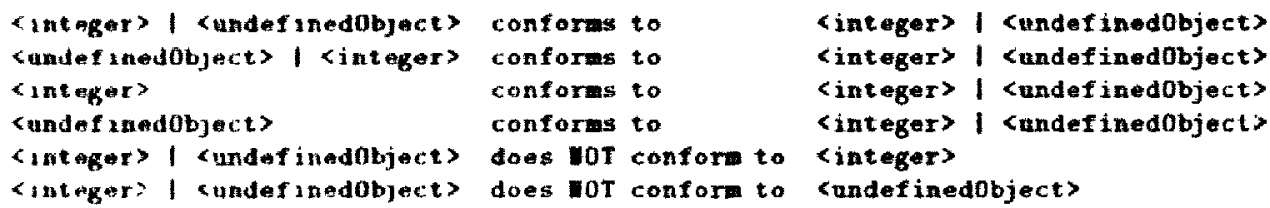

Figne 3s: Interfare Detinition conformance examples

Nene that interfare atinition conformanee is defined by a subset relationship, sine an interface definition is alefined to reguire an object conforming to one or more potoneds in the corresponding disjunetion. The sthbet relationship follows dimetly from this detinition.

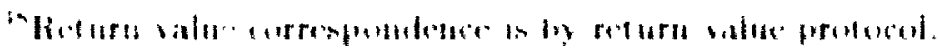

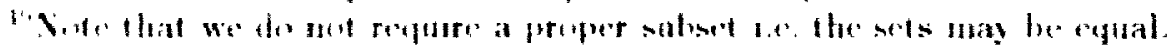




\subsubsection{Parameter Aliasing Conformance}

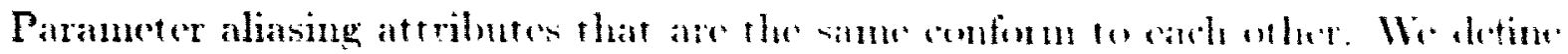
the following additional conformaner relationshipe annong the pitmaneter aliasing attributes:

- captured conforms to unspecified.

- uncaptured conforms to unspecified.

These follow trivially sine both captured and uncaptured satify tha comfon mance predicate inplied by unspecified. since unspecified impmen mon whe tions.

\subsubsection{Return Value Aliasing Attribute Conformance}

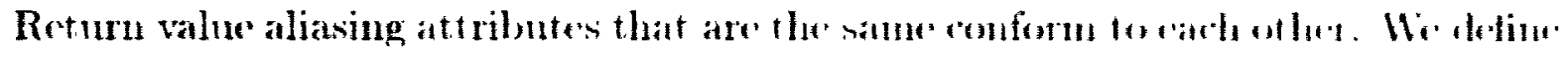
the following additional conformane relat ionship anmeng the retum value alia ing attributes:

- state ronforms to unspecified.

- new conforms to unspecified.

Again, these follow trivially since any alianing atribute satistios the predimate

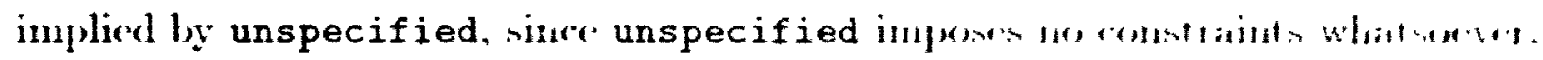

\subsubsection{Behavioral Description Conformance}

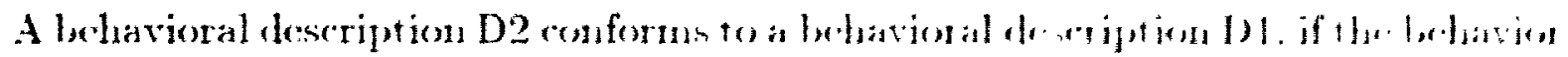
described by D1 is juplied by D2. Wr dediue the following sule for lethation descriptions.

- D2 includes the text of D1. and may only and anditirnat wat 


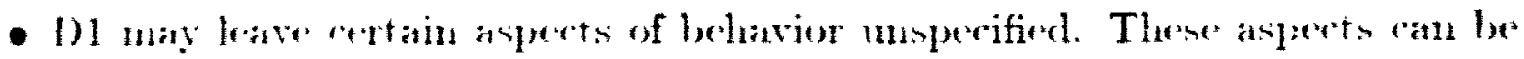
nwerified by $\mathrm{D}_{2}$.

- IV2 may unt contrialiot D1.

Given tha: D2 includen the text of D1, it is more diftienlt for a designer to acei-

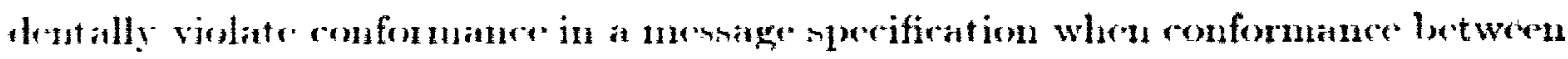
proterols has loen asserted. In most cases, contradictions are readily apparent.

The conformatner rules for belavioral deseriptions reflect the fact that substitulability requires that behavior be strictly additive. Conformant protocols may mly define new mestages, or provide more precise statements concerning the behation of existing messages.

\subsection{Refinement}

The retinement relation can be applied wherever we have defined conformance. and is defined as follows. Given any A and B such that there is a conformance swation defined on $A$ and $B$, then $A$ is a refinement of $B$ if $A$ conforms to $B$ but B dow not conform to A. Refinement applies to protocols, message specifications. interfare definitions, and aliasing attributes. It is also convenient to say that if $\mathrm{A}$ is a refine'ment of $B$. the'n $A$ refine's $B$.:

Retinement makes a st ronger statement than conformanes. Refinement deseribes the property which relates protocols in a sy that allows them to make progressively more and more precise statcments concerning objoct behavior, while still satisfying anformatice.

IVic call at mensage specification in a protocol $\langle\mathrm{P}\rangle$ a definition if it is not included in iny pretereol to which $\langle P\rangle$ conforms. Otherwise it is a refinement. The protocol

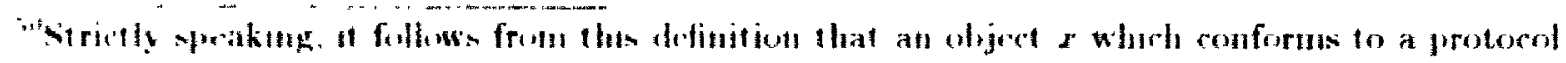

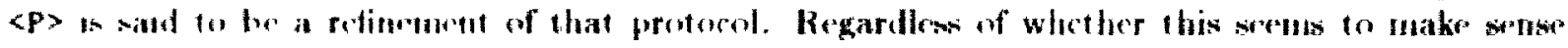

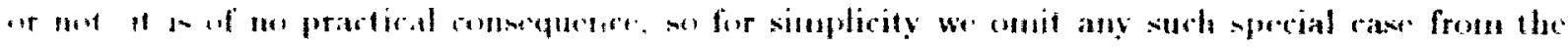
thetimuthll 


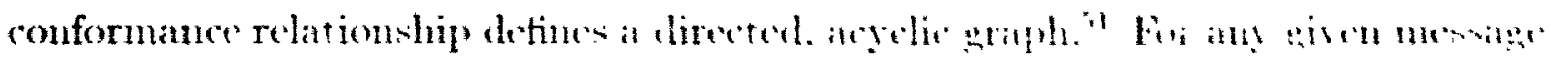

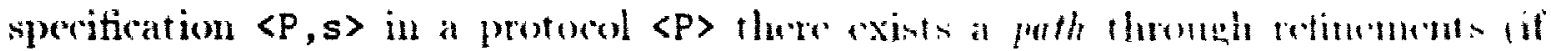
any) to the definatzon $\left\langle\mathrm{P}^{\prime}, \mathrm{s}^{\prime}\right\rangle$ of the mesiage speritiontion. The set of all pathe

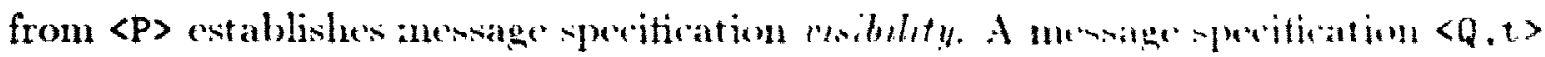
is risible from a protocol $\langle P\rangle$ if either $\langle P\rangle=\langle Q\rangle$ on then exints a path from $\langle p\rangle$

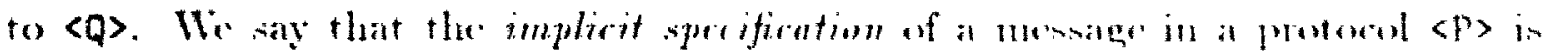

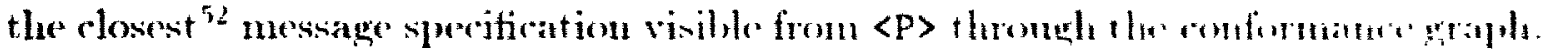
Thus the implicit specification may be cither in $\langle\mathrm{P}\rangle$, or in some protenel to whicle

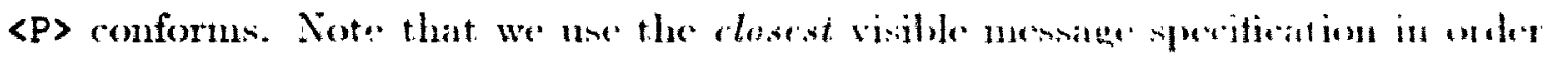

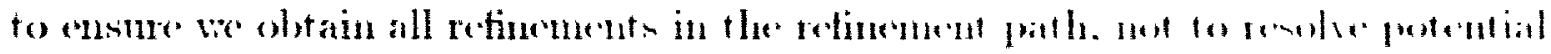

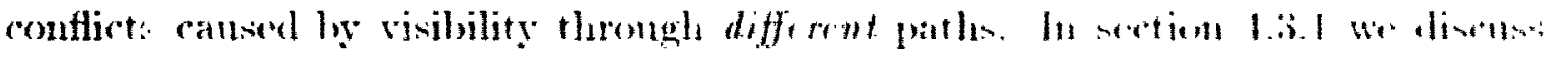

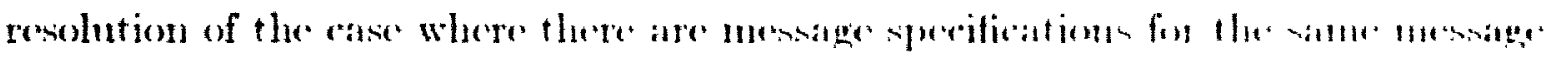
select or visible through different path".

Figure 39 shows a segment of a conformance graph tateing the visibility of the \#add: message for the <orderedCollection> proterol.

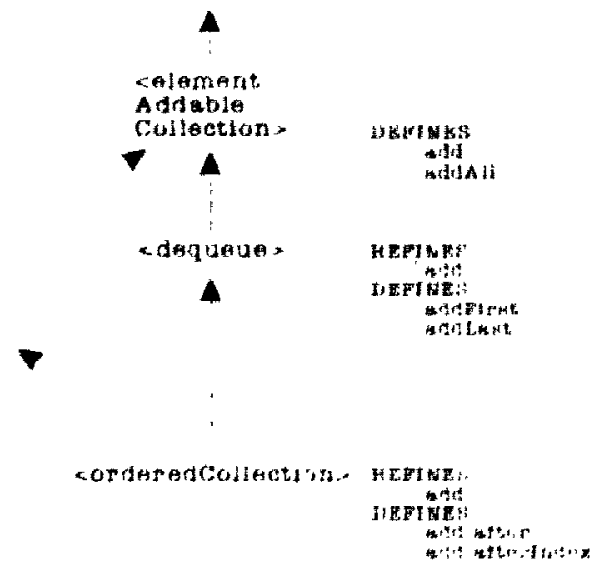

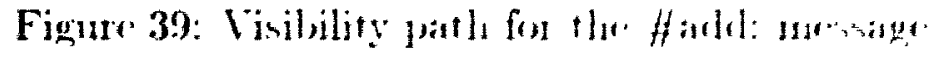

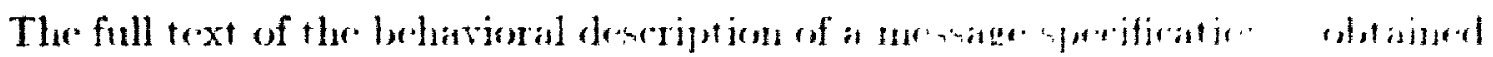

\footnotetext{
"In particular it forms a latlere

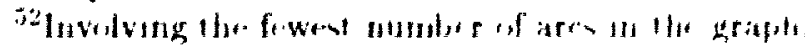




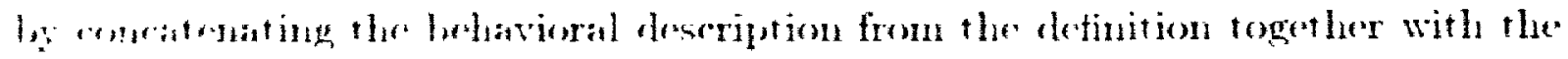

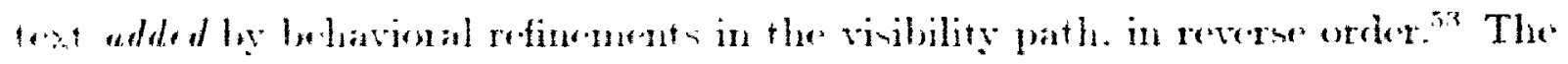

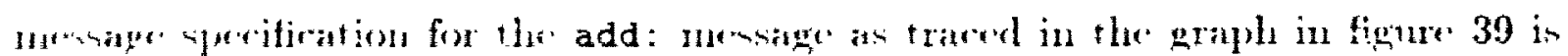
shrwn in figur. 40 .

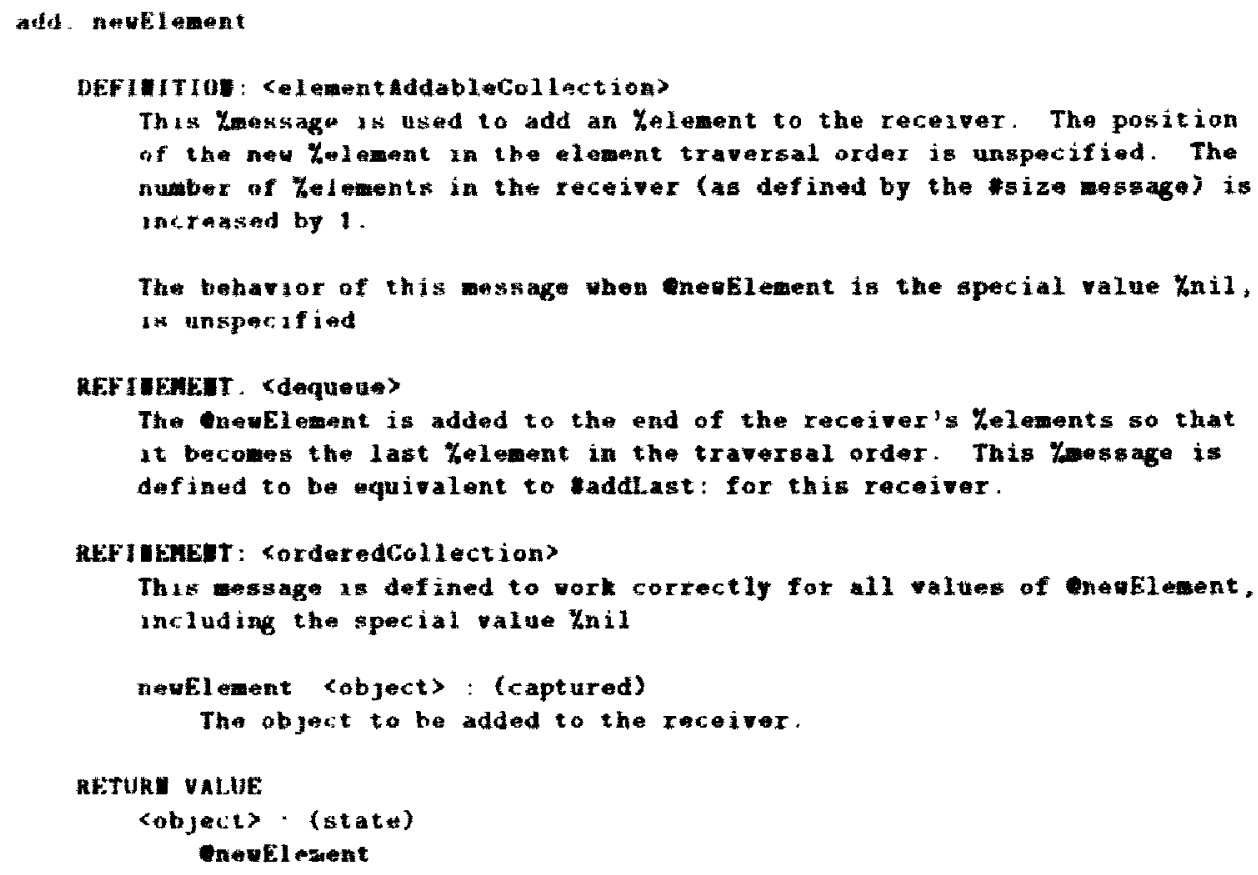

Figme 10: The \#add: nessage for Orderelcollection

In this 'xamplo, <elementaddablecollection> defines the adding of an alrment to it collection. hut does not sperify where in the collection the elemant in moded. Adhitionally since sonte collect jons use the value nil specially in

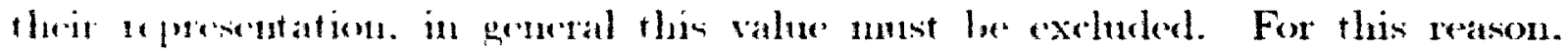
selementAddablecollection> disallows the valus. The <dequeue> protocol define the ability to ald and remore from both and of a collection. and refines the \#add: message to indieate that chenents are alded to the end of the collection. Fi-

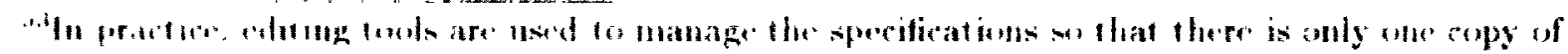

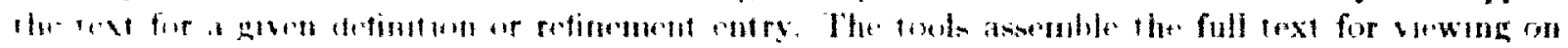
(i. 


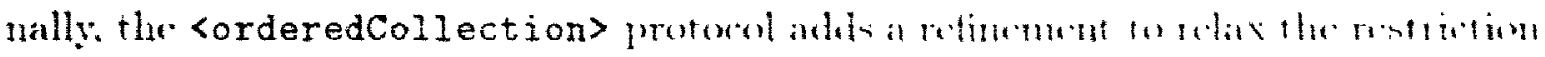
on nil valued parameters.

\subsection{Properties of Conformance and Refinement}

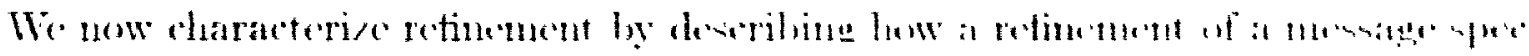

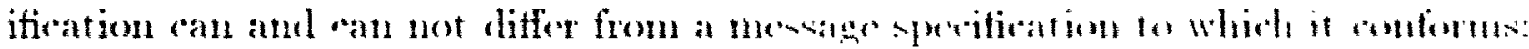

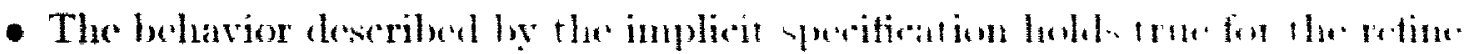
ment (conformanec).

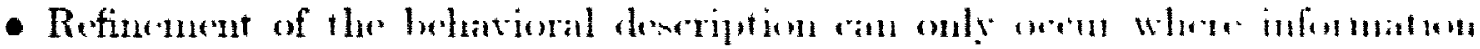

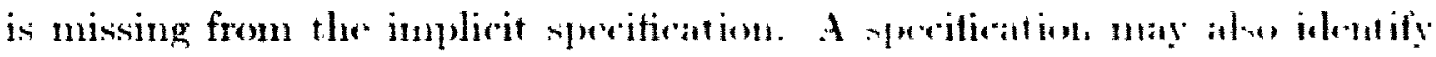

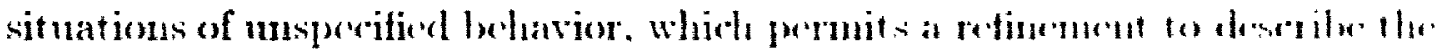

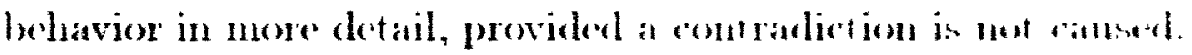

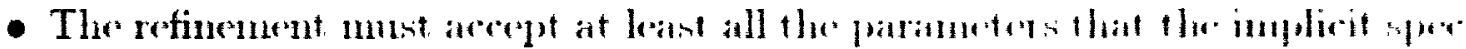

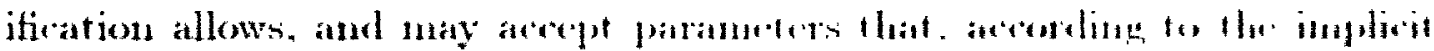

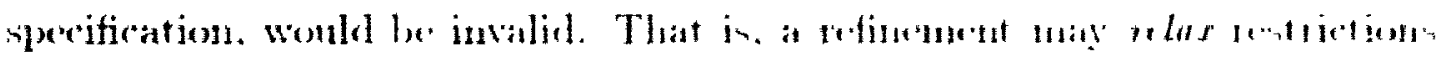

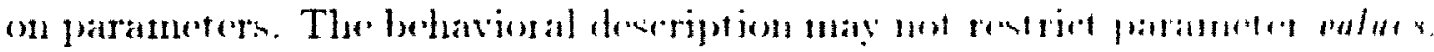
(parameter cont ravarianec)

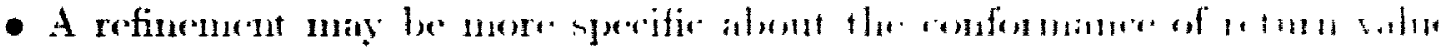

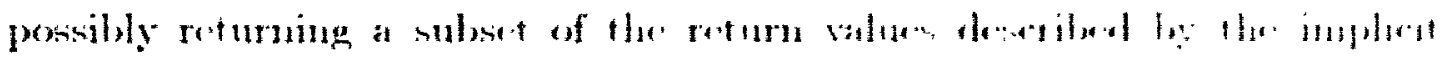

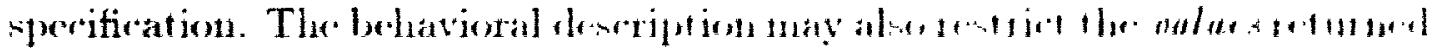
freturn value covarianes)

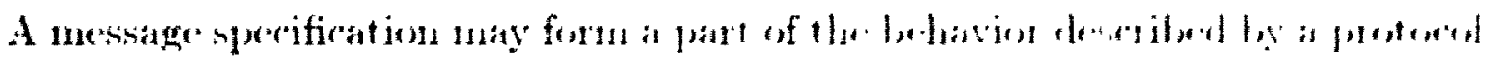
〈P> in the following ways:

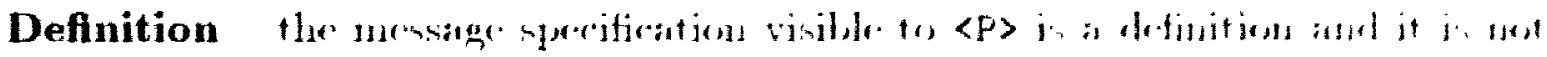

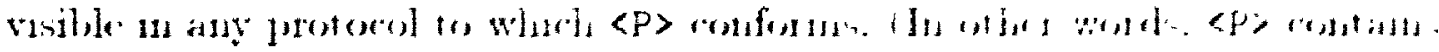
the definitions. 


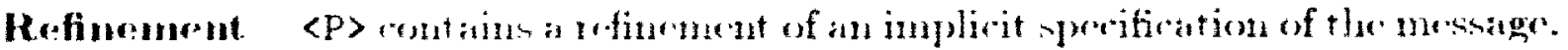
Conformance an implicit newage sperification is visible and there in no refineIII n in in $\langle P\rangle$.

\subsubsection{Conflict Resolution}

Since protorol conformane forms a directed aryelie graph. there can be multiple conformane paths to the sanc mestage specitication. Consider the example conformanere praph shown in figure 41 .

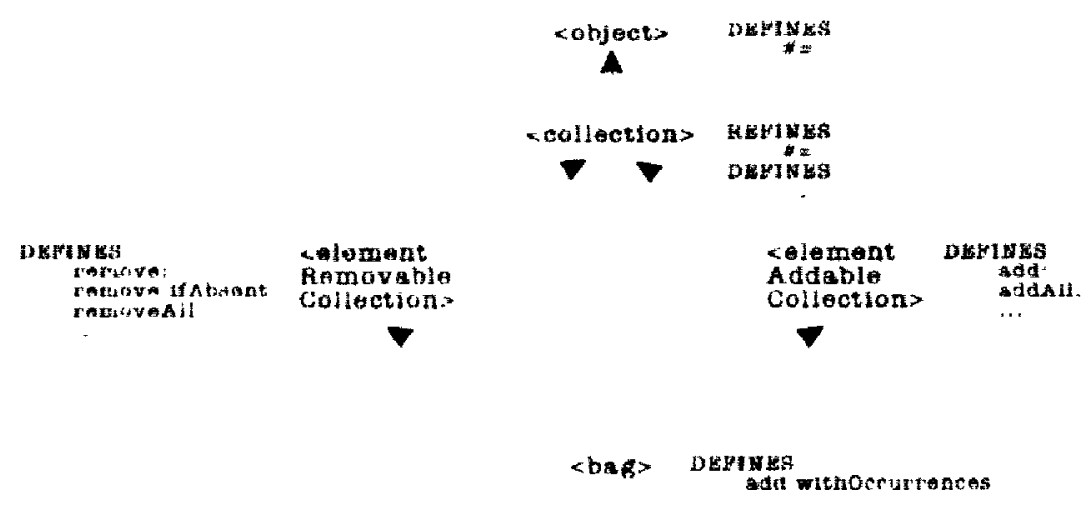

Fignre 11: The potential for specitication conflicts

Note that <bag> implicitly conforms to <collection> and <object> throngh transitivity. A protocol or olyject conll conform to <elementAddableCollection>. <elementRemovableCollection>. or both simultancously. There is the potential for an inconsintency if. for exanple. <elementaddableCollection> and <elementRemovableCollection> both defined or refined the same message. This

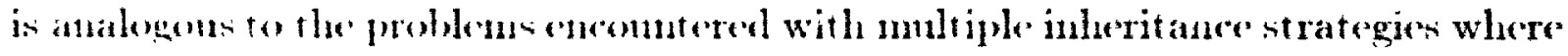
a nethert implenentation in inherited from two or more superelasses. We resolve this an follows.

If a mesnge specitiontion for a given message forms a part of the belarior deseribed ly a protecol (in any of the abeve ways). we say that the protocol supports 
the mesage. Given a protocol and messange whith in supperted ather hy deting

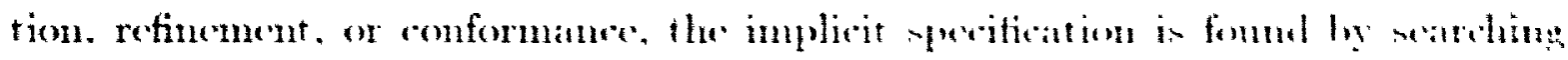
for the first retinement or definition in the conformantere path frem the protencol. Esing the above example, the semrec of the speritiantion for the \#= me satge for the

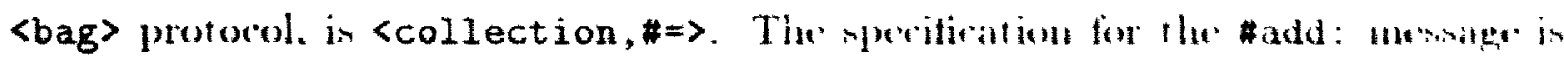
<elementAddableCollection, \#add:>. In orthr to prevent ambinity and cout at

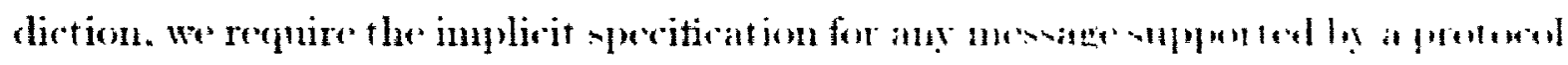
to be the sane <protocol, selectors pair regardlese of whing path is whe That

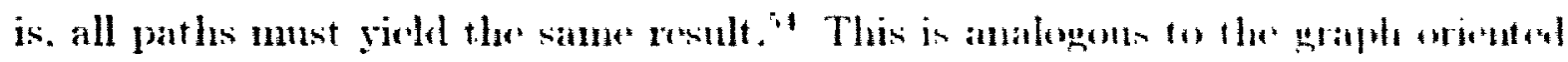
solution for resolving nultiple inheritanes [Sicter $\times 6$ ].

\subsubsection{Substitutability}

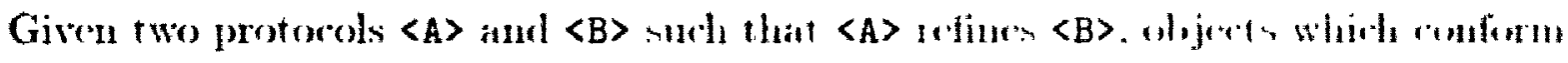

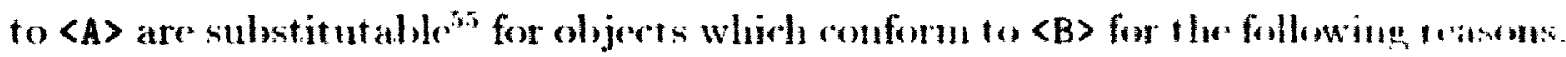

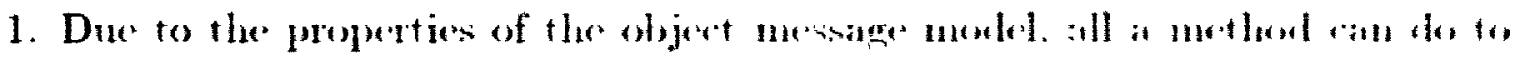

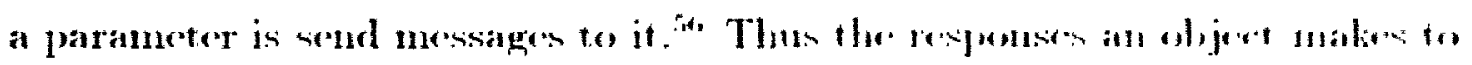
these messages fully describes its extrually visible ledhavion.

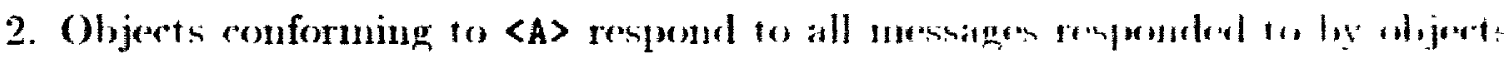
conforming to $\langle\mathrm{B}\rangle$.

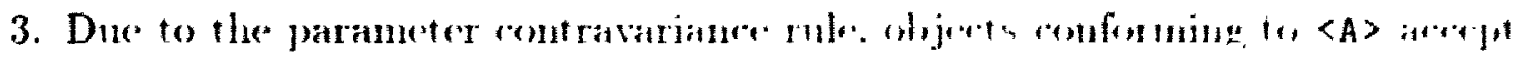

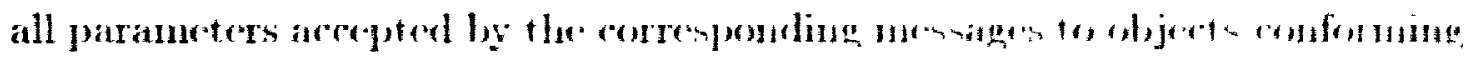
to $\langle B\rangle$.

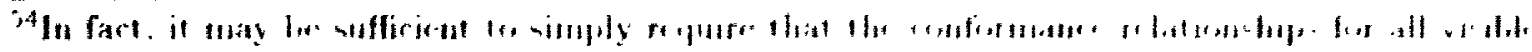

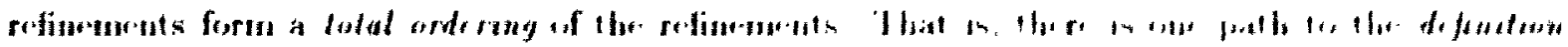

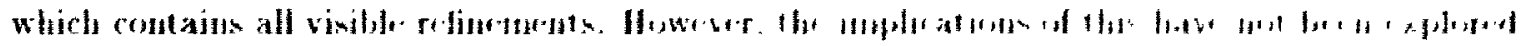

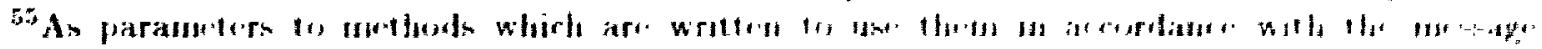
spereifientions in $\langle B\rangle$.

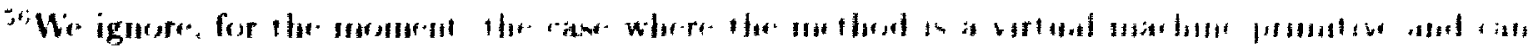

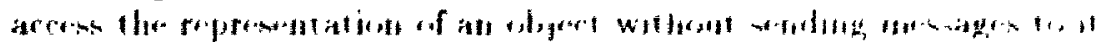




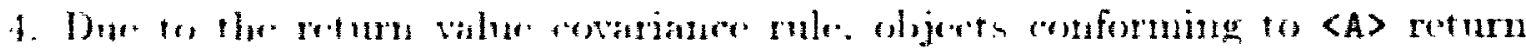

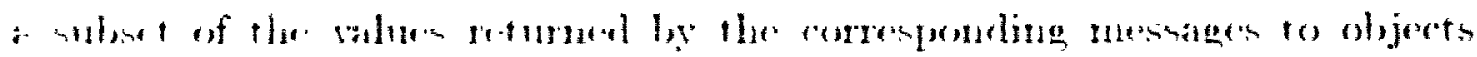
conforming $t$ (o) $\langle\mathrm{B}\rangle$.

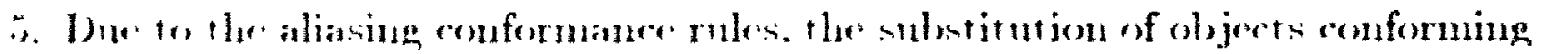

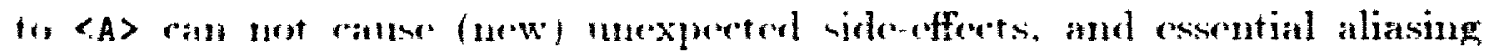

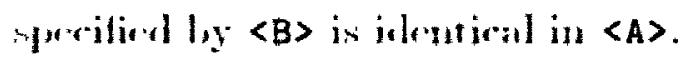

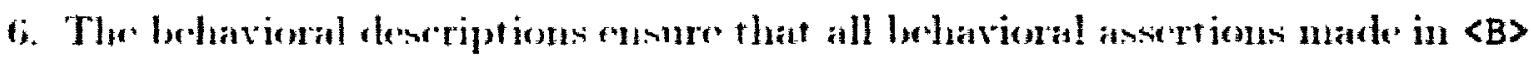
lwhl in $\langle A\rangle$.

\subsection{Summary}

In this dhapter we have explained how protocols define nembership in a group of

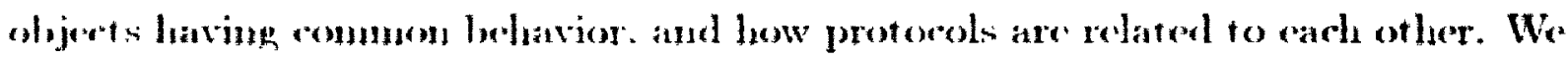
have discusised the properties of romformance and refinement. and how they establish substitutability, Since protocols do not form a partition of messuge arectors, we

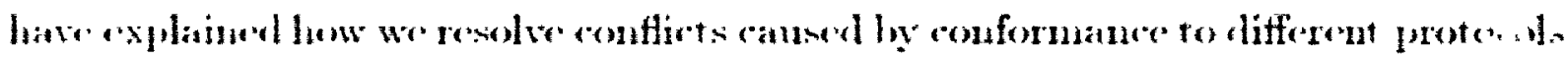

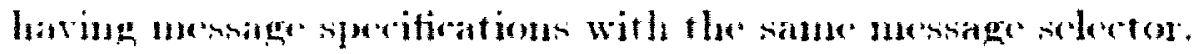

In the mext chapter. we anderes practionl issues involved in applying the approbeh. and present our fareming of the Collection clasises. eontrasting it to that of $[$ conk 92$\}$. 


\section{Chapter 5}

\section{Applying the Model}

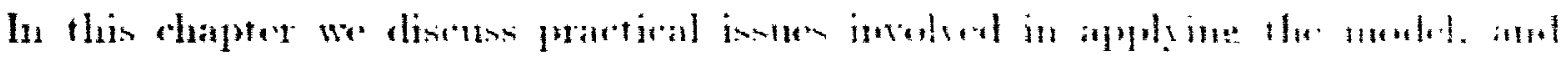

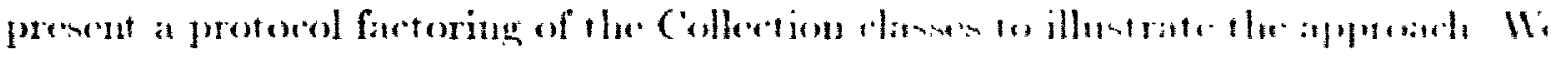

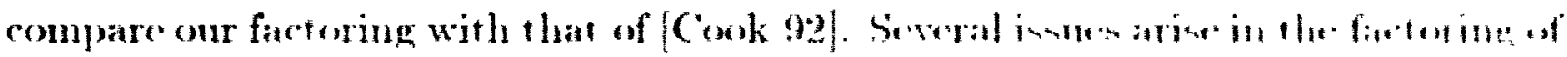

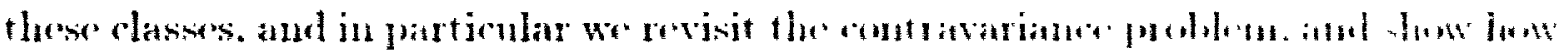

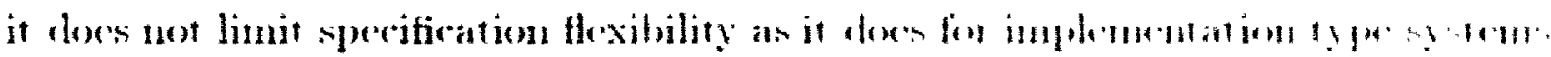

\subsection{Abstract and Concrete Protocols}

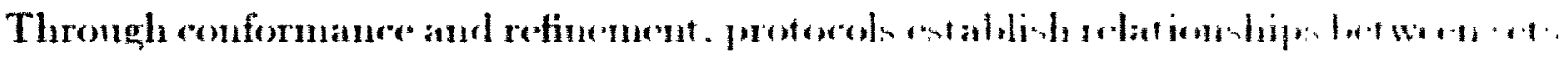

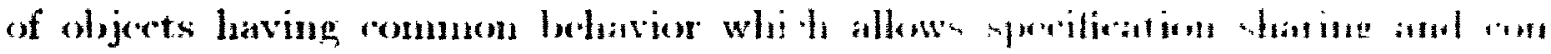

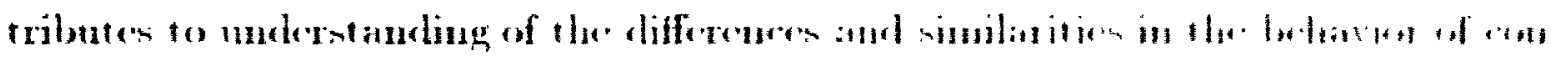

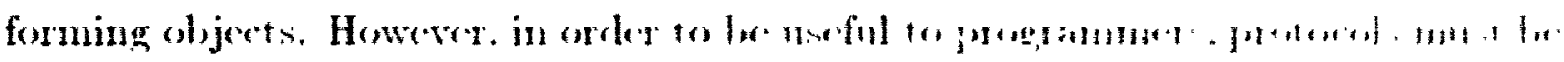

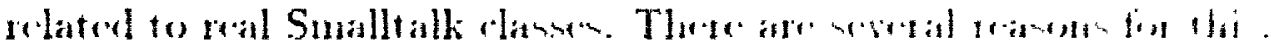

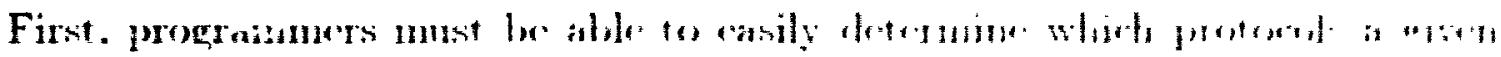

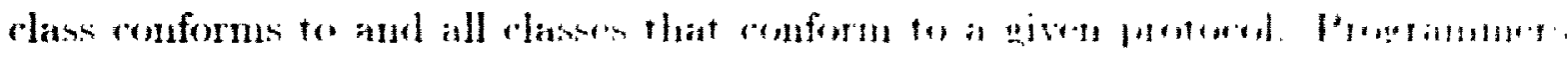

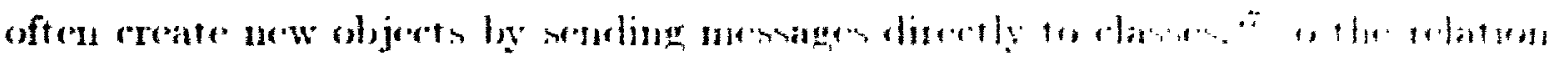

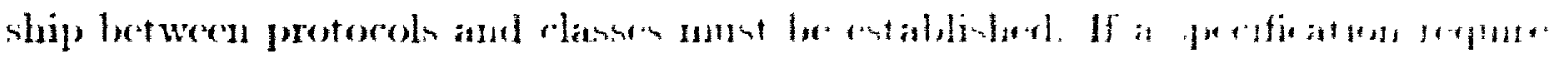

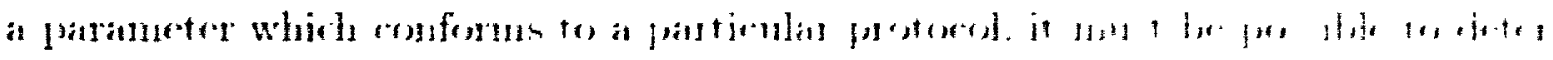

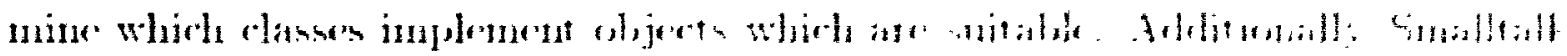

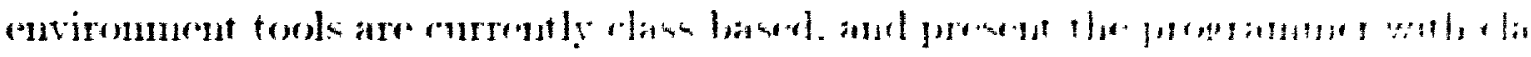

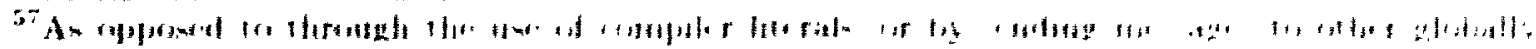
known thights
} 


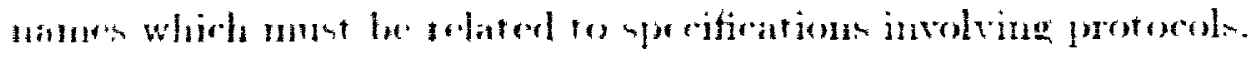

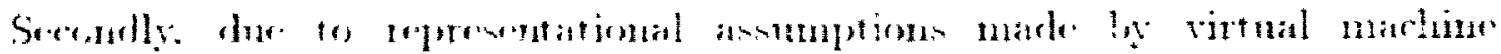

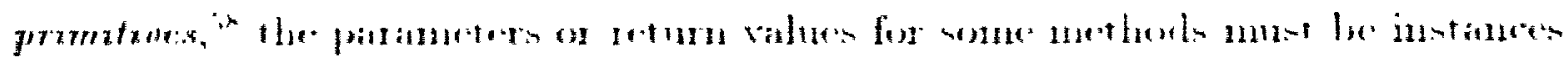

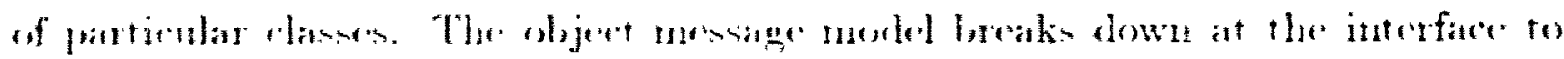

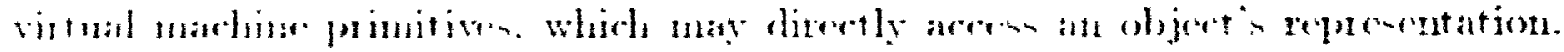

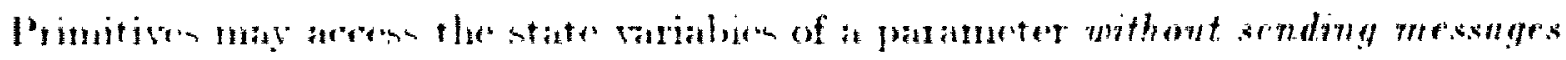
16, it.

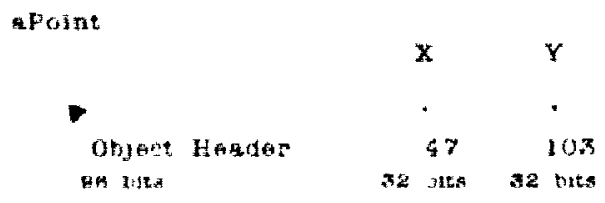

\section{Fignar. 42: ()liject representation}

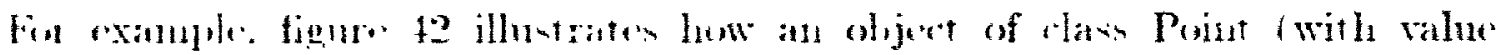

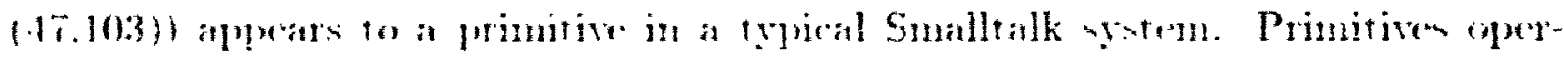

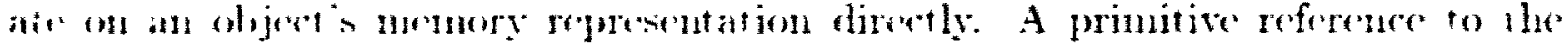

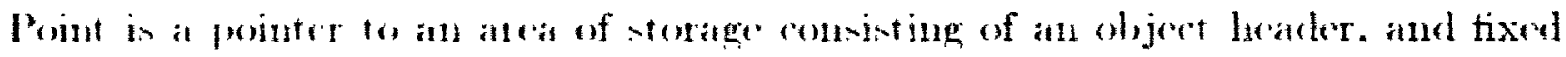

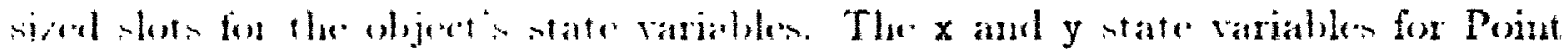

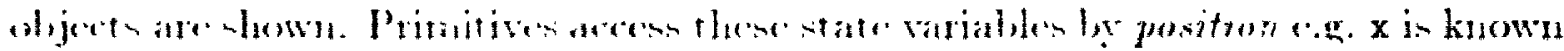

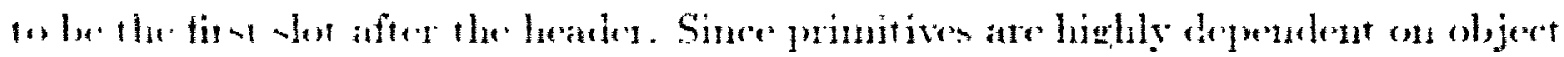

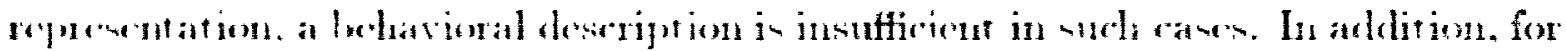

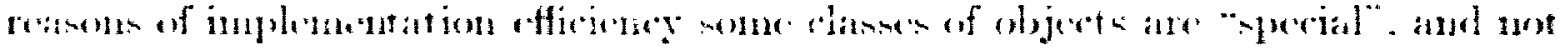

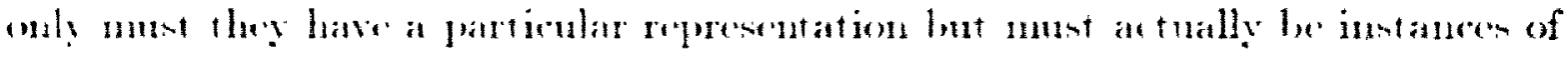

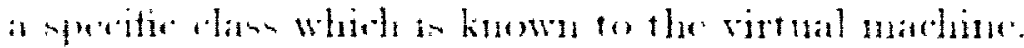

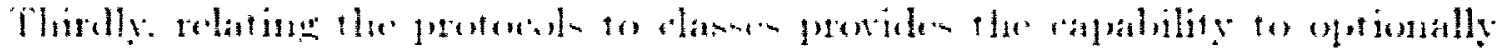

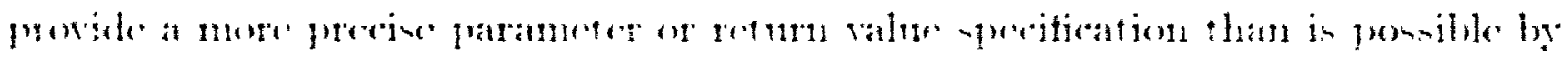

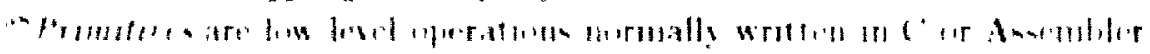




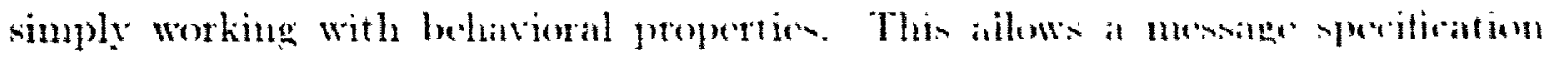
to state that it retume or repuires instames of a partionlat alas. pather than an instane of some momown clasin that helaves in a compatible way.

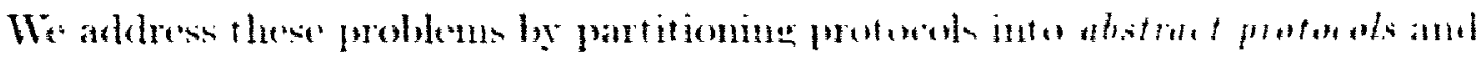

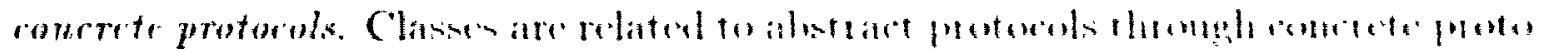

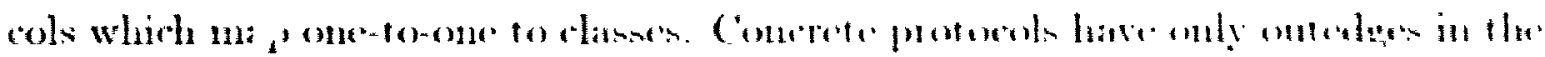

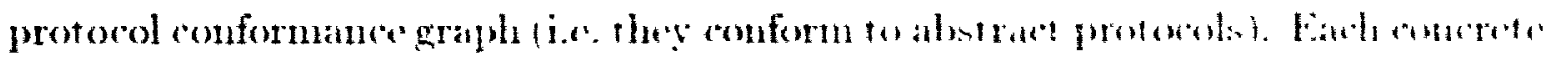

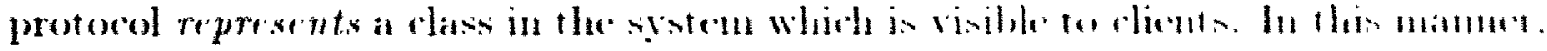

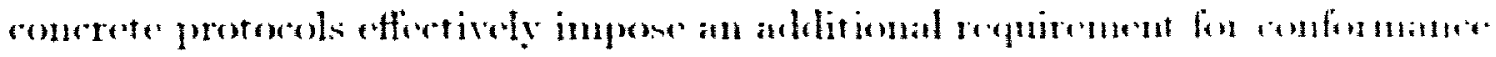
that of membership in a partionlar class.

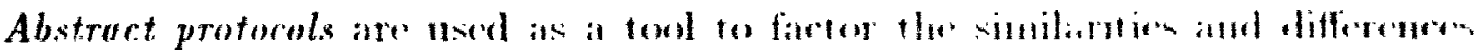

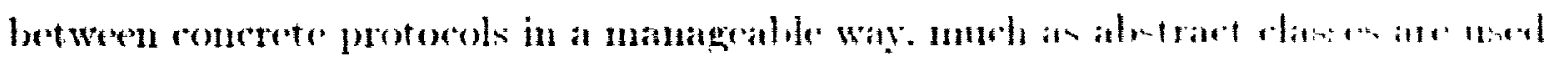

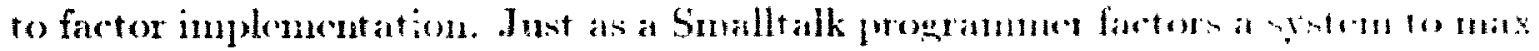

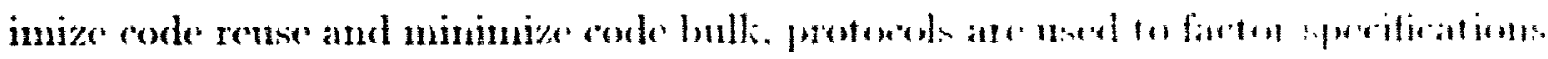

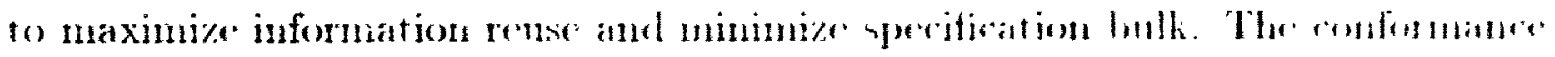

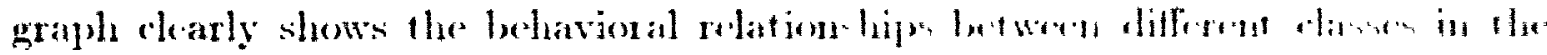

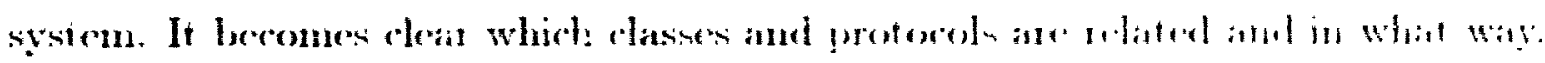

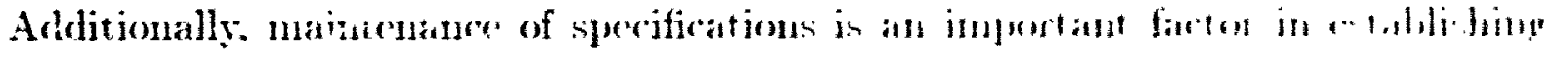

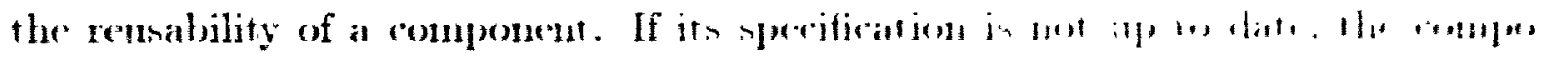

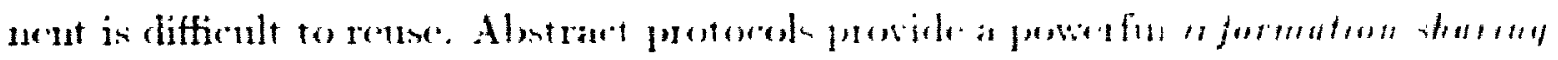

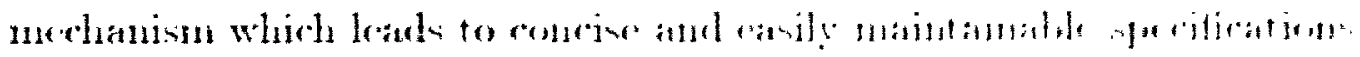

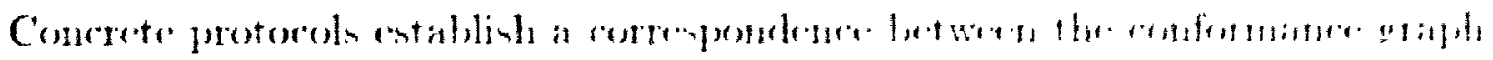

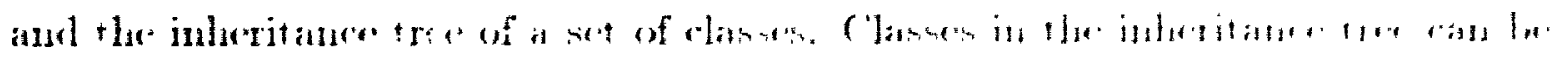

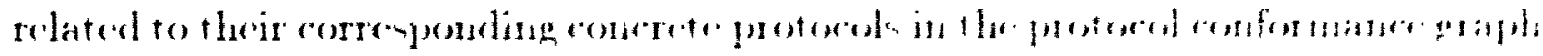

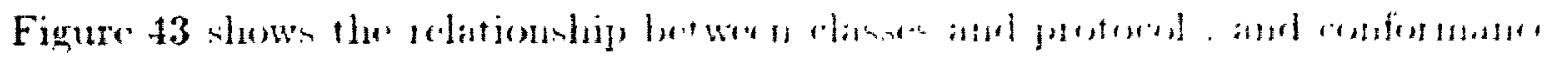

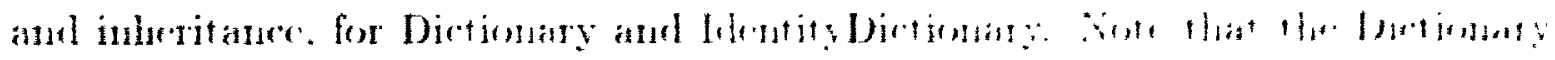

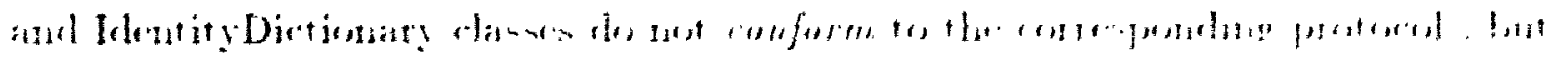

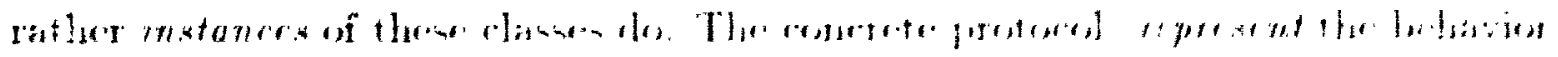




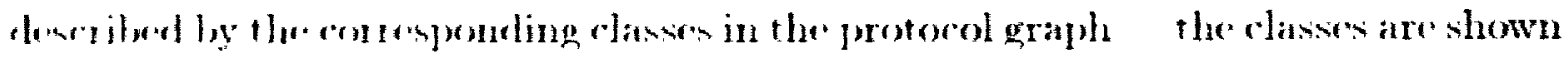

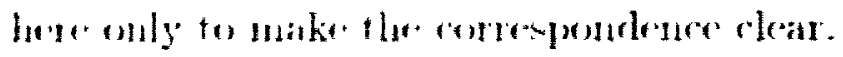

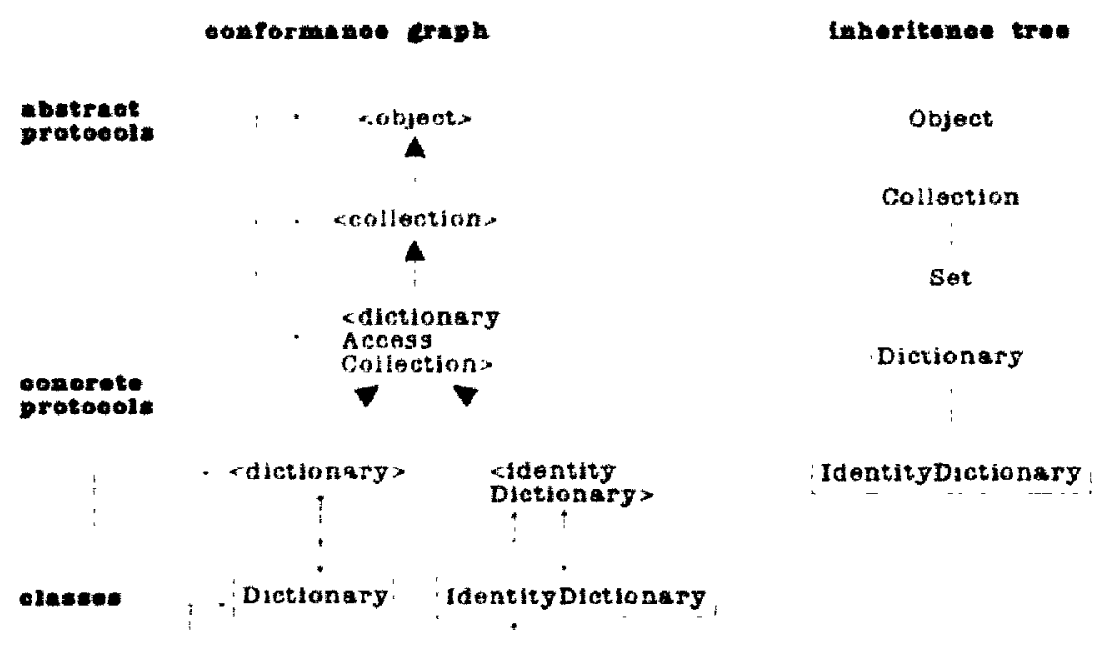

Figure 43: Protocols and Clasines

For convenience, we nom mally cheose enerete protocol names that are the same as theit correspomeling dass names. lut it is important to note that this

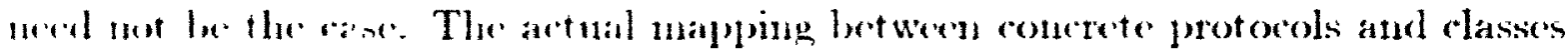
nay he phitform speritie. For example. While the <string> protocol describes instances of String in Suallalk/V [Digitalk 90), it describes instances of ByteString in Smallalk-80 [PPS 92]. A String class exists in Smalltalk-80. hut it sorves as an

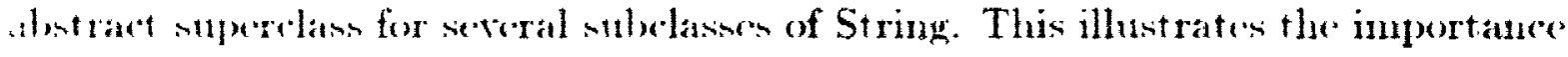

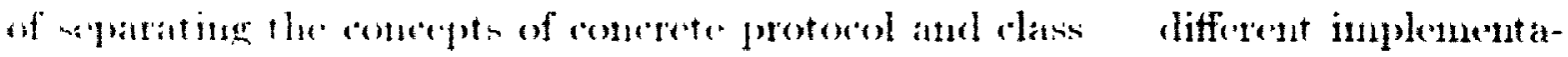

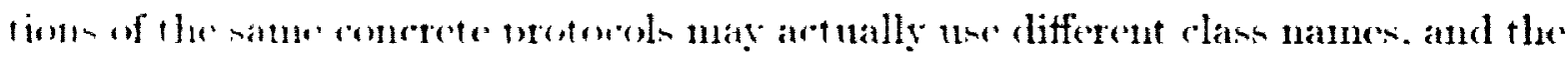
artual matpline is platform dependent.

Rolating protorols to clanese allowe questions about the relationship between protorole and atasen to be answered. Given any dast in a syitem. the sot of all

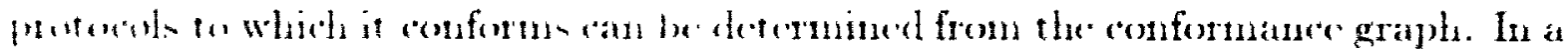

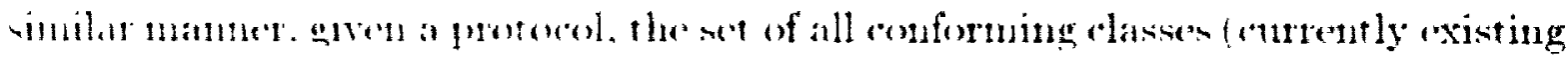


in the system an be determined.

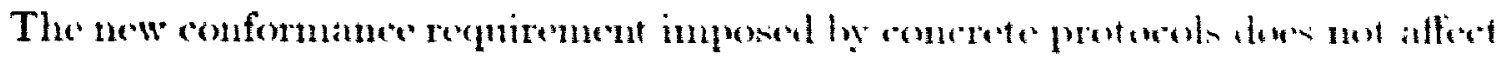

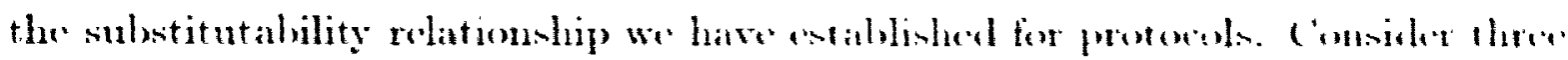

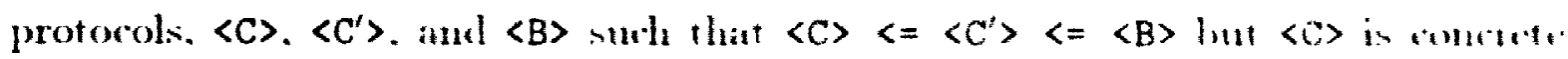

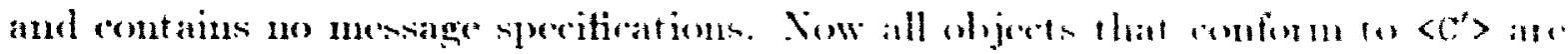
substitutable for objects that conform to $\langle B\rangle$. The protonol $\langle\mathrm{C}\rangle$ in a and ty the

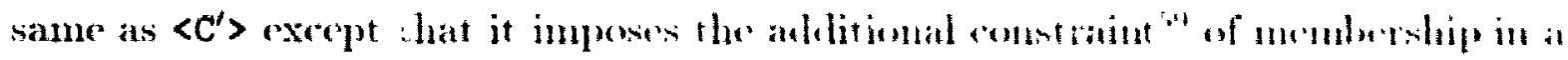
particular class. Thus the ohjeets that conform to $\langle\mathrm{C}\rangle$ are neressirily a subset of

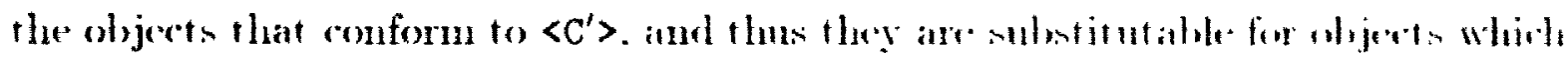

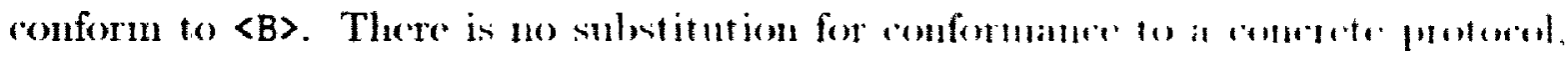
sine the class is sperified exactly.

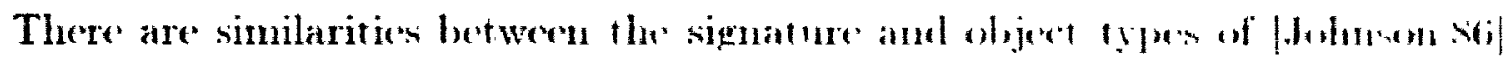

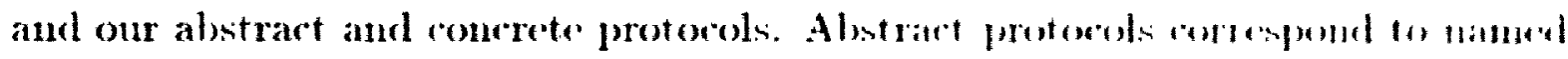

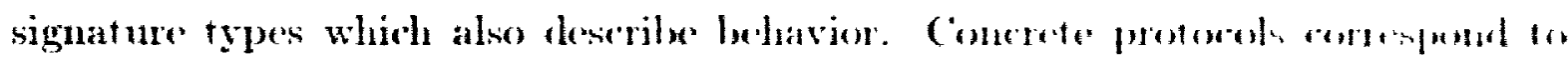

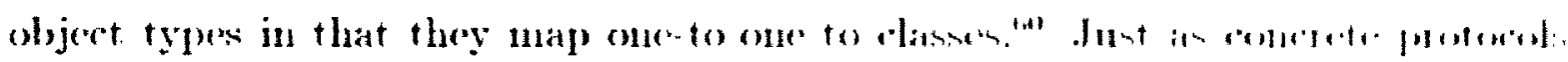

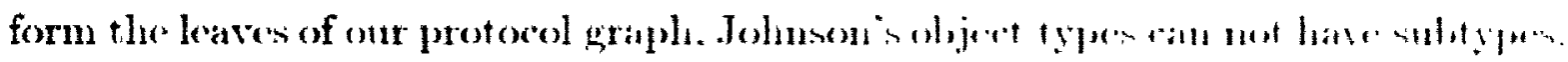

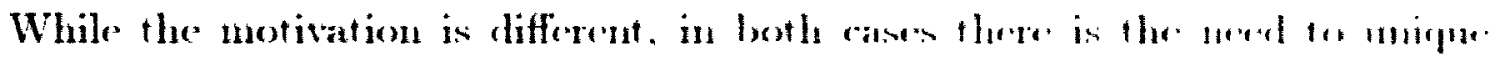

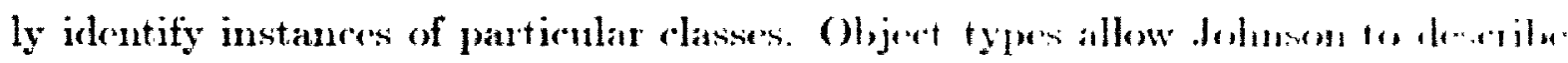

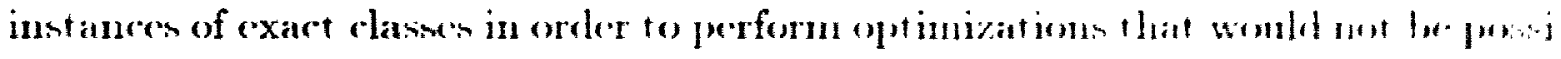

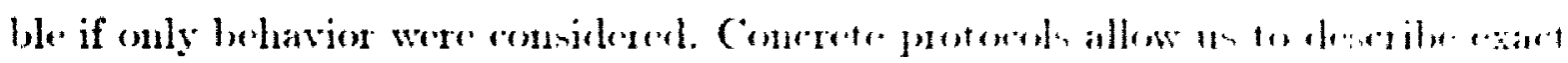

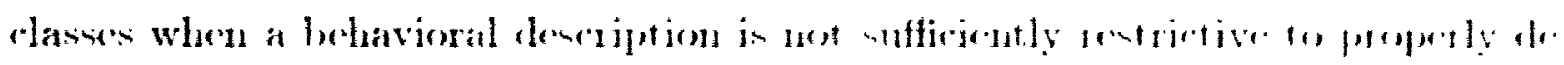

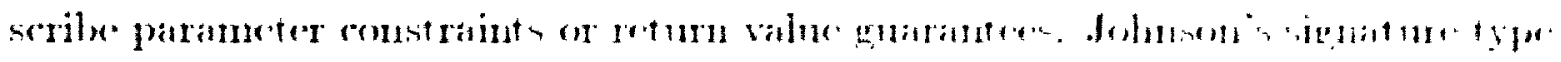

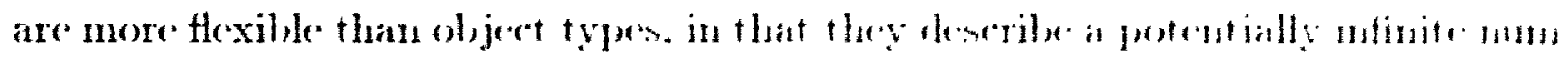

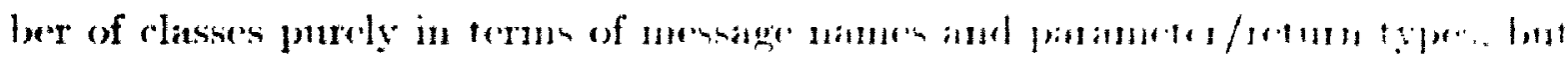

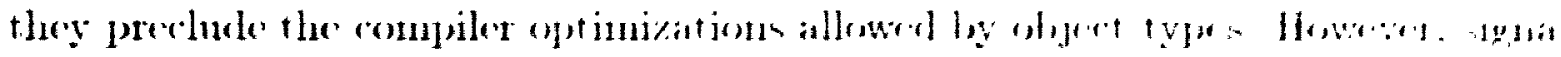

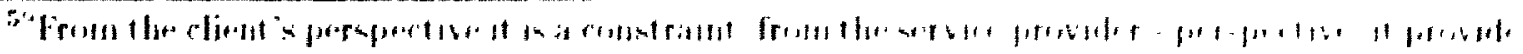
addicunal enformaluon.

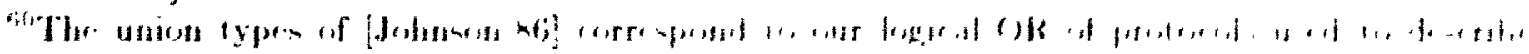
paramelers and returin values
} 
ture tyou permit metherls to be typed in a way that allows parameters which are intanes of elaces that ate wot get inplemented. One abstract protorols allow the sinn ffexibility as signather types, and they also proxide implementation flexilility when usel to decrib* retum values. Arlditionally throngh conformane and

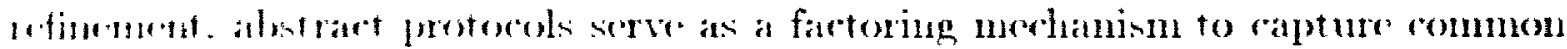

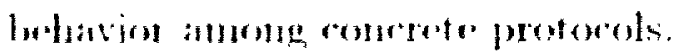

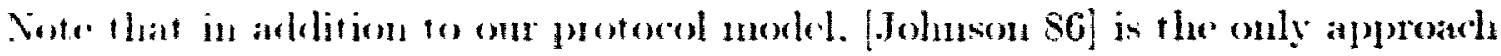
revirewel which has the alility to numbignously restriet paramerers and/or return value to instancen of particular elatses. All the of her approades permit substitution of iustances of different elasses, provided they are behaviorally substitutable. Such approalues can not describe situations where such substitutions are not acreptialile.

\subsection{Special Protocols}

Mi. Anfime three sperial protocols as follows:

<cbject> A protemel to which all other protocols eonform.

<NONE> A protocol conforming to all oflere protocoln.

<RECEIVER> A notational comenience which represents the protocol to which the recivery of the me sage anforms.

All whiecte are detined to ronform to the <object> protocol. Although the

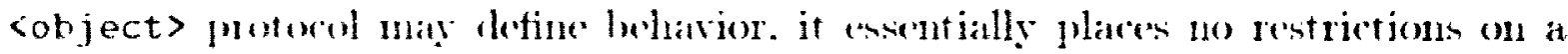
paramerer defintion sine it allows all possible paraneters. This is equivalent to

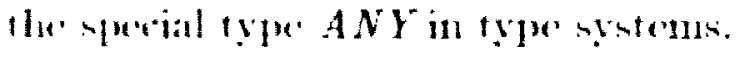

The Herial protoon <NONE> de tine no new lndavior of its own. It is equivalent

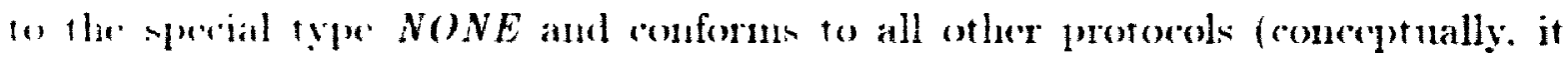

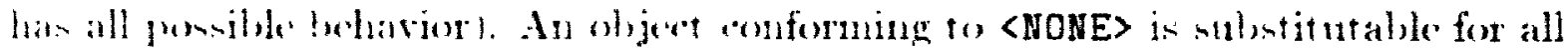

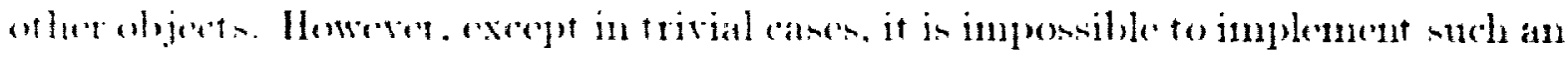




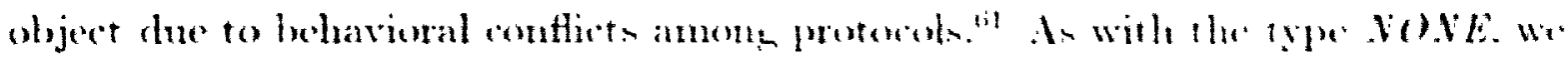

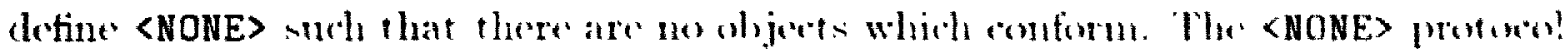

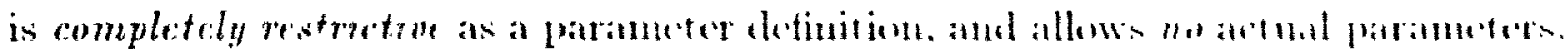

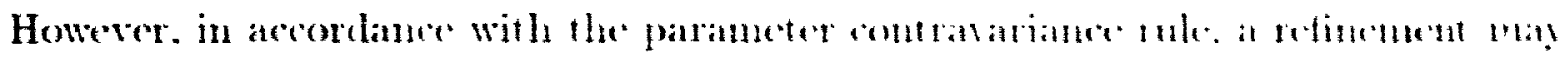

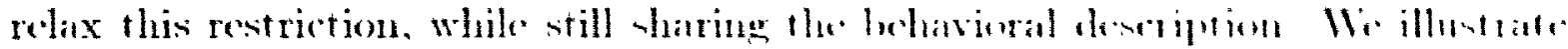
this property in the next section.

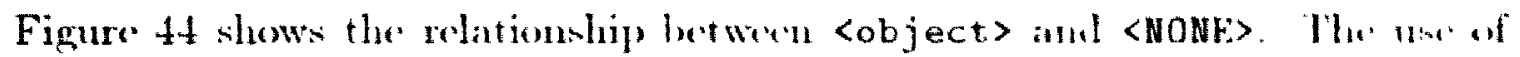

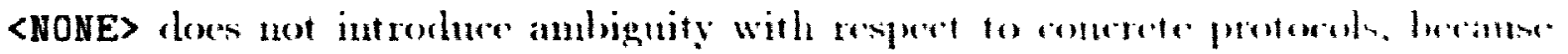
by definition it allows no conforming objects.

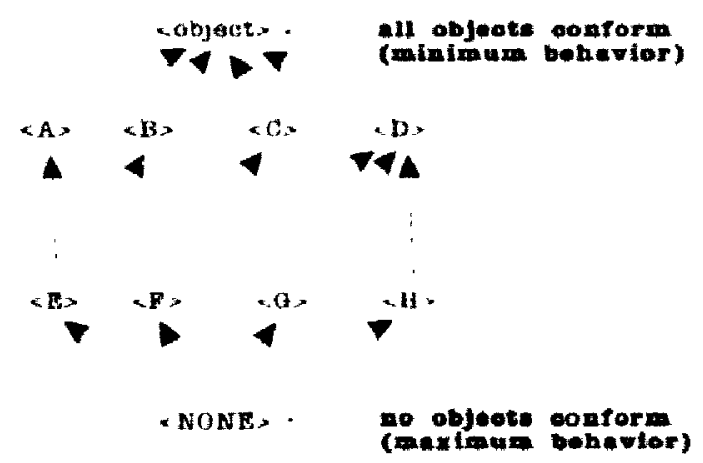

Finure 44: Dotining All and Nolling:

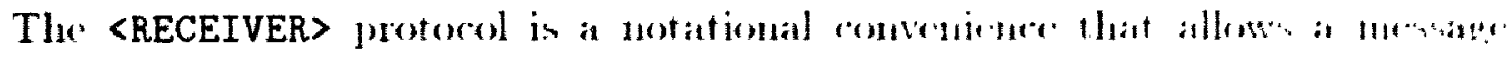

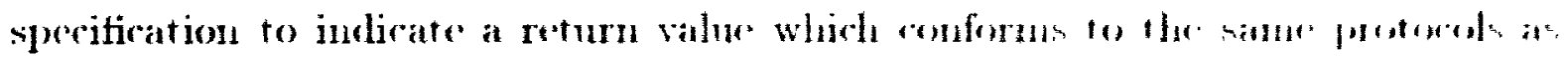

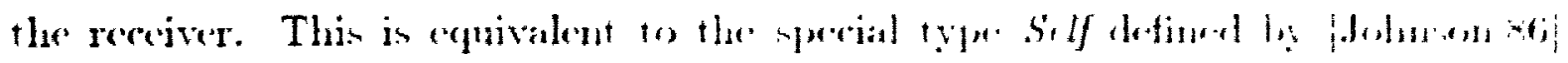

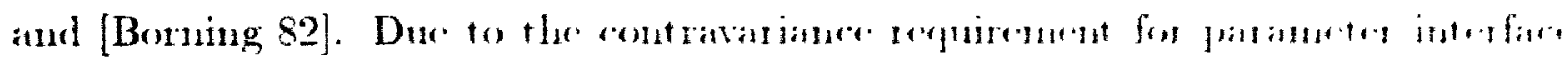

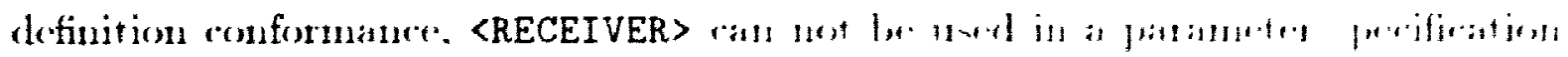

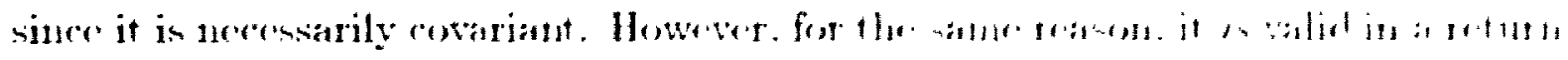
value sperifiontion.

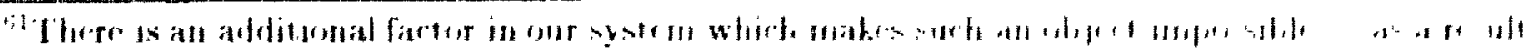

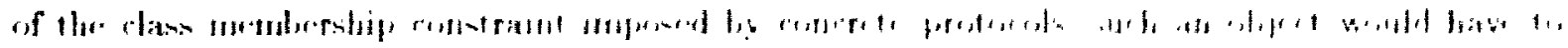

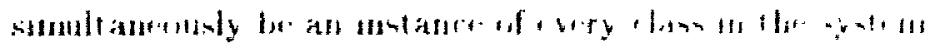




\section{$5.3 \quad$ A Factoring of The Collection Classes}

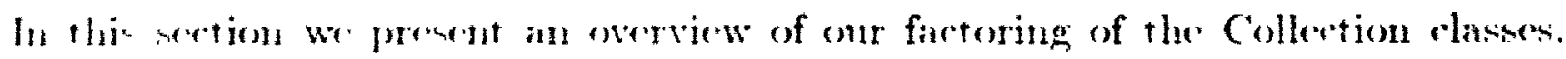
An important part of the motivation for this work was to develop a behaviomal sereifiation that womblallow portablo applieations to be written for several of lla majen Smallatk sy htems. In particnalar we considered three of the most popular Simallatk implementarion [PPS 92]. [Digitalk 90]. [Digitalk S9]. and the Blue Book [Coldlerg 85], as the basis for a sperification. The strategy used to detine the seope of the inhavior was as follows. We started with the behavior reseribed in the Blue Bowk and adrled all methods which have berome de facto standard. We consider a methol to be de facto standard if it is supported by both vendors in a compatible way.

An initial set of the mentagen supported by the Collertion rlasses was computed antomatically by looking at implemented and inlorited methods in a manner sinilar to that described by [Cook 92]. axerpt that three implementations (in addition to the Blue Book were involved instead of ome. Remoring methods that are canceled ly suluelasmes does not chiminate all of the problem areas. Each method must be mamually minsered and tested as required to determine it artual behavior. The following are the major problems found:

- Campllation Inleritod mothorls are not supported.

- Indireer Cancellation lnherited methods are implemented using methods whinh have hen anuelled.

- Coimeduat Saming Methods with the same name have different behavior and axpert different patamedens.

- Sublass Parameter Restrietion Subclasses arecent only a subset of the pa-

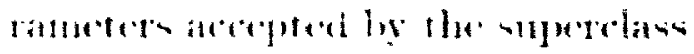




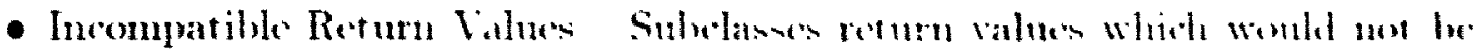
returned by stuperelassies.

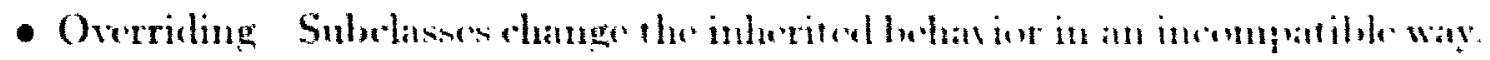

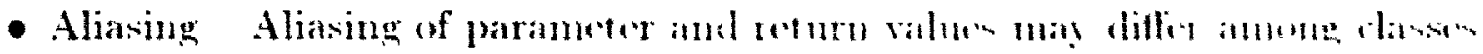

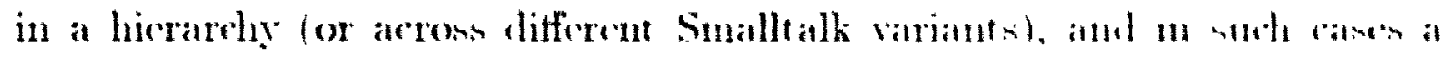

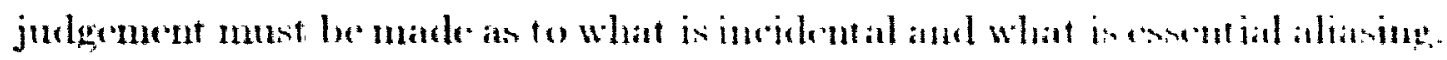

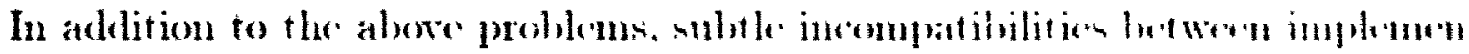
tations were discovered. and these were resolved by making the speritiention mene

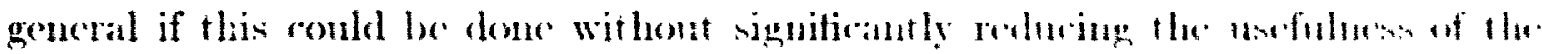

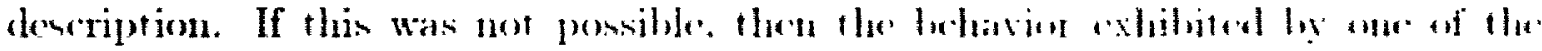

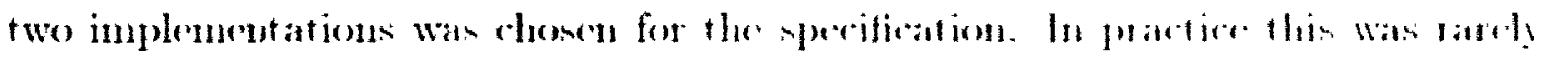
necessary:

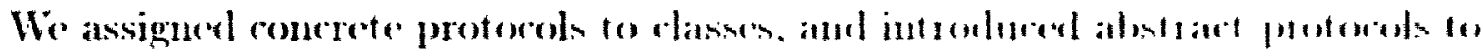

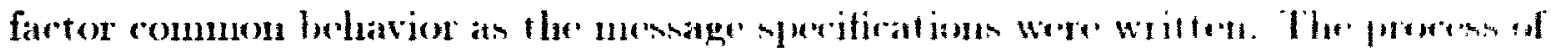

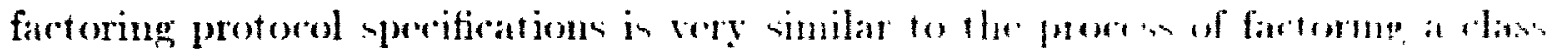

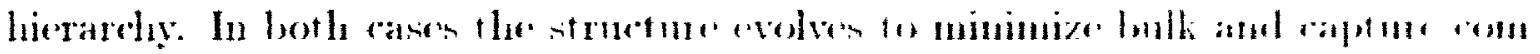

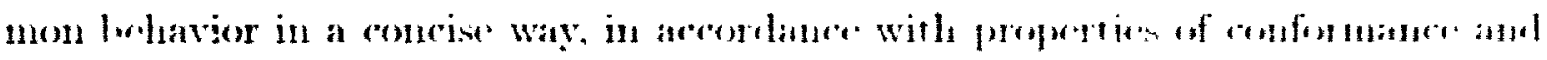

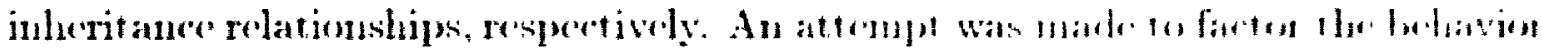

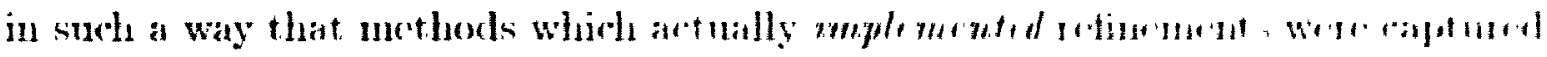
as such in the specifieation wherever ponsible.

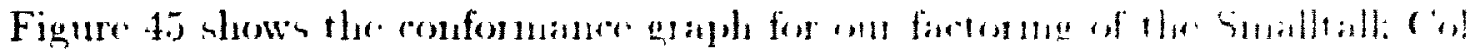

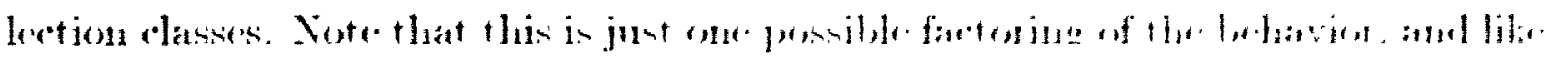

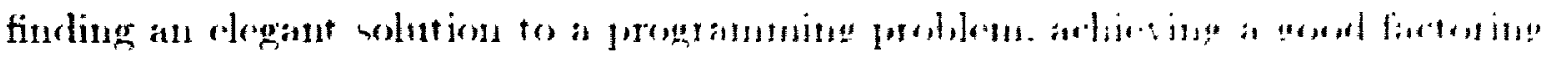

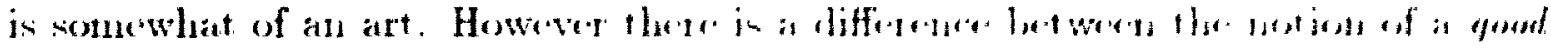

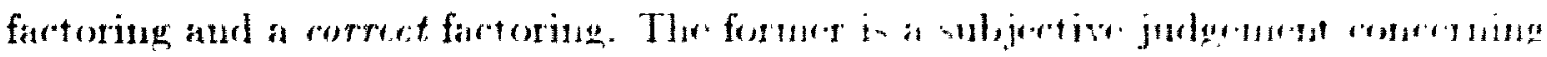

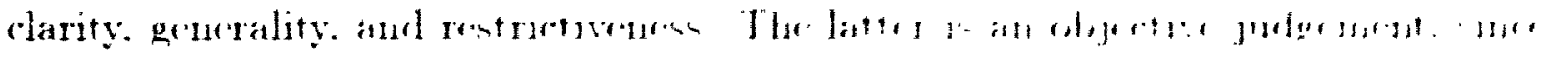

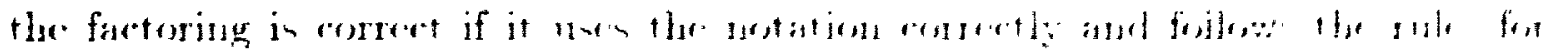


whiforanuer and refinement.

In the next sections we present an overview of each protocol. and explore the issues that an ise in mone detail. As an example. the full specification for the <collection> protomol is providerl in appendix A.

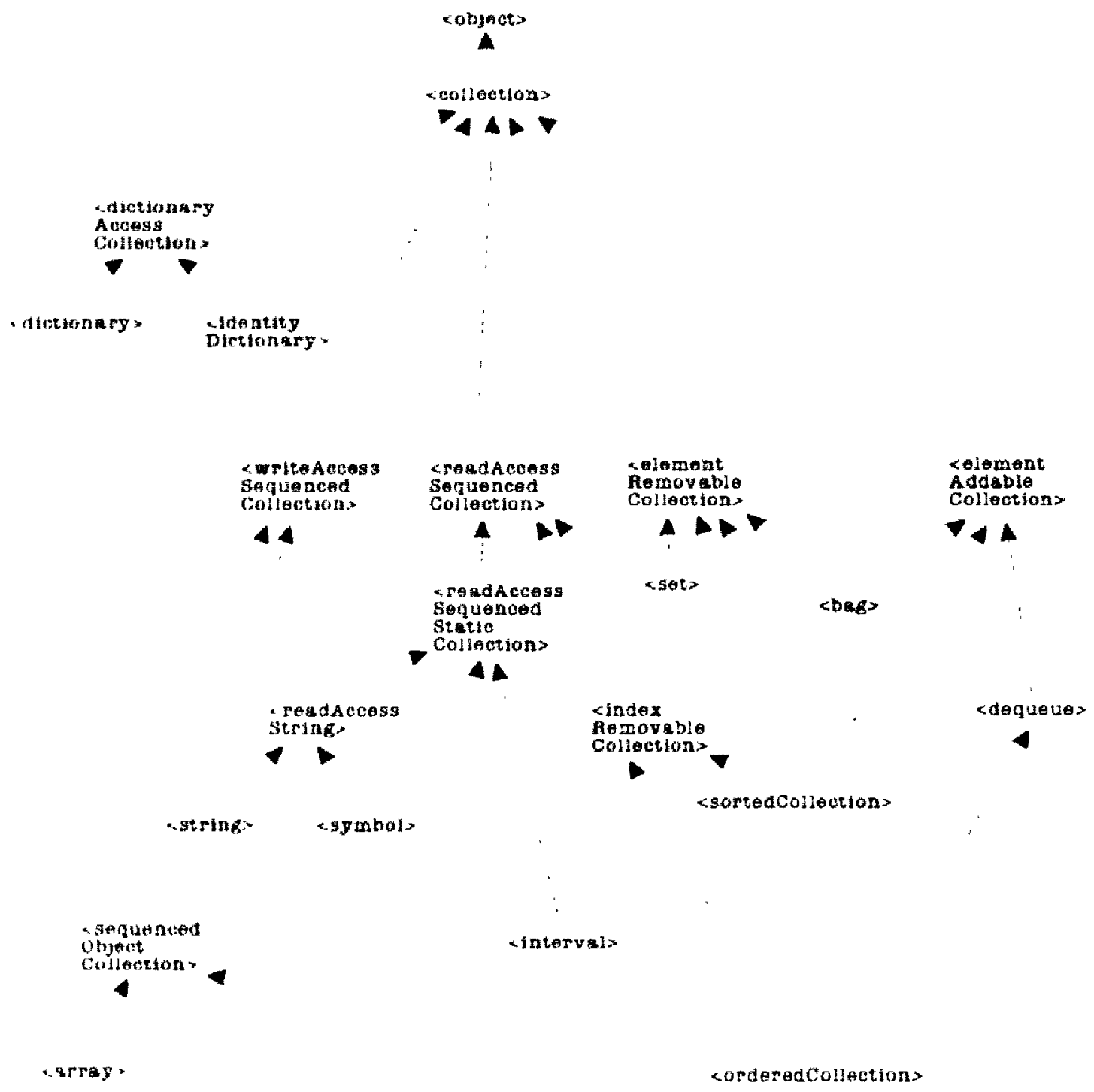

Finure 45: Conformatuce (rraph for the Collection classess 


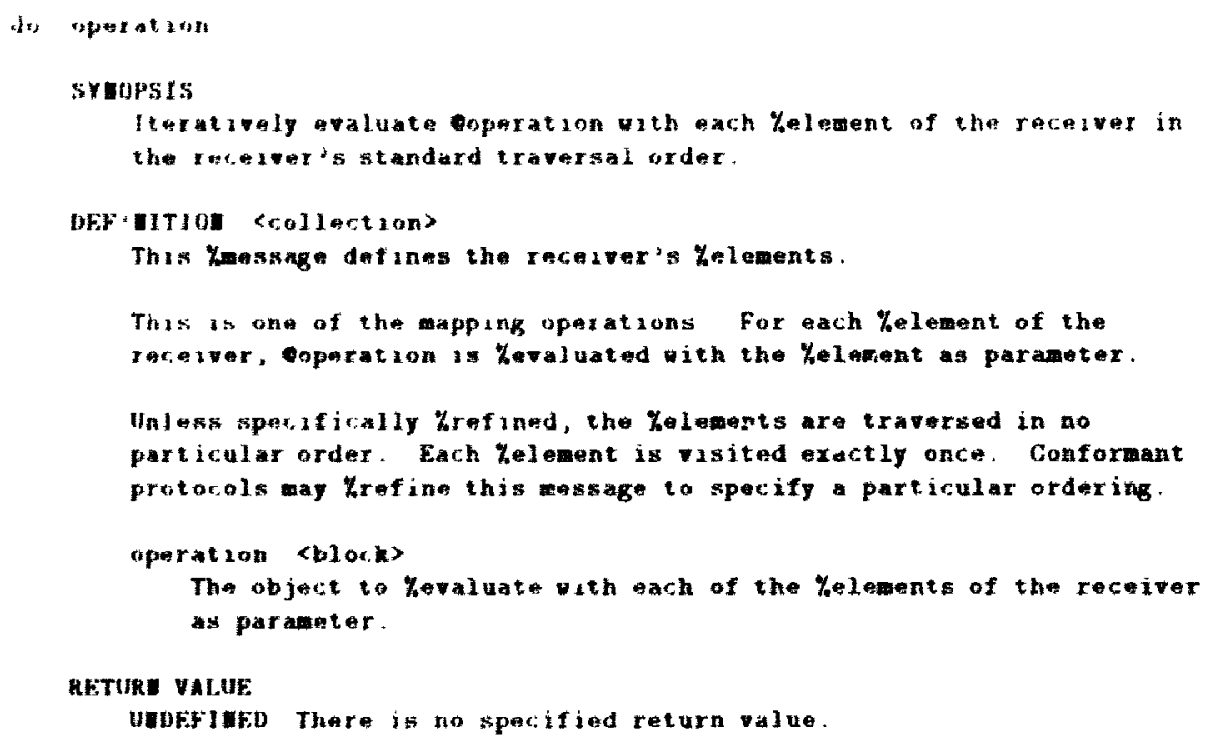

Figure 47: The \#do: message sperification

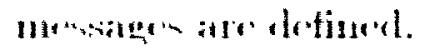

Netice also that many of the other menatges in this protocol follow directly from He ability to traverse the chenents. In this ase all of the other messages rould be inplemented usine only the \#do: mesage. Thus the only thing that can be said

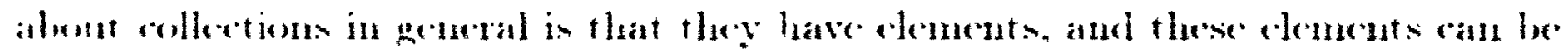
traverocel in whme minperitied order.

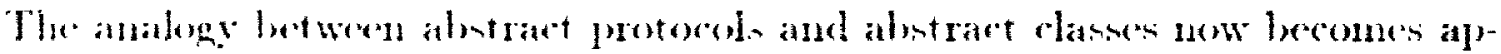

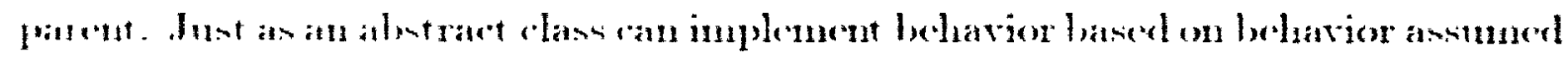

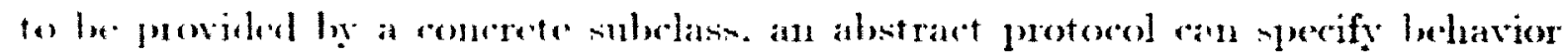

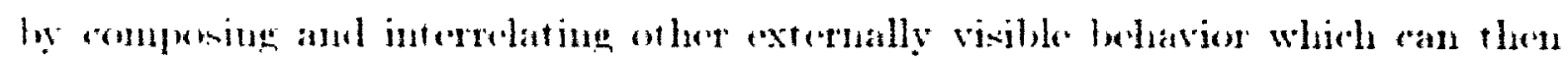

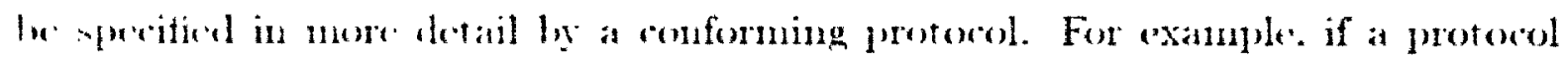

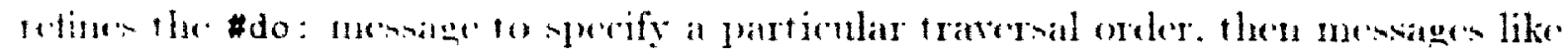

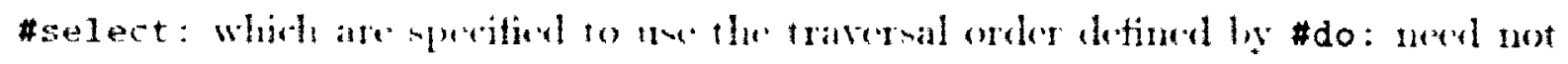

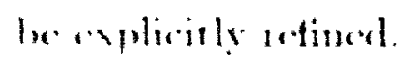

Lowhing at the wext level of the conformane graph in figure 45 . we see that the 


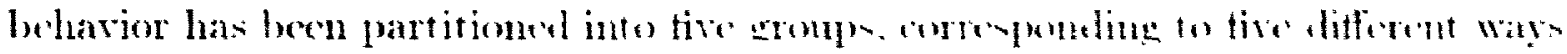

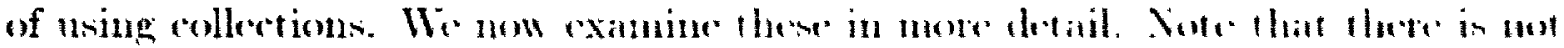

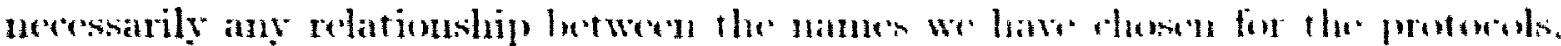

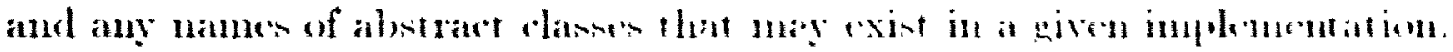

\subsubsection{Dictionary AccessCollection}

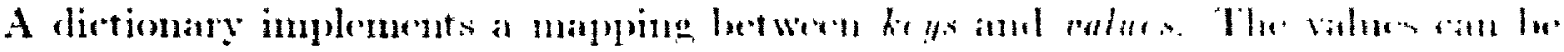

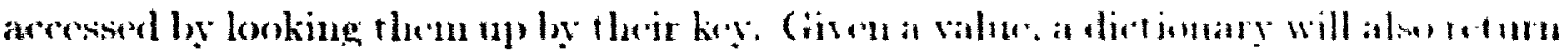

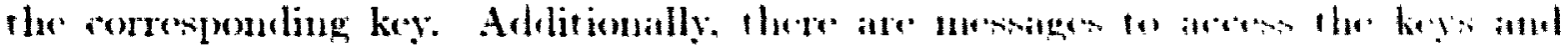

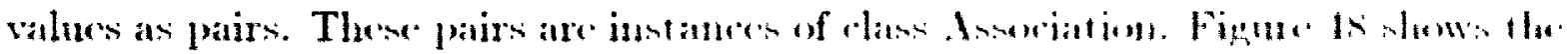

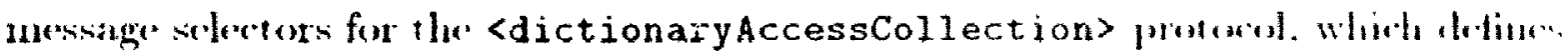

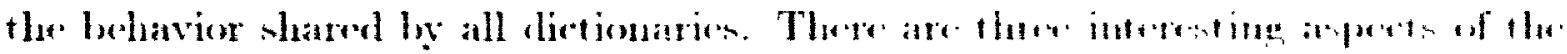
dirtionary protocols.

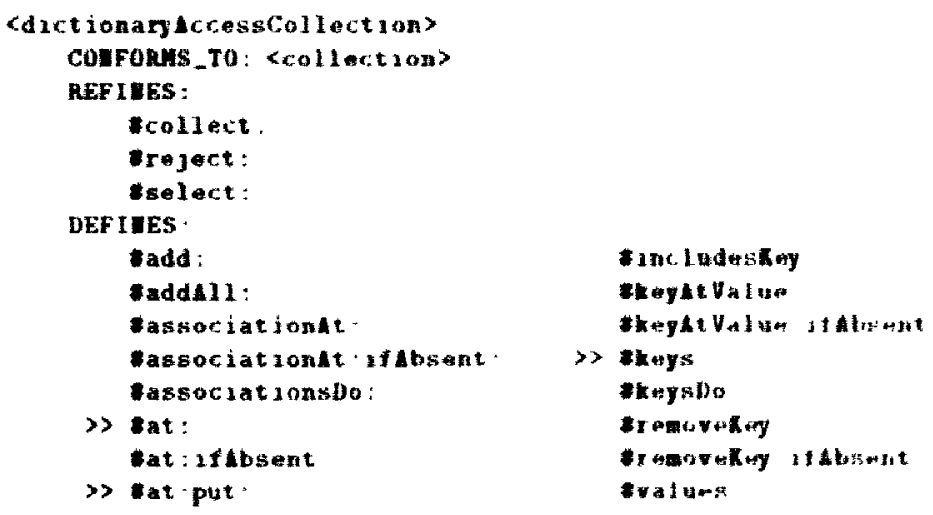

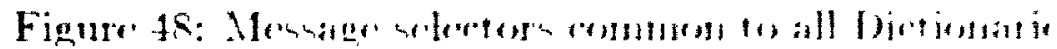

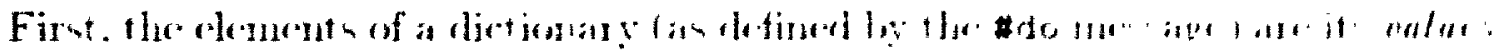

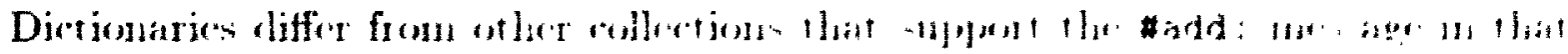

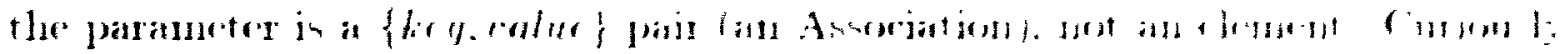

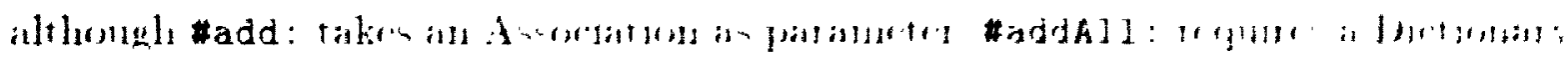

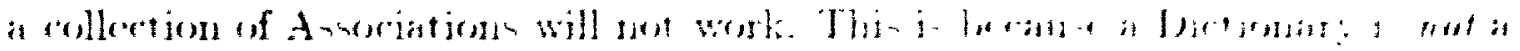




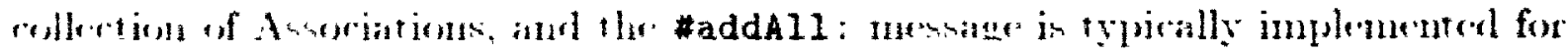

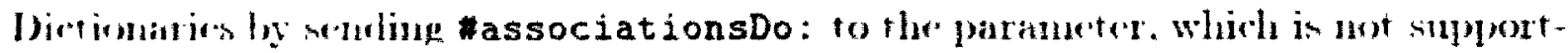

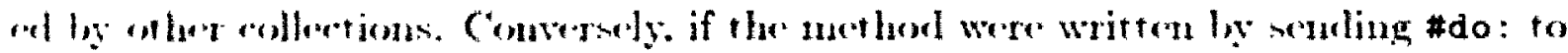

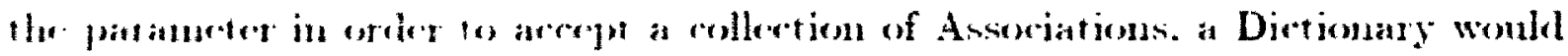

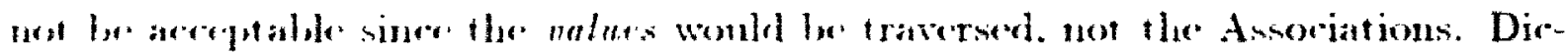
tionaries are deseriled in a come what eonfusing mammer by [Goldberg S5] as being

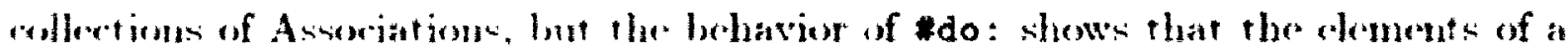
dietiomary ate sortually its malues.

Siromd, lhe thro mapphng mosiges (\#select:. \#reject : and \#collect:) are refined. The" mescagen are defined in <collection> to collent the appropriate

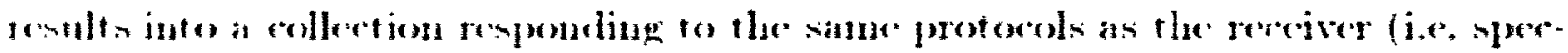
ified using the <RECEIVER> protorol). The <dictionar $>$ protorol refiues these to further anerify that the collected values are asseriated in the resulting Dietionary with their cormesponding keys from the original Dietionary. Thes the definition in <collection> applim. fut important additional information is provided.

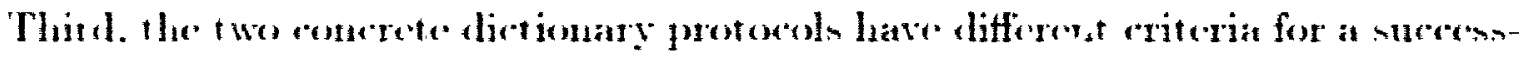

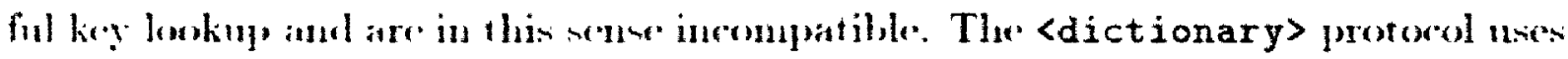

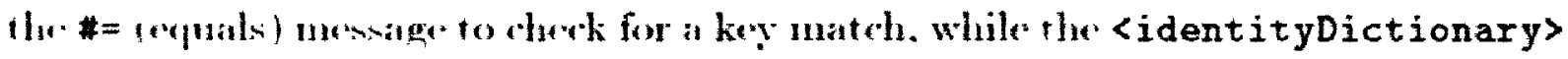

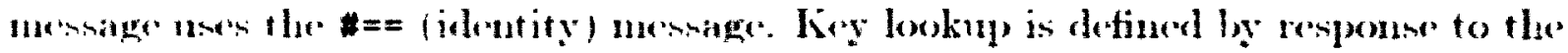
\#at: mensage. However. no uneful speritiotion for the key lookup criteria can be prowhed wh that one of the eriteria conforme the the other. The problem is that

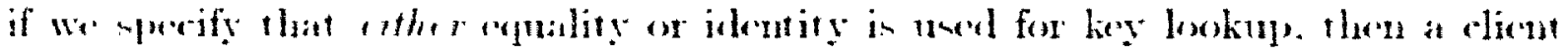

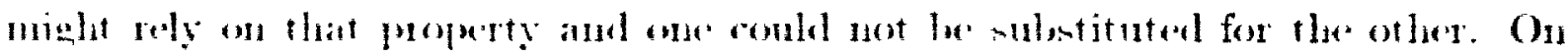

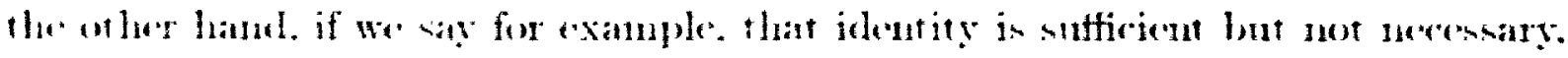
When we can define a conformane selation based on ahe fact that equadity lookup

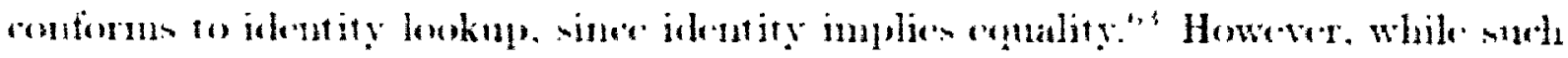

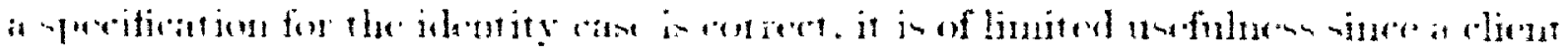

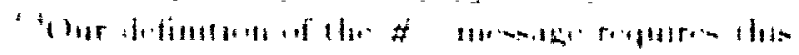




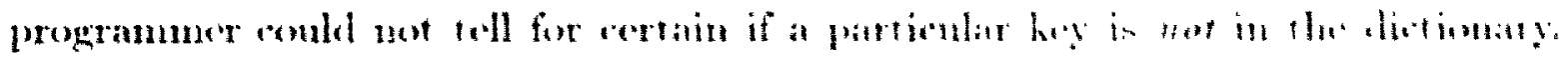

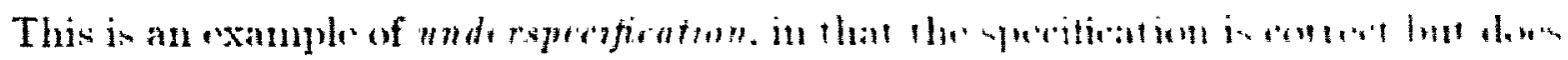

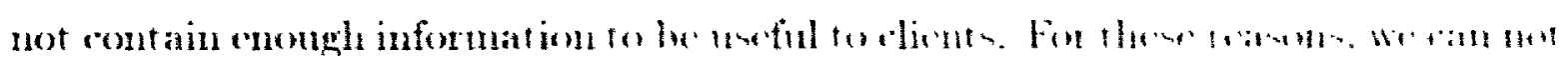

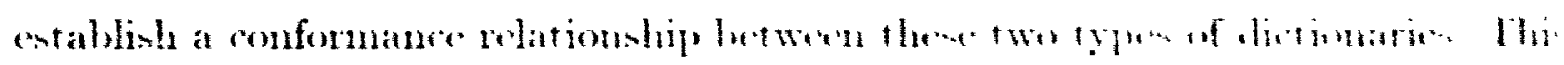

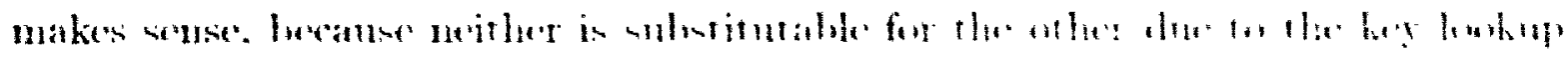
differences.

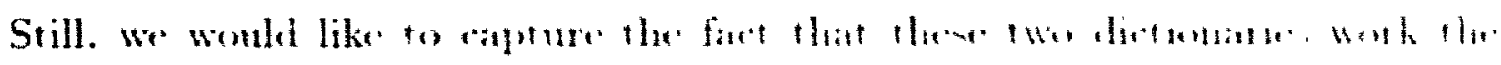

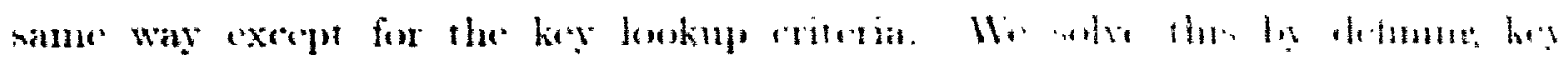

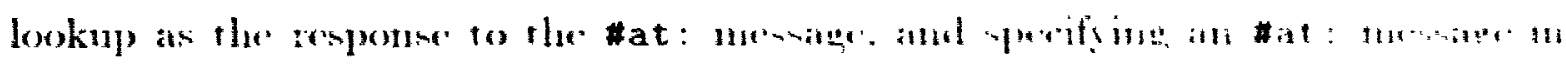

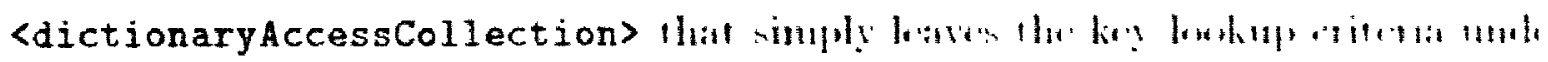

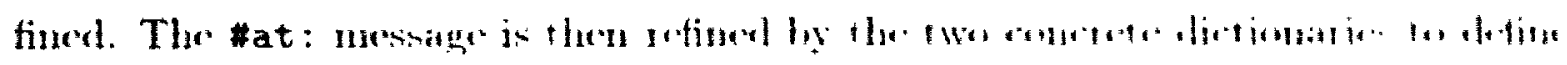

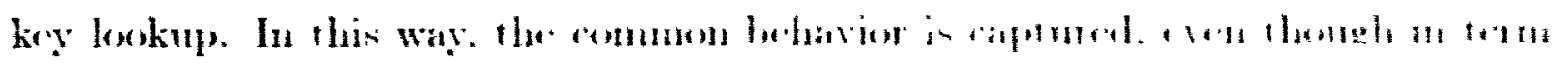

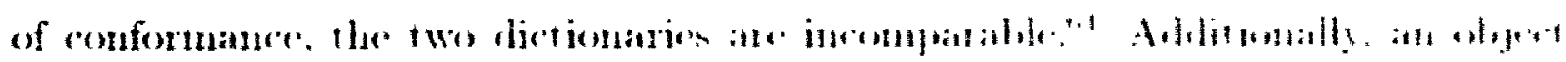

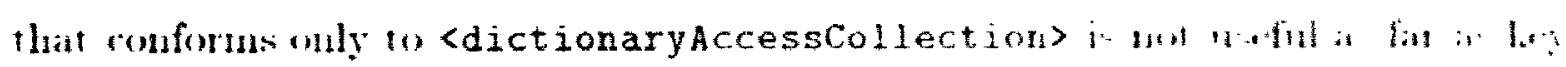

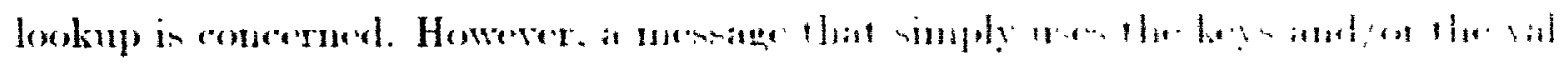

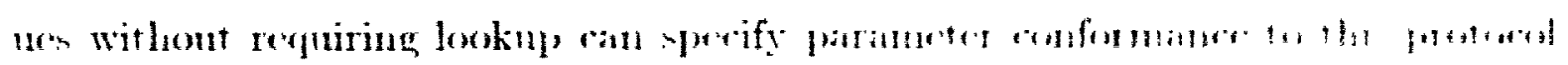

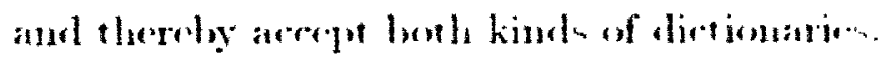

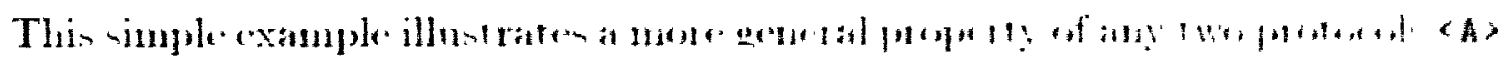

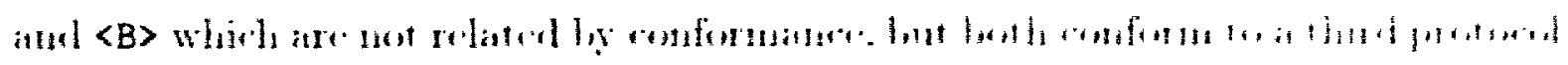

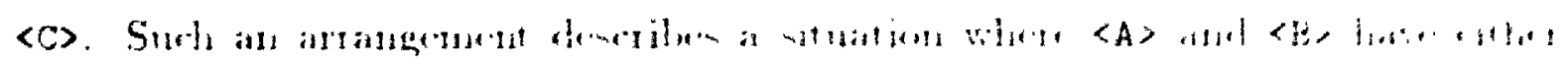

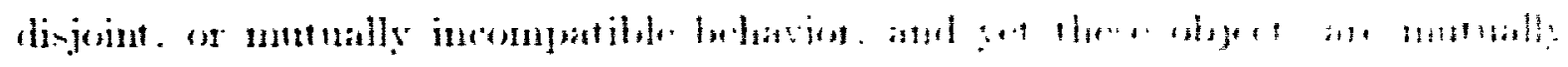

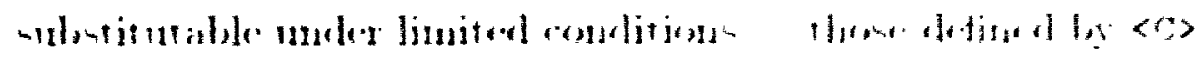

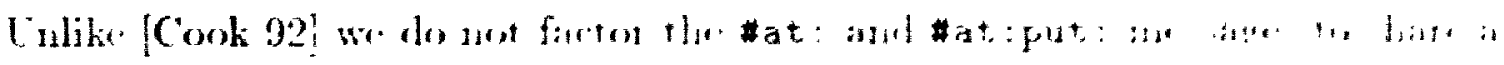

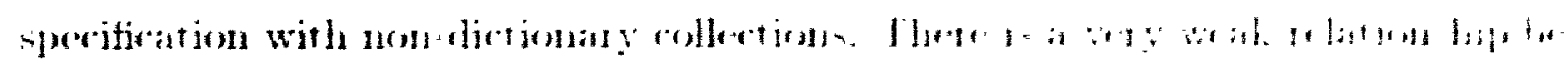

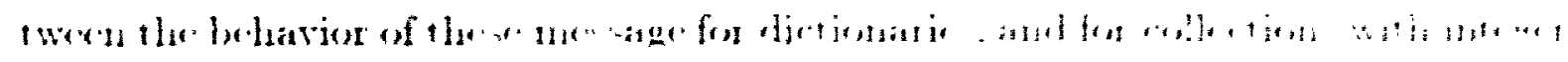

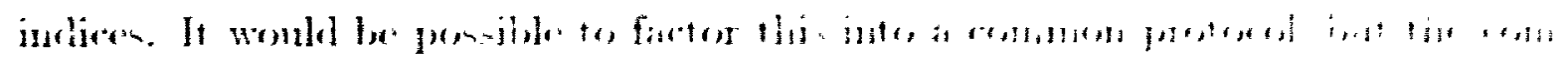

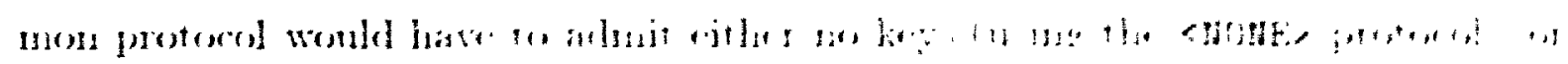

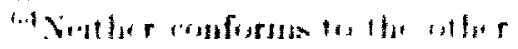




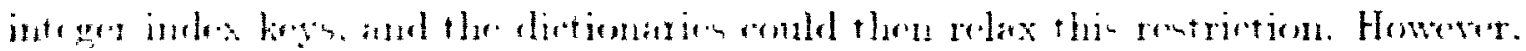

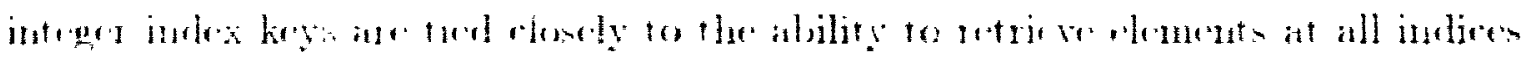

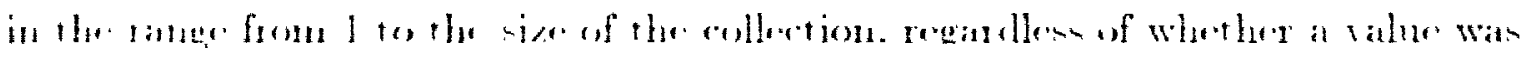

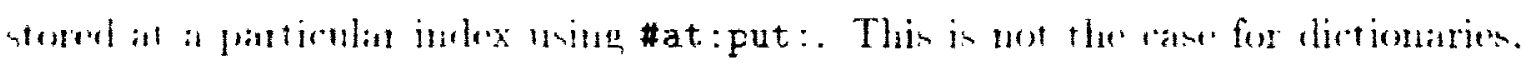

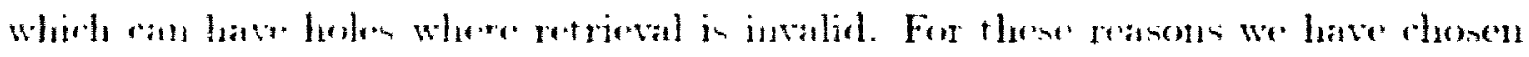

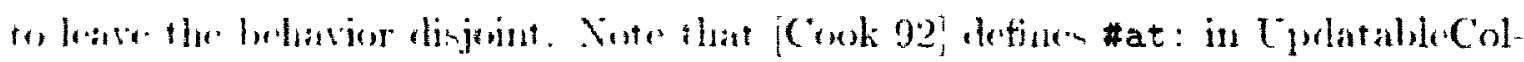

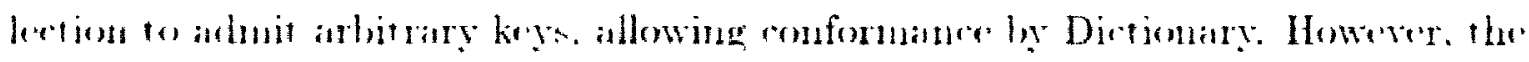

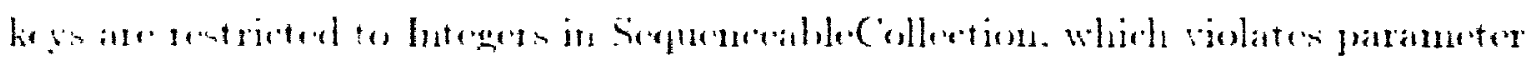

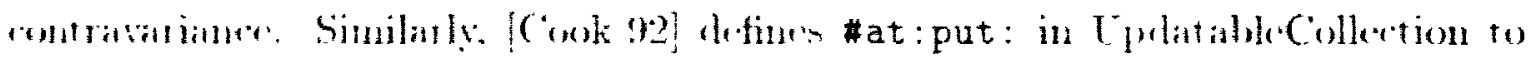

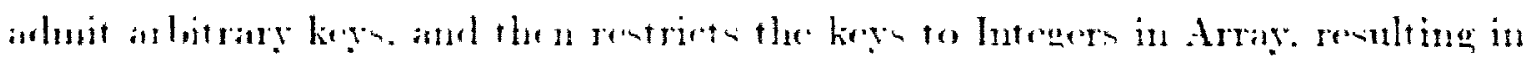
the siture problene.

\subsubsection{WriteA aressorpuencedtollection}

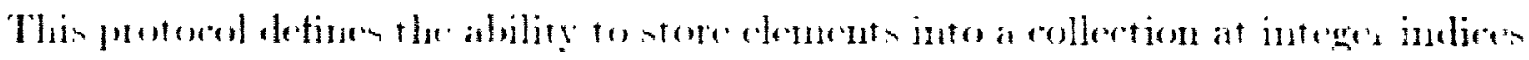

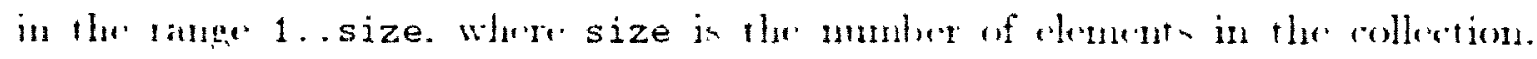

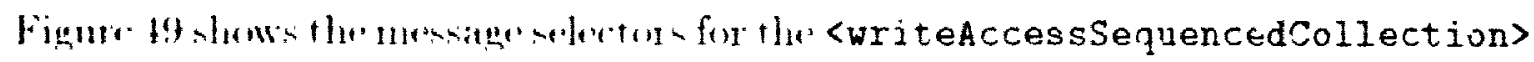
protorol.

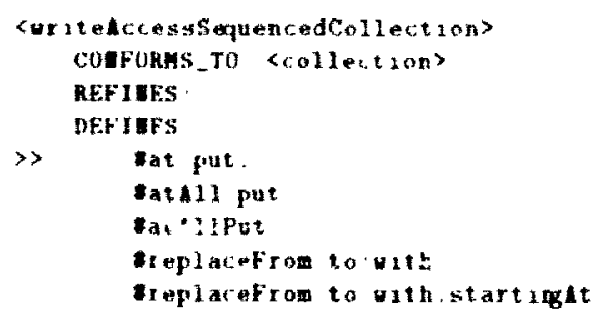

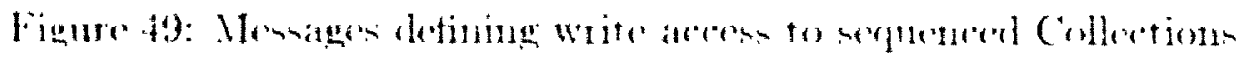

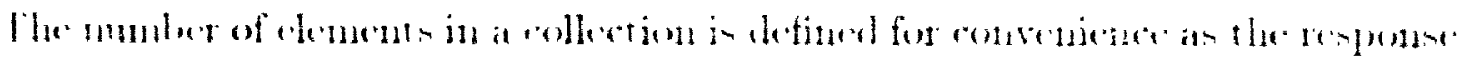

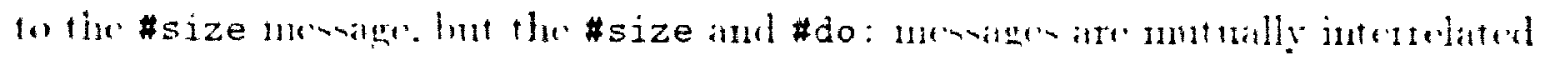

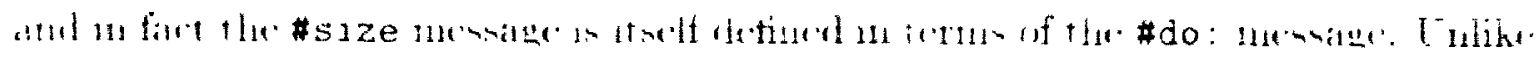

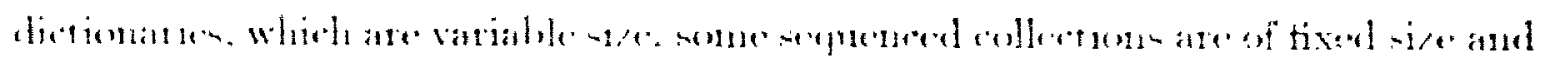




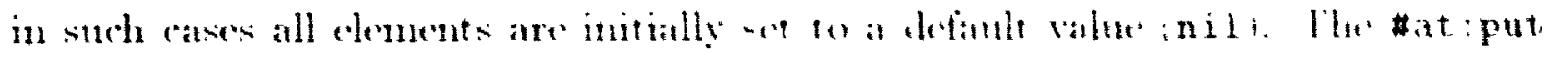

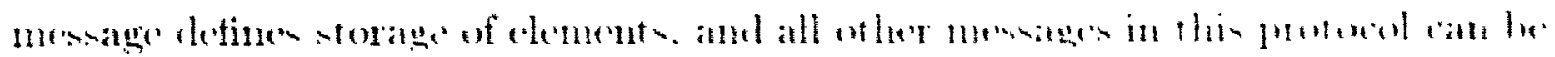
defined in terms of this mestage.

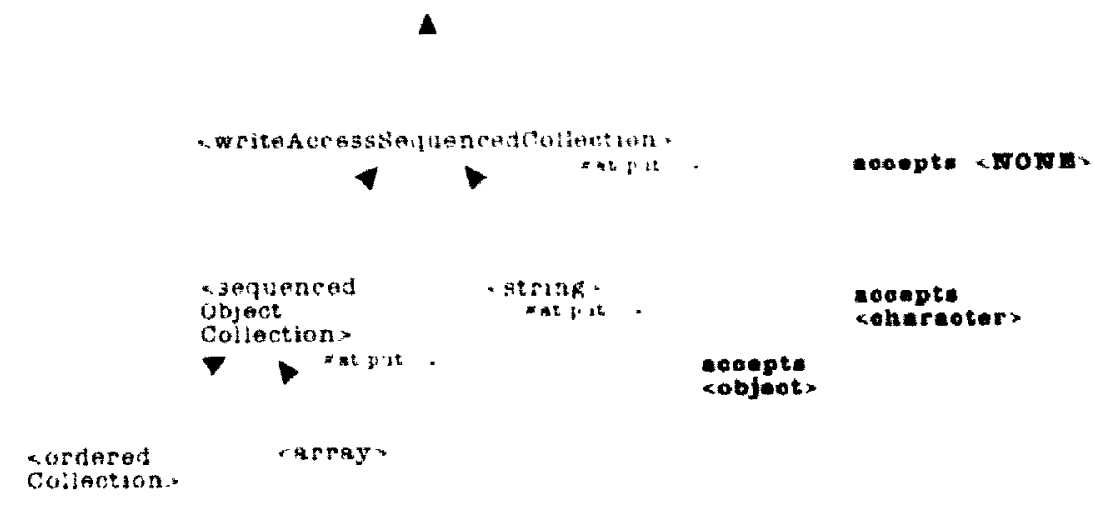

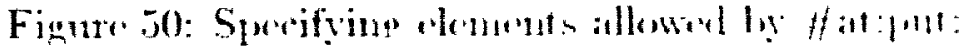

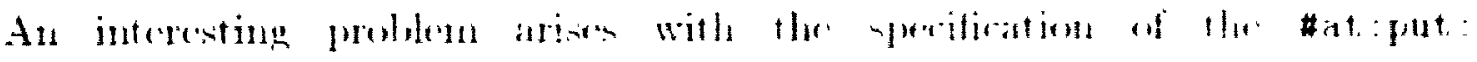

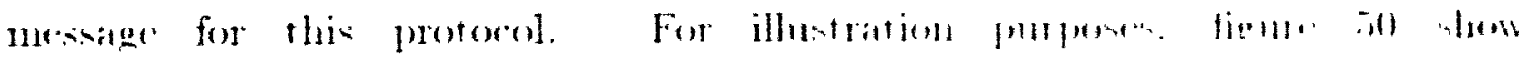

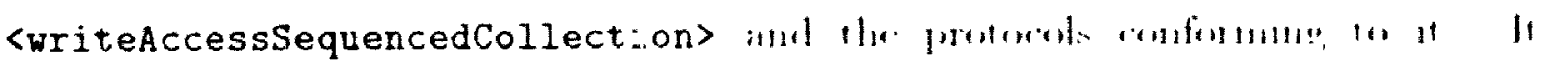

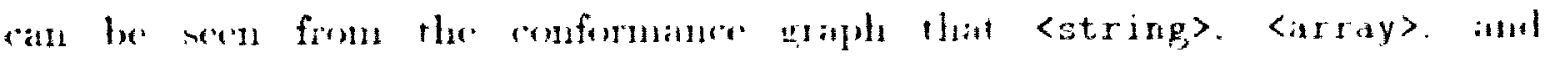

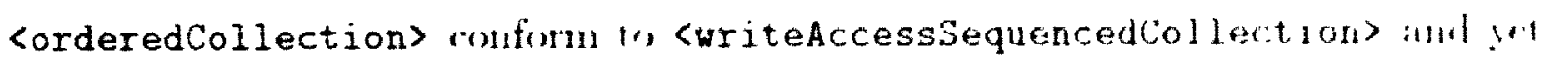

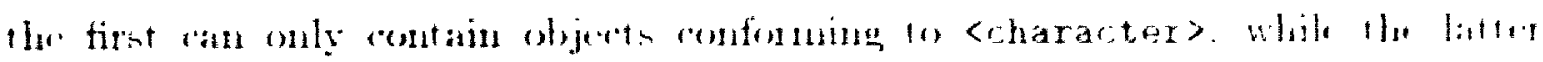

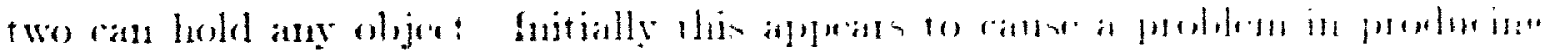

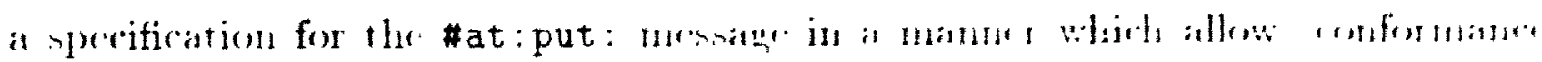

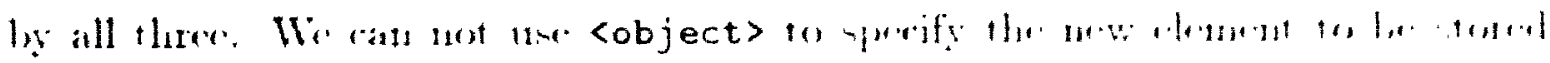

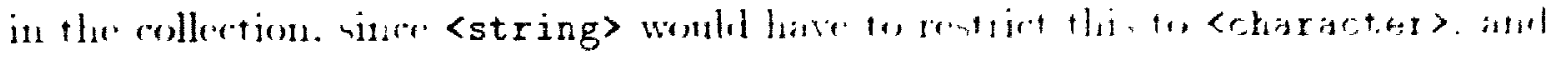

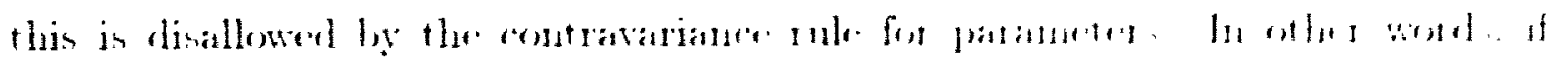

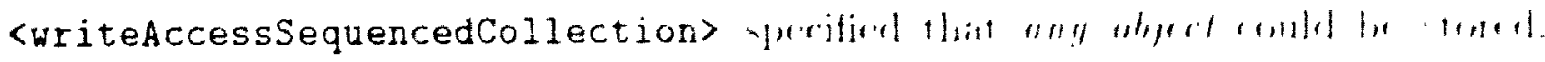

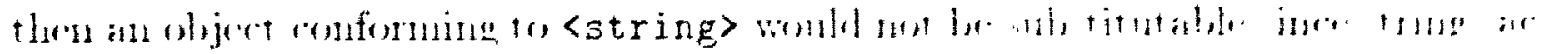

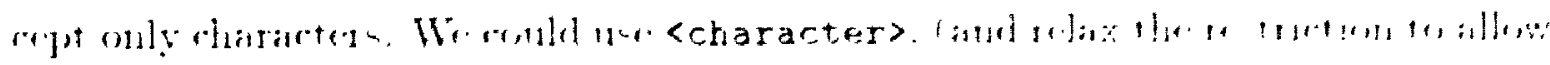

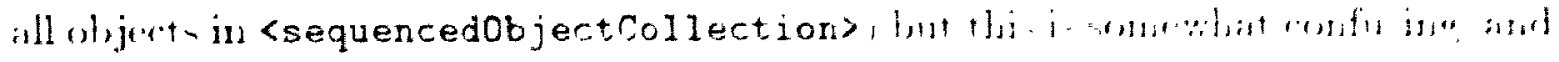


womld predurle conformanere by objects of classes such as Bytedrray which restrict new elenent in of les incompanthe ways.

In inchality <object> is exactly the opposate from what we need. The solution

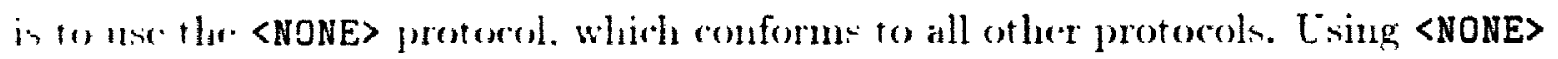
in a paranuter sperifiontion is totally restrictive since there are no objects which conform." Sincr <writeAccessSequencedCollection> is an abstract protorol, wo ran we it to define the Bhavio: for \#at:put: without making a commitment to allow any parteralar elements to be stored and in fact wo allow none. Wo can thrn whe this matriction in <sequencedobjectCollection> to allow any objert to le stored. by nerifying the new densent parameter of \#at:put: using <object>. Similarly we can relax tle restriotion in 〈string> to allow the storage of elements conforming to <character>. The selution is also thexible in that we conld add other wowots whels an <byteArray> which relax the restrietion in different ways. This

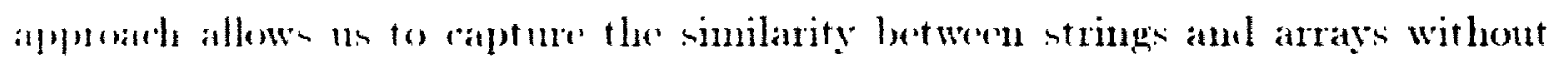
riolating the contratratiner mule.

When und in a parameter sperification. the <NONE> protocol allows us to leave parameter conformance requitenents unspecified. and defen the specitiontion to conformat protocols. Howeves, we ata still apture common asperts of beharior which are independent of the particular parameters." Sote that inece return values must

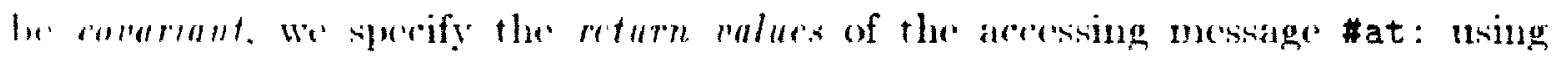
〈object>.

Notre that [Cook 92) show String as conforming to Arrag (figure 24). In order tor enture sulestitutability we can not do the same. due to the parameter restrietion String placen on messages supported by Array. Intuitively: at String is not

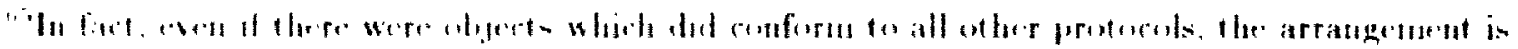

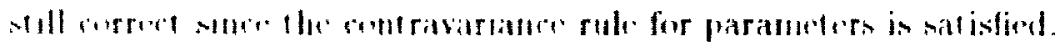

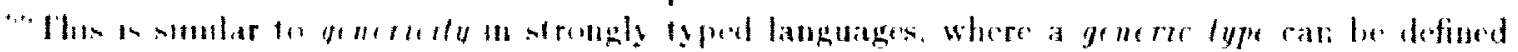

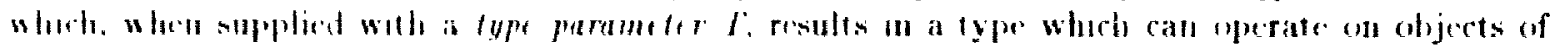

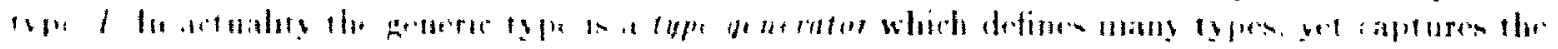

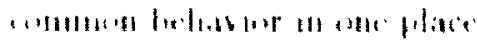




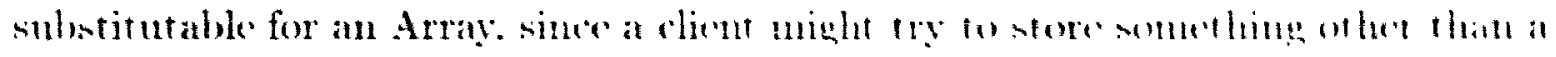
Character into it.

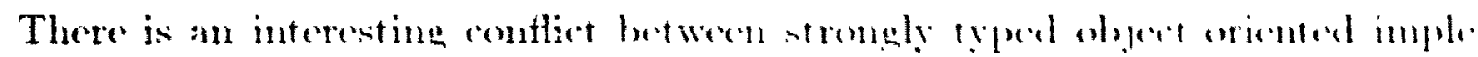

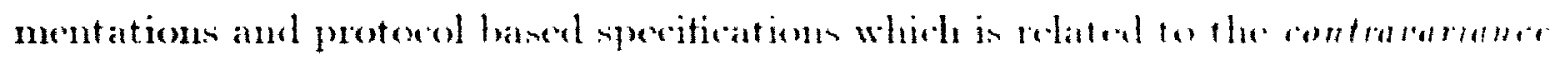

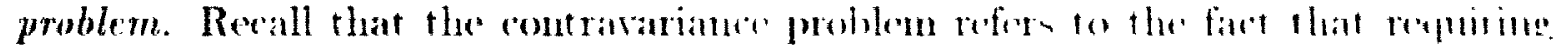

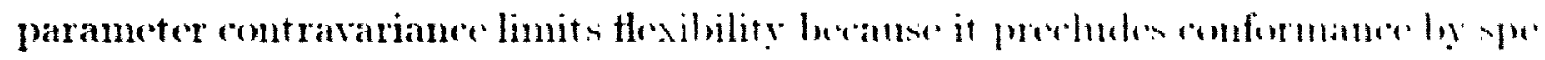

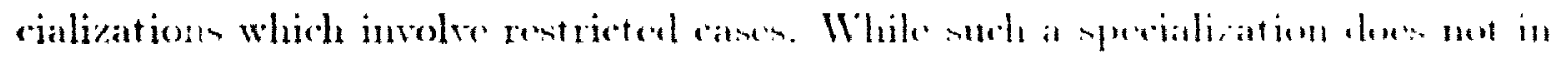

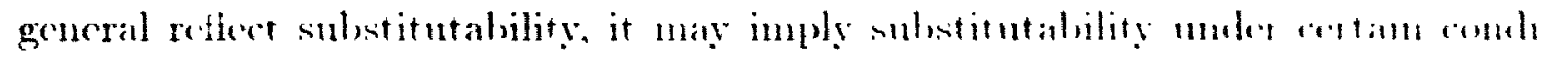
tions. For example, a String is substitutable for an Array an long an mo attempt in made to store into it. Comsider the arrangement of chasses shown in fiene it. in which String and Bytedray are restrieted anes of Arrayede 'ollewtion.

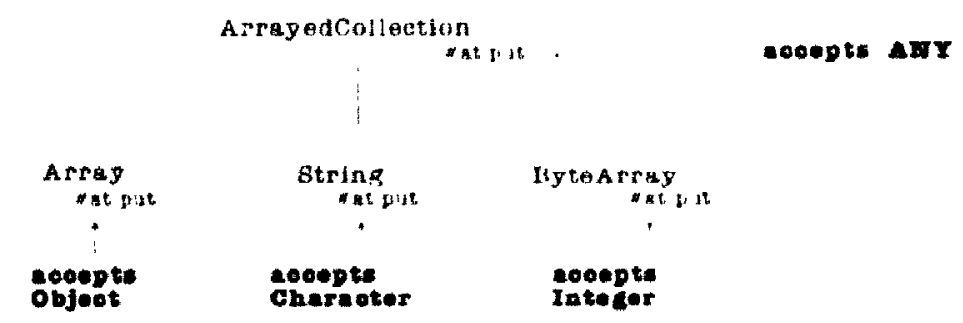

Figne 51: The Contravariand Pablem

In this scenario, the Arrayed Collection clase powides a defandt inplementatum

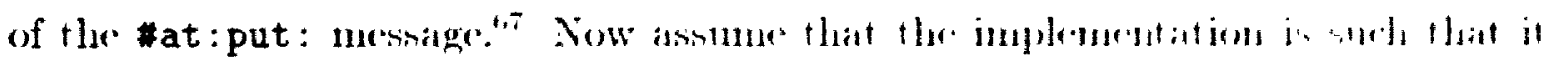

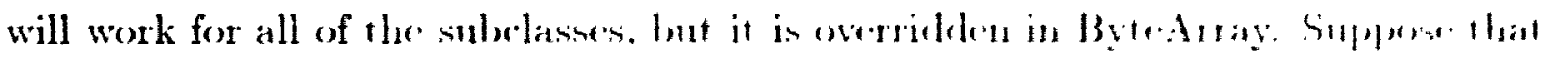

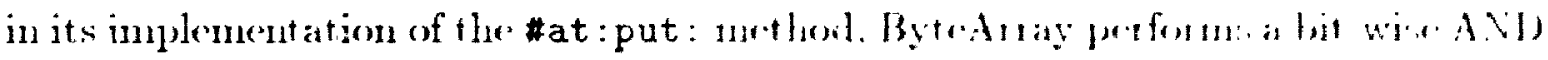

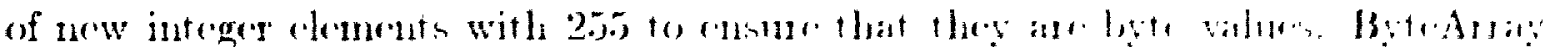

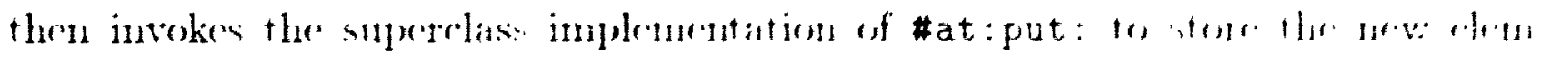

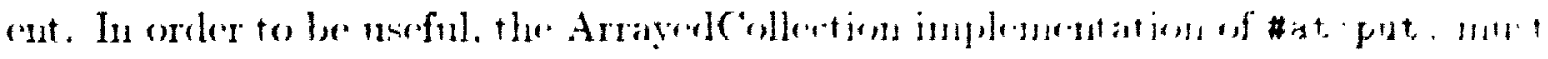

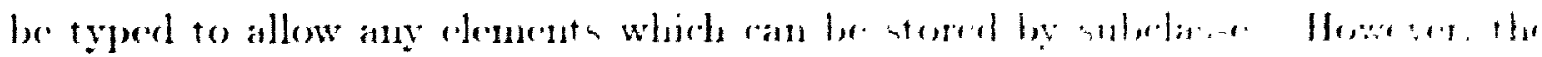

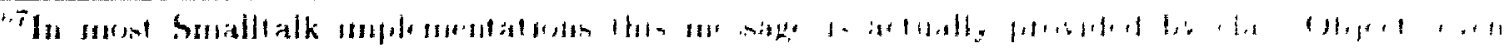

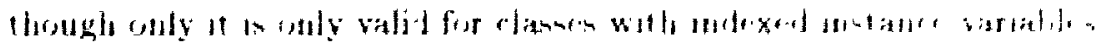




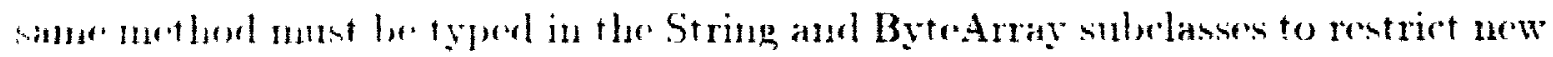

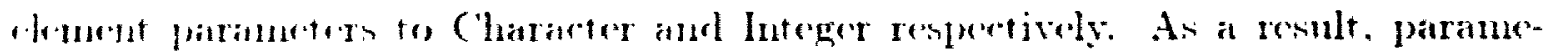

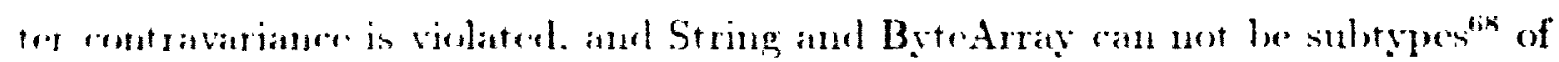
Artayedollontion.

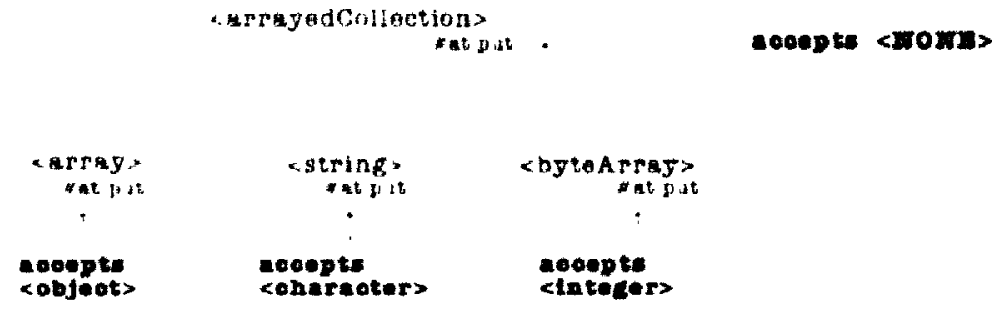

Figure 52: Conformatuce of restricted anses

However, as shown in tigne 52, we have no tromble specifying the same scenario ming proforoh. Wi simply define \#at : put: in <arrayedCollection> to allow no Parameters (uning <NONE>) instead of any. and then proceed to relas the restrietion in the suluelasses. It makes an sense to do the same in the implementation, because if the implementation of \#at: put: in ArrayedCollection allowed no parameters, it conde not be inveled. The <NONE> parameter definition allows no paraneters, capmuing the fare the: a String is sulstitutable for an Array. providing it is not stored into. This a.proach is alfferent from simply removing the definition of \#at:put: from <arrayedCollection> and detining it in only the conformant protocols. Such

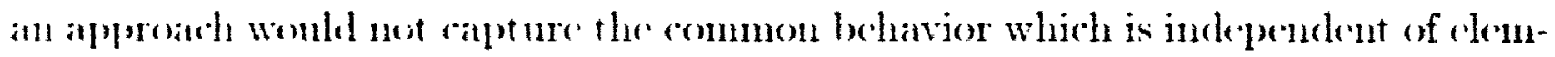

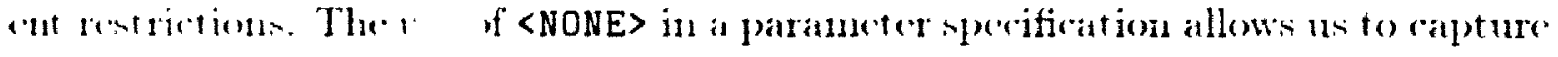

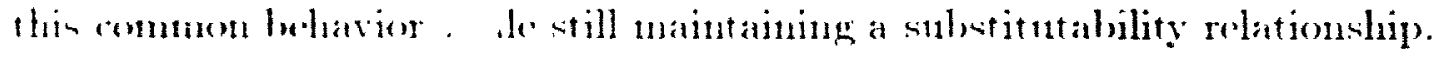

The distinction hetwen $N O N E$ and $A N Y$ in mblle and sometimes eonfuning. The <NONE> protocol includes mastmam pessible behavior. hut mo objects. The

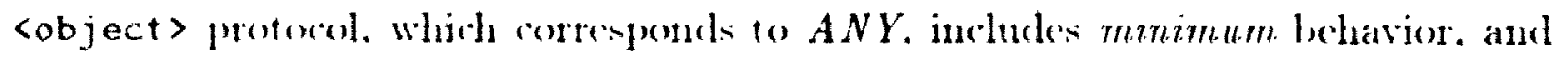

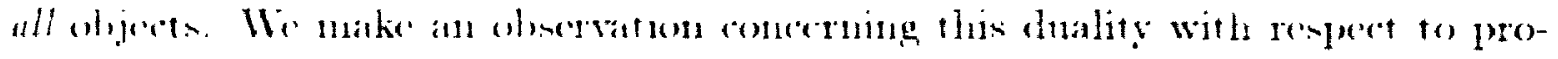

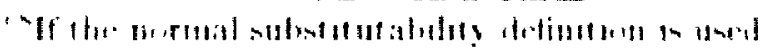


gramming in Smallalk. Consider the method comment in tigume is for mat put:

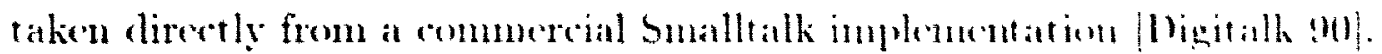

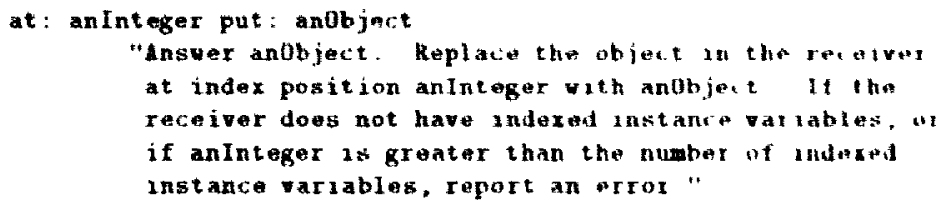

Figne 53: The Hattput: nethenl comment

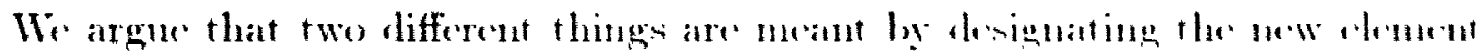
parameter as anobject." In terme of the implenentation of this parter alas me thad

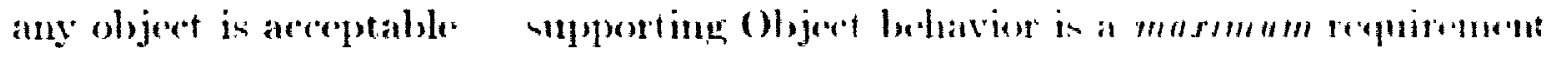
for the parameter since that is sutticient to implenent this nethoml. It it also the most that the programmer can say about the parameder in thie centext Howeret.

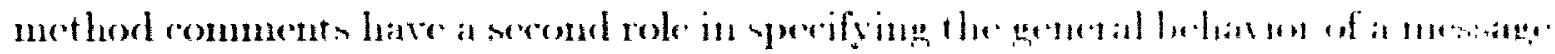

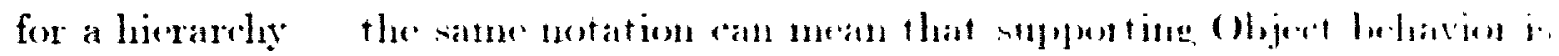

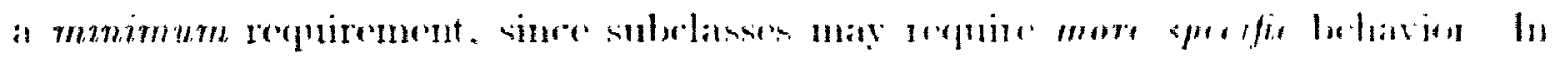

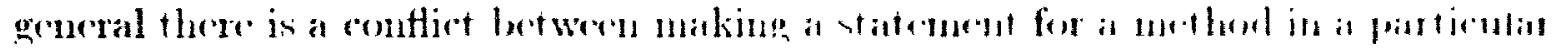

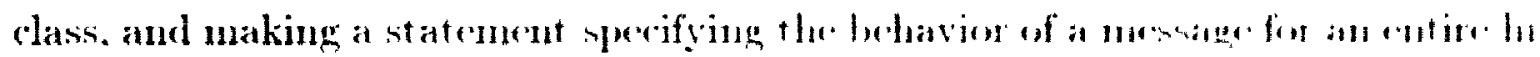

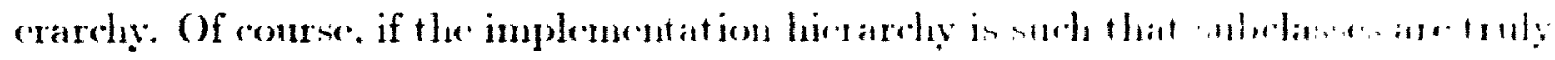

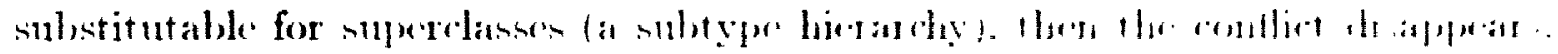

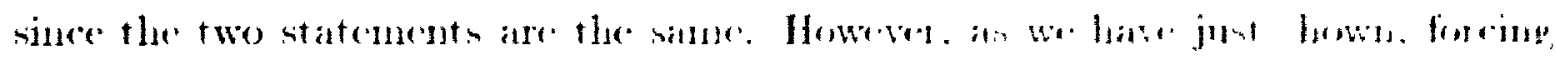

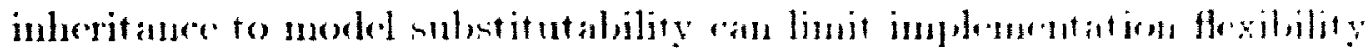

\subsubsection{ReadAccessSequencedCollection}

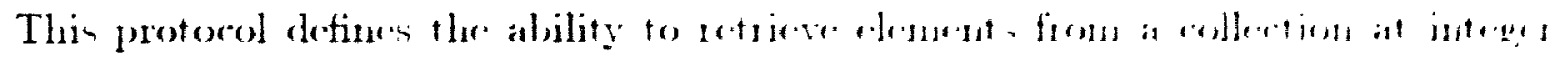

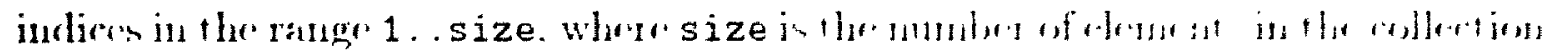

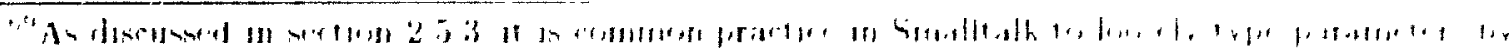

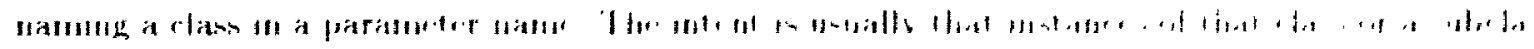

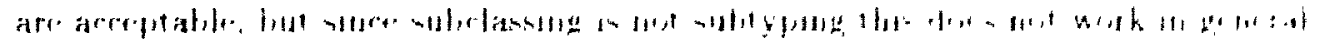




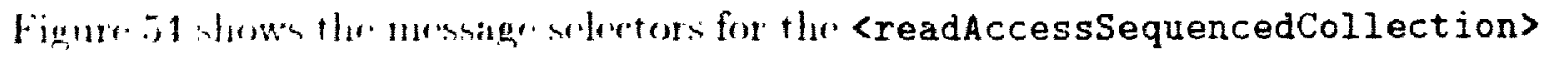
protionst.

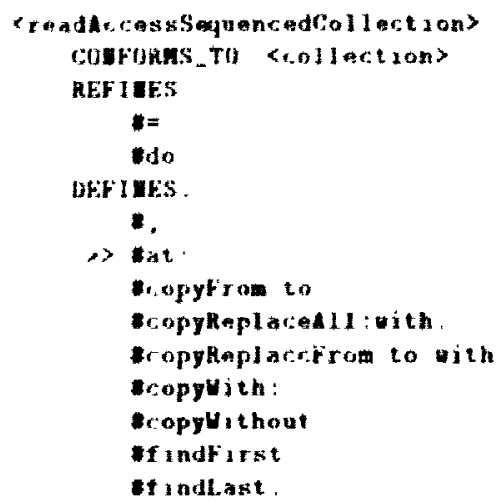

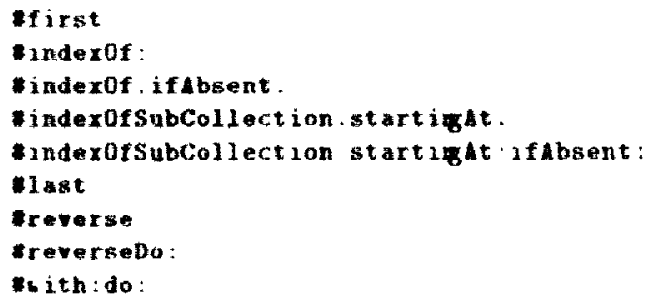

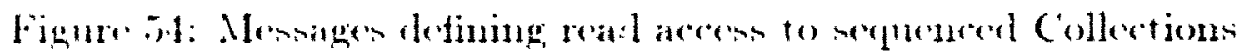

The \#= nuessige in rotined from <object> to indicate that two ohjerets ronforming wh the potened ane equal if their romesponding elements are cqual. The definition

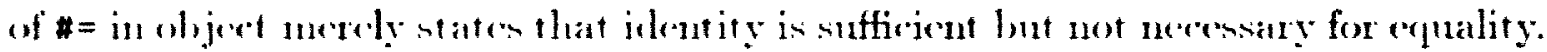
A refinement of $\#=$ ann not be provided by <collections becanse cquality for the Sel abso in implemented as identity. The reasoms for this are not clear, but it may be

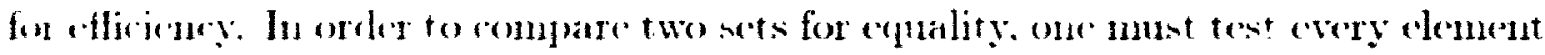

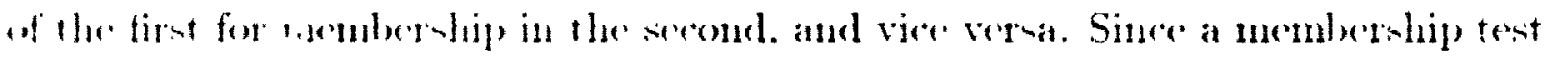

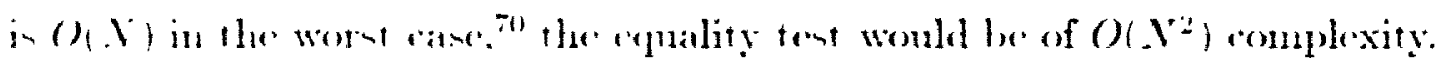

The \#do: message in refined ly <readAccessSequencedCollection> to indimate that the elements ase traversed in index onder. The \#at : menage defines the ability to retrieve an clement at an index, and the remaining messiges in this protocol can lw yprified in trom of \#at:. Non aloo that \#reverse in nom-destructive. and

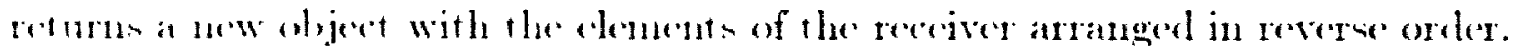

Thr <readAccessSequencedStaticCollection> descriles the havior common io seguened collections that do not reorganize their clenents. in contrast to

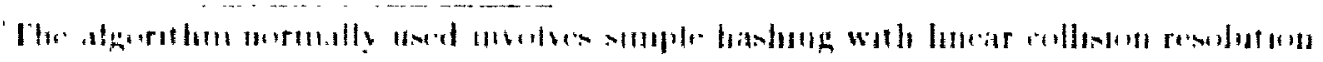




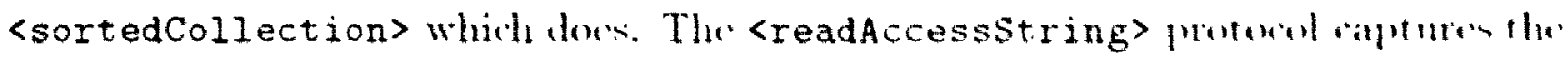

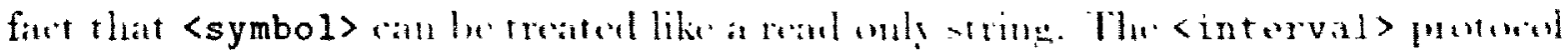

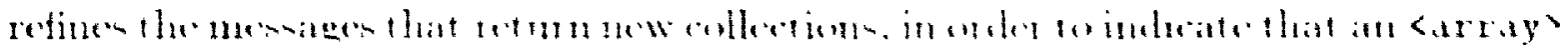

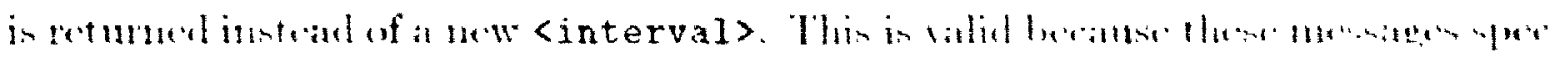

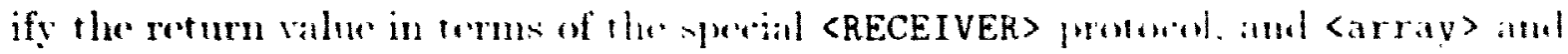
<interval> hoth onform to <readAccesssequencedstaticcollect inn>.

Buth the <sortedCollection> mil corderedcollection> putunt: anfum

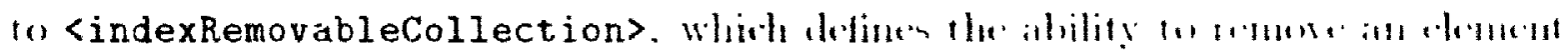

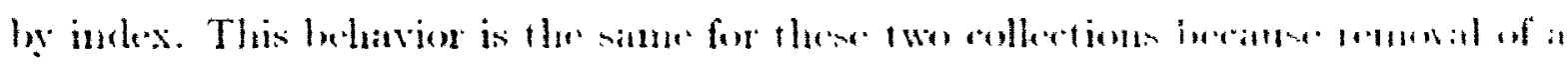

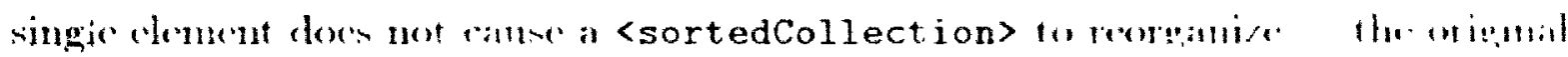
ordering is preserved.

\subsubsection{ElementRemovablecollection}

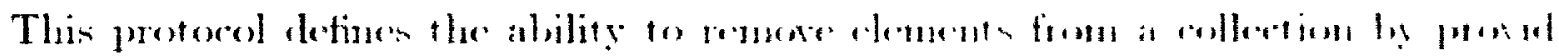

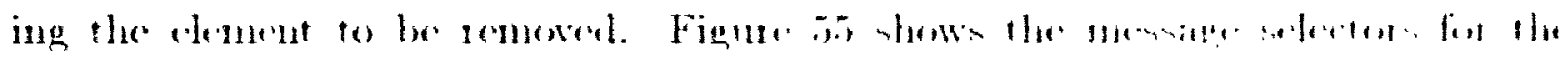
<elementRemovableCollection> pandul.

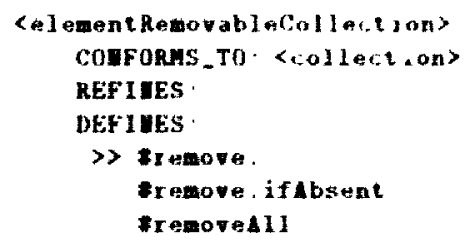

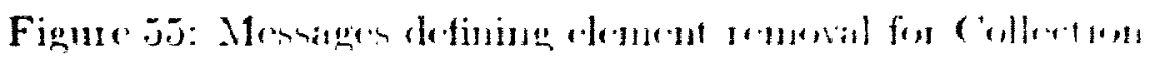

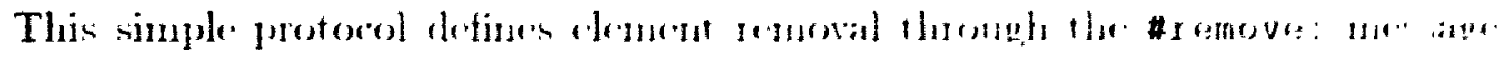

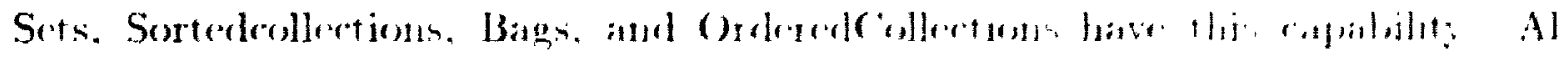

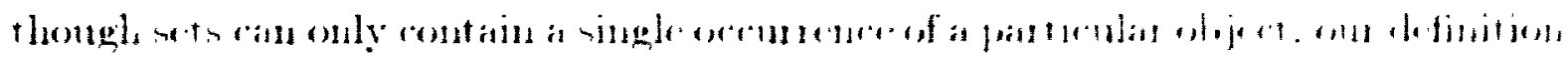

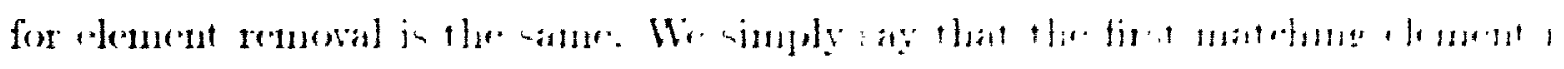

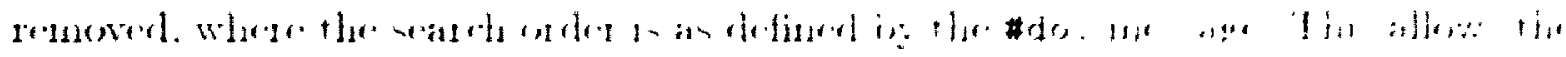

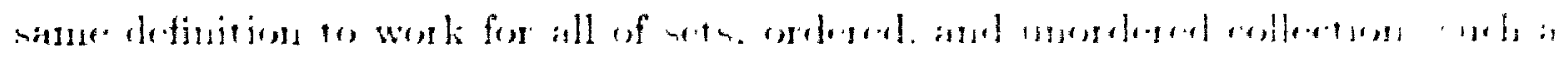




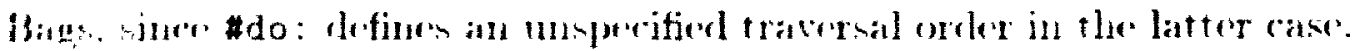

This is in contrat to [Conk 92] which detiun \#remove: for seth to be jurompat.

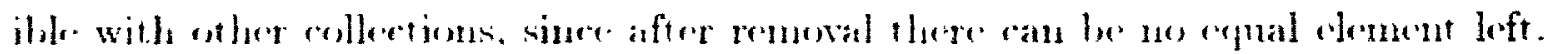

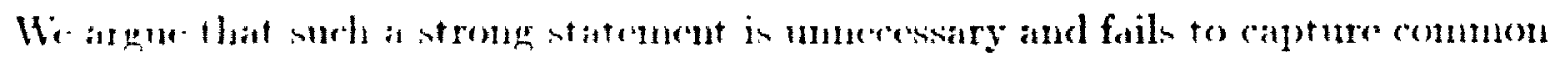

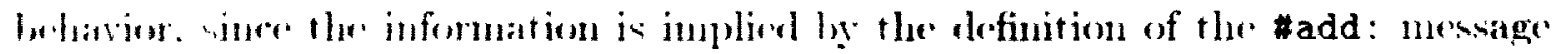

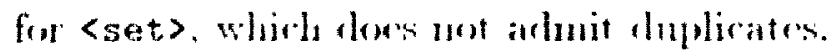

\subsubsection{Wloment AddableCollection}

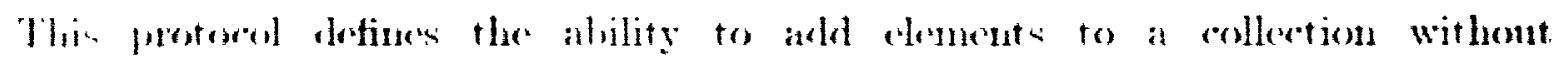
moniline a key on index. Figun go hows the mesage selectors for the <elementAddableCollections protoml.

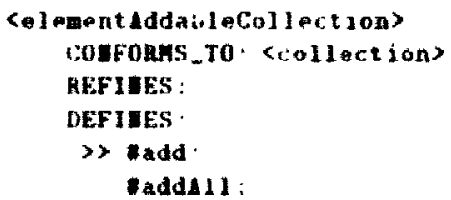

Figure 56: Mlswages defining element arling for Collertions

This protorol detines the ability to add an chement to a collection at some

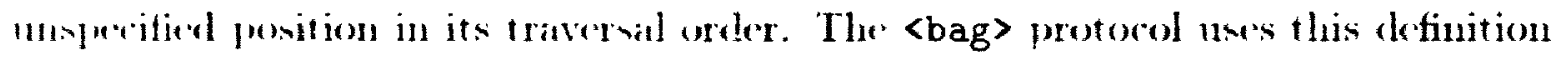
dimenly, and the <dequeue> protorol refines it to adel orclering information.

Mhe <dequeues protorol detimes the ability to ald and remore elements from cither the heginning or the end of the traversal order. but uot anywhere betweon. It Hotius the \#add: mensige from <elementaddableCollection> to define it to add t'e. elenuent to the enul.

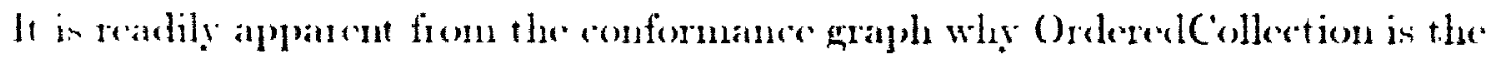

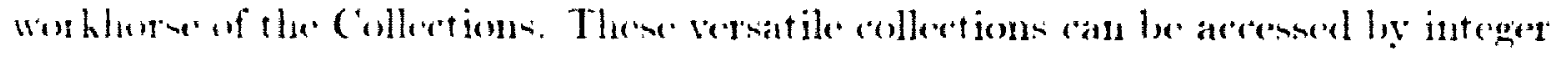
molion and allow adding and remowne by elenent or by index and to both cum

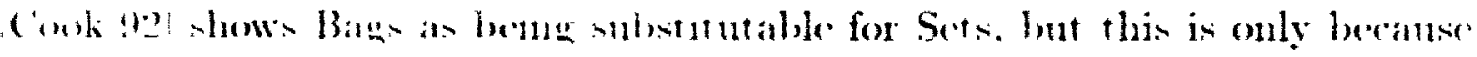




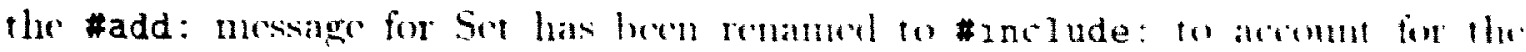

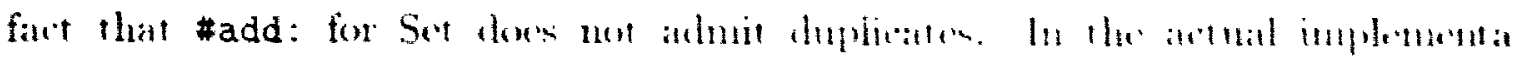

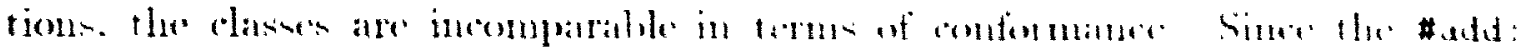

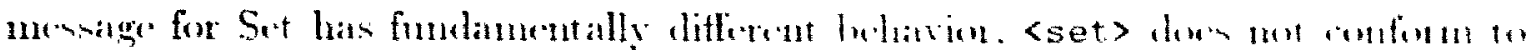

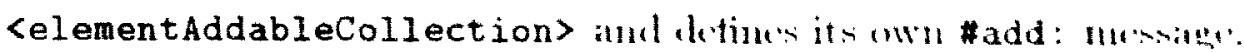

\subsection{Summary}

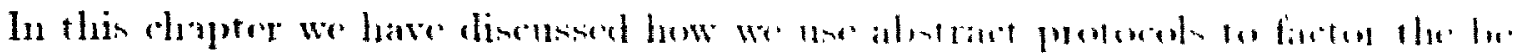

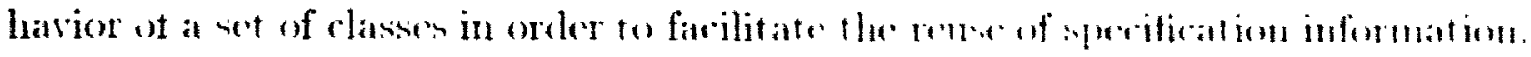

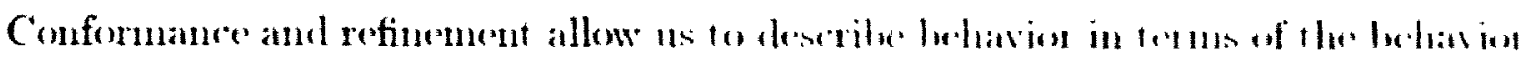

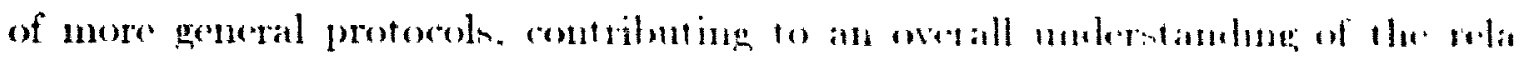

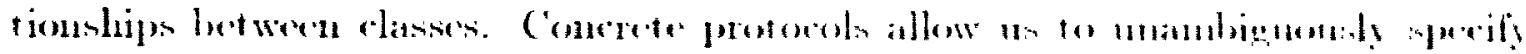

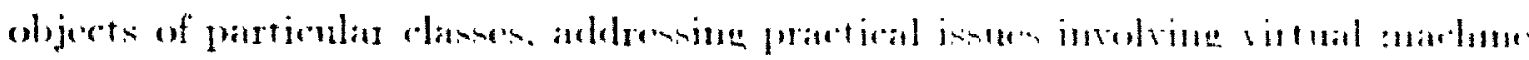
primitives.

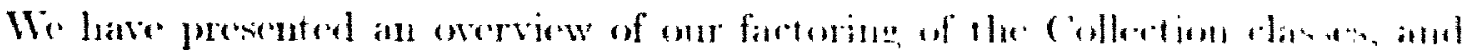

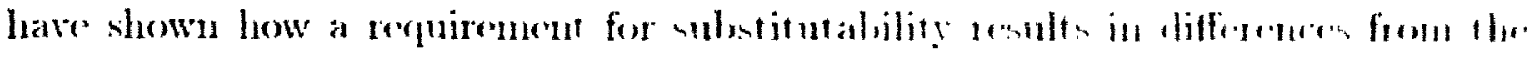

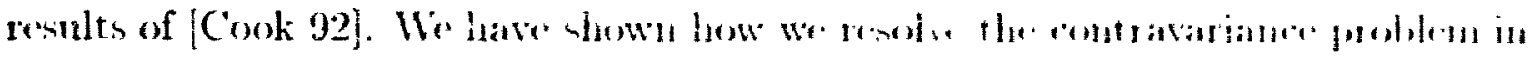

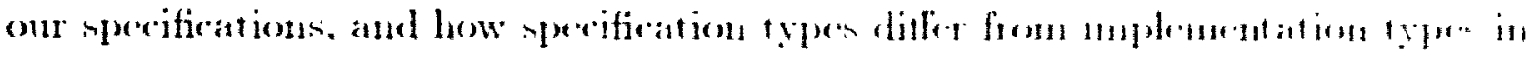
this regard.

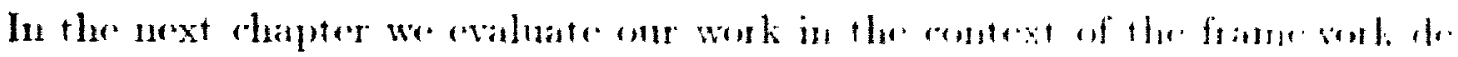

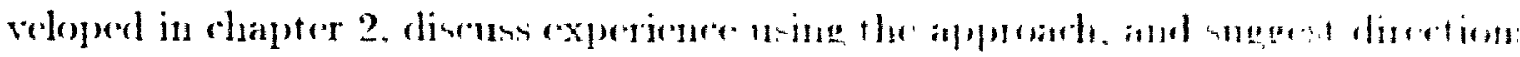
for filture research. 


\section{Chapter 6}

\section{Conclusions and Future Work}

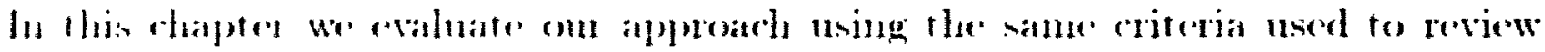

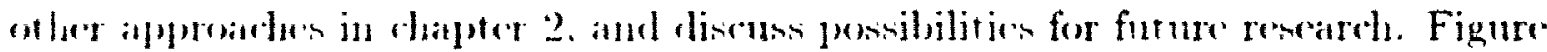

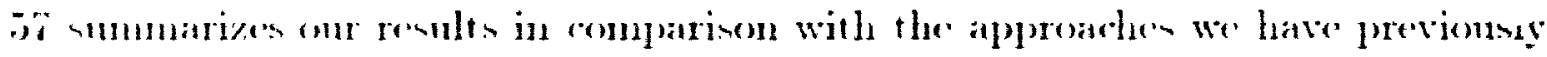
revinued.

\begin{tabular}{|c|c|c|c|c|c|c|c|c|c|}
\hline 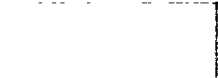 & 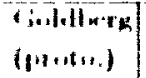 & $\begin{array}{l}\text { (inllin'ta } \\
\text { (minl) }\end{array}$ & IHMI & Herrting & $\begin{array}{l}\text { Jollongent } \\
\text { (1 Jast) }\end{array}$ & 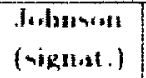 & Wills & (n)k & $\begin{array}{l}\text { Irentacul } \\
\text { atmorled }\end{array}$ \\
\hline $1 \ldots 11$ & din & Ine. & Hine & Jar./malen. & "pptintais. & intints. & velif. & dine. & ton. \\
\hline 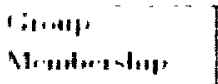 & 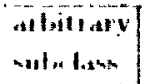 & $\begin{array}{l}\text { allitrats } \\
\text { suthe lans }\end{array}$ & Whiavinor & bignatut & ation af & Gignature & In haviog & lehavior & 1 Jhavion \\
\hline 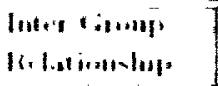 & miblit. & inhatit & $\therefore$ inforiti. & anf.:Fin & -utuate & inforni. & renfirnis. & iconformi. & enfonn. \\
\hline 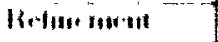 & $n$ & nin & nin & Tintiand & 116 & $y+6$ & $y+\infty$ & I11 & $y+\infty$ \\
\hline Gabintituthing & $n$ & in. & in, & In." & $3+4$ & 116, & sex & $n$ & $y+6$ \\
\hline 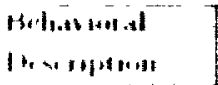 & - armumest & ||$A \mid t^{2}$ & tomb1twent & nower & comles & 1611\%" & $\begin{array}{l}\text { lne/fnemt } \\
\text { and! }\end{array}$ & $\begin{array}{l}\text { Hrotpast } \\
\text { antit }\end{array}$ & $\begin{array}{l}\text { anmut. } \\
t \cdot x t\end{array}$ \\
\hline$(3,1 / 1) .4$ & |IIIX) & "1 & mixen & $N / A$ & $\therefore / A$ & $\therefore / A$ & A. 1. & $\operatorname{dr} 1$ & mixad \\
\hline Mlosshik balie & ment। & $=4 \times 16$ & ni" & $X / A$ & $a x+10$ & $\mathrm{N/A}$ & 114 & $m *$ & $y+4$ \\
\hline I'stant/liot & - Misis & nithine & st+111* & yes & $5 \cdot x$ & $y+4$ & ins & nin & $y+\infty$ \\
\hline 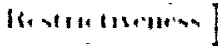 & $\lim$ & limili & $\operatorname{lon}$ & $\log x$ & lingh & los & hingh & averatse & avit ande \\
\hline lialow tialsts & an-tises & lin & |ा|kी & highl & $1+1$ & livil. & histe & hish & lifin \\
\hline thats & l. $w$ & 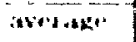 & Nertate & astitage & $N / A$ & $5 / 1$ & aveliage & av+rast" & hiph \\
\hline
\end{tabular}

Figure 57: Comparion of approadede

\subsection{Evaluation}

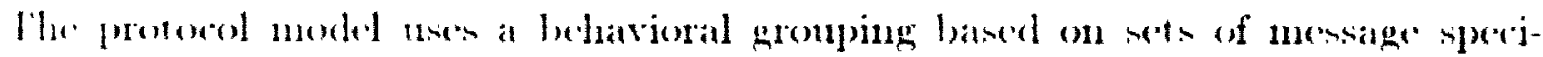

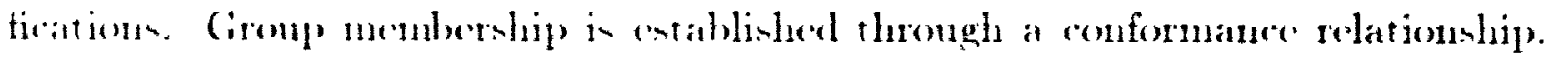

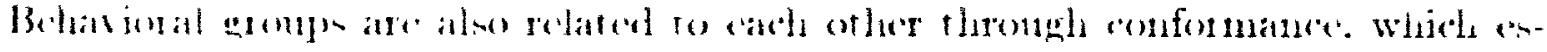

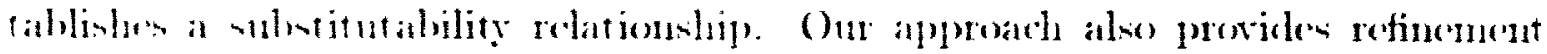




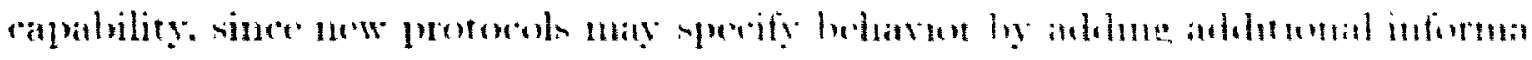

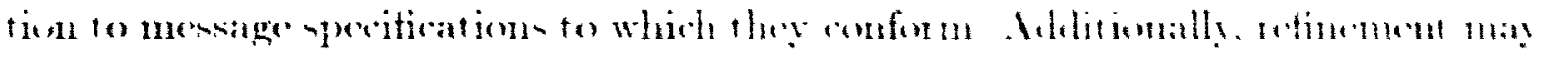

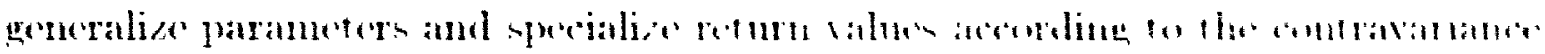
and covariance rules for substitutalitity.

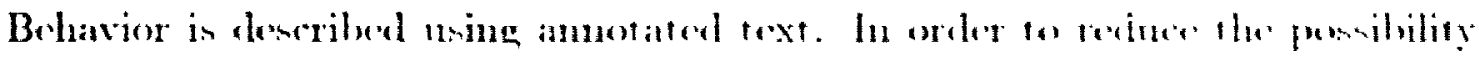

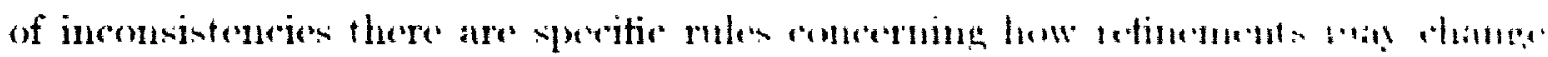

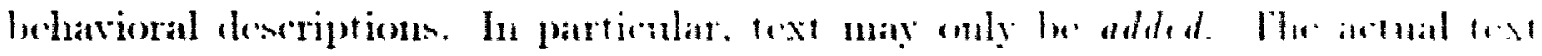

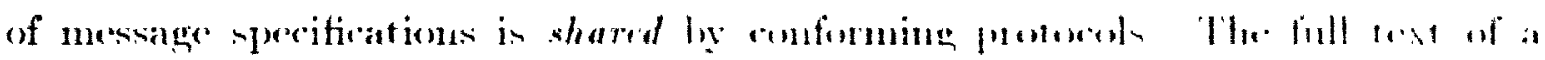

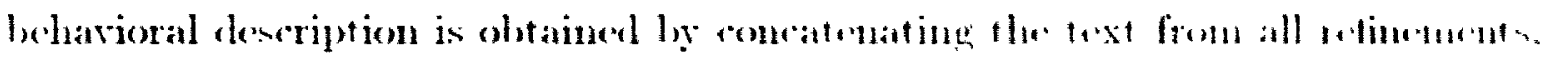

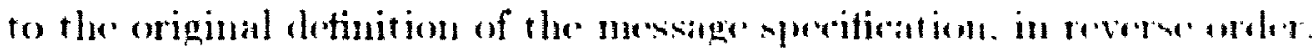

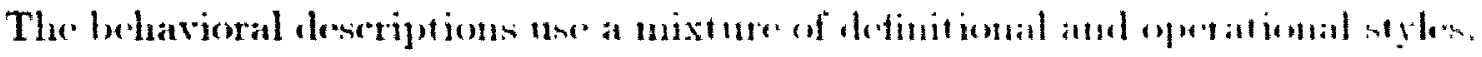

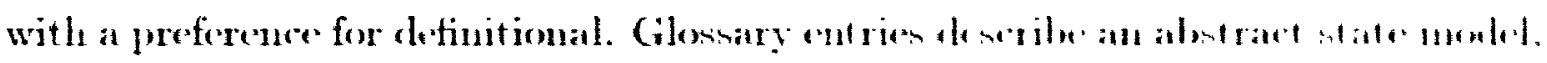

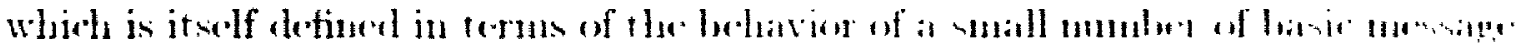

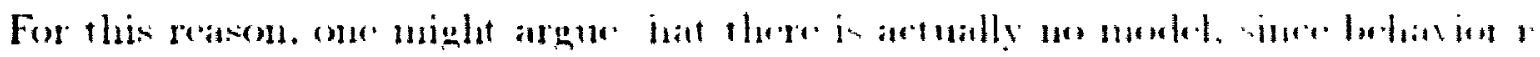

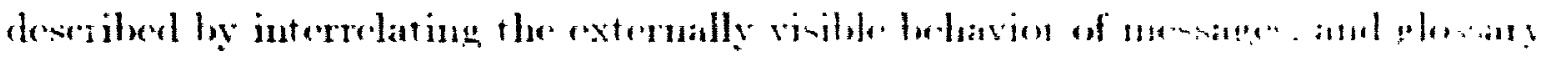

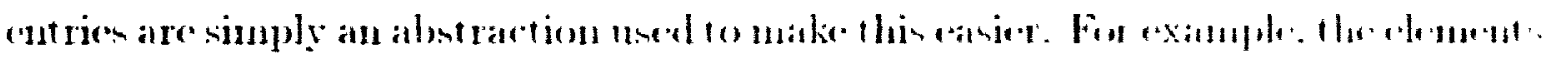

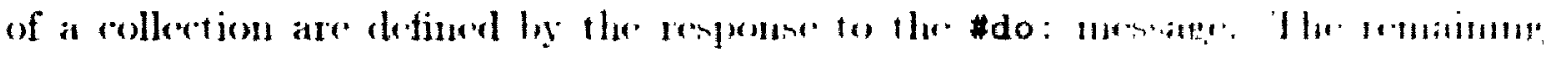

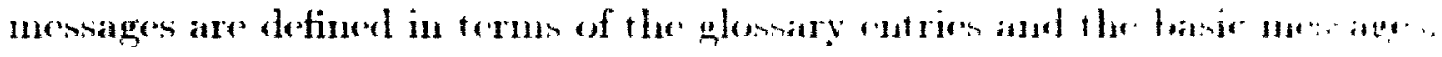

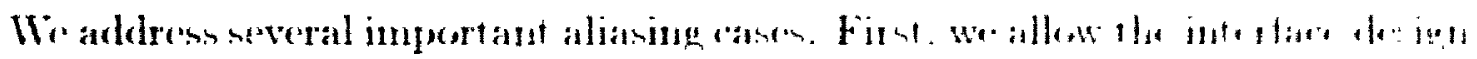

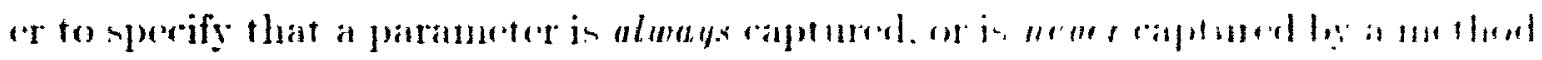

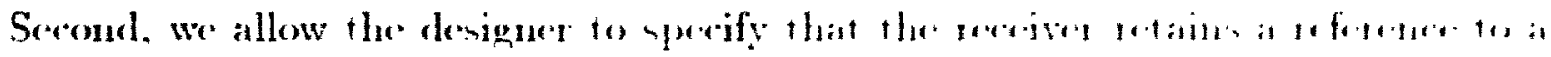

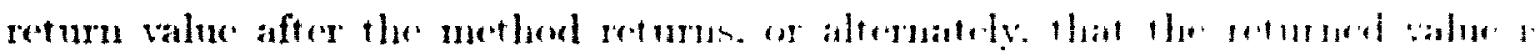

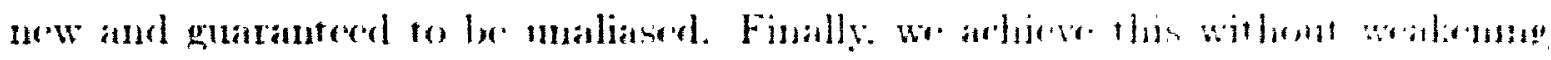

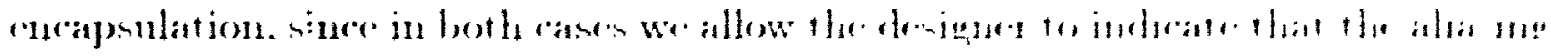

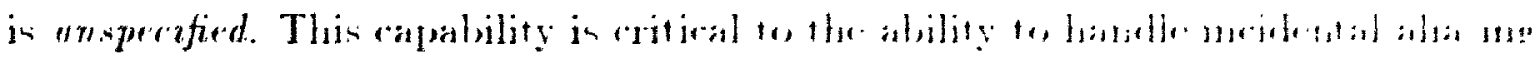

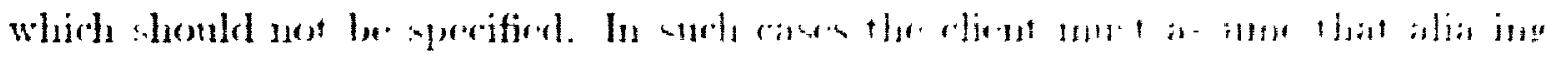

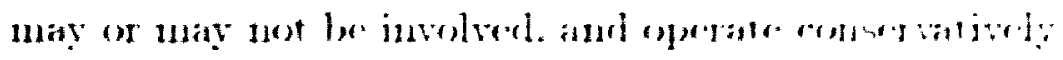

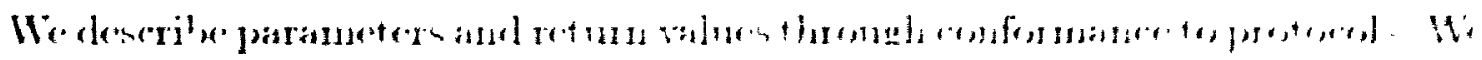




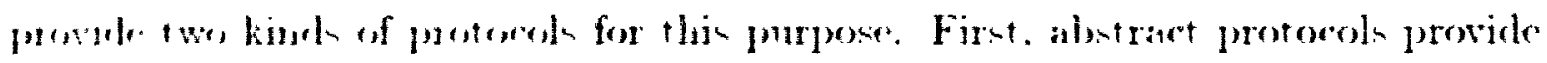

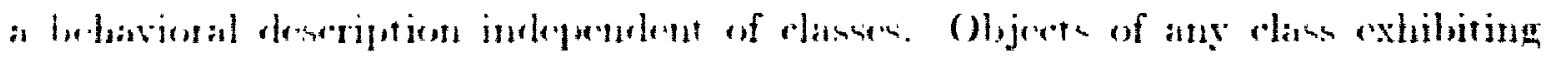

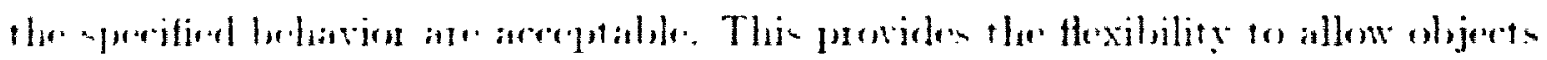

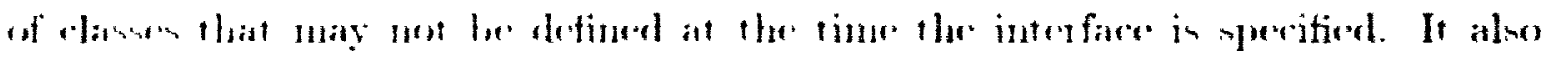

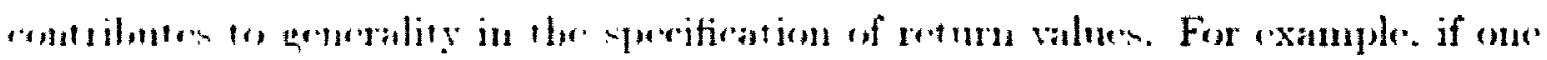

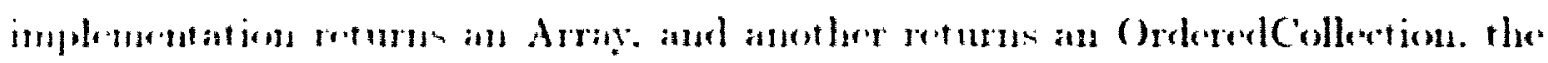

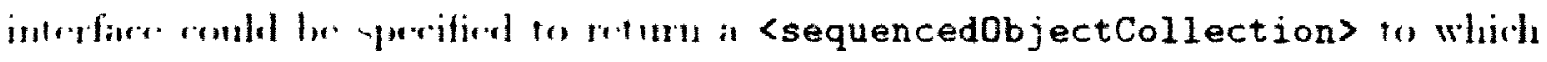

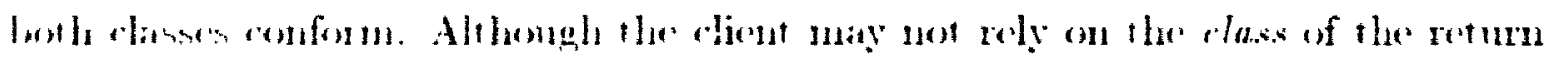

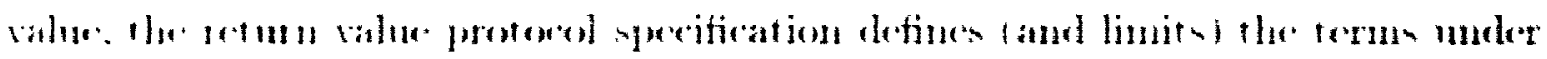

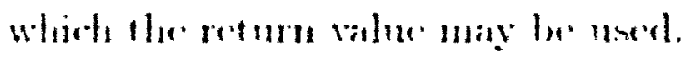

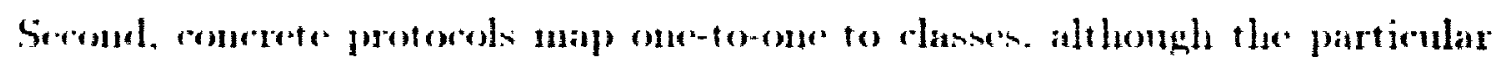

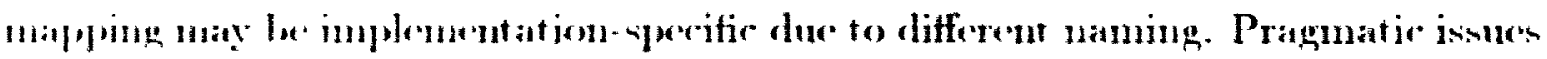

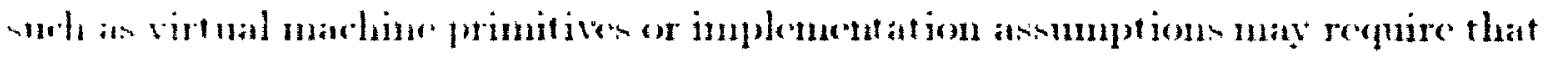
parameter be limited to ohjects of a particular class. Comerete protocols allow the

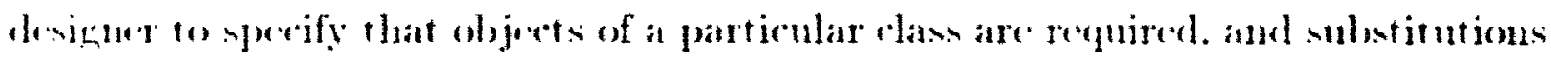

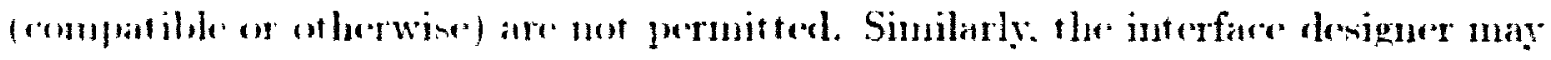

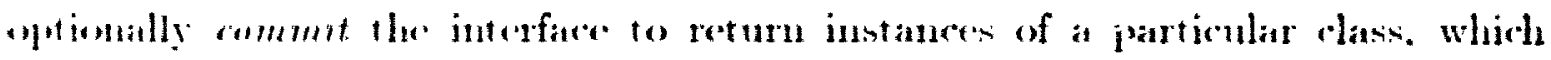

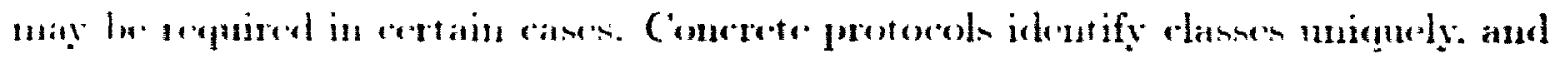

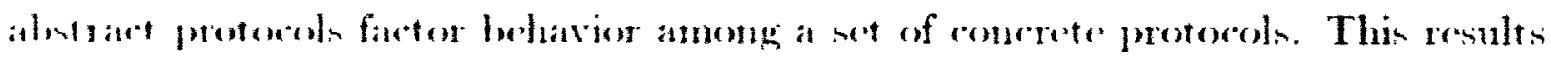
in extensive information -latring.

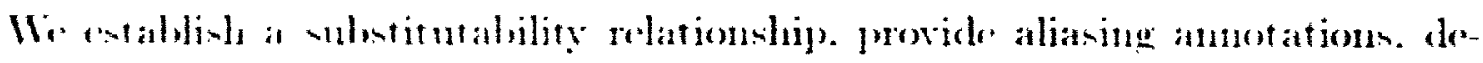

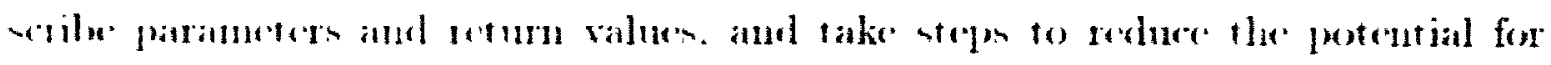

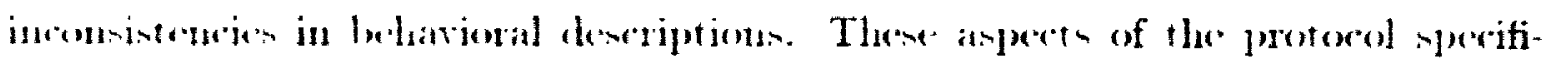

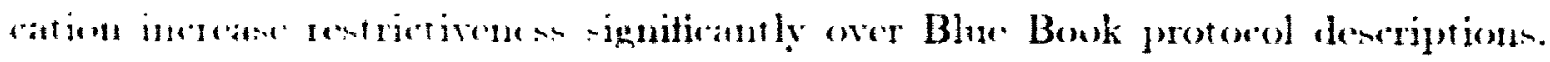
Howeres. the wey anpert of the protosol model which makes it suitable at refor-

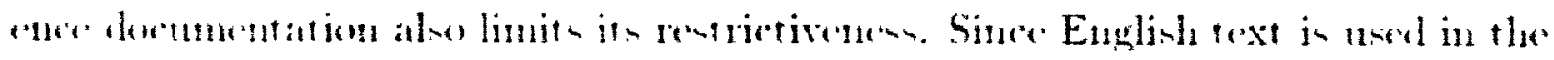

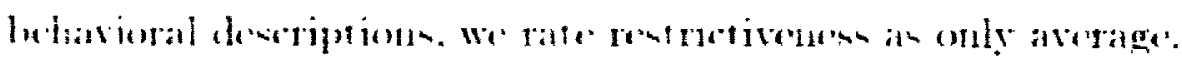

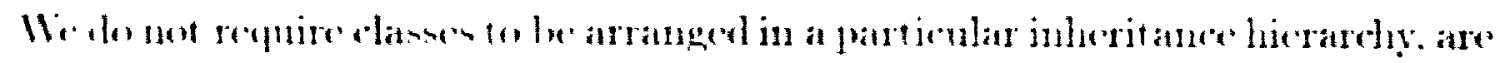




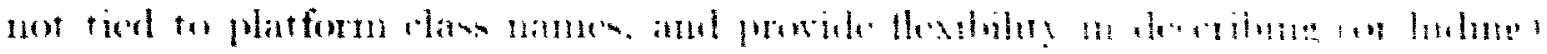

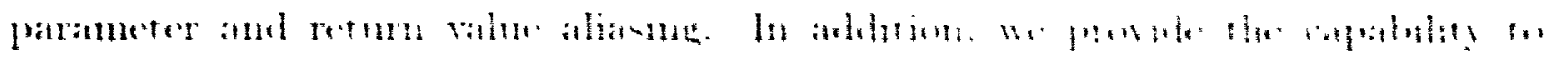

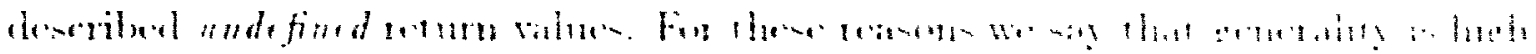

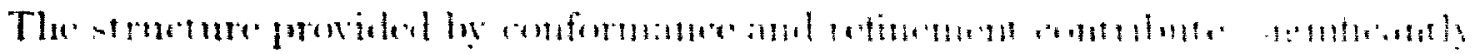

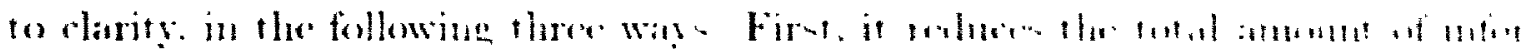

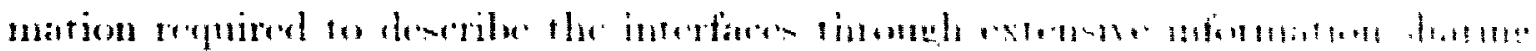

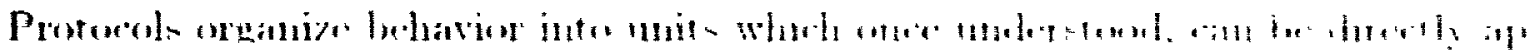

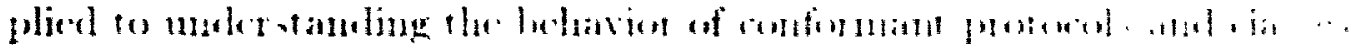

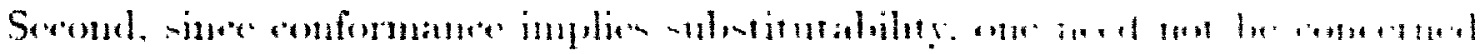

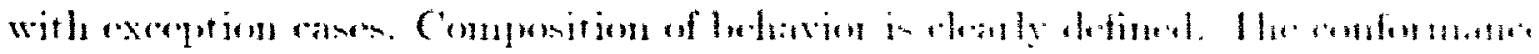

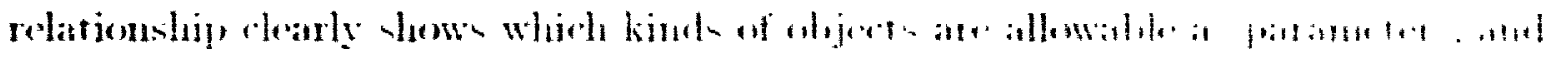

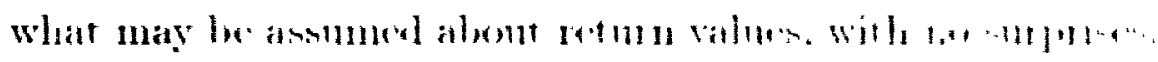

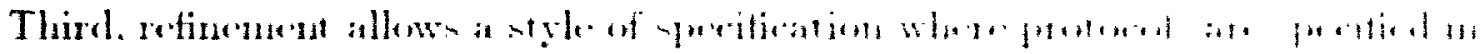

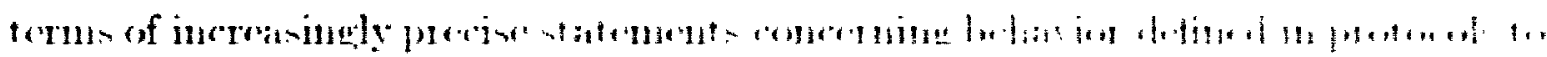

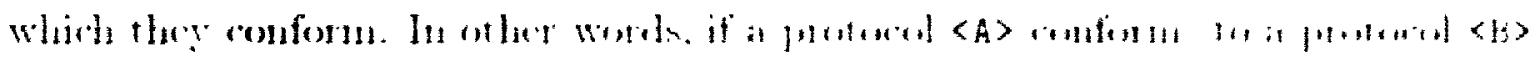

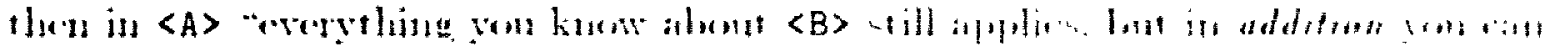
aluo assmum the following..."

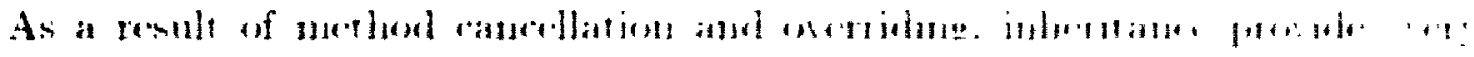

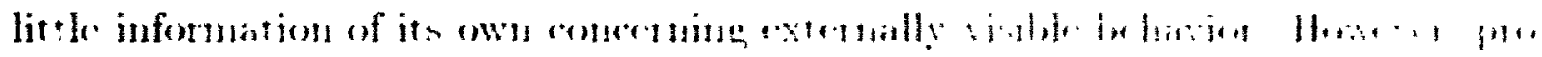

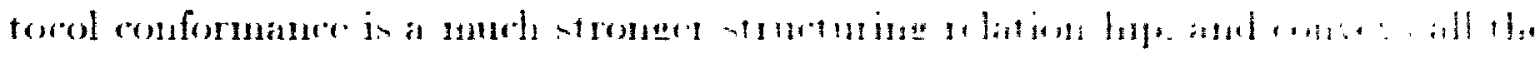
information implied ly sulemitutalilit:

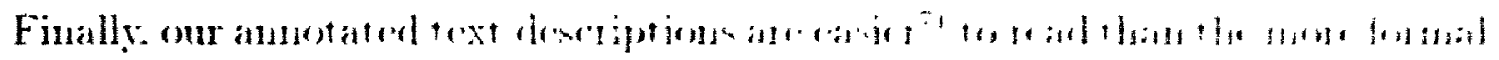

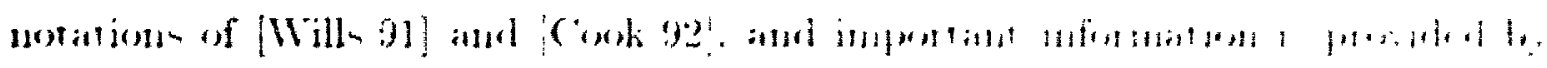

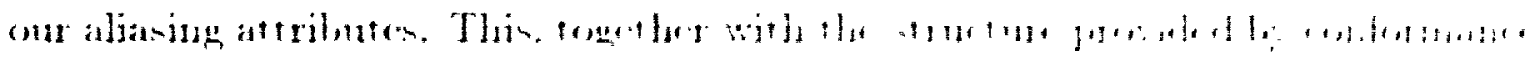
result - in at high dregle. of ala! il:?

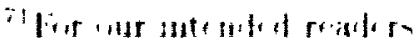




\section{(i.1.1 Discussion}

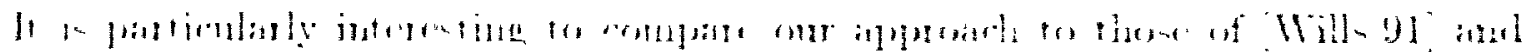

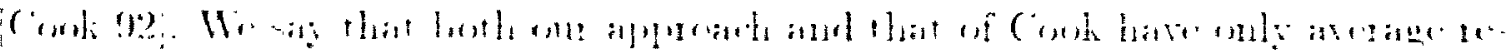

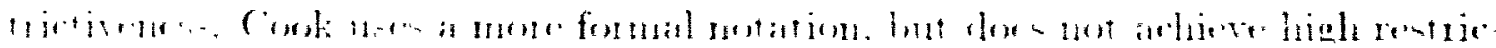

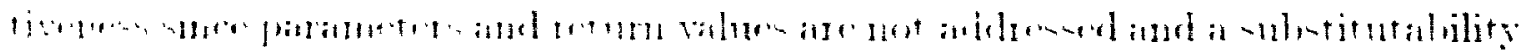

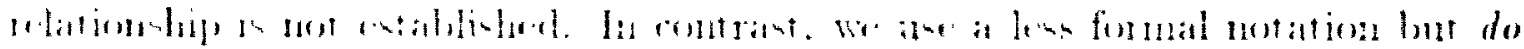

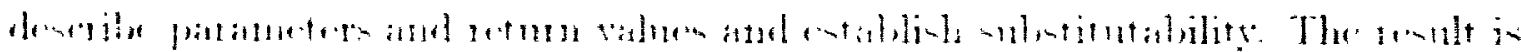

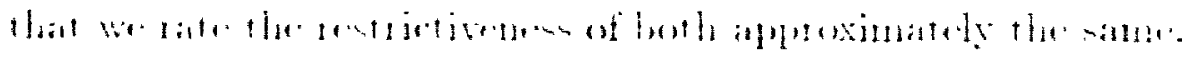

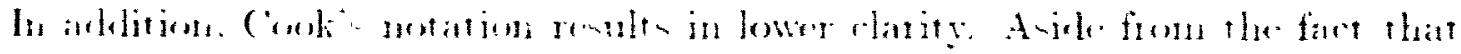

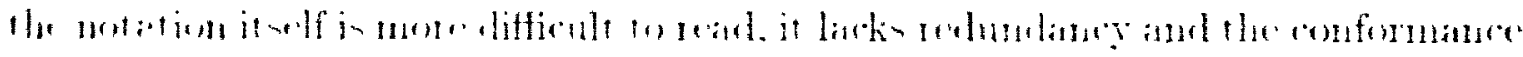

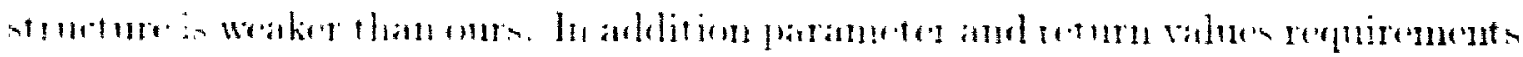

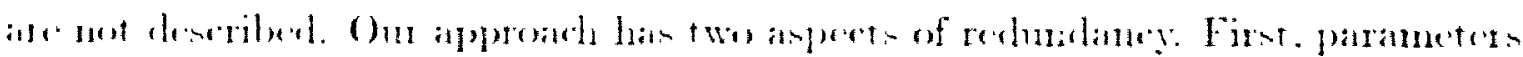

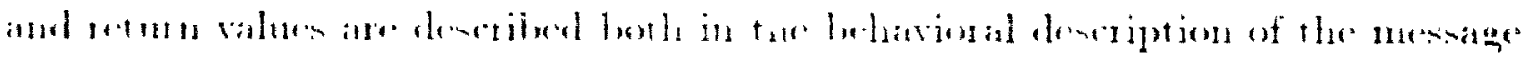

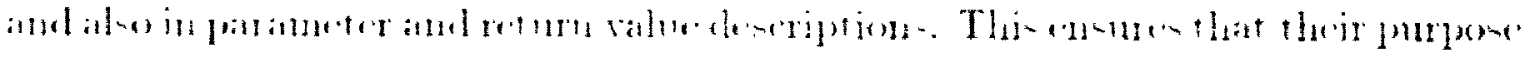

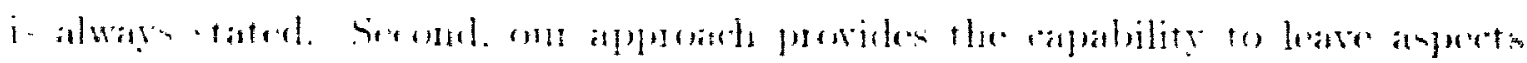

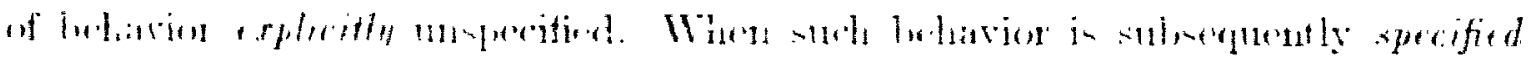

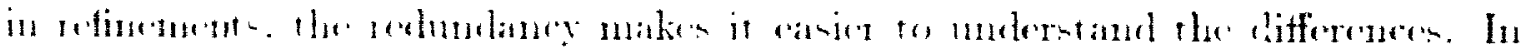

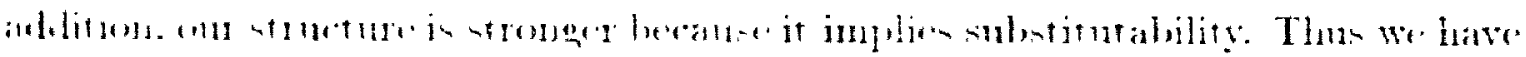

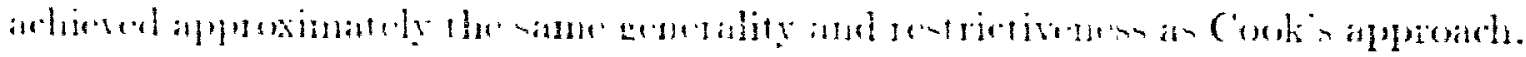

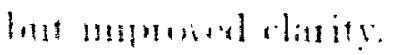

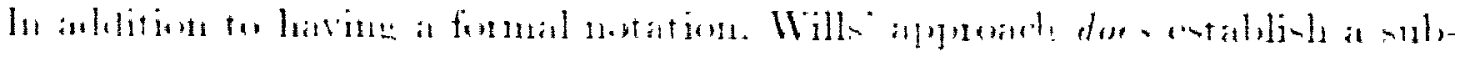

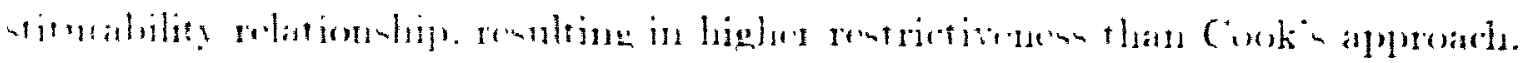

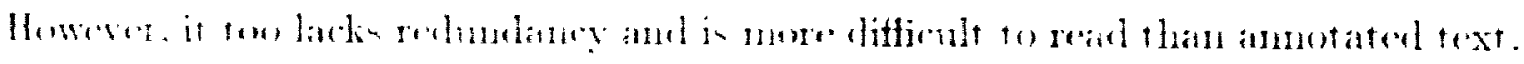

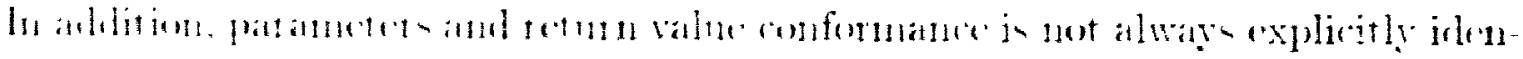

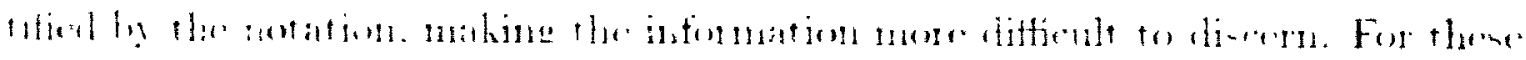

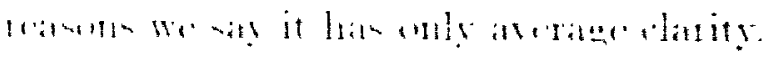

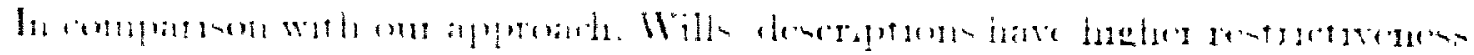

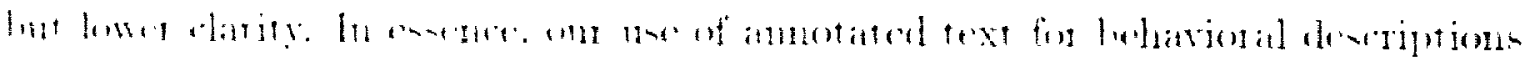




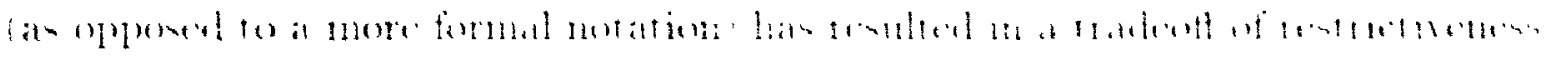

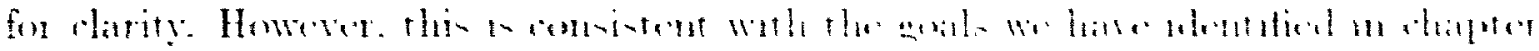

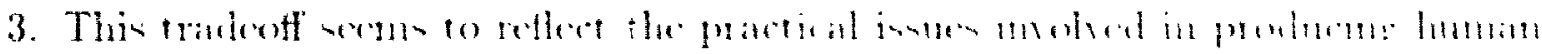

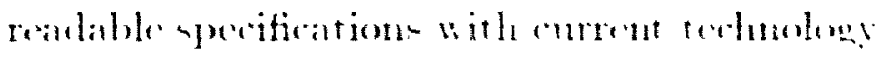

\subsection{Conclusions}

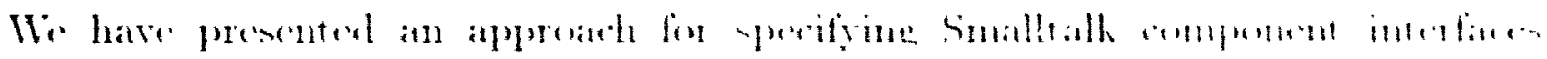

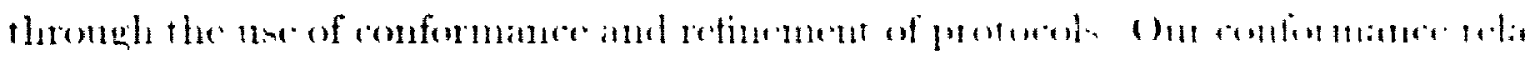

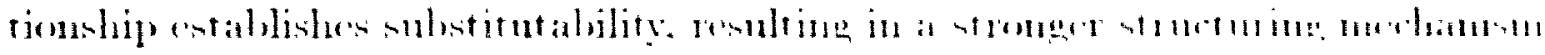
than inheritance. This. fogether with on 10 .

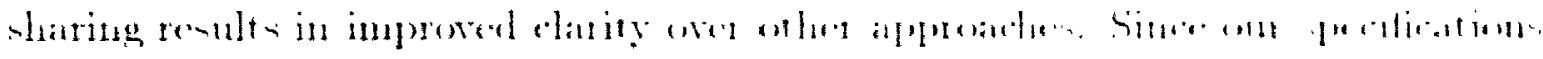

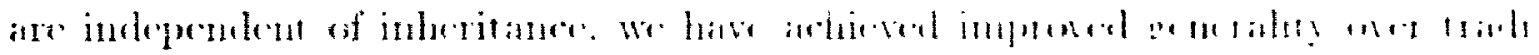

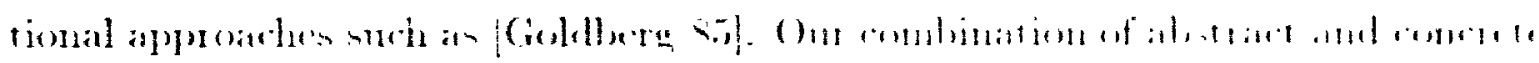

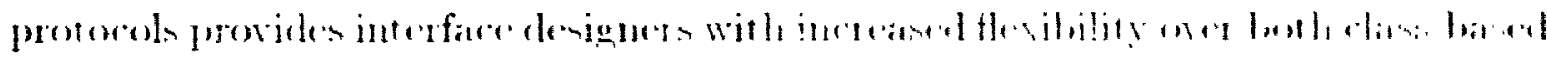

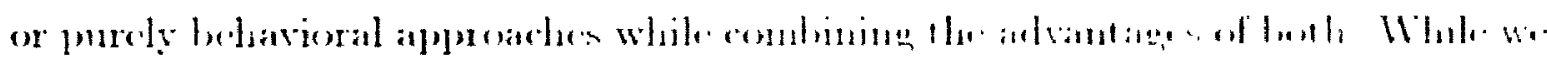

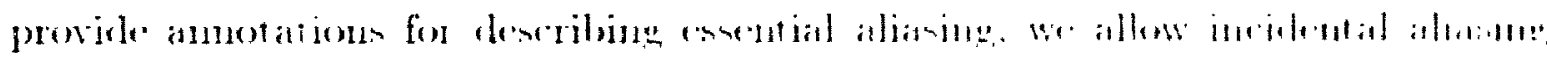

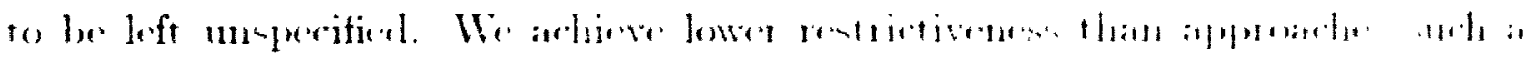

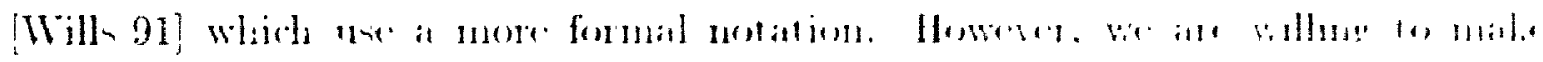

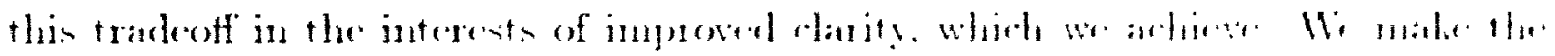
following olmeivations:

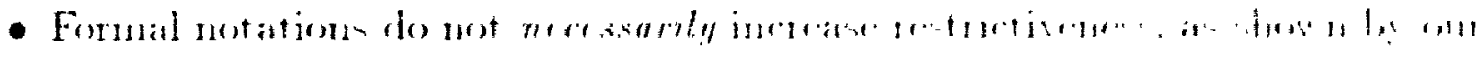

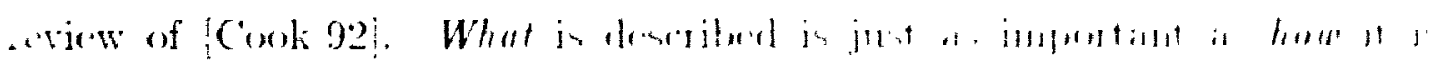
described.

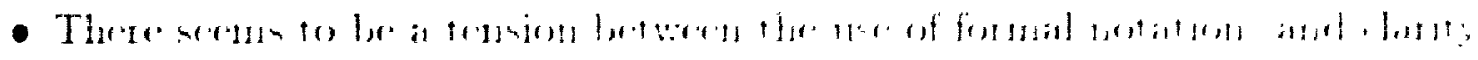

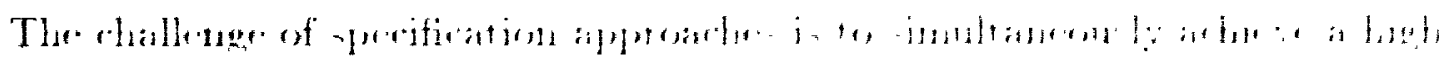

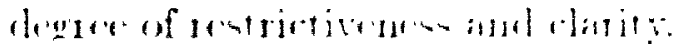




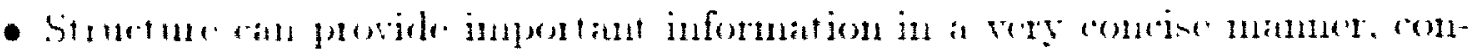

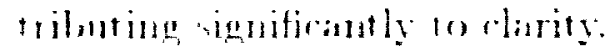

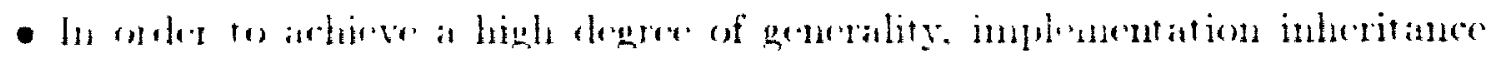

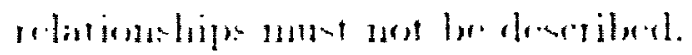

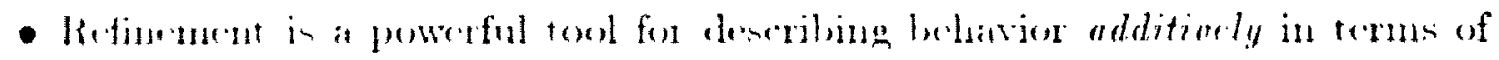

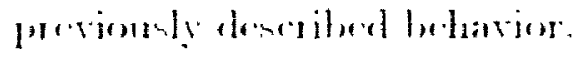

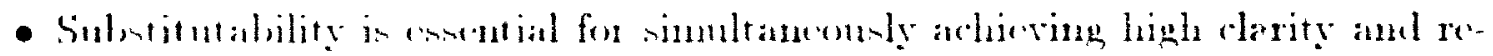
strietivenumens.

- Fof pantical watoms, any Suallalk specifieation approach must be able to

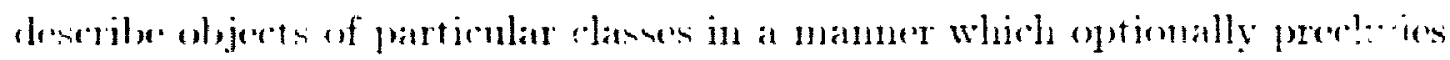
nhost itutability.

\subsubsection{Experience}

The protorol moded has been in use for a year now at (OTl. It was developed

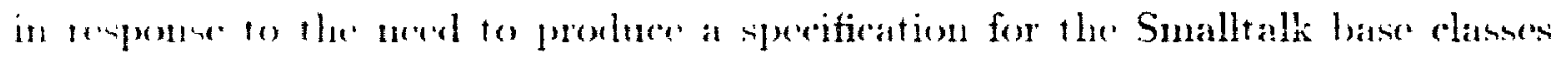
indegendenty of implementations. in otder to facilitate derelopment of applioations

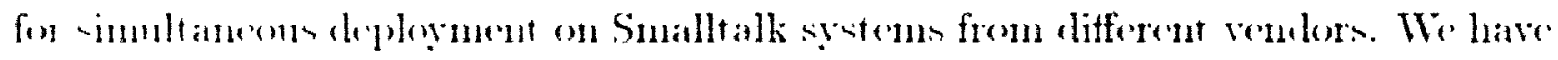

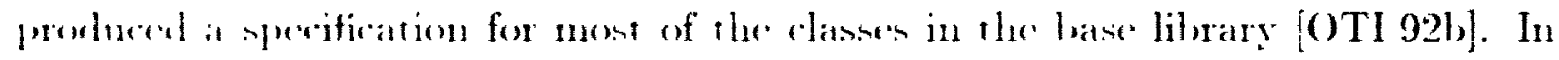
mhlition. we have also uned the appoach to sperify interfaces for subsepurent inde pendent implementition. The latter work irlentified the nend to renolve aliasing ambientiter thomgh andutations.

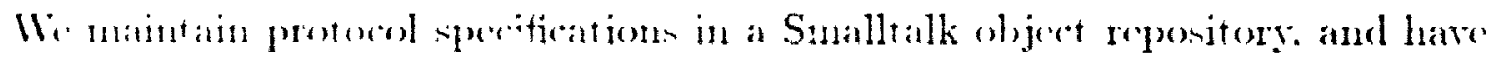

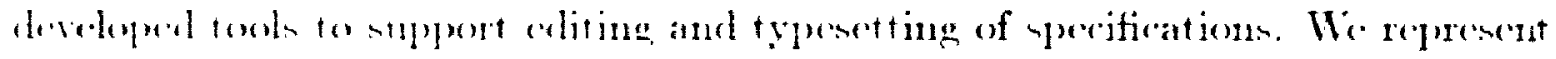

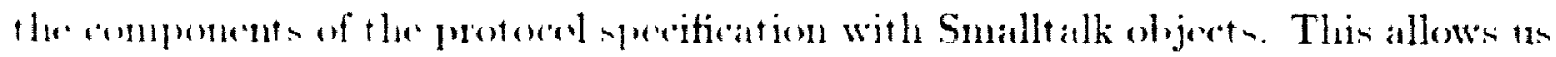

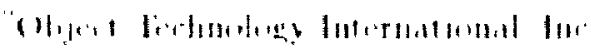




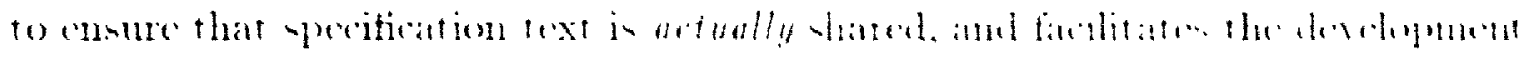

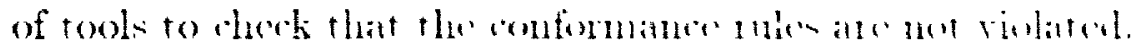

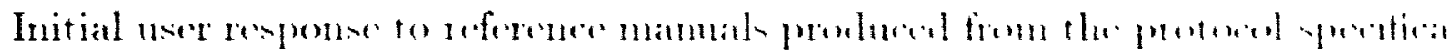

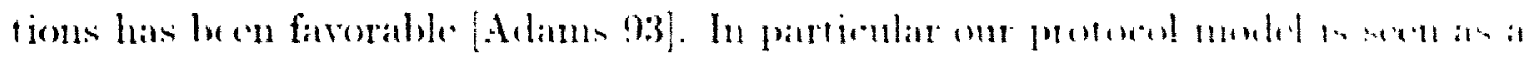

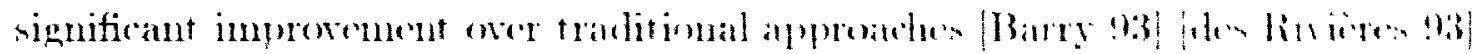

\subsection{Future Work}

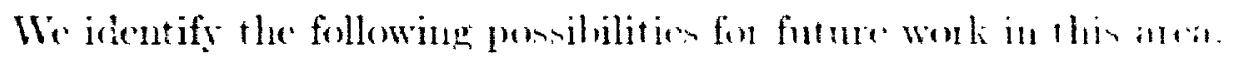

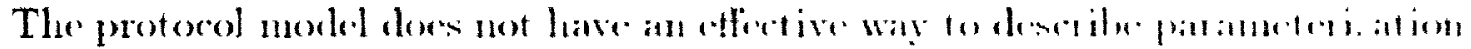

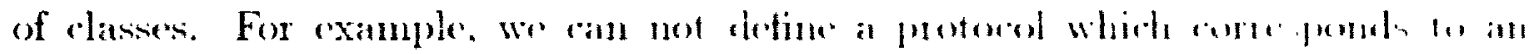

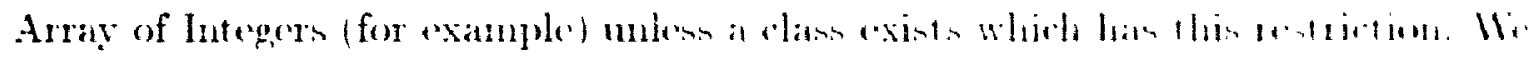

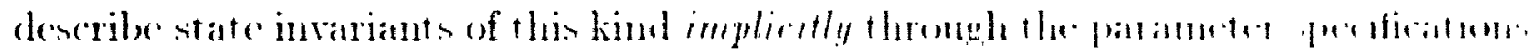

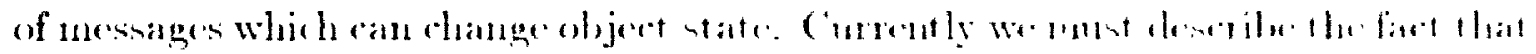

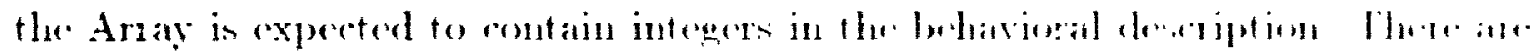

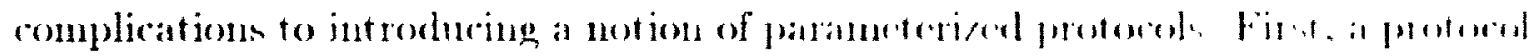

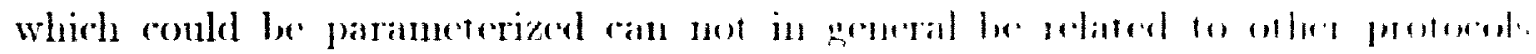

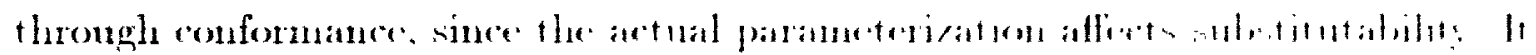

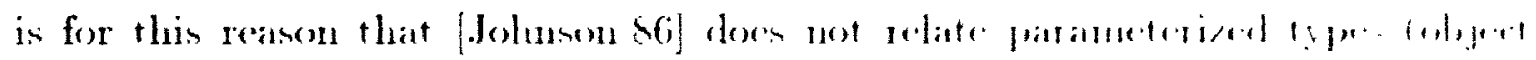

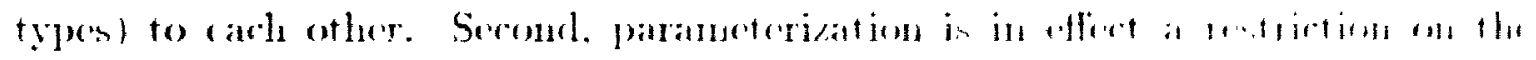

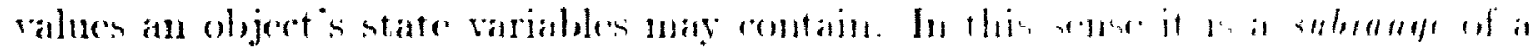

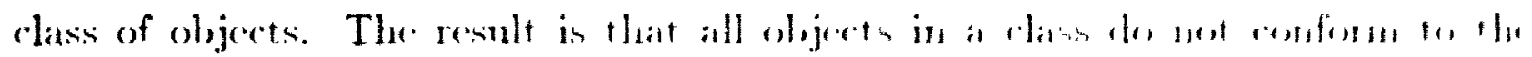

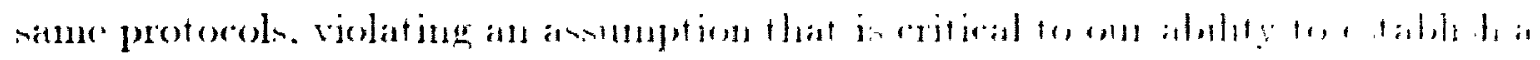

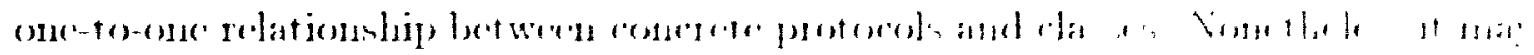

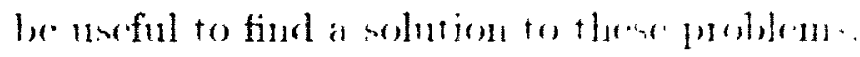

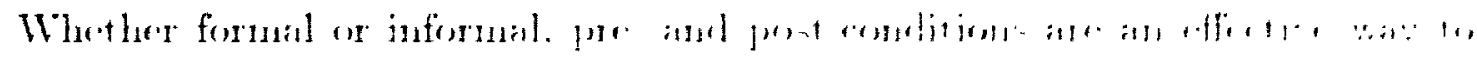

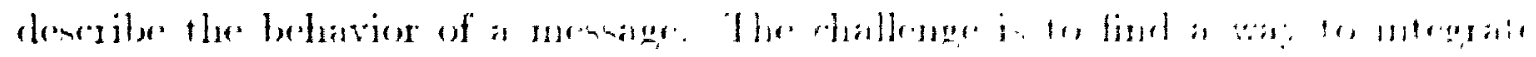

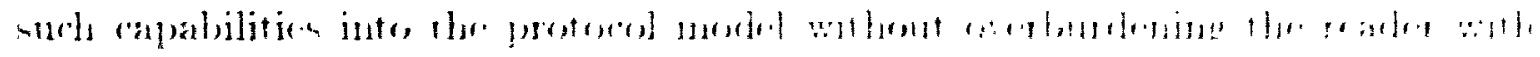

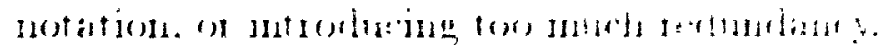




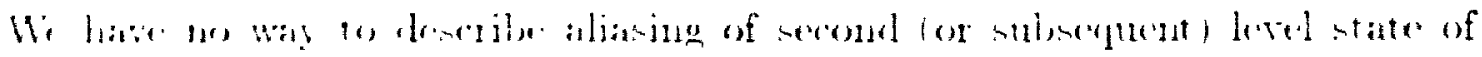

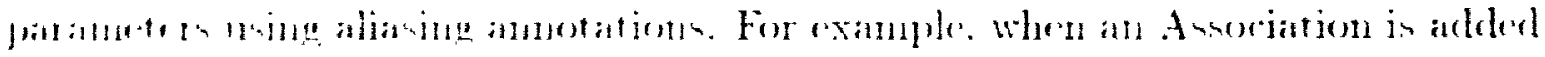

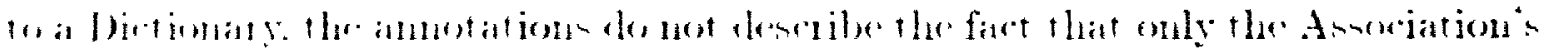

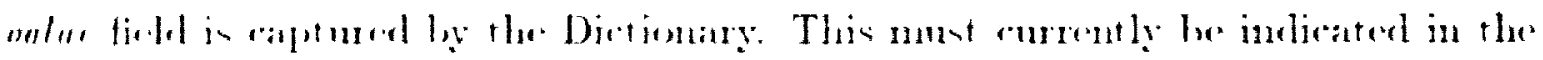
le havinal dereniption.

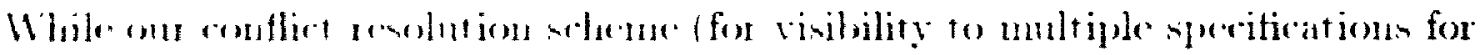

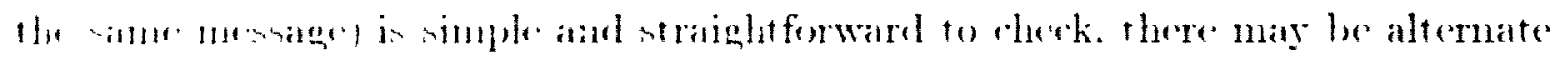

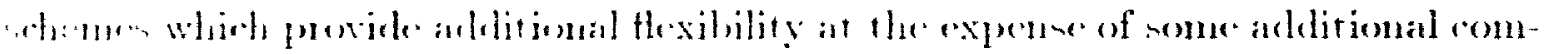
plexily.

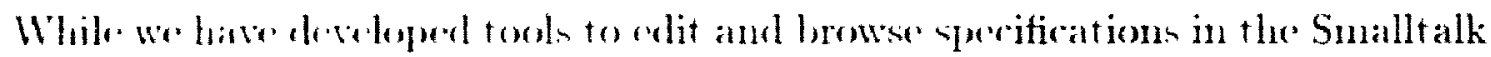

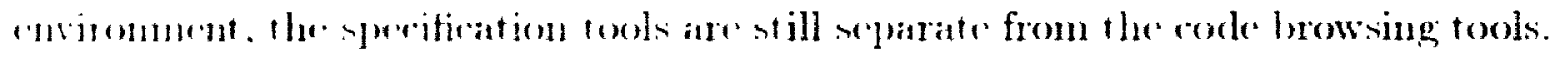

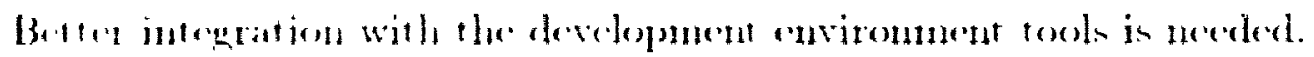

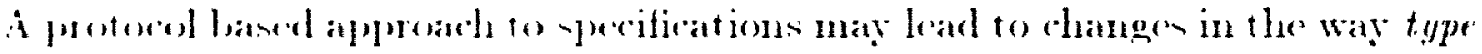

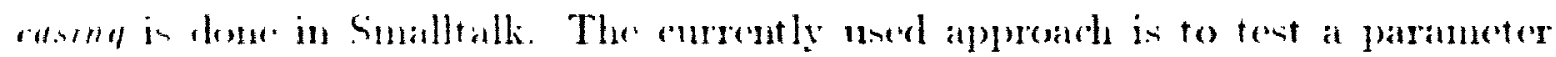

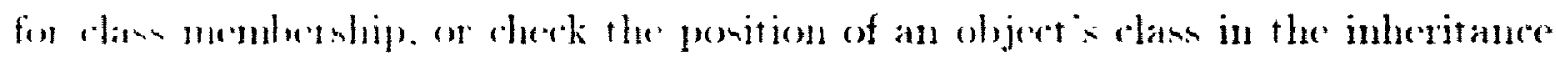

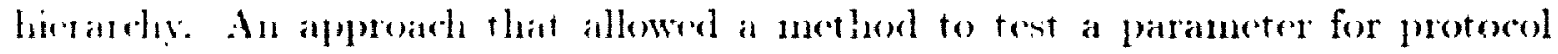

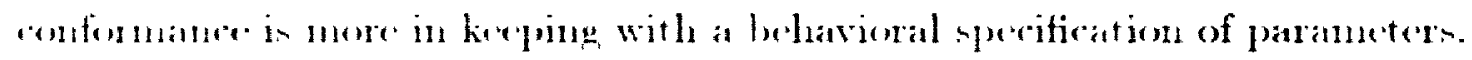

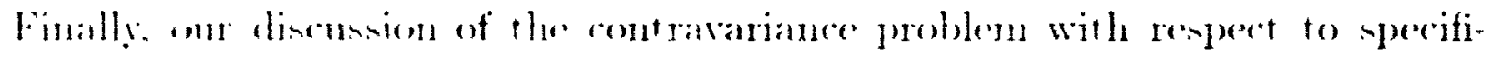

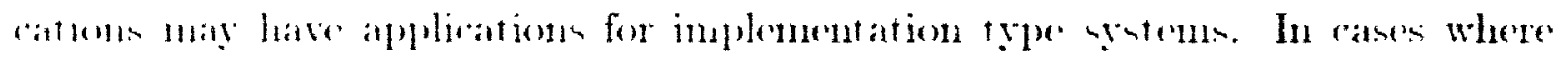

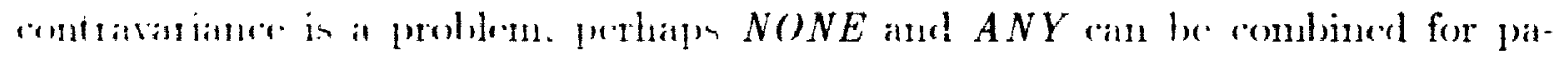

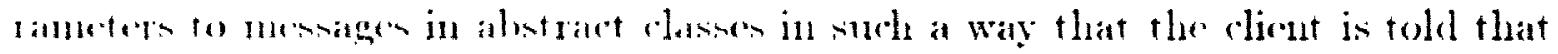

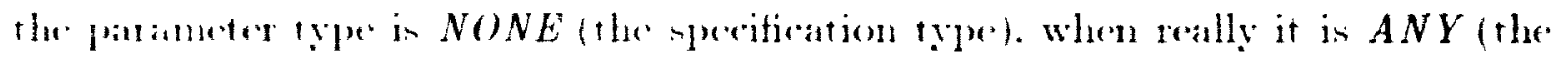
implementation type). This wonld support rense of the method by subelashes which

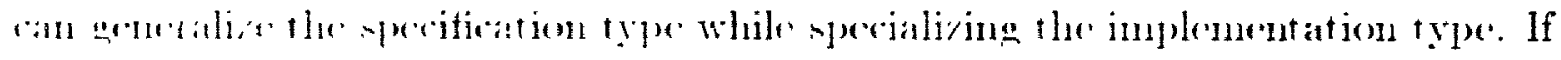

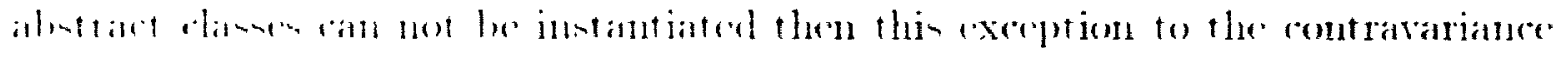

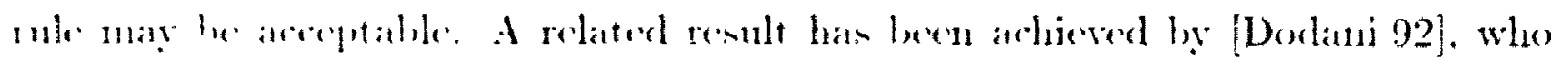

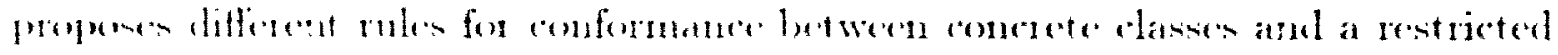

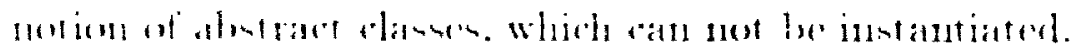




\subsection{The Final Word}

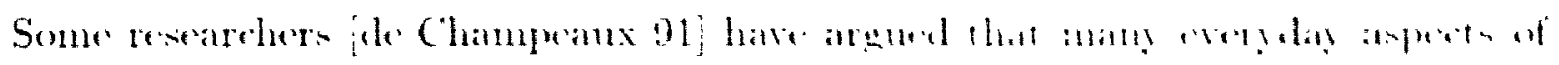

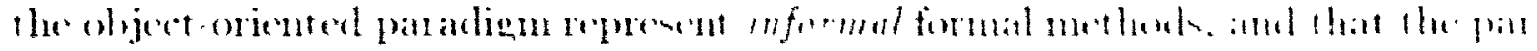

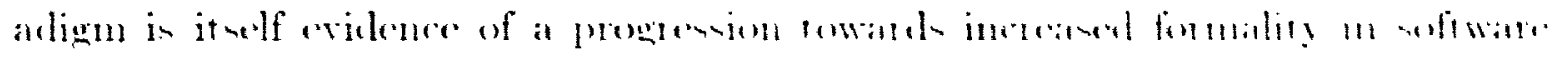

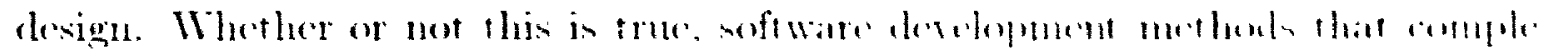

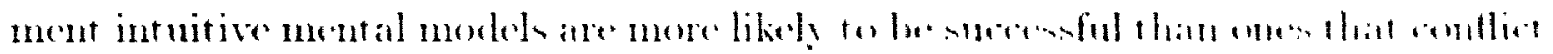
with them. 


\section{References}

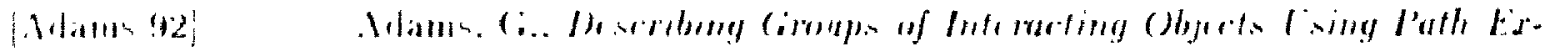

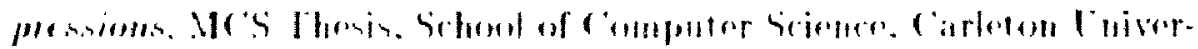
i1 1.19192

1.1.111-12:

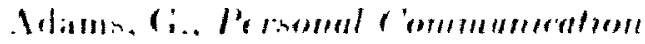

$\mid \ln +1+1+1)$

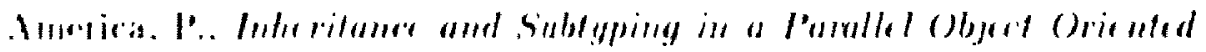

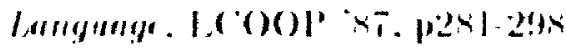

Mmirira 90$)$

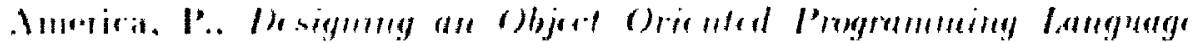

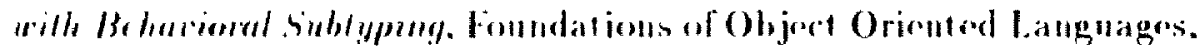
I.Nis $1 \times 9$. prol !n

$|1.281: 13|$

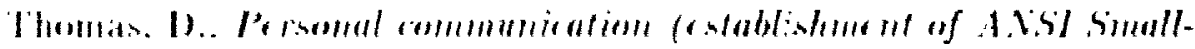
talk ( immmiller)

[13.11: 92 !

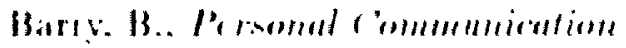

$[18.11,48\}$

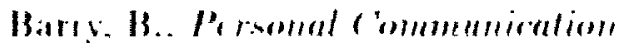

|lwning $x 2 \mid$

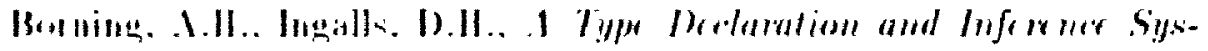

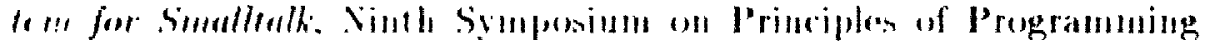
Languages. pli33 111, Jath 19822

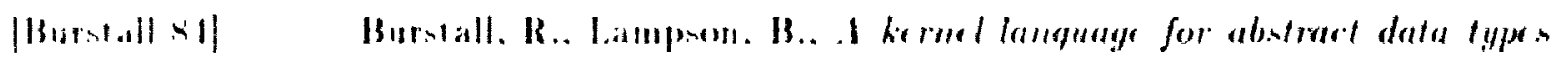

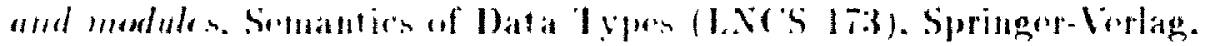
$|!| s \mid$

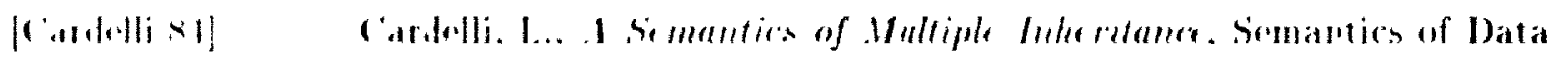

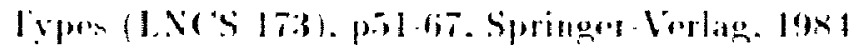

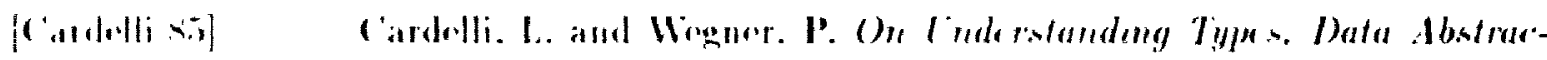

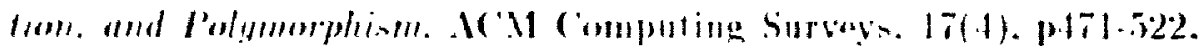
llac Istit

$\mid(1 \ldots+1) \times$

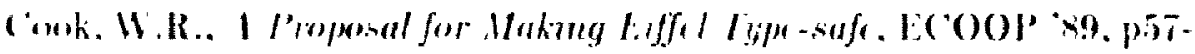
70

[inh in!

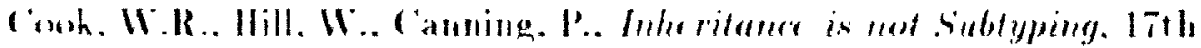
Imual lo .11 Symposium on Principles of Programming Languages. Jan l!m!1

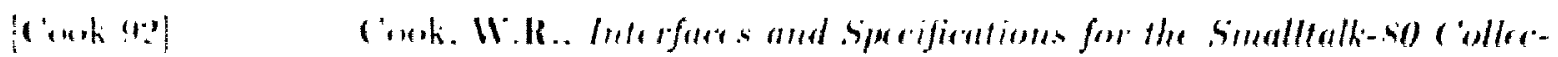

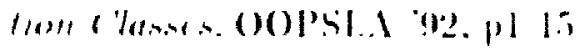

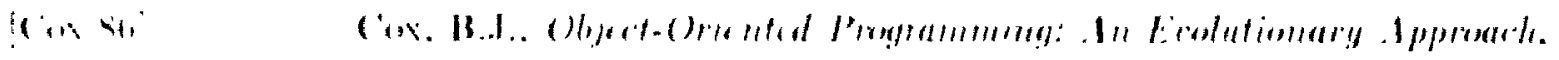

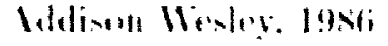

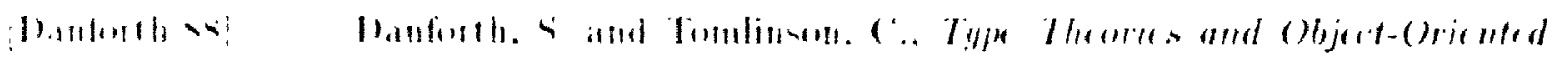

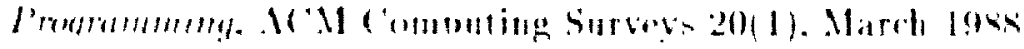




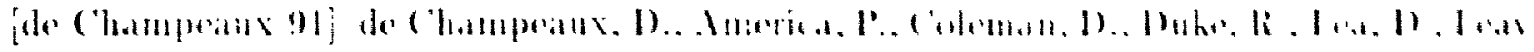

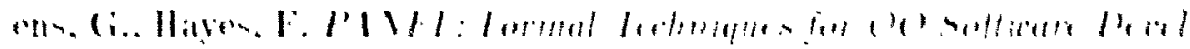

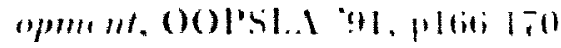

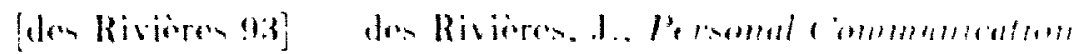

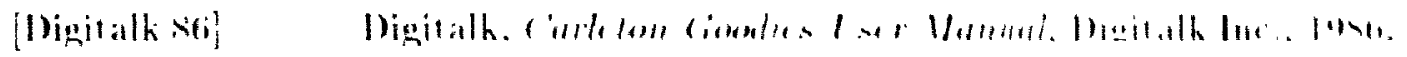

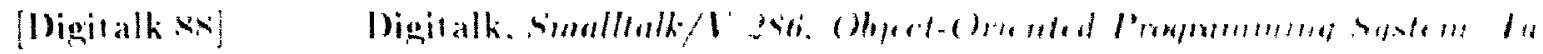

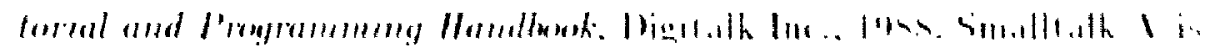
a registored Irademath of Digitalh Inir.

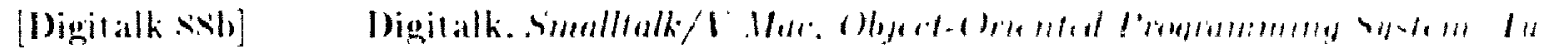

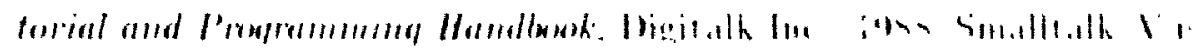
a registored trademark of Digilalk Int.

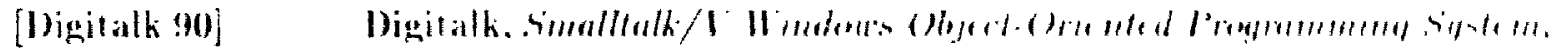

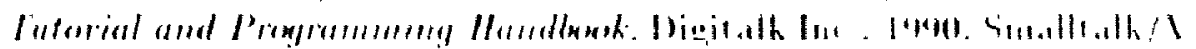
in a registered tradomath of ligitall lin.

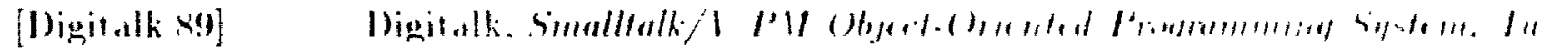

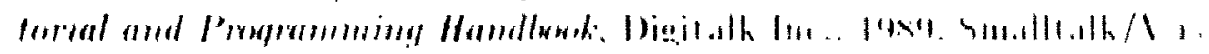

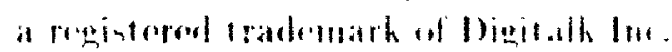

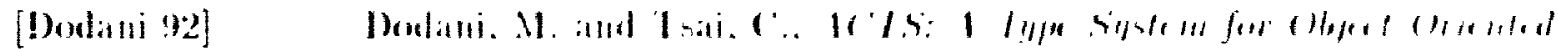

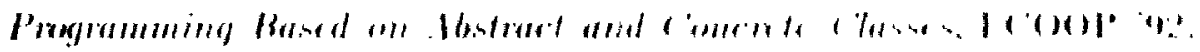
p.30!) 329

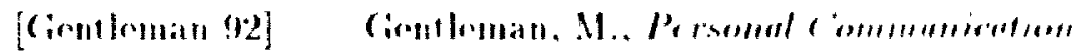

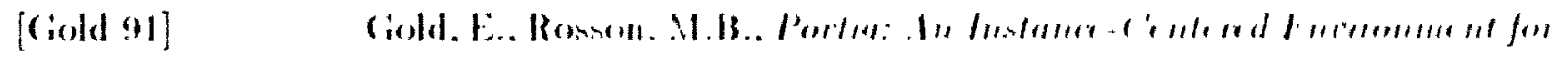

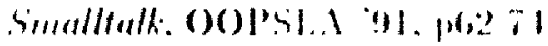

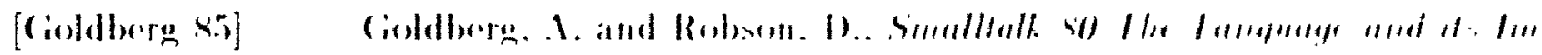

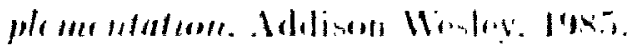

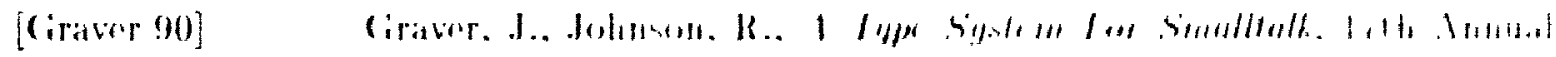

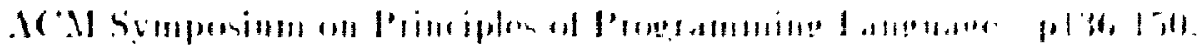
Jan $\ln (9)$

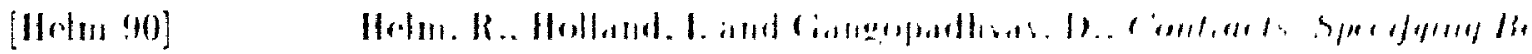

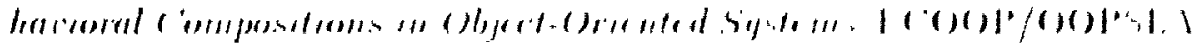
(3), plog Ia(1).

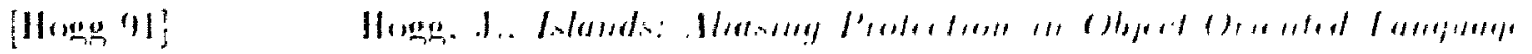

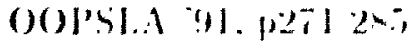

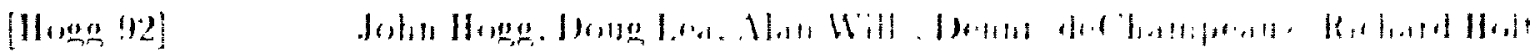

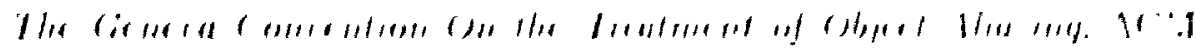
o() 
'Hall ' 2 '.

IIs:1 $12:$

[II I I. '11!

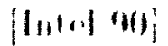

[.Hhin:en: $\times(6)$ ]

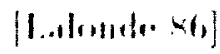

[Halninlonai]

$|1, \cdot 1+14: 90|$

|lowherhere xy |

llinhor sil

[Mnoris

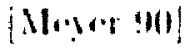

philnes is)

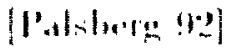

$[1,116: 42]$

(1)!1!:!

(1) $11 \%$

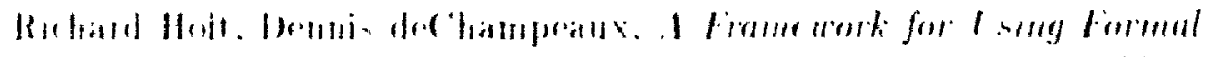

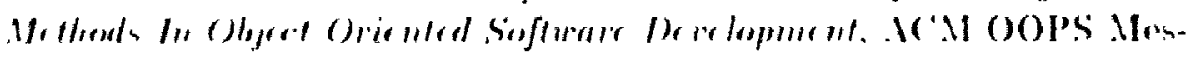

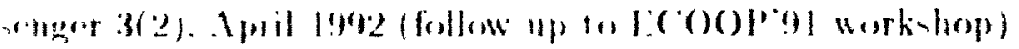

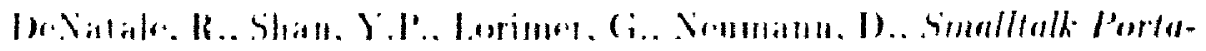

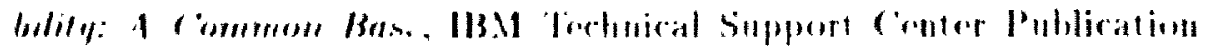
in. $0 ; 0 ; 2130903000.19192$

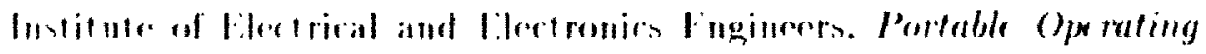

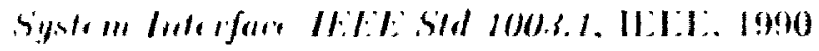

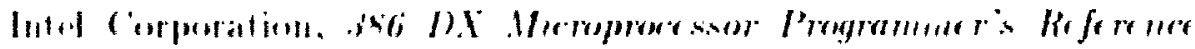
Manural. latwl 1990)

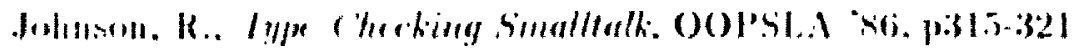

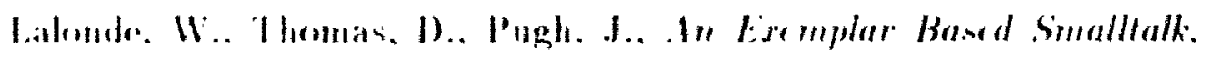

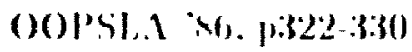

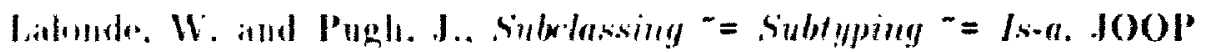
3(5). Jan 1901. pis 6i2

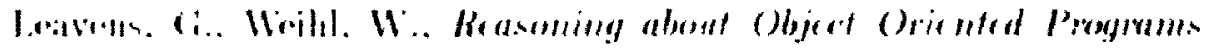

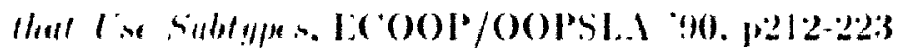

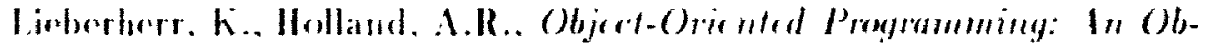

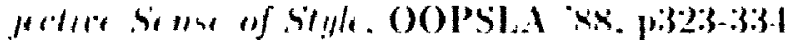

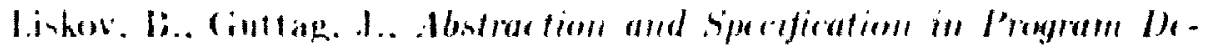

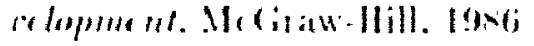

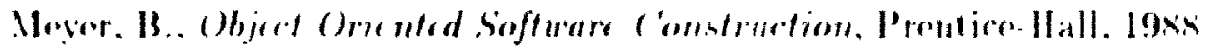

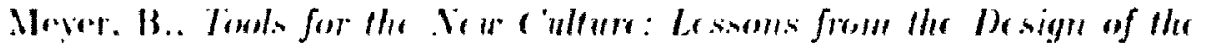

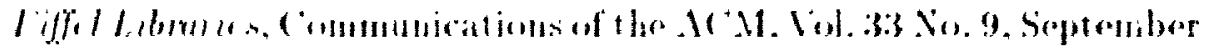
19!90. p69s sti.

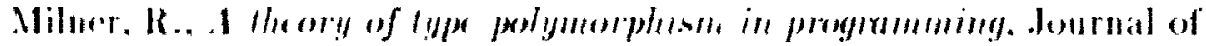

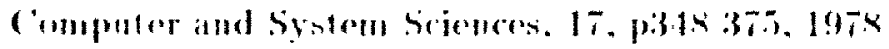

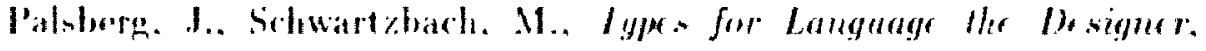

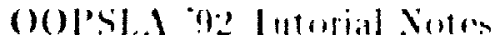

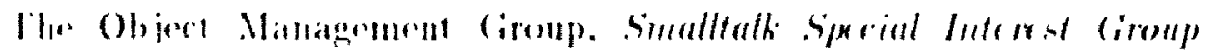

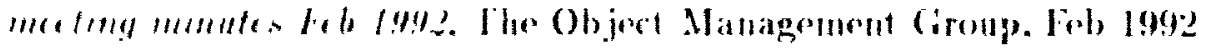

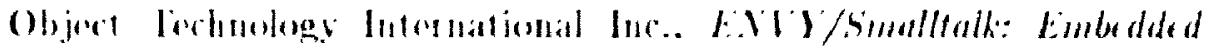

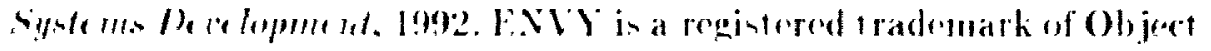
lerhoulogy lowernational lire.

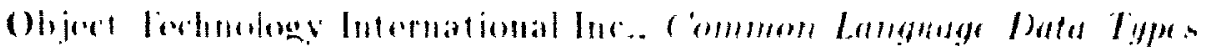

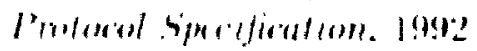


[Oxhoj 12?!

[Palshere 91]

[Palsbers 92]

[larmas xi]

[Iortor (12)]

[I'P'S !y-2]

[Shatfort si]

[Skublies 91]

[inydor x6]

[Sumuki si]

[Ta(n)ल $\times 9$ ]

[( hambers!)]

[1 nix -3$]$

[11).1 90$]$

[Mrener $\times 7$ ]

Mrankex

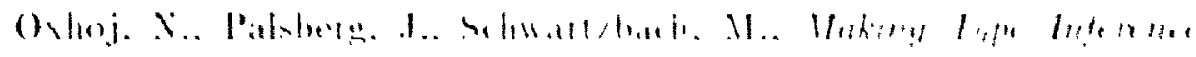

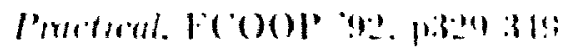

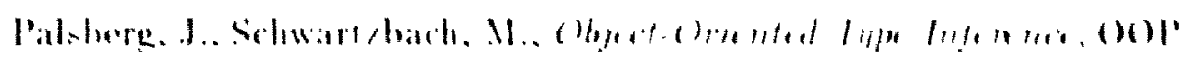
Sil. 91. pllti $\mid$ til

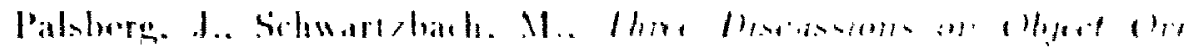

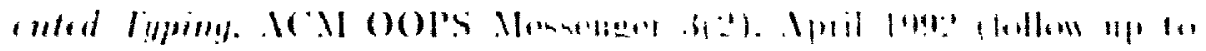

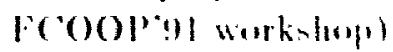

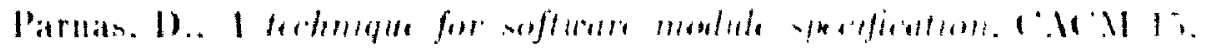
$1: 3: 30: 3: 36,19: 2$

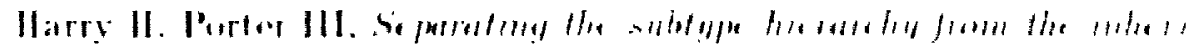

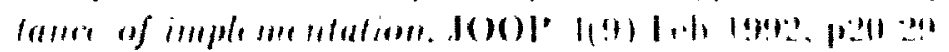

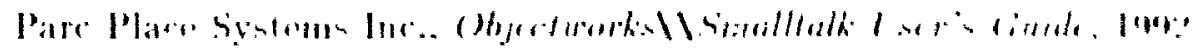

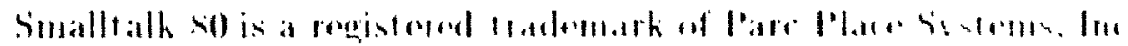

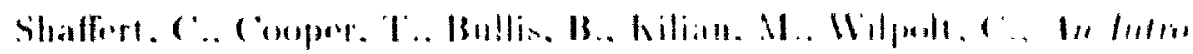

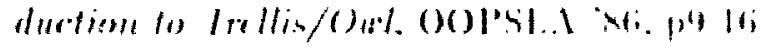

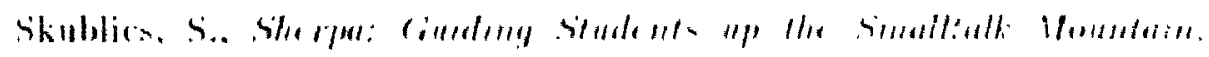

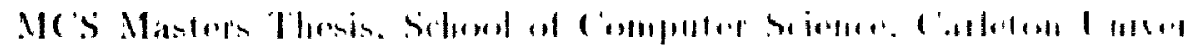
ily. 1991

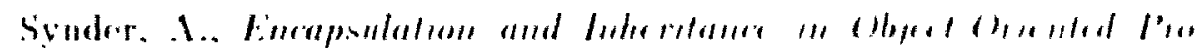

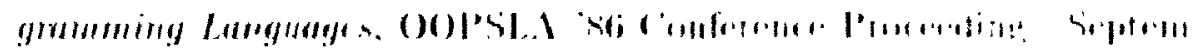
ber lakti.pisk.15

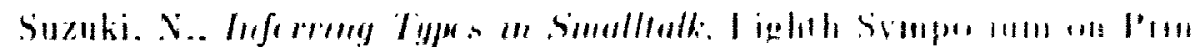

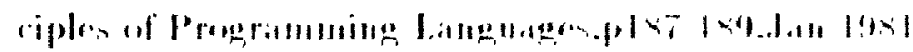

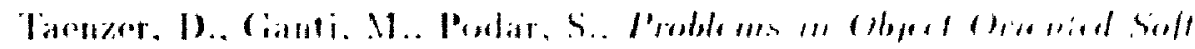

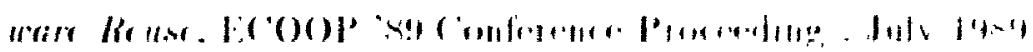

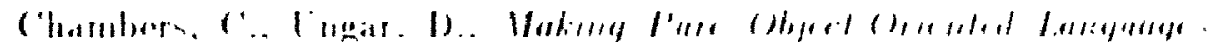

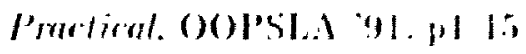

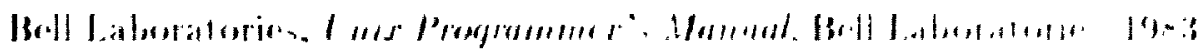

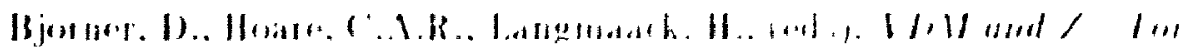

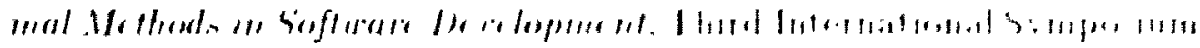

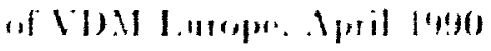

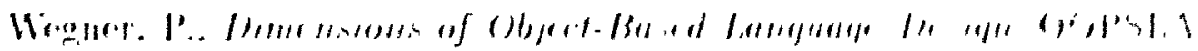

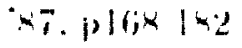

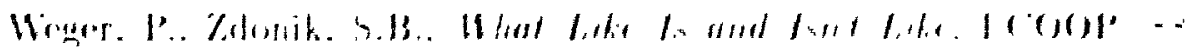
i., 


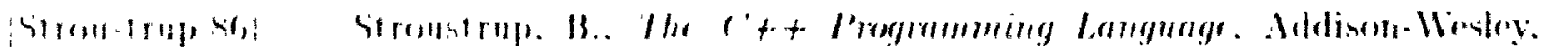
I!sa;

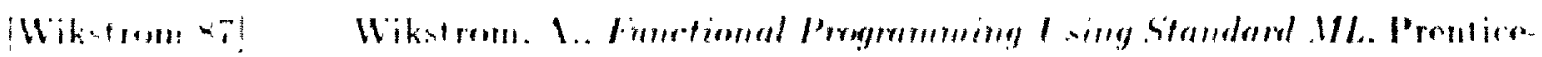
II.All. IMT

WII.

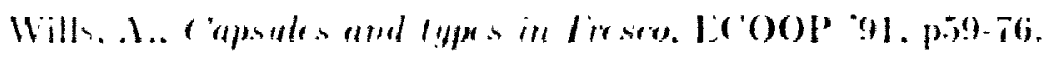

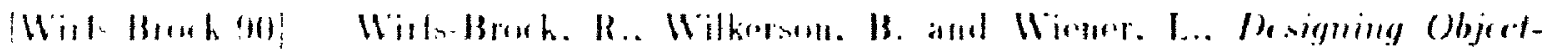

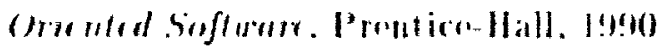




\section{A Appendix A: Sample Protocol Specification}

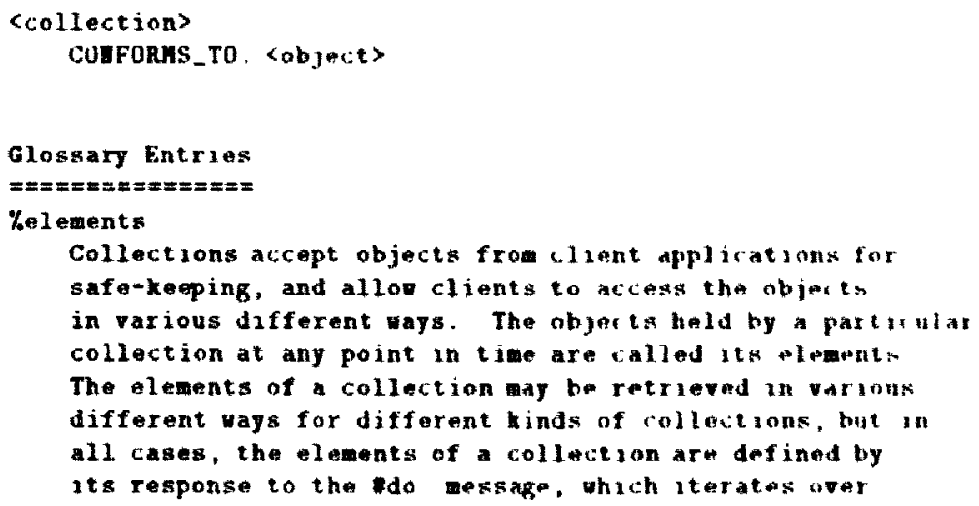




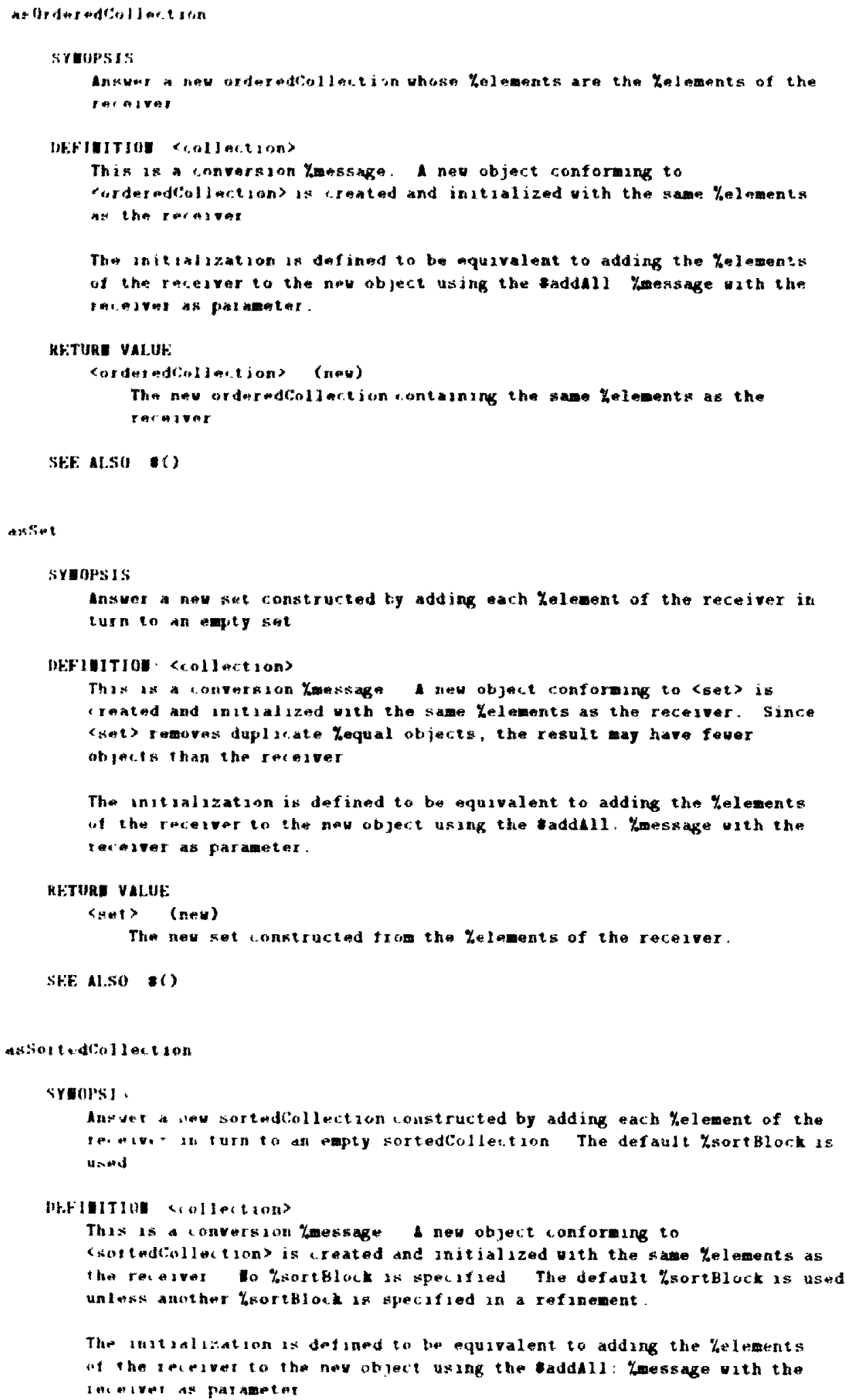


Sortedcollection). (neu)

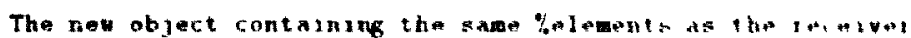

SEE ALSO (asSortedCollection fortbinck)

asSortedCollection discriminator

SYEOPS1S

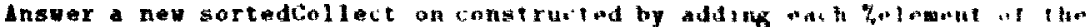

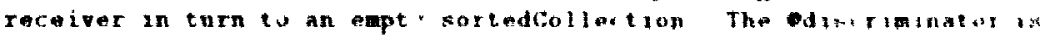

used as the \%sortBloxk for the new sartediollow ion

DEFIUIJION scollection>

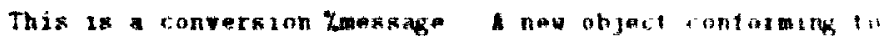

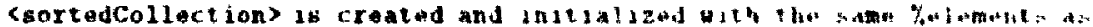

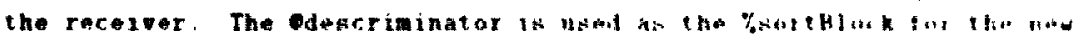

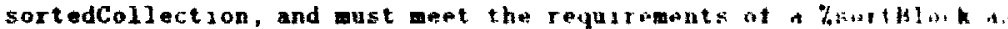

specified by <rortedcollection?

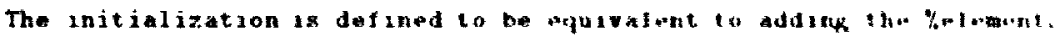

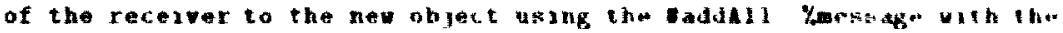
receiver as parameter

discriminator (block>

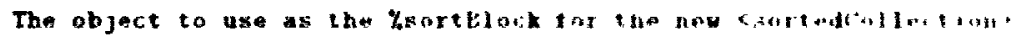

RETURE VALUE

<sortedCollection?, (nev)

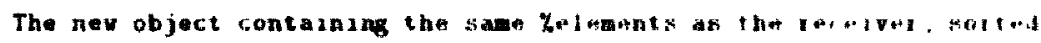
according to the order determined by the edexeriminatur yosthint

SEE ALSO: (asSar:edCollection sortblo,k)

collect: transformer

SYDOPSIS

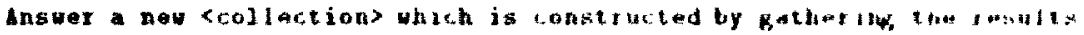

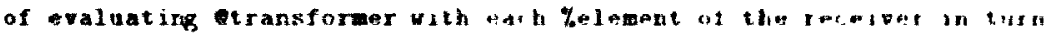

DEFIHITIOU - Scollection>

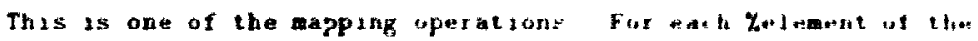

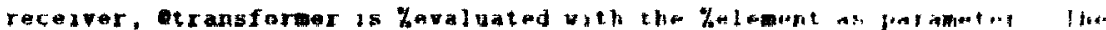

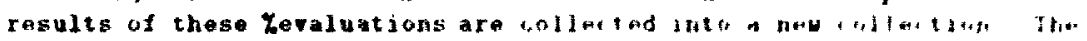

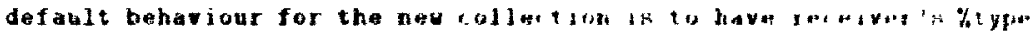

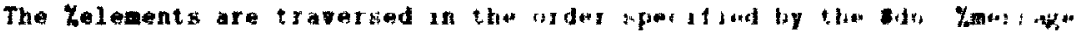
for thie raceivet

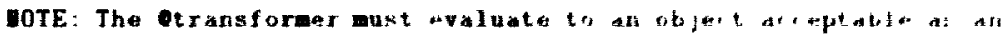

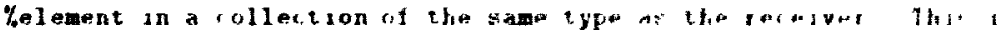

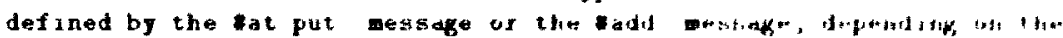

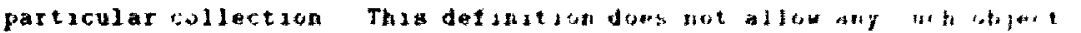
it is essentialiy abstad.t

transformer (b)ock

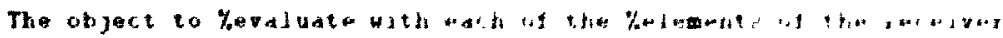
as paraseter

\section{HETUR: VALUE}

〈AECEIVER> (new)

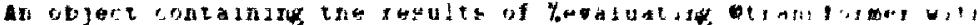

earh of the rachiger's tapleants. 


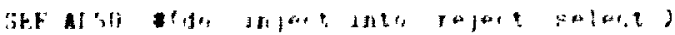

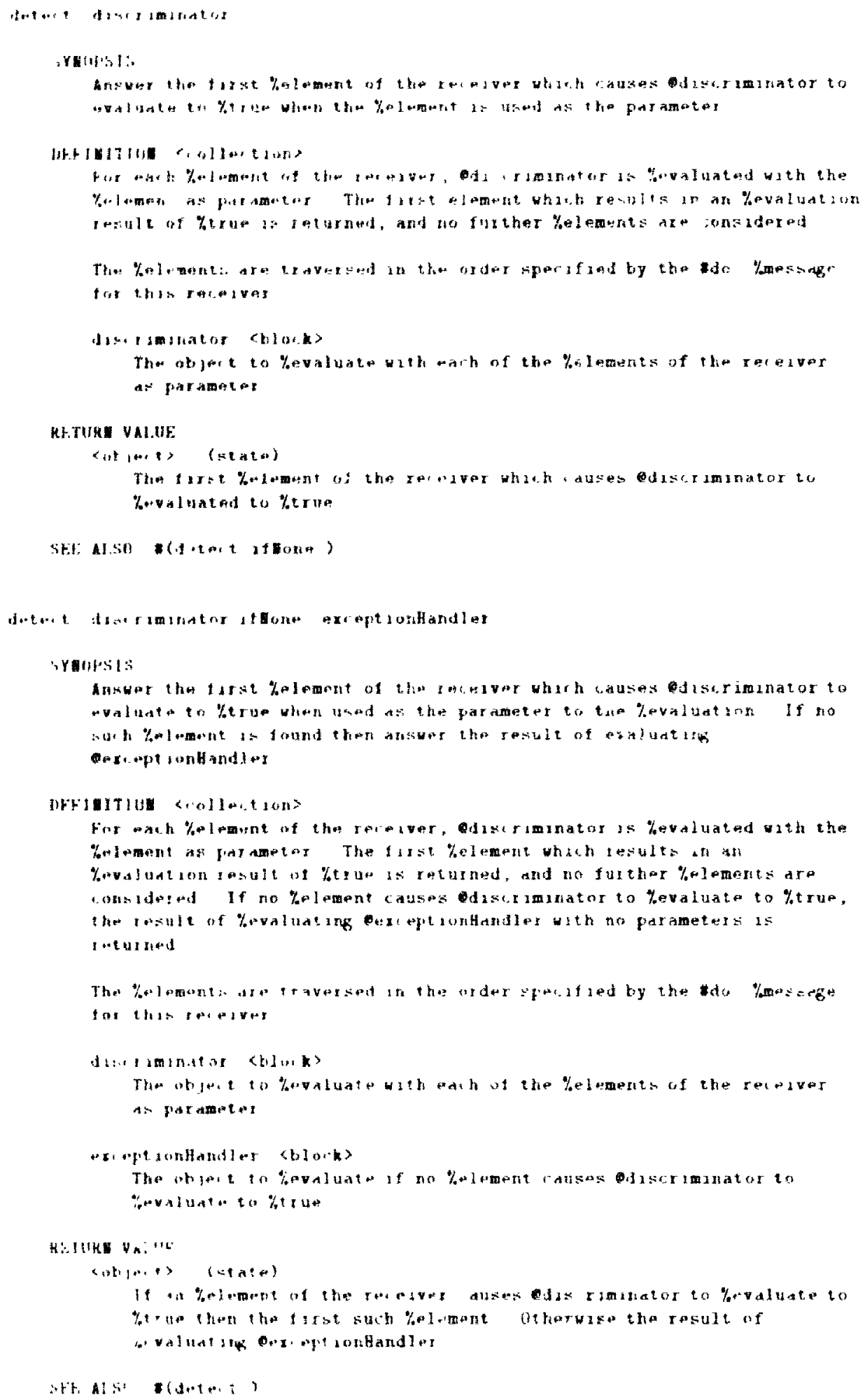


do. operation

SYMopsis

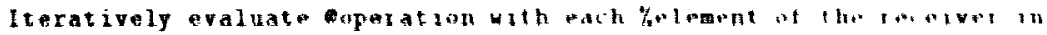

the recelver's standard travarsal order

DEFIDITIOE $\langle$ collection

This ymessage defines the racelver's \%olmmets

This is one of the mapping operstinns for each \%olnment of tho recelver, eoperation is \%ovaluated with tho \%eloment as patametes

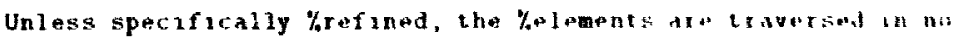

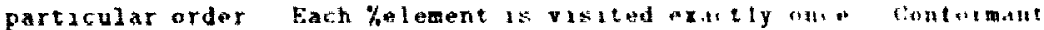

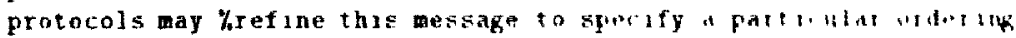

operation 〈block〉

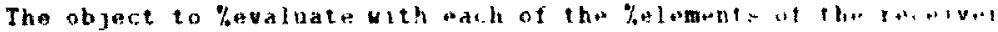
as parameter

RETUR: VALUE

UIDEFINED There is no spen difed return value

SEF ILSO E(collect injert into rajert selet)

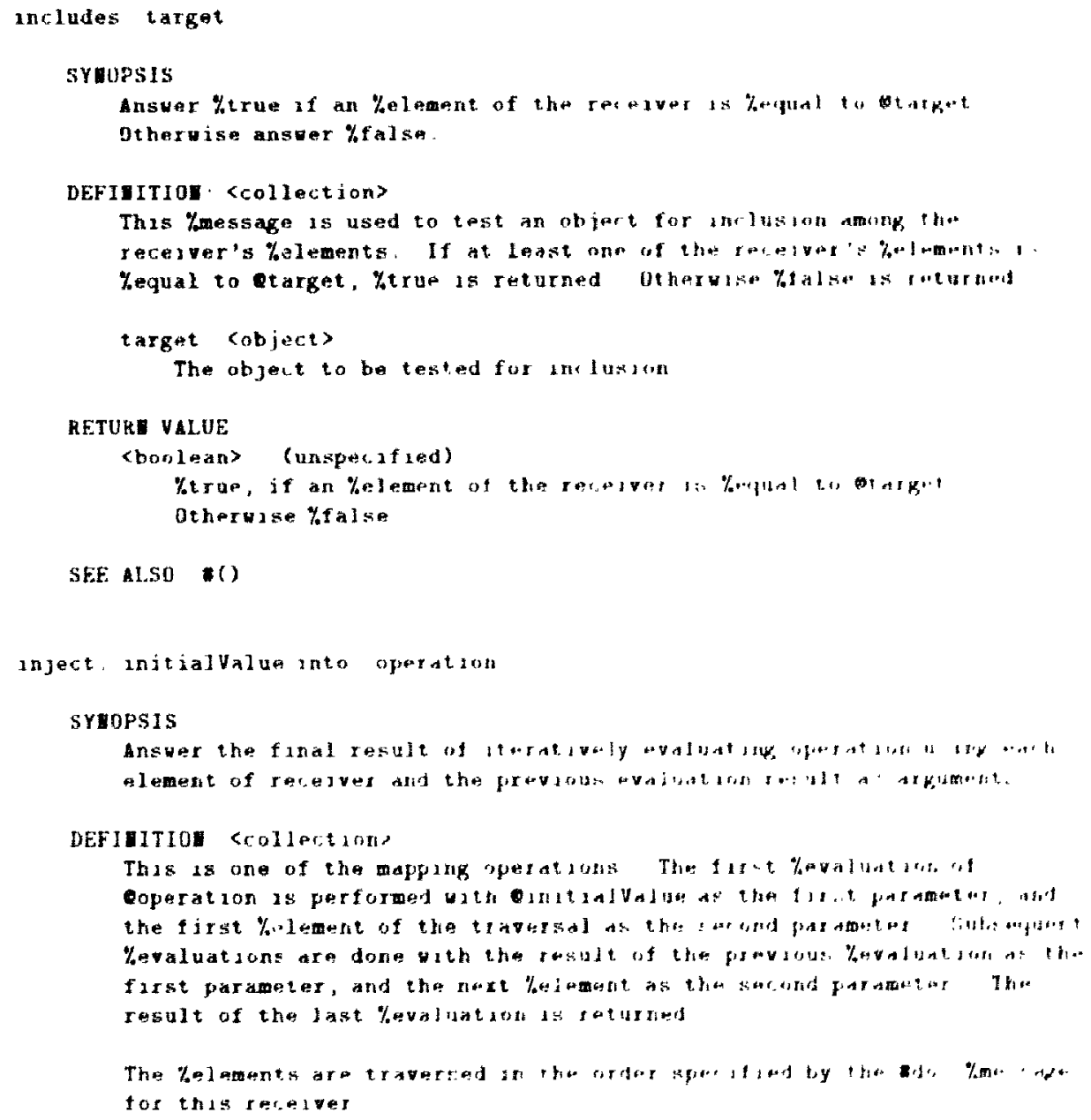




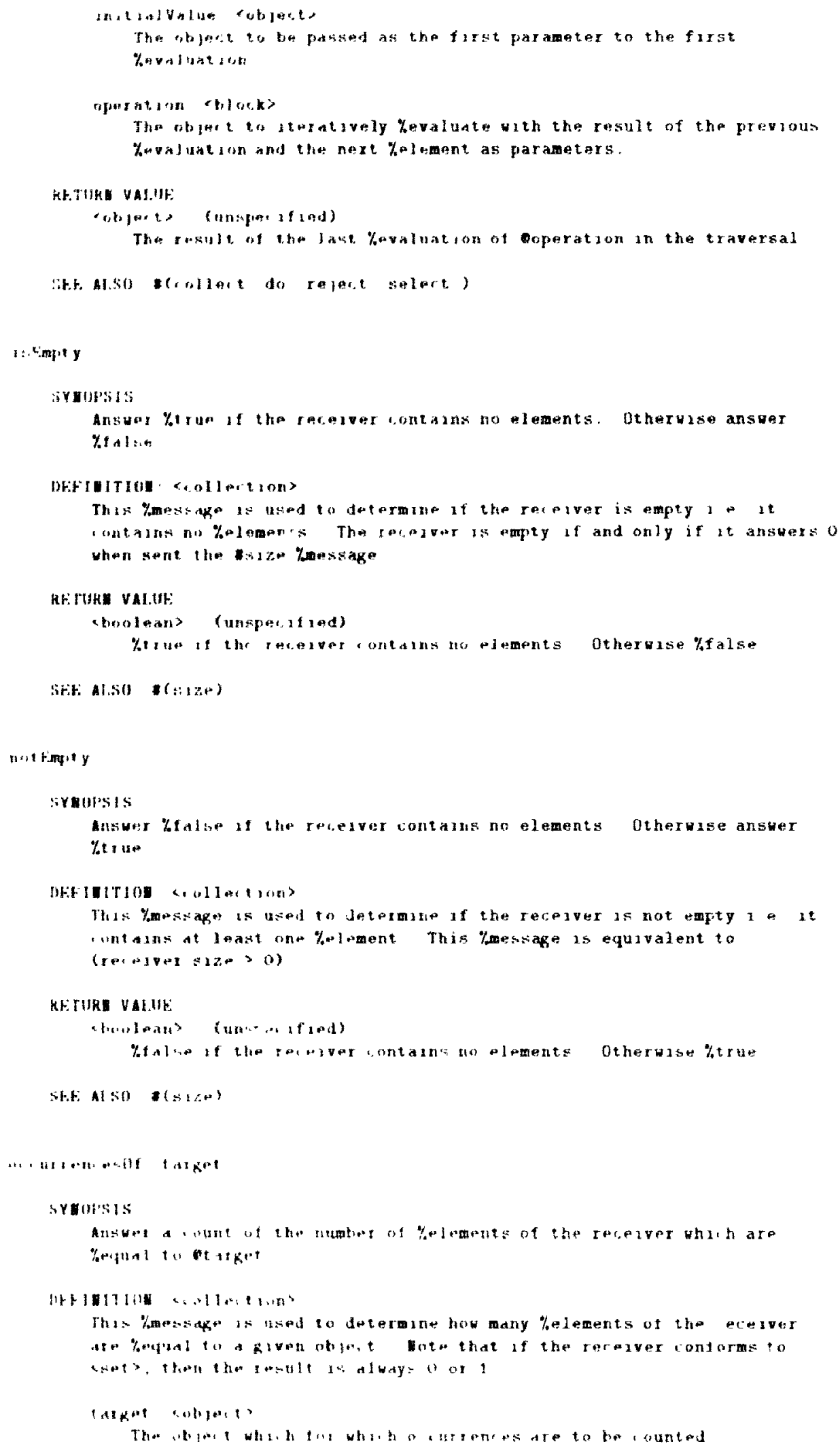


RETUR VALUE

〈nteger> (unspecified)

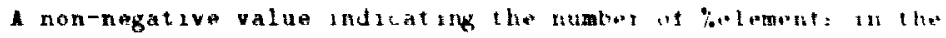
receiver

SEE ALSO (Indiudes)

reject, discriminator

SYDOPSIS

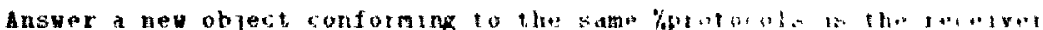

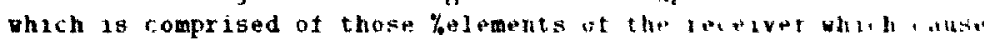

ediactiminator to \%evaluate to \% fa? ino

DEFINITIOA: 〈collection>

Thys is one of the rapping nperations for adth \%+l amest of thes

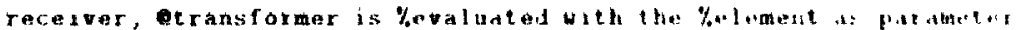

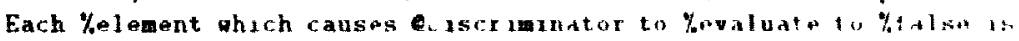

added to the new collertion

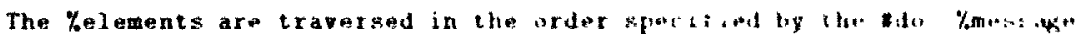
for this receiver

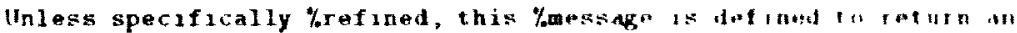

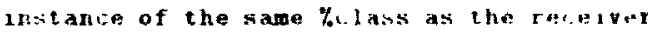

discrimator 〈block>

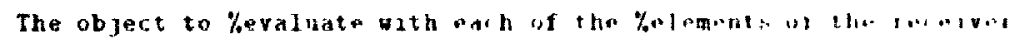

as parameter

RETURE VALUE

〈RECEIVER> (new)

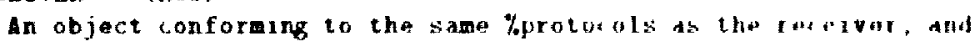

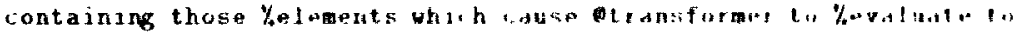
\%false.

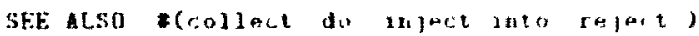

select. dascriminator

SYIOPSIS

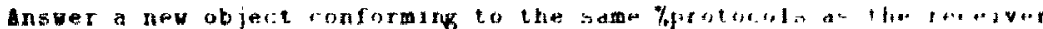

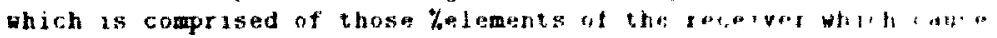

ediscriminator to \%evaluate ta $\%$, ruf

DEFIITION ( Collpction)

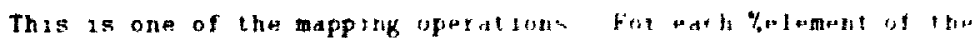

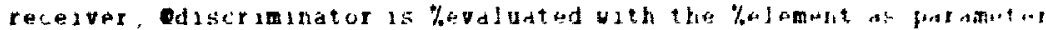

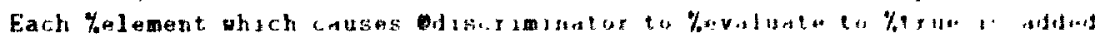
to the nev collection

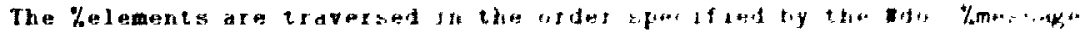
for this rereliar

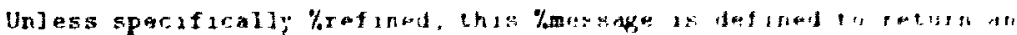

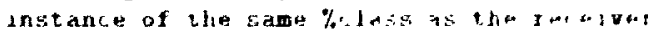

discriminator (blocks

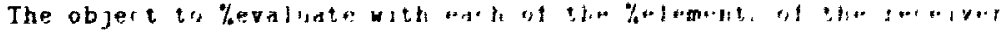

as parameter

RETURE VALUE

(MECEIVER) $(n+w)$ 


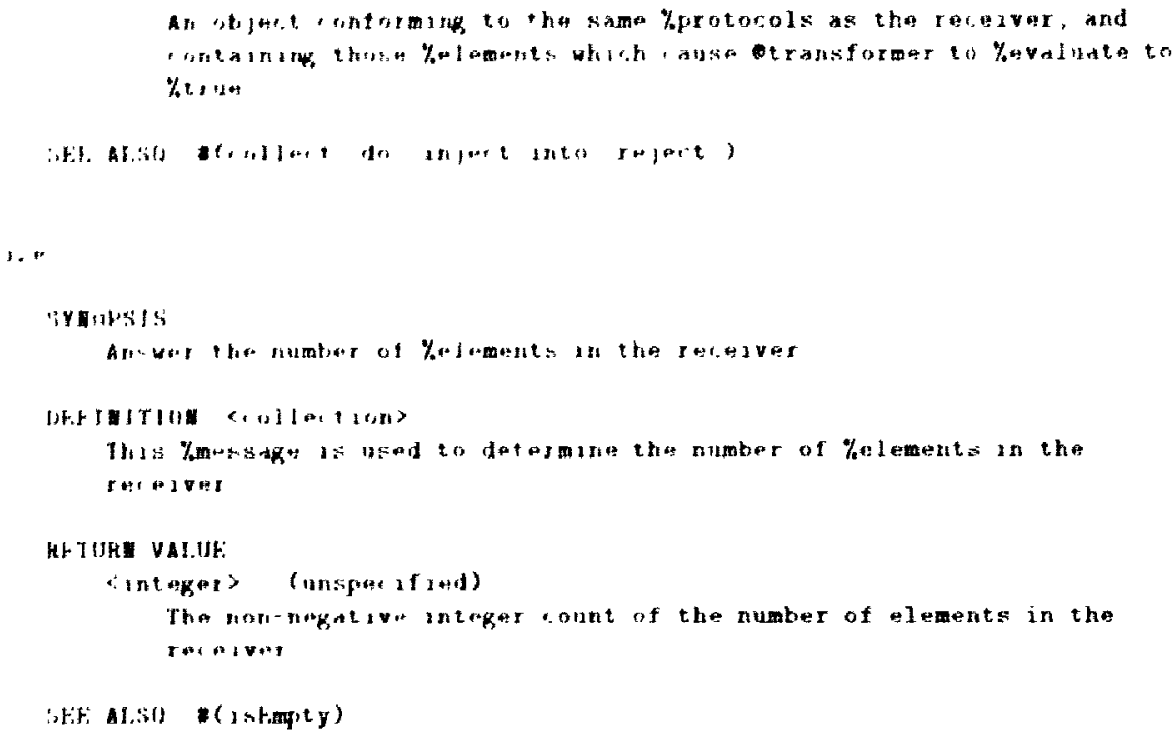



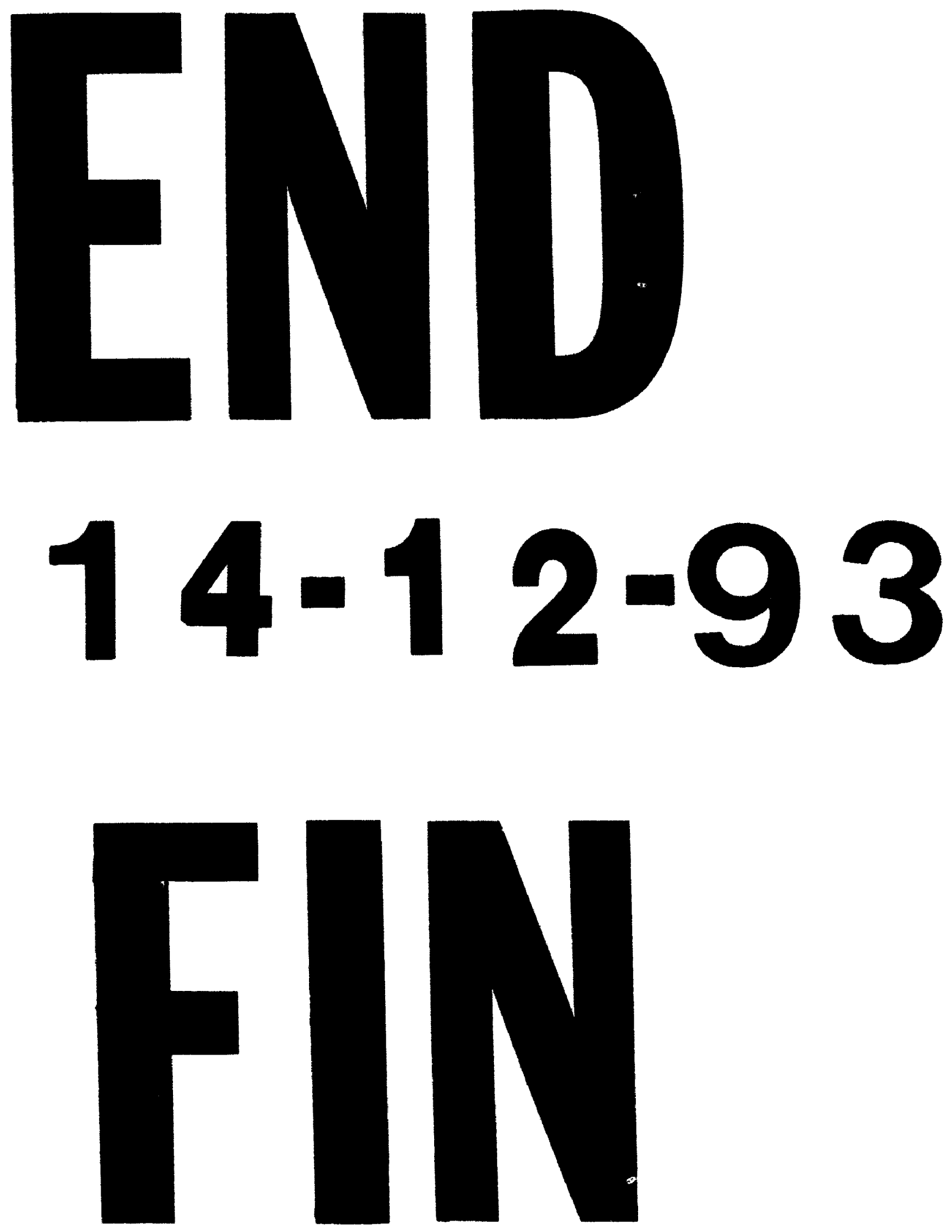